\title{
FLOODING EXPERIMENTS WITH STEAM AND WATER IN A LARGE DIAMETER VERTICAL TUBE
}

\author{
A Thesis \\ by \\ SUSAN NICOLE WILLIAMS \\ Submitted to the Office of Graduate Studies of \\ Texas A\&M University \\ in partial fulfillment of the requirements for the degree of \\ MASTER OF SCIENCE
}

August 2009

Major Subject: Nuclear Engineering 


\title{
FLOODING EXPERIMENTS WITH STEAM AND WATER IN A LARGE DIAMETER VERTICAL TUBE
}

\author{
A Thesis \\ by \\ SUSAN NICOLE WILLIAMS

\begin{abstract}
Submitted to the Office of Graduate Studies of
Texas A\&M University

in partial fulfillment of the requirements for the degree of

MASTER OF SCIENCE
\end{abstract}

Approved by:

Chair of Committee, Karen Vierow

Committee Members, Debjyoti Banerjee

Frederick R. Best

Head of Department, Raymond J. Juzaitis

August 2009

Major Subject: Nuclear Engineering 


\begin{abstract}
Flooding Experiments with Steam and Water in a Large Diameter Vertical Tube. (August 2009)

\author{
Susan Nicole Williams, B.S., Texas A\&M University \\ Chair of Advisory Committee: Dr. Karen Vierow
}

An experimental study on flooding with steam and water in a large diameter vertical tube was conducted. This research has been performed to provide a better prediction of flooding in a pressurized water reactor (PWR) pressurizer surge line to be used in reactor safety codes. Experiments were conducted using a 3-inch $(76.2 \mathrm{~mm})$ diameter tube 72 inches $(1.83 \mathrm{~m})$ long with subcooled water and superheated steam at atmospheric pressure as the working fluids. Water flows down the inside walls of the tube as an annulus while the steam flows upward in the middle. The water flow rates ranged from 3.5 to 12 gallons per minute (GPM) (0.00022 to $0.00076 \mathrm{~m}^{3} / \mathrm{s}$ ) and the water inlet temperature was approximately $70{ }^{\circ} \mathrm{C}$. The steam inlet temperature was approximately $110^{\circ} \mathrm{C}$. The size of the test section as well as the flow ranges of the working fluids was determined based on a scaling analysis of a PWR pressurizer surge line.

Two distinct trends were observed in the data. It was found that for water flow rates below 6 GPM $\left(0.00038 \mathrm{~m}^{3} / \mathrm{s}\right)$ the amount of steam required for flooding to occur decreases with an increasing water flow rate. For water flow rates above 6 GPM the amount of steam required for flooding to occur increases with an increasing water flow rate. In addition, axial water temperature data was collected. Axial water temperatures have not been recorded in previous flooding experiments with steam and water. 
A new correlation for predicting flooding with steam and water was proposed. This correlation was an improvement from previous correlations because it included the amount of steam condensation. Incorporation of steam-water mass exchange promotes a better prediction of behavior in reactor systems. This data for flooding with steam and water in a large diameter vertical tube can lead to a mechanistic model for flooding. 
TO MY PARENTS

AND

TO THE LOVE OF MY LIFE 


\section{ACKNOWLEDGMENTS}

I would like to thank all the members of the Laboratory for Nuclear Heat Transfer Systems for their help building, insulating, and operating the steam-water facility. I would also like to thank Professor Karen Vierow for her guidance in this project. This research would not have been possible without her help.

I would also like to thank all of my thesis committee members: Professors Karen Vierow, Debjyoti Banerjee, and Fred Best. Their support has been greatly appreciated throughout this process.

I would also like to thank my family. My parents, Frank and Susan Williams, have given me encouragement during my entire college career. My sister, Christine, has helped me enjoy life outside of work and forget about stress. Last, but not least, my fiance, Philip Ritchey, has listened to me and motivated me to the very end. 


\section{NOMENCLATURE}

ABBREVIATIONS

$\begin{array}{ll}\text { ASME } & \text { American Society of Mechanical Engineers } \\ \text { DAQ } & \text { data acquisition system } \\ \text { dP } & \text { differential pressure along the test section } \\ \text { GPM } & \text { gallons per minute } \\ \text { ID } & \text { inner diameter } \\ \text { LOCA } & \text { loss of coolant accident } \\ \text { NPT } & \text { national pipe thread } \\ \text { OD } & \text { outer diameter } \\ \text { PWR } & \text { pressurized water reactor } \\ \text { TMI-2 } & \text { Three Mile Island Unit } 2\end{array}$

SYMBOLS

A

cross sectional area

Bo

Bond number

C

constant used in the Wallis correlation

$C_{d}$

drag coefficient

$C_{k}$

constant used in the Kutateladze-type correlation

$C_{o}$

drift flux constant

$c_{p}$

specific heat capacity

$D$

test section diameter

$E_{P}$

energy increase in the system

$f$

fraction of condensed steam

$\operatorname{Fr}_{D L} \quad$ densimetric liquid Froude number

$g$

acceleration due to gravity

$h_{i} \quad$ enthalpy of the $i$ phase 


\begin{tabular}{|c|c|}
\hline$h_{f g}$ & latent heat \\
\hline$j$ & superficial velocity \\
\hline$j_{g f}$ & drift flux \\
\hline$j_{i}$ & superficial velocity of the $i$ phase \\
\hline$j_{i}^{*}$ & Wallis number of the $i$ phase \\
\hline$k$ & thermal conductivity \\
\hline$K u_{i}$ & Kutateladze number of the $i$ phase \\
\hline$m$ & constant used in the Wallis correlation \\
\hline$m$ & constant used in the Kutateladze-type correlation \\
\hline$m$ & mass \\
\hline$\dot{m}$ & mass flow rate \\
\hline$O h$ & Ohnesorge number \\
\hline$P_{H}$ & heater power \\
\hline$P_{L}$ & heat loss \\
\hline$Q$ & energy \\
\hline$q^{\prime \prime}$ & heat flux \\
\hline$R e$ & Reynolds number \\
\hline$R_{T}$ & thermodynamic ratio \\
\hline$T$ & temperature \\
\hline$\Delta T$ & temperature difference \\
\hline$\Delta t$ & change in time \\
\hline$u_{i}$ & velocity of the $i$ phase \\
\hline$u_{g j}$ & drift velocity \\
\hline$V$ & voltage \\
\hline$W e$ & Weber number \\
\hline$w_{i}$ & mass flow rate of the $i$ phase \\
\hline$x$ & distance \\
\hline
\end{tabular}


Greek symbols:

$\begin{array}{ll}\alpha & \text { void fraction } \\ \delta & \text { film thickness } \\ \mu & \text { dynamic viscosity } \\ \nu & \text { kinematic viscosity } \\ \rho & \text { density } \\ \sigma & \text { surface tension }\end{array}$

Subscripts:

$\begin{array}{ll}c & \text { critical } \\ c d & \text { condensed } \\ f & \text { liquid } \\ g & \text { gas } \\ g e & \text { effective gas } \\ \text { in } & \text { in } \\ \text { out } & \text { out } \\ s & \text { saturated } \\ S S & \text { stainless steel } \\ \text { st } & \text { steam } \\ \text { sub } & \text { subcooled }\end{array}$


TABLE OF CONTENTS

Page

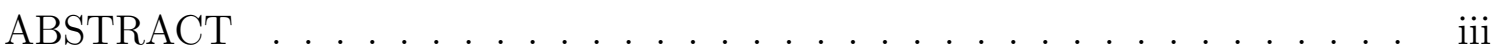

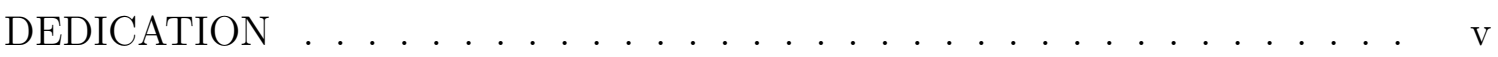

ACKNOWLEDGMENTS ................................... vi

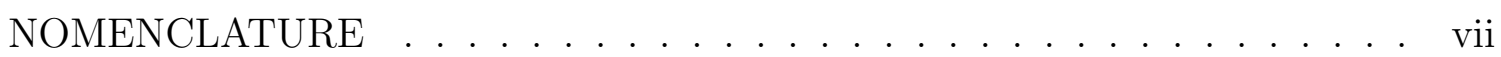

TABLE OF CONTENTS .................... . .

LIST OF FIGURES ........................ xiii

LIST OF TABLES ........................ . . . . . . . . . . . . . .

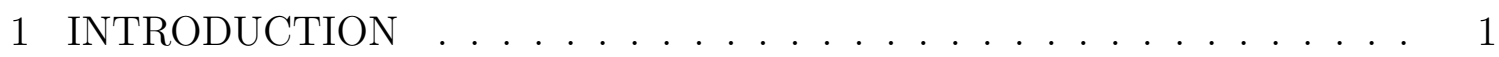

1.1 Importance of Flooding . . . . . . . . . . . . . . . . . . . . . . . 1

1.2 Significance of Steam-Water Tests . . . . . . . . . . . . . . . . . . . . . . . . . .

1.3 Objectives and Technical Approach . . . . . . . . . . . . . . . . 3

1.4 Thesis Organization . . . . . . . . . . . . . . . . . . . . . . . 4

2 LITERATURE SURVEY . . . . . . . . . . . . . . . . . . 6

2.1 Previous Experimental Work . . . . . . . . . . . . . . 6

2.2 Previous Theoretical Work . . . . . . . . . . . . . . . . 11

2.2.1 Kinematic Waves . . . . . . . . . . . . . . . . . . 12

2.2.2 Upward Liquid Film Flow . . . . . . . . . . . . . . . . . . 13

2.2.3 Droplet Entrainment . . . . . . . . . . . . . . . 14

2.3 Previous Steam-Water Flooding Experiments . . . . . . . . . . . 15

3 SCALING ANALYSIS AND FACILITY CHARACTERIZATION . . . . . 20

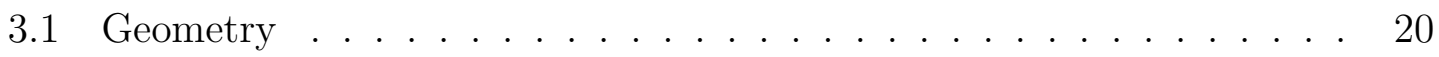

3.1.1 Entrance and Exit Effects . . . . . . . . . . . . . 20

3.1.2 Tube Diameter . . . . . . . . . . . . . . . . . 21

3.1.3 Inducing Annular Flow . . . . . . . . . . . . . . . . . 22

3.2 Steam First Versus Water First Operating Procedures . . . . . . . . . 25

3.3 Results of Scaling Analysis . . . . . . . . . . . . . . . . 26

4 FACILITY DESCRIPTION . . . . . . . . . . . . . . 30 
4.1 Test Section Tube . . . . . . . . . . . . . . . . . . . . . 30

4.2 Water Supply System . . . . . . . . . . . . . . . . . . . . 33

4.3 Steam Supply System . . . . . . . . . . . . . . . . . . . . . . 34

4.4 Steam Outlet . . . . . . . . . . . . . . . . . . . . . . . . . . . . . . . . . . . . . . . .

4.5 Water Collection and Recirculation . . . . . . . . . . . . . . 38

4.6 Instrumentation . . . . . . . . . . . . . . . . . . . . . . . . . . . 39

4.6.1 Instruments and Equipment . . . . . . . . . . . . . . . . 40

4.6.2 Data Acquisition System . . . . . . . . . . . . . . . . . . . . 42

4.6.3 Data Reduction . . . . . . . . . . . . . . . . . . 43

4.7 Vortex Flowmeter Calibration . . . . . . . . . . . . . . . . . . . 45

4.7.1 System Heat Loss Tests . . . . . . . . . . . . . . . . . . 45

4.7 .2 Calibration .................. . . 46

5 EXPERIMENTAL OPERATING PROCEDURES AND TEST MATRIX . 49

5.1 Data Acquisition System . . . . . . . . . . . . . . . . . . . . . . 49

5.2 Filling the Water Tank . . . . . . . . . . . . . . . . . . 50

5.3 Filling the Steam Generator . . . . . . . . . . . . . . . . 51

5.4 Emergency Stop . . . . . . . . . . . . . . . . . . . 51

5.5 Purging the Differential Pressure Transducer Lines . . . . . . . . . . 52

5.6 Hot Water Pump Operation . . . . . . . . . . . . . . . 53

5.7 Recirculation Pump Operation . . . . . . . . . . . . . . 54

5.8 Steam Generator Operation . . . . . . . . . . . . . . . . . . 54

5.9 Cooling System Operation . . . . . . . . . . . . . . . . . . . 55

5.10 Collecting Data . . . . . . . . . . . . . . . . . . 56

5.11 Shut Down . . . . . . . . . . . . . . . . . . 57

5.12 Experimental Test Conditions . . . . . . . . . . . . . . 58

6 AIR-WATER RESULTS AND DISCUSSION . . . . . . . . . . . . . . . . . 59

6.1 Raw Data and Observations . . . . . . . . . . . . . . . . . 59

6.2 Reduced Data . . . . . . . . . . . . . . . . . 61

6.3 Comparison with Previous Air-Water Data . . . . . . . . . . . . . . . 62

7 STEAM-WATER RESULTS AND DISCUSSION . . . . . . . . . . . . . 65

7.1 Raw Data and Observations . . . . . . . . . . . . . . 65

7.2 Reduced Data . . . . . . . . . . . . . . . . . . . 69

7.3 Error Analysis . . . . . . . . . . . . . . . . . . . . . . . . . . . . . . . 72

7.4 Empirical Model Development . . . . . . . . . . . . . . . . . 74

7.5 Comparison with Air-Water Tests . . . . . . . . . . . . . . . . . 82

8 CONCLUSIONS AND RECOMMENDED FUTURE WORK . . . . . . . . 85 


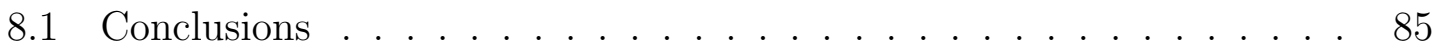

8.2 Recommended Future Work . . . . . . . . . . . 86

REFERENCES . . . . . . . . . . . . . . . . . . . . . . . . 88

APPENDIX A: STEAM WATER TEST SECTION DRAWINGS . . . . . . . 92

APPENDIX B: REDUCED DATA SET . . . . . . . . . . . . . . . 124

APPENDIX C: MATLAB SCRIPTS . . . . . . . . . . . . . . 130

APPENDIX D: GRAPHICAL DATA . . . . . . . . . . . . . . . . . . . 140

VITA . . . . . . . . . . . . . . . . . . . . . . 298 


\section{LIST OF FIGURES}

FIGURE

Page

2.1 A comparison between the results of Lobo [13] and Sherwood [14] and the

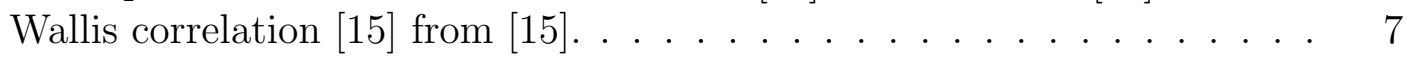

2.2 The large spread in flooding data reported by McQuillan [24]. . . . . . . 11

2.3 A graphical solution to flooding [25] which is also known as the flooding curve. . . . . . . . . . . . . . . . . 13

2.4 Flooding data from Wallis plotted against Equation 2.16 [37]. . . . . . . 18

3.1 Annular film inside the test section. . . . . . . . . . . . . . . . . 24

3.2 Film thickness of the annular liquid film plotted with water flow rate. . . 25

3.3 Flooding boundaries recorded by Wallis [37] . . . . . . . . . . . . 26

4.1 A schematic of the entire test facility. . . . . . . . . . . . . . . 31

4.2 The test section prior to insulation. . . . . . . . . . . . . . . 32

4.3 The water injection device prior to insulation. . . . . . . . . . . . . 34

4.4 A cross sectional schematic of the water injection device. . . . . . . . . . 35

4.5 The steam generator before insulation. . . . . . . . . . . . . . 36

4.6 The steam generator after insulation. . . . . . . . . . . . . . . 36

4.7 The steam-water outlet hose connected to the blowdown tank. . . . . . . 39

4.8 A schematic of the test facility with the locations of the instrumentation. 41

4.9 A picture of the LabVIEW interface used for collecting data. . . . . . . . 44

4.10 The steam generator pressure as a function of time. . . . . . . . . . . 47

4.11 Vortex flowmeter calibration line. . . . . . . . . . . . . . . . . . . 48 
6.1 The differential pressure measured along the test section plotted with time for a water flow rate of $6.89 \mathrm{GPM}\left(0.00043 \mathrm{~m}^{3} / \mathrm{s}\right) \ldots \ldots . . . . .60$

6.2 The pressure in the water exit tank plotted with time. . . . . . . . . 61

6.3 The air velocity in the test section plotted with time. . . . . . . . . . 62

6.4 The full set of air data obtained from the current facility and compared to the Kutateladze-type correlation [20]. . . . . . . . . . . . . 63

6.5 Air data from the current facility compared with the air data from Sol$\operatorname{mos}[23] \ldots \ldots \ldots \ldots \ldots \ldots$

7.1 The differential pressure measured along the test section plotted with time for a water flow rate of $6.28 \mathrm{GPM}\left(0.00040 \mathrm{~m}^{3} / \mathrm{s}\right) \ldots \ldots 6$

7.2 Temperature measurements in the test section plotted with time for a

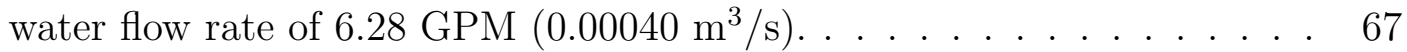

7.3 Pressure in the water exit tank plotted with time for a water flow rate of

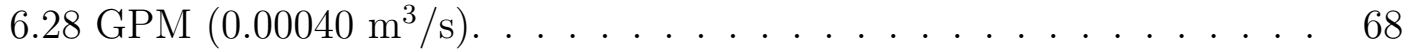

7.4 Steam velocity in the piping leading up to the test section plotted with

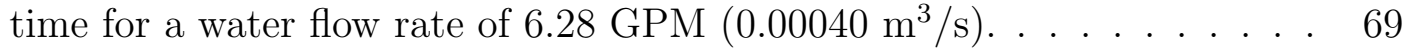

7.5 The steam velocity in the test section plotted with the water flow rate. $\quad 70$

7.6 The drop in the $\mathrm{dP}$ plotted with the water flow rate. . . . . . . . . 71

7.7 The steam velocities when flooding occurs inside the test section tube for

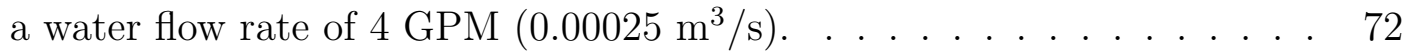

7.8 The steam velocities when flooding occurs inside the test section tube for

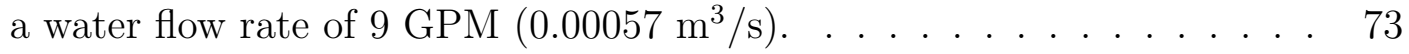

7.9 The steam flooding data plotted with error bars. . . . . . . . . . . . . 74

7.10 The steam data plotted as the Wallis parameters along with the Wallis correlation. . . . . . . . . . . . . . . . . . . . 75 
7.11 The steam data plotted as the Kutateladze parameters along with the Kutateladze-type correlation. . . . . . . . . . . . . . . 76

7.12 The steam data plotted as the effective Kutateladze parameters along with the Kutateladze-type correlation. . . . . . . . . . . . . . . . . . 77

7.13 A graphical depiction of the relative temperature values in the test section. 78

7.14 The fraction of condensed steam plotted with the water flow rate. . . . . 80

7.15 The water temperature difference plotted with the water flow rate. . . . 81

7.16 The steam data plotted with the proposed correlation and lines at $95 \%$ and $105 \%$ of the correlation. . . . . . . . . . . . . . 82

7.17 The air and steam volumetric flow rates plotted with the water flow rate. 83

7.18 The air and effective steam volumetric flow rates plotted with the water flow rate. . . . . . . . . . . . . . . . . . 84 


\section{LIST OF TABLES}

TABLE

Page

3.1 Scaling of surge line specifications and reactor conditions. . . . . . . . . . 29

4.1 The equipment used in the steam-water facility. . . . . . . . . . . . . 40

4.2 The instrumentation used in the steam-water facility. . . . . . . . . . . . 42

5.1 Test conditions for steam-water tests. . . . . . . . . . . . . . . 58

B.1 The steam-water reduced data set. . . . . . . . . . . . . . . . . 125 


\section{INTRODUCTION}

The current fleet of nuclear reactors in the United States is aging. Current and future reactor designs need to incorporate the newest accident mitigation techniques to ensure the safety of the public in the event of an accident. There are several locations within the reactor cooling system which may become blocked during reflood that could lead to the core melting. Greater knowledge of the phenomena that occur during an accident coupled with better component design would prevent major damage of the core from occuring. Electricity generation from nuclear power is expected to increase by $13 \%$ from 2007 to 2030 [1]. This increase will come from the addition of new nuclear power plants and upgrades to existing units around the country to increase overall capacity and generation [2]. It is more important than ever that these reactors remain safe to operate.

\subsection{Importance of Flooding}

Within the field of two-phase flow there are many phenomena which are not fully understood. This lack of understanding affects engineering design by adding significant uncertainty to calculations of pressure drops, heat transfer characteristics, and predictions of the sequence of events in accident situations. Flooding is one such phenomenon which greatly affects a variety of systems, including nuclear power plants. With the growing need for electricity production from non-fossil fuel sources, nuclear power is more important to society's future than ever before. Therefore, engineers need to ensure the safety of nuclear power plants through a better understanding of the flooding phenomenon and its potential impact on plant behavior.

In a countercurrent, two-phase flow system, flooding is commonly defined as

This thesis follows the style of International Journal of Heat and Mass Transfer. 
onset of flow reversal which results in cocurrent flow [3]. In general, flooding includes significantly more liquid than entrained liquid droplets. Flooding can also be perceived as a limit to stable two-phase countercurrent flow. The envelope for stable countercurrent flow for a given system is defined by pairs of liquid and gas flow rates $[4-6]$.

An interest in the flooding phenomenon has recently resurged because flow reversal may have an impact on nuclear reactor safety. For example, flooding in the AP600 pressurizer surge line can affect the vessel refill rate following a small break LOCA [7]. Analysis of hypothetical severe accidents with current simplified flooding models show that these models represent the largest uncertainty in steam generator tube creep rupture $[8,9]$.

Results of recent severe accident analyses demonstrate the need to model flooding accurately in the pressurizer surge line as well as the primitive level of current modeling in severe accident analysis codes [8-10]. In the analysis of hypothetical severe accidents and the Three Mile Island Unit 2 (TMI-2) accident by several codes, the predictions of flooding in the pressurizer surge line were shown to include large uncertainty. The flooding results greatly impact the calculated progression of the TMI-2 severe accident, and the creep rupture behaviors of the surge line and steam generator tubes. Currently no satisfactory mechanistic flooding models exist yet, so current safety analysis codes employ empirical correlations to predict flooding. With their default flooding models, the SCDAP/RELAP5, MELCOR and MAAP severe accident codes predict significant discrepancy in flooding taking place in the surge line in a hypothetical station blackout severe accident scenario [9].

Although considerable work has been done in the past few decades, there is significant uncertainty concerning the mechanisms that cause flooding as well as appropriate correlations. Due to the complexity of the mechanisms involved in flooding, an empirical correlation is an efficient approach to predict flooding in a given scenario. 


\subsection{Significance of Steam-Water Tests}

While air-water flooding data can provide an insight into the mechanisms of the flooding phenomenon, steam-water flooding data is needed to provide experimental conditions more similar to those in a PWR pressurizer surge line. More specifically, the effect of condensation is present in steam-water tests that is not present in air-water tests. In addition, due to the higher temperatures, the properties of the fluids are different than in air-water tests and affect the behavior of the water and the steam. For example, the viscosity of water is lower at higher temperatures. A lower water viscosity means the liquid Reynolds number is higher. Conducting steam-water tests will gain a better phenomenological understanding of flooding at conditions more closely simulating reactor conditions. In addition, steam-water tests

will contribute to reactor safety calculations. The empirical correlation resulting from steam-water experiments will provide a more satisfactory method to evaluate the conditions in which flooding occurs in current reactor safety analysis codes.

\subsection{Objectives and Technical Approach}

This thesis research investigates the phenomenon known as flooding to reduce uncertainties and increase the knowledge in the field of two-phase flow. A better understanding of flooding in a steam-water system will lead to a more accurate method to evaluate the conditions in which flooding occurs. While there have been many experimental investigations of the flooding phenomenon, the current investigation provides information not previously reported. The main objectives of this thesis research are to obtain a better understanding of the flooding phenomenon and develop a correlation for steam-water flooding in a large diameter vertical tube. To meet this objective the following tasks were defined: 
1. To design and build an experimental facility for acquiring flooding data in a large diameter, vertical tube using both air-water and steam-water as the working fluids.

2. To extend the flooding database beyond previous experiments by obtaining more detailed measurements of the conditions in which flooding occurs in order to better understand the effects of condensation on flooding.

3. To develop a correlation from the data that may be used in nuclear reactor safety analysis to predict flooding in a steam-water system.

A comprehensive literature survey of papers related to the flooding phenomenon has been conducted. This survey provides information on methods and techniques used in previous experiments as well as methods for analysis of new data gained from this research. In addition, a scaling analysis has been performed to aid in the design of the experimental facility. The facility was built so that it is properly scaled to a prototypical pressurizer surge line. An experimental test range and operating procedures have been determined to safely and efficiently collect data applicable to reactor systems. The collected data has been analyzed and compared with previous experimental investigations. Finally, conclusions have been drawn from the data and determined how these conclusions will impact the field of two-phase flow.

\subsection{Thesis Organization}

This thesis is organized into nine sections. The first section is an introduction to the research. This includes a brief description of the problem, the objectives of the research, and the layout of the thesis. Section 2 is a survey of the available literature related to flooding. The information presented in this section explains the methods and rationale behind the design of the experiments as well as the methods for analysis of the collected data. It also provides data from previous experiments that is compared with the data in this research. The scaling analysis performed to 
aid the experiemental design is discussed in Section 3. This section also contains the characterization tests performed on the facility and discusses geometry concerns as well as the annular film inside the test section. Section 4 contains a detailed description of the constructed facility and the equipment used. The location of each piece of instrumentation and the information obtained from the measurements are explained. Section 4 also contains the calibration of the vortex flowmeter. Section 5 describes the experimental procedures followed in every test. The experimental test conditions are explained along with the test matrix. Section 6 presents the air-water data and observations. The collected air-water data is compared with previous air-water data. Section 7 presents the steam-water data and observations as well as an error analysis. It also presents the final correlation along with a comparison to previous data sets. Section 8 contains the conclusions drawn from the data. The future work that can be done to further the understanding of the flooding phenomenon with steam and water is also described. Lastly, appendices are provided which contain the technical drawings of the test section, the reduced data, the MATLAB scripts used to reduce the data, and the time-dependent data in graphical form. 


\section{LITERATURE SURVEY}

Considerable work has been done concerning the flooding phenomenon. The previous studies can be sorted into theoretical research and experimental investigations. Since this thesis describes an experimental investigation of flooding, emphasis is placed on previous experimental papers. This section is a review of the literature on the theory, experiments, and correlations regarding flooding.

This literature survey is organized into three sections. The first section details the background on the phenomenon including early experimental investigations on flooding and the correlations resulting from these experiments. The second section covers the theoretical approaches that characterize flooding. This includes the mechanisms that are thought to explain the conditions in which flooding occurs. The last section describes experiments on flooding with steam and water as the working fluids. These steam-water studies are of great interest since they closely relate to this thesis research.

\subsection{Previous Experimental Work}

The research related to the flooding phenomenon has led to many correlations to predict flooding in various geometries. Experiments involving flooding were first accomplished by chemical engineers studying packed towers, however the work performed by Wallis [11] and Kutateladze [12] laid the foundation for subsequent correlation development by others. Flooding experiments performed by Lobo [13] and Sherwood [14] in vertical tubes identified the velocities of the working fluids as important parameters. More importantly, the inverse relationship between the gas and liquid velocities when flooding occurs was discovered. This effect was seen by Wallis [15] when he plotted the data in one of his early studies as seen in Figure 2.1.

As the liquid superficial velocity is increased, the gas superficial velocity required to achieve flooding decreases. This same trend appears in much of the flooding 


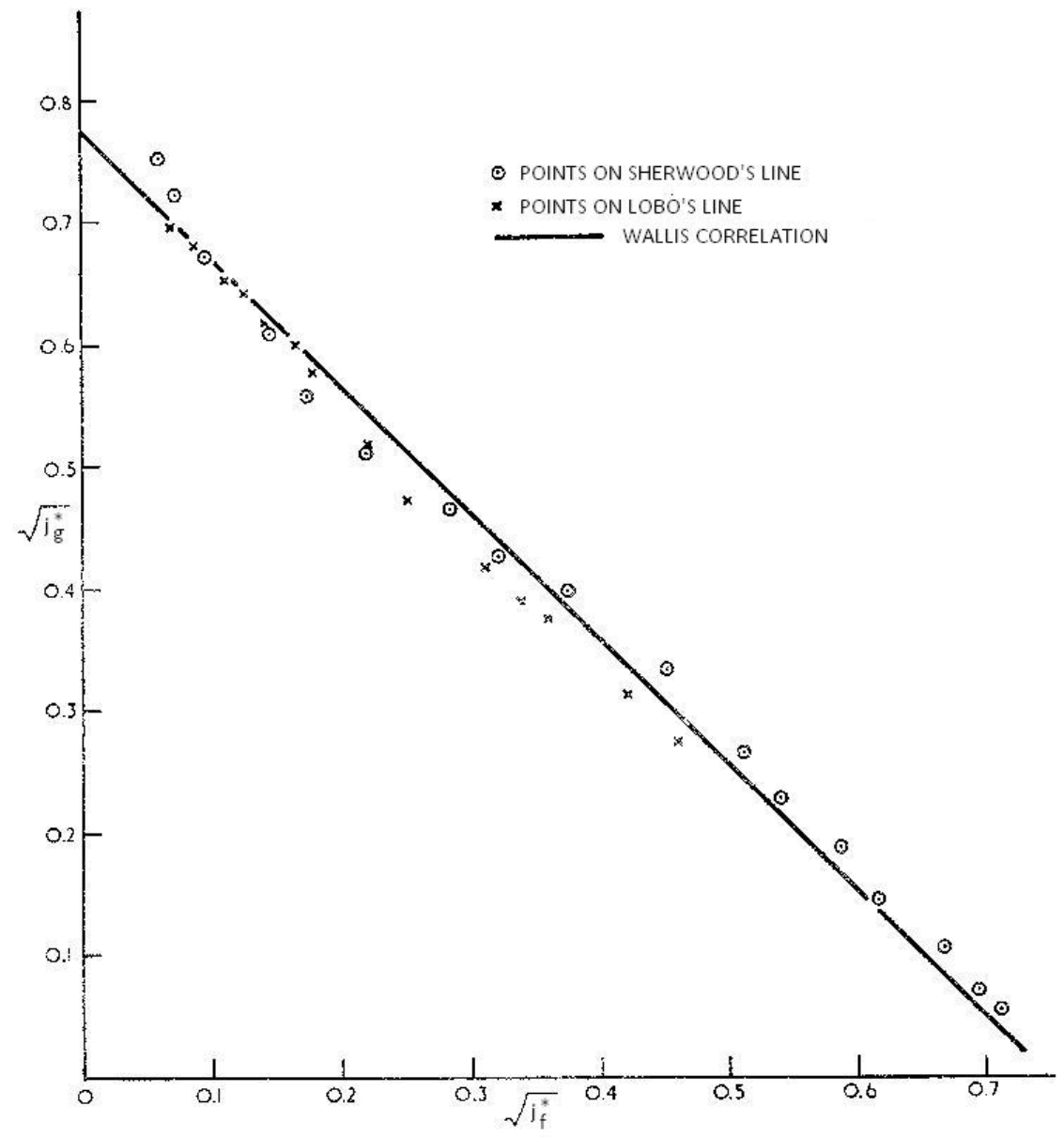

Fig. 2.1.: A comparison between the results of Lobo [13] and Sherwood [14] and the Wallis correlation [15] from [15].

data with air and water. In this work Wallis defines two numbers, known as the Wallis parameters, that nondimensionalize the superficial gas and superficial liquid velocities.

$$
j_{f}^{*}=j_{f} \sqrt{\frac{\rho_{f}}{g D\left(\rho_{f}-\rho_{g}\right)}}
$$

and

$$
j_{g}^{*}=j_{g} \sqrt{\frac{\rho_{g}}{g D\left(\rho_{f}-\rho_{g}\right)}}
$$

With these two numbers defined, Wallis concluded that the sum of the square root of these dimensionless parameters is equal to a constant [15]. The resulting 
equation is known as the Wallis correlation. In this equation, $m$ and $C$ are constants determined by experimental investigation. In his early work, Wallis used a value of $m=1$ and discovered that the value for $C$ depended on the geometry [15].

$$
\sqrt{j_{g}^{*}}+m \sqrt{j_{f}^{*}}=C
$$

Despite his efforts, Wallis did not fully define the phenomena in his investigation and neglected to consider large diameter tubes. Clift [16] performed a similar experimental investigation and concluded that the Wallis correlation is suitable to predict flooding. He also states that his results match those of Wallis due to similar geometries in the experimental apparati. He suggests that dissimilar results from other experimental investigations are due to different entry conditions [16].

In his correlation, Wallis suggests that there are four factors that affect flooding. These include the diameter of the tube, gravity, the densities of the fluids, and the superficial velocities of the fluids. A limitation to his correlation is that he only considered small diameter tubes in his experiments. Later, Wallis [17] and Vijayan [18] determined that there is a difference between "large" diameter tubes and "small" diameter tubes concerning flooding. While the Wallis correlation describes flooding conditions in small diameter tubes, the Kutateladze-type correlation describes flooding conditions for large diameter tubes $[12,19,20]$.

The Kutateladze criterion for the gas velocity that causes a breakdown of the liquid film, or flooding, was first used by Pushkina and Sorokin [19] in their flooding experiments using air with water, glycerine, and ethyl alcohol. It has been experimentally confirmed for large tube diameters. This criterion was later used to form a Kutateladze-type correlation. They define the Kutateladze criterion in terms of the maximum possible flooding gas velocity. According to them, velocities above this value are not physically possible.

$$
K u_{g}=\frac{j_{g} \rho_{g}^{1 / 2}}{\left(g \sigma\left(\rho_{f}-\rho_{g}\right)\right)^{1 / 4}}=3.2
$$


The result of this criterion is that the liquid flow rate is not important to the conditions in which flooding occurs, which contradicts the Wallis correlation. It should also be noted that it does not contain a tube diameter dependence. Because none of Pushkina's data seemed to have a tube diameter dependence in his experiments, he concluded that there should not be a dependence on the tube diameter in flooding conditions [19]. He neglected any diameter effect because he determined that flooding is more dependent on the formation of "crests" on the liquid film, which have no tube diameter dependence.

The Kutateladze-type correlation used today was not defined by Kutateladze nor by Pushkina, but instead by Tien [20]. He created an analogy to the Wallis correlation using the Kutateladze criterion. Like Wallis, Tien also used a value of $m=1$.

$$
\sqrt{K u_{g}}+m \sqrt{K u_{f}}=C_{k}
$$

Tien uses the original form of the Kutateladze criterion for $K u_{g}$ but also defines a similar term for the liquid phase.

$$
K u_{f}=\frac{j_{f} \rho_{f}^{1 / 2}}{\left(g \sigma\left(\rho_{f}-\rho_{g}\right)\right)^{1 / 4}}
$$

Tien also adds that the value of the constant $C_{k}$ is equal to $\sqrt{3.2}$ which is similar to the Kutateladze criterion. The Kutateladze criterion has been experimentally confirmed for use with large diameter tubes by using the square root of the Bond number [19]. The Bond number is a dimensionless tube diameter defined as the ratio between gravitational forces to surface tension forces. A "large" diameter tube is considered to have the square root of the Bond number greater than 30 [5].

$$
B o=\frac{\rho g D^{2}}{\sigma}
$$

Zapke [21] suggests that the Kutateladze-type correlation is not sufficient to correlate flooding data because it does not take into account the length of the tube. Even though he focuses on rectangular ducts, the conclusions drawn relate to general flow situations. In addition, Zapke introduces two dimensionless numbers not 
previously used in flooding correlations. These are the Froude and Ohnesorge numbers. The Froude number used by Zapke is defined as the densimetric liquid Froude number.

$$
F r_{D L}=\frac{\rho_{f} u_{f}^{2}}{g D\left(\rho_{f}-\rho_{g}\right)}
$$

Zapke also defined the liquid phase Ohnesorge number.

$$
O h_{f}=\sqrt{\frac{\mu_{f}^{2}}{\rho_{f} D \sigma}}
$$

In his analysis, Zapke discusses that the Froude number represents a ratio of the drag force on the liquid phase and the weight of the liquid film [21]. This implies that the drag force must exceed the gravitational force on the liquid phase for flooding to occur. In his correlation he uses the Ohnesorge number to relate the liquid properties to the flooding gas velocity [22].

Solmos [23] conducted flooding experiments with air and water in a vertical large diameter test section. His data followed the same trend seen by previous air-water experiments. The air flow rate required for flooding to occur decreased with an increasing water flow rate. In addition, Solmos measured the characteristic change in the pressure drop across the test section when flooding occured. He pointed out that the Wallis and Kutateladze-type correlations did not well represent his data and a new correlation is needed to predict flooding. Finally, Solmos included visual images, taken with a high speed camera, of the violent process that occurs inside the test section when flooding occurs. While the images produced by Solmos help identify the flow behavior just prior to flooding, his investigation provides no information regarding an applicability to flooding with steam and water.

Due to the large number of experimental investigations that have been conducted, a standard way of reporting the flooding data has emerged. Throughout the literature the Wallis parameters have been used to plot data [5]. Even so, the flooding data found in the literature has a large spread. McQuillan [24] plotted flooding data from 24 experimental studies which can be seen in Figure 2.2. By analyzing this data, he 
observed that most of the correlations accurately predict data only from a particular experiment.

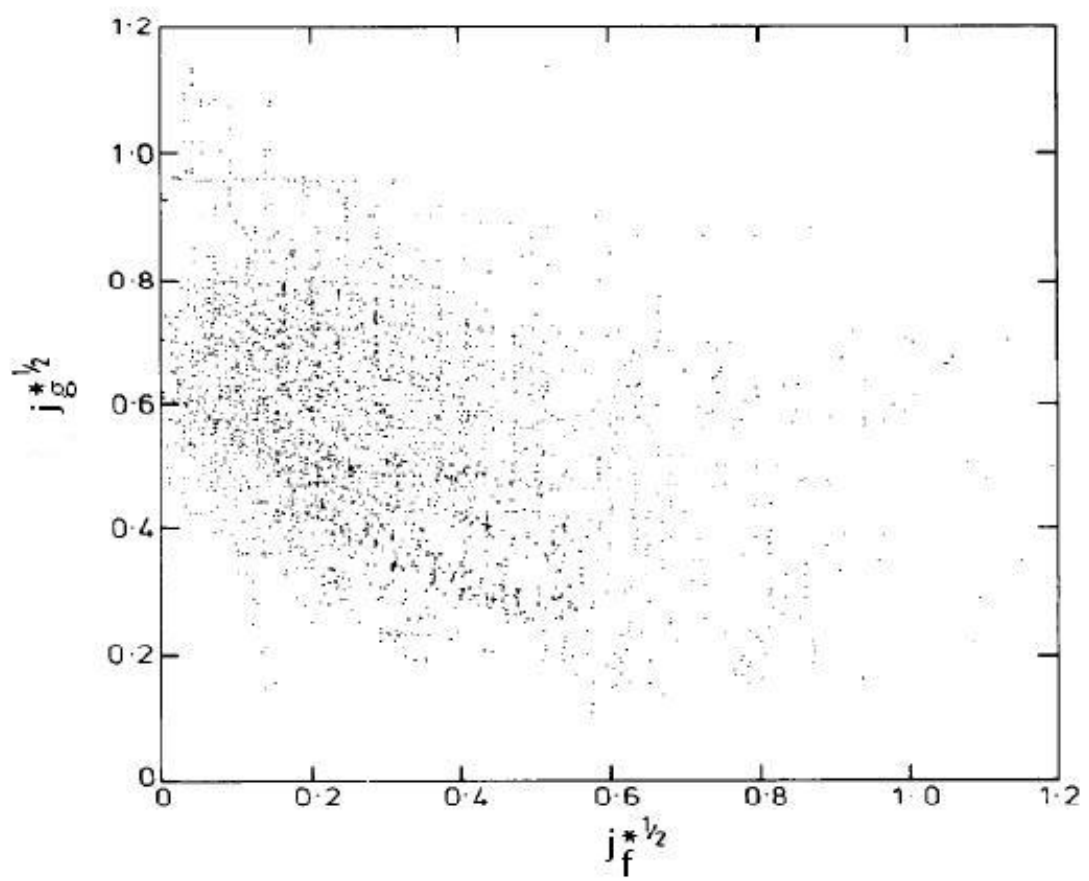

Fig. 2.2.: The large spread in flooding data reported by McQuillan [24].

\subsection{Previous Theoretical Work}

The literature provides various theories that have been proposed to explain the conditions in which flooding will occur. Bankoff and Lee [5] and Levy [25] have suggested three broad categories in their literature reviews that all of the theoretical models can be reduced to. These categories are kinematic waves, upward liquid film flow, and droplet entrainment. These three mechanisms are thought to provide a comprehensive view of the factors that contribute to flooding. 


\subsubsection{Kinematic Waves}

The kinematic wave mechanism that is thought to cause flooding is produced directly from the drift flux model of two-phase flow [25]. By comparing the relative velocity of the gas phase and the liquid phase to the drift flux, Wallis formulated a drift flux solution to flooding [11]. In this model the shear forces at the interface are negligible compared to the gravity forces acting on the liquid phase. Kinematic waves are formed by density differences and depend only on the continuity equation and not the momentum equation [25]. Because of this, the acceleration and frictional pressure losses are neglected. What remains is the drift flux relationship defined by Wallis [11].

$$
\overline{j_{g}}=\left(C_{o} \bar{j}+\overline{u_{g j}}\right) \bar{\alpha}
$$

It can be assumed that the drift velocity $\overline{u_{g j}}$ is only a function of physical properties and the average void fraction. Using Equation 2.10 and setting $C_{o}=1$, a simple relationship for the drift flux emerges.

$$
\overline{j_{g f}}=\bar{\alpha}\left(\overline{u_{g j}}\right)
$$

This equation is plotted in Figure 2.3 so that a graphical solution for the drift flux $\overline{j_{g f}}$ can be found. If the velocities of the gas phase and liquid phase are known, the drift flux is dependent only on the void fraction. The numbered lines on the graph correspond to different values for the volume flux. The first line represents cocurrent flow. This can be seen because the values for $\overline{j_{f}}$ and $\overline{j_{g}}$ have the same sign and therefore are moving in the same direction. The second line represents stable countercurrent flow. Again, this can be seen because the values for the gas and liquid superficial velocities have different signs and are therefore moving in opposite directions. The third line is tangent to the curve and represents the flooding point. It is the only solution that results in a singular value for the drift flux. The fourth line does not intersect with the curve and has no solution. It is physically impossible. 


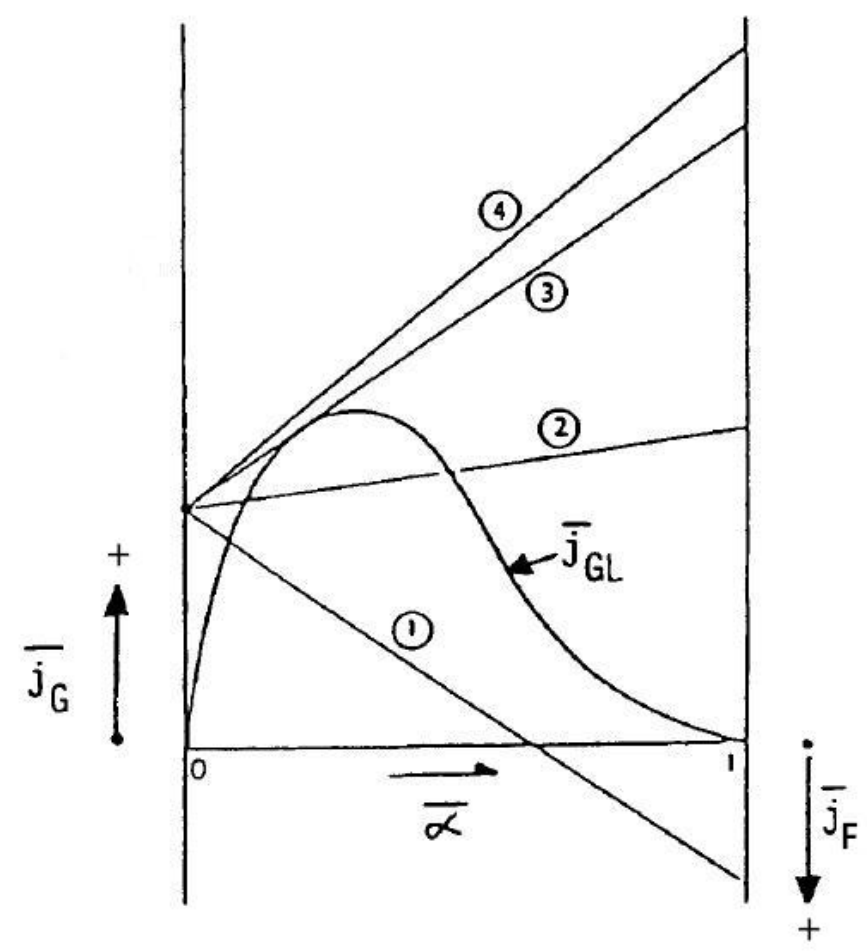

Fig. 2.3.: A graphical solution to flooding [25] which is also known as the flooding curve.

Since Figure 2.3 has three variables, $j_{f}, j_{g}$, and $\alpha$, the curve shown can only be constructed from experimental data. Because of this, the solution will only provide a qualitative picture of flooding. A deterministic prediction of flooding is not possible [25]. Other experimental studies have been performed to further investigate the kinematic wave theory [15,26-28], although more than half of them were conducted on small diameter tubes.

\subsubsection{Upward Liquid Film Flow}

Unlike the kinematic wave theory, the upward liquid film flow model assumes dynamic waves. In this model, a change in the wave amplitude on the fluid surface leads to bridging, which then leads to flooding [26]. This theory is dependent 
on the shear stresses acting on the interface between the gas phase and the liquid phase [29]. Cetinbudaklar [30] argues that the shear forces on the liquid interface can be considered only if the wave is propagating in the same direction as the gas flow.

According to Chung [29], the upward liquid film flow model does not have the acceptance of the Wallis and Kutateladze-type correlations because of the complex analysis. Taitel [31] claims that if the interfacial shear forces are known, then the characteristics of the flooding phenomenon can be found. In addition, entrance effects can be attributed to their effect on interfacial shear, and therfore on flooding. Dukler [32] followed this analysis with an experimental investigation concerning the liquid film movement in vertical tubes. He claims that the upward shear force on the liquid phase from the gas phase is enough to lift a liquid film upwards. In addition, the Reynolds number of the liquid contributes to the friction factor at the interface which affects flooding. The friction factor is proportional to the ratio of the film thickness to the tube diameter. Barnea's work suggests physical agreement with this theory [33].

\subsubsection{Droplet Entrainment}

Dukler [32] was the first to mention the droplet entrainment model with respect to the momentum transfer of entrained droplets of the liquid phase in the gas phase. The model suggests that the small liquid drops that can be seen being ripped from the liquid film just prior to flooding may lead to flooding [34]. Based on this information, flooding occurs when the gas velocity is capable of suspending the largest stable liquid drop. To analyze this problem, a force balance between the drag forces and gravitational forces on a liquid drop must be performed. Moalem [34] calculates the 
gas velocity using the critical Weber number $W e_{c}$ and the drag coefficient $C_{d}$ on the liquid drop.

$$
u_{g}=\left(\frac{4 W e_{c}}{3 C_{d}}\right)\left(\frac{\sigma g\left(\rho_{f}-\rho_{g}\right)}{\rho_{g}^{2}}\right)^{1 / 4}
$$

He also demonstrates that the results of this analysis match the flooding correlation developed by Pushkina $[19,34]$. Based on these conclusions, the droplet entrainment model seems to give a decent approximation to the occurance of flooding. However, the interfacial waves must be small to maintain a high air volume fraction.

\subsection{Previous Steam-Water Flooding Experiments}

Flooding correlations with condensation and heat transfer have largely been variations on the Wallis correlation and the Kutateladze-type correlation. One of the first of these was developed by Tien [20]. Tien incorporated the effect of vapor condensation by the subcooled liquid in the Kutateladze-type correlation. He defined an effective vapor flow $K u_{g e}$ that took into account the reduction in steam flow. He deduced that the condensation latent heat of the saturated steam would be balanced by the specific heat capacity needed to raise the subcooled water to its saturation temperature $[20]$.

$$
K u_{g e}=K u_{g}-f K u_{f}\left(\frac{c_{p} \Delta T_{s u b}}{h_{f g}}\right)\left(\frac{\rho_{f}}{\rho_{g}}\right)^{1 / 2}
$$

The constant $f$ is the fraction of steam that has condensed which is determined empirically. Tien then substituted Equation 2.13 as the gas Kutateladze number into Equation 2.5 [20]. In his equation development Tien makes a number of assumptions. First, he assumes that the steam is saturated without any superheat. While this may be true in some experiments, it says nothing about the effect of superheating the steam. In addition, with superheated steam there is the possibility that it will not condense, but only transfer enough of its energy to become saturated. In this 
case, the fraction of condensed steam is zero, causing Tien's effective gas Kutateladze number to equal the gas Kutateladze number originally calculated.

Another one of Tien's assumptions is that the subcooled water reaches saturation at the point of flooding. Once again, this may be true in some experiments, but it ignores the alternative case. To obtain an accurate calculation using Tien's method, the actual water temperature at the point of flooding must be measured and substituted in Equation 2.13 instead of the saturation temperature. This thesis research determines the axial water temperatures to determine the amount of heating of the liquid along the test section.

Rothe and Crowley [35] developed a similar correlation to Tien [20] using the Wallis correlation. This correlation takes into account the effect of vapor condensation by the subcooled liquid. They also defined an effective vapor flow $j_{g e}^{*}$ that takes into account the reduction in steam flow. Like Tien, they deduced that the condensation latent heat of the saturated steam would be balanced by the specific heat capacity needed to raise the subcooled water to its saturation temperature.

$$
j_{g e}^{*}=j_{g}^{*}-f j_{f}^{*}\left(\frac{c_{p}\left(T_{s}-T_{f}\right)}{h_{f g}}\right) \sqrt{\frac{\rho_{f}}{\rho_{g}}}
$$

Rothe and Crowley inserted Equation 2.14 into Equation 2.3 as the gas Wallis number. The constants $C, m$, and $f$ are determined empirically. Rothe and Crowley made assumptions similar to Tien's in their equation development. In their experiments they used saturated steam, which works with their correlation. They did not study the effect of superheating the steam which is more similar to reactor conditions. In addition, they also assumed that the subcooled water reaches saturation. Without temperature data at the point of flooding, it cannot be known if this is a valid assumption.

One of the conclusions made by Rothe and Crowley [35] from their experimental investigation is that at reasonable values of pressure and subcooling, the saturated water data and subcooled water data are similar. In addition, they addressed pressure scaling issues and concluded that for saturated water behavior in small-scale facilities, 
the dimensionless Wallis parameters properly scale the effect of system pressure. This statement needs to be validated in large diameter tubes.

Crowley [36] studied flooding with steam and water in a pressurized water reactor downcomer annulus. In his experimental setup, he "unwrapped" the annulus to obtain a space between two vertical walls. In 1980 Wallis performed a series of flooding experiments with steam and subcooled water in a "small" diameter tube [37]. In these experiments he varied the inlet and outlet geometry type as well as the operating procedures. He achieved flooding in two different ways. The first was by increasing the steam flow rate with a steady water flow rate, called "water first" experiments. He also achieved flooding by increasing the water flow rate with a steady steam flow rate, called "steam first" experiments.

Wallis first examined the data from Crowley and added a thermodynamic ratio term to a plot of his data $[36,37]$. This thermodynamic ratio $R_{T}$ is a ratio between the energy required to heat the water up to its saturation temperature and the energy required to condense the steam. When $R_{T}=1$, there is just enough water flow to condense all of the steam.

$$
R_{T}=\frac{w_{f} c_{p}\left(T_{s}-T_{f}\right)}{w_{g} h_{f g}}
$$

Using $R_{T}=1$ Wallis rearranged the terms in Equation 2.15 to obtain a relationship between the Wallis numbers.

$$
j_{g}^{*}=\left(\frac{\rho_{f}^{1 / 2} c_{p}\left(T_{s}-T_{f}\right)}{\rho_{g}^{1 / 2} h_{f g}}\right) j_{f}^{*}
$$

Wallis plotted Equation 2.16 with his data [37]. One plot of his results can be seen in Figure 2.4. In this plot, the steam-water flooding data can be seen with two different trends. Boundary 1 represents the first trend where the steam flow required to achieve flooding decreases with increasing water flow. Boundary 2 represents the second trend where the steam flow required to achieve flooding increases with increasing water flow. It is important to note that neither boundary lies on the line from Equation 2.16. Instead, it appears that the line from Equation 2.16 crosses 
the data where the two boundaries intersect at a minimum gas Wallis parameter. Despite these findings, neither Wallis nor Crowley produced a flooding correlation specific to steam and water.

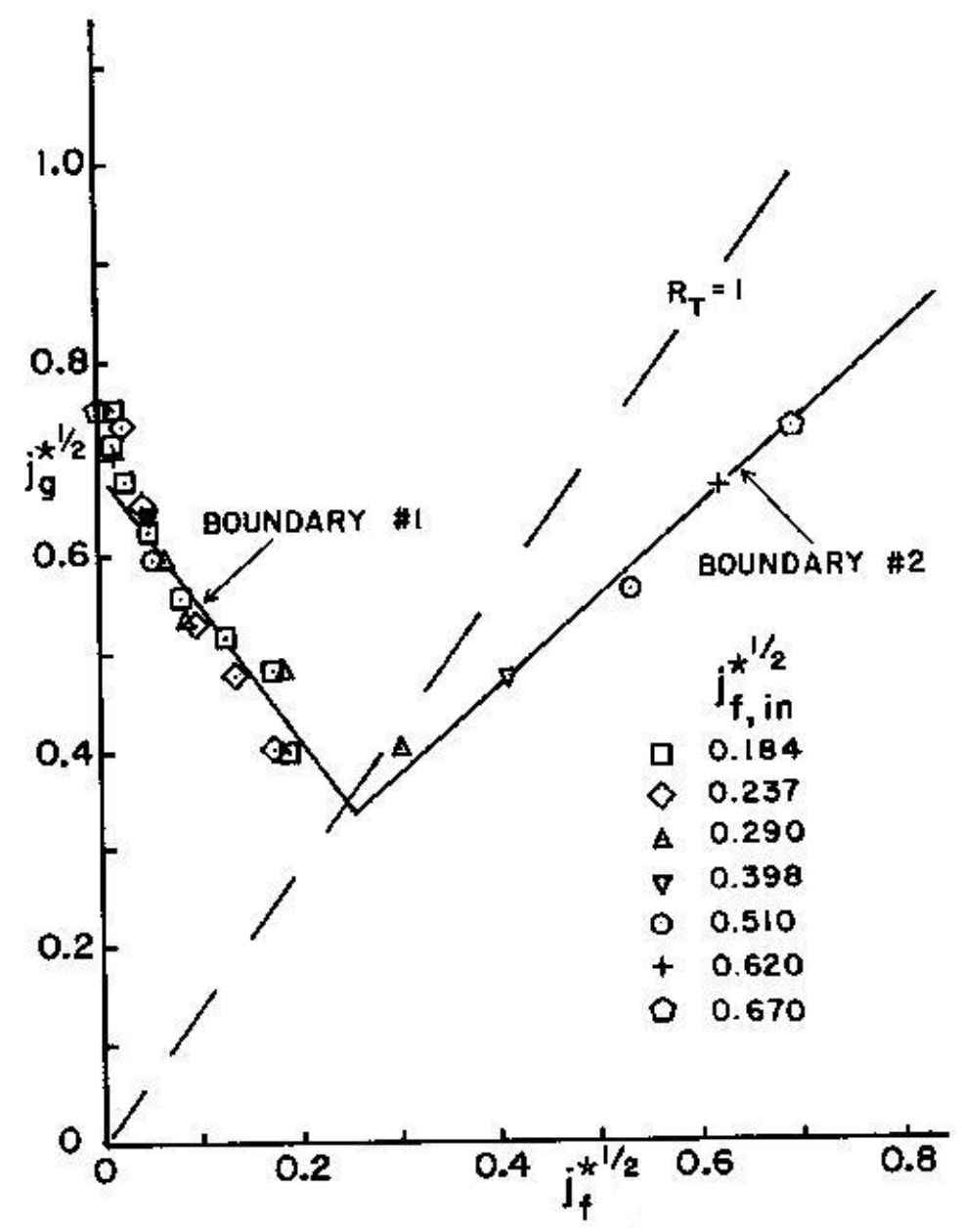

Fig. 2.4.: Flooding data from Wallis plotted against Equation 2.16 [37].

The trends seen in the data from Wallis [37] and Crowley [36] are not present in air-water flooding data. This means that steam condensation is an important parameter that affects flooding in non-adiabatic systems. Furthermore, it means that researchers lack a complete understanding of flooding with steam and water and more detailed studies are needed. 
Flooding experiments with steam and water have also been performed in inclined channels. The mechanics of flooding in inclined channels is different from the mechanics of flooding in vertical tubes. In vertical tubes there is annular flow while in inclined tubes there is stratified flow. Flooding experiments with steam and water performed in inclined channels can be found in the literature [38-40]. 


\section{SCALING ANALYSIS AND FACILITY CHARACTERIZATION}

An experimental investigation using a full scale typical PWR pressurizer surge line cannot be performed so a scaled down facility has been designed and constructed. This section discusses the prototype PWR pressurizer surge line and the scaled down dimensions of the experimental facility. This section also covers the geometric dependencies on flooding and how these are taken into consideration with the design of the current facility. In addition, it describes the characterization of the water flow inside the test section.

\subsection{Geometry}

The geometry of the test section is very important to consider when designing a flooding experiment. Wallis was the first to report that the entrance geometry affects the conditions inside the test section [15]. He classified entrances as "smooth" and "sharp" and discovered that flooding occurs under different conditions for both types. In addition, tube diameter is a primary factor that must be properly scaled in the current research. The configuration of the diffuser inside the pressurizer and pressurizer surge line determine the flow regime that must be reproduced in the test section. The entrance geometry, tube diameter, and flow regime are discussed as well as how they impact the design of the facility.

\subsubsection{Entrance and Exit Effects}

The "smooth" entrance that Wallis refers to indicates rounded flanges where the water enters the test section. The "sharp" entrance indicates flat flanges where the water enters the test section so that the water passes over a sharp edge as opposed to a round one [15]. The water exit is also classified as "smooth" and "sharp." Chung [29] further explained this effect and determined that the entrance and exit 
distrubances affect the diameter dependence of the facility. He then suggested that the constants used in the Kutateladze-type correlation be altered to agree with experimental data for different geometry types. In the end Chung concluded that the effect of the entrance conditions decreases with an increase of the test section diameter. McQuillan [24] suggested that the disagreement in the flooding data is a result of differing entrance conditions.

Wallis [37] performed a series of steam-water tests using both smooth and sharp entrance and exit geometries. He discovered that a smooth water exit on the test section tended to disperse the water over a larger volume and provided a larger interface between the water and steam in the steam entrance plenum. This in turn led to more steam condensation. Wallis also came to the conclusion that disagreement in flooding data is a result of different entrance and exit conditions.

\subsubsection{Tube Diameter}

The test section diameter is an important geometric consideration. In an early flooding experiment, Wallis determined that the flooding point has a dependence on the test section diameter [15]. He illustrated this dependence by incorporating the test section diameter into the Wallis parameters seen in Equation 2.1 and Equation 2.2. The dependence on the test section diameter is not specific to the transition between countercurrent flow and cocurrent flow, but works between other flow regimes [41]. Pushkina [19] claims that there is not a test section diameter dependence on flooding other than the limit to the Bond number. Many experimental and theoretical studies have been performed to determine the accuracy of each correlation with different diameters $[6,24,26,42,43]$.

Despite the numerous studies on test section diameter dependence, it is still unclear what diameter should be used as a cutoff between large and small pipes. Richter [43] suggested pipes with a diameter less than $50.8 \mathrm{~mm}$ should be considered small, while pipes with a diameter greater than $152 \mathrm{~mm}$ should be considered 
large. Unfortunately, there is a large gap of pipe diameters that are not addressed. Jayanti [44] claims that a diameter dependence is limited only to its effect on the droplet entrainment and wave transport flooding mechanisms. He argued that as the diameter of the test section increased, the gas velocity required to deliver entrained liquid out of the test section is less than the gas velocity required to move a wave up the test section. He does not provide a pipe diameter for this transition to occur.

Vijayan [18] performed flooding experiments with several different test section diameters to fill in the gaps from other studies. He used three different test section diameters of 25, 67 and $99 \mathrm{~mm}$. He discovered that flooding in the $25 \mathrm{~mm}$ test section occured via the upward movement of large waves, while flooding in the 67 and $99 \mathrm{~mm}$ test sections occured by droplet entrainment. He concluded that test section diameters above $67 \mathrm{~mm}$ can be considered large and the Kutateladze-type correlation should be used.

\subsubsection{Inducing Annular Flow}

The surge line geometry is particular to every reactor and may consist of several pipe sections at various inclinations. This thesis focuses on the section of pipe connected to the pressurizer. Descriptions of the diffuser at the bottom of the pressurizer tank, which determines the water flow configuration into the surge line, are difficult to obtain. As predicted by the SCDAP/RELAP5 code for a typical 4-loop Westinghouse PWR in natural circulation during a hypothetical station blackout [9], the flow regime in the junction where the surge line connects to the hot leg is bubbly flow. The flow regime in the junction where the surge line connects to the pressurizer is either slug or annular flow.

Two types of diffuser configurations are described herein [45]. In the first configuration, the cylindrical wall of the surge line is extended about 2 feet $(0.61 \mathrm{~m})$ into the bottom of the pressurizer tank and is capped on top with a solid circular plate. Liquid flow passes through rectangular axial slots located around the periphery of 
the cylindrical pipe. In the second configuration, the surge line terminates with a smooth penetration on the bottom of the tank. The diffuser is a hemispherical screen covering the surge line opening on the bottom of the tank. The screen is constructed of a perforated plate with circular holes. For the current research, the simplifying assumption is made that the diffuser configuration will produce an annular liquid film inside the surge line.

Since the liquid film inside the pressurizer surge line is assumed to be in the annular flow regime, care must be taken to ensure that the liquid inside the test section forms a continuous annular film. Several air-water characterization tests were run with the steam inlet and steam outlet removed from the test section. Looking down from the top, the inside of the test section can be seen along with the liquid film. Figure 3.1 shows a picture of the inside of the test section with the falling liquid film. The water is flowing at 2.5 GPM $\left(0.00016 \mathrm{~m}^{3} / \mathrm{s}\right)$. The image has been enhanced so that the liquid film is easier to see.

For water flow rates below about $3 \mathrm{GPM}\left(0.00019 \mathrm{~m}^{3} / \mathrm{s}\right)$ a continuous liquid annular film was not produced for a significant period of time. Because of this, the minimum water flow rate for steam-water flooding tests is 3.5 GPM $(0.00022$ $\left.\mathrm{m}^{3} / \mathrm{s}\right)$. For water flow rates between 3.5 and 8 GPM $\left(0.00022\right.$ and $\left.0.00050 \mathrm{~m}^{3} / \mathrm{s}\right)$ a continuous liquid annular film was produced a portion of the time. To ensure an annular film, the water flow rate first had to be increased to about 8 GPM $(0.00050$ $\mathrm{m}^{3} / \mathrm{s}$ ) to form an annular film, then reduced to the desired water flow rate where the film remained annular.

Both the water and the steam flowing through the test section are in turbulent flow. This was determined by calculating the Reynolds number based on the superficial velocity for each phase using Equation 3.1. For the water, all of the Reynolds numbers were above 9,000. For the steam, all of the Reynolds numbers were above 


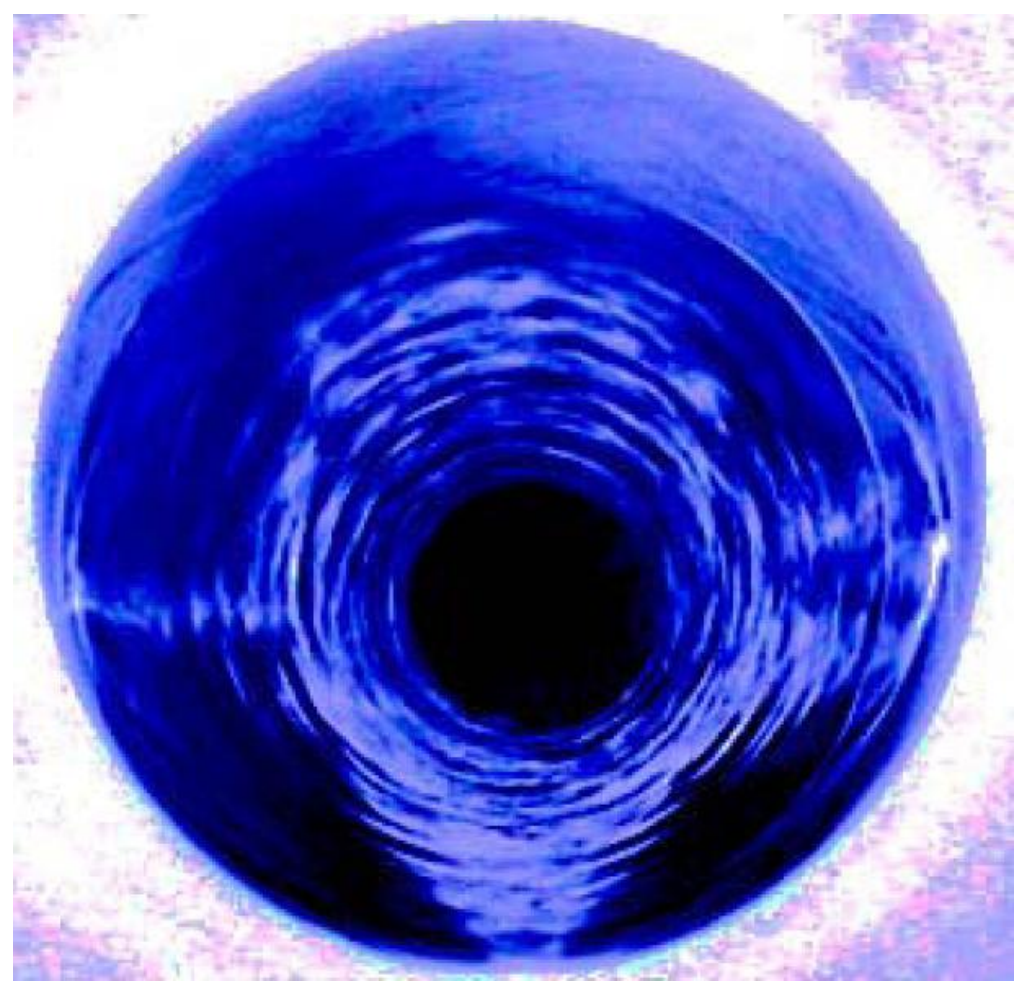

Fig. 3.1.: Annular film inside the test section.

32,000 . Since all of the Reynolds numbers are above 2,300 , both the water and the steam are turbulent [46].

$$
R e_{i}=\frac{\rho_{i} j_{i} D}{\mu_{i}}
$$

The film thickness of the annular liquid film was calculated using Equation 3.2 [11, 47]. As the water flow rate increases, the film thickness also increases. The film thickness ranges from $0.5 \mathrm{~mm}$ to $0.75 \mathrm{~mm}$ for the water flow rates used. Figure 3.2 shows a plot of the film thickness versus water flow rate.

$$
\delta=0.909\left(\frac{\nu_{f}^{2}}{g\left(1-\frac{\rho_{g}}{\rho_{f}}\right)}\right)^{1 / 3} R e_{f}^{1 / 3}
$$




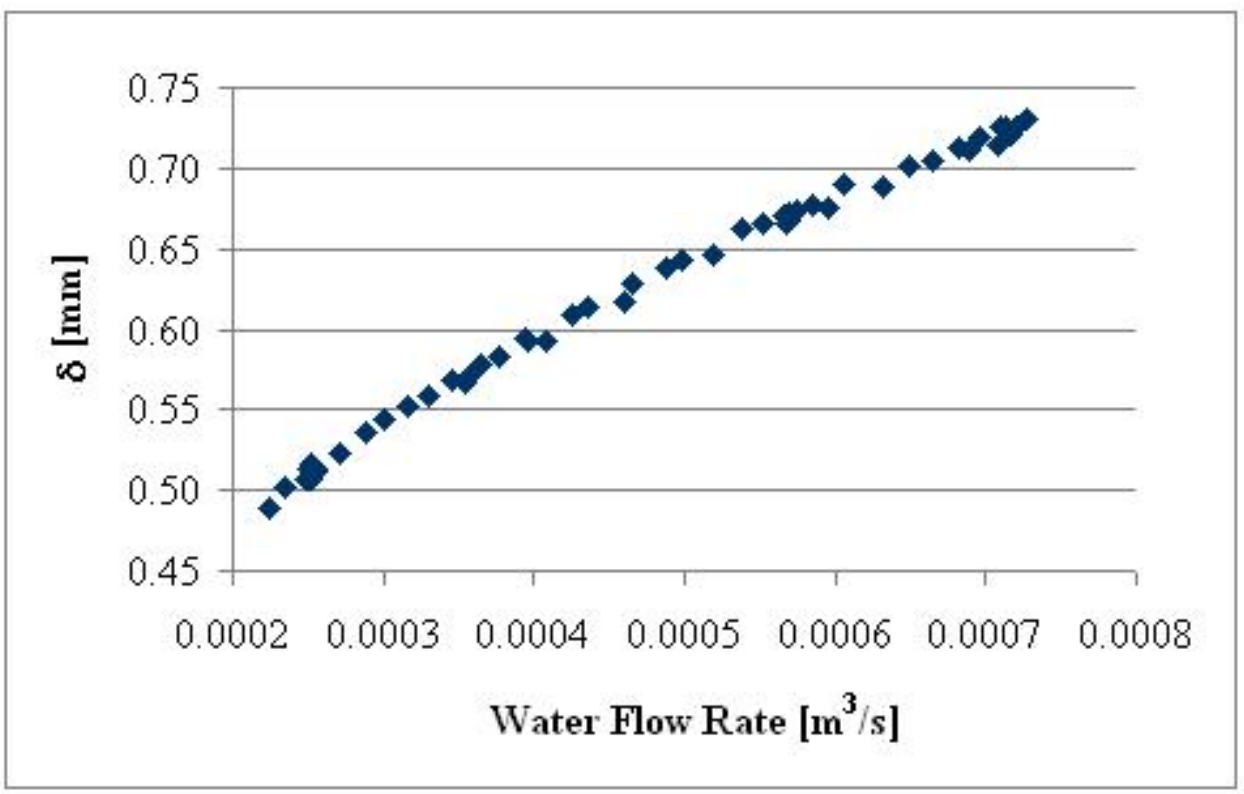

Fig. 3.2.: Film thickness of the annular liquid film plotted with water flow rate.

\subsection{Steam First Versus Water First Operating Procedures}

Wallis [37] ran a series of flooding tests with steam and water that utilized two procedures to achieve flooding. The first was called "water first" where a fixed water flow rate was established in the facility and the steam flow rate was increased. The second was called "steam first" where a fixed steam flow rate was established in the facility and the water flow rate was increased. As seen in Figure 3.3, different boundaries for flooding are obtained with the two different procedures.

Boundaries 1 and 2 are for water first tests and boundaries 3 and 4 are for steam first tests. Boundaries 1 and 3 represent the conditions in which flooding occurs for low water flow rates. For both procedures this boundary remains the same. Boundaries 2 and 4 represent the conditions in which flooding occurs for high water flow rates. The boundary for the water first tests is not the same as the boundary for the steam first tests. Boundary 5 represents the steam flow rate at which partial water delivery no longer occurs and complete flow reversal is present. The procedure 


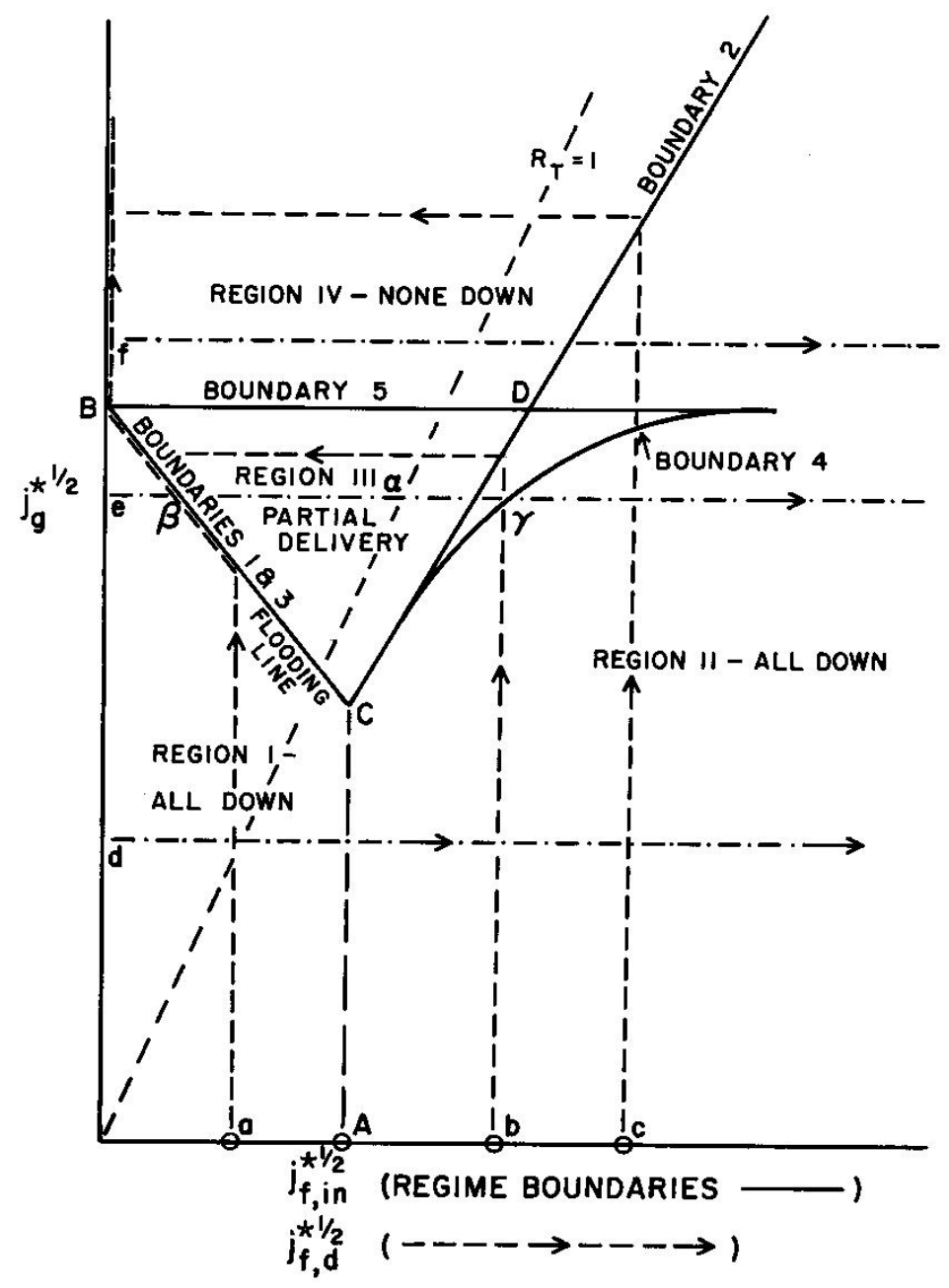

Fig. 3.3.: Flooding boundaries recorded by Wallis [37].

followed in the current research is water first because a fixed water flow rate is established before steam flows through the experiment.

\subsection{Results of Scaling Analysis}

The top of the test section is unique in its design compared to previous flooding experiments and does not exactly match the descriptions of "smooth" or "sharp" entrances given by Wallis [15]. However, the steam-water facility is considered to 
have a "sharp" test section entrance and exit. This geometry was chosen so that it would induce an annular film inside the test section without interfering with the steam exiting the test section.

Since a reference PWR pressurizer surge line inner diameter is 10 inches (250 $\mathrm{mm})$, the experimental facility must have a large diameter test section. An inner diameter of 3 inches, or $76.2 \mathrm{~mm}$, was chosen for the test section based on the criteria by Vijayan [18]. In previous air-water flooding tests 72 inches, or $1.83 \mathrm{~m}$, provided sufficient length for flooding to occur [23]. A tube length of 72 inches $(1.83 \mathrm{~m})$ was chosen to allow sufficient length for flooding in the current steam-water tests.

The fluid density ratio in a PWR cannot be reproduced in flooding experiments with air and water. The current flooding experiment with steam and water has a lower steam to water density ratio than in an actual PWR system because the tests are run at a lower pressure. The current facility was built to operate at atmospheric pressure because capping off the ends of the test section to pressurize it would affect the flooding phenomenon.

Liao [8] evaluated the expected conditions in a PWR surge line and estimated a liquid Reynolds number of about 218,000 based on a $j_{f}$ of $0.1 \mathrm{~m} / \mathrm{s}$, a system pressure of 160 bar, and a temperature of $630 \mathrm{~K}$. This Re cannot be preserved in the current research, but the liquid Froude number can be. The liquid phase Froude number is estimated to be about 0.0004 for the actual system. The same liquid Froude number requires a $j_{f}$ of $0.055 \mathrm{~m} / \mathrm{s}$. The corresponding water volumetric flow rate of $4.2 \mathrm{GPM}$ $\left(0.00026 \mathrm{~m}^{3} / \mathrm{s}\right)$ is within the capabilities of the current facility.

Chung [29] reasoned that an increase in liquid viscosity will result in flooding at a lower air flow rate because waves on the film surface are formed with smaller radii of curvature. Counteracting this destabilizing effect, viscosity also has a damping effect on interface oscillation, thereby delaying the onset of an instability. The destabilizing effect of increased liquid viscosity was confirmed by experiment, however the effect is only important when the viscosity is changed by an order of magnitude or more. 
Zapke and Kroger [48] refute the conclusion that liquid viscosity has a small effect by plotting Chung's data in terms of a dimensionless parameter that demonstrates the non-negligible effect of liquid viscosity. The liquid viscosity in the current experiment is lower that the liquid viscosity used in previous air-water flooding experiments.

A Wallis type dimensionless volumetric flux was used for scaling. The results of the scaling analysis are provided in Table 3.1. The test section pressure is maintained at atmospheric pressure. While the tests would ideally be performed at higher pressures, a lower pressure was chosen because key flooding parameters such as the superficial velocities can be matched. Furthurmore, there are safety and equipment limitations for higher pressure tests. It is noted that most flooding experiments with steam and water have been performed at atmospheric pressure. 
Table 3.1: Scaling of surge line specifications and reactor conditions.

\begin{tabular}{|c|c|c|c|}
\hline Parameter & Surge Line & Experiment & Comment \\
\hline $\begin{array}{l}\text { Test Section } \\
\text { Diameter }(\mathrm{mm})\end{array}$ & 250 & 76.2 & "Large" diameter \\
\hline $\begin{array}{l}\text { Test Section } \\
\text { Length }(\mathrm{m})\end{array}$ & $\begin{array}{l}\text { Reactor } \\
\text { specific }\end{array}$ & 1.83 & \\
\hline $\begin{array}{l}\text { Test Section } \\
\text { Inclination } \\
\text { (degrees) }\end{array}$ & $0-90$ & Vertical & $\begin{array}{l}\text { Surge line is com- } \\
\text { prised of multiple } \\
\text { pipe section }\end{array}$ \\
\hline $\begin{array}{l}\text { Facility Pressure } \\
(\mathrm{atm})\end{array}$ & 160 & 1 & $\begin{array}{l}\text { Determines fluid } \\
\text { density ratio }\end{array}$ \\
\hline $\begin{array}{l}\text { Steam } \\
\text { Temperature }\end{array}$ & $\begin{array}{l}\text { Saturated } \\
\text { to } 25 \quad \mathrm{~K} \\
\text { superheat }\end{array}$ & $\begin{array}{ll}10 & K \\
\text { superheat } & \end{array}$ & \\
\hline $\begin{array}{l}\text { Water } \\
\text { Temperature }\end{array}$ & $\begin{array}{l}\text { Subcooled to } \\
\text { saturated }\end{array}$ & Subcooled & \\
\hline $\begin{array}{l}\text { Liquid Superficial } \\
\text { Velocity }(\mathrm{m} / \mathrm{s})\end{array}$ & 0.055 & 0.055 & $\begin{array}{l}\text { Corresponds to } 4.2 \\
\operatorname{GPM}\left(0.00026 \mathrm{~m}^{3} / \mathrm{s}\right)\end{array}$ \\
\hline
\end{tabular}




\section{FACILITY DESCRIPTION}

The major components of the steam-water test facility are the test section tube, water supply system, steam supply system, steam-water outlet at the upper end of the test section, and water collection and recirculation system. The facility, including the test section, was constructed out of stainless steel (SS304) to withstand the steam and hot water environment. The entire facility was insulated with 2-inch $(51 \mathrm{~mm})$ thick fiberglass insulation to prevent steam condensation and cooling of the hot water in the delivery piping and to minimize other heat losses. A schematic of the entire system can be seen in Figure 4.1. In addition, engineering drawings of the test section can be found in Appendix A.

\subsection{Test Section Tube}

The steam-water test section tube was designed similar to the air-water test section tube from Solmos [23]. This was done to provide a second facility to compare data. The test section tube is a 72-inch $(1.83 \mathrm{~m})$ long, 3-inch $(76.2 \mathrm{~mm})$ ID tube with 1/4-inch $(6.35 \mathrm{~mm})$ wall thickness. There are five 1/8-inch $(3.17 \mathrm{~mm})$ NPT threaded half couplings welded to the test section tube for pressure and thermocouple ports. Three ports are located 14.5 inches $(0.37 \mathrm{~m})$ from the top of the test section tube and two are located 2 inches $(0.05 \mathrm{~m})$ from the bottom of the test section tube. Two of the top ports and both of the bottom ports are pressure ports while the remaining top port is a thermocouple port. A mounting bracket is welded 18 inches $(0.46 \mathrm{~m})$ below the top of the test section tube to support the weight of the structure. The mounting bracket is attached to a pillow block bearing via two 3/8-inch $(9.52 \mathrm{~mm})$ bolts that rest on a 1-inch $(25.4 \mathrm{~mm})$ stainless steel rotational rod. The size of the bearings and rod were chosen so that it could hold the largest possible mass of the test section filled with water with a factor of safety. In addition, a second mounting bracket is welded 6 inches $(0.15 \mathrm{~m})$ from the bottom of the test section tube and is 


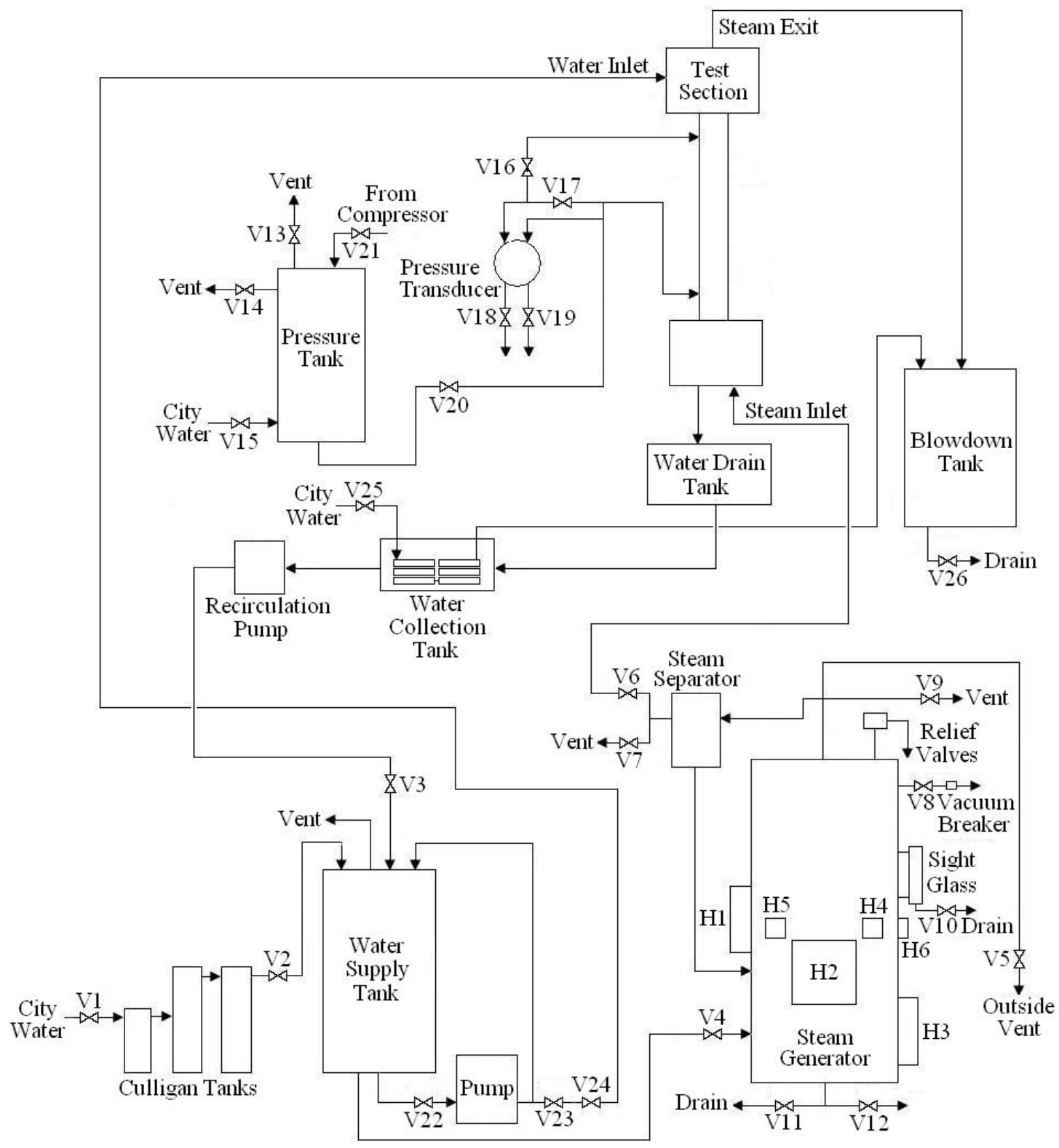

Fig. 4.1.: A schematic of the entire test facility. 
attached to a hook so that the structure may be inclined. For vertical tests, a pipe clamp was attached to the test section tube to hold it in a vertical position. The test section can be seen prior to insulation in Figure 4.2.

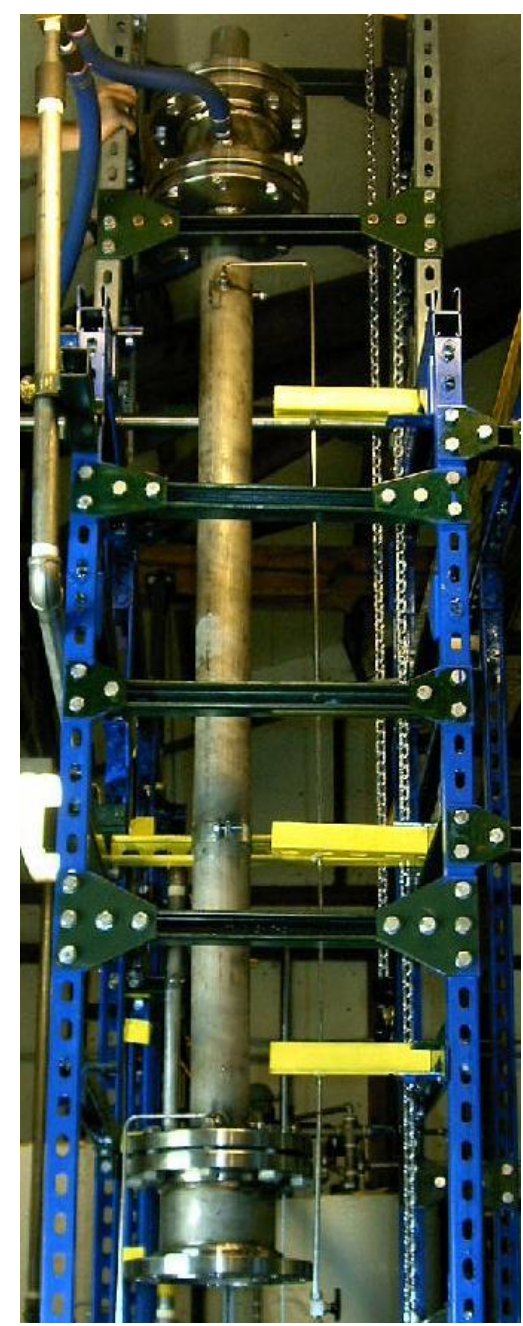

Fig. 4.2.: The test section prior to insulation. 


\subsection{Water Supply System}

The water supply system consists of the Culligan Water Services tanks, a water storage tank, a hot water pump, and a water injection device. Deionized water is used for both the steam and water in the facility. The water is treated by Culligan Water Services filters. City water passes through the Culligan tanks and is stored in a large water storage tank. The water storage tank is a 24-inch $(0.61 \mathrm{~m})$ diameter, 7.5 -foot $(2.28 \mathrm{~m})$ tall vessel. It is open to the atmosphere to prevent it from being pressurized. It also has a $5 \mathrm{~kW}$ heater to maintain an appropriate water temperature.

The hot water pump is a Deanline Vertical Incline pump and pumps water up to 13 GPM $\left(0.00082 \mathrm{~m}^{3} / \mathrm{s}\right)$ into the test section. The pump uses 1/2-horsepower (373 $\mathrm{W})$ and the maximum operating temperature is $250^{\circ} \mathrm{F}\left(121^{\circ} \mathrm{C}\right)$. Two gate valves are located in series after the pump on the water line to control the flow rate of water into the test section.

The water injection device in the steam-water facility was designed similar to the air-water water injection device from Solmos [23]. It allows the creation of an annular falling film inside the test section and allows for unimpeded flow of steam out of the test section. The design consists of a 7 3/8-inch $(0.19 \mathrm{~m})$ long, 6-inch (152 mm) pipe acting as a plenum surrounding the top of the 3-inch $(76.2 \mathrm{~mm})$ ID, 3.5-inch (88.8 mm) OD test section tube. There are four 3/4-inch $(19 \mathrm{~mm})$ NPT threaded half couplings welded to the plenum to facilitate water injection that are spaced at 90 degrees from each other. Only two of them are used for experimental tests in this research. Twelve $1 / 4$-inch $(6.35 \mathrm{~mm})$ holes were drilled into the top portion of the test section tube equally spaced along the circumference. A 2-3/4 inch (69.8 $\mathrm{mm})$ OD , 2-1/4 inch (57 $\mathrm{mm}$ ) ID tube is inserted inside the test section to create an annular film approximately 1/8-inch $(3.17 \mathrm{~mm})$ thick. Water enters the plenum, flows through the twelve 1/4-inch $(6.35 \mathrm{~mm})$ holes where it comes into contact with the inner tube and is forced downward into the test section. Both the bottom and top of the tube have a bevel of 15 degrees to the vertical. The purpose of the bevel 
is to prevent the formation of vortices and prevent disrupting the water inlet. A picture of the water inlet can be seen in Figure 4.3.

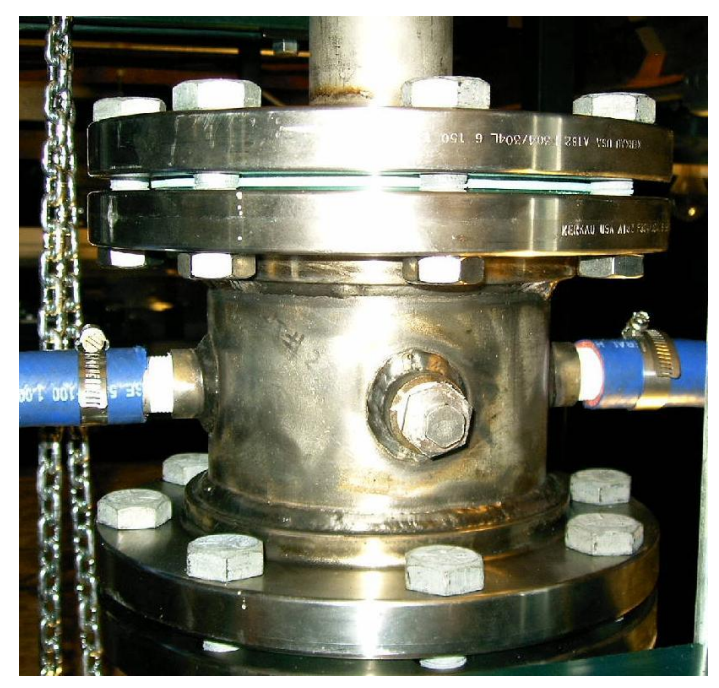

Fig. 4.3.: The water injection device prior to insulation.

A cross sectional schematic of the water injection device can be seen in Figure 4.4. The outer ring represents the plenum surrounding the top of the test section tube. There are two holes spaced opposite of each other that represent the path of the water into the plenum. The middle ring represents the test section tube. There are twelve evenly spaced holes that represent the twelve 1/4-inch $(6.35 \mathrm{~mm})$ holes drilled into the test section tube. The inner ring represents the inner tube. When water flows through the twelve holes in the test section tube, it comes into contact with the inner tube and an annular film is induced. The gap between the inner tube and the test section tube is $1 / 8$-inch $(3.17 \mathrm{~mm})$.

\subsection{Steam Supply System}

The steam supply system consists of the Culligan Water Services tanks, the steam generator, and the steam injection device. In addition, filters in the tanks remove 


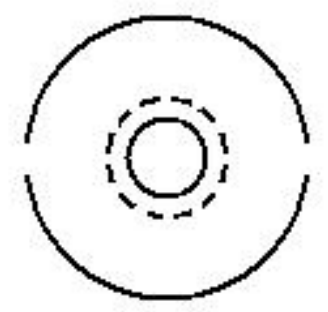

Fig. 4.4.: A cross sectional schematic of the water injection device.

large particles of dirt from the water. The Culligan Water Services tanks are connected to the water storage tank. The water storage tank is connected to the steam generator. The deionized water is able to flow between the water storage tank and the steam generator when the steam generator is depressurized and a valve is opened. In this way, the water storage tank and the steam generator can be refilled at the same time.

The steam generator was designed and manufactured for previous projects and consists of a pressure vessel, immersion heaters, and a control panel. The pressure vessel was manufactured by Kennedy Tank and Manufacturing Co., Inc in Indianapolis, IN. The steam generator is shown uninsulated in Figure 4.5 and insulated in Figure 4.6. The pressure vessel shell is Schedule 10 stainless steel 304 pipe, 60 inches $(1.52 \mathrm{~m})$ in height and 24 inches $(0.61 \mathrm{~m})$ in diameter, along with two 24 -inch $(0.61 \mathrm{~m})$, Schedule 10 stainless steel end caps that were welded to the top and bottom of the body. A drain line from the center of the bottom cap, two blowdown lines from the top, weld necks for the heaters and several other penetrations were added. The vessel was built for $150 \mathrm{psi}$ (10.3 bar) and hydrotested at $180 \mathrm{psi}$ (12.4 bar) for 12 hours.

The two pressure relief valves are $1 / 2$-inch $(12.7 \mathrm{~mm})$ bronze valves manufactured by Kunkle and are factory set to open at 105 psig $(7.24$ bar $)$. A vacuum breaker line with a check valve inboard of the vacuum breaker is also attached. During cool 


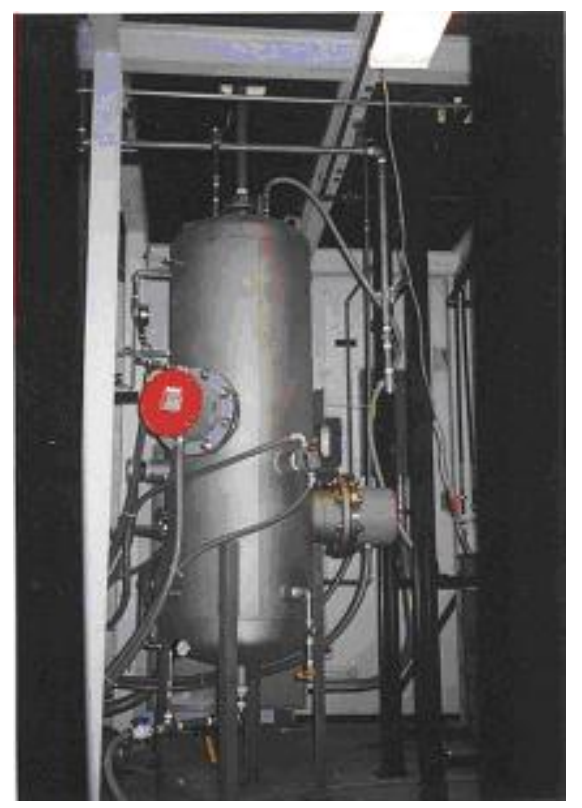

Fig. 4.5.: The steam generator before insulation.

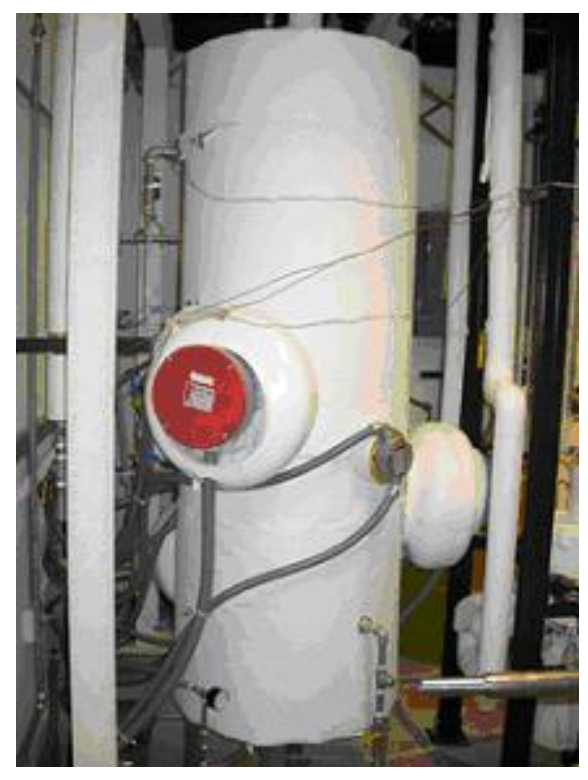

Fig. 4.6.: The steam generator after insulation.

down, the pressure falls below atmospheric pressure, causing the vacuum breaker valve to open. This allows air to flow into the steam supply and avoids placing the 
vessel under a vacuum. An air filter inside the vacuum breaker prevents dust from entering the pressure vessel.

There are three 8-inch $(0.2 \mathrm{~m})$, flanged immersion heaters manufactured by Watlow Process Systems used for the current project. The heaters have inconel sheaths. Each heater has a total output of $50 \mathrm{~kW}$. Two of the heaters have two $25 \mathrm{~kW}$ circuits and one heater has eight $6.25 \mathrm{~kW}$ circuits. The possible power levels are up to 150 $\mathrm{kW}$ in increments of $6.25 \mathrm{~kW}$. Type $\mathrm{K}$ thermocouples are used to measure the heater sheath temperature. Watlow Series 146 Temperature Regulators receive the thermocouple signal and break the circuit if an overtemperature condition is detected. The temperature regulators are set to activate when the sheath temperature exceeds $600{ }^{\circ} \mathrm{F}\left(316^{\circ} \mathrm{C}\right)$.

Power is supplied to the steam generator from a $200 \mathrm{amp}, 180 \mathrm{~kW}$ source via the control panel. The control panel was custom designed and manufactured by Watlow. Up to $50 \mathrm{~kW}$ may be supplied to each of the heaters.

Orion instruments supplied the magnetic liquid level indicator. This device shows the water level inside the steam generator without exposing glass to high pressure, as is the usual design of sight glasses. The Atlas model indicator comes with a Reed switch device to shut off all heater power when the liquid level falls below a prescribed level of $35 \mathrm{~cm}$ on the sight glass.

A separator removes water droplets from the steam exiting the steam supply. Because the separator is also a pressure vessel, an ASME-certified unit from Clark Reliance Corporation was installed. A one inch $(25.4 \mathrm{~mm})$ stainless steel steam line is used to transport steam from the separator to the steam line. The steam line expands to a 1-1/2 inch $(38.1 \mathrm{~mm})$ line before it enters the test section. A vortex flow meter for measuring the steam flow rate is on the $1-1 / 2$ inch $(38.1 \mathrm{~mm})$ steam line.

The steam injection device consists of a 7-inch $(0.18 \mathrm{~m})$ long, 6-inch $(0.15 \mathrm{~m})$ pipe acting as a plenum. Within the plenum, a 1 1/2-inch $(38.1 \mathrm{~mm})$ pipe serves as 
the steam inlet. It is insulated by a 2 -inch $(50.8 \mathrm{~mm})$ pipe and reducing coupling welded at the top and bottom to create an air pocket. This air pocket minimizes steam condensation before entering the test section.

\subsection{Steam Outlet}

The steam outlet must be leak-tight to prevent any exiting steam and hot water from ejecting into the laboratory. Attached to the $23 / 4$-inch $(69.8 \mathrm{~mm})$ OD, 2 $1 / 4$-inch $(57.1 \mathrm{~mm})$ ID tube in the water injection device is a $23 / 4$-inch $(69.8 \mathrm{~mm})$ silicone hose. This hose is able to withstand up to $250{ }^{\circ} \mathrm{F}\left(121^{\circ} \mathrm{C}\right)$ which is greater than the temperatures achieved during a test. In addition, the silicone hose has the added benefit of being flexible. The hose connects the top of the test section to a 55 gallon $(208 \mathrm{~L})$ drum that acts as a blowdown tank. The drum has a hose of city water constantly running into the top of it to condense the exiting steam. At the bottom of the drum a hose is connected to drain the heated water and condensed

steam. Another hose open to the atmosphere is attached at the top of the drum to ensure that the drum does not become pressurized. The blowdown tank can be seen in Figure 4.7.

\subsection{Water Collection and Recirculation}

To prevent the need for constantly deionizing new water, a water recirculation system was installed. The hot water exits at the bottom of the test section via four hoses and collects in a stainless steel tank. The stainless steel tank drains into a larger tank made of aluminum. The aluminum tank contains two coiled copper tubes. City water runs through the copper tubes to cool the hot water exiting the test section. The water in the aluminum tank then runs through a small recirculation pump back into the water storage tank. The recirculation pump can not operate with water temperatures close to saturation so it is necessary to cool the water to prevent 


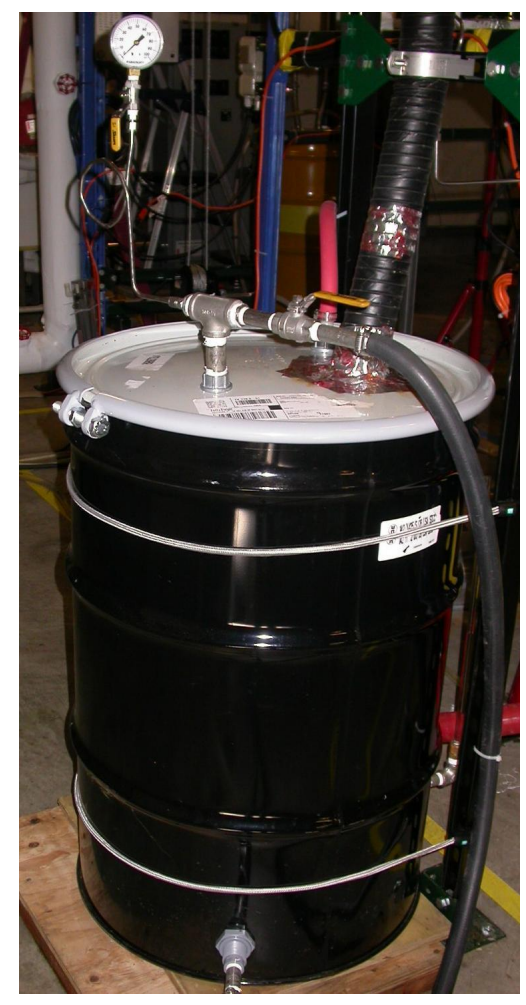

Fig. 4.7.: The steam-water outlet hose connected to the blowdown tank.

cavitation in the pump. The coiled copper tubes cool the water by about $30{ }^{\circ} \mathrm{C}$. Information about the equipment used in the facility is listed in Table 4.1.

\subsection{Instrumentation}

A total of 14 temperatures, 6 absolute pressures, 2 differential pressures, and 2 flow rates are recorded. The data is recorded by a data acquisition system assembled from National Instruments components. The LabVIEW software is used to display and save data. The locations of the instrumentation are shown in Figure 4.8. 
Table 4.1: The equipment used in the steam-water facility.

\begin{tabular}{|c|c|c|}
\hline Equipment & Model & Range \\
\hline $\begin{array}{l}\text { Culligan Water Services } \\
\text { Tanks }\end{array}$ & Mixed Bed System & $\mathrm{N} / \mathrm{A}$ \\
\hline Hot Water Pump & $\begin{array}{l}\text { Deanline Vertical Incline } \\
100412\end{array}$ & $\begin{array}{l}0-13 \text { GPM } \\
(0-0.00082 \\
\left.\mathrm{m}^{3} / \mathrm{s}\right)\end{array}$ \\
\hline $\begin{array}{l}\text { Steam Generator } \\
\text { Pressure Vessel }\end{array}$ & $\begin{array}{l}\text { Kennedy Tank and } \\
\text { Manufacturing Co. }\end{array}$ & $\begin{array}{l}0-135 \text { psig }(0 \\
-9.3 \text { bar })\end{array}$ \\
\hline $\begin{array}{l}\text { Pressure Relief Valves } \\
\text { on Steam Generator }\end{array}$ & $\begin{array}{l}\text { Kunkle } \\
\text { 6021DC01-AM0105 }\end{array}$ & $\begin{array}{l}\text { Set pressure } \\
\text { of } 105 \text { psig } \\
(7.24 \text { bar })\end{array}$ \\
\hline Immersion Heaters & Watlow Process Systems & $0-50 \mathrm{~kW}$ \\
\hline
\end{tabular}

\subsubsection{Instruments and Equipment}

Temperature measurements are made at the water inlet, steam inlet, water exit, along the test section, and steam generator. There are three temperature measurements taken on the outside surface of the test section. In addition, a temperature measurement is taken inside the top of the test section in the vapor space. All of the thermocouples are T-type (copper-constantan). All but the surface thermocouples on the test section tube are mounted through CONAX fittings sealed with Teflon disks. The surface thermocouples on the test section are attached with a high temperature epoxy.

Honeywell absolute pressure transducers are used for measurements on the steam line, the water line, and the water collection tank. An Omega absolute pressure 


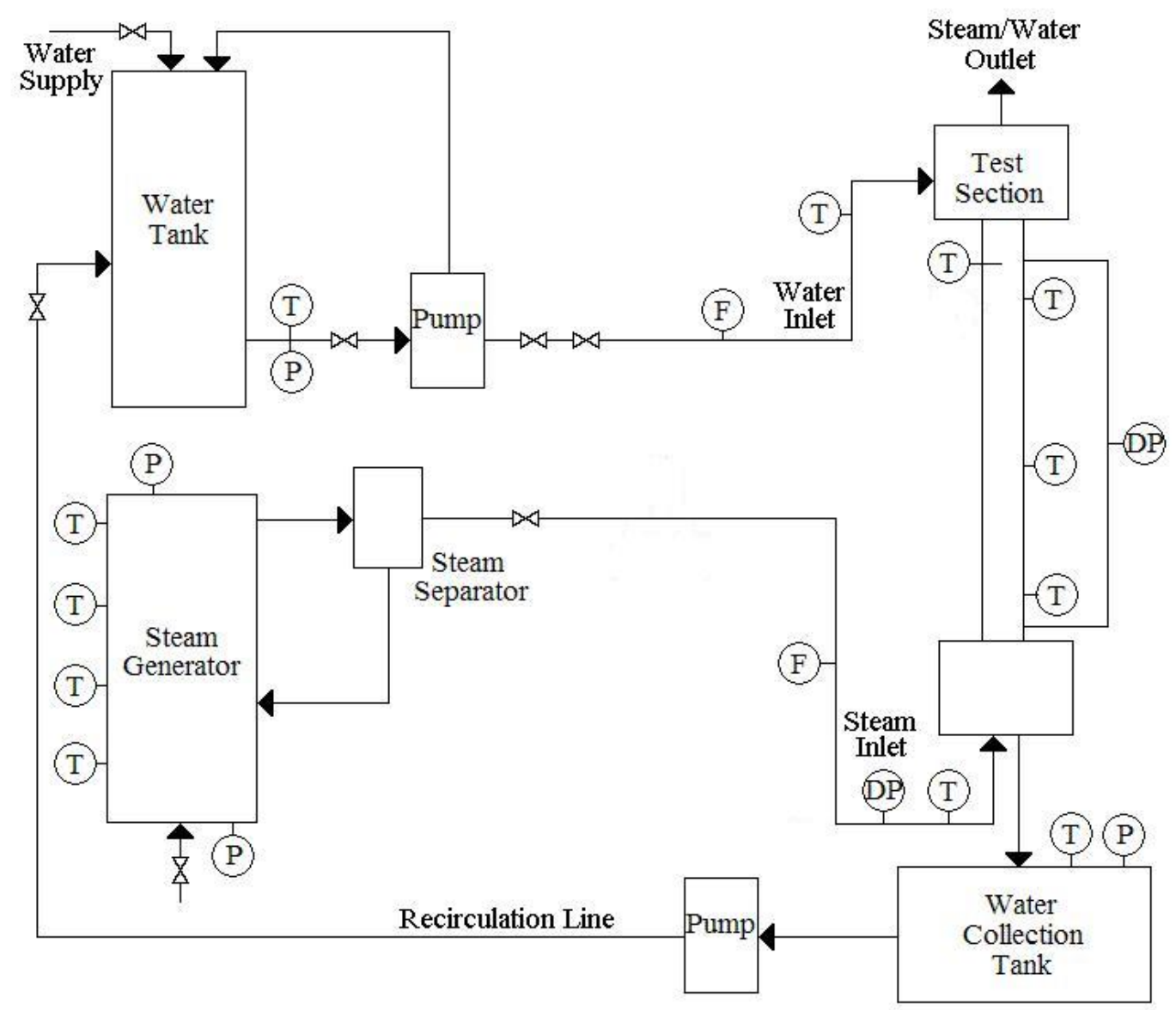

Fig. 4.8.: A schematic of the test facility with the locations of the instrumentation.

transducer is used for a pressure measurement at the top of the steam generator. A Dwyer pressure transducer is located at the bottom of the steam generator and is used to measure the water level inside. For a pressure differential across the test section, a Honeywell differential pressure transmitter is used.

Flow rates are recorded for the water inlet and the steam inlet. A Yamatake magnetic flow meter measures the water flow rate into the test section. A Foxboro vortex flow meter measures the steam flow rate into the test section. The information about the instrumentation is listed in Table 4.2. 
Table 4.2: The instrumentation used in the steam-water facility.

\begin{tabular}{|c|c|c|c|}
\hline Instrument & Quantity & Model & Range \\
\hline Thermocouple & Temperature & $\begin{array}{lll}\text { Omega } & 1.0 \quad \mathrm{~mm} \\
\text { T-Type } & & \end{array}$ & $-250-350^{\circ} \mathrm{C}$ \\
\hline $\begin{array}{l}\text { Absolute Pressure } \\
\text { Transducer }\end{array}$ & $\begin{array}{l}\text { Absolute } \\
\text { Pressure }\end{array}$ & Honeywell STA940 & $0-500 \mathrm{kPa}$ \\
\hline $\begin{array}{l}\text { Absolute Pressure } \\
\text { Transducer }\end{array}$ & $\begin{array}{l}\text { Steam } \\
\text { Pressure }\end{array}$ & $\begin{array}{l}\text { Omega } \\
\text { PX303-100GV }\end{array}$ & $\begin{array}{l}0-100 \text { psig } \\
(6.89 \text { bar })\end{array}$ \\
\hline $\begin{array}{l}\text { Absolute Pressure } \\
\text { Transducer }\end{array}$ & $\begin{array}{l}\text { Water } \\
\text { Pressure }\end{array}$ & Dwyer Series 673 & $\begin{array}{l}0-100 \text { psig } \\
(6.89 \text { bar })\end{array}$ \\
\hline $\begin{array}{l}\text { Differential Pressure } \\
\text { Transmitter }\end{array}$ & $\begin{array}{l}\text { Differential } \\
\text { Pressure }\end{array}$ & Honeywell STD-924 & $\begin{array}{l}0 \text { - } 400 \text { inches } \\
\text { of water }(747 \\
\mathrm{mm} \mathrm{Hg})\end{array}$ \\
\hline $\begin{array}{l}\text { Magnetic Flow } \\
\text { Meter }\end{array}$ & $\begin{array}{l}\text { Water Flow } \\
\text { Rate }\end{array}$ & $\begin{array}{l}\text { Yamatake MagneW } \\
3000 \text { Plus } 1 / 2 \text {-inch } \\
(12.7 \mathrm{~mm})\end{array}$ & $\begin{array}{l}0-28 \text { GPM } \\
(0-0.00177 \\
\left.\mathrm{m}^{3} / \mathrm{s}\right)\end{array}$ \\
\hline Vortex Flow Meter & $\begin{array}{l}\text { Steam Flow } \\
\text { Rate }\end{array}$ & $\begin{array}{lr}\text { Foxboro } & 83 \mathrm{~F}-\mathrm{A} \\
1-1 / 2 \text {-inch } & (38.1 \\
\mathrm{mm}) & \end{array}$ & $0-30 \mathrm{~g} / \mathrm{s}$ \\
\hline
\end{tabular}

\subsubsection{Data Acquisition System}

The data acquisition system (DAQ) is used to read information from the instrumentation and record data. It consists of a Dell Precision Desktop connected to a National Insturments SCXI-1000 chassis. In the SCXI-1000 chasses is a SCXI-1102b analog module connected to a SCXI-1300 terminal block. All of the data connections 
to the instrumentation are connected to this block. The data is sampled at $200 \mathrm{~Hz}$. Every 20 points that are collected are averaged and the average value is recorded so that data is recorded at a rate of $10 \mathrm{~Hz}$.

The DAQ system accepts analog voltage signals from the instrumentation betwen 0 and $5 \mathrm{~V}$. For the instruments that produce current signals, a terminal box converts these into voltages that the DAQ can read. The thermocouples output a signal between 0 and $10 \mathrm{mV}$ that is conditioned and amplified by the terminal block. A LabVIEW program displays the gathered data on the computer monitor and records it to a specified file. A picture of the LabVIEW interface is shown in Figure 4.9.

\subsubsection{Data Reduction}

Once data has been collected for a test, it needs to be reduced to something that can be easily analyzed. MATLAB scripts were written to read the data files, perform calculations, and output desired information. These scripts can be found in

Appendix C. One script reads in the data files and creates time dependent graphs of the recorded data. Time dependent graphical data for every steam-water test run can be found in Appendix D.

Another script analyzes the data to determine the point at which flooding occured. The data that is actually of interest is the steady state data just prior to flooding. The point at which flooding occurs is determined by the sudden drop in the differential pressure measured along the test section. This script looks for the instance in the data that a sudden drop in the differential pressure occurs. Once it has found this point, it outputs all of the recorded measurements from the instrumentation just prior to that point in time. This data is the steady state data measured just prior to flooding. 


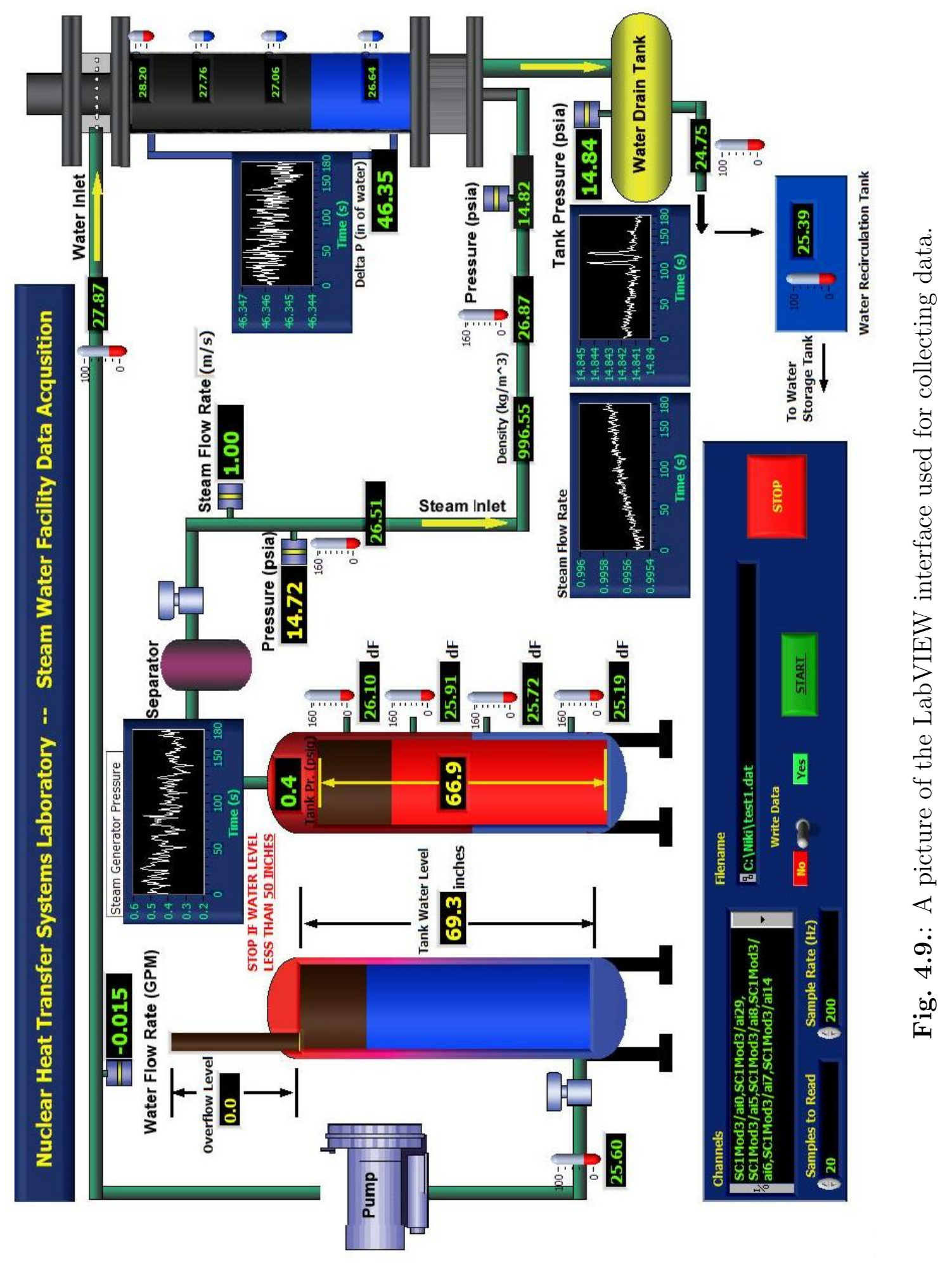




\subsection{Vortex Flowmeter Calibration}

The Foxboro vortex flowmeter used in the current research determines the flow rate of a fluid based on the frequency of vortices created inside the instrument. A 1$\mathrm{cm}$ wide bar impedes the fluid flow and vortices are created downstream. As the flow rate is increase, the frequency of the vortices increases. The presence of a vortex is measured by a piezoelectric sensor. The small changes in pressure caused by a vortex alters the voltage output of the sensor.

To gain an accurate measurement from the vortex flowmeter, first it needed to be calibrated. To do this, a known flow rate of steam was allowed to flow through the piping and the voltage output on the flowmeter was recorded. To accurately determine the steam flow rate, first the heat loss of the system had to be measured.

\subsubsection{System Heat Loss Tests}

Heat loss tests were performed on the steam generator to determine the exact heat loss. These tests were performed by first heating up the steam generator to the experimental operating pressure of 35 psig $(2.4$ bar). Next, all heater power was turned off except for one $2 \mathrm{~kW}$ heater. The steam generator was allowed to sit with only $2 \mathrm{~kW}$ of power for over 2 hours. The pressure inside the steam generator slowly increased with time which means the total heat loss is less than $2 \mathrm{~kW}$. The heat loss data recorded was used to calculate the exact heat loss. The vortex flowmeter calibration is more accurate by using this information.

The exact heat loss was calculated using an energy balance. Since no valves were open there is no mass entering or leaving the facility. The only energy added to the system $Q_{i n}$ is from the $2 \mathrm{~kW}$ heater. The energy leaving the system corresponds to the heat loss $Q_{\text {out }}$. The energy increase in the system $E_{P}$ is seen by an increase in 
the steam generator pressure. The energy balance for this system in steady state is seen in Equation 4.1.

$$
Q_{\text {in }}=Q_{\text {out }}+E_{P}
$$

The work done by the system is determined by the change in energy of the system with time. The energy at a point in time is calculated by multiplying the total mass $m$ of the system by the enthalpy, which is a function of temperature and pressure. This relationship is seen in Equation 4.2. The water inside the steam generator is always at the saturation temperature corresponding to the measured pressure. The work done by the system was calculated to be approximately $0.4 \mathrm{~kW}$ which corresponds to a heat loss of the system of approximately $1.6 \mathrm{~kW}$.

$$
W_{P}=\frac{m\left(h_{f, i}-h_{f, f}\right)}{\Delta t}
$$

\subsubsection{Calibration}

The following procedures were followed to obtain data in order to calibrate the vortex flowmeter. First a predetermined heater power level was turned on. The steam generator was allowed to heat up to a predetermined pressure. Without altering the heater power level, the valve on the steam line was slowly opened. The steam valve was adjusted until the steam generator maintained a constant pressure. The system was allowed to remain at a steady state with the steam valve partially opened and the steam generator at a constant pressure for a minimum of 10 minutes. After this time, the steam valve was closed and the system was shut down. Figure 4.10 shows the steam generator pressure as a function of time. This test was run with a heater power of $37.5 \mathrm{~kW}$.

The steady state data was analyzed to determine the steam mass flow rate exiting the steam generator compared to the voltage output on the vortex flowmeter. Steady state calibration tests were run at three different heater powers and three different steam generator pressures. The steam mass flow rate versus the voltage recorded 


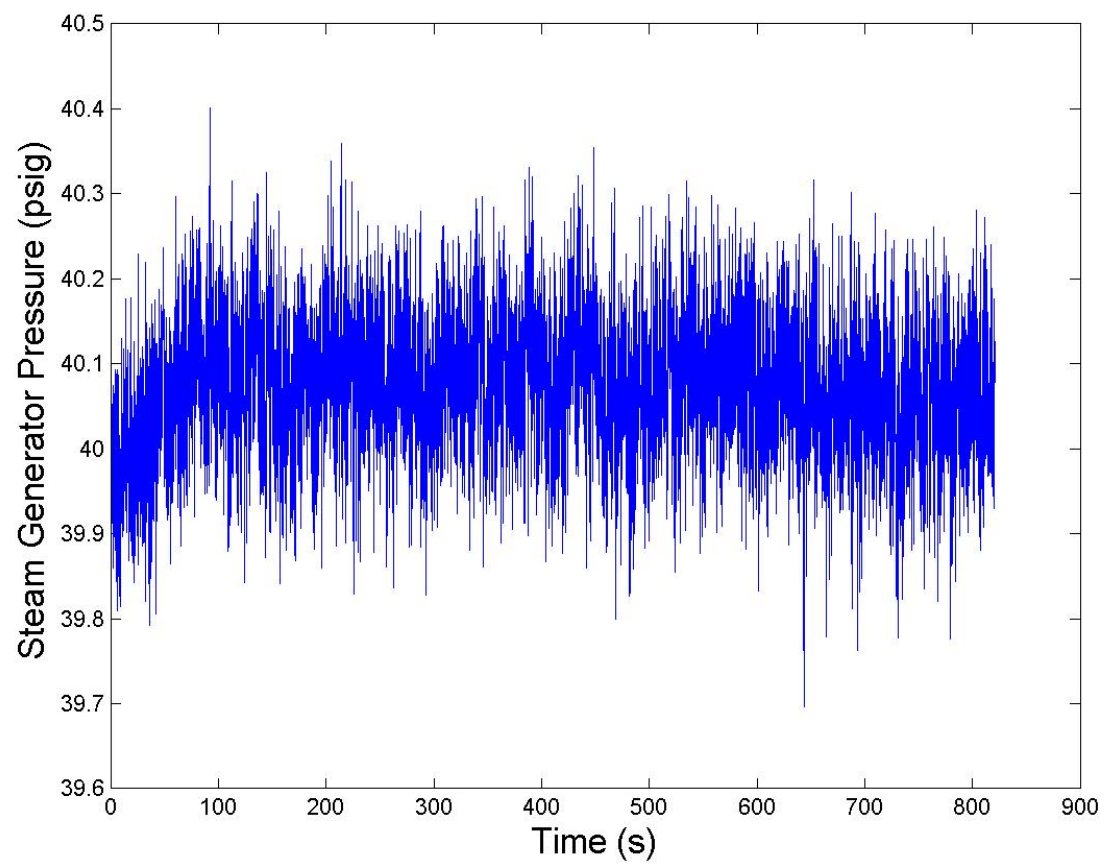

Fig. 4.10.: The steam generator pressure as a function of time.

by the vortex flowmeter is shown in Figure 4.11 along with a calibration line. This calibration line is shown in Equation 4.3. The steam mass flow rate was calculated based on the heater power using Equation 4.4.

$$
\begin{gathered}
\dot{m}=15.78 \mathrm{~V}-15.674 \\
\dot{m}=\frac{P_{H}-P_{L}}{h_{f g}}
\end{gathered}
$$

In Figure 4.11 it can be seen that the steam generator pressure has no effect on the steam mass flow rate as long as the steam is in a state of choked flow. Choked flow occurs when a fluid flows through a restriction, such as a valve, into a lower pressure environment [46]. Based on the conservation of mass, the velocity of the fluid increases as it passes through this restriction, while the static pressure decreases due to the Venturi effect. When a fluid is under a choked flow condition, the mass flow rate will not increase with a decrease in the pressure downstream of the restriction. 


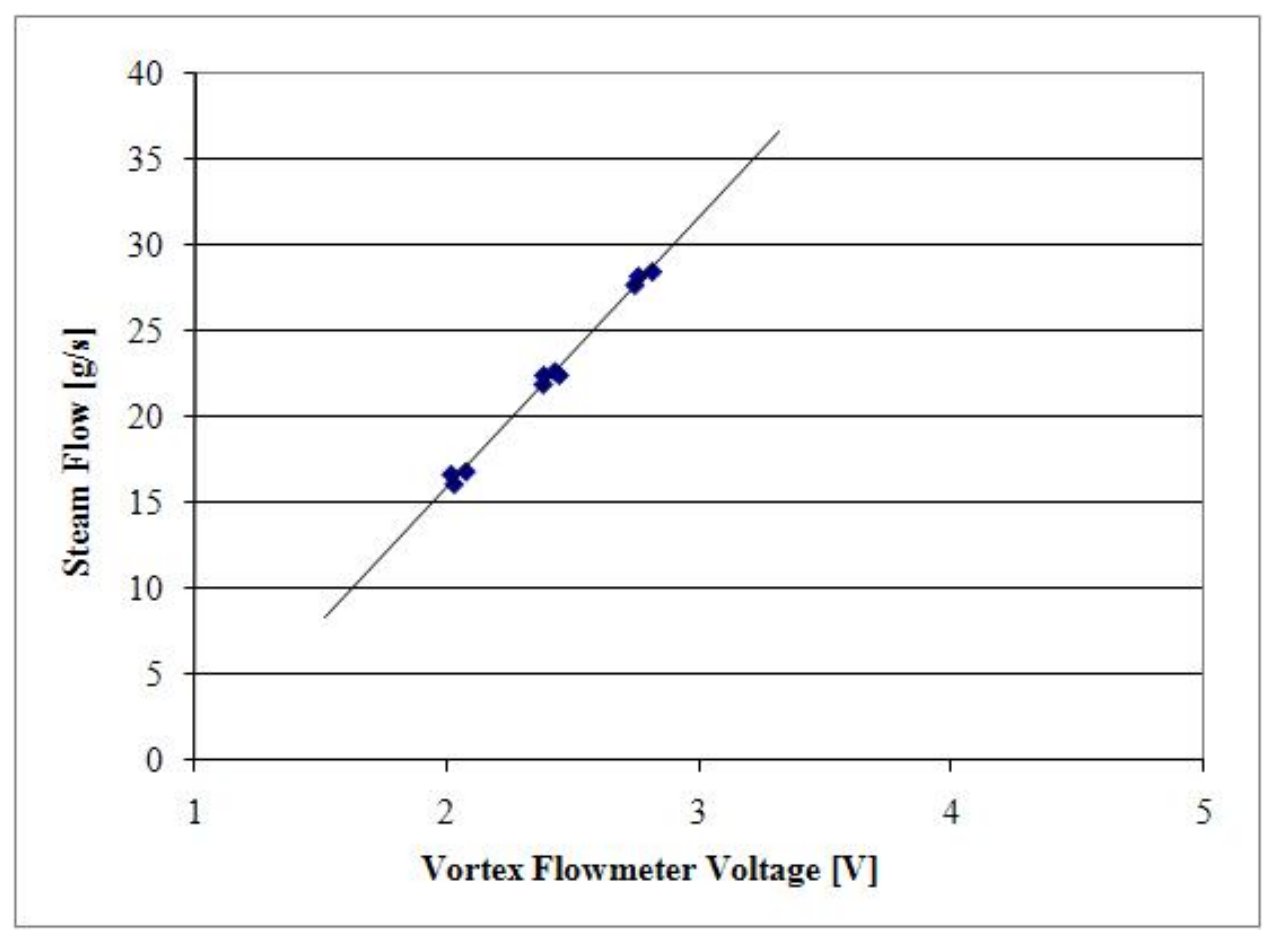

Fig. 4.11.: Vortex flowmeter calibration line.

The mass flow rate can only increase with an increase in the pressure upstream of the restriction.

To achieve choked flow, a minimum pressure ratio of the upstream pressure to the downstream pressure is required. For steam, the minimum pressure ratio required for choked flow is approximately 1.86. When the downstream pressure is atmospheric, the required pressure inside the steam generator to produce choked flow is 12 psig (0.83 bar). All steam-water flooding experiments were run with a steam generator pressure between 30 and 40 psig (2.1 and 2.8 bar). This corresponds to a pressure ratio of 3.5 which is well above the required pressure ratio for choked flow. Since a relatively constant steam generator pressure is maintained throughout a test, the only way to alter the steam flow rate is by adjusting the steam valve. 


\section{EXPERIMENTAL OPERATING PROCEDURES AND TEST MATRIX}

The steam-water facility utilizes a large number of instruments and equipment. Operating procedures were developed so that the facility may be run safely and consistently for every test. For safety in operating the steam generator, a minimum of two people are needed to operate the facility. The operating procedures are divided into eleven parts that describe the operation of each individual piece of equipment, instruction for operating an entire test, and procedures for shutting down the facility. For valve locations refer to Figure 4.1.

\subsection{Data Acquisition System}

The data acquisition system records the output of all the instrumentation and records it to a file. In addition, it displays the information on a computer screen so that it can be easily read during a test. Below are the procedures for operating the DAQ.

- Restart computer

- Open file "SW_CCFL_July.vi" in the "Steam_Water" folder on the desktop

- Turn on power supply

- Click the "Run" button on the toolbar to start the program

- Turn the switch labeled "Write Data" to "Yes"

- Check that the numbers the instruments are outputting make sense

- Enter a file name

- Click "Start" to collect data

- Click "Click to stop" to stop collecting data 
- Enter a different file name for each data collection sequence

- Click "Stop" to end the program

- Turn off power supply

- Close file "SW_CCFL_July.vi"

\subsection{Filling the Water Tank}

The water storage tank holds deionized water for use during a test. The hot water pump requires a minimum of 50 inches of water $(93.4 \mathrm{~mm} \mathrm{Hg})$ for sufficient net positive suction head so it is necessary to fill the water storage tank periodically. Below are the procedures for filling the water storage tank.

- Open valve V1

- Open valve V2

- Check that the light on the Culligan tanks is green

- Open valve V3 for recirculation when the recirculation water tank level is above the minimum line

- Turn "RECIRC PUMP" switch on panel to "ON" to recirculate water from the recirculation tank to the water tank

- Turn "RECIRC PUMP" switch on panel to "OFF" when the water tank is at most 90 inches of water full or the recirculation tank is below the minimum line

- Close valve V3

- Close valve V2 when the water tank is at most 90 inches of water full as indicated on DAQ 
- Close valve V1

\subsection{Filling the Steam Generator}

The steam generator is filled with deionized water to generate steam. The heaters inside the steam generator must remain submerged during operation so that the heater elements do not become damaged. The minimum water level inside the steam generator to ensure that the heaters remain covered is $35 \mathrm{~cm}$. Below are the procedures for filling the steam generator.

- When the steam generator is depressurized open valve V5

- Open valve V4

- Close valve V4 when the water level is between 60 and $70 \mathrm{~cm}$ on the sight glass

- Close valve V5

\subsection{Emergency Stop}

In the event of an accident in the laboratory the facility requires immediate shut down. Below are the emergency stop procedures for the facility.

- To stop all pumps in case of an emergency, push the red button labeled "SCRAM" on panel

- To turn off the heaters in the steam generator, flip the breaker to "OFF"

- To restart all pumps, pull the red button labeled "SCRAM" on panel

- To restart the heaters in the steam generator, flip the breaker to "ON" 


\subsection{Purging the Differential Pressure Transducer Lines}

The differential pressure transducer measures the pressure drop along the test section. The pressure lines must be primed with water periodically to ensure an accurate measurement. Below are the procedures for purging the differential pressure transducer lines.

- Pressurize compressor to at least 30 psi

- Open valve V13

- Open valve V14

- Open valve V15

- Fill the pressure tank until water flows out of valve V14

- Close valve V15

- Close valve V14

- Close valve V13

- Open and close valve V21 to pressurize the tank between 10 and 15 psig

- Open valve V16

- Open valve V17

- Open valve V20

- Open and close valve V21 to maintain pressure in the tank between 10 and 15 psig

- Open valve V18

- Open valve V19 
- Close valves V18 and V19 when air bubbles have escaped the pressure lines

- Close valve V17 when the pressure lines are full of water

- Close Valve V20

- Open valve V13 to relieve pressure

- Check that the differential pressure reading on DAQ is 55.75 inches of water (104 mm Hg)

\subsection{Hot Water Pump Operation}

The hot water pump provides water flow into the test section. Below are the procedures for operating the hot water pump.

- Check that the water tank is at least 50 inches of water $(93.4 \mathrm{~mm} \mathrm{Hg})$ full as indicated on the DAQ

- Open valve V22

- Open valve V23

- Open valve V24

- Turn "HOT WATER PUMP" switch on panel to "ON"

- Open valve V24 to obtain a water flow rate of at least 8 GPM $\left(0.00050 \mathrm{~m}^{3} / \mathrm{s}\right)$

- Open and close valves V23 and V24 as needed to obtain desired water flow rate

- Turn "HOT WATER PUMP" switch on panel to "OFF" when water tank level is below 50 inches of water $(93.4 \mathrm{~mm} \mathrm{Hg}$ ) or test is complete 


\subsection{Recirculation Pump Operation}

A recirculation system was added to the facility to eliminate the need to contantly deionize new water. The recirculation pump also maintains an appropriate water level inside the water storage tank. Below are the procedures for operating the recirculation pump.

- Open valve V3 for recirculation when the recirculation tank water level is above the minimum line

- Turn "RECIRC PUMP" switch on panel to "ON" to recirculate water from the recirculation tank to the water tank

- Turn "RECIRC PUMP" switch on panel to "OFF" when the water tank is at most 90 inches of water $(168 \mathrm{~mm} \mathrm{Hg})$ full or recirculation tank is below the minimum line

- Close valve V3

\subsection{Steam Generator Operation}

The steam generator is a complex system that generates the steam used in a test. For safety, a minimum of two people must be present to operate the steam generator. Below are the procedures for operating the steam generator.

- Check that the steam generator water level is between 60 and $70 \mathrm{~cm}$ on the sight glass

- Close all valves connected to the steam generator

- Flip breaker to "ON"

- Turn the master power switch on control panel to "ON" 
- Turn heater switches to "ON" to obtain a predetermined power level

- Open valve V5 when the steam generator has a pressure of 10 psig to purge air out of the system

- Close valve V5 when air is no longer in the system

- Air is no longer in the system when the temperature of the steam is the same as the temperature of the water in the steam generator

- Open valve V6 to allow steam to flow into the test section when the steam generator has reached a predetermined pressure

- When the test is finished or the water level drops below $40 \mathrm{~cm}$ on the sight glass turn all heater switches to "OFF"

- Turn the master power switch on control panel to "OFF"

- Flip breaker to "OFF"

- Close valve V6 to stop steam from flowing into the test section

- Open valve V5 to relieve pressure

- Close valve V5 when the steam generator pressure is 0 psig (1 bar)

- Open valve V8 to prevent a vacuum from forming while the steam generator cools down

\subsection{Cooling System Operation}

The water exiting the test section is at a temperature close to saturation. Since the recirculation pump cannot pump water with a temperature higher than about $95{ }^{\circ} \mathrm{C}$, the water collecting in the water collection tank must be cooled. In addition, the steam exiting the test section needs to be condensed to prevent steam from 
leaking into the laboratory. A cooling system was implemented to cool the hot water and to condense the steam at the same time. Below are the procedures for operating the cooling system.

- Open valve V25

- Open valve V26

- Adjust valve V25 position to maintain drum water level about half full

- After valve V6 has closed, close valve V26

- Close valve V25

\subsection{Collecting Data}

All of the equipment in the facility must be operated at the same time to successfully run a test and collect data. Below are the procedures for operating the entire facility to collect data.

- Turn on DAQ (See Section 5.1)

- Collect baseline data with no water or steam flow

- Turn on steam generator (See Section 5.8)

- Turn on hot water pump (See Section 5.6)

- Turn on recirculation pump as needed (See Section 5.7)

- Continually monitor the water level in the water tank

- Continually monitor the pressure in the steam generator

- Open valve V24 on the water line to obtain a water flow rate of at least 8 GPM $\left(0.00050 \mathrm{~m}^{3} / \mathrm{s}\right)$ 
- Open and close valves V23 and V24 as needed to obtain desired water flow rate

- Begin data collection sequence (See Section 5.1)

- Increase the steam flow rate in increments until flooding occurs

- Wait 2-5 minutes between each increment

- Flooding occurs when the instrumentation shows a sharp decrease in the differential pressure and a sharp increase in the exit water tank pressure

- Decrease the steam flow rate after flooding occurs

- Continue to record data for 2 minutes after flooding occurs

- Stop data collection when enough data is collected or when the water tank level is below 50 inches of water $(93.4 \mathrm{~mm} \mathrm{Hg})$

- Turn off steam generator (See Section 5.8)

- Turn off recirculation pump (See Section 5.7)

- Turn off hot water pump (See Section 5.6)

- Turn off DAQ (See Section 5.1)

\subsection{Shut Down}

After data has been collected the system must be shut down while it is not in use. Below are the procedures to shut down the facility.

- Turn off all equipment

- Open steam line drain valve to drain condensed steam

- Push red button labeled "SCRAM" on panel to disable circuit 


\subsection{Experimental Test Conditions}

All tests were operated under the same procedures and with many of the same conditions. In every test the steam generator pressure was high enough so that the steam was under a choked flow condition. This allowed for a more steady flow rate that could only be altered by opening the valve on the steam line further. The steam exiting the steam generator and entering the test section is superheated by about $10{ }^{\circ} \mathrm{C}$. The superheated steam corresponds to the conditions in a pressurizer surge line.

All tests had a water inlet temperature of $70{ }^{\circ} \mathrm{C}$. This temperature was chosen to give a $10{ }^{\circ} \mathrm{C}$ safety margin from the maximum operating temperature of the recirculation pump. The minimum water flow rate is based on the minimum water flow rate to produce an annular film. The maximum water flow rate is based on the water flow rate with the valves fully open on the water line. The range of water flow rates allows the liquid Froude number of the test section to match the liquid Froude number of the pressurizer surge line. The ranges of conditions for these experiments are shown in Table 5.1.

Table 5.1: Test conditions for steam-water tests.

\begin{tabular}{|c|c|}
\hline Parameter & Range \\
\hline Test Section Pressure & $1 \mathrm{~atm}$ \\
\hline Steam Generator Pressure & $35 \mathrm{psig}(2.4 \mathrm{bar})$ \\
\hline Steam Inlet Temperature & $110^{\circ} \mathrm{C}$ \\
\hline Steam Flow Rate & $0-35 \mathrm{~g} / \mathrm{s}$ \\
\hline Water Inlet Temperature & $70{ }^{\circ} \mathrm{C}$ \\
\hline Water Flow Rate & $3.5-12 \mathrm{GPM}\left(0.00022-0.00076 \mathrm{~m}^{3} / \mathrm{s}\right)$ \\
\hline
\end{tabular}




\section{AIR-WATER RESULTS AND DISCUSSION}

Prior to running steam-water flooding tests, air-water flooding tests were performed in the steam-water facility. This air data serves as a benchmark for steamwater data. A total of 25 flooding points were recorded over a water flow rate range of 4 to 12 GPM $\left(0.00025\right.$ to $\left.0.00076 \mathrm{~m}^{3} / \mathrm{s}\right)$. The air data collected in the steam-water facility was compared to previous air-water flooding data to benchmark the system.

The steam-water facility was first constructed to operate flooding tests with air and water before it was modified to operate with steam and water. The only difference between the two configurations is the gas inlet. The air source for air-water testing consists of a regenerative blower with a hose connecting it to the test section. The air flow rate was measured using a pitot tube. The air-water flooding tests were run at atmospheric pressure and room temperature.

\subsection{Raw Data and Observations}

The test section is in a stable state of countercurrent flow for some time before flooding occurs during a test. Since the test section is made of stainless steel and is not optically transparent, flooding is detected based on the data acquired from the instrumentation. The primary indication of flooding is seen in the differential pressure drop ( $\mathrm{dP}$ ) along the test section. When flooding occurs, the dP drops suddenly by more than one inch of water. After this point, until deflooding occurs, the dP oscillates. Figure 6.1 shows the $\mathrm{dP}$ as a function of time. This test was run at a water flow rate of 6.89 GPM $\left(0.00043 \mathrm{~m}^{3} / \mathrm{s}\right)$.

A secondary indication of flooding is seen in the absolute pressure of the water exit tank. Prior to flooding the system is at steady state operating conditions. During this time, the pressure in the water exit tank is atmospheric, 14.7 psia (1 atm). The test section and the water exit tank are not pressurized and are both indirectly open to the atmosphere. When flooding occurs the pressure in the water exit tank rises 


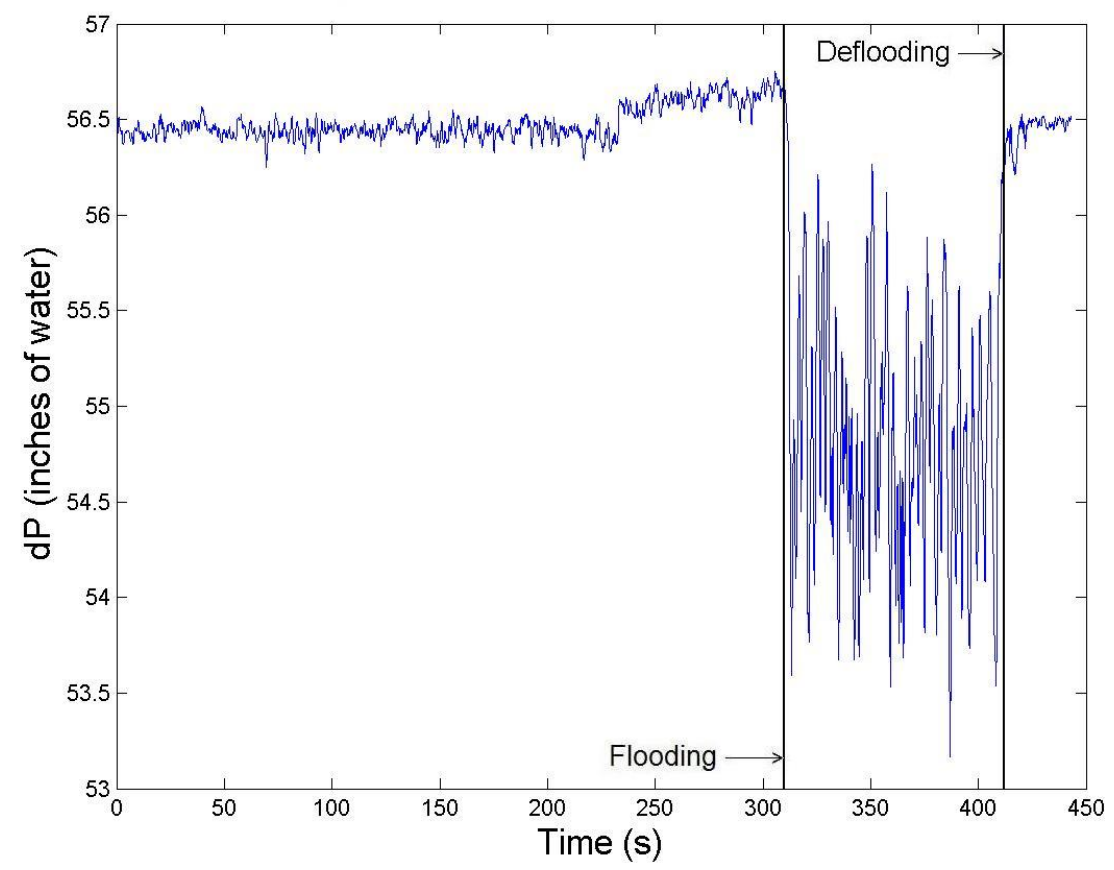

Fig. 6.1.: The differential pressure measured along the test section plotted with time for a water flow rate of $6.89 \mathrm{GPM}\left(0.00043 \mathrm{~m}^{3} / \mathrm{s}\right)$.

by more than 0.2 psia (0.01 bar). After this point, until deflooding occurs, the water exit tank pressure oscillates similar to the $\mathrm{dP}$ in the test section. Figure 6.2 shows the water exit tank pressure as a function of time. This test was run at a water flow rate of $6.89 \mathrm{GPM}\left(0.00043 \mathrm{~m}^{3} / \mathrm{s}\right)$ and corresponds to the test seen in Figure 6.1.

A third indication of flooding in air testing is seen in the air velocity. Prior to flooding the air flow rate is incrementally increased until flooding occurs. Each time the air flow rate is increased, the system is allowed to stay in a steady state for some time before the air flow rate is increased furthur. This is because flooding may not occur immediately after the air flow rate is increased as seen by Solmos [23]. When flooding occurs the air velocity drops suddenly similar to the $\mathrm{dP}$ inside the test section. After this point, until deflooding occurs, the air velocity oscillates similar to the $\mathrm{dP}$ and the water exit tank pressure. This is due to the back pressure built up 


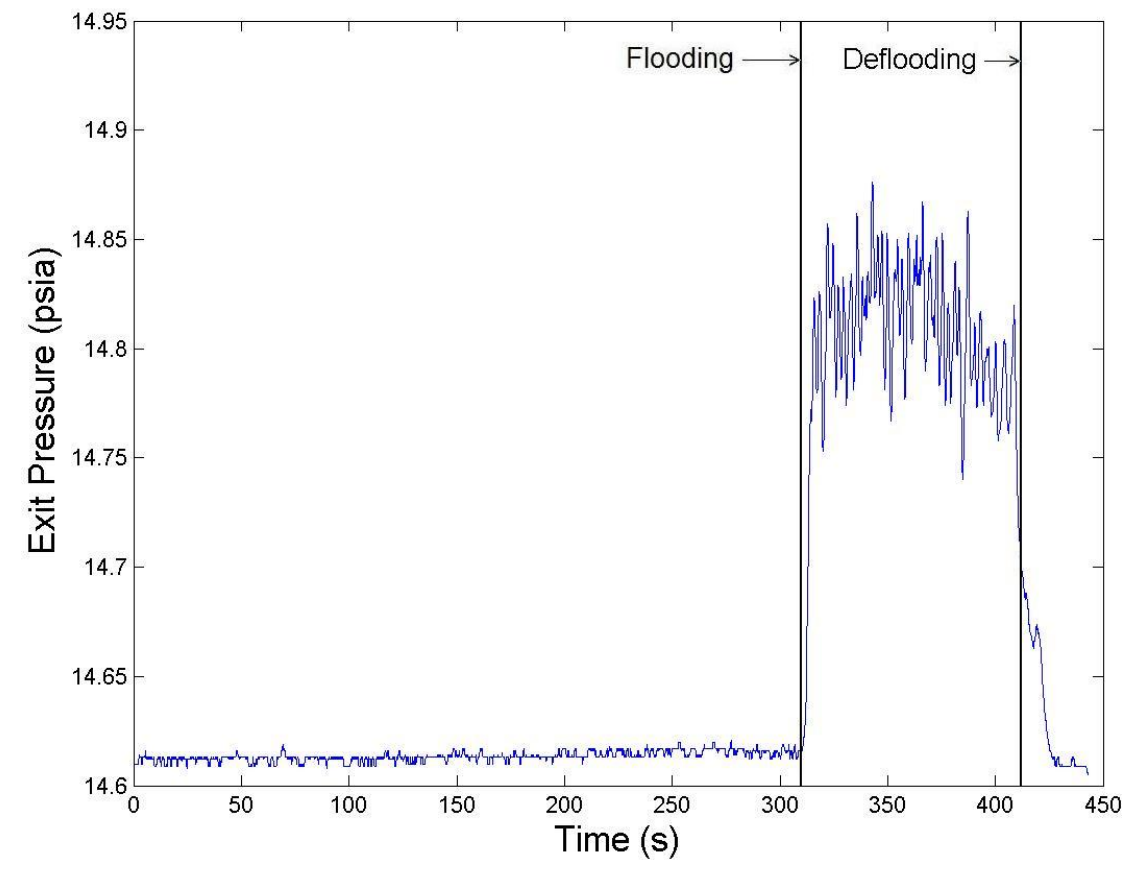

Fig. 6.2.: The pressure in the water exit tank plotted with time.

inside the test section affecting the blower used to generate the air flow. Figure 6.3 shows the air velocity as a function of time. This test was run at a water flow rate of 6.89 GPM and corresponds to the test seen in Figure 6.1 and Figure 6.2.

\subsection{Reduced Data}

The recorded time-dependent data was analyzed and reduced down to the information at the point of flooding. Flooding was determined to occur when the differential pressure drop in the test section suddenly dropped by more than one inch of water $(1.9 \mathrm{~mm} \mathrm{Hg})$. The data that is of interest is the steady state data just prior to flooding. These are considered the conditions in which flooding occurs.

The full set of air data from the current facility is shown in Figure 6.4. The data is plotted as the Kutateladze numbers since the test section is considered a 


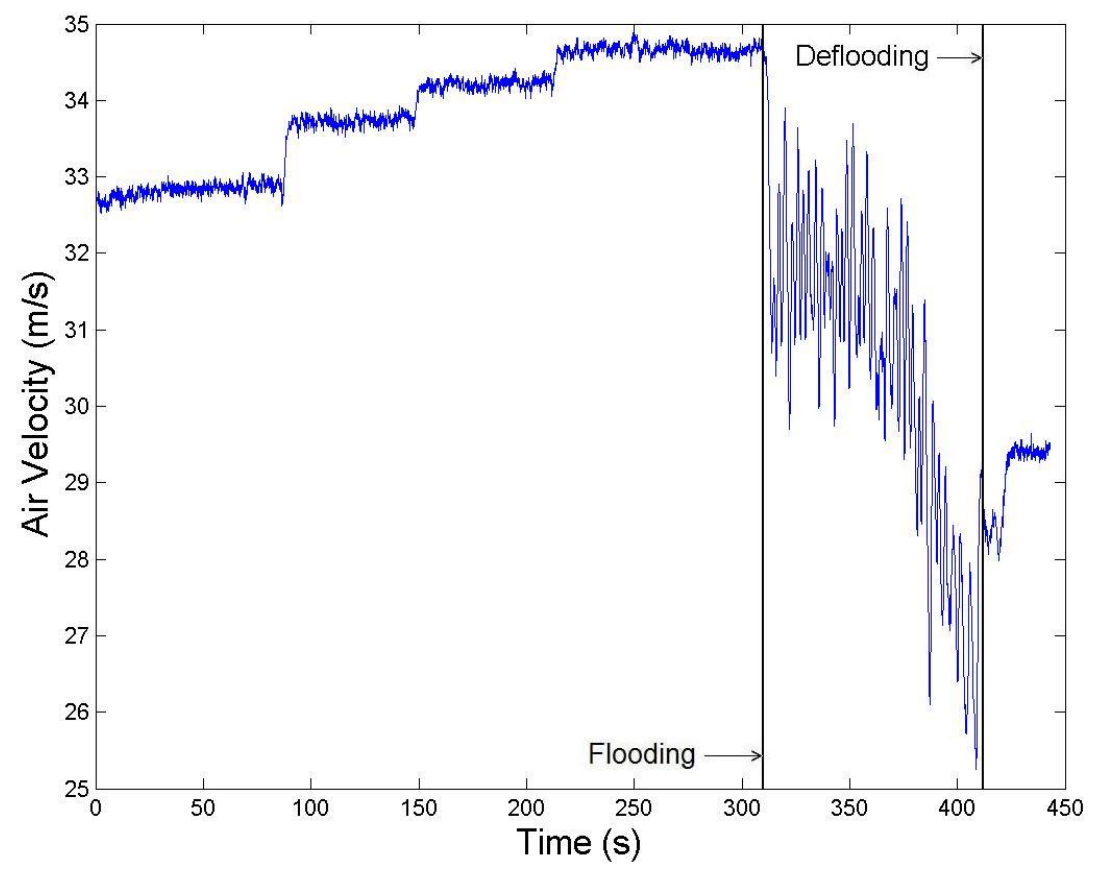

Fig. 6.3.: The air velocity in the test section plotted with time.

large diameter tube. The Kutateladze-type correlation developed by Tien [20] is also shown on the same graph. As the water flow rate increases, the required air flow rate to achieve flooding decreases. It is important to note that even though the air data has the same trend as the correlation proposed by Tien, the data does not lie on the correlation line.

\subsection{Comparison with Previous Air-Water Data}

The air data collected in the steam-water facility was compared to the air data collected by Solmos [23]. The basic geometry of the facility used by Solmos is the same as the current facility. However, the materials used are different. The airwater facility used by Solmos is made of acrylic while the current facility is made of stainless steel. The material difference between the two facilities means that the 


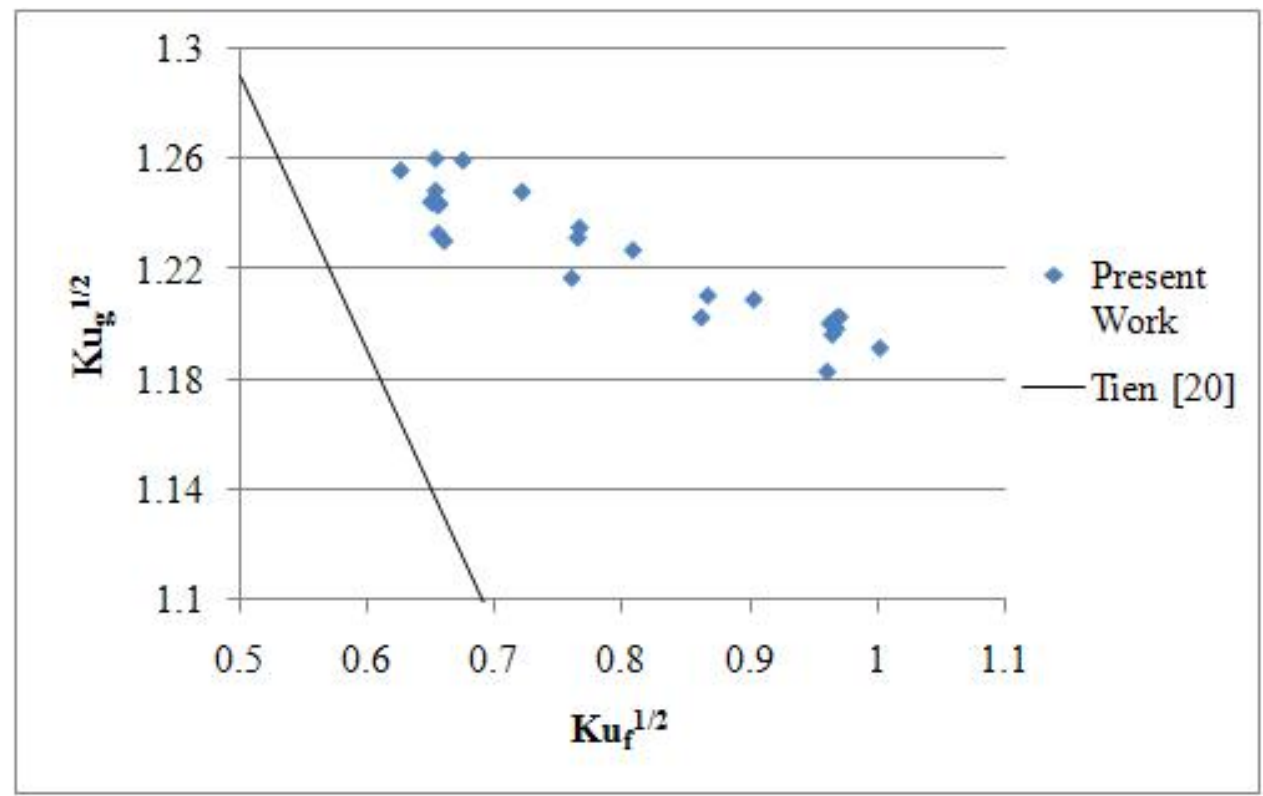

Fig. 6.4.: The full set of air data obtained from the current facility and compared to the Kutateladze-type correlation [20].

surface roughness is different, which could affect the water flow inside the test section. Other differences in the facilities include the water outlet and the air/steam outlet. In the air-water facility the water exiting the test section falls into an open container. In the current facility the water exits into a closed container and is recycled. In the air-water facility the air exit is open to the atmosphere. When flooding occurs the air and entrained water are allowed to evacuate into the laboratory. In the current facility the steam exit is connected to a flexible silicone hose that leads to a blowdown tank. The steam and hot water are not allowed to evacuate into the laboratory for safety reasons. Any discrepancies in the air data between the two facilities are attributed to these differences.

The data from the two facilities is shown in Figure 6.5. This is the reduced data from both facilities and is plotted as the volumetric air flow rate versus the volumetric water flow rate. The current facility extends the water flow rate range of Solmos by almost double. The general trend seen in previous flooding experiments with air 
and water is also seen in the figure [5]. The air flow rate needed for flooding to occur decreases with an increase in the water flow rate.

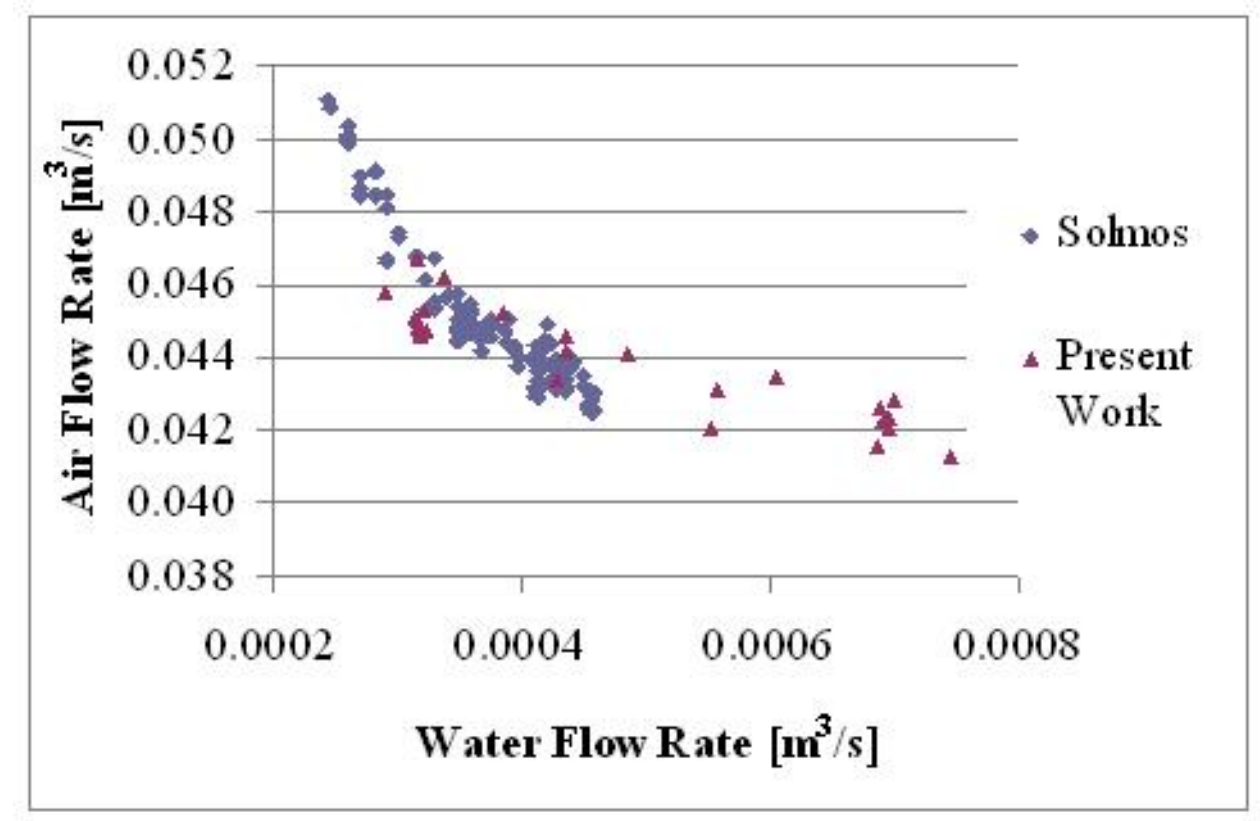

Fig. 6.5.: Air data from the current facility compared with the air data from Sol$\operatorname{mos}[23]$.

These air water tests were performed in the steam-water facility to compare with data from an air-water facility. There is good agreement between the two data sets despite small differences in geometry and materials. The following section will describe in detail the steam data obtained in the steam-water facility. The steam data is compared with the air data obtained in the same facility to determine the effect of condensation, temperature differences, and density differences on flooding. 


\section{STEAM-WATER RESULTS AND DISCUSSION}

This section presents the flooding data acquired in the steam-water facility. It contains a description of the raw data and observations from a typical test. It also describes the reduced flooding data and general trends seen in the data. The error analysis of the data is explained. The reduced steam data is compared with the reduced air data obtained in the current facility. Finally, an empirical correlation is developed based on the steam data and validated with data from previous experiments.

\subsection{Raw Data and Observations}

During a test, the test section is at steady state for some time before flooding occurs. After flooding occurs, however, a chaotic process occurs inside the test section. Since the test section is made of stainless steel and is covered in fiberglass insulation, flooding cannot be visually observed. However, flooding can be detected based on the data acquired from the instrumentation.

The primary indication of flooding is seen in the differential pressure drop (dP) along the test section. When there is no water or steam flow in the test section, the $\mathrm{dP}$ is 55.75 inches of water $(104 \mathrm{~mm} \mathrm{Hg})$, which corresponds to the hydrostatic head and the measured distance between the two pressure ports. When the annular flow is established inside the test section, the $\mathrm{dP}$ is slightly higher, between 56 and 57 inches of water (105 and $106 \mathrm{~mm} \mathrm{Hg}$ ), depending on the water flow rate. When flooding begins, the $\mathrm{dP}$ drops by more than one inch of water, depending on the water flow rate. After flooding has occurred and before deflooding occurs, the $\mathrm{dP}$ oscillates. In Figure 7.1, the $\mathrm{dP}$ as a function of time is shown. This test was run at a water flow rate of 6.28 GPM $\left(0.00040 \mathrm{~m}^{3} / \mathrm{s}\right)$ and flooding began at 116 seconds.

Regarding temperature measurements, the thermocouple in the center of the top of the test section measures the outlet steam temperature prior to flooding. After 


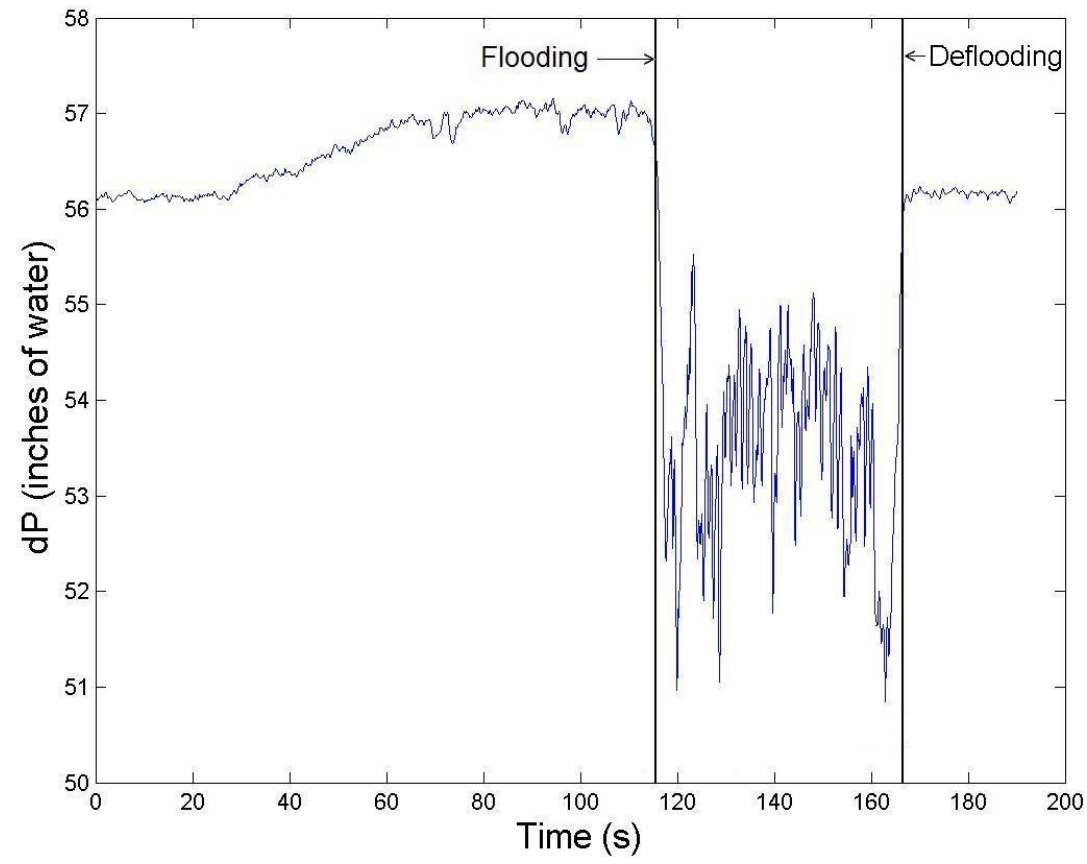

Fig. 7.1.: The differential pressure measured along the test section plotted with time for a water flow rate of $6.28 \mathrm{GPM}\left(0.00040 \mathrm{~m}^{3} / \mathrm{s}\right)$.

flooding occurs, this thermocouple measures the temperature of a mixture of steam and entrained water. The three thermocouples on the outer surface of the test section provide information about the water temperature. As would be expected, the water is coolest at the top of the test section and warmest at the bottom. This indicates that steam is condensing inside the test section causing the water to heat up prior to exiting the test section. Temperatures have not been recorded axially along a previous steam-water flooding experiment to the knowledge of the author [37]. Figure 7.2 shows the steam and entrained water temperature measurements as a function of time for the same test as in Figure 7.1. The solid black line shows the temperature inside the test section while the three other lines show the temperatures on the outside surface of the test section at the bottom, middle, and top, respectively. "TS Surface 1" refers to the surface thermocouple at the top of the test section while 
"TS Surface 2" and "TS Surface 3" refer to the surface thermocouples at the middle and bottom of the test section respectively. Additionally, the water inlet temperature is plotted to compare with the temperatures along the test section. It should be noted that prior to flooding the water does not reach the saturation temperature. Just after flooding occurs the surface thermocouples record a rise in temperature. The thermocouple at the bottom of the test section records the rise first, followed by the middle and top thermocouples. This observation infers that flooding occurs in the bottom third of the test section. Without knowing the exact location of flooding, it is impossible to know the exact water temperature when and where flooding occurs.

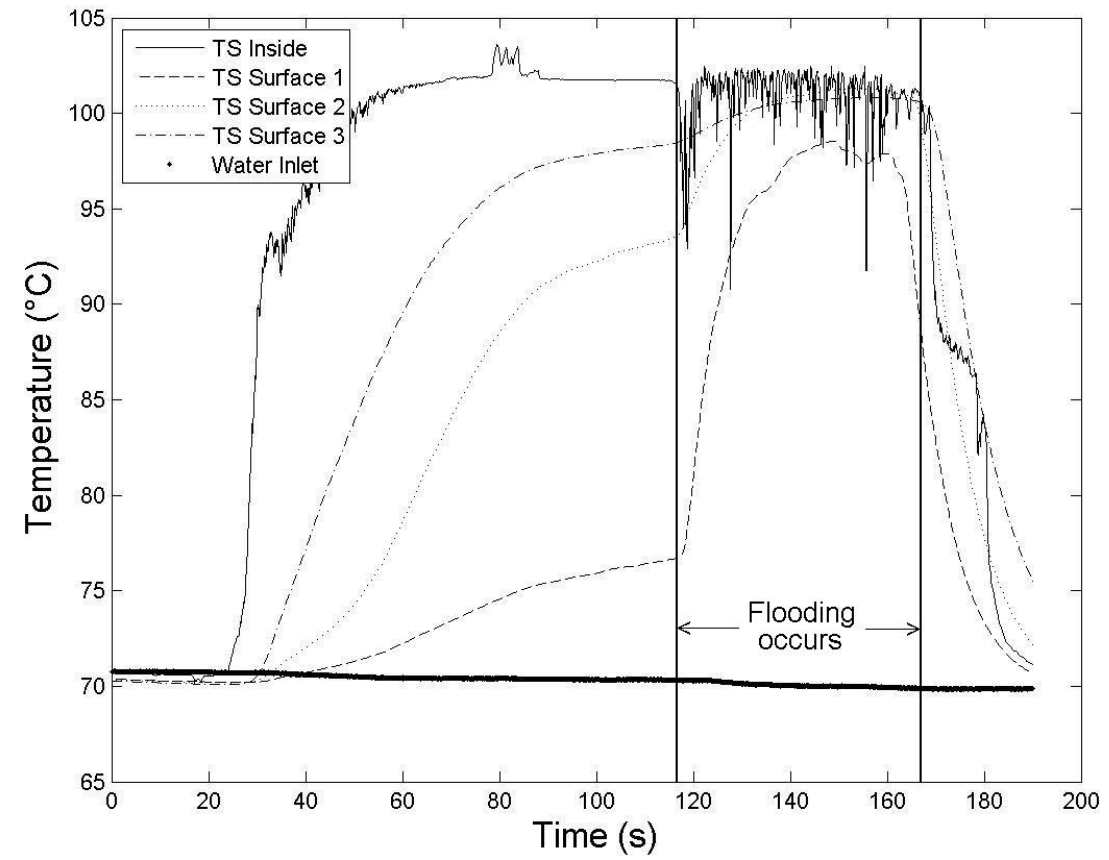

Fig. 7.2.: Temperature measurements in the test section plotted with time for a water flow rate of $6.28 \mathrm{GPM}\left(0.00040 \mathrm{~m}^{3} / \mathrm{s}\right)$.

In the air flooding data, the pressure in the water exit tank rose when flooding occurred and oscillated similar to the dP inside the test section. In the steam flooding 
data the same trend is seen. The rise in pressure in the water exit tank is due to the rise in pressure in the bottom of the test section when flooding occurs. The rise in pressure in the test section comes from the momentum of the air or steam entering the test section. When the inlet steam encounters the steam and water mixture inside the test section during flooding, the pressure builds up and forces the steam and water mixture out the top of the test section. Figure 7.3 shows the pressure in the water exit tank as a function of time for the same test as in Figure 7.1 and Figure 7.2.

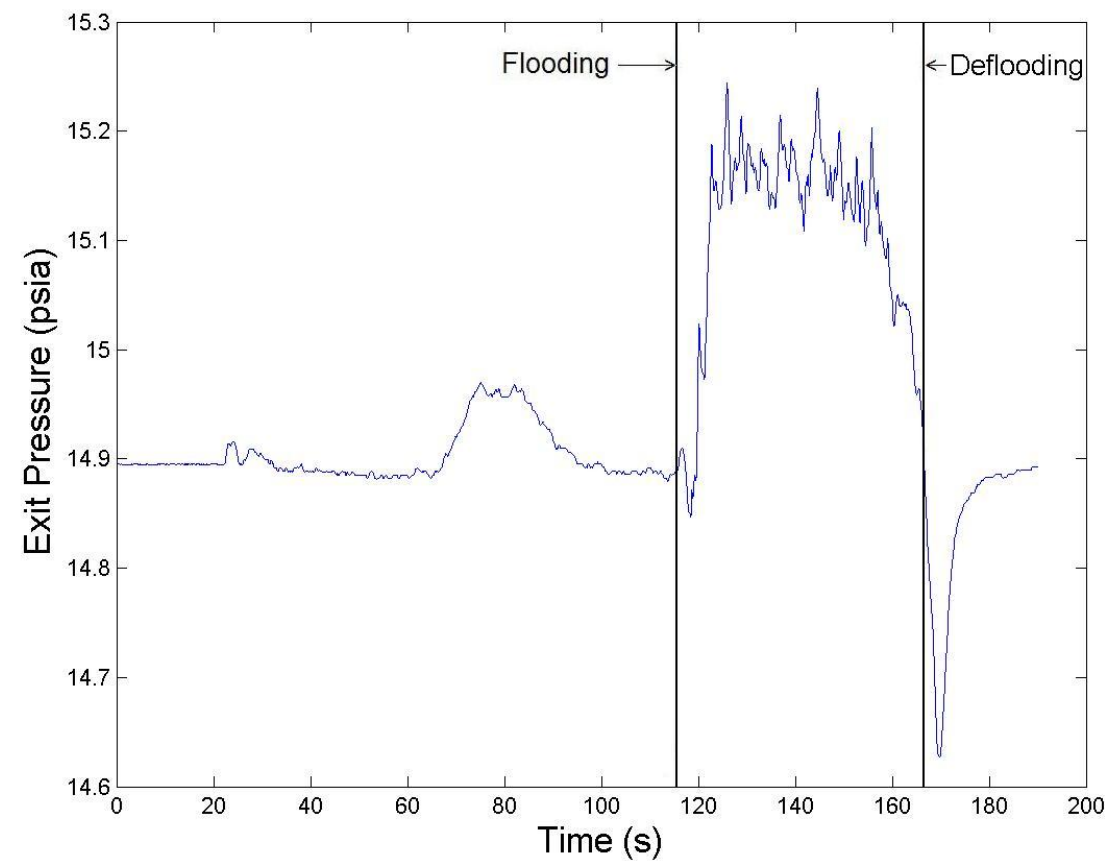

Fig. 7.3.: Pressure in the water exit tank plotted with time for a water flow rate of $6.28 \operatorname{GPM}\left(0.00040 \mathrm{~m}^{3} / \mathrm{s}\right)$.

In the air flooding data, the air velocity oscillated once flooding occurred due to the blower. In the steam flooding data, the steam velocity did not display the oscillatory behavior. Instead, the steam velocity remained fairly constant until the steam valve was closed and deflooding occurred. This is becasue the steam generator 
is not affected by any back pressure generated in the test section from flooding. It is able to supply a constant mass flow rate of steam to the test section. Figure 7.4 shows the steam velocity inside the piping leading up to the test section as a function of time for the same test as in Figures 7.1, 7.2, and 7.3.

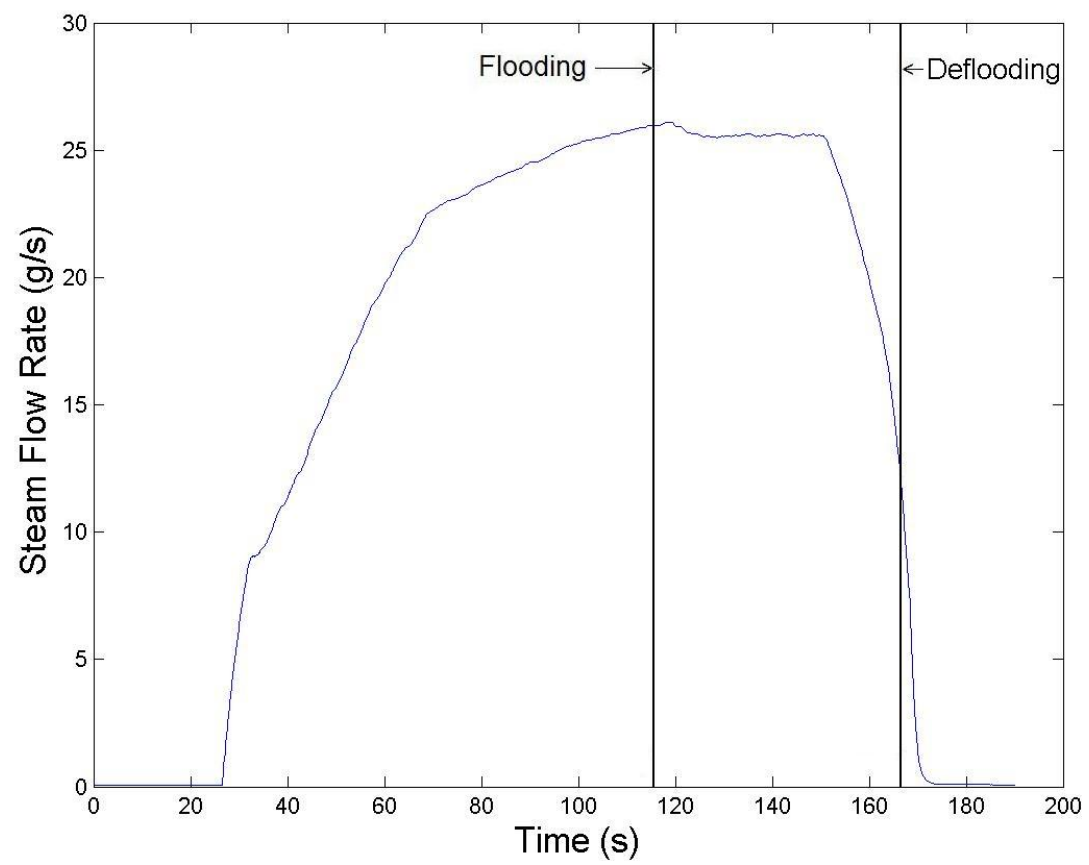

Fig. 7.4.: Steam velocity in the piping leading up to the test section plotted with time for a water flow rate of $6.28 \mathrm{GPM}\left(0.00040 \mathrm{~m}^{3} / \mathrm{s}\right)$.

\subsection{Reduced Data}

The time-dependent flooding data was reduced down to the information at the time when flooding occurred. This data consists of the steady state conditions just prior to flooding. The velocity of the steam entering the test section when flooding occurred was graphed as a function of the water flow rate and is shown in Figure 7.5. As shown in the graph, two distinct trends are obtained. For water flow rates below 
about 6 GPM $\left(0.00038 \mathrm{~m}^{3} / \mathrm{s}\right)$ there is a decreasing trend in the steam velocity with an increasing water flow rate. This is the same trend that is seen in the air data. For water flow rates above about $6 \mathrm{GPM}\left(0.00038 \mathrm{~m}^{3} / \mathrm{s}\right)$ there is an increasing trend in the steam velocity with an increasing water flow rate. This is different than the trends seen in air-water data in previous experiments [24], but a similar trend has been seen in previous steam-water experiments [37].

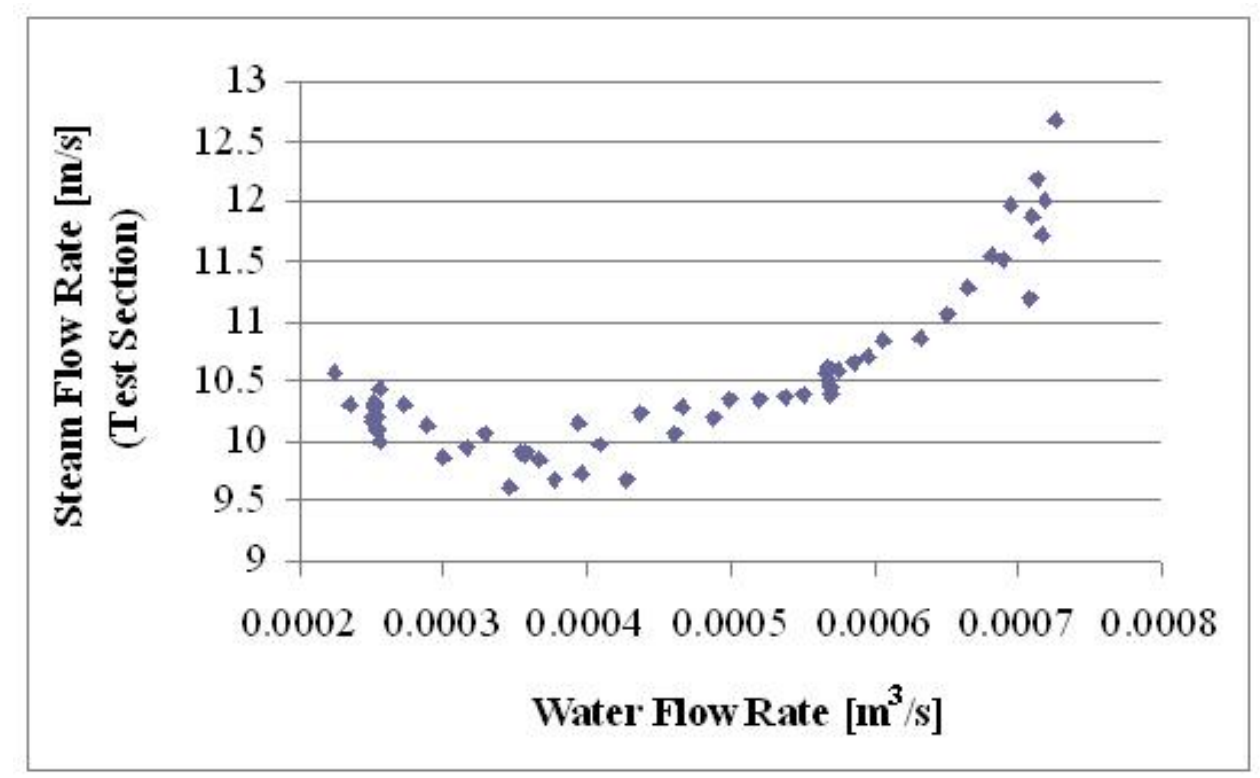

Fig. 7.5.: The steam velocity in the test section plotted with the water flow rate.

For water flow rates below about 6 GPM $\left(0.00038 \mathrm{~m}^{3} / \mathrm{s}\right)$, there is not enough water to condense a significant amount of steam. At low water flow rates flooding is primarily driven by fluid dynamics, rather than condensation effects, and the trends are analogous to those in adiabatic air-water tests. At higher water flow rates above $6 \operatorname{GPM}\left(0.00038 \mathrm{~m}^{3} / \mathrm{s}\right)$, there is significant steam condensation which lowers the effective steam flow rate. In this region, the greater the water flow rate, the more steam condenses inside the test section. Because of this, a higher inlet steam flow rate is needed for flooding to occur at higher water flow rates. 
When flooding occurs, the $\mathrm{dP}$ measured along the test section displays a characteristic drop. After flooding occurs, the dP oscillates. The characteristic drop was calculated for each steam test by subtracting the minimum dP recorded immediately after flooding occurs from the dP recorded just prior to flooding. This value represents the drop in the $\mathrm{dP}$ measured along the test section. Figure 7.6 shows the drop in the $\mathrm{dP}$ plotted with the water flow rate. The larger the water flow rate when flooding occurs, the larger the drop in the dP measured in the test section. This means that the pressure at the bottom of the test section increases by a larger amount when a higher water flow rate is used. The pressure at the bottom of the test section increases by a smaller amount when a lower water flow rate is used giving a lower measurement of the $\mathrm{dP}$. The pressure increases with higher water flow rates because the steam flowing into the test section encounters a larger amount of water.

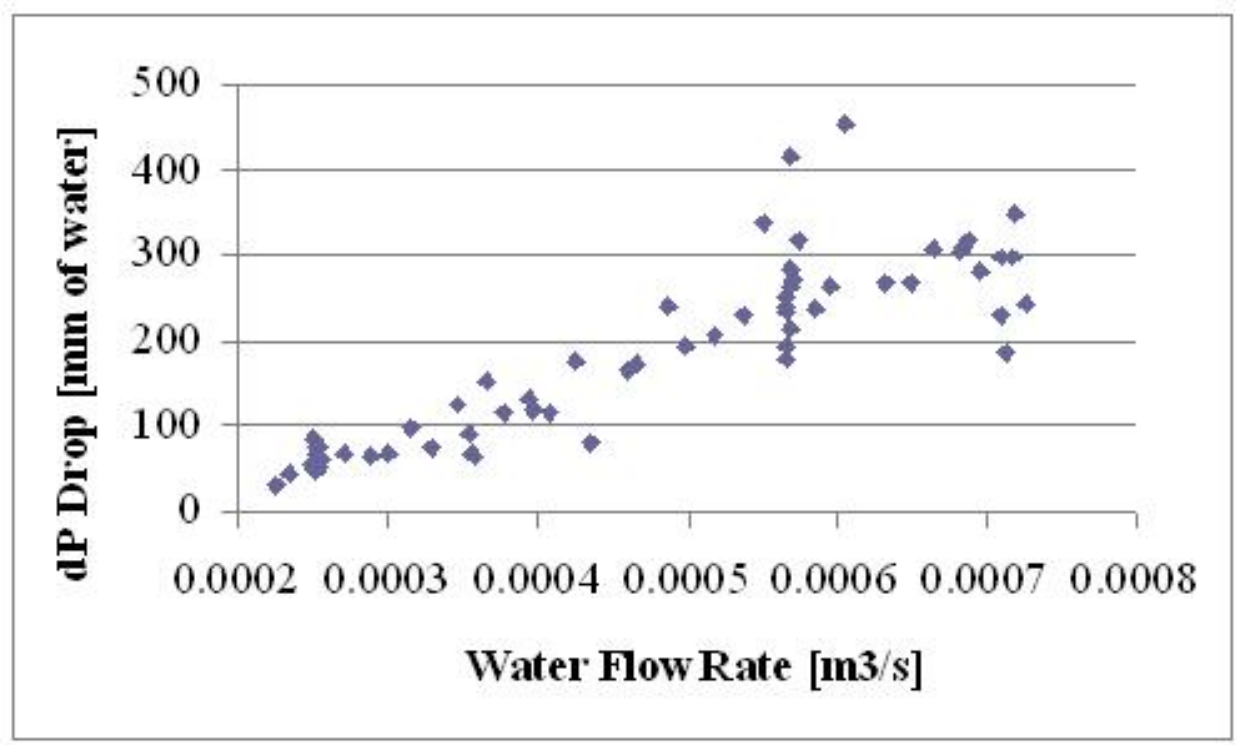

Fig. 7.6.: The drop in the $\mathrm{dP}$ plotted with the water flow rate. 


\subsection{Error Analysis}

The error associated with the steam data was calculated. The error in the data consists of random error, instrumentation error, and error in converting the data from analog to digital. To calculate the random error, 12 tests were run at a water flow rate of $4 \mathrm{GPM}\left(0.00025 \mathrm{~m}^{3} / \mathrm{s}\right)$ and 10 tests were ran at a water flow rate of $9 \operatorname{GPM}\left(0.00057 \mathrm{~m}^{3} / \mathrm{s}\right)$. These two water flow rates were chosen for repeatability tests because each of them lies in the middle of the two distinct trends seen in the reduced flooding data in Figure 7.5. The measured steam velocities inside the test section tube collected for a water flow rate of 4 GPM $\left(0.00025 \mathrm{~m}^{3} / \mathrm{s}\right)$ are shown in Figure 7.7. The average steam velocity inside the test section is approximately 10.21 $\mathrm{m} / \mathrm{s}$ and the standard deviation for the 12 data points is approximately $0.12 \mathrm{~m} / \mathrm{s}$.

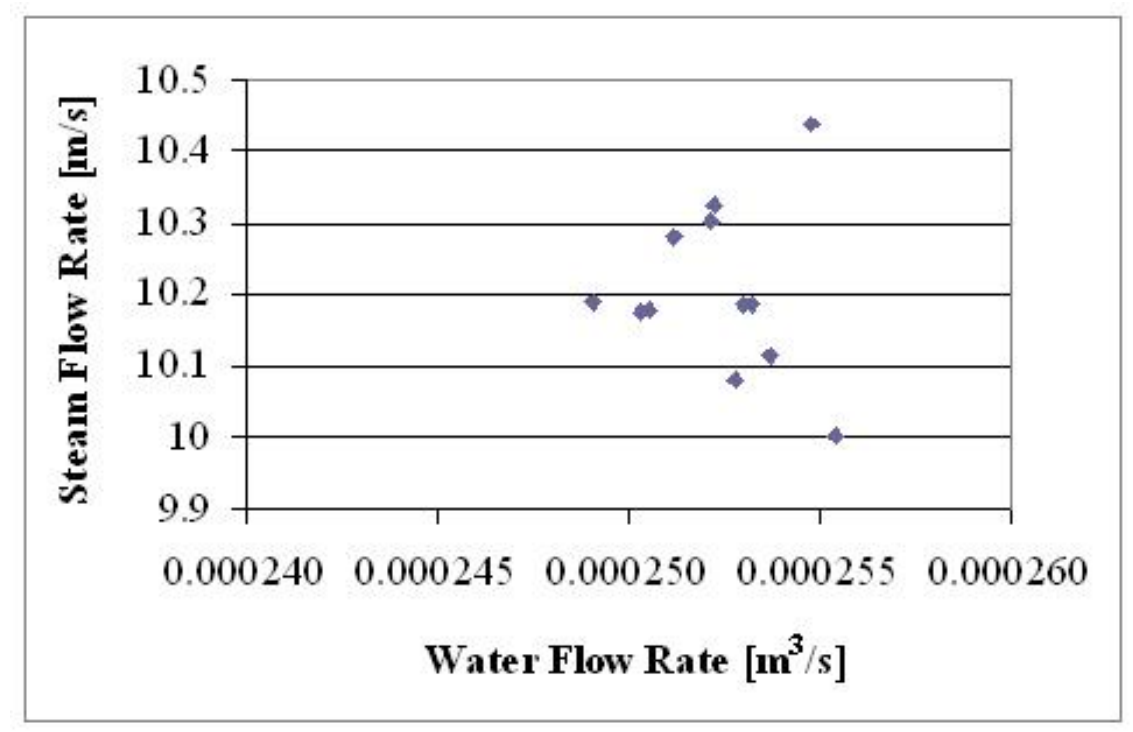

Fig. 7.7.: The steam velocities when flooding occurs inside the test section tube for a water flow rate of 4 GPM $\left(0.00025 \mathrm{~m}^{3} / \mathrm{s}\right)$.

The measured steam velocities inside the test section tube collected for a water flow rate of 9 GPM $\left(0.00057 \mathrm{~m}^{3} / \mathrm{s}\right)$ are shown in Figure 7.8 . The average steam 
velocity inside the test section tube is approximately $10.54 \mathrm{~m} / \mathrm{s}$ and the standard deviation for the 10 data points is approximately $0.08 \mathrm{~m} / \mathrm{s}$. The error associated with the data points taken at 4 GPM $\left(0.00025 \mathrm{~m}^{3} / \mathrm{s}\right)$ is higher than the error associated with the data points taken at 9 GPM $\left(0.00057 \mathrm{~m}^{3} / \mathrm{s}\right)$.

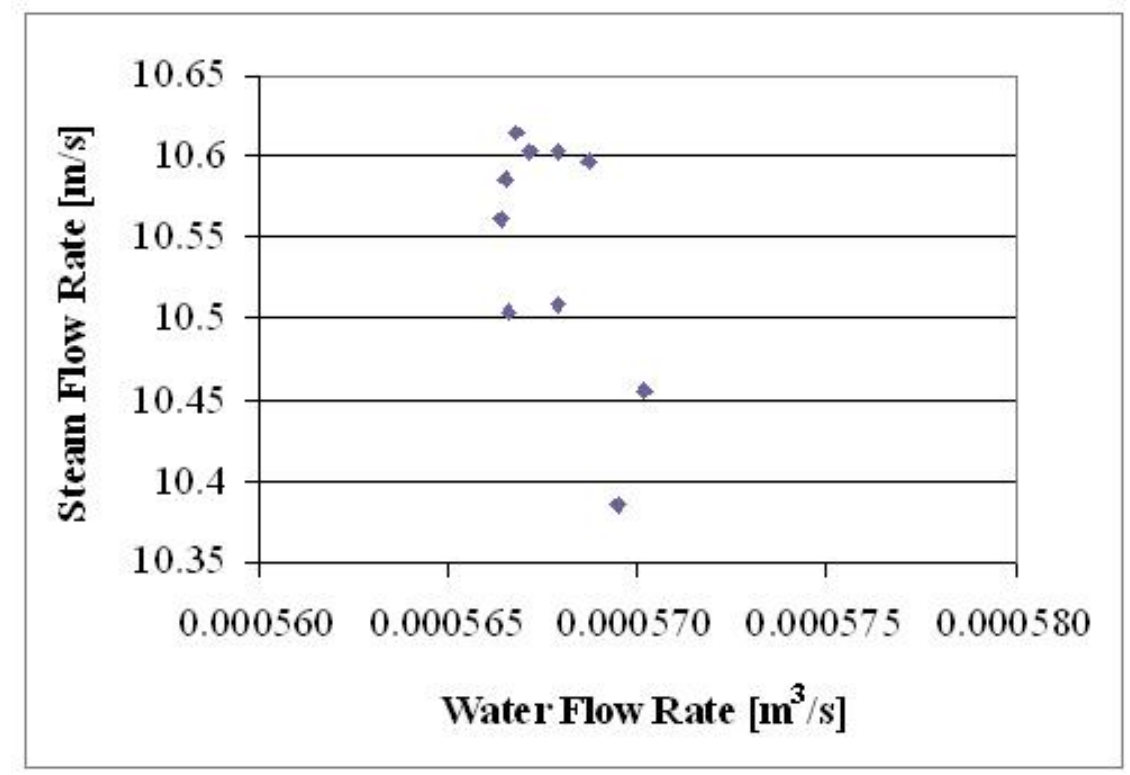

Fig. 7.8.: The steam velocities when flooding occurs inside the test section tube for a water flow rate of 9 GPM $\left(0.00057 \mathrm{~m}^{3} / \mathrm{s}\right)$.

Since the random error associated with the data points taken at 4 GPM $(0.00025$ $\mathrm{m}^{3} / \mathrm{s}$ ) is higher than the random error associated with the data points taken at 9 GPM $\left(0.00057 \mathrm{~m}^{3} / \mathrm{s}\right)$, the random error for the entire reduced steam data set was assumed to be the error associated with the data points taken at 4 GPM $(0.00025$ $\mathrm{m}^{3} / \mathrm{s}$ ). This was done so that the calculated error for the entire data set would be conservative. The error associated with the instrumentation is approximately $1 \%$ of the measured value. The error associated with converting the data signal from analog to digital is calculated to be approximately $0.0005 \mathrm{~m} / \mathrm{s}$. The total error was calculated based on the error from the three different sources. Figure 7.9 shows the 
reduced steam flooding data plotted with error bars associated with the total error.

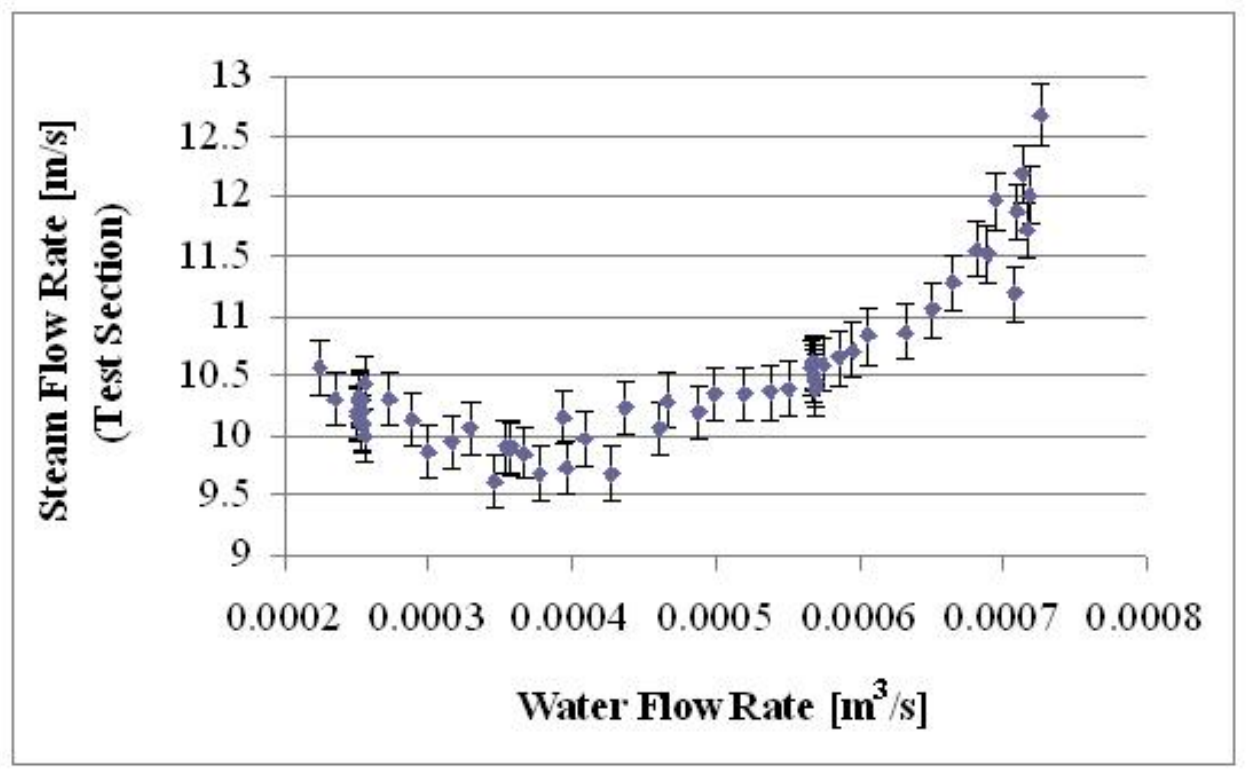

Fig. 7.9.: The steam flooding data plotted with error bars.

\subsection{Empirical Model Development}

The steam data was plotted as the Wallis parameters and is shown in Figure 7.10 along with the Wallis correlation from Equation 2.3. The Wallis correlation does not predict the trend seen in the steam data nor does it predict values close to the collected data. For flooding with steam and water in a large diameter tube, the Wallis correlation does not accurately predict the conditions in which flooding occurs.

The steam data was also plotted as the Kutateladze parameters and is shown in Figure 7.11 along with the Kutateladze-type correlation from Equation 2.5. The Kutateladze-type correlation also does not predict the trend seen in the steam data nor does it predict values close to the collected data. For flooding with steam and 


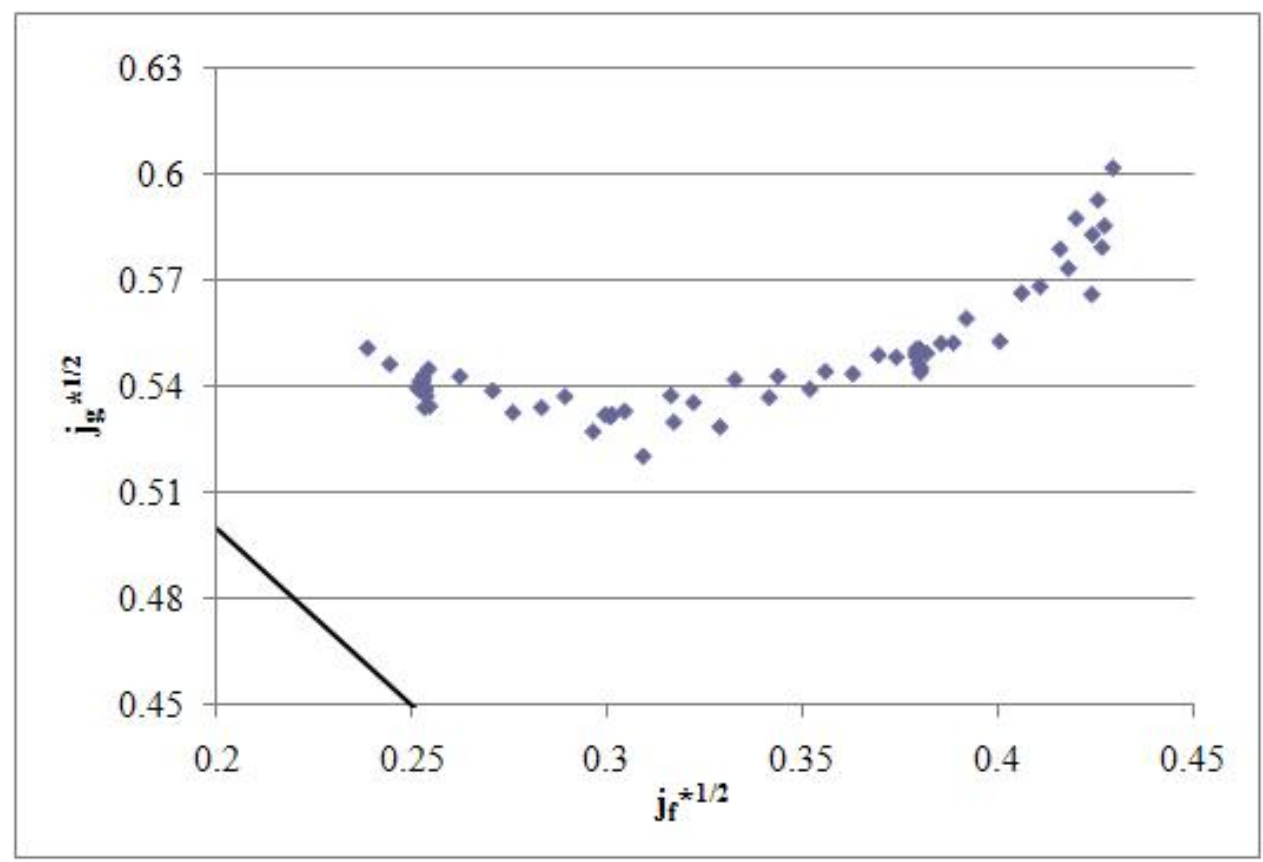

Fig. 7.10.: The steam data plotted as the Wallis parameters along with the Wallis correlation.

water, the Kutateladze-type correlation does not accurately predict the conditions in which flooding occurs.

Next the steam data was plotted using the effective gas Kutateladze parameter developed by Tien [20] shown in Equation 2.13. Figure 7.12 shows the steam data plotted using the effective gas Kutateladze parameter along with the Kutateladzetype correlation. There is not a significant difference when the data is plotted using the effective gas Kutateladze parameter. The Kutateladze-type correlation still does not accurately predict the conditions in which flooding occurs even when an effective Kutateladze parameter is used.

Since neither the Wallis correlation nor the Kutateladze-type correlation accurately predict the steam data, a new empirical correlation is needed to predict the conditions in which flooding occurs. Since the amount of steam condensation affects flooding with steam and water, the fraction of condensed steam needs to be calcu- 


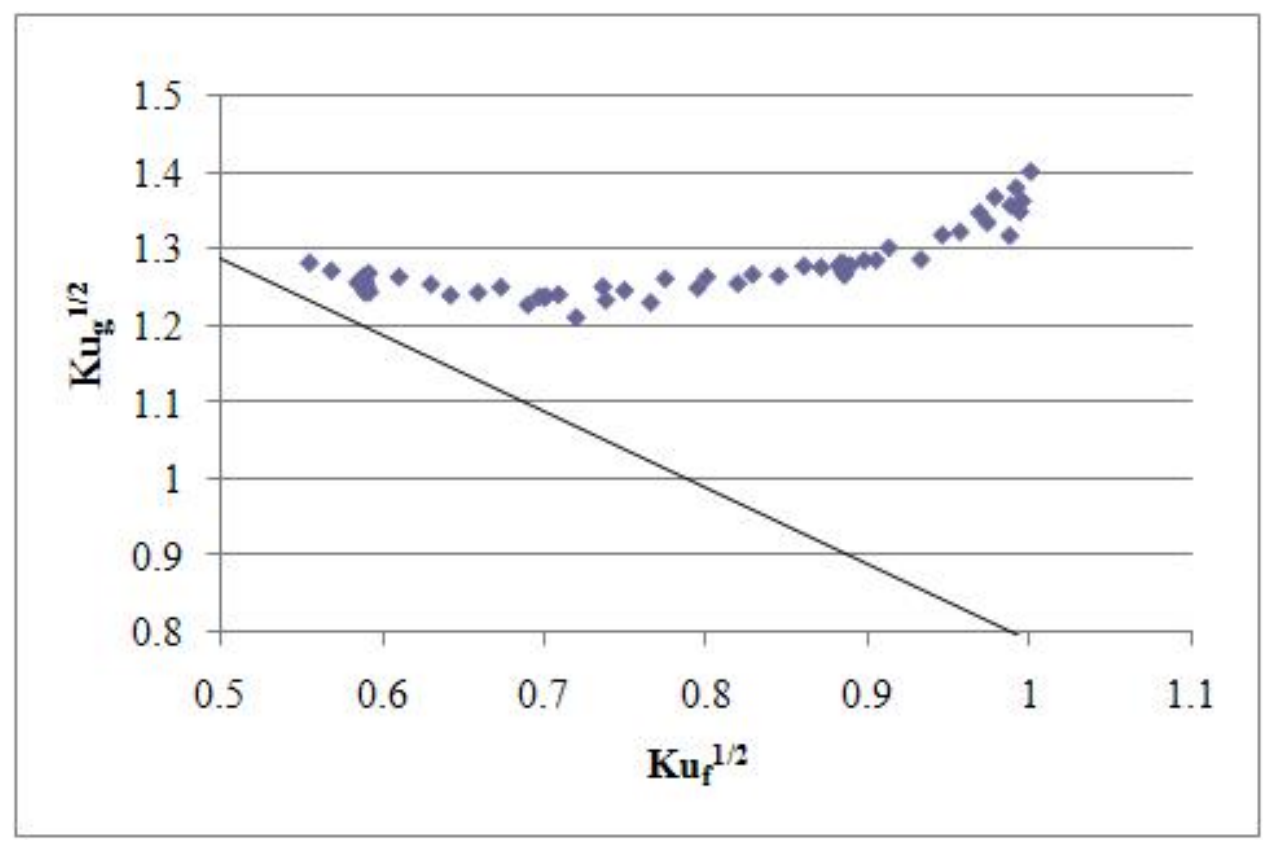

Fig. 7.11.: The steam data plotted as the Kutateladze parameters along with the Kutateladze-type correlation.

lated. This value can be calculated using an energy balance between the superheated steam and subcooled water. The energy released when the steam condenses is equal to the energy gained by the water. This relationship is seen in Equation 7.1.

$$
\dot{m}_{s t, c d}\left(h_{s t}-h_{f}\right)=\dot{m}_{f} c_{p}\left(T_{s}-T_{f}\right)
$$

To gain a more accurate calculation of the fraction of condensed steam, the actual temperature of the water must be calculated. The temperatures recorded on the outer surface of the test section approximate the temperatures of the water inside the test section. The temperature of the water inside the test section can be calculated using a simple heat flux relationship. Equation 7.2 shows the relationship between temperature and heat flux.

$$
q^{\prime \prime}=-k \frac{\Delta T}{\Delta x}
$$




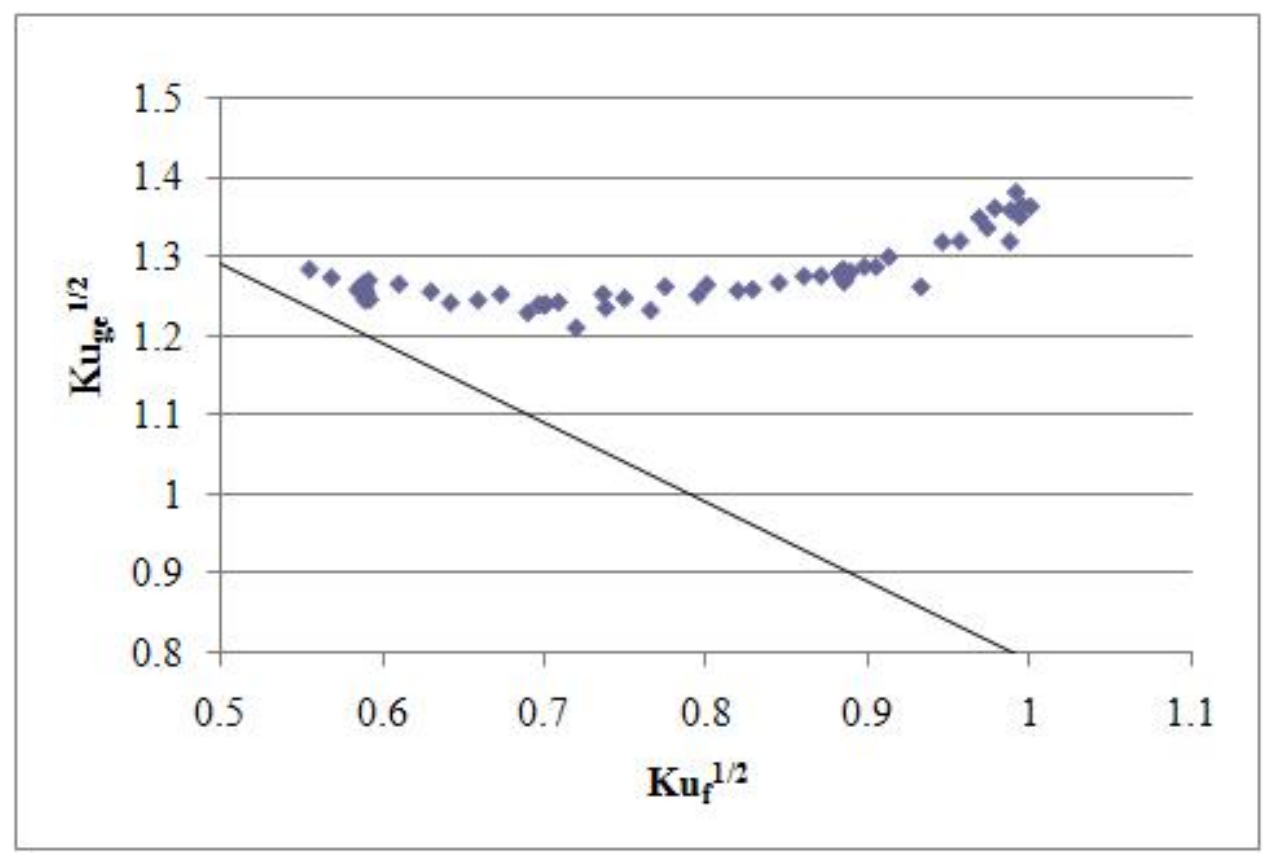

Fig. 7.12.: The steam data plotted as the effective Kutateladze parameters along with the Kutateladze-type correlation.

The heat flux across the film of water in the test section is equal to the heat flux across the stainless steel test section. The heat flux is assumed to be azimuthally uniform. The water at the steam-water interface is assumed to be at the saturation temperature. The relationship between the heat flux in the water and the heat flux in the stainless steel test section at the bottom surface thermocouple is shown in Equation 7.3.

$$
k_{S S}\left(\frac{T_{\text {wall }}-T_{\text {bottom }}}{\delta_{S S}}\right)=k_{f}\left(\frac{T_{s}-T_{\text {wall }}}{\delta_{f}}\right)
$$

The thickness of the stainless steel test section wall is 0.25 inches $(6.35 \mathrm{~mm})$. The water film thickness is not constant and increases with an increasing water flow rate. The water film thickness was calculated using Equation $3.2[11,47]$.

Since the temperature at the bottom of the outer surface of the test section, $T_{\text {bottom }}$, has been measured, the water temperature on the inside surface of the test section can be calculated by rearranging Equation 7.3 to get Equation 7.4. Equa- 
tion 7.4 is an approximation of the wall temperature assuming that the system is in equilibrium. Since the data of interest are the conditions just prior to flooding, this approximation is valid because the temperatures in the test section just prior to flooding are relatively constant as seen in Figure 7.2.

$$
T_{\text {wall }}=\frac{T_{s}+\left(\frac{k_{S S}}{k_{f}}\right)\left(\frac{\delta_{f}}{\delta_{S S}}\right) T_{\text {bottom }}}{1+\left(\frac{k_{S S}}{k_{f}}\right)\left(\frac{\delta_{f}}{\delta_{S S}}\right)}
$$

Figure 7.13 is a graphical depiction of the relative temperature values calculated using Equation 7.4. The temperature difference across the test section is smaller than the temperature difference across the water film. This is because the thermal conductivity of stainless steel is much higher than the thermal conductivity of water.

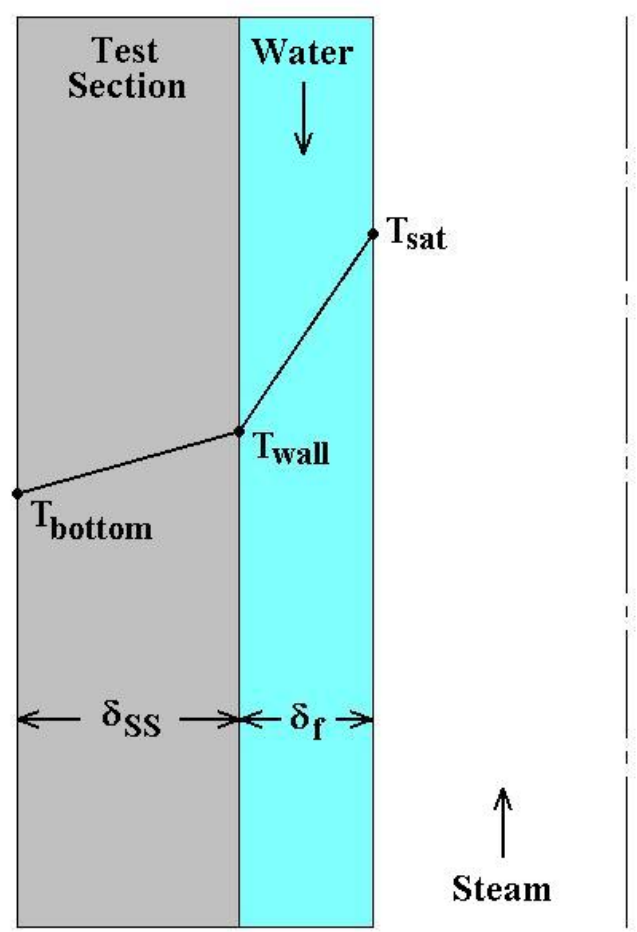

Fig. 7.13.: A graphical depiction of the relative temperature values in the test section. 
Now that the actual temperature of the water inside the test section has been calculated, the fraction of condensed steam can be calculated. Rearranging Equation 7.1 and solving for the mass flow rate of steam gives Equation 7.5. This is the mass flow rate of the steam that condenses inside the test section from the steam inlet to the temperature measurement taken at the bottom surface of the test section. Flooding is assumed to initiate at the same axial location as the bottom surface thermocouple. This assumption is valid because in previous experiments flooding was seen to initiate at the bottom of the test section [23].

$$
\dot{m}_{s t, c d}=\frac{\dot{m}_{f} c_{p}\left(T_{s}-T_{\text {wall }}\right)}{h_{s t}-h_{f}}
$$

The fraction of condensed steam is simply the mass flow rate of the steam that condenses divided by the total mass flow rate of the steam. This ratio is seen in Equation 7.6. It is noted that some non-condensible gases may be present inside the test section since it is indirectly open to the atmosphere. The presence of noncondensible gases causes a smaller fraction of steam to condense. Since air is purged from the steam generator prior to conducting a test and leaks in the steam and water lines are negligible, the amount of air entering the test section can be considered very small. Assuming the effect on the fraction of steam condensed in the test section is negligible, this means that Equation 7.6 is slightly conservative.

$$
f=\frac{\dot{m}_{f} c_{p}\left(T_{s}-T_{\text {wall }}\right)}{\dot{m}_{s t}\left(h_{s t}-h_{f}\right)}
$$

For a constant inlet water temperature of $70^{\circ} \mathrm{C}$, the fraction of condensed steam increases with an increasing water flow rate. This trend is shown in Figure 7.14. Two factors affect the fraction of condensed steam. One factor is the water flow rate. A higher water flow rate means there is physically more water in the test section to absorb the energy of the condensed steam. The second factor is the degree of subcooling of the water. The larger the water temperature difference is from saturation, the more energy the water can absorb from the condensed steam. For a constant inlet water temperature of $70{ }^{\circ} \mathrm{C}$, this temperature difference varies with the water 
flow rate. The water temperature difference plotted with the water flow rate is shown in Figure 7.15.

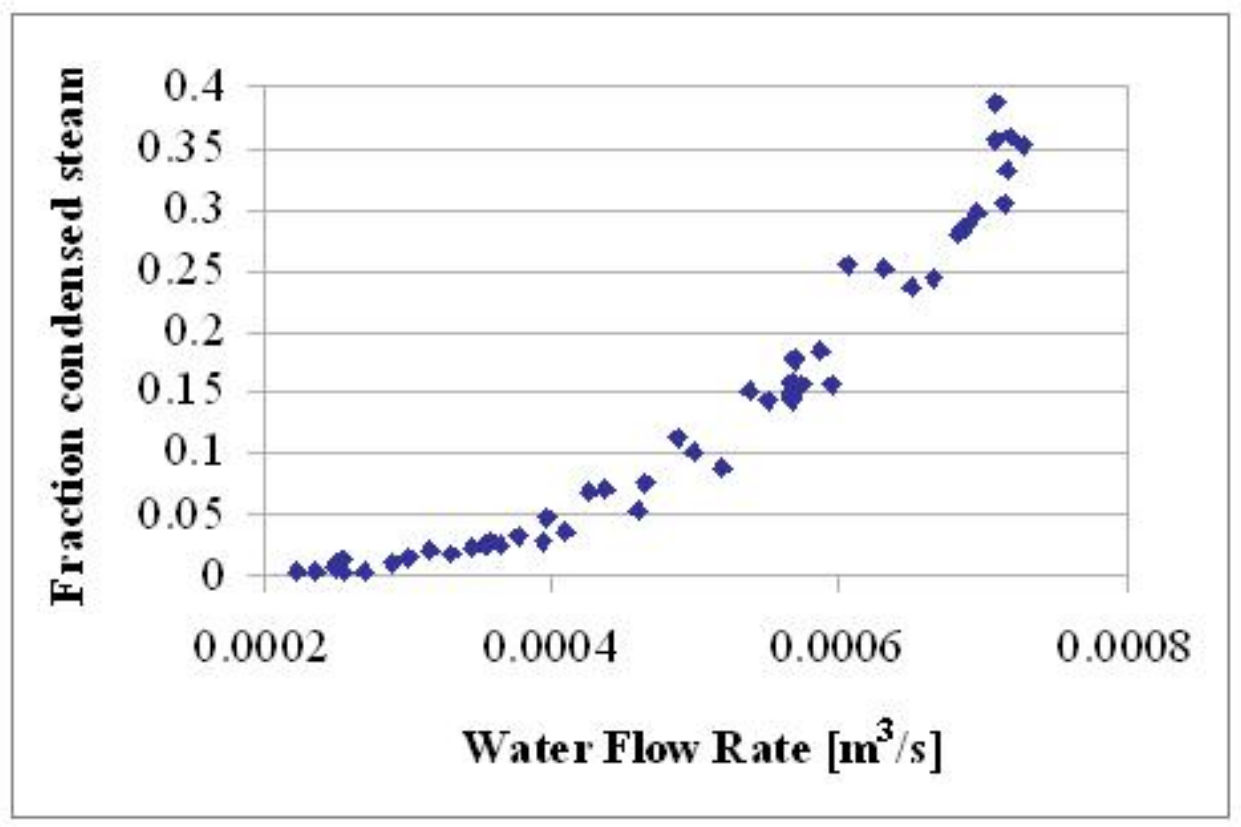

Fig. 7.14.: The fraction of condensed steam plotted with the water flow rate.

Now that the fraction of condensed steam is known, an effective steam mass flow rate can be calculated. The effective steam mass flow rate is simply the fraction of steam that has not condensed. This calculation is shown in Equation 7.7.

$$
\dot{m}_{g e}=\dot{m}_{g}(1-f)
$$

The superficial velocity of the steam is directly related to the mass flow rate, which is shown in Equation 7.8.

$$
\dot{m}_{g}=j_{g} \rho_{g} A
$$

Since the superficial velocity is directly related to the mass flow rate, the effective superficial velocity of the steam is also related to the fraction of steam that has not 


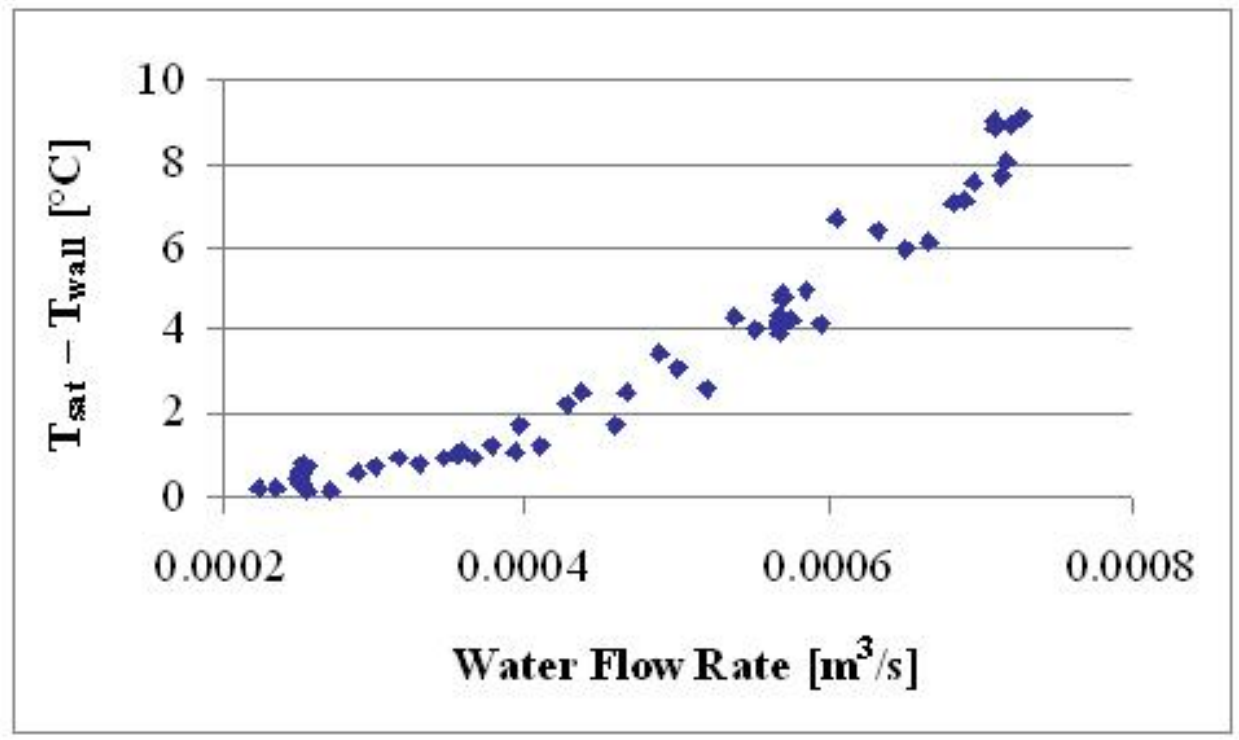

Fig. 7.15.: The water temperature difference plotted with the water flow rate.

condensed. Substituting the effective steam superficial velocity into the gas Kutateladze number from Equation 2.4 gives the effective gas Kutateladze number, shown in Equation 7.9. This calculation of the effective gas Kutateladze number is vastly different from the calculation performed by Tien [20] and shown in Equation 2.13.

$$
K u_{g e}=\frac{j_{g e} \rho_{g}^{1 / 2}}{\left(g \sigma\left(\rho_{f}-\rho_{g}\right)\right)^{1 / 4}}=\frac{j_{g} \rho_{g}^{1 / 2}(1-f)}{\left(g \sigma\left(\rho_{f}-\rho_{g}\right)\right)^{1 / 4}}=K u_{g}(1-f)
$$

The steam data was correlated by substituting the effective gas Kutateladze number from Equation 7.9 into the Kutateladze-type correlation from Equation 2.5. The steam data is plotted as the effective gas Kutateladze number and liquid Kutateladze number in Figure 7.16. When the data is plotted taking into account the effective steam flow rate, a linear trend is seen. For an increasing water flow rate, the effective steam flow rate required to achieve flooding decreases. This is the same general trend seen in flooding data with air and water. The proposed correlation is a fit to the data and is plotted along with lines at $95 \%$ and $105 \%$ of the correlation. The proposed correlation is shown in Equation 7.10. 


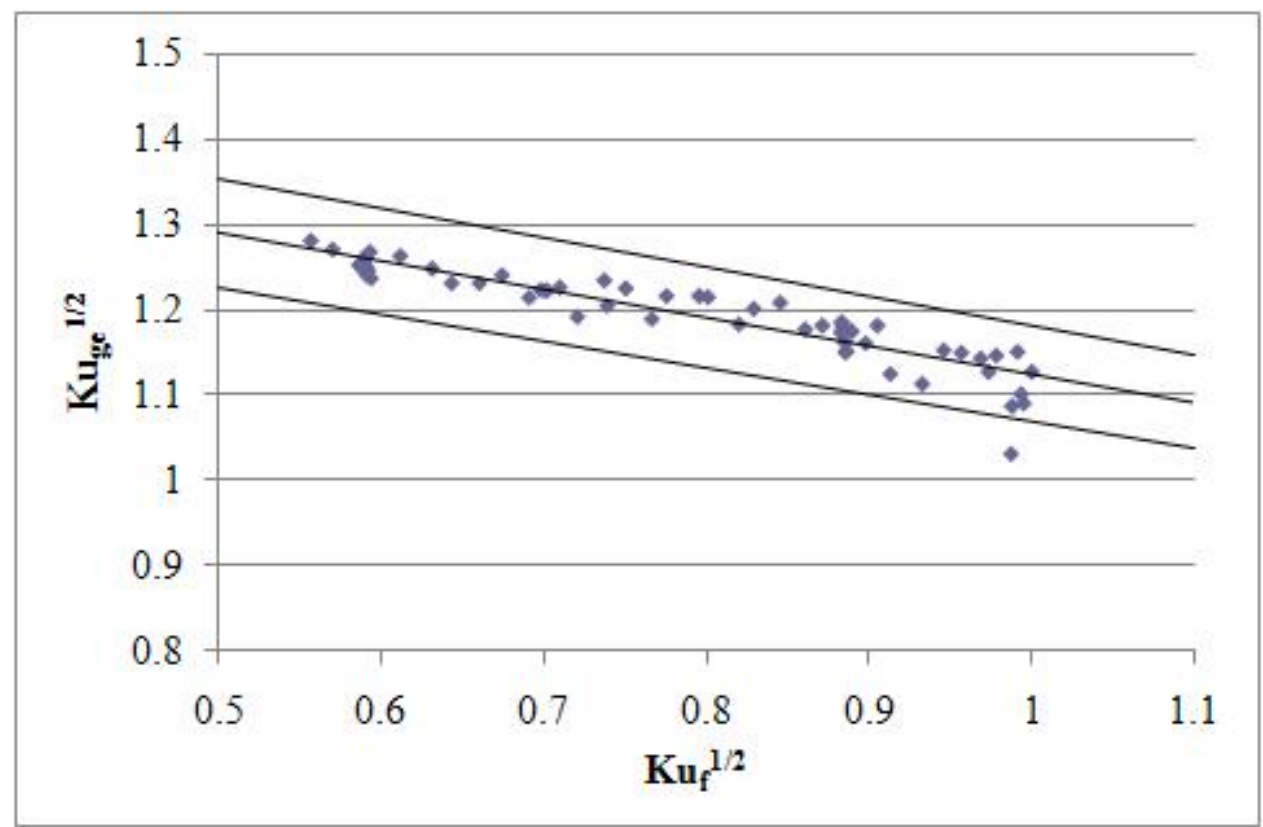

Fig. 7.16.: The steam data plotted with the proposed correlation and lines at $95 \%$ and $105 \%$ of the correlation.

$$
K u_{g e}^{1 / 2}+0.33 K u_{f}^{1 / 2}=1.45
$$

\subsection{Comparison with Air-Water Tests}

The reduced steam flooding data was compared to the reduced air flooding data. The volumetric flow rates for both the steam and the air are plotted with the water flow rate in Figure 7.17. For water flow rates below about 6 GPM $(0.00038$ $\mathrm{m}^{3} / \mathrm{s}$ ) the steam data overlays the air data. Water flow rates above about $6 \mathrm{GPM}$ $\left(0.00038 \mathrm{~m}^{3} / \mathrm{s}\right)$ show that the volumetric steam flow rate required for flooding to occur increases and is significantly higher than the volumetric air flow rate.

Next the effective steam flooding data was compared to the air flooding data. The effective volumetric flow rates for both the steam and the air are plotted with the water flow rate in Figure 7.18. The effective steam volumetric flow rate data 


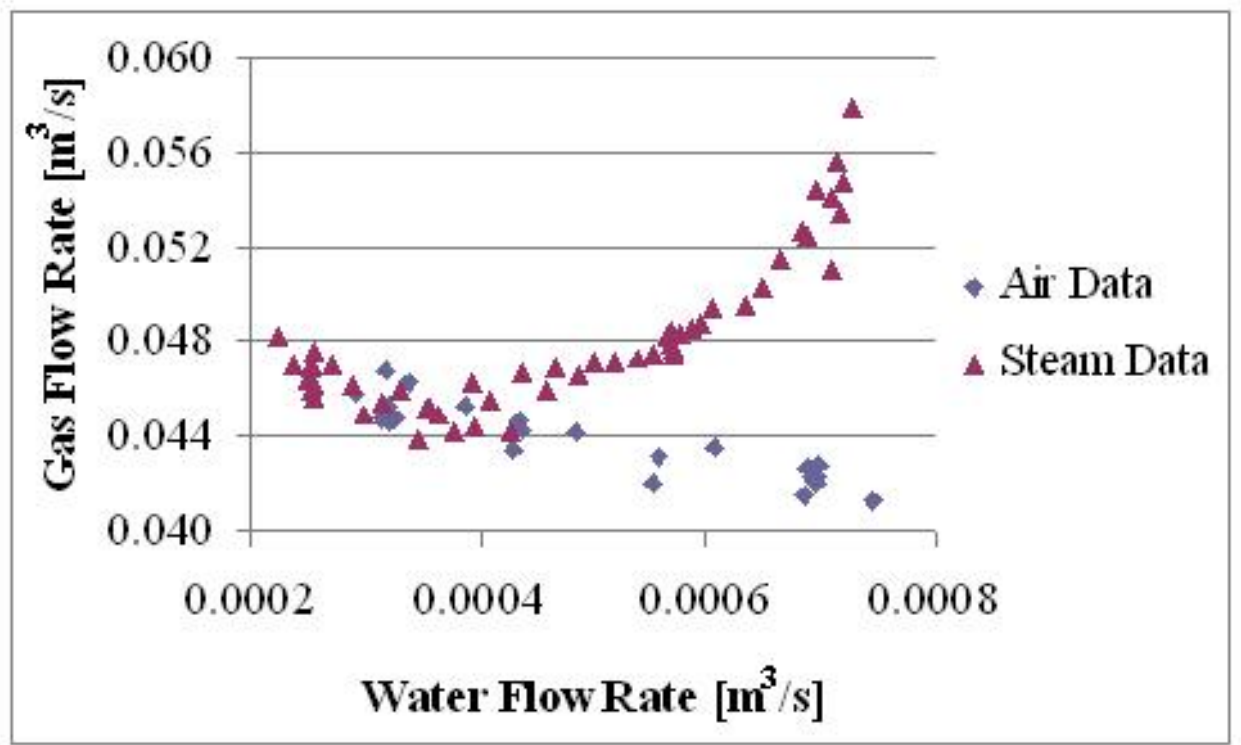

Fig. 7.17.: The air and steam volumetric flow rates plotted with the water flow rate.

to achieve flooding overlaps the air data almost completely. This shows that if condensation of the steam is accounted for, the conditions in which flooding occurs with steam are equivalent to the conditions in which flooding occurs for air.

The empirical correlation developed in this thesis can be applied to reactor safety analysis. It can be directly implemented into severe accident analysis codes for nuclear reactors to predict flooding in the pressurizer surge line. The knowledge gained from predicting flooding can impact the calculated progression of a severe accident, specifically the creep rupture behavior of the surge line and steam generator tubes. In addition, the data and observations collected in this thesis will serve as a knowledge base for validating a mechanistic model to predict flooding with steam and water in large diameter vertical tubes. 


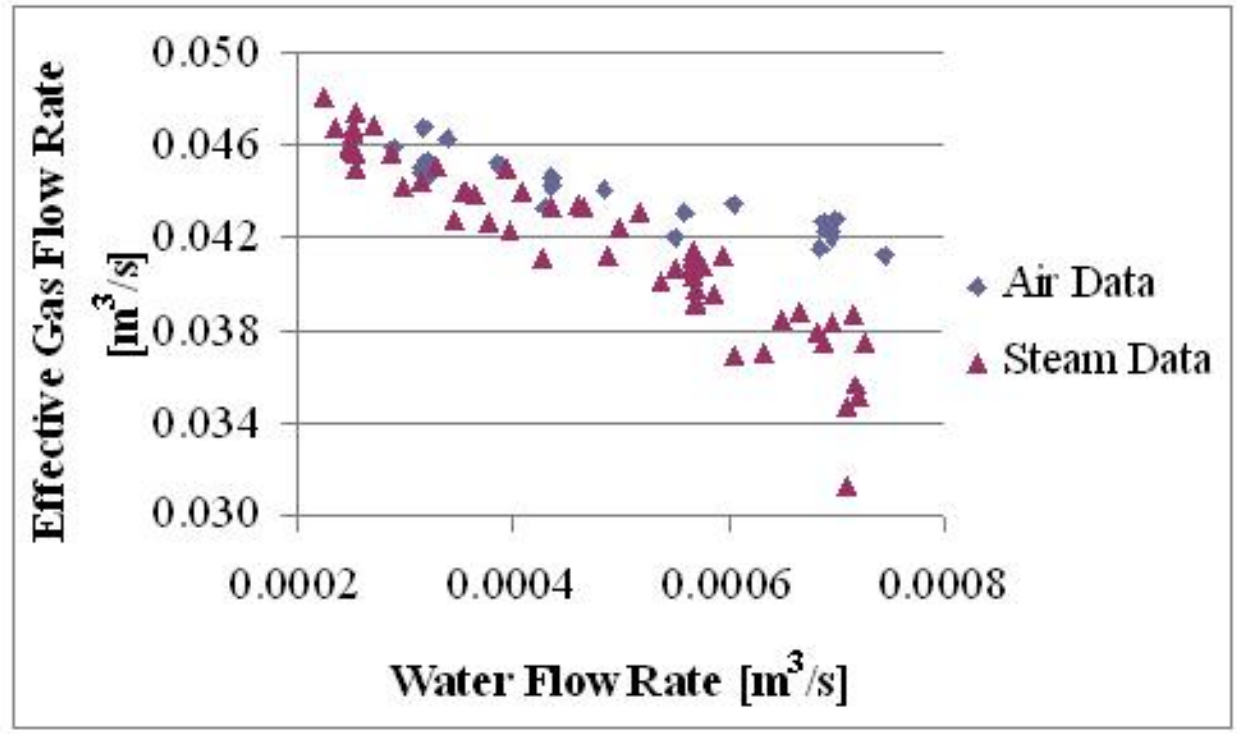

Fig. 7.18.: The air and effective steam volumetric flow rates plotted with the water flow rate. 


\section{CONCLUSIONS AND RECOMMENDED FUTURE WORK}

\subsection{Conclusions}

The phenomenon of flooding with steam and water was experimentally investigated to provide a better prediction of flooding in a PWR pressurizer surge line. This investigation has provided valuable knowledge on the conditions which lead to flooding in non-adiabatic steam-water systems. These conditions more accurately reflect those in a nuclear reactor when compared to previous air-water flooding data. In addition, an axial temperature profile along the tube wall outer surface was obtained in the test section that provides information on steam condensation. This type of data has not been presented for previous steam-water flooding experiments; only inlet and outlet temperature conditions have been reported. As a result, previous studies have looked at steam-water flooding on the global scale of the experiment, but this thesis research was able to look at steam-water flooding on a local basis. The data collected in this experiment can be used to validate a mechanistic model of flooding with steam and water.

The facility was designed and constructed as a part of this thesis research and is capable of measuring the conditions in which flooding occurs for ranges of steam and water flow rates that correspond to expected reactor ranges in a PWR pressurizer surge line. The collected data displayed similar trends to previous flooding investigations with steam and water. The first trend observed is a decrease in the steam flow rate required for flooding to occur with an increase in the water flow rate for water flow rates below 6 GPM $\left(0.00038 \mathrm{~m}^{3} / \mathrm{s}\right)$. The second trend observed is an increase in the steam flow rate required for flooding to occur with an increase in the water flow rate for water flow rates above $6 \mathrm{GPM}\left(0.00038 \mathrm{~m}^{3} / \mathrm{s}\right)$. The Wallis and Kutateladze-type correlations obtained from the literature were compared to the collected data and found to be insufficient for predicting flooding with steam and water. 
A suitable correlation to predict flooding with steam and water in a large diameter vertical tube was developed from the collected data. This correlation is based on the Kutateladze-type correlation, but takes into account the condensation of the steam inside the test section. As a result, an effective steam Kutateladze number is used to predict flooding. This correlation correctly predicts flooding with steam and water for the current test section for water flow rates between 3.5 and 12 GPM (0.00022 and $0.00076 \mathrm{~m}^{3} / \mathrm{s}$ ). This research has been performed to provide a better prediction of flooding in a PWR pressurizer surge line to be used in reactor safety codes.

\subsection{Recommended Future Work}

The following are suggestions for future work in the area of flooding with steam and water.

- An investigation in varying the water inlet temperature will provide more information about how water subcooling affects the conditions in which flooding occurs. It is expected that varying the water inlet temperature will produce a family of correlations. Based on these correlations, the effect of water subcooling on flooding can be determined.

- An investigation determining the exact location of flooding inside the test section will provide more information concerning the mechanisms that cause flooding. In flooding experiments with steam and water, flooding can occur at both the top and the bottom of the test section. If the exact location is known, it is possible to obtain local steam-water flooding conditions that will aid in developing a mechanistic model.

- Pressure scaling issues have been addressed by Rothe and Crowley [35] for saturated water in small diameter tubes. Pressure effects on flooding still need to be addressed in large diameter tubes. In addition, the affect of pressure on subcooled water in flooding also needs to be addressed. 
- An investigation determining the effect of inclination on flooding with steam and water in a large diamter tube will provide knowledge on other components of the prototype, since the pressurizer surge line contains many bends and angles.

- A mechanistic model of flooding with steam and water would provide insight into the mechanisms that cause flooding. A model would be valuable to reactor safety analysis because it could be applied in a safety code. The data provided in this thesis will serve as a basis for validating such a model. 


\section{REFERENCES}

[1] Annual Energy Outlook 2009, DOE/EIA-0383(2009), Energy Information Administration, March, 2009, 〈http://www.eia.doe.gov/oiaf/aeo//.

[2] United States Nuclear Regulatory Commission, New reactors, August, 2008, $\langle$ http://www.nrc.gov/reactors/new-reactors.html $\rangle$.

[3] G.F. Hewitt, In search of two-phase flow, Transactions of the ASME, Journal of Heat Transfer 118 (1996) 518-527.

[4] K.J. Hogan, K. Vierow, A new drift-flux based approach to predict flooding, in: U.S. Japan Seminar on Two-Phase Flow Dynamics, Santa Monica, CA, 14-18 September, 2008.

[5] S.G. Bankoff, S.C. Lee, A critical review of the flooding literature, NUREG/CR3060, Dept. Chem. Eng., Northwestern U., Evanston, IL, 1983.

[6] A.H. Govan, G.F. Hewitt, H.J. Richter, A. Scott, Flooding and churn flow in vertical pipes, Int. J. Multiphase Flow 17 (1991) 27-44.

[7] K. Takeuchi, M.Y. Young, A.F. Gagon, Flooding in the pressurizer surge line of AP600 plant and analyses of APEX data, Nuclear Engineering Design 192 (1999) 45-58.

[8] Y. Liao, K. Vierow, MELCOR analysis of steam generator tube creep rupture in station blackout severe accident, Nuclear Technology 152 (2005) 302-313.

[9] K. Vierow, Y. Liao, J. Johnson, M. Kenton, R. Gauntt, Severe accident analysis of a PWR station blackout with the MELCOR, MAAP4, and SCDAP/RELAP5 codes, Nuclear Engineering and Design 234 (2004) 129-145.

[10] C. Burns, Y. Liao, K. Vierow, MELCOR code assessment by simulation of TMI2, in: Proc. of 11th International Topical Meeting on Nuclear Reactor Thermal Hydraulics (NURETH-11), Avignon, France, 2005.

[11] G.B. Wallis, One Dimensional Two Phase Flow, 1st ed., McGraw-Hill, Great Britain, 1969, pp. 315-343.

[12] S.S. Kutateladze, Elements of the hydrodynamics of gas-liquid systems, Fluid Mechanics Soviet Research 1 (1972) 29-50.

[13] W.E. Lobo, L. Friend, F. Hashmall, F. Zenz, Limiting capacity of dumped tower packings, Transactions of the AIChE (1945) 693-710.

[14] T.K. Sherwood, G.H. Shipley, F.A.L. Holloway, Flooding velocities in packed columns, Industrial and Engineering Chemistry (1938) 765-769.

[15] G.B. Wallis, Flooding velocities for air and water in vertical tubes, AEEW-R123, United Kingdom Atomic Energy Authority, Reactor Group, Atomic Energy Establishment, Winfrith, Dorset, 1961. 
[16] R. Clift, C.L. Pritchard, R.M. Nedderman, The effect of viscosity on the flooding conditions in wetted wall columns, Chemical Engineering Science 21 (1966) 87-95.

[17] G.B. Wallis, J.T. Kuo, The behavior of gas-liquid interfaces in vertical tubes, Int. J. Multiphase Flow 2 (1976) 521-536.

[18] M. Vijayan, S. Jayanti, A.R. Balakrishnan, Effect of tube diameter on flooding, Int. J. Multiphase Flow 27 (2001) 797-816.

[19] O.L. Pushkina, Y.L. Sorokin, Breakdown of liquid film motion in vertical tubes, Heat Transfer Sov. Res. 1 (1969) 56-64.

[20] D.L. Tien, A simple analytical model for counter-current flow limiting phenomena with vapor condensation, Letters in Heat and Mass Transfer 4 (1977) 231-238.

[21] A. Zapke, D.G. Kroger, Countercurrent gas-liquid flow in inclined and vertical ducts II: the validity of the Froude-Ohnesorge number correlation for flooding, International Journal of Multiphase Flow 26 (2000) 1457-1468.

[22] A. Zapke, D.G. Kroger, Countercurrent gas-liquid flow in inclined and vertical ducts I: flow patterns, pressure drop characteristics and flooding, International Journal of Multiphase Flow 26 (2000) 1439-1455.

[23] M. Solmos, An Experimental Investigation of the Countercurrent Flow Limitation, MS thesis, Texas A\&M University, College Station, TX, 2008.

[24] K.W. McQuillan, P.B. Whalley, Comparison between flooding correlations and experimental flooding data for gas-liquid flow in vertical circular tubes, Chem. Eng. Sci. 40 (1985) 1425-1440.

[25] S. Levy, Two-Phase Flow in Complex Systems, 1st ed., Wiley-IEEE, New York, 1999, pp. 264-299.

[26] H. Imura, H. Kusuda, S. Funatsu, Flooding velocity in a countercurrent annular two-phase flow, Chemical Engineering Science 32 (1977) 79-87.

[27] G. Karimi, M. Kawaji, Flooding in vertical counter-current annular flow, Nuclear Engineering and Design 200 (2000) 95-105.

[28] A.A. Mouza, S.V. Paras, A.J. Karabelas, Incipient flooding in inclined tubes of small diameter, International Journal of Multiphase Flow 29 (2003) 1395-1412.

[29] S.K. Chung, L.P. Liu, C.L. Tien, Flooding in two-phase countercurrent flow-II experimental investigation, Physicochem. Hydrodyn. 1 (1980) 209-220.

[30] A.G. Cetinbudaklar, G.J. Jameson, The mechanisms of flooding in vertical countercurrent two-phase flow, Chemical Engineering Science 24 (1969) 1669-1680.

[31] Y. Taitel, D. Barnea, A.E. Dukler, A film model for the prediction of flooding and flow reversal for gas-liquid flow in vertical tubes, International Journal of Multiphase Flow 8 (1982) 1-10.

[32] A.E. Dukler, L. Smith, A. Chopra, Flooding and upward film flow in tubes I: experimental studies, International Journal of Multiphase Flow 10 (1984) 585-597. 
[33] D. Barnea, B. Yoseph, Y. Taitel, Flooding in inclined pipes-effet of entrance section, Canadian Journal of Chemical Engineering 64 (1986) 177-184.

[34] D. Moalem Maron, A.E. Dukler, Flooding and upward film flow in vertical tubes II: speculations on film flow mechanisms, International Journal of Multiphase Flow 10 (1984) 599-621.

[35] P.H. Rothe, C.J. Crowley, Scaling pressure and subcooling for countercurrent flow, NUREG/CR-0464, CREARE-TN-285, prepared by Creare, Inc. for U.S. Nuclear Regulatory Commission, 1978.

[36] C.J. Crowley, G.B. Wallis, E.L. Ludwig, Steam water interaction in a scaled pressurized water reactor downcomer annulus, C00-2294-4, Thayer School of Engineering, September 1974.

[37] G.B. Wallis, D.C. deSieyes, R.J. Rosselli, J. Lacombe, Countercurrent annular flow regimes for steam and subcooled water in a vertical tube, NP-1336, Research Project 443-2, Prepared by Dartmouth College for Electric Power Research Institute, 1980.

[38] S.C. Lee, S.G. Bankoff, Stability of steam-water countercurrent flow in an inclined channel: flooding, Journal of Heat Transfer 105 (1983) 713-718.

[39] S.C. Lee, Stability of Steam-Water Countercurrent Stratified Flow, PhD thesis, Northwestern University, Evanston, IL, 1983.

[40] M.H. Chun, S.O. Yu, Effect of steam condensation on countercurrent flow limiting in nearly horizontal two-phase flow, Nuclear Engineering and Design 196 (2000) 201-217.

[41] Y. Taitel, D. Barnea, A.E. Dukler, Modelling flow pattern transitions for steady upward gas-liquid flow in vertical tubes, AIChE Journal 26 (1980) 345-354.

[42] H.J. Richter, G.B. Wallis, M.S. Speers, Effect of scale on two-phase countercurrent flow flooding, NUREG/CR-0312, Thayer School of Engineering, Dartmouth College, Hanover, NH, 1979.

[43] H. Richter, Flooding in tubes and annuli, International Journal of Multiphase Flow 7 (1981) 647-658.

[44] S. Jayanti, A. Tokarz, G.F. Hewitt, Theoretical investigation of the diameter effect on flooding in countercurrent flow, Int. J. Multiphase Flow 22 (1996) 307324.

[45] D. Fletcher ISL. Inc., email to K. Vierow, 2005, Regarding pressurizer diffuser configurations.

[46] R.W. Fox, A.T. McDonald, P.J. Pritchard, Introduction to Fluid Mechanics, 6th ed., John Wiley \& Sons, New York, 2003, pp. 632-633.

[47] J.R.F. Guedes Carvalho, M.A.R. Talaia, Interfacial shear stress as a criterion for flooding in counter current film flow along vertical surfaces, Chemical Engineering Science 53 (1998) 2041-2051. 
[48] A. Zapke, D.G. Kroger, The influence of fluid properties and inlet geometry on flooding in vertical and inclined tubes, Int. J. Multiphase Flow 22 (1996) 461-472. 


\section{APPENDIX A}

\section{STEAM WATER TEST SECTION DRAWINGS}

The following are engineering drawings of the steam water facility test section. These drawings show the exact location of the components in the facility. In addition, the drawings show how the components fit together. 


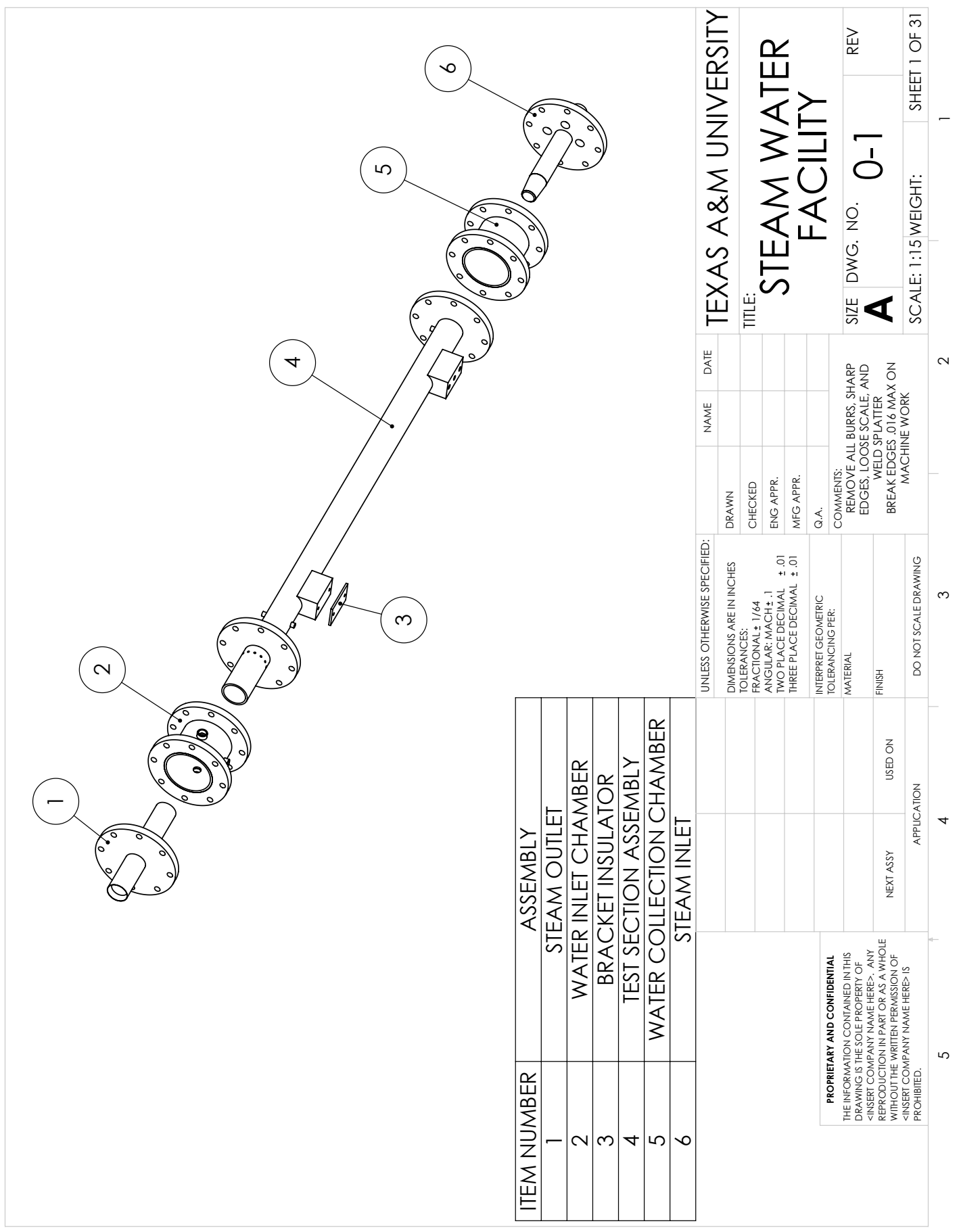



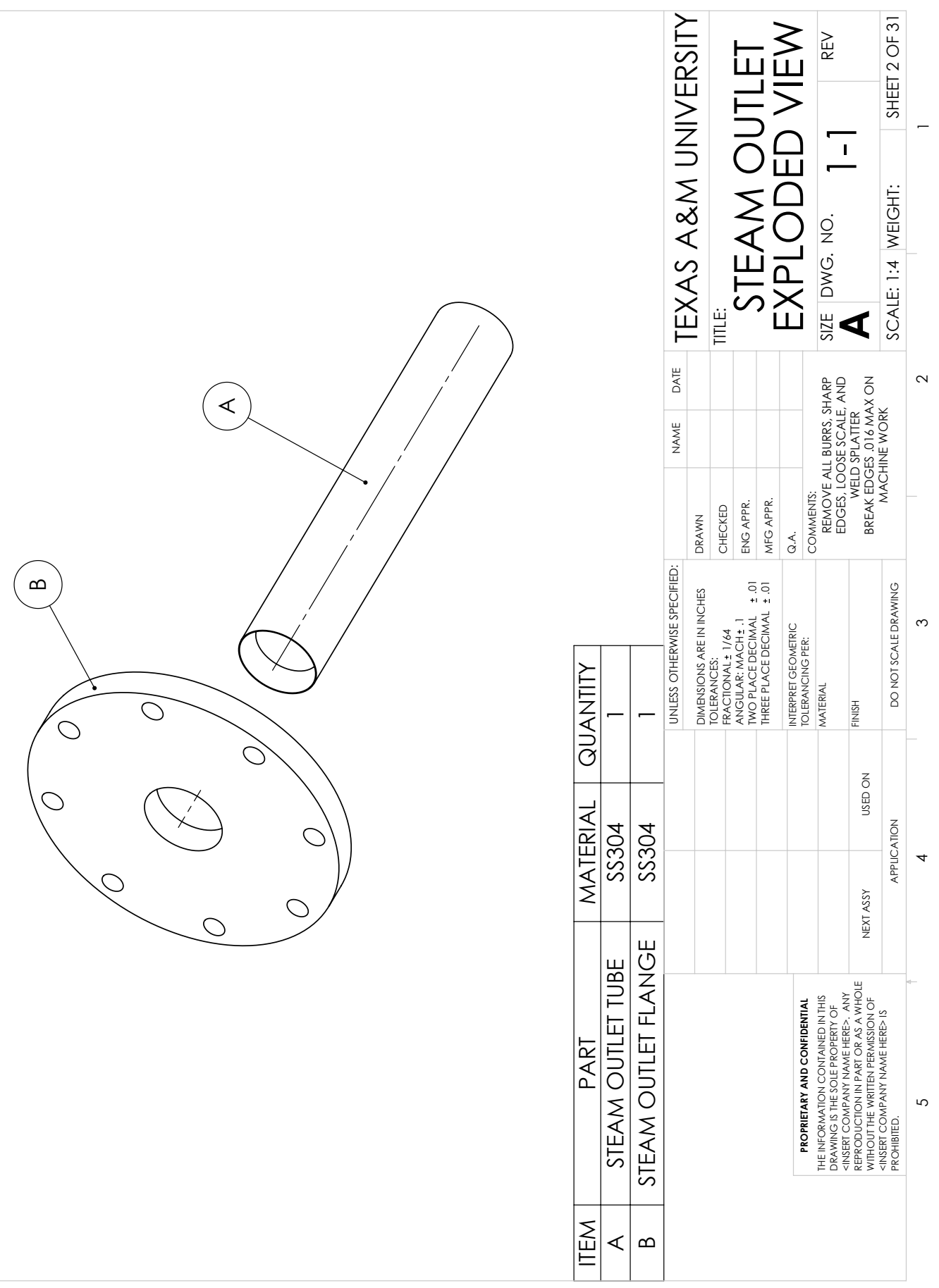

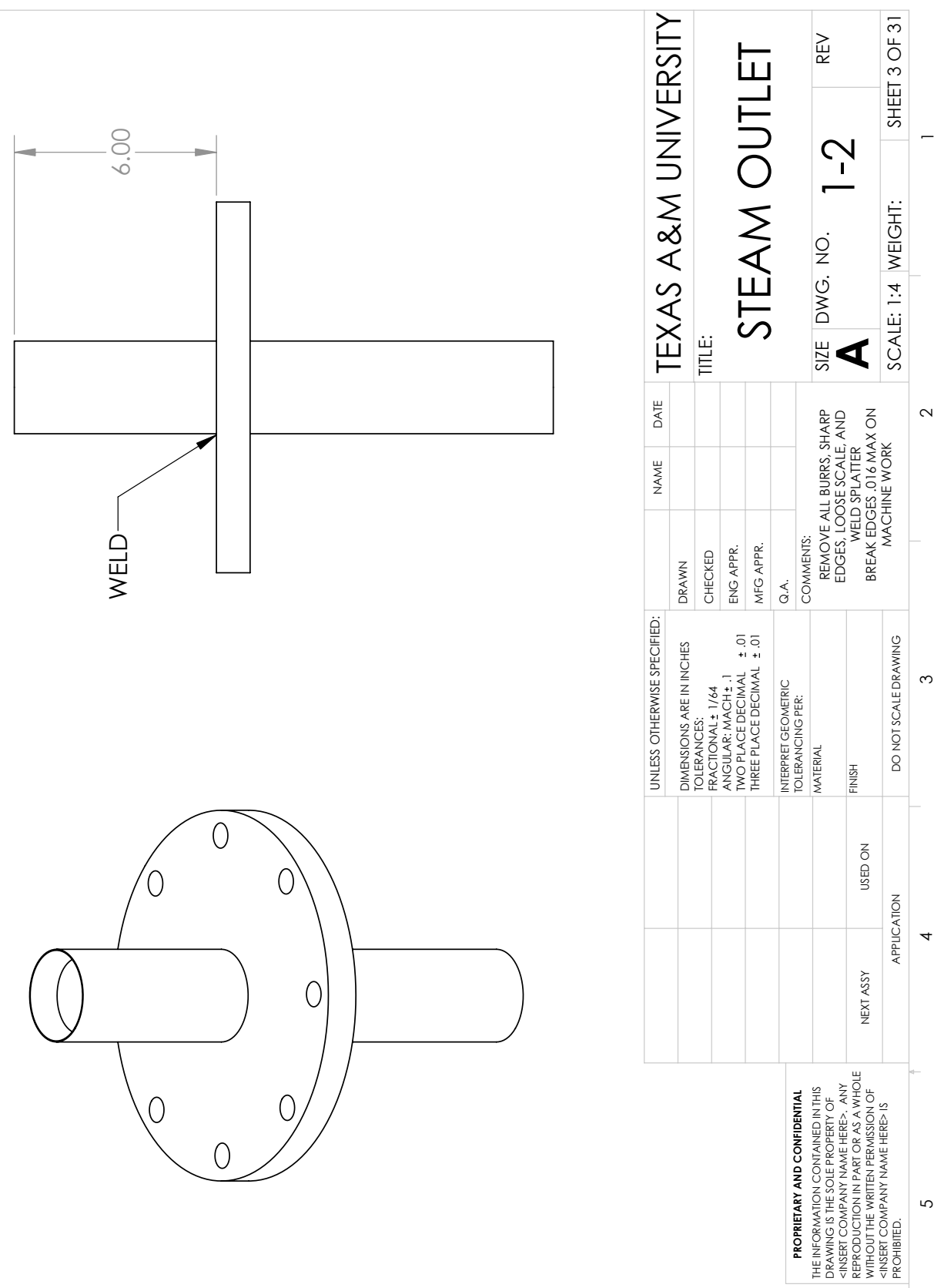


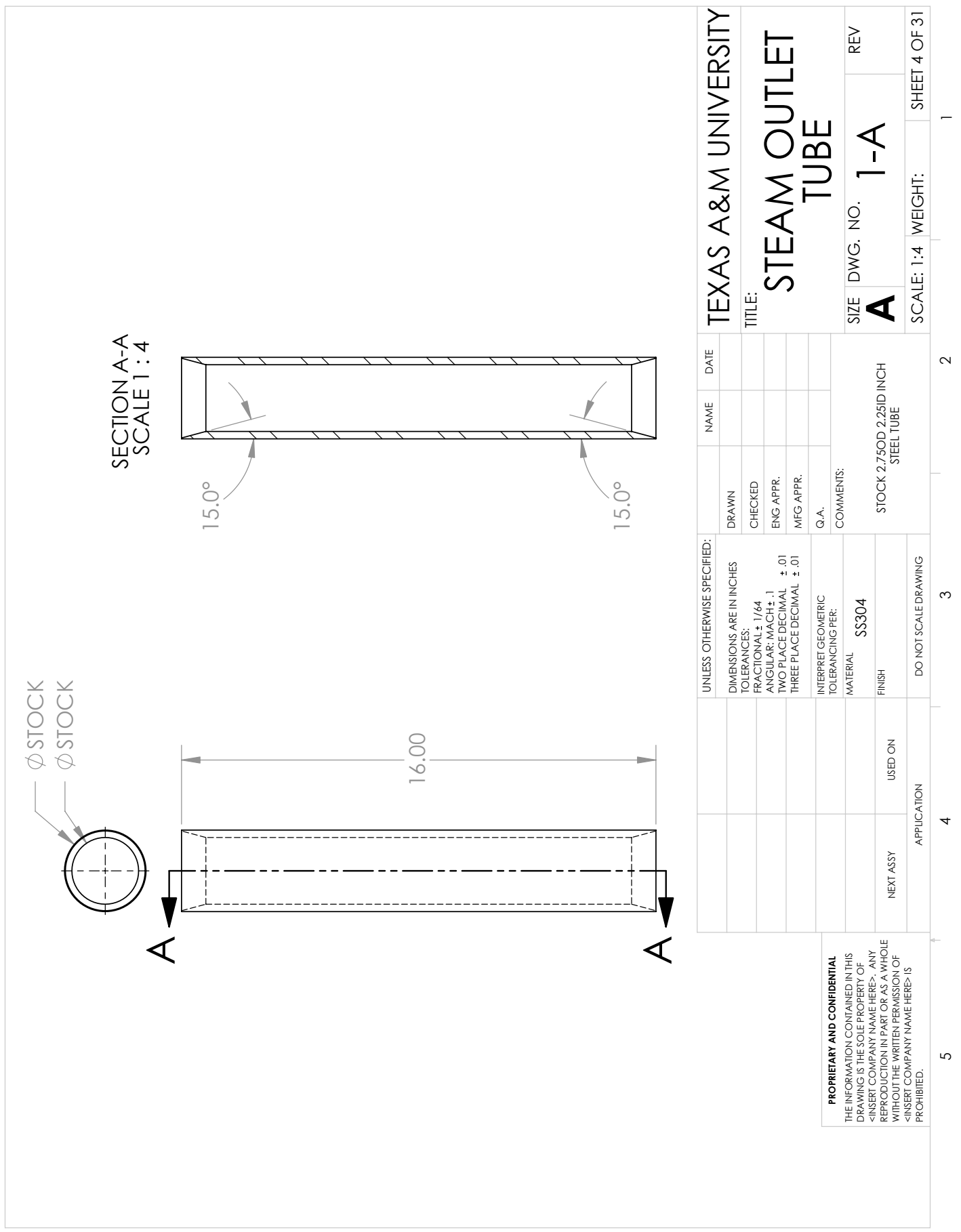




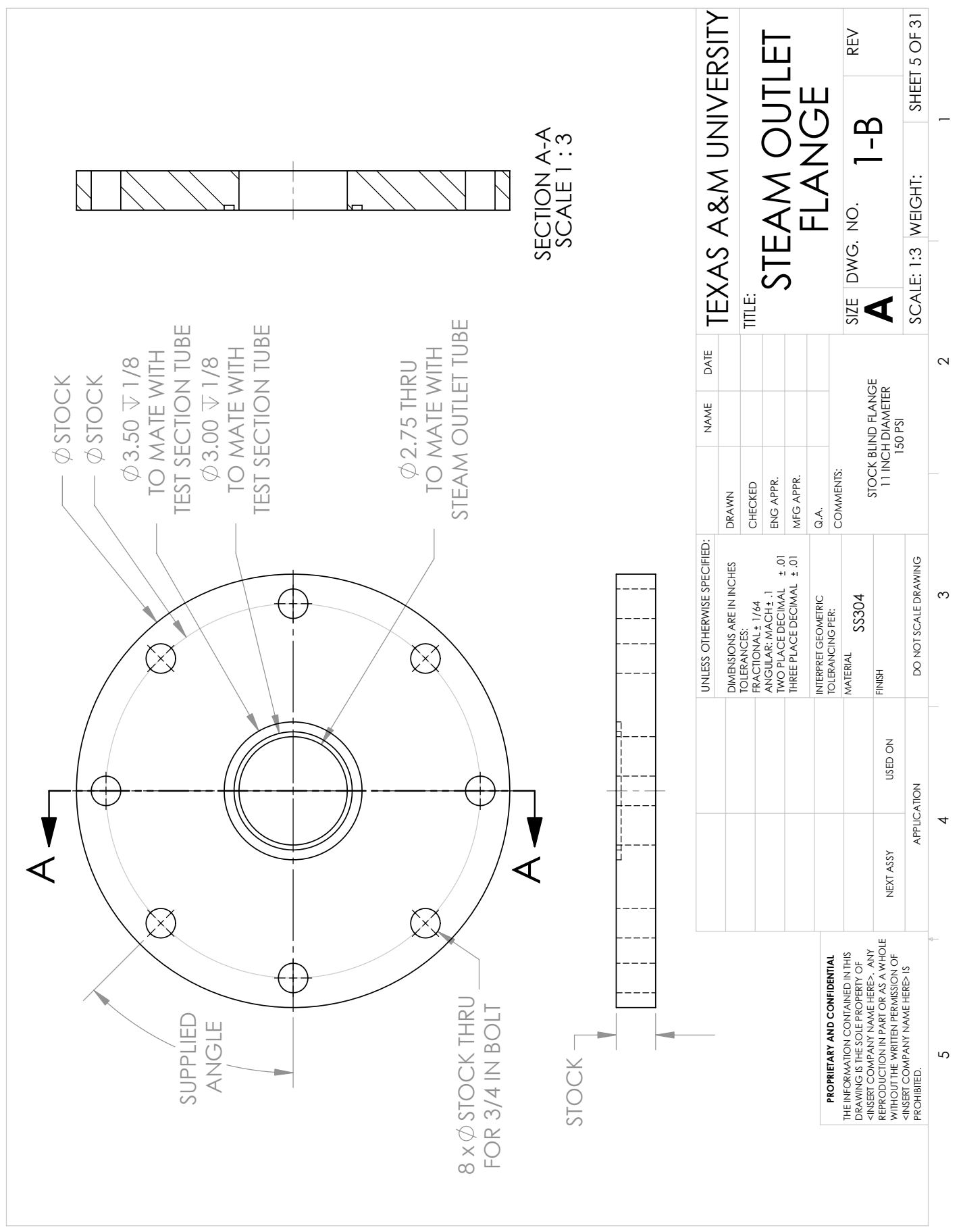




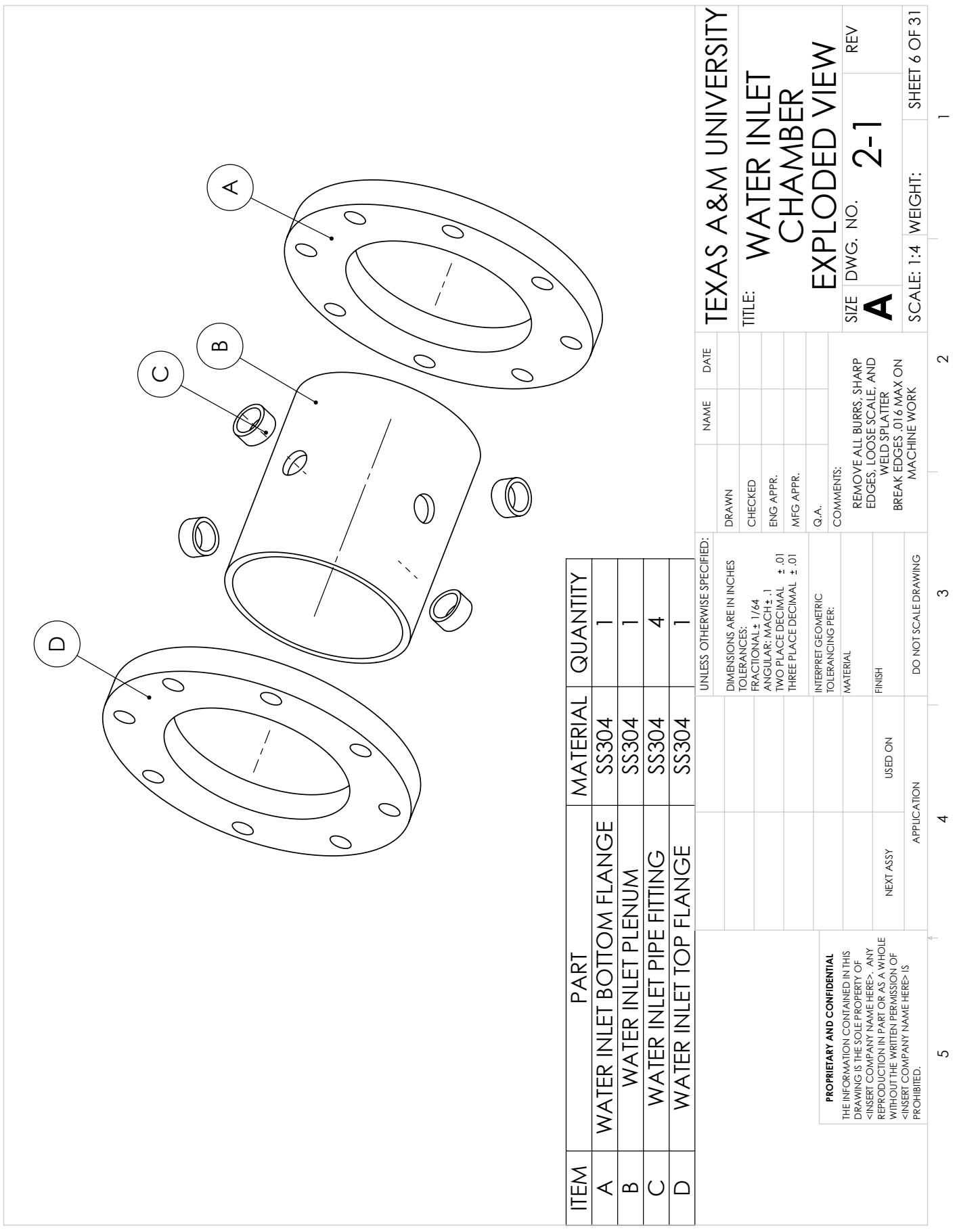



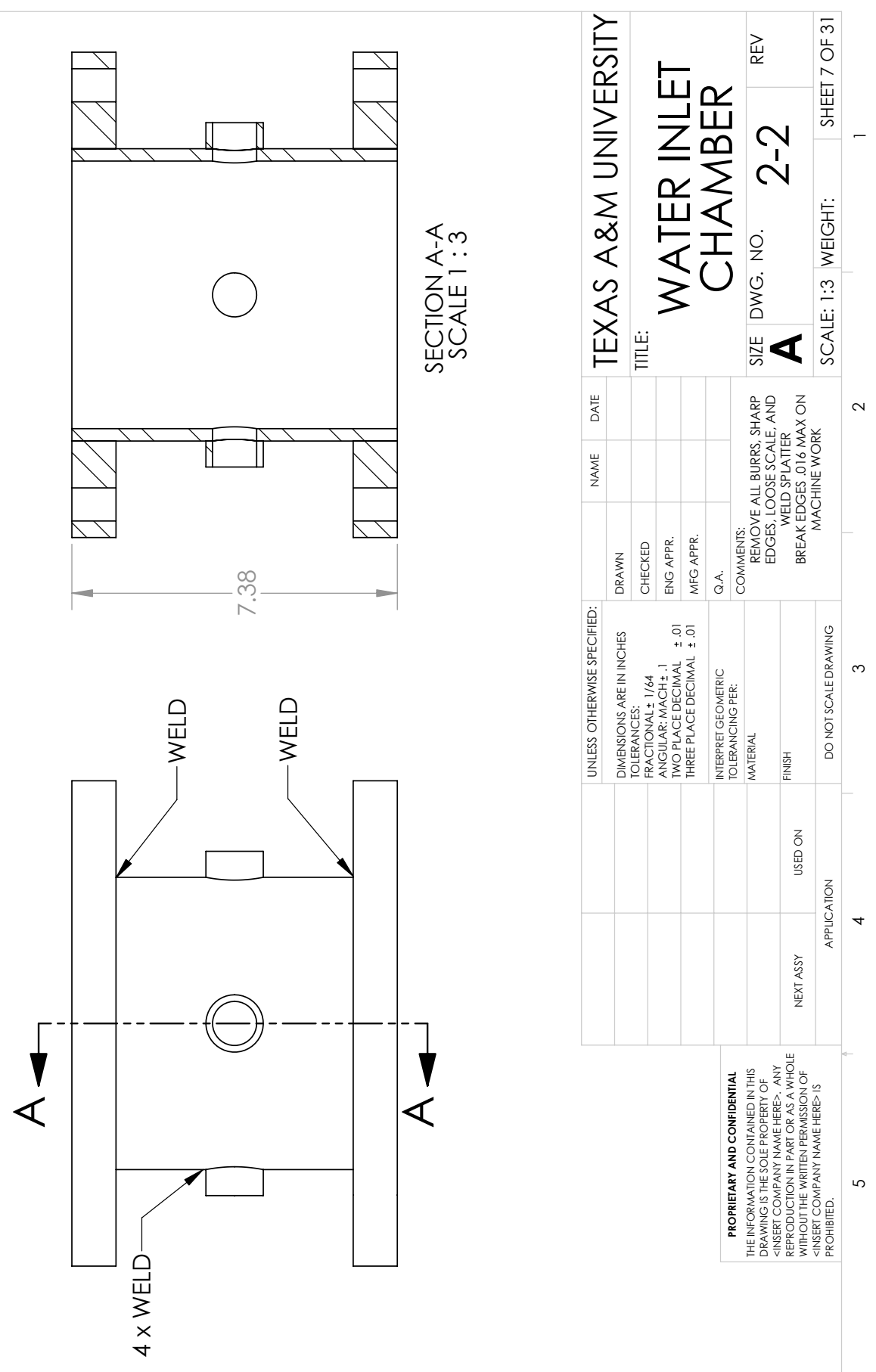


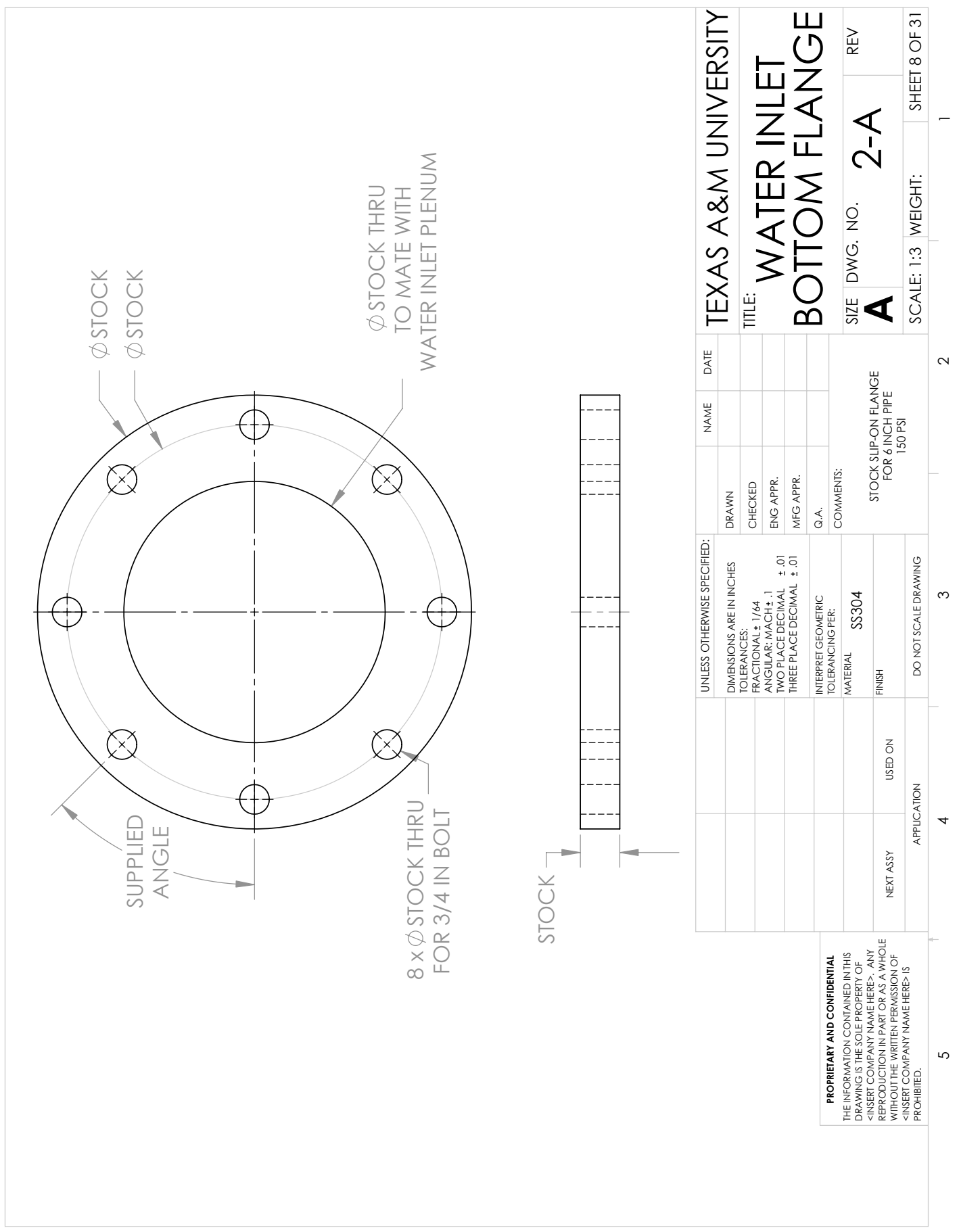




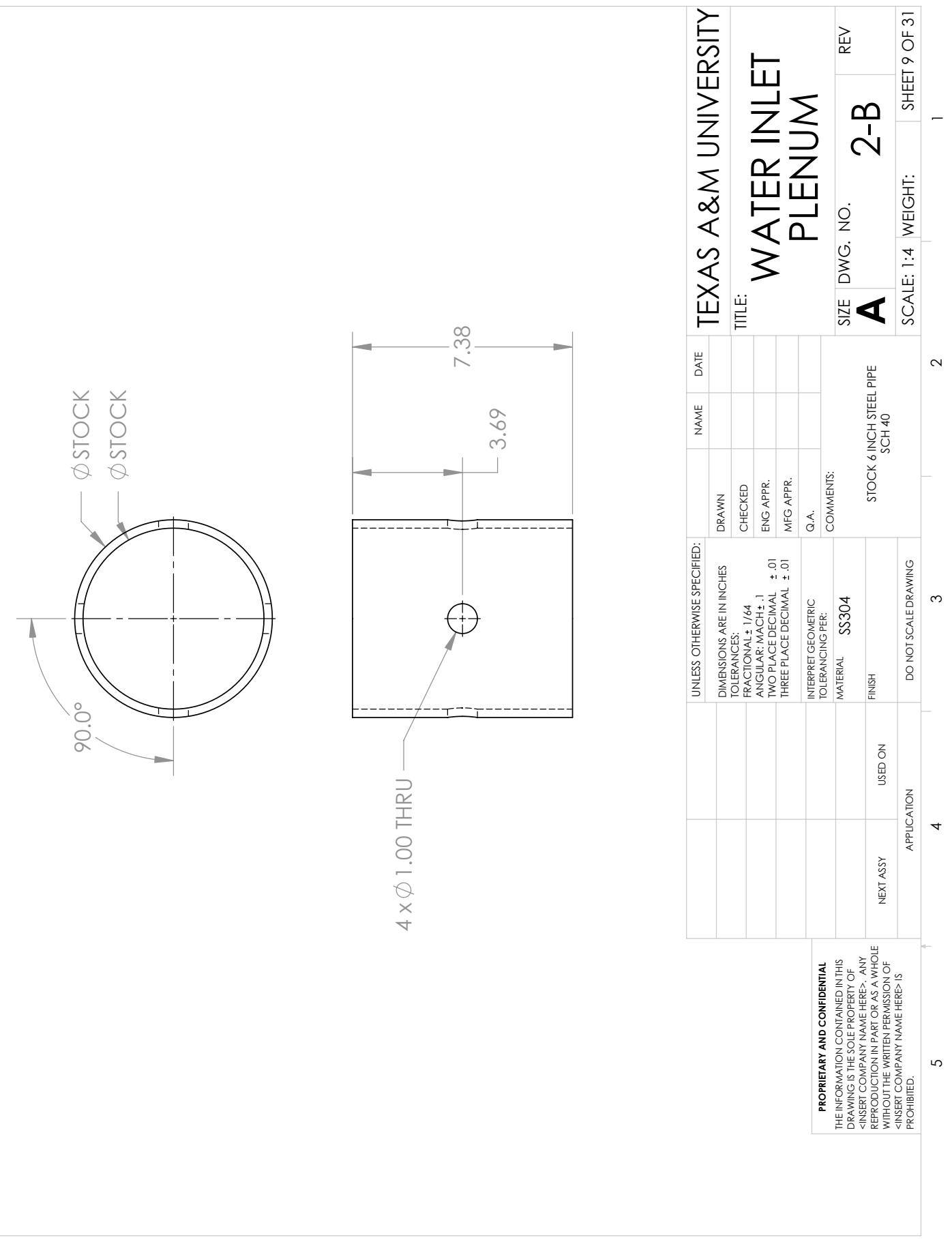



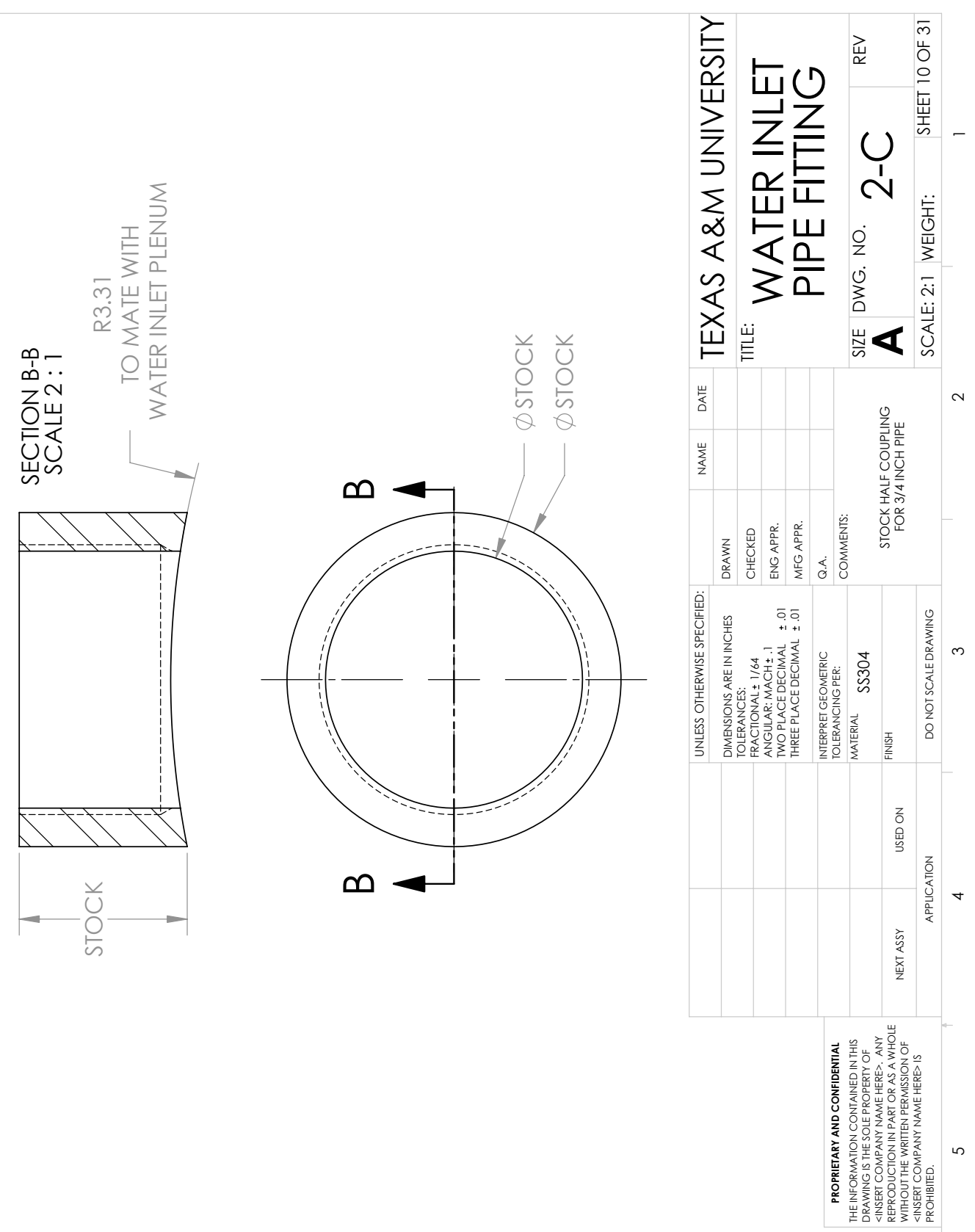

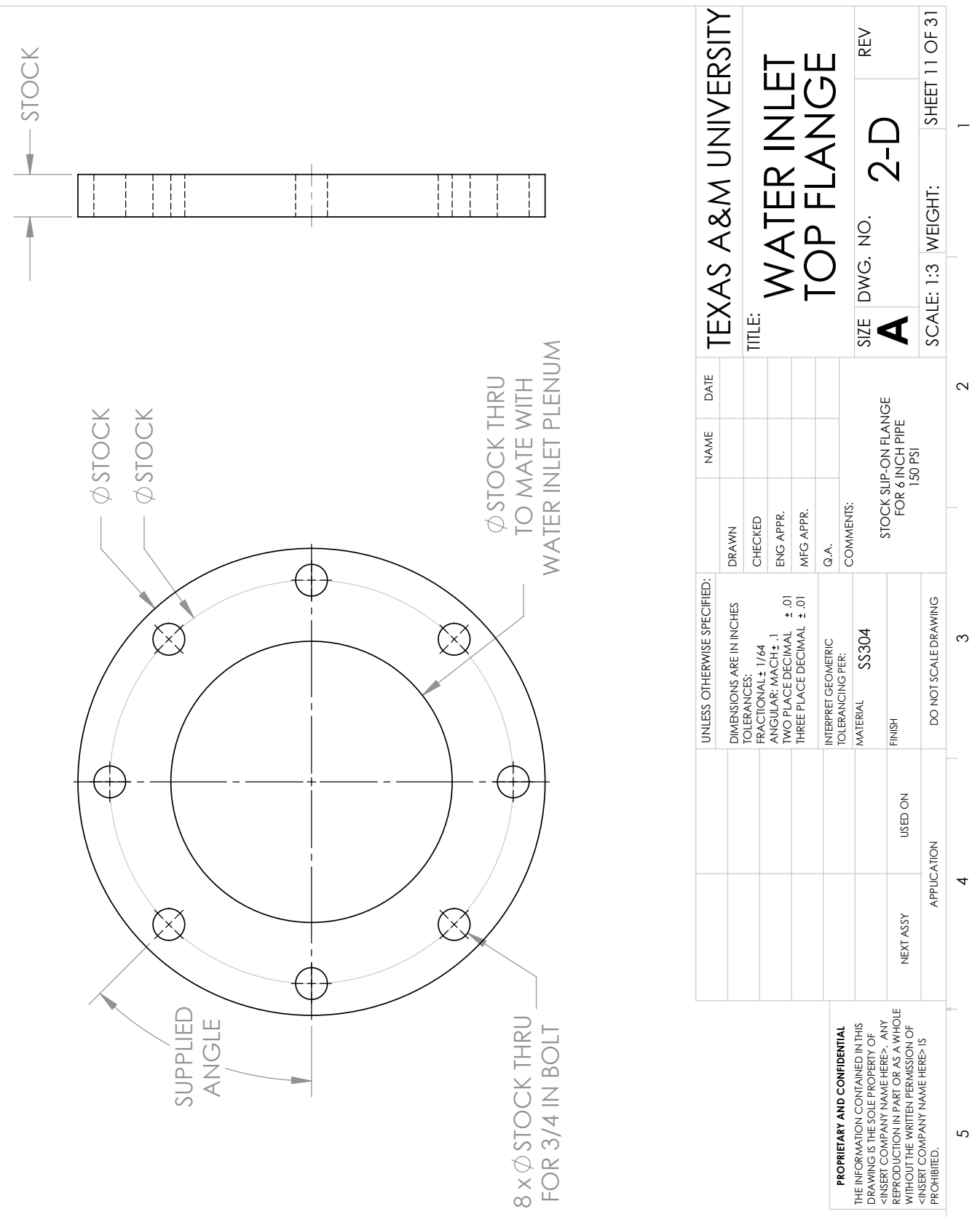


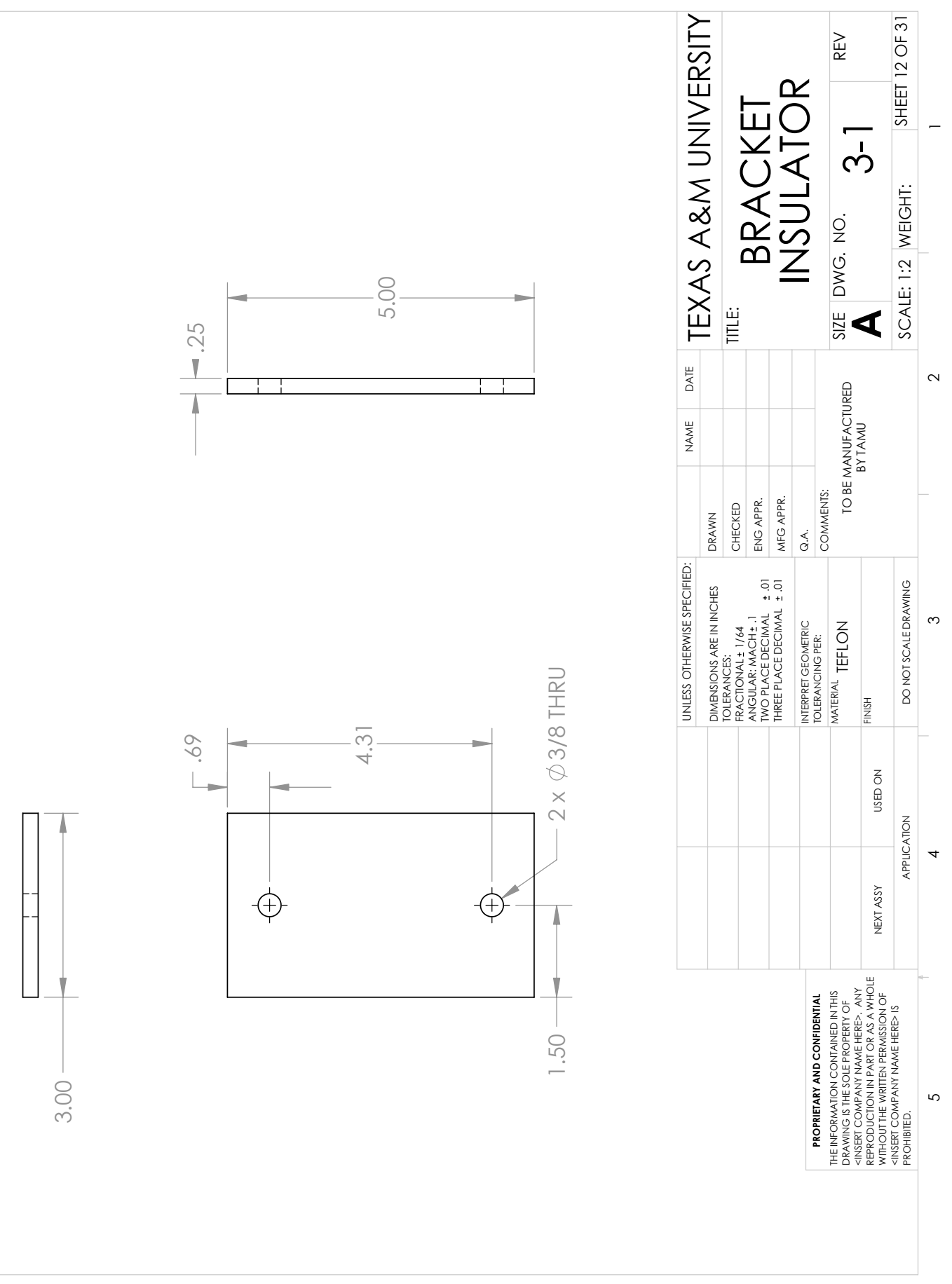




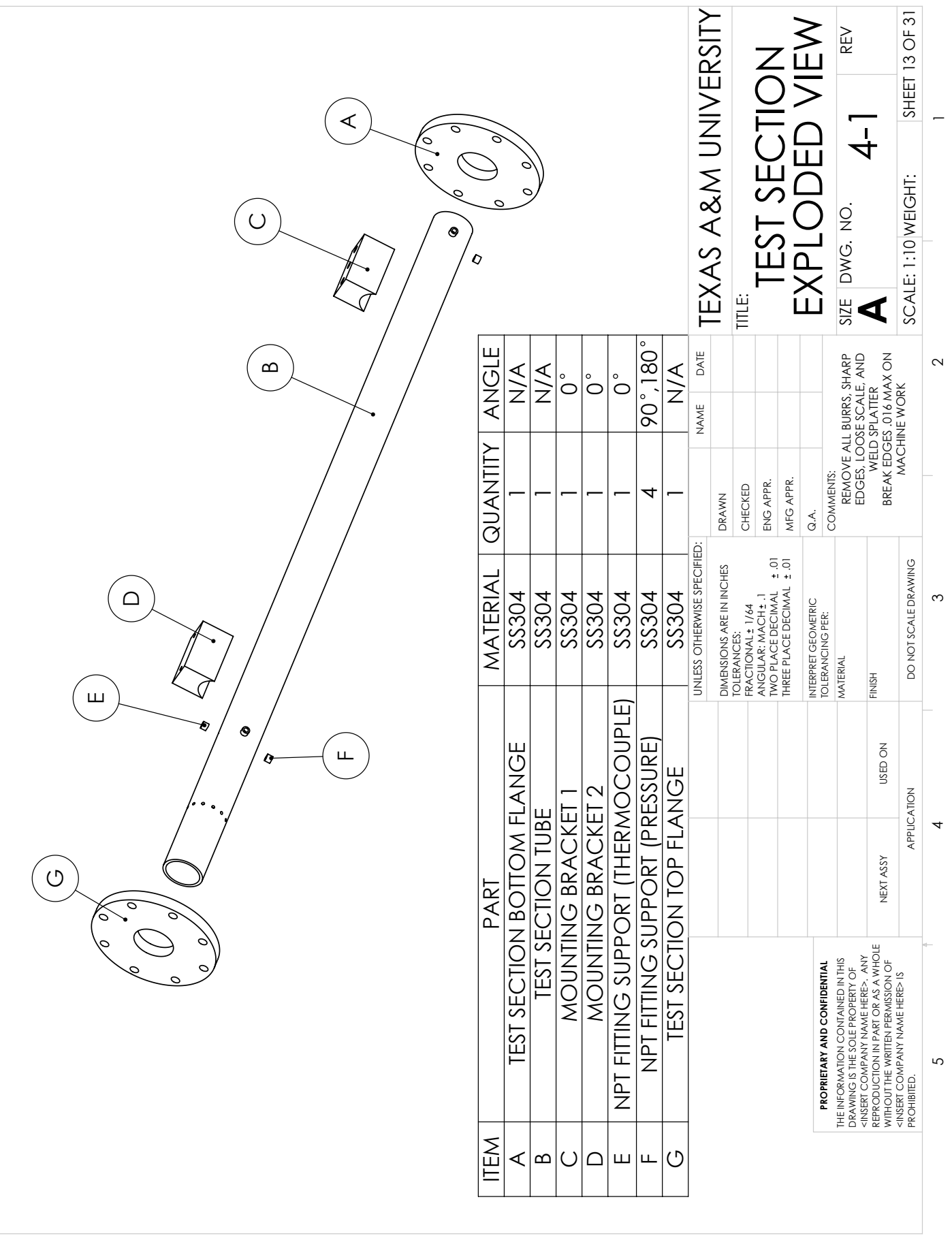




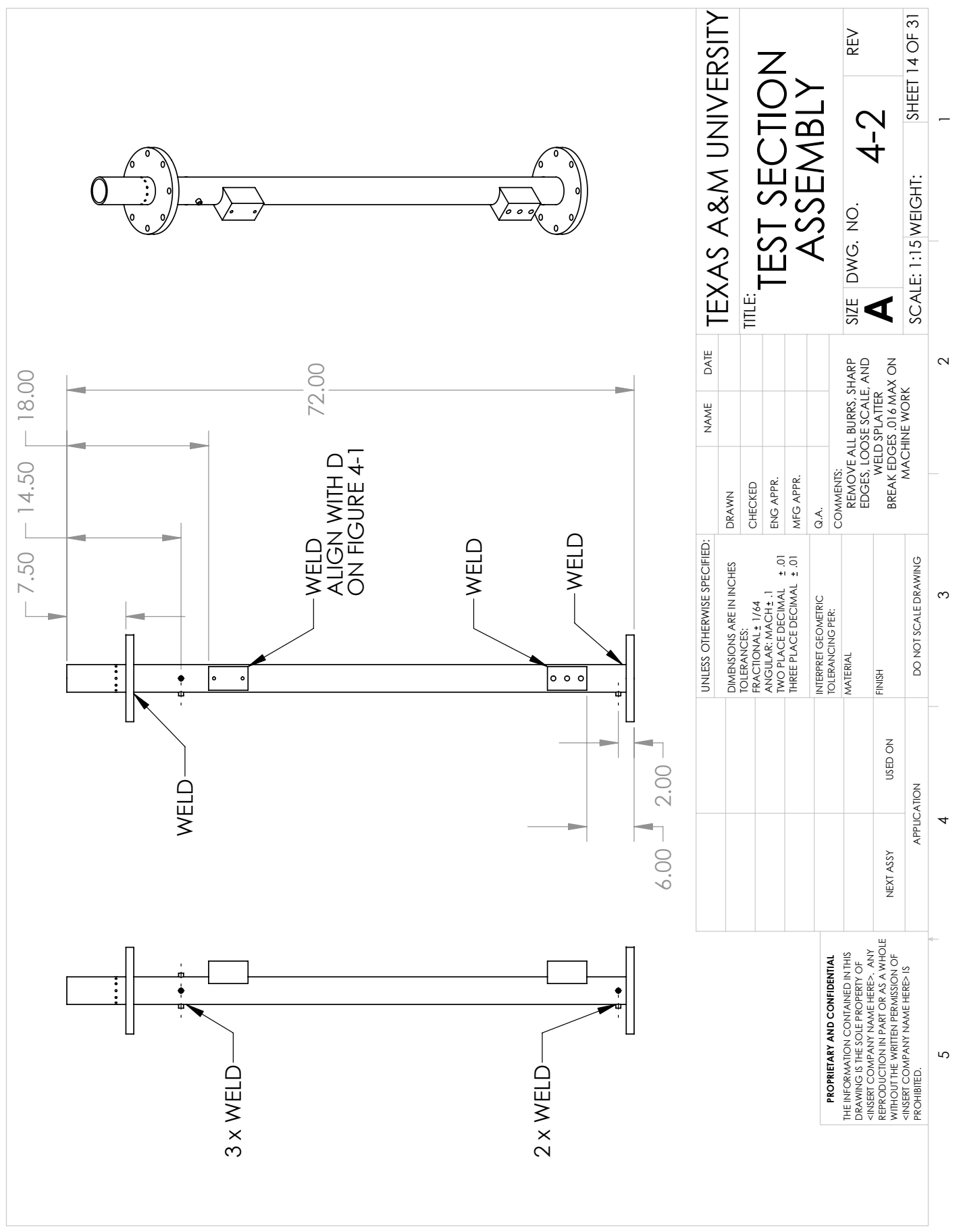




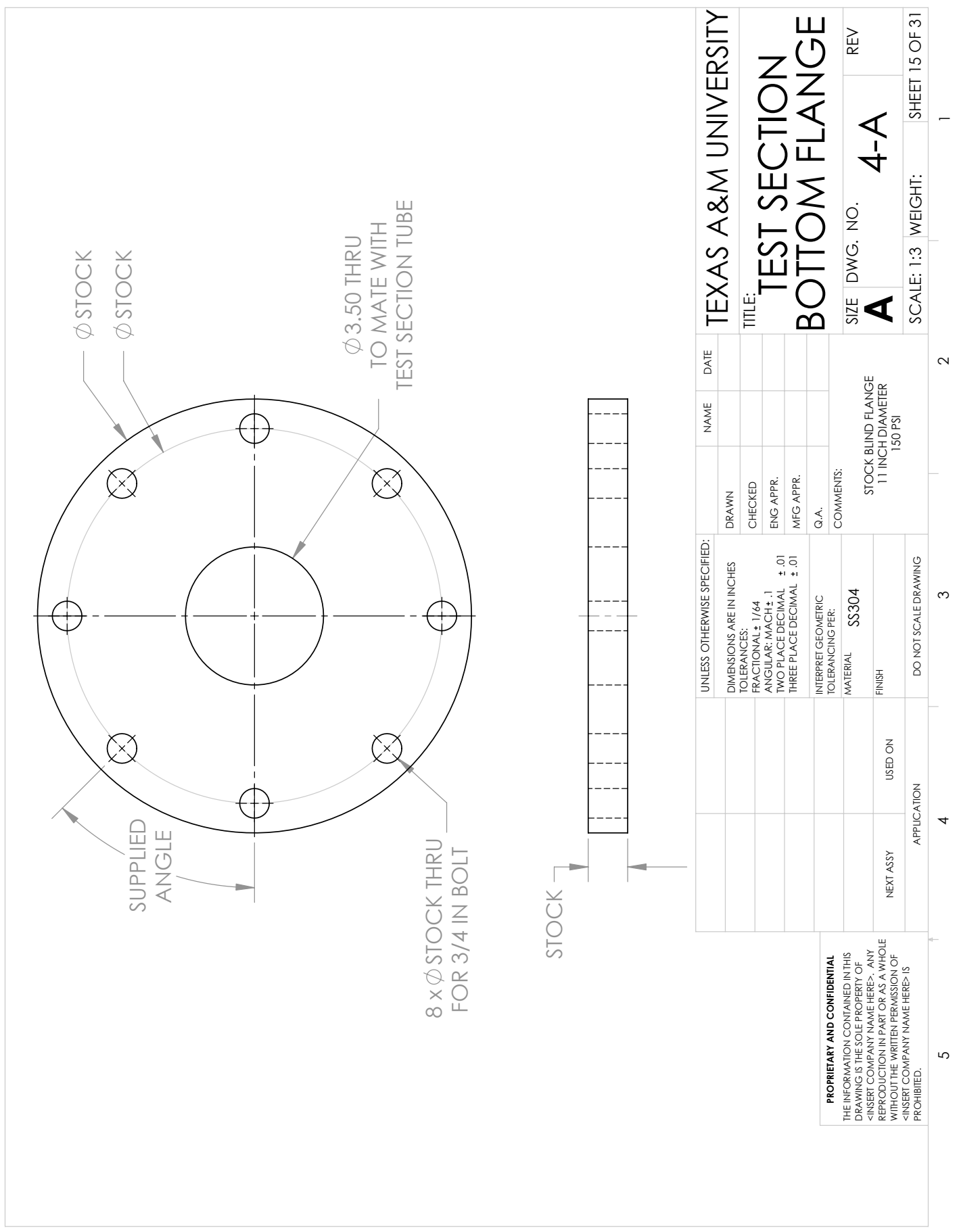



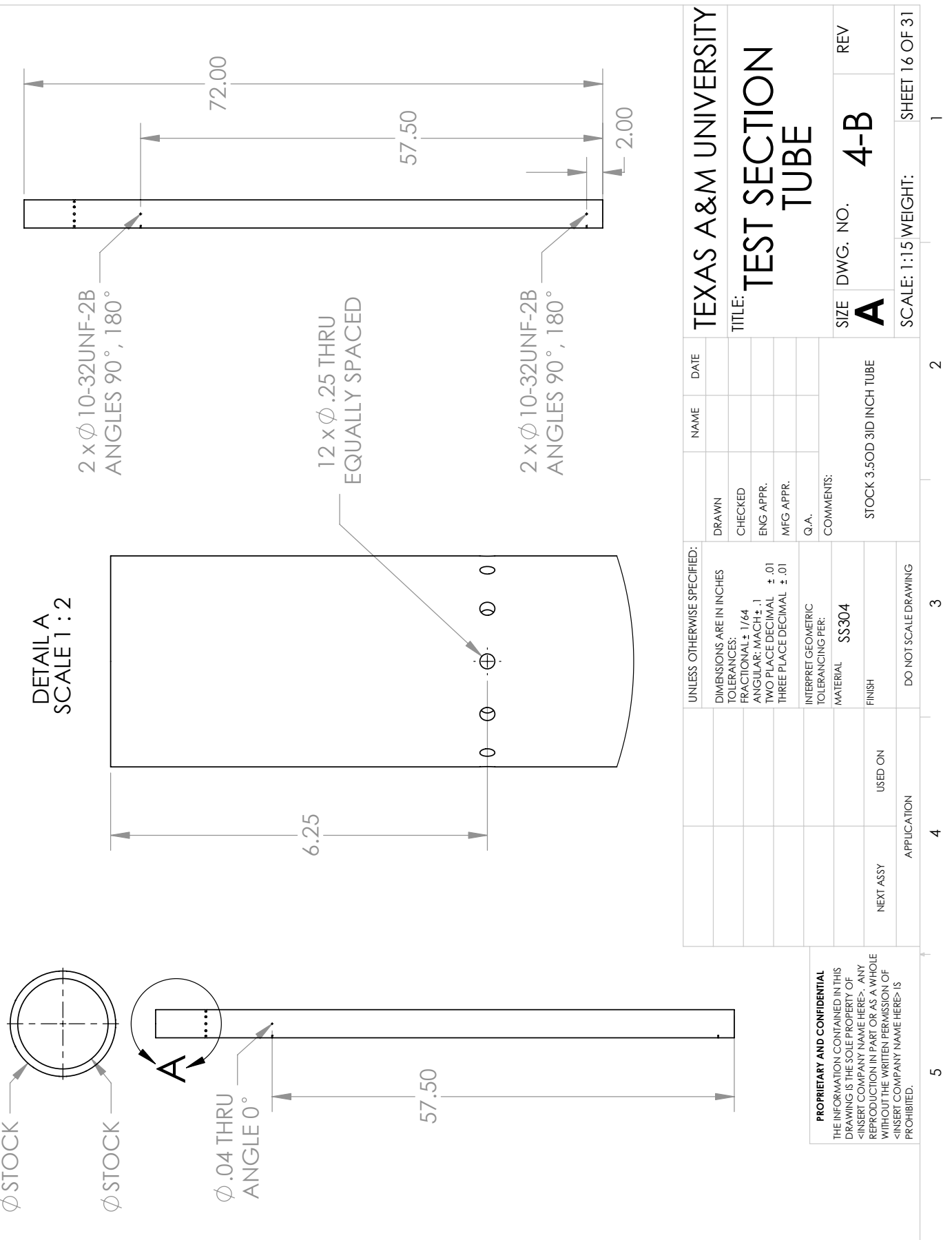


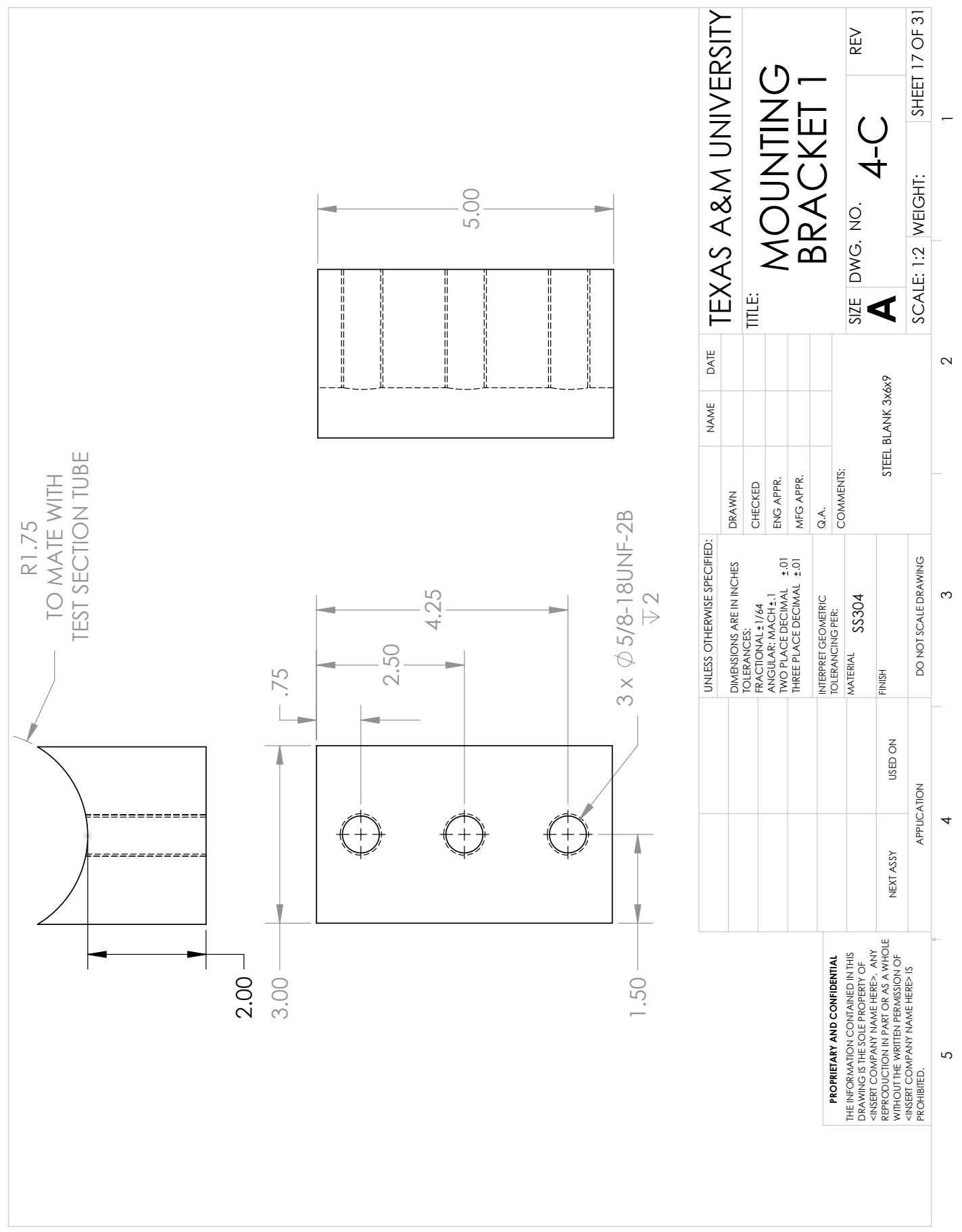




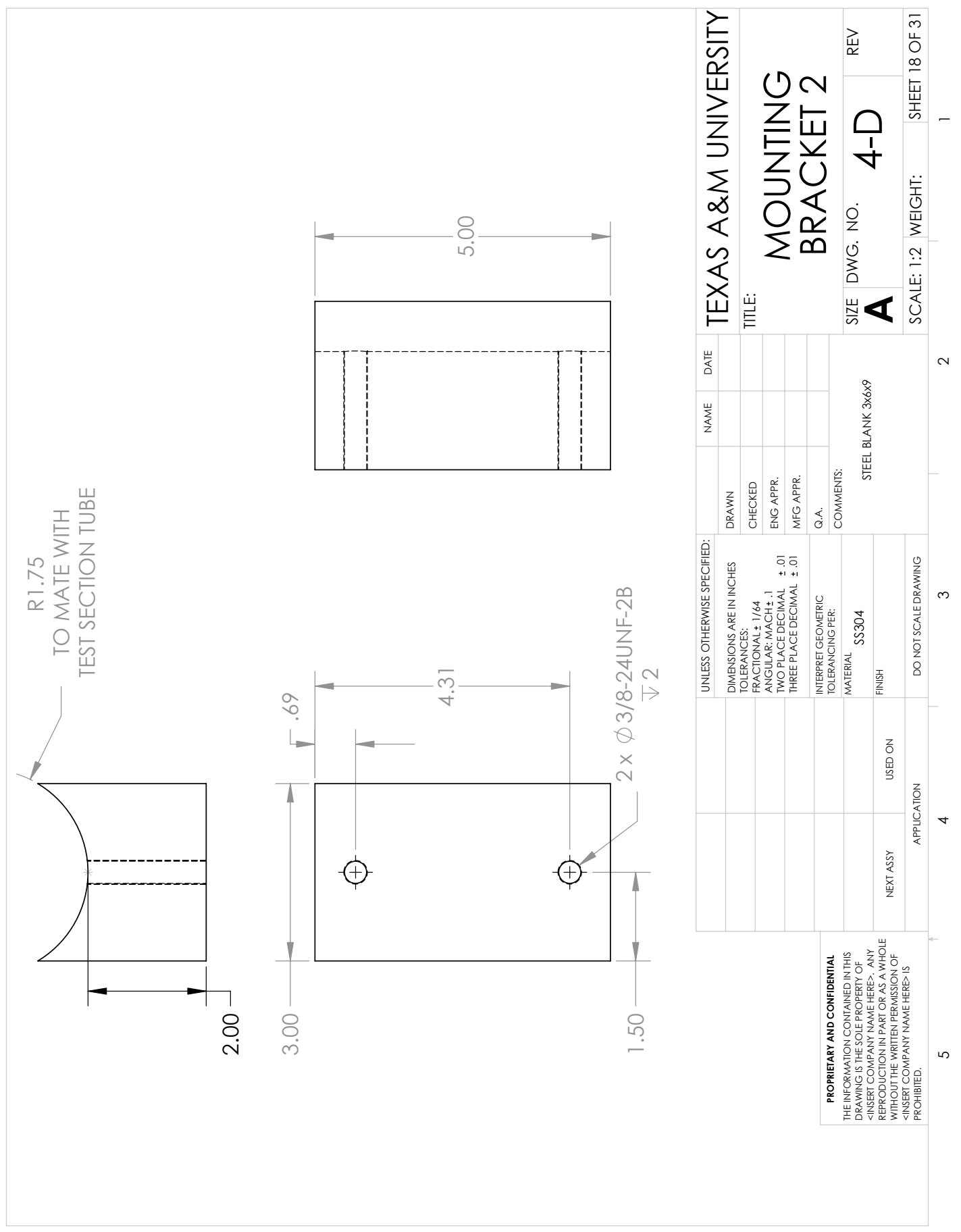




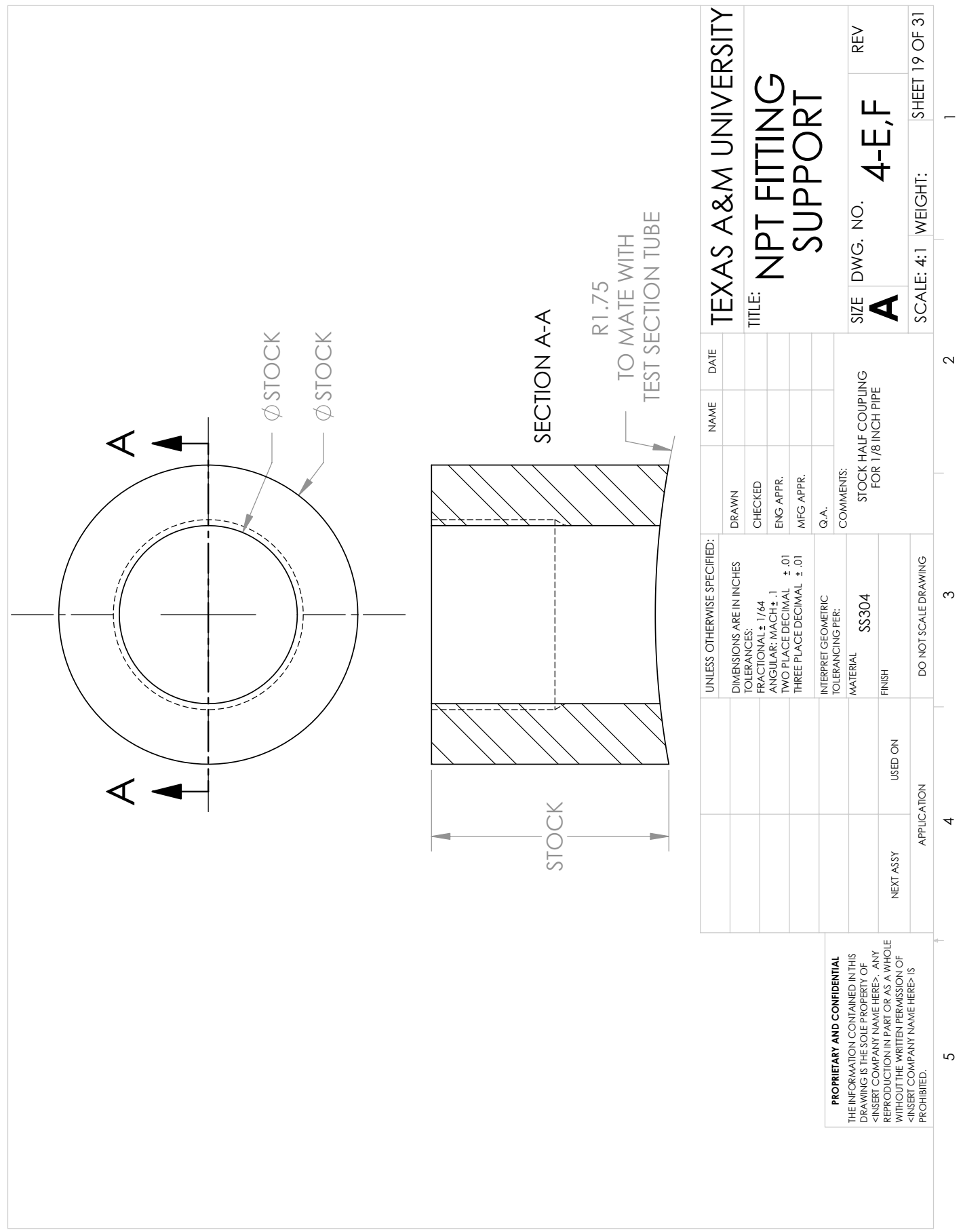




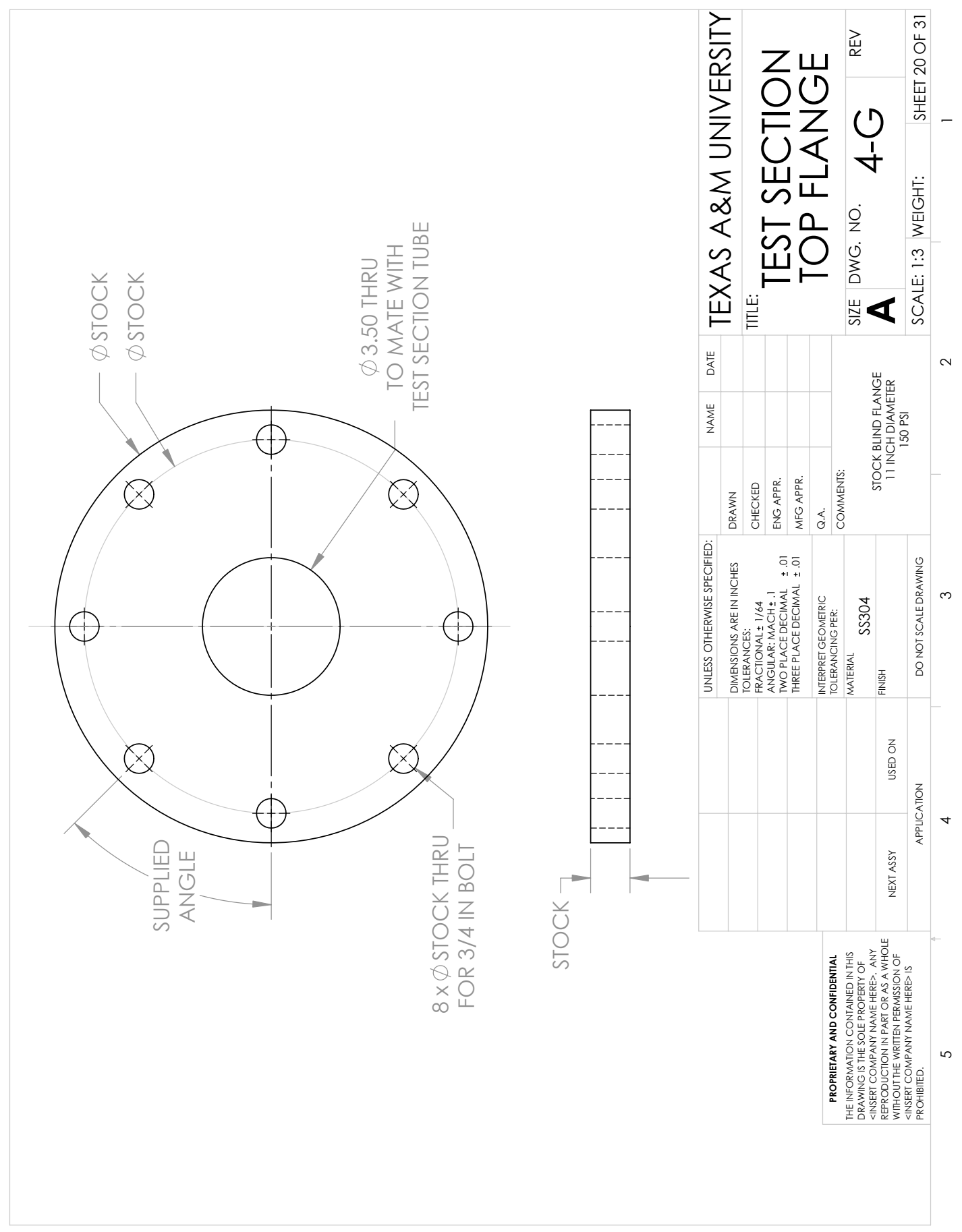




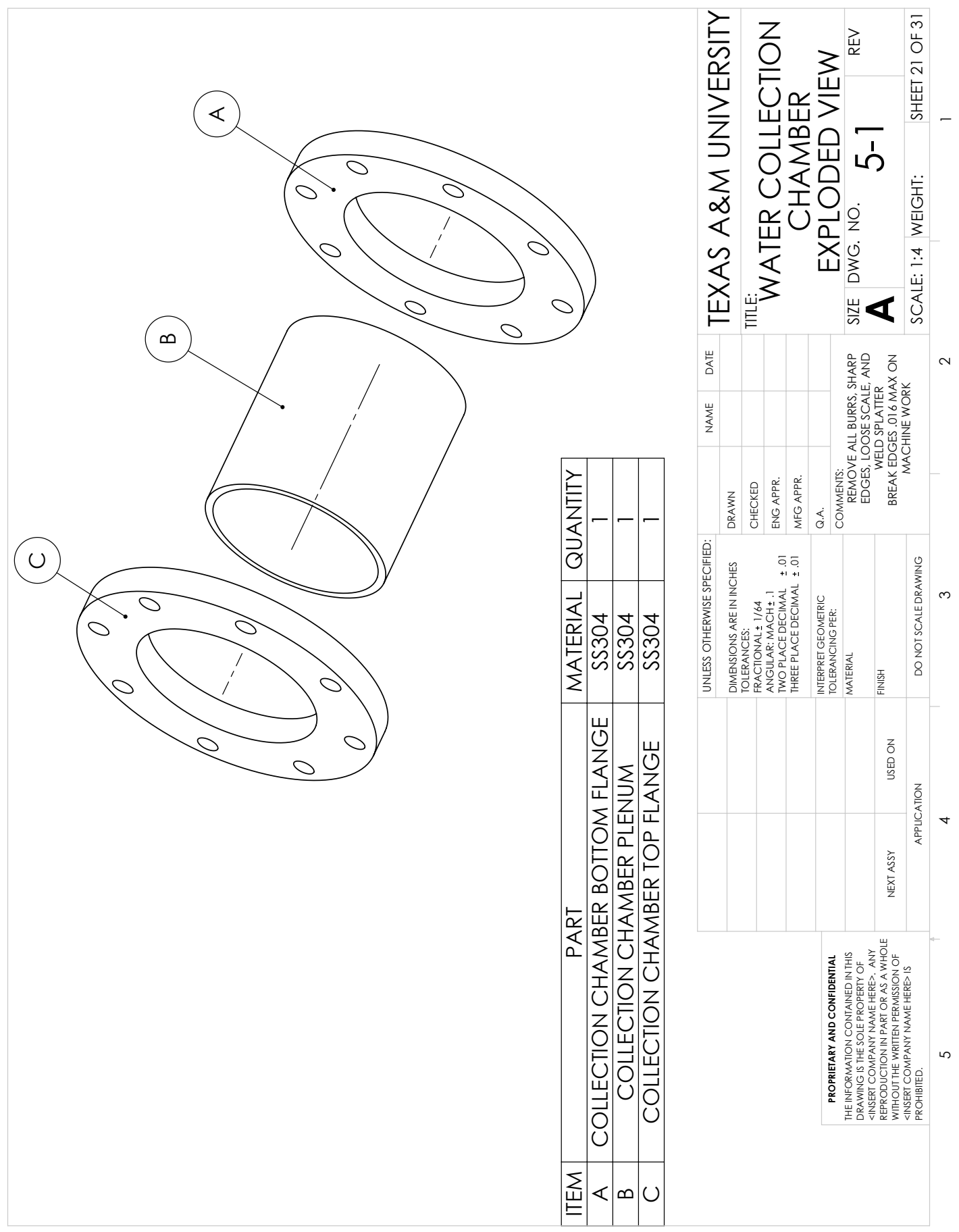



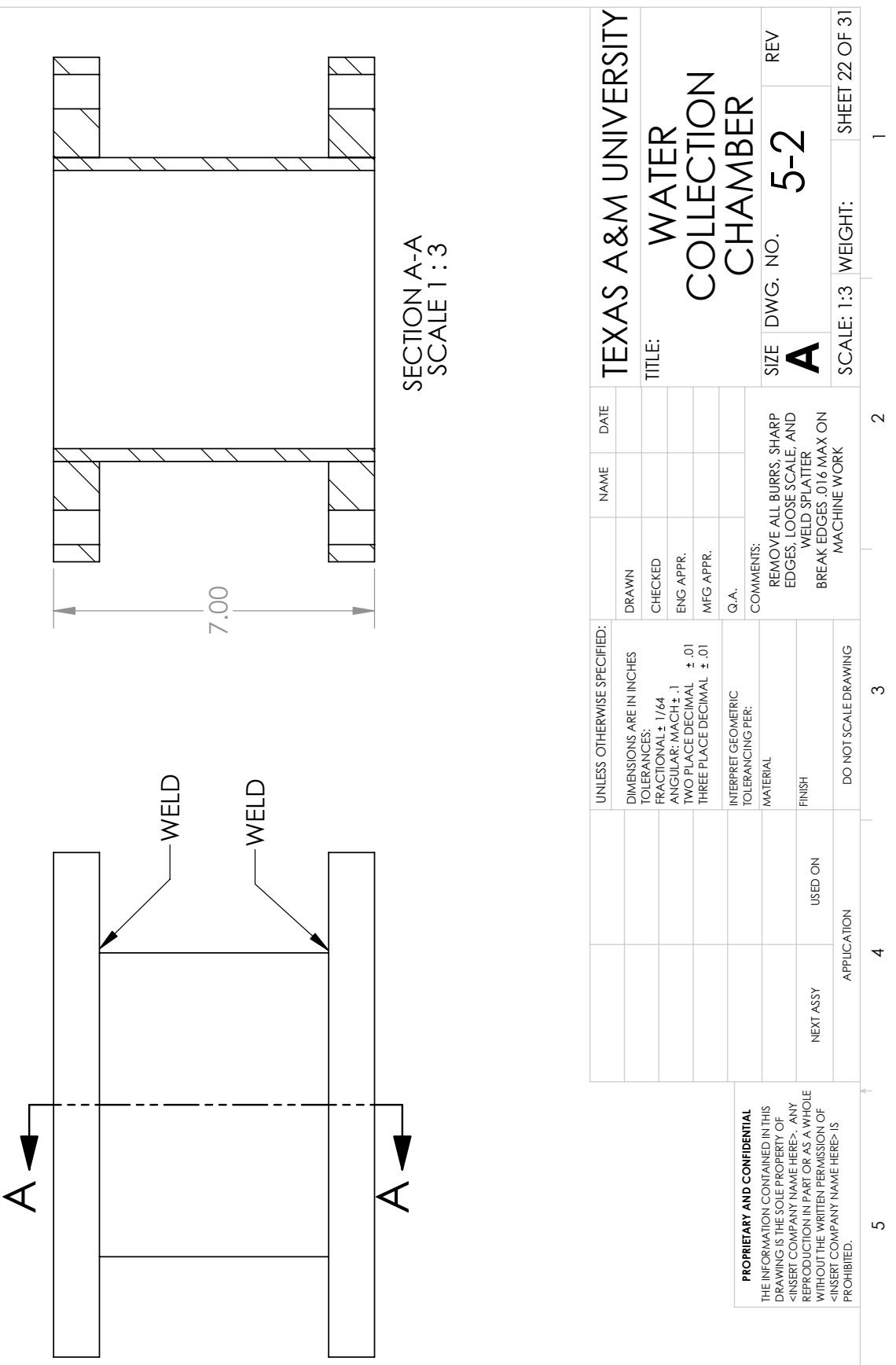


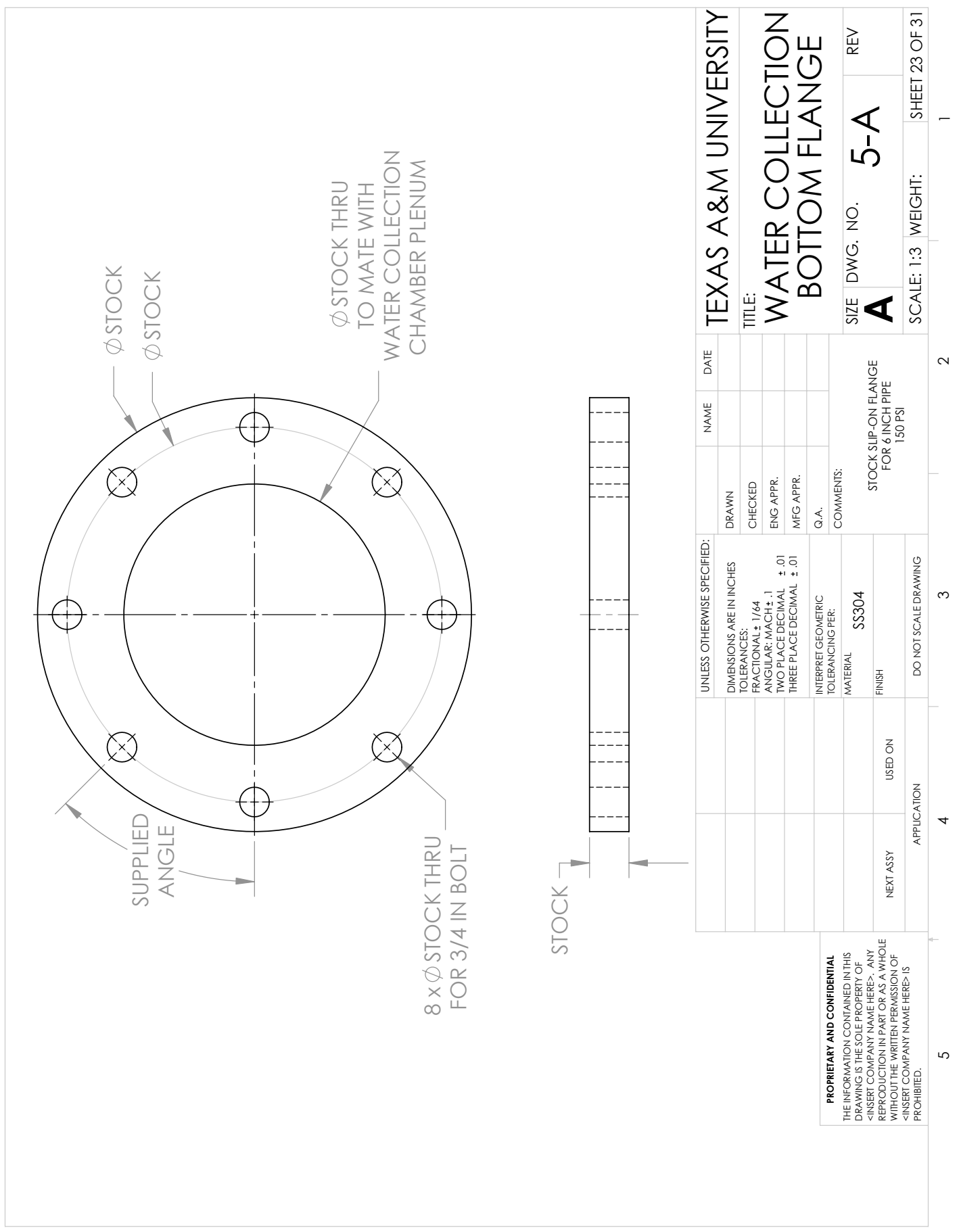



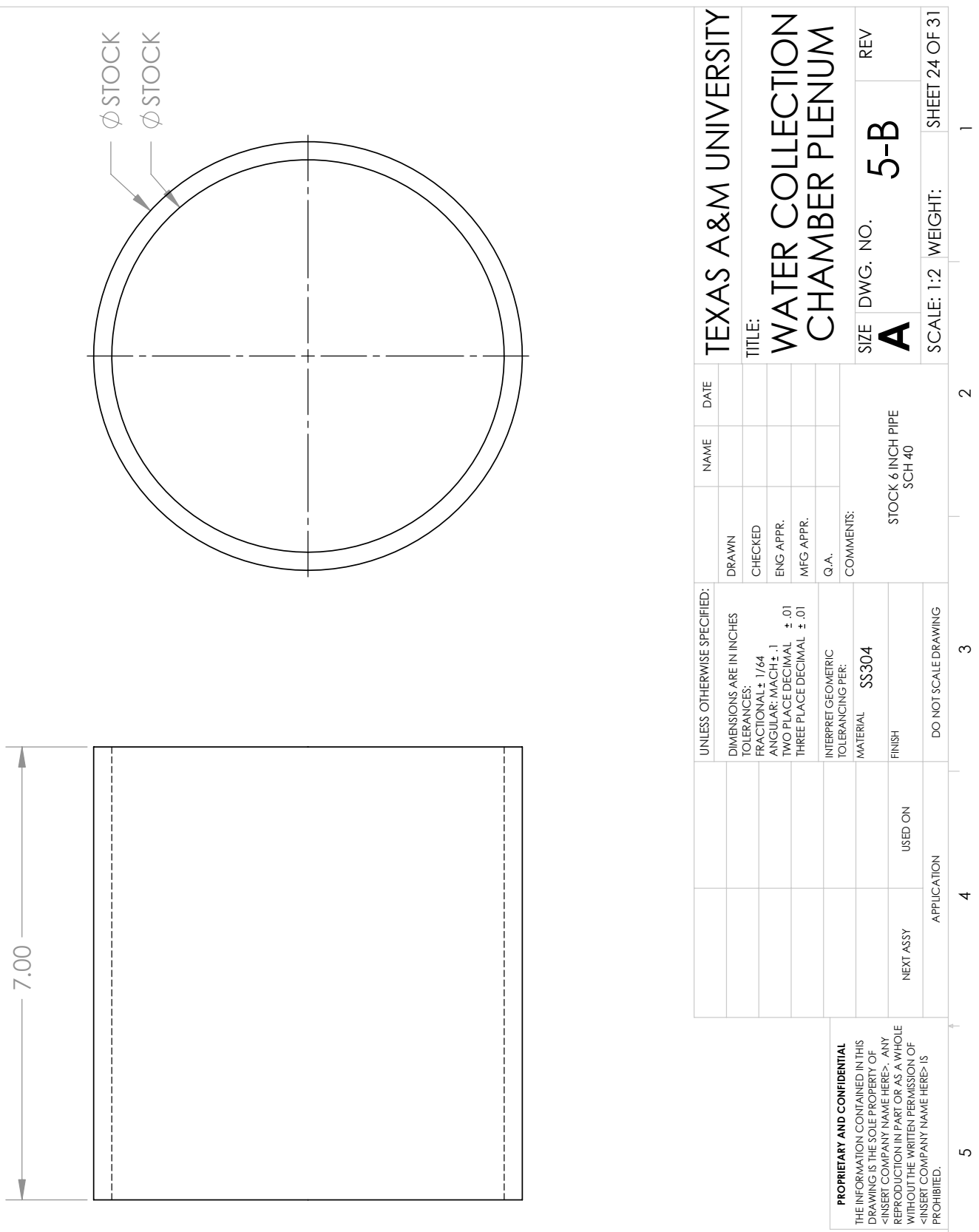


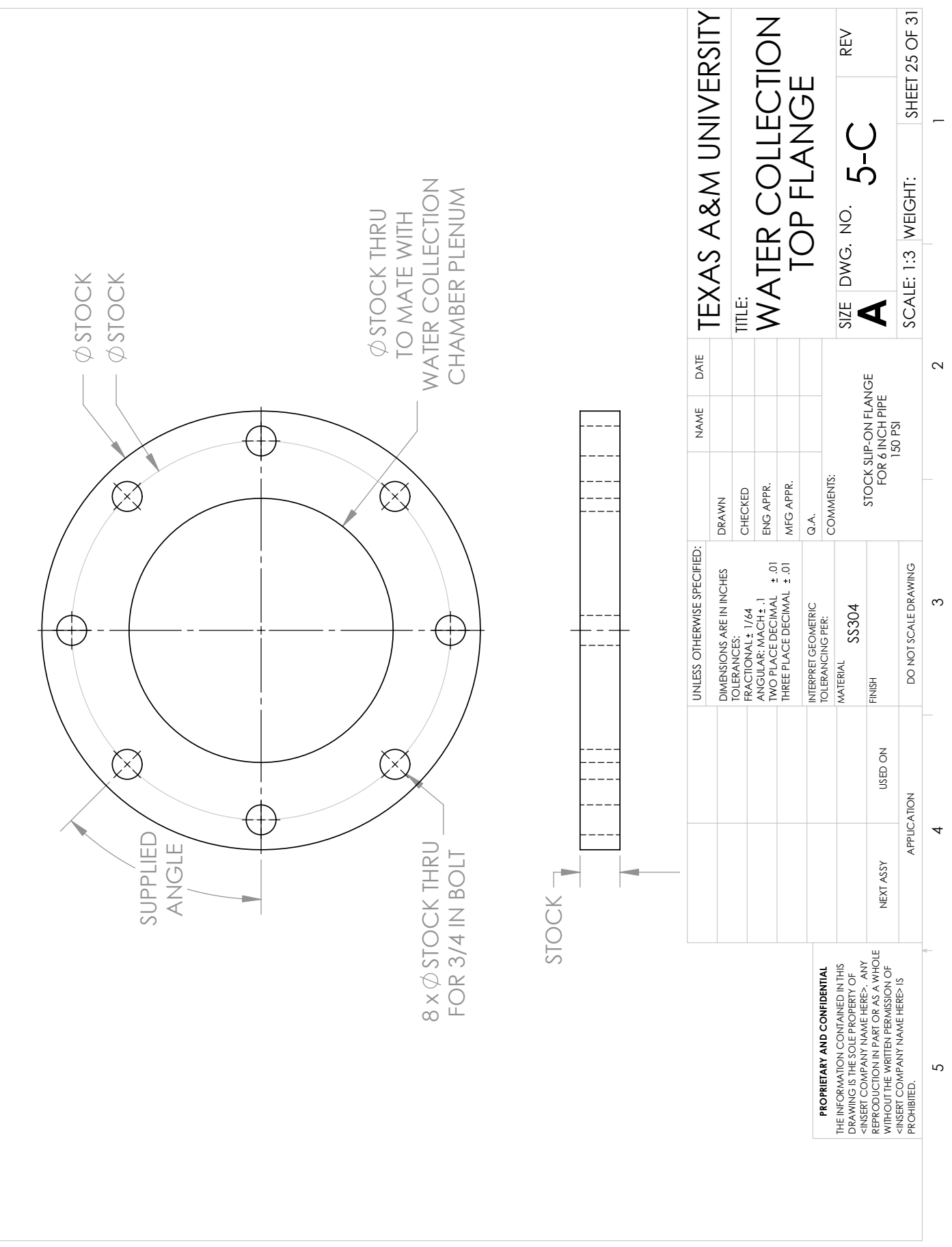




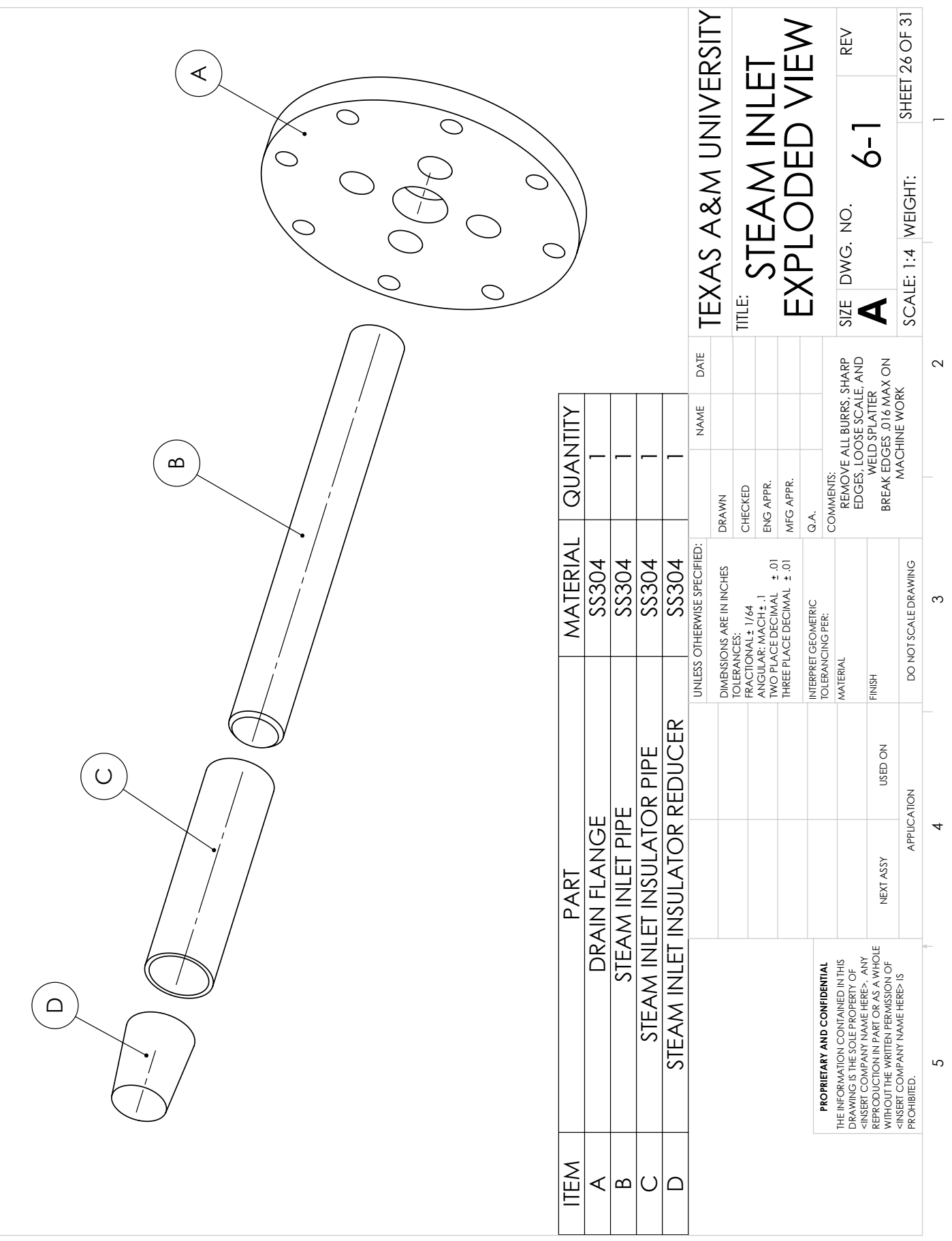




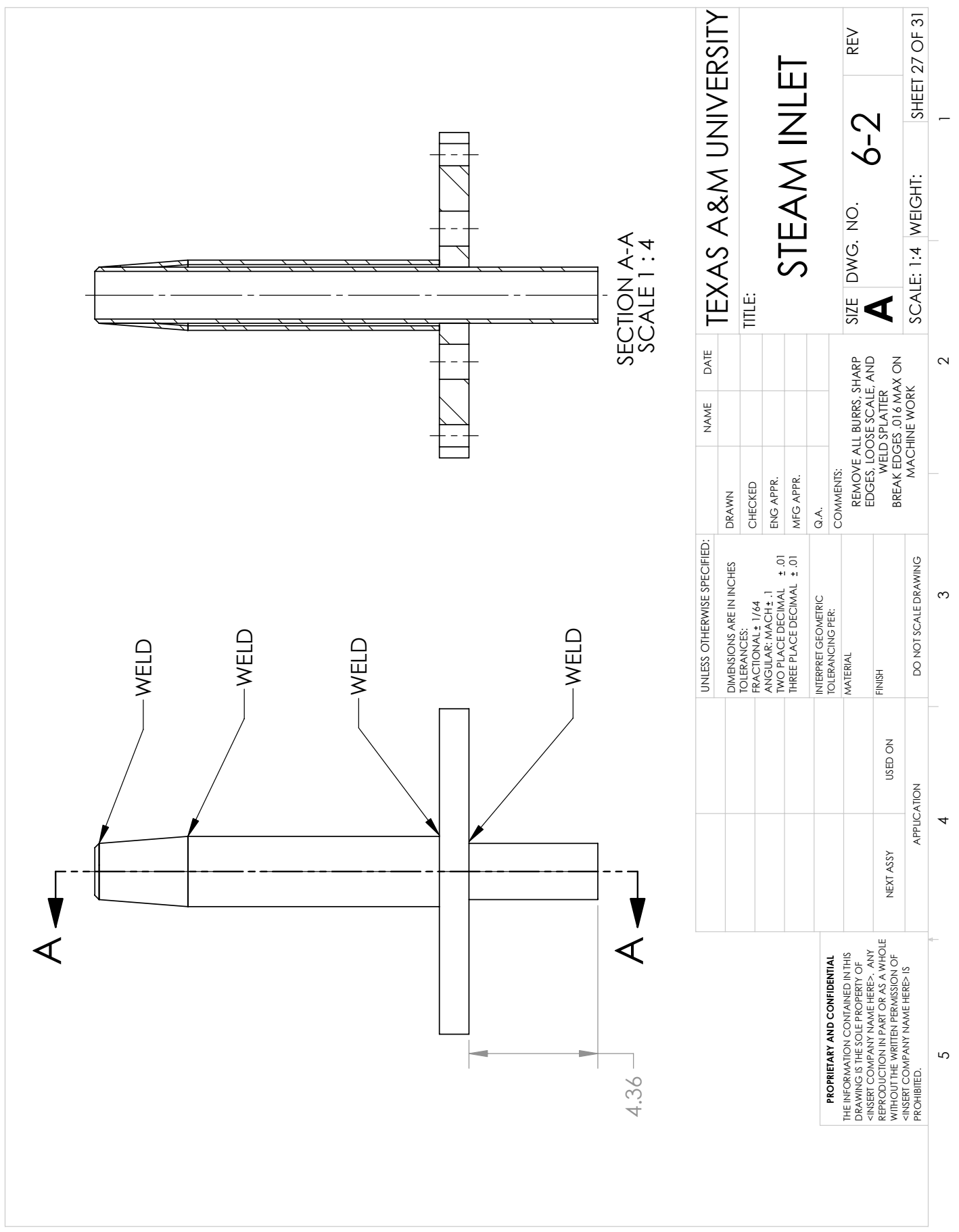



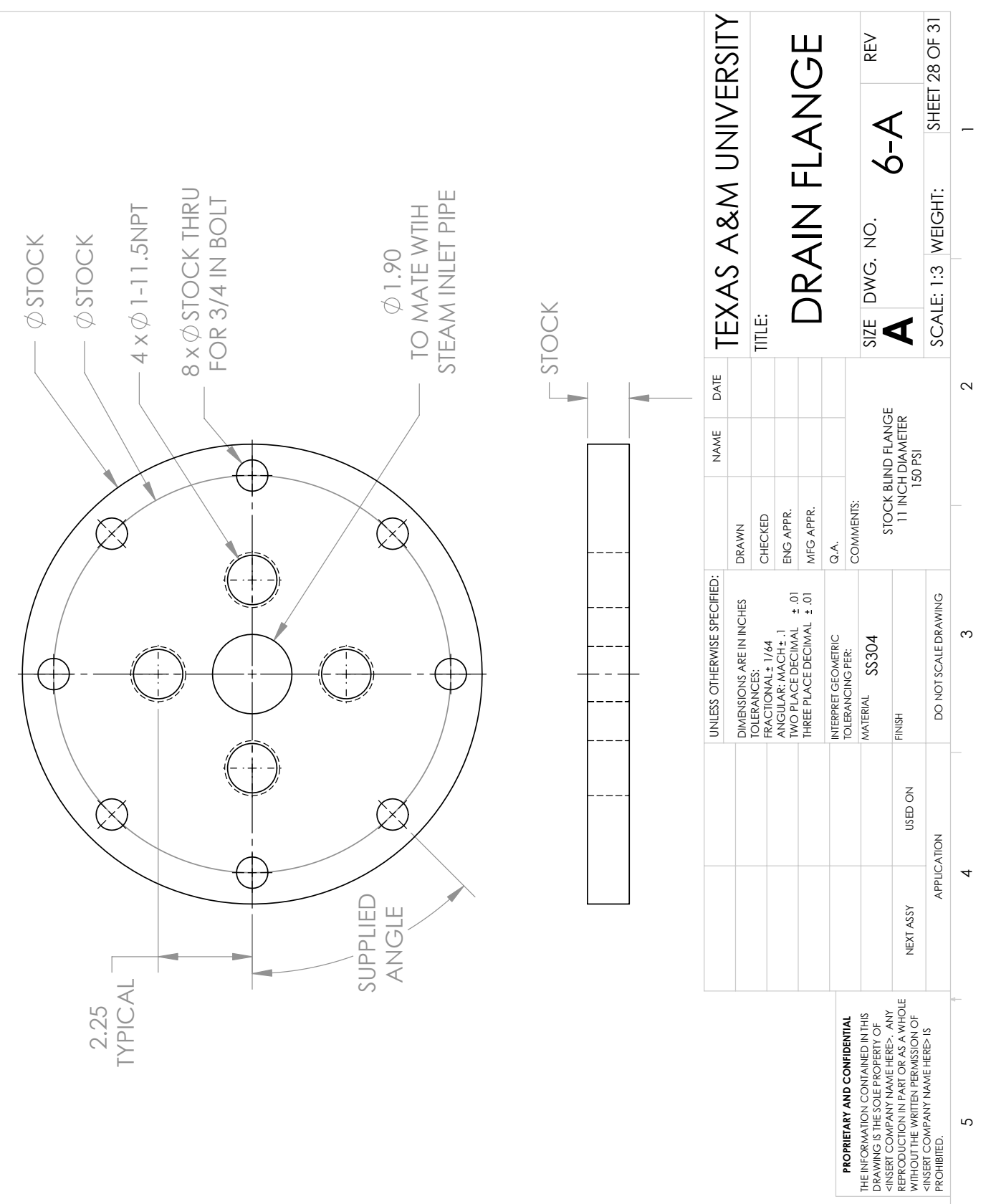


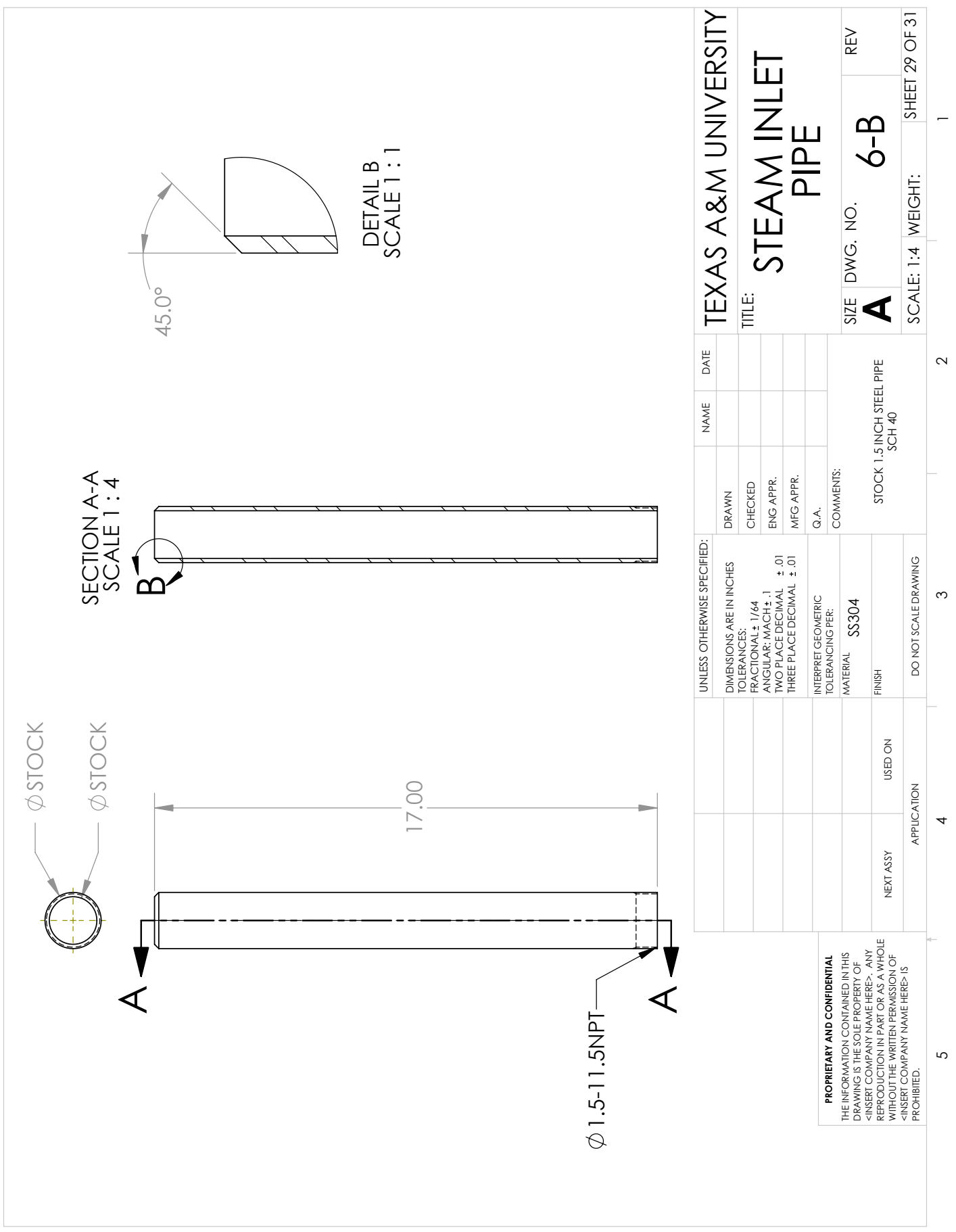




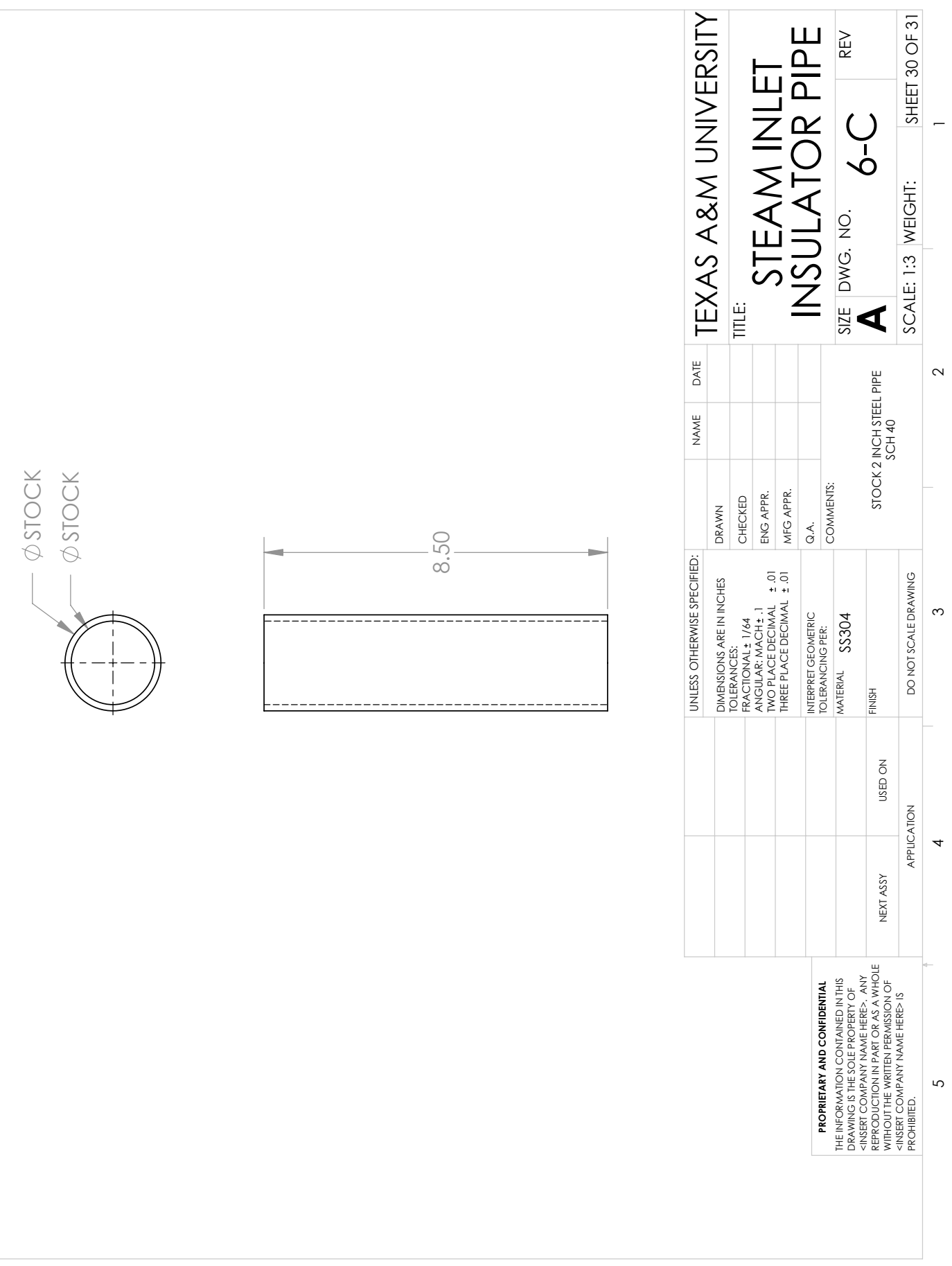



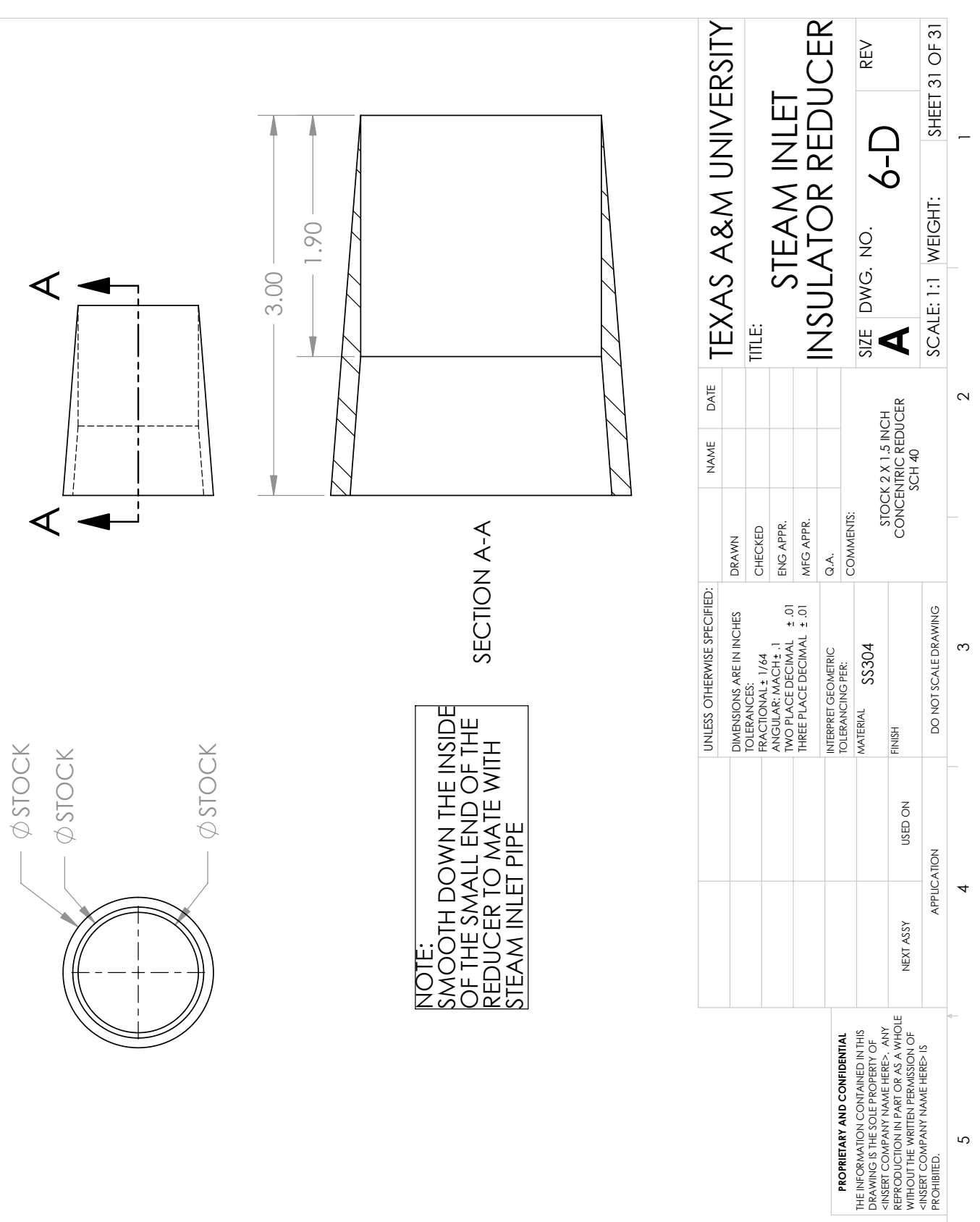


\section{APPENDIX B REDUCED DATA SET}

The following table contains all of the steam-water reduced data collected by the DAQ. The units are given in the table heading. The data is listed in chronological order starting with the earliest run. 


\begin{tabular}{|c|c|c|c|c|c|c|c|c|c|c|c|c|c|c|}
\hline $\begin{array}{l}\stackrel{0}{1} \\
\dot{0} \\
\tilde{\theta}\end{array}$ & 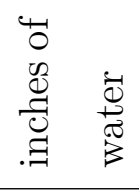 & $\begin{array}{l}\stackrel{2}{\infty} \\
\stackrel{+}{+} \\
\stackrel{+}{+}\end{array}$ & $\begin{array}{l}0 \\
0 \\
20 \\
0 \\
0 \\
-1\end{array}$ & $\begin{array}{l}\overrightarrow{\tilde{B}} \\
\dot{0} \\
\dot{0}\end{array}$ & 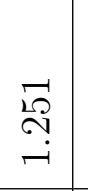 & $\begin{array}{l}\stackrel{8}{0} \\
\stackrel{0}{1}\end{array}$ & 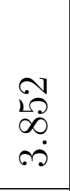 & $\mid \begin{array}{l}2 \\
\vec{N} \\
\infty \\
\infty\end{array}$ & 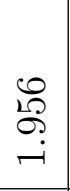 & $\begin{array}{l}8 \\
\mathscr{8} \\
\stackrel{0}{0} \\
\stackrel{-}{1}\end{array}$ & 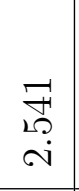 & $\begin{array}{l}20 \\
\infty \\
0 \\
0\end{array}$ & 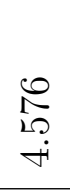 & $\begin{array}{l}\stackrel{m}{9} \\
\stackrel{0}{0}\end{array}$ \\
\hline 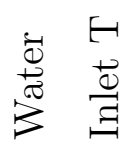 & $0_{0}^{0}$ & $\begin{array}{l}0 \\
\stackrel{0}{1} \\
i \\
i\end{array}$ & $\begin{array}{l}\stackrel{8}{\mathscr{S}} \\
\stackrel{\leftrightarrow}{亡}\end{array}$ & $\begin{array}{l}\underset{N}{\hat{N}} \\
\infty \\
0\end{array}$ & $\begin{array}{l}0 \\
\stackrel{0}{0} \\
\stackrel{\sim}{1} \\
\end{array}$ & $\begin{array}{l}\stackrel{9}{N} \\
\stackrel{8}{0}\end{array}$ & $\begin{array}{l}20 \\
\infty \\
+ \\
\stackrel{0}{0}\end{array}$ & 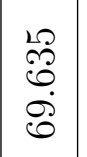 & $\begin{array}{l}0 \\
\stackrel{1}{1} \\
\dot{0}\end{array}$ & 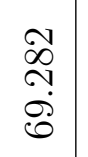 & $\begin{array}{l}\stackrel{9}{\sharp} \\
\stackrel{\leftrightarrow}{0}\end{array}$ & $\begin{array}{l}0 \\
\text { i⿱ } \\
\text { i⿱ } \\
\text { g. }\end{array}$ & $\begin{array}{l}1 \\
1 \\
\infty \\
i \\
i \\
i\end{array}$ & $\begin{array}{l}\stackrel{p}{1} \\
\infty \\
\infty \\
0 \\
0\end{array}$ \\
\hline 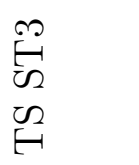 & $\bigcup_{0}^{0}$ & $\begin{array}{l}\stackrel{\infty}{=} \\
\overrightarrow{\mathscr{B}} \\
\mathscr{8}\end{array}$ & $\begin{array}{l}\stackrel{0}{0} \\
0 \\
\dot{\sigma}\end{array}$ & \begin{tabular}{l}
$\stackrel{N}{1}$ \\
\multirow{1}{*}{} \\
$\infty$ \\
$\infty$
\end{tabular} & $\begin{array}{l}\infty \\
0 \\
: 0 \\
\dot{0} \\
\stackrel{0}{0}\end{array}$ & 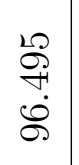 & $\begin{array}{l}\vec{i} \\
i \\
\dot{8} \\
\dot{8}\end{array}$ & 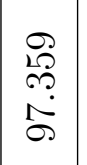 & $\begin{array}{l}\vec{F} \\
\stackrel{1}{0} \\
\stackrel{0}{-}\end{array}$ & 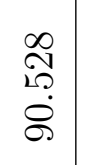 & $\begin{array}{l}\hat{0} \\
\stackrel{1}{0} \\
\stackrel{0}{0}\end{array}$ & 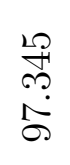 & $\begin{array}{l}8 \\
\stackrel{0}{1} \\
\dot{8}\end{array}$ & $\begin{array}{l}\infty \\
\stackrel{0}{0} \\
\dot{\infty} \\
\dot{b}\end{array}$ \\
\hline 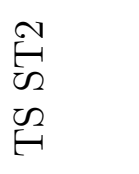 & $\bigcup_{0}^{0}$ & 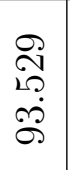 & $\begin{array}{l}\vec{S} \\
\stackrel{+}{+} \\
\stackrel{\infty}{\infty}\end{array}$ & 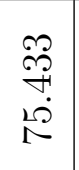 & $\begin{array}{l}\infty \\
\infty \\
0 \\
\dot{0} \\
\dot{0}\end{array}$ & 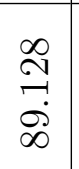 & $\begin{array}{l}\infty \\
\& \\
\mathscr{8} \\
\mathscr{\delta}\end{array}$ & $\mid \begin{array}{l}m \\
\stackrel{9}{+} \\
\dot{8} \\
8\end{array}$ & $\begin{array}{l}\stackrel{m}{\vec{\beta}} \\
\ddot{\delta}\end{array}$ & $\begin{array}{l}\overrightarrow{1} \\
20 \\
10 \\
0 \\
1 \\
10\end{array}$ & $\begin{array}{l}\stackrel{R}{2} \\
\sim \\
\infty \\
\infty\end{array}$ & $\begin{array}{l}\stackrel{\infty}{0} \\
\stackrel{+}{\sigma} \\
\dot{\sigma}\end{array}$ & $\begin{array}{l}0 \\
\stackrel{2}{1} \\
\dot{\sigma}\end{array}$ & $\begin{array}{l}\vec{m} \\
\stackrel{20}{10}\end{array}$ \\
\hline $\begin{array}{l}E \\
\text { E } \\
\text { D } \\
\text { E }\end{array}$ & O & $\begin{array}{l}9 \\
0 \\
0 \\
0 \\
1\end{array}$ & $\begin{array}{l}\vec{S} \\
\stackrel{+}{p} \\
\stackrel{p}{P}\end{array}$ & $\begin{array}{l}\stackrel{9}{4} \\
\stackrel{9}{0}\end{array}$ & $\begin{array}{l}m \\
\stackrel{m}{i} \\
2 \dot{0} \\
\infty\end{array}$ & 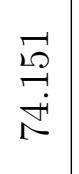 & 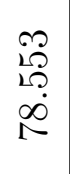 & 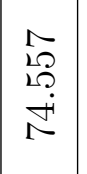 & $\begin{array}{l}\vec{b} \\
\infty \\
\infty \\
\infty \\
\infty\end{array}$ & $\begin{array}{l}\stackrel{9}{9} \\
0 \\
\stackrel{R}{R}\end{array}$ & $\begin{array}{l}\infty \\
\infty \\
1 \\
\infty \\
\infty\end{array}$ & $\begin{array}{l}\text { ․․ } \\
\stackrel{1}{10} \\
10 \\
10\end{array}$ & $\begin{array}{l}8 \\
10 \\
\infty \\
\infty \\
10\end{array}$ & $\underset{\stackrel{P}{\leftrightarrow}}{\stackrel{\oplus}{\leftarrow}}$ \\
\hline 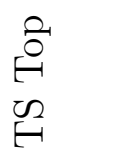 & $\bigcup_{0}^{0}$ & $\begin{array}{l}\hat{N} \\
\hat{0} \\
\dot{0} \\
0\end{array}$ & $\begin{array}{l}\stackrel{ }{1} \\
\stackrel{1}{0} \\
\dot{0} \\
\end{array}$ & $\begin{array}{l}\infty \\
\stackrel{2}{a} \\
\stackrel{+}{+} \\
\stackrel{\varphi}{1}\end{array}$ & $\begin{array}{l}\infty \\
2 \\
\infty \\
\infty \\
\dot{0} \\
-1\end{array}$ & 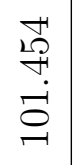 & $\begin{array}{l}\overrightarrow{0} \\
0 \\
\dot{0} \\
0\end{array}$ & 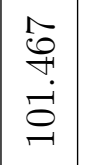 & $\begin{array}{l}R \\
? \\
0 \\
\dot{0} \\
-1\end{array}$ & 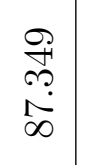 & $\begin{array}{l}0 \\
0 \\
0 \\
\dot{0} \\
0\end{array}$ & $\stackrel{\stackrel{\rho}{P}}{\stackrel{9}{+}}$ & 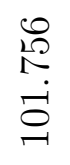 & 崩 \\
\hline 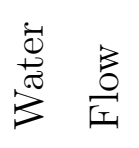 & $\sum_{\text {O }}^{-}$ & 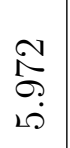 & $\begin{array}{l}\stackrel{g}{0} \\
\dot{0} \\
\dot{0}\end{array}$ & 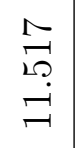 & $\begin{array}{l}\infty \\
2 \\
10 \\
10 \\
\infty\end{array}$ & $\begin{array}{l}\stackrel{\vartheta}{\sigma} \\
\stackrel{2}{\sim}\end{array}$ & $\begin{array}{c}\stackrel{0}{0} \\
\stackrel{0}{10} \\
\dot{10}\end{array}$ & $\left|\begin{array}{l}0 \\
\sigma \\
0 \\
0\end{array}\right|$ & $\begin{array}{l}\stackrel{\mathscr{\theta}}{\mathscr{\theta}} \\
\stackrel{\leftrightarrow}{+}\end{array}$ & $\begin{array}{c}\infty \\
\overrightarrow{0} \\
\dot{\vec{\prime}}\end{array}$ & 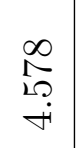 & $\begin{array}{l}\infty \\
\stackrel{\infty}{\infty} \\
\stackrel{?}{\sim}\end{array}$ & 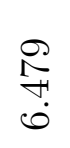 & $\begin{array}{l}\stackrel{2}{2} \\
i \overrightarrow{2} \\
\infty\end{array}$ \\
\hline 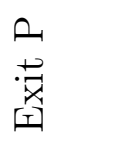 & 䨔 & 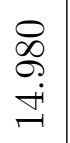 & $\begin{array}{l}\mathscr{2} \\
\mathscr{D} \\
\mathscr{O} \\
\dot{+} \\
+\end{array}$ & 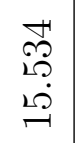 & $\begin{array}{l}1 \\
8 \\
8 \\
10 \\
-1\end{array}$ & $\begin{array}{l}\overrightarrow{\vec{I}} \\
\stackrel{\vec{D}}{\rightarrow}\end{array}$ & $\begin{array}{l}\mathscr{O} \\
\mathscr{O} \\
\stackrel{+}{+} \\
\dot{H}\end{array}$ & $\mid \begin{array}{l}\sigma \\
\vec{\sigma} \\
\dot{+} \\
-\end{array}$ & 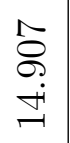 & $\begin{array}{l}0 \\
\stackrel{2}{D} \\
\sim \\
\stackrel{2}{2} \\
\sim\end{array}$ & $\begin{array}{l}\infty \\
\stackrel{\infty}{\circ} \\
\dot{+} \\
-\end{array}$ & 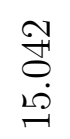 & 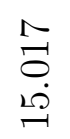 & 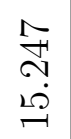 \\
\hline$\theta$ & 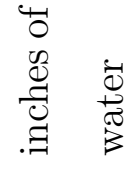 & 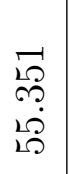 & $\begin{array}{l}0 \\
0 \\
0 \\
0 \\
0 \\
0\end{array}$ & $\begin{array}{l}\infty \\
0 \\
2 \\
0 \\
0 \\
10\end{array}$ & $\begin{array}{l}\infty \\
\infty \\
0 \\
1 \dot{0} \\
10\end{array}$ & $\begin{array}{l}0 \\
\infty \\
\infty \\
10 \\
10 \\
10\end{array}$ & $\begin{array}{l}\infty \\
\infty \\
+1 \\
10 \\
10\end{array}$ & $\left|\begin{array}{l}\vec{D} \\
\infty \\
+1 \\
20 \\
10\end{array}\right|$ & $\begin{array}{l}\vec{F} \\
\overrightarrow{20} \\
20 \\
20\end{array}$ & $\begin{array}{l}1 \mathcal{1} \\
20 \\
10 \\
\dot{6} \\
10\end{array} \mid$ & 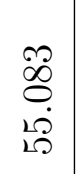 & $\begin{array}{l}1 \\
\infty \\
1 \\
20 \\
10\end{array}$ & $\begin{array}{l}7.7 \\
10 \\
20 \\
20\end{array}$ & $\begin{array}{l}10 \\
8 \\
8 \\
10 \\
10\end{array}$ \\
\hline 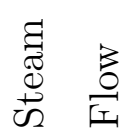 & $\mathbb{U}_{\mathscr{N}}$ & $\begin{array}{l}\frac{1}{2} \\
\infty \\
\infty \\
\stackrel{2}{N}\end{array}$ & $\begin{array}{l}\stackrel{10}{0} \\
0 \\
\dot{2}\end{array}$ & 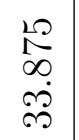 & $\begin{array}{l}\stackrel{0}{1} \\
\sim \\
\infty \\
\sim \\
\sim\end{array}$ & 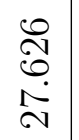 & 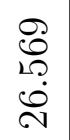 & 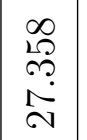 & $\begin{array}{l}\mathbb{R} \\
\text { D } \\
\stackrel{1}{N} \\
\text { N }\end{array}$ & 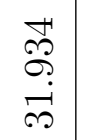 & 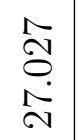 & $\begin{array}{l}\stackrel{+}{\infty} \\
\stackrel{+}{+} \\
\stackrel{N}{N}\end{array}$ & $\begin{array}{l}\infty \\
\stackrel{\infty}{0} \\
\dot{0} \\
\stackrel{N}{N}\end{array}$ & 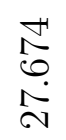 \\
\hline 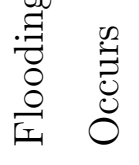 & $\frac{\infty}{\infty}$ & $\begin{array}{l}\stackrel{+}{+} \\
\stackrel{+}{+} \\
\stackrel{5}{\circ}\end{array}$ & $\begin{array}{l}\infty \\
\dot{D} \\
\dot{\infty}\end{array}$ & $\begin{array}{r}\Re \\
\stackrel{\leftrightarrow}{\leftrightarrow} \\
\stackrel{N}{N}\end{array}$ & 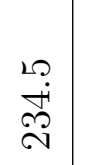 & $\begin{array}{l}\infty \\
\stackrel{\oplus}{\vec{N}} \\
\stackrel{N}{N}\end{array}$ & $\begin{array}{l}\stackrel{0}{1} \\
\stackrel{+}{ \pm} \\
\sim\end{array}$ & $\begin{array}{l}10 \\
0 \\
0 \\
9 \\
-1\end{array}$ & 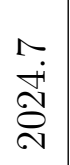 & $\begin{array}{l}\stackrel{\rho}{\circ} \\
\stackrel{\infty}{\stackrel{\rho}{\sim}}\end{array}$ & $\begin{array}{l}\stackrel{\sim}{\sim} \\
\stackrel{2}{\sim} \\
\stackrel{2}{N}\end{array}$ & $\stackrel{\Re}{\stackrel{\leftrightarrow}{\mathcal{H}}}$ & $\stackrel{ }{\stackrel{1}{2}}$ & $\begin{array}{c}0 \\
\stackrel{\text { in }}{\mathrm{O}}\end{array}$ \\
\hline 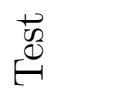 & & - & $\sim$ & $\infty$ & $\not$ & 10 & 0 & $\curvearrowright$ & $\infty$ & 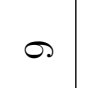 & 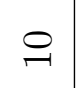 & $\exists$ & $\stackrel{\sim}{\sim}$ & $\stackrel{m}{\rightarrow}$ \\
\hline
\end{tabular}




\begin{tabular}{|c|c|c|c|c|c|c|c|c|c|c|c|c|c|c|c|c|}
\hline 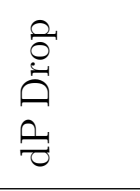 & 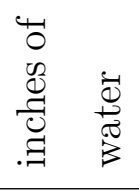 & 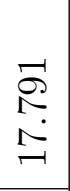 & 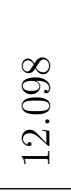 & $\underset{\mathcal{F}}{\stackrel{N}{-}}$ & $\begin{array}{l}\vec{J} \\
\overrightarrow{0} \\
i\end{array}$ & 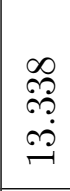 & 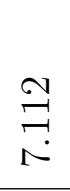 & $\begin{array}{l}\infty \\
0 \\
0 \\
0 \\
0 \\
-1\end{array}$ & 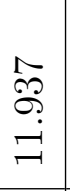 & $\begin{array}{l}\vec{b} \\
\infty \\
+ \\
+\end{array}$ & $\begin{array}{l}\hat{0} \\
\hat{O} \\
\dot{0}\end{array}$ & 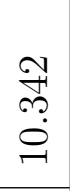 & $\mid \begin{array}{l}\overrightarrow{0} \\
\stackrel{\leftrightarrow}{\sim} \\
\sim\end{array}$ & $\begin{array}{l}20 \\
200 \\
20\end{array}$ & $\begin{array}{l}\infty \\
\stackrel{D}{\rho} \\
\stackrel{0}{0} \\
0\end{array}$ & $\begin{array}{l}\vec{F} \\
\stackrel{\sigma}{0}\end{array}$ \\
\hline 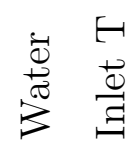 & O & 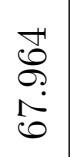 & 管 & $\mid \begin{array}{l}17 \\
10 \\
0 \\
0 \\
0\end{array}$ & 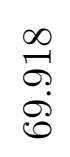 & 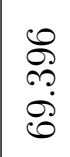 & $\begin{array}{l}\stackrel{\leftrightarrow}{0} \\
\stackrel{0}{0} \\
\dot{0}\end{array}$ & $\begin{array}{l}9 \\
\stackrel{0}{0} \\
\dot{0}\end{array}$ & $\begin{array}{l}\mathscr{2} \\
\infty \\
\infty \\
\dot{0}\end{array}$ & 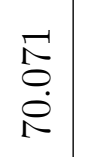 & $\begin{array}{l}\overrightarrow{0} \\
\stackrel{0}{0} \\
8 \\
8\end{array}$ & $\begin{array}{l}\infty \\
\infty \\
\infty \\
1 \\
i \\
\Gamma\end{array}$ & 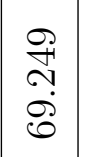 & $\begin{array}{l}\infty \\
2 \\
\infty \\
0 \\
0 \\
0\end{array}$ & $\underset{\hat{O}}{0}$ & $\begin{array}{l}\text { तै } \\
\text { के } \\
\stackrel{0}{0}\end{array}$ \\
\hline 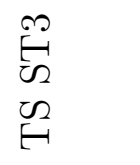 & 0 & $\begin{array}{l}0 \\
8 \\
0 \\
\dot{\sigma} \\
\sigma\end{array}$ & 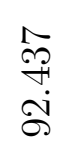 & \begin{tabular}{l}
$\vec{F}$ \\
0 \\
$\dot{0}$ \\
\hdashline \\
\end{tabular} & 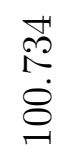 & \begin{tabular}{l}
0 \\
2 \\
\multirow{2}{*}{} \\
$\stackrel{2}{0}$
\end{tabular} & 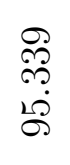 & $\begin{array}{l}\stackrel{N}{\vec{H}} \\
\stackrel{\sigma}{i}\end{array}$ & $\begin{array}{l}\stackrel{\curvearrowright}{N} \\
\stackrel{\sigma}{\sigma}\end{array}$ & $\begin{array}{l}0 \\
10 \\
10 \\
8 \\
8\end{array}$ & $\begin{array}{l}\vec{E} \\
\ddot{0} \\
\stackrel{8}{8}\end{array}$ & $\begin{array}{l}\vec{\imath} \\
\overrightarrow{3} \\
\stackrel{2}{\sigma}\end{array}$ & 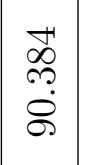 & $\begin{array}{l}\stackrel{2}{8} \\
\stackrel{2}{\circ} \\
\stackrel{8}{8}\end{array}$ & 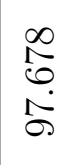 & 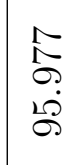 \\
\hline $\begin{array}{l}\tilde{v} \\
\tilde{L} \\
\text { Wn } \\
H\end{array}$ & 0 & 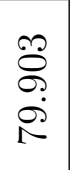 & 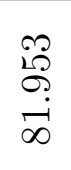 & $\begin{array}{l}0 \\
\infty \\
\infty \\
\dot{O} \\
\dot{\delta}\end{array}$ & $\begin{array}{l}19 \\
\infty \\
\infty \\
\infty \\
\infty\end{array}$ & $\begin{array}{l}\infty \\
0 \\
0 \\
0 \\
\infty \\
\infty\end{array}$ & $\begin{array}{l}\vec{H} \\
b \\
10 \\
\infty\end{array}$ & $\underset{\overrightarrow{0}}{\stackrel{\overrightarrow{0}}{-}}$ & $\begin{array}{l}\mathscr{8} \\
\infty \\
\infty \\
\infty \\
1\end{array}$ & $\begin{array}{l}\infty \\
\infty \\
0 \\
\dot{8}\end{array}$ & 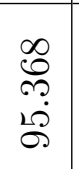 & $\begin{array}{l}\mathscr{8} \\
\stackrel{\infty}{\infty}\end{array}$ & $\begin{array}{c}0 \\
\mathscr{0} \\
\infty \\
\stackrel{0}{1} \\
1\end{array} \mid$ & 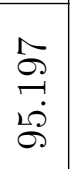 & & $\begin{array}{l}\infty \\
+ \\
\infty \\
\infty \\
\infty\end{array}$ \\
\hline $\begin{array}{l}ت \\
E S \\
\text { ED } \\
E\end{array}$ & ? & $\begin{array}{l}\infty \\
\dot{0} \\
\dot{0}\end{array}$ & 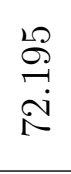 & $\begin{array}{l}\mathscr{O} \\
\stackrel{2}{N} \\
\ddot{\infty} \\
\infty\end{array}$ & $\begin{array}{l}\vec{b} \\
\stackrel{\infty}{\infty}\end{array}$ & $\begin{array}{l}\mathcal{O} \\
\stackrel{2}{R} \\
i \\
i\end{array}$ & $\begin{array}{l}\vec{D} \\
\text { 员 } \\
\text { în }\end{array}$ & $\frac{\stackrel{N}{0}}{\stackrel{+}{i}}$ & 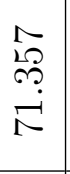 & 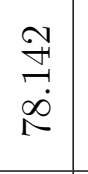 & 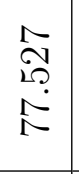 & $\begin{array}{l}\stackrel{1}{B} \\
\stackrel{2}{+} \\
\stackrel{+}{1}\end{array}$ & $\begin{array}{l}\stackrel{+}{N} \\
\stackrel{\sim}{P} \\
\stackrel{R}{R}\end{array}$ & $\underset{N}{\stackrel{N}{N}}$ & $\begin{array}{l}0 \\
8 \\
80 \\
10 \\
10 \\
10\end{array}$ & 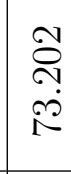 \\
\hline 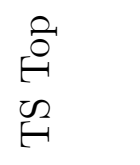 & 0 & $\begin{array}{l}1 \\
8 \\
\infty \\
\infty \\
\infty \\
\delta\end{array}$ & $\begin{array}{l}\stackrel{2}{8} \\
\stackrel{8}{0} \\
\stackrel{0}{0}\end{array}$ & 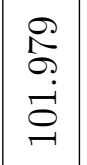 & 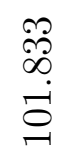 & 曷 & 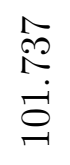 & $\begin{array}{l}\stackrel{1}{0} \\
\stackrel{8}{8}\end{array}$ & 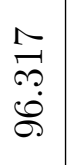 & $\begin{array}{l}\vec{B} \\
\stackrel{0}{0} \\
\stackrel{0}{0}\end{array}$ & 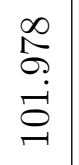 & 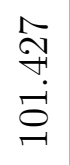 & 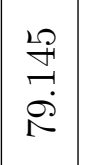 & $\begin{array}{l}\approx \\
0 \\
\dot{0} \\
\dot{0}\end{array}$ & $\begin{array}{l}\overrightarrow{\stackrel{D}{D}} \\
\overrightarrow{0} \\
\overrightarrow{0}\end{array}$ & $\begin{array}{l}\underset{+1}{20} \\
\stackrel{2}{0}\end{array}$ \\
\hline 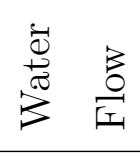 & $\sum_{\vec{D}}$ & $\begin{array}{l}\overrightarrow{8} \\
.0 \\
0 \\
0\end{array}$ & $\begin{array}{l}\overrightarrow{71} \\
\stackrel{10}{0} \\
\stackrel{9}{-1}\end{array}$ & $\begin{array}{l}\stackrel{P}{p} \\
i \\
\dot{n}\end{array}$ & $\begin{array}{l}\infty \\
\stackrel{\infty}{9} \\
\stackrel{+}{+}\end{array}$ & $\begin{array}{l}1 \\
\infty \\
\infty \\
\infty \\
\infty\end{array}$ & 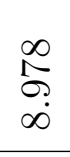 & 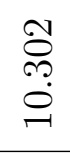 & $\begin{array}{l}20 \\
\infty \\
\infty \\
0 \\
- \\
\end{array}$ & $\begin{array}{l}\infty \\
\infty \\
+1 \\
10\end{array}$ & $\begin{array}{l}\vec{D} \\
i \\
i s\end{array}$ & 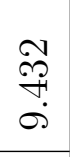 & 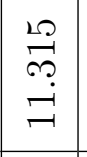 & $\begin{array}{l}\stackrel{9}{H} \\
\stackrel{\sim}{0} \\
\end{array}$ & $\begin{array}{l}0 \\
20 \\
12 \\
6 \\
0\end{array}$ & 总 \\
\hline 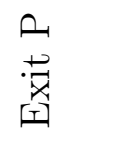 & 苟 & 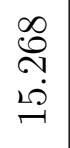 & $\begin{array}{l}\vec{H} \\
\stackrel{H}{10} \\
\stackrel{10}{\sim}\end{array}$ & $\begin{array}{c}20 \\
8 \\
0 \\
10 \\
\end{array}$ & $\begin{array}{l}8 \\
8 \\
0 \\
10 \\
-1\end{array}$ & 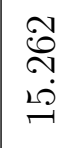 & $\begin{array}{l}0 \\
8 \\
0 \\
10 \\
10\end{array}$ & $\begin{array}{l}\infty \\
0 \\
0 \\
\stackrel{0}{10} \\
\longrightarrow\end{array}$ & 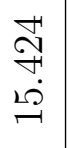 & $\underset{\stackrel{N}{7}}{\stackrel{20}{\longrightarrow}}$ & $\begin{array}{l}\stackrel{2}{2} \\
\stackrel{4}{2} \\
\stackrel{2}{-}\end{array}$ & $\begin{array}{l}\infty \\
\mathscr{D} \\
\stackrel{+}{+} \\
=\end{array}$ & $\mid \begin{array}{c}\stackrel{\odot}{\leftrightarrow} \\
\stackrel{\leftrightarrow}{\leftrightarrow} \\
\stackrel{2}{=}\end{array}$ & $\begin{array}{c}\infty \\
0 \\
0 \\
\stackrel{1}{\rightleftharpoons}\end{array}$ & $\begin{array}{l}\infty \\
\infty \\
\infty \\
+ \\
+\end{array}$ & $\begin{array}{l}\infty \\
\mathscr{O} \\
\stackrel{8}{+} \\
\stackrel{+}{+}\end{array}$ \\
\hline f & 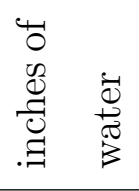 & $\begin{array}{l}\text { N } \\
0 \\
0 \\
6 \\
\llcorner\end{array}$ & $\begin{array}{l}0 \\
i 0 \\
i \stackrel{0}{10} \\
0 \\
0\end{array}$ & $\begin{array}{l}0 \\
0 \\
0 \\
20 \\
20 \\
20\end{array}$ & $\begin{array}{l}7 \\
0 \\
10 \\
10 \\
10\end{array}$ & 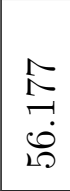 & $\begin{array}{l}\text { Dे } \\
i 0 \\
0 \\
0 \\
10\end{array}$ & $\begin{array}{l}0 \\
\stackrel{0}{0} \\
\stackrel{0}{0} \\
\dot{0}\end{array}$ & 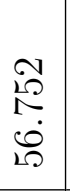 & $\begin{array}{l}\text { 令 } \\
\text { iv } \\
10 \\
10\end{array}$ & 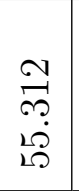 & 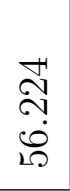 & $\mid \begin{array}{l}\Re \\
\stackrel{P}{H} \\
\dot{H} \\
\llcorner \\
\llcorner\end{array}$ & 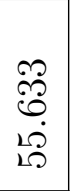 & $\begin{array}{l}\infty \\
0 \\
10 \\
10 \\
10\end{array}$ & $\begin{array}{l}10 \\
10 \\
0 \\
10 \\
10\end{array}$ \\
\hline 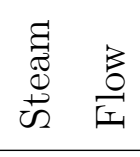 & $\underset{\mathscr{W}}{\mathscr{W}}$ & $\begin{array}{l}\stackrel{0}{.} \\
\delta \\
\infty \\
\sim \\
\sim\end{array}$ & $\begin{array}{l}\vec{D} \\
\stackrel{0}{0} \\
\stackrel{0}{0}\end{array}$ & 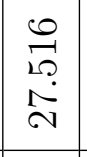 & 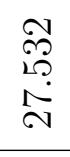 & 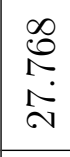 & 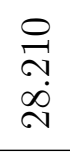 & $\begin{array}{l}\overrightarrow{0} \\
\stackrel{0}{0} \\
\stackrel{2}{1}\end{array}$ & $\begin{array}{l}\overrightarrow{0} \\
\infty \\
\dot{\infty}\end{array}$ & 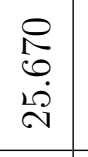 & $\begin{array}{l}\vec{D} \\
\infty \\
\stackrel{\leftrightarrow}{\oplus} \\
\sim\end{array}$ & $\begin{array}{l}20 \\
0 \\
\infty \\
\infty \\
\infty\end{array}$ & 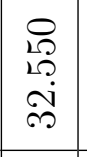 & 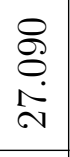 & 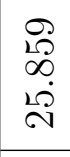 & 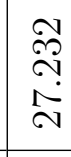 \\
\hline 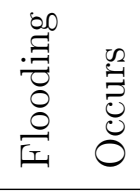 & $\frac{\infty}{\infty}$ & 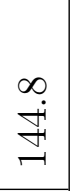 & 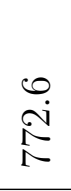 & $\begin{array}{l}\overrightarrow{+} \\
\stackrel{\sim}{\sim}\end{array}$ & 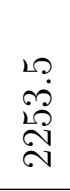 & $\begin{array}{l}0 \\
2 \dot{S} \\
29 \\
-1 \\
\end{array}$ & $\stackrel{\vec{H}}{\stackrel{H}{I}}$ & $\begin{array}{l}\stackrel{N}{0} \\
\stackrel{0}{-}\end{array}$ & $\begin{array}{l}\overrightarrow{10} \\
\overrightarrow{20} \\
\Rightarrow\end{array}$ & 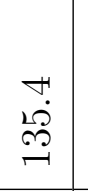 & 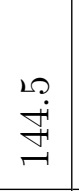 & 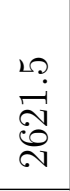 & $\begin{array}{l}\stackrel{\sim}{+} \\
\stackrel{\sim}{二} \\
ت\end{array}$ & $\begin{array}{l}\overrightarrow{8} \\
\stackrel{8}{8} \\
\stackrel{-}{-}\end{array}$ & $\underset{0}{\ddot{\theta}}$ & 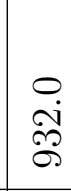 \\
\hline$\stackrel{\overrightarrow{y^{2}}}{\stackrel{\Theta}{-1}}$ & & $\underset{\sim}{ت}$ & $\stackrel{10}{\longrightarrow}$ & $\stackrel{0}{-1}$ & $\stackrel{ }{\sim}$ & - & $\stackrel{\Omega}{\rightarrow}$ & ๙ & $\vec{N}$ & ন & $\stackrel{\curvearrowright}{\sim}$ & $\vec{\sim}$ & $\stackrel{\mathscr{D}}{\mathrm{N}}$ & $\stackrel{\sim}{\sim}$ & $\stackrel{N}{\sim}$ & $\stackrel{\infty}{\sim}$ \\
\hline
\end{tabular}




\begin{tabular}{|c|c|c|c|c|c|c|c|c|c|c|c|c|c|c|c|c|}
\hline 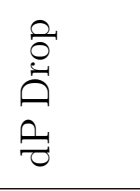 & 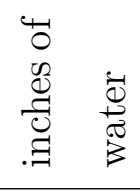 & $\begin{array}{l}\stackrel{\vec{N}}{\stackrel{1}{*}} \\
\stackrel{\infty}{\infty}\end{array}$ & $\begin{array}{l}\hat{N} \\
\stackrel{2}{2} \\
\stackrel{\sigma}{0}\end{array}$ & $\mid \begin{array}{c}\mathcal{N} \\
10 \\
0 \\
0\end{array}$ & 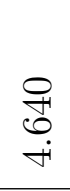 & 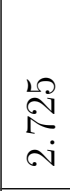 & 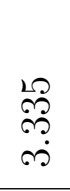 & 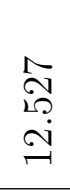 & \begin{tabular}{l}
$\infty$ \\
\multirow{2}{0}{} \\
$\infty$ \\
$\infty$
\end{tabular} & $\begin{array}{l}8 \\
8 \\
0 \\
ت \\
-1\end{array}$ & 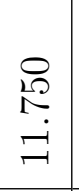 & 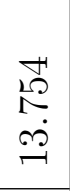 & 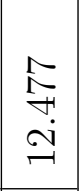 & 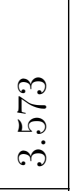 & $\begin{array}{l}\mathfrak{N} \\
\stackrel{N}{0} \\
\stackrel{i}{i}\end{array}$ & 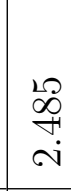 \\
\hline 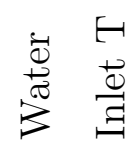 & $\bigcup_{0}^{0}$ & $\begin{array}{l}\infty \\
\stackrel{\infty}{\rho} \\
\stackrel{\Gamma}{\Gamma} \\
\end{array}$ & 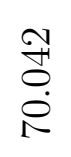 & $\begin{array}{l}\stackrel{2}{2} \\
\stackrel{f}{7} \\
\stackrel{i}{1}\end{array}$ & 棜 & $\mid \begin{array}{l}\infty \\
\infty \\
-1 \\
8 \\
0\end{array}$ & $\begin{array}{l}\mathcal{P} \\
\stackrel{1}{0} \\
0 \\
0\end{array}$ & $\begin{array}{l}1 \\
\infty \\
\infty \\
0 \\
0\end{array}$ & $\begin{array}{l}\stackrel{i}{i} \\
\stackrel{P}{+} \\
\stackrel{i}{i}\end{array}$ & $\begin{array}{l}8 \\
\infty \\
\infty \\
\dot{0}\end{array}$ & 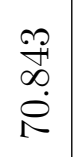 & $\begin{array}{l}0 \\
8 \\
0 \\
0 \\
0 \\
0\end{array}$ & $\mid \begin{array}{l}\stackrel{N}{N} \\
\stackrel{i}{0}\end{array}$ & 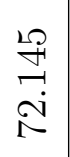 & $\begin{array}{l}\infty \\
\stackrel{\infty}{\infty} \\
\stackrel{+}{i}\end{array}$ & $\begin{array}{l}\hat{2} \\
\stackrel{2}{\circ} \\
\stackrel{1}{1}\end{array}$ \\
\hline 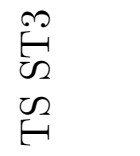 & $0_{0}^{0}$ & 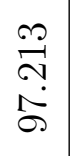 & $\begin{array}{l}0 \\
0 \\
0 \\
8 \\
0\end{array}$ & $\begin{array}{c}\stackrel{P}{+} \\
\stackrel{1}{1} \\
\infty \\
\infty\end{array}$ & $\begin{array}{l}\stackrel{9}{P} \\
\stackrel{P}{+} \\
\infty \\
\infty\end{array}$ & $\begin{array}{l}\tilde{D} \\
\infty \\
\dot{\delta}\end{array}$ & $\begin{array}{l}\overline{8} \\
8 \\
\dot{8}\end{array}$ & $\begin{array}{l}\stackrel{20}{\stackrel{9}{\hookrightarrow}} \\
\stackrel{\sigma}{-}\end{array}$ & 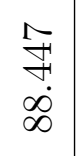 & $\begin{array}{l}\stackrel{p}{P} \\
1 \\
\infty \\
\infty \\
\infty\end{array}$ & $\begin{array}{l}20 \\
\dot{0} \\
\infty \\
\infty \\
\infty\end{array}$ & $\begin{array}{l}\vec{t} \\
\stackrel{1}{\infty} \\
\infty\end{array}$ & 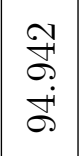 & $\begin{array}{l}\infty \\
\infty \\
\infty \\
\stackrel{8}{8}\end{array}$ & $\begin{array}{l}\mathscr{8} \\
\stackrel{6}{+1} \\
\stackrel{8}{8}\end{array}$ & 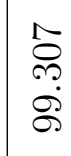 \\
\hline $\begin{array}{l}\tilde{v} \\
\tilde{L} \\
\text { Wn } \\
H\end{array}$ & $U_{0}^{0}$ & $\begin{array}{l}\frac{10}{10} \\
3 \\
\stackrel{8}{8} \\
8\end{array}$ & $\begin{array}{l}\infty \\
\text { in } \\
i \\
+\infty \\
+\infty\end{array}$ & $\begin{array}{l}\infty \\
0 \\
0 \\
\dot{\sigma} \\
0\end{array}$ & $\begin{array}{l}\circ \\
\stackrel{0}{10} \\
\ddot{0} \\
\ddot{0}\end{array}$ & $\begin{array}{l}0 \\
0 \\
0 \\
\dot{1} \\
\delta\end{array}$ & $\begin{array}{l}\infty \\
\infty \\
\infty \\
\infty \\
\infty\end{array}$ & $\begin{array}{l}\infty \\
0 \\
10 \\
0 \\
\infty\end{array}$ & $\begin{array}{l}\overrightarrow{8} \\
\dot{0} \\
\stackrel{0}{1}\end{array}$ & $\begin{array}{l}\vec{H} \\
0 \\
\dot{0} \\
1\end{array}$ & $\begin{array}{l}\infty \\
\infty \\
\infty \\
\infty \\
1\end{array}$ & $\begin{array}{l}20 \\
\infty \\
N \\
\stackrel{1}{1}\end{array}$ & $\mid \begin{array}{c}\infty \\
\infty \\
\infty \\
2.0 \\
\infty \\
\infty\end{array}$ & $\begin{array}{l}0 \\
20 \\
10 \\
\mathscr{8} \\
8\end{array}$ & 阜 & $\begin{array}{l}1 \\
28 \\
0 \\
8\end{array}$ \\
\hline $\begin{array}{l}ت \\
E S \\
\text { ED } \\
E\end{array}$ & 0 & 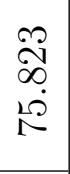 & $\begin{array}{l}\vec{D} \\
\stackrel{N}{1} \\
i \\
i\end{array}$ & \begin{tabular}{|l|}
2 \\
$\stackrel{2}{0}$ \\
+1 \\
$\infty$ \\
1
\end{tabular} & $\begin{array}{l}20 \\
0 \\
0 \\
0 \\
0\end{array}$ & \begin{tabular}{|l}
$\frac{1}{4}$ \\
6 \\
0 \\
0
\end{tabular} & 年 & $\begin{array}{l}\stackrel{N}{\vec{D}} \\
\stackrel{\infty}{\perp} \\
\dot{\Gamma}\end{array}$ & 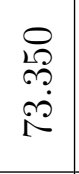 & $\begin{array}{l}0 \\
\stackrel{1}{1} \\
\dot{0}\end{array}$ & $\begin{array}{l}\vec{i} \\
\stackrel{i}{i} \\
\end{array}$ & $\begin{array}{l}\stackrel{8}{2} \\
\stackrel{i}{R}\end{array}$ & $\begin{array}{c}\stackrel{O}{1} \\
\stackrel{i}{1} \\
\stackrel{i}{i}\end{array}$ & $\begin{array}{l}\stackrel{0}{\Xi} \\
\stackrel{0}{\infty} \\
\infty\end{array}$ & 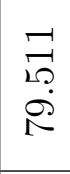 & $\begin{array}{l}12 \\
\infty \\
\infty \\
\infty \\
\infty \\
1\end{array}$ \\
\hline 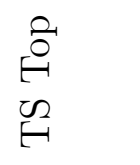 & $0_{0}^{0}$ & 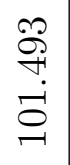 & $\begin{array}{l}m \\
\infty \\
\dot{\infty} \\
\infty\end{array}$ & 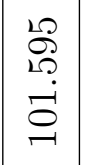 & $\begin{array}{l}\stackrel{+1}{1} \\
\stackrel{1}{20} \\
\stackrel{0}{0}\end{array}$ & $\begin{array}{l}\vec{\rho} \\
\dot{0} \\
\dot{0}\end{array}$ & $\begin{array}{l}\stackrel{ }{1} \\
\stackrel{1}{+} \\
\stackrel{0}{0}\end{array}$ & $\begin{array}{l}\Re 0 \\
\stackrel{0}{0} \\
\stackrel{8}{8}\end{array}$ & $\begin{array}{l}20 \\
\mathscr{8} \\
\infty \\
\infty \\
0\end{array}$ & $\begin{array}{l}\infty \\
\stackrel{9}{\rightarrow} \\
\infty \\
\infty\end{array}$ & $\begin{array}{l}\mathscr{8} \\
\ddot{8} \\
\ddot{\delta}\end{array}$ & 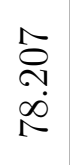 & 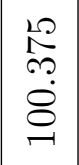 & $\begin{array}{l}\stackrel{0}{0} \\
\stackrel{+}{+} \\
\stackrel{0}{0}\end{array}$ & $\underset{\stackrel{\infty}{+}}{\stackrel{\stackrel{+}{+}}{+}}$ & $\begin{array}{l}\stackrel{\overbrace{}}{+} \\
\stackrel{ }{\circ}\end{array}$ \\
\hline 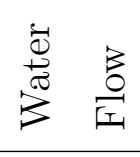 & $\sum_{0}$ & $\begin{array}{l}\stackrel{2}{\mathbb{N}} \\
\underset{\sim}{0} \\
\infty\end{array}$ & $\begin{array}{l}\vec{\infty} \\
\stackrel{\sim}{0} \\
\vec{\sigma}\end{array}$ & $\begin{array}{c}\mathscr{0} \\
\stackrel{0}{0} \\
\stackrel{N}{1}\end{array}$ & 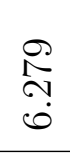 & 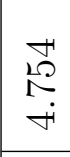 & $\begin{array}{l}\vec{I} \\
\text { o. } \\
\text { is }\end{array}$ & $\begin{array}{l}20 \\
\sigma \\
0 \\
0\end{array}$ & $\begin{array}{c}\stackrel{9}{\oplus} \\
\stackrel{\sim}{=} \\
=\end{array}$ & 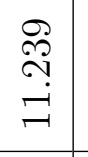 & $\begin{array}{l}\stackrel{R}{R} \\
\stackrel{9}{\longrightarrow} \\
=\end{array}$ & 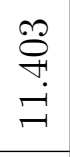 & $\begin{array}{l}0 \\
8 \\
0 \\
0\end{array}$ & $\begin{array}{l}\mathscr{\theta} \\
0 \\
\dot{0} \\
\dot{0}\end{array}$ & $\begin{array}{c}\text { î } \\
0 \\
0 \\
20\end{array}$ & $\begin{array}{l}\hat{0} \\
\stackrel{0}{0} \\
i 0\end{array}$ \\
\hline 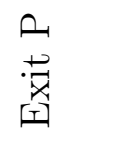 & 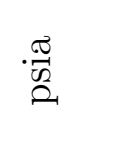 & $\begin{array}{l}\overrightarrow{4} \\
\vec{\rightleftarrows} \\
\stackrel{\vec{D}}{\rightleftharpoons}\end{array}$ & $\begin{array}{l}\infty \\
\infty \\
0 \\
1 \dot{0} \\
\end{array}$ & 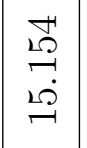 & 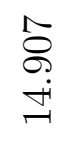 & $\stackrel{N}{N}$ & 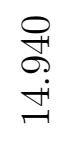 & 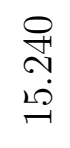 & 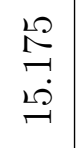 & $\stackrel{10}{\stackrel{10}{10}}$ & 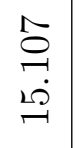 & $\begin{array}{l}\vec{\curvearrowright} \\
\stackrel{\sim}{0} \\
\stackrel{\Delta}{\rightleftharpoons}\end{array}$ & 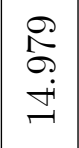 & $\begin{array}{l}\stackrel{\odot}{1} \\
\infty \\
\stackrel{+}{-}\end{array}$ & $\begin{array}{l}\stackrel{\sim}{\infty} \\
\stackrel{\infty}{+} \\
\overrightarrow{+}\end{array}$ & 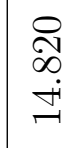 \\
\hline f & 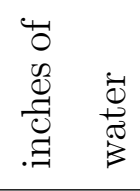 & 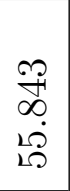 & $\begin{array}{l}0 \\
\vdots \\
0 \\
\dot{0} \\
10\end{array}$ & $\begin{array}{l}\mathscr{D} \\
\infty \\
1 \\
20 \\
20\end{array}$ & $\begin{array}{l}8 \\
0 \\
0 \\
10 \\
10\end{array}$ & $\begin{array}{l}\stackrel{8}{\circ} \\
10 \\
20\end{array}$ & 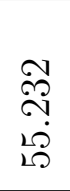 & $\begin{array}{l}\vec{N} \\
\stackrel{N}{0} \\
0 \\
\llcorner\end{array}$ & $\begin{array}{l}\overrightarrow{0} \\
-1 \\
0 \\
0 \\
20\end{array}$ & $\begin{array}{l}\mathscr{8} \\
\stackrel{+}{4} \\
\dot{0} \\
\llcorner\end{array}$ & 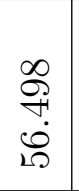 & $\begin{array}{l}\stackrel{8}{9} \\
\stackrel{+}{0} \\
\stackrel{0}{0}\end{array}$ & $\mid \begin{array}{l}0 \\
1 \\
n \\
0 \\
0 \\
10 \\
10\end{array}$ & $\begin{array}{l}\infty \\
0 \\
10 \\
10 \\
10 \\
100\end{array}$ & $\begin{array}{l}\mathscr{8} \\
\stackrel{8}{1} \\
10 \\
10\end{array}$ & 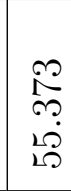 \\
\hline 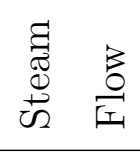 & $\underset{\mathscr{W}}{\mathscr{U}}$ & 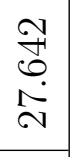 & $\begin{array}{l}\text { 年 } \\
\text { 足 } \\
\text { i }\end{array}$ & 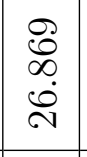 & 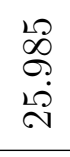 & 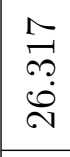 & 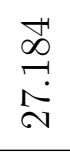 & $\begin{array}{l}\overrightarrow{10} \\
0 \\
0 \\
0\end{array}$ & $\begin{array}{l}\infty \\
\infty \\
\infty \\
\stackrel{i}{i}\end{array}$ & 官 & $\begin{array}{c}\stackrel{n}{\infty} \\
\stackrel{\infty}{*} \\
\infty\end{array}$ & 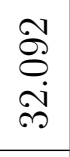 & $\mid \begin{array}{l}\infty \\
\stackrel{p}{a} \\
\sim \\
\sim \\
\sim \\
\end{array}$ & 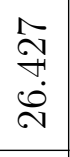 & $\begin{array}{l}\vec{F} \\
\stackrel{H}{\oplus} \\
\stackrel{1}{1}\end{array}$ & 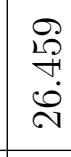 \\
\hline 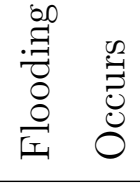 & $\frac{n}{\infty}$ & 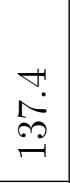 & $\stackrel{\overrightarrow{+}}{\stackrel{\vec{H}}{8}}$ & $\begin{array}{l}\overrightarrow{1} \\
\stackrel{0}{\rightarrow} \\
\stackrel{9}{\rightarrow}\end{array}$ & $\stackrel{\overrightarrow{0}}{\stackrel{\leftrightarrow}{=}}$ & 兽 & 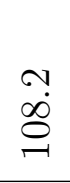 & $\begin{array}{l}29 \\
10 \\
\infty \\
1 \\
-1\end{array}$ & 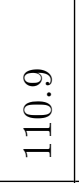 & $\begin{array}{c}\mathfrak{N} \\
\infty \\
\stackrel{0}{O} \\
-1\end{array}$ & $\begin{array}{l}\stackrel{\vec{i}}{\mathrm{I}} \\
\vec{\exists}\end{array}$ & 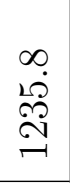 & $\mid \begin{array}{l}0 \\
0 \\
0 \\
0 \\
0 \\
-1 \\
\end{array}$ & 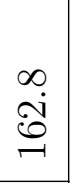 & $\begin{array}{l}0 \\
\infty \\
10 \\
\stackrel{10}{-}\end{array}$ & $\stackrel{\infty}{\stackrel{\leftrightarrow}{\sharp}}$ \\
\hline$\stackrel{\overrightarrow{y^{2}}}{\stackrel{\Theta}{-1}}$ & & $\stackrel{\curvearrowright}{ }$ & ఠి & $\vec{m}$ & กี & $\ddot{m}$ & $\vec{m}$ & $\stackrel{10}{\curvearrowleft}$ & $\infty$ & 宓 & $\begin{array}{l}\infty \\
\infty\end{array}$ & ஓి & 아 & F & F & $\stackrel{9}{Ұ}$ \\
\hline
\end{tabular}




\begin{tabular}{|c|c|c|c|c|c|c|c|c|c|c|c|c|c|c|c|c|}
\hline 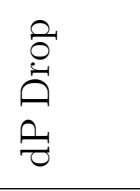 & 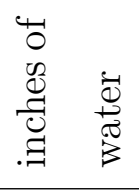 & 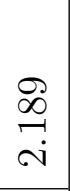 & 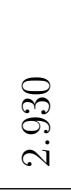 & $\mid \begin{array}{l}2 \\
\stackrel{9}{+} \\
\mathscr{O}\end{array}$ & 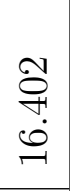 & $\begin{array}{l}\overrightarrow{0} \\
\infty \\
0 \\
0\end{array} \mid$ & 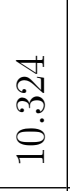 & 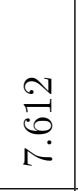 & $\begin{array}{l}\overrightarrow{0} \\
\stackrel{-}{-} \\
ت\end{array}$ & 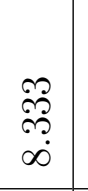 & 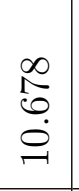 & $\stackrel{\mathscr{Q}}{\stackrel{\leftrightarrow}{-}}$ & 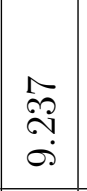 & $\mid \begin{array}{c}0 \\
\stackrel{0}{0} \\
\stackrel{i}{i}\end{array}$ & $\begin{array}{l}\stackrel{R}{R} \\
\text { a } \\
\text { i }\end{array}$ & 笋 \\
\hline 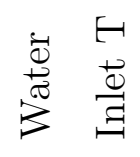 & O & $\begin{array}{l}0 \\
0 \\
0 \\
0 \\
i\end{array}$ & $\begin{array}{l}0 \\
\stackrel{+}{\sharp} \\
\stackrel{R}{R}\end{array}$ & $\mid \begin{array}{l}21 \\
0 \\
0 \\
8 \\
0\end{array}$ & $\begin{array}{l}0 \\
0 \\
\infty \\
0 \\
i\end{array}$ & \begin{tabular}{|l|}
$\infty$ \\
20 \\
$\infty$ \\
8 \\
0 \\
0
\end{tabular} & $\begin{array}{l}\stackrel{0}{1} \\
13 \\
8 \\
0\end{array}$ & $\begin{array}{l}20 \\
8 \\
8 \\
8 \\
0\end{array}$ & $\begin{array}{l}\stackrel{\Re}{N} \\
\stackrel{R}{R}\end{array}$ & 角 & $\begin{array}{l}\dot{D} \\
\infty \\
\dot{0}\end{array}$ & 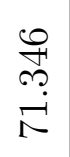 & $\begin{array}{l}\hat{n} \\
\infty \\
\infty \\
\dot{0}\end{array} \mid$ & \begin{tabular}{|l}
$\stackrel{O}{+}$ \\
$\stackrel{+}{i}$ \\
$i$
\end{tabular} & $\begin{array}{l}\infty \\
\infty \\
\stackrel{2}{?} \\
\stackrel{R}{1}\end{array}$ & 胥 \\
\hline 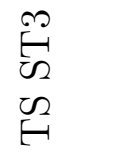 & 0 & $\begin{array}{l}\overrightarrow{2} \\
\stackrel{2}{0} \\
\stackrel{8}{0}\end{array}$ & $\begin{array}{l}8 \\
8 \\
8 \\
8\end{array}$ & 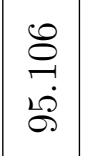 & 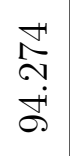 & $\begin{array}{l}\infty \\
\infty \\
0 \\
\dot{\sigma} \\
0\end{array}$ & $\begin{array}{l}\vec{\theta} \\
\dot{\theta} \\
\dot{\theta}\end{array}$ & 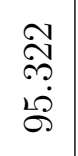 & 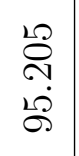 & \begin{tabular}{l}
$\hat{0}$ \\
\multirow{2}{*}{} \\
$\stackrel{1}{\sigma}$
\end{tabular} & $\begin{array}{l}\infty \\
\stackrel{\sim}{1} \\
\stackrel{+}{\circ}\end{array}$ & 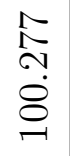 & $\begin{array}{l}\mathcal{I} \\
\dot{\infty} \\
\dot{\sigma} \\
\tilde{\sigma}\end{array}$ & $\begin{array}{l}8 \\
8 \\
1 \\
8 \\
-1\end{array}$ & $\begin{array}{l}\mathscr{8} \\
\infty \\
\dot{\delta}\end{array}$ & $\begin{array}{l}\stackrel{9}{10} \\
\stackrel{10}{8} \\
0\end{array}$ \\
\hline $\begin{array}{l}\mathcal{N} \\
\text { wn } \\
\text { Wn }\end{array}$ & 0 & 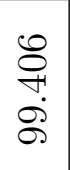 & $\begin{array}{l}\vec{I} \\
\vec{\Xi} \\
\stackrel{g}{g}\end{array}$ & $\left|\begin{array}{|l}120 \\
20 \\
20 \\
0 \\
\infty\end{array}\right|$ & $\begin{array}{l}20 \\
0 \\
0 \\
10 \\
\infty\end{array}$ & $\left|\begin{array}{l}0 \\
0 \\
0 \\
\dot{0} \\
\infty\end{array}\right|$ & $\begin{array}{l}\infty \\
\stackrel{\infty}{0} \\
\dot{\infty} \\
\infty\end{array}$ & $\begin{array}{l}\mathscr{0} \\
\llcorner \\
\dot{1} \\
\dot{\infty}\end{array}$ & $\begin{array}{l}\hat{0} \\
20 \\
0 \\
\infty \\
\infty\end{array}$ & 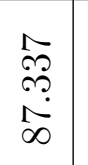 & $\begin{array}{l}\overrightarrow{\mathscr{P}} \\
\stackrel{\vec{p}}{+} \\
\dot{\infty}\end{array}$ & $\begin{array}{l}\stackrel{g}{\sharp} \\
\stackrel{\leftrightarrow}{\mathscr{g}}\end{array}$ & $\left|\begin{array}{l}m \\
\overrightarrow{0} \\
2 \dot{8} \\
\infty\end{array}\right|$ & $\begin{array}{l}\overrightarrow{\widetilde{N}} \\
\ddot{\sigma} \\
\dot{\delta}\end{array}$ & $\begin{array}{l}\vec{F} \\
\text { 여 } \\
\stackrel{2}{\sigma}\end{array}$ & $\begin{array}{l}\infty \\
\infty \\
\stackrel{1}{\circ}\end{array}$ \\
\hline $\begin{array}{l}\vec{E} \\
\text { Wn } \\
\text { W2 } \\
H\end{array}$ & ? & $\begin{array}{l}\stackrel{\mathscr{N}}{\hat{N}} \\
\dot{\infty} \\
\infty\end{array}$ & $\begin{array}{l}\mathcal{R} \\
\stackrel{1}{N} \\
\text { a } \\
\infty\end{array}$ & $\begin{array}{l}m \\
\stackrel{q}{R} \\
i \\
i\end{array}$ & 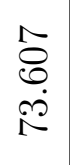 & 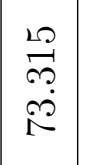 & 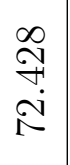 & 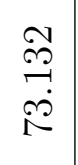 & $\begin{array}{l}\infty \\
\infty \\
\cdots \\
i \\
i\end{array}$ & 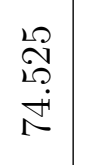 & $\begin{array}{l}R \\
\stackrel{R}{1} \\
\stackrel{i}{R}\end{array}$ & $\begin{array}{l}\infty \\
\infty \\
\infty \\
\infty \\
\infty\end{array}$ & 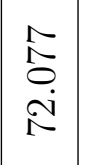 & $\begin{array}{c}\infty \\
\infty \\
\infty \\
\infty \\
\infty \\
\infty \\
\infty\end{array}$ & $\begin{array}{l}1 \\
1 \\
\infty \\
\infty \\
1\end{array}$ & $\begin{array}{l}20 \\
0 \\
0 \\
\text { id } \\
\infty\end{array}$ \\
\hline 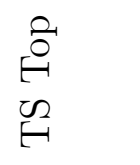 & 0 & 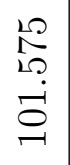 & 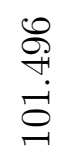 & $\begin{array}{l}12 \\
0 \\
0 \\
0 \\
0 \\
\end{array}$ & \begin{tabular}{l}
8 \\
8 \\
0 \\
8 \\
8 \\
\hdashline
\end{tabular} & 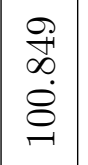 & 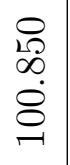 & $\begin{array}{l}20 \\
2 \\
0 \\
\dot{0} \\
0 \\
-1\end{array}$ & $\begin{array}{l}0 \\
\infty \\
\infty \\
\dot{0} \\
0\end{array}$ & $\begin{array}{l}\overrightarrow{0} \\
\stackrel{+}{\dot{0}} \\
\overrightarrow{0}\end{array}$ & $\begin{array}{l}\stackrel{\vec{N}}{\hat{N}} \\
\stackrel{8}{0}\end{array}$ & $\begin{array}{l}\stackrel{+}{0} \\
\stackrel{0}{+} \\
\stackrel{0}{0}\end{array}$ & $\begin{array}{l}\tilde{P} \\
\tilde{R} \\
\vdots \\
\sigma \\
\sigma\end{array}$ & 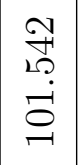 & $\begin{array}{l}\stackrel{+1}{10} \\
\stackrel{0}{0} \\
\dot{0}\end{array}$ & $\begin{array}{l}\overrightarrow{10} \\
\dot{0} \\
\dot{0}\end{array}$ \\
\hline 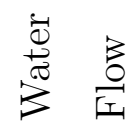 & $\sum_{\vec{O}}$ & $\begin{array}{l}\infty \\
\stackrel{\infty}{1} \\
\infty \\
\infty\end{array}$ & $\begin{array}{l}\text { ָे } \\
\stackrel{\text { Dे }}{+}\end{array}$ & $\mid \begin{array}{l}\infty \\
\infty \\
0 \\
\infty \\
\infty\end{array}$ & $\begin{array}{l}\mathscr{O} \\
0 \\
O \\
\dot{0}\end{array}$ & $\left|\begin{array}{l}\vec{\infty} \\
\infty \\
\infty \\
\infty\end{array}\right|$ & $\begin{array}{l}\vec{a} \\
\vec{\sigma} \\
\dot{\sigma}\end{array}$ & $\begin{array}{l}\vec{\infty} \\
\stackrel{0}{0} \\
\infty\end{array}$ & 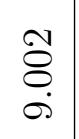 & $\begin{array}{l}\overrightarrow{8} \\
\dot{0}\end{array}$ & $\begin{array}{l}\hat{a} \\
\ddot{\theta} \\
\dot{\theta}\end{array}$ & $\begin{array}{l}1 \\
\infty \\
\infty \\
\infty \\
\text { s. }\end{array}$ & $\left|\begin{array}{l}0 \\
\infty \\
0 \\
\infty \\
\infty\end{array}\right|$ & $\begin{array}{l}\infty \\
0 \\
0 \\
\infty \\
\infty\end{array}$ & \begin{tabular}{l}
$\mathscr{N}$ \\
\multirow{2}{*}{}
\end{tabular} & $\begin{array}{l}\hat{\sigma} \\
\text { ब. } \\
\text { is }\end{array}$ \\
\hline 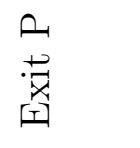 & 苟 & $\begin{array}{l}\vec{D} \\
\infty \\
\stackrel{+}{+}\end{array}$ & $\begin{array}{l}\stackrel{\infty}{\infty} \\
\infty \\
\dot{+} \\
+\end{array}$ & 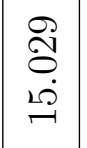 & $\begin{array}{l}\vec{H} \\
\vec{\vdots} \\
\stackrel{\Delta}{=}\end{array}$ & $\left|\begin{array}{c}0 \\
0 \\
0 \\
10 \\
-10\end{array}\right|$ & $\begin{array}{c}\stackrel{\leftrightarrow}{0} \\
0 \\
\stackrel{10}{\rightleftharpoons}\end{array}$ & $\begin{array}{l}\stackrel{8}{8} \\
\stackrel{8}{+} \\
\dot{+} \\
=\end{array}$ & $\begin{array}{l}\mathscr{8} \\
\mathscr{8} \\
\dot{+} \\
-1\end{array}$ & $\begin{array}{l}\vec{H} \\
\stackrel{H}{+}\end{array}$ & 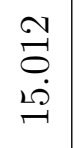 & $\begin{array}{l}\infty \\
\infty \\
\infty \\
\dot{+} \\
=\end{array}$ & $\left|\begin{array}{l}\mathscr{R} \\
\infty \\
\infty \\
\dot{H} \\
-1\end{array}\right|$ & $\begin{array}{l}\vec{H} \\
\infty \\
\infty \\
\dot{0} \\
\overrightarrow{+} \\
ت\end{array}$ & $\begin{array}{l}\stackrel{0}{1} \\
\infty \\
\stackrel{+}{+}\end{array}$ & $\begin{array}{l}\overrightarrow{1} \\
\infty \\
\stackrel{+}{+} \\
\stackrel{+}{+}\end{array}$ \\
\hline$\xi$ & 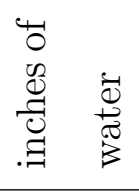 & $\begin{array}{l}0 \\
0 \\
0 \\
10 \\
10 \\
20\end{array}$ & $\begin{array}{l}0 \\
\stackrel{1}{1} \\
\text { 1 } \\
10 \\
10\end{array}$ & 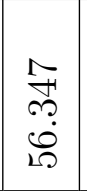 & $\begin{array}{l}\vec{\infty} \\
0 \\
0 \\
0 \\
\llcorner\end{array}$ & \begin{tabular}{|l|}
20 \\
20 \\
00 \\
10 \\
20 \\
10
\end{tabular} & 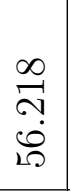 & $\begin{array}{l}\overrightarrow{8} \\
\dot{0} \\
\dot{0}\end{array}$ & $\begin{array}{l}\overrightarrow{2} \\
8 \\
1 \\
20 \\
20\end{array}$ & $\begin{array}{l}\Gamma \\
\infty \\
10 \\
10 \\
10\end{array}$ & 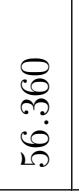 & $\begin{array}{l}\stackrel{9}{二} \\
\stackrel{20}{10}\end{array}$ & 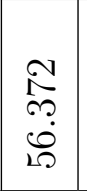 & $\begin{array}{l}9 \\
2 \\
20 \\
10 \\
10\end{array}$ & $\begin{array}{l}5 \\
\stackrel{0}{0} \\
10 \\
20 \\
10\end{array}$ & 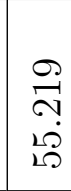 \\
\hline 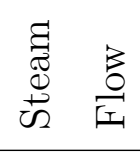 & $\underset{\mathscr{W}}{\mathscr{W}}$ & $\begin{array}{l}0 \\
\stackrel{N}{7} \\
\stackrel{\sim}{\sim} \\
\text {. }\end{array}$ & $\begin{array}{l}\vec{\Xi} \\
\text { స. } \\
\text { ลे }\end{array}$ & 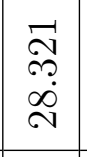 & 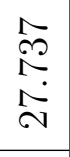 & 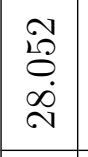 & $\begin{array}{l}20 \\
\infty \\
\infty \\
\infty \\
\sim \\
\sim\end{array}$ & 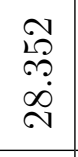 & $\begin{array}{l}\vec{\sim} \\
\sigma \\
\infty \\
\stackrel{\sim}{\sim} \\
\end{array}$ & $\begin{array}{l}\infty \\
\mathscr{8} \\
\infty \\
\stackrel{\infty}{~}\end{array}$ & 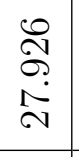 & 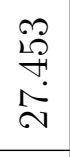 & $\begin{array}{l}\stackrel{p}{\sim} \\
\sim \\
\infty \\
\sim \\
\sim \\
\end{array}$ & 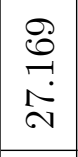 & 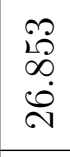 & 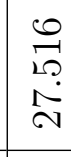 \\
\hline 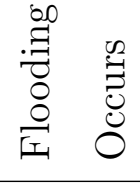 & $\frac{\infty}{\infty}$ & 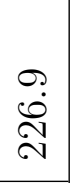 & 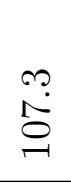 & $\begin{array}{l}0 \\
\dot{\vec{D}} \\
\stackrel{0}{0} \\
\stackrel{10}{\longrightarrow}\end{array}$ & $\begin{array}{l}0 \\
\dot{0}\end{array}$ & $\left|\begin{array}{c}0 \\
\dot{D} \\
-1 \\
-1\end{array}\right|$ & 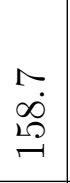 & 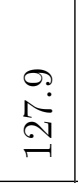 & $\begin{array}{l}\stackrel{\sim}{\ddot{g}} \\
\stackrel{\theta}{=}\end{array}$ & 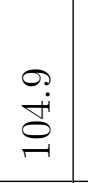 & $\begin{array}{l}\stackrel{2}{0} \\
\stackrel{2}{2} \\
\stackrel{2}{N}\end{array}$ & 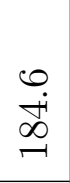 & 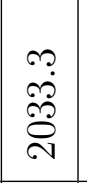 & 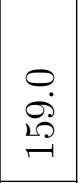 & $\begin{array}{l}\infty \\
\dot{0} \\
\infty \\
\sim\end{array}$ & $\begin{array}{l}\infty \\
\stackrel{\infty}{\infty} \\
\stackrel{N}{N}\end{array}$ \\
\hline$\stackrel{\overrightarrow{y^{2}}}{\stackrel{\Theta}{-1}}$ & & $\not{F}$ & $\stackrel{10}{f}$ & $\stackrel{0}{\circ}$ & 午 & $\stackrel{\infty}{\leftrightarrow}$ & $\stackrel{\rightarrow}{\rightarrow}$ & 80 & $\sqrt{20}$ & iิ & 诵 & $\overrightarrow{B D}$ & 20 & $\mathscr{L}$ & 官 & 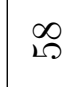 \\
\hline
\end{tabular}




\begin{tabular}{|c|c|c|c|c|c|c|c|c|}
\hline $\begin{array}{l}\stackrel{2}{\circ} \\
\stackrel{0}{0} \\
\stackrel{0}{\sigma}\end{array}$ & & 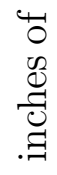 & 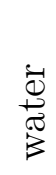 & $\begin{array}{l}\infty \\
\infty \\
\infty \\
\sim \\
\sim\end{array}$ & $\begin{array}{l}\stackrel{2}{+} \\
\stackrel{+}{N}\end{array}$ & 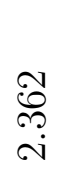 & $\underset{\sim}{\stackrel{10}{0}}$ & 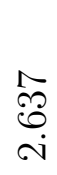 \\
\hline$\frac{\dot{\vec{D}}}{\stackrel{ \pm}{*}}$ & $\begin{array}{l}E \\
\Xi \\
\Xi \\
\Xi\end{array}$ & $\bigcup_{0}^{0}$ & & 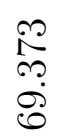 & $\begin{array}{l}\stackrel{2}{R} \\
\stackrel{0}{0}\end{array}$ & $\begin{array}{l}0 \\
\stackrel{0}{0} \\
\stackrel{1}{0} \\
\stackrel{1}{1}\end{array}$ & $\begin{array}{l}\infty \\
\infty \\
\infty \\
\infty \\
\infty \\
0\end{array}$ & $\begin{array}{l}\stackrel{10}{5} \\
0 \\
0 \\
\infty \\
0\end{array}$ \\
\hline $\begin{array}{l}\tilde{\theta} \\
\tilde{H} \\
\tilde{\sigma} \\
\tilde{E}\end{array}$ & & $\bigcup_{0}^{0}$ & & $\begin{array}{l}\overbrace{0} \\
\stackrel{3}{0} \\
\stackrel{8}{0}\end{array}$ & $\begin{array}{l}1 \\
20 \\
\rho \\
\Omega \\
\Omega\end{array}$ & $\begin{array}{l}\infty 0 \\
\infty \\
\dot{D} \\
\dot{\sigma}\end{array}$ & $\begin{array}{l}10 \\
0 \\
0 \\
0 \\
\delta\end{array}$ & $\begin{array}{l}\stackrel{ }{N} \\
\text { i̊ } \\
\stackrel{8}{\circ}\end{array}$ \\
\hline $\begin{array}{l}\mathcal{Y} \\
\tilde{E} \\
\tilde{U} \\
\tilde{E}\end{array}$ & & $\bigcup_{0}^{0}$ & & $\begin{array}{l}0 \\
\stackrel{0}{2} \\
10 \\
\infty \\
\infty\end{array}$ & $\begin{array}{l}\text { ND } \\
10 \\
0 \\
0 \\
0\end{array}$ & $\begin{array}{l}F \\
\stackrel{1}{0} \\
\infty\end{array}$ & $\begin{array}{l}\infty \\
\text { †ै } \\
\dot{\infty} \\
0\end{array}$ & $\begin{array}{l}\stackrel{8}{2} \\
\stackrel{0}{9} \\
\infty \\
\infty\end{array}$ \\
\hline $\begin{array}{l}E \\
{\left[\begin{array}{l}\sigma_{2} \\
\tilde{E}\end{array}\right.}\end{array}$ & & $\bigcup_{0}^{0}$ & & 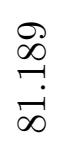 & $\begin{array}{l}\overrightarrow{0} \\
\infty \\
\infty \\
\infty\end{array}$ & $\begin{array}{l}\vec{t} \\
\underset{0}{\infty} \\
\dot{\infty}\end{array}$ & 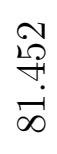 & 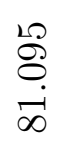 \\
\hline $\begin{array}{l}\stackrel{?}{0} \\
\tilde{E} \\
\tilde{E}\end{array}$ & & $\bigcup_{0}^{0}$ & & 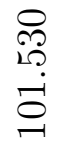 & 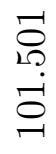 & 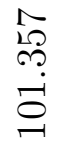 & 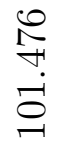 & 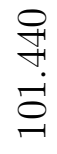 \\
\hline$\frac{\dot{D}}{\stackrel{ \pm}{*}}$ & $\frac{3}{a}$ & $\underset{\vec{\sigma}}{\sum_{\vec{j}}}$ & & $\begin{array}{l}\infty \\
\stackrel{\infty}{2} \\
\infty\end{array}$ & $\underset{+}{\stackrel{\vec{\sigma}}{\sigma}}$ & $\underset{+}{\stackrel{\infty}{+}}$ & $\underset{\vec{\sigma}}{\sigma}$ & $\stackrel{\curvearrowright}{\varnothing}$ \\
\hline 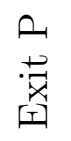 & & $\frac{\tilde{\sigma}}{\sqrt[n]{2}}$ & & $\begin{array}{l}\stackrel{D}{\varnothing} \\
\stackrel{+}{+}\end{array}$ & $\begin{array}{l}0 \\
\stackrel{\infty}{\infty} \\
\underset{+}{J}\end{array}$ & $\begin{array}{l}\vec{J} \\
\stackrel{\infty}{+} \\
\underset{\sim}{+}\end{array}$ & $\begin{array}{l}0 \\
\stackrel{\infty}{+} \\
\underset{+}{+}\end{array}$ & $\begin{array}{l}\stackrel{\llcorner}{\ominus} \\
\infty \\
\stackrel{+}{-1}\end{array}$ \\
\hline$\nexists$ & & 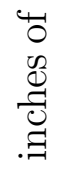 & $\begin{array}{l}\dot{D} \\
\frac{ \pm}{\tilde{\sigma}} \\
\ddot{3}\end{array}$ & $\begin{array}{l}\stackrel{N}{N} \\
\stackrel{2}{2} \\
20\end{array}$ & $\begin{array}{l}0 \\
10 \\
N \\
10 \\
10\end{array}$ & & $\begin{array}{l}0 \\
\mathscr{0} \\
\sim \\
10 \\
10\end{array}$ & 皃 \\
\hline 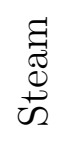 & $\frac{b}{a}$ & $\underset{\Omega}{\mathscr{D}}$ & & $\begin{array}{l}\stackrel{0}{N} \\
\stackrel{N}{N}\end{array}$ & $\begin{array}{l}\stackrel{尺}{\curvearrowright} \\
\stackrel{N}{N}\end{array}$ & $\begin{array}{l}\underset{F}{F} \\
\stackrel{ }{\circ}\end{array}$ & $\begin{array}{c}\stackrel{\overbrace{}}{\curvearrowright} \\
\stackrel{N}{N}\end{array}$ & $\begin{array}{l}0 \\
\sigma \\
\sigma \\
\stackrel{\sigma}{\sigma}\end{array}$ \\
\hline 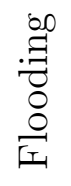 & 芯 & $\frac{\infty}{\infty}$ & & $\begin{array}{l}\Re \\
0 \\
0 \\
\stackrel{0}{0} \\
\stackrel{2}{N}\end{array}$ & $\stackrel{r}{\stackrel{ }{\sharp}}$ & $\stackrel{\infty}{\stackrel{\infty}{N}}$ & $\begin{array}{l}\infty \\
\stackrel{\leftrightarrow}{\Omega}\end{array}$ & $\begin{array}{l}\stackrel{0}{\underset{H}{F}} \\
\underset{\sim}{\sim}\end{array}$ \\
\hline$\stackrel{\vec{v}}{\vec{e}}$ & & & & 10 & 0 & 6 & ชิ & 3 \\
\hline
\end{tabular}




\section{APPENDIX C}

\section{MATLAB SCRIPTS}

This appendix contains the MATLAB script used to graph the time dependent data. It also includes the MATLAB script used to reduce the data. In addition, it includes the MATLAB script used to analyze the vortex flowmeter calibration data.

Below is the MATLAB script used to graph the time dependent data.

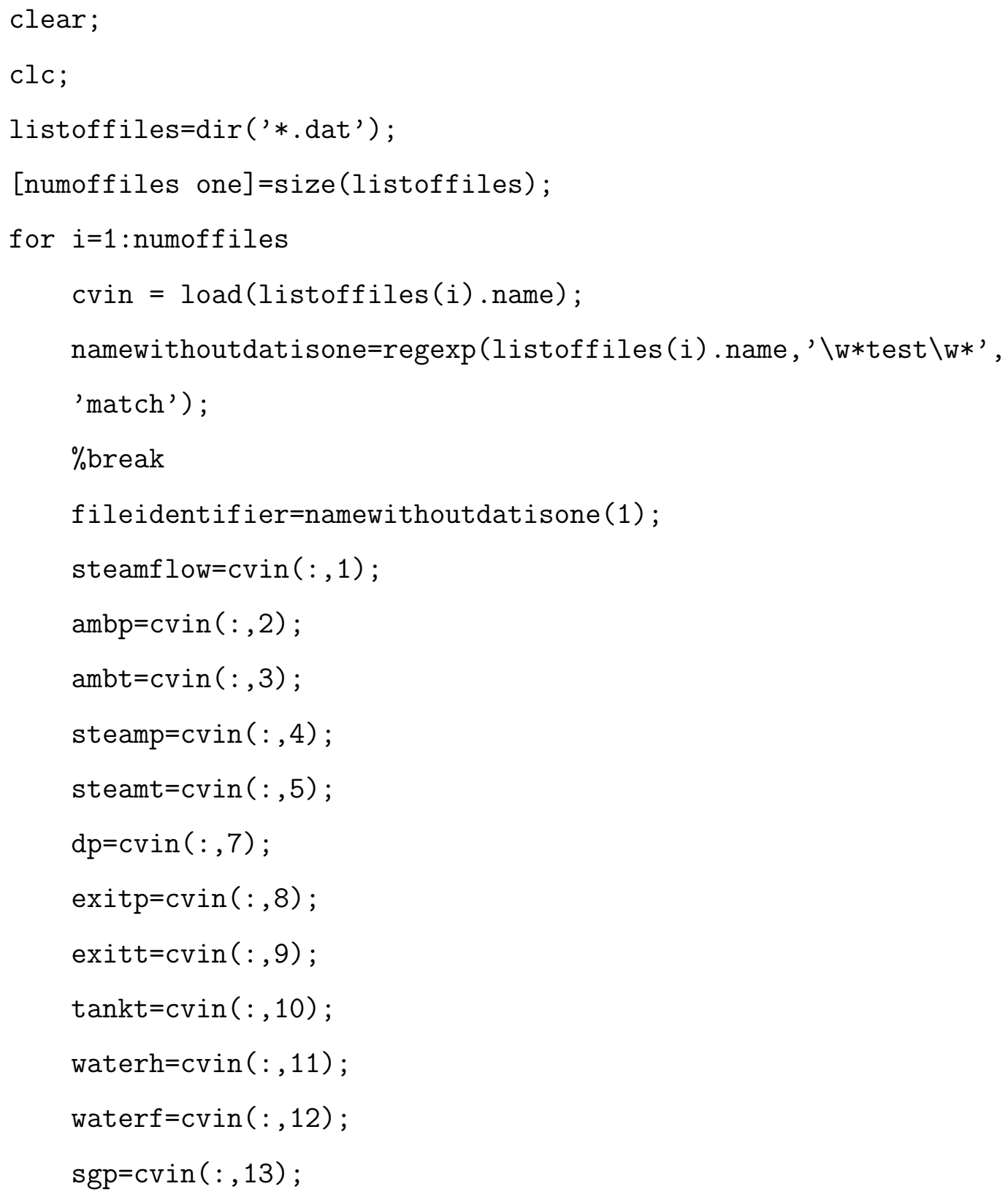




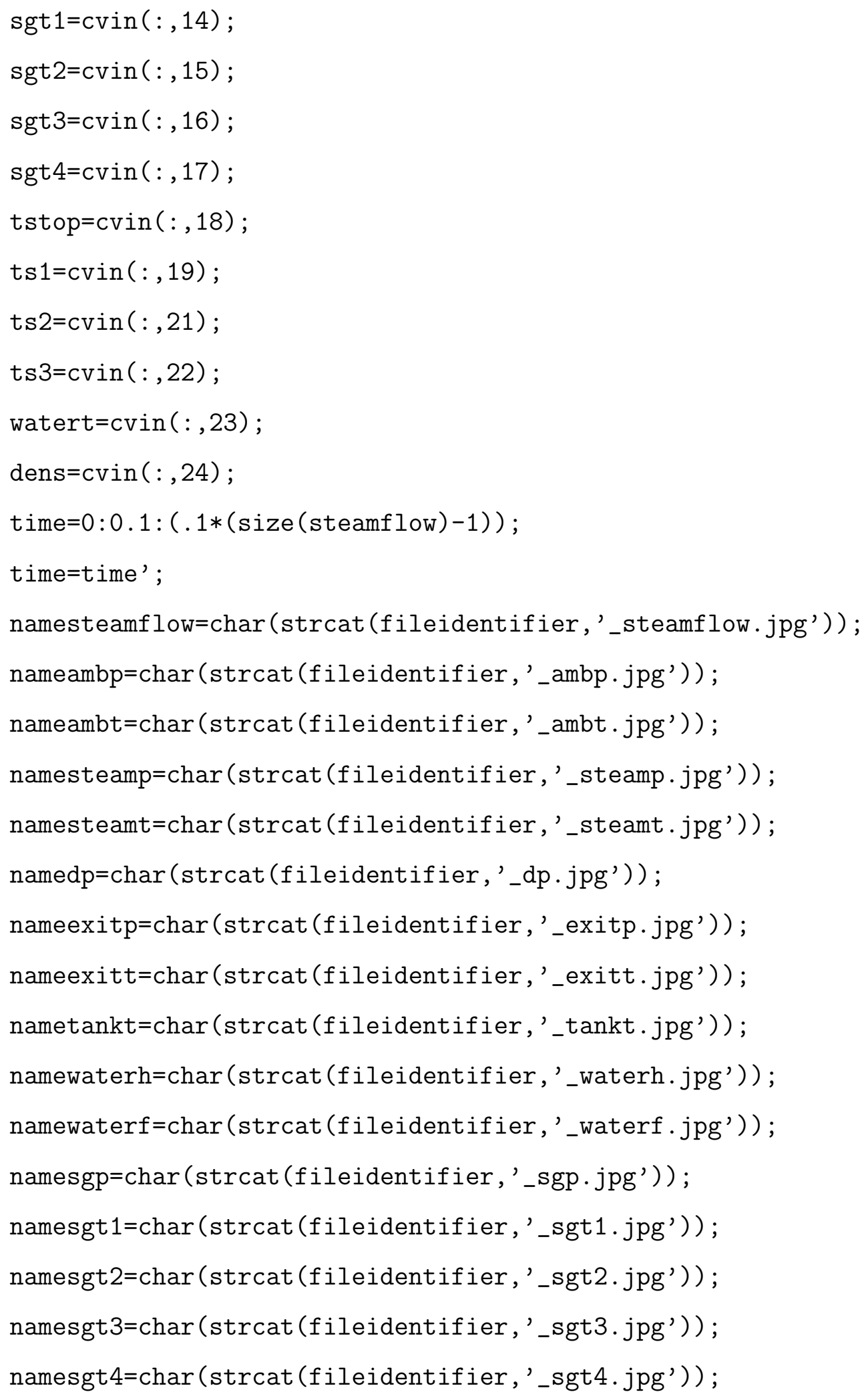




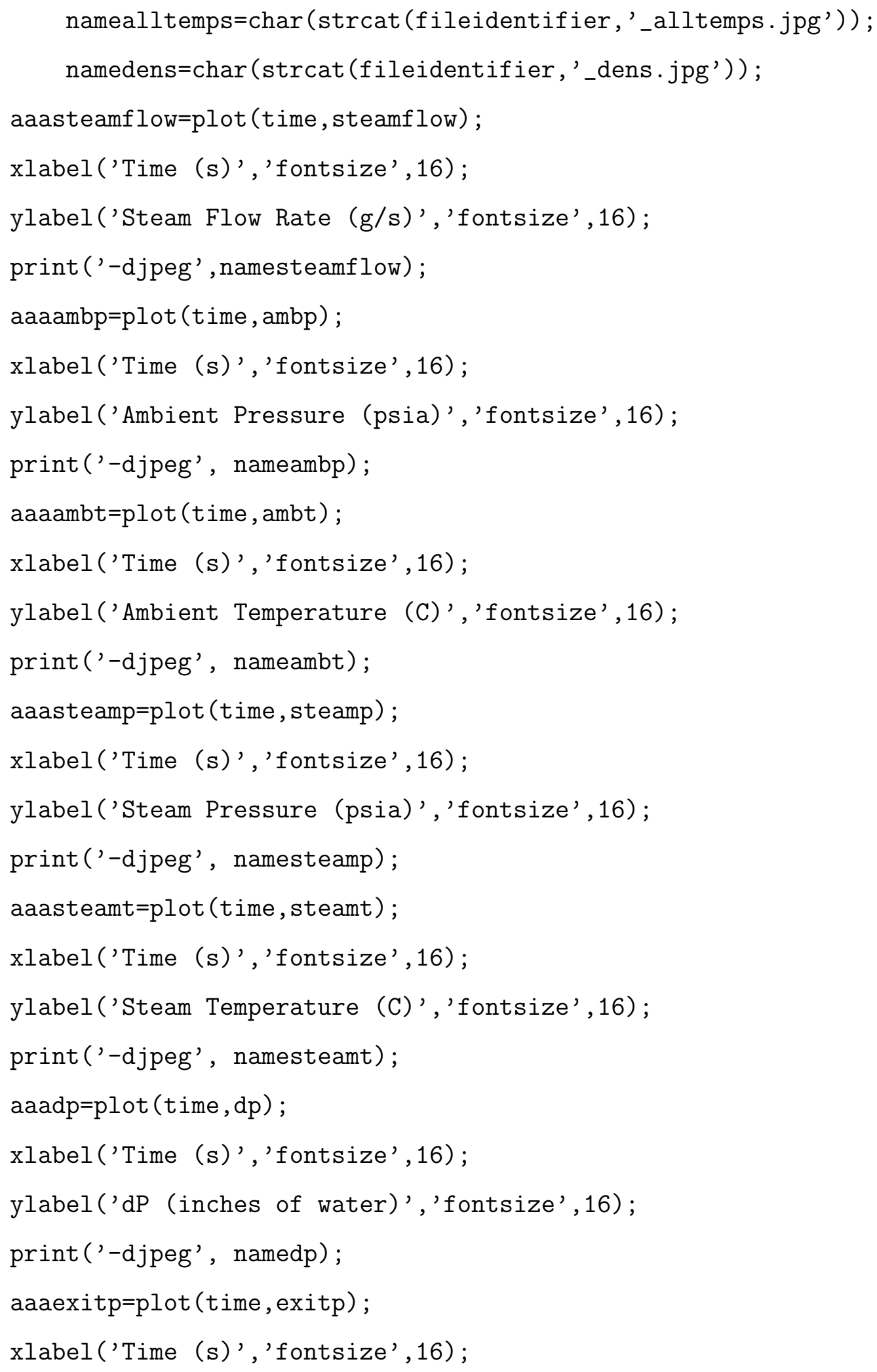




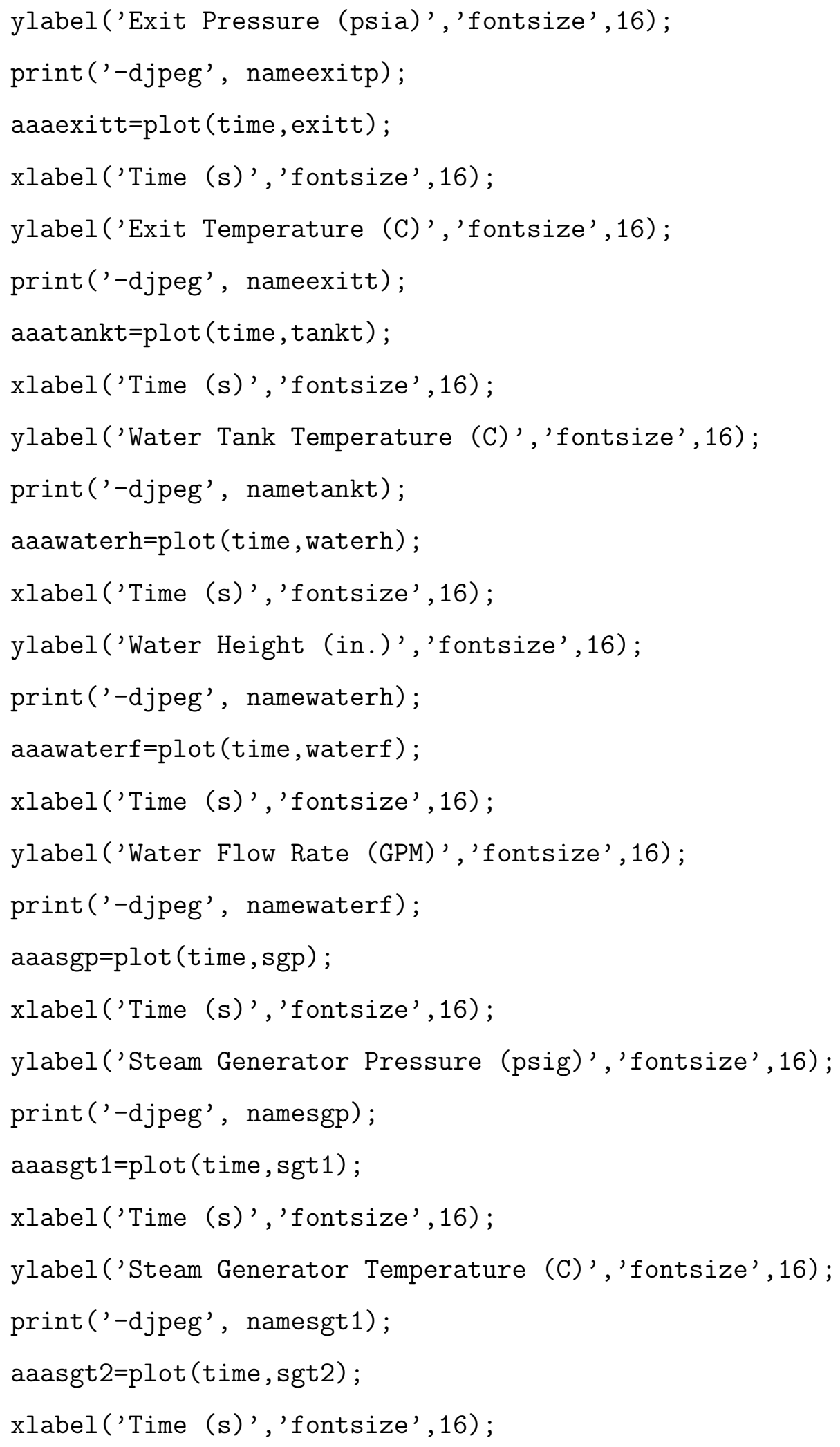


ylabel('Steam Generator Temperature 2(C)', 'fontsize',16);

print('-djpeg', namesgt2);

aaasgt $3=$ plot (time, sgt3);

xlabel ('Time (s)', 'fontsize', 16);

ylabel ('Steam Generator Temperature 3 (C)', 'fontsize',16);

print ('-djpeg', namesgt3);

aaasgt $4=$ plot (time, sgt 4$)$;

xlabel ('Time (s)', 'fontsize',16);

ylabel('Steam Generator Temperature 4(C)', 'fontsize',16);

print('-djpeg', namesgt4);

aaadens $=$ plot $($ time, dens $)$;

$y \lim \left(\left[\begin{array}{ll}0.5 & 0.7\end{array}\right]\right)$;

xlabel ('Time (s)', 'fontsize', 16);

ylabel ('Steam Density (kg/m3)', 'fontsize',16);

print ('-djpeg', namedens);

aaatstop=plot (time, tstop, 'k');

xlabel ('Time (s)', 'fontsize', 16);

ylabel ('Temperature (C)', 'fontsize', 16);

hold on;

aaats1=plot (time, ts1, 'r');

aaats $2=p l o t\left(\right.$ time, $\left.t s 2, g^{\prime}\right)$;

aaats3=plot (time, ts3, 'b');

aaawatert=plot (time, watert, 'm') ;

hold off;

legend('TS Inside', 'TS Surface 1', 'TS Surface 2','TS Surface 3',

'Water Inlet');

legend('Location', 'NorthWest') ;

print('-djpeg', namealltemps); 
end

print('-djpeg', 'test.jpg'); 
Below is the MATLAB script used to reduce the data.

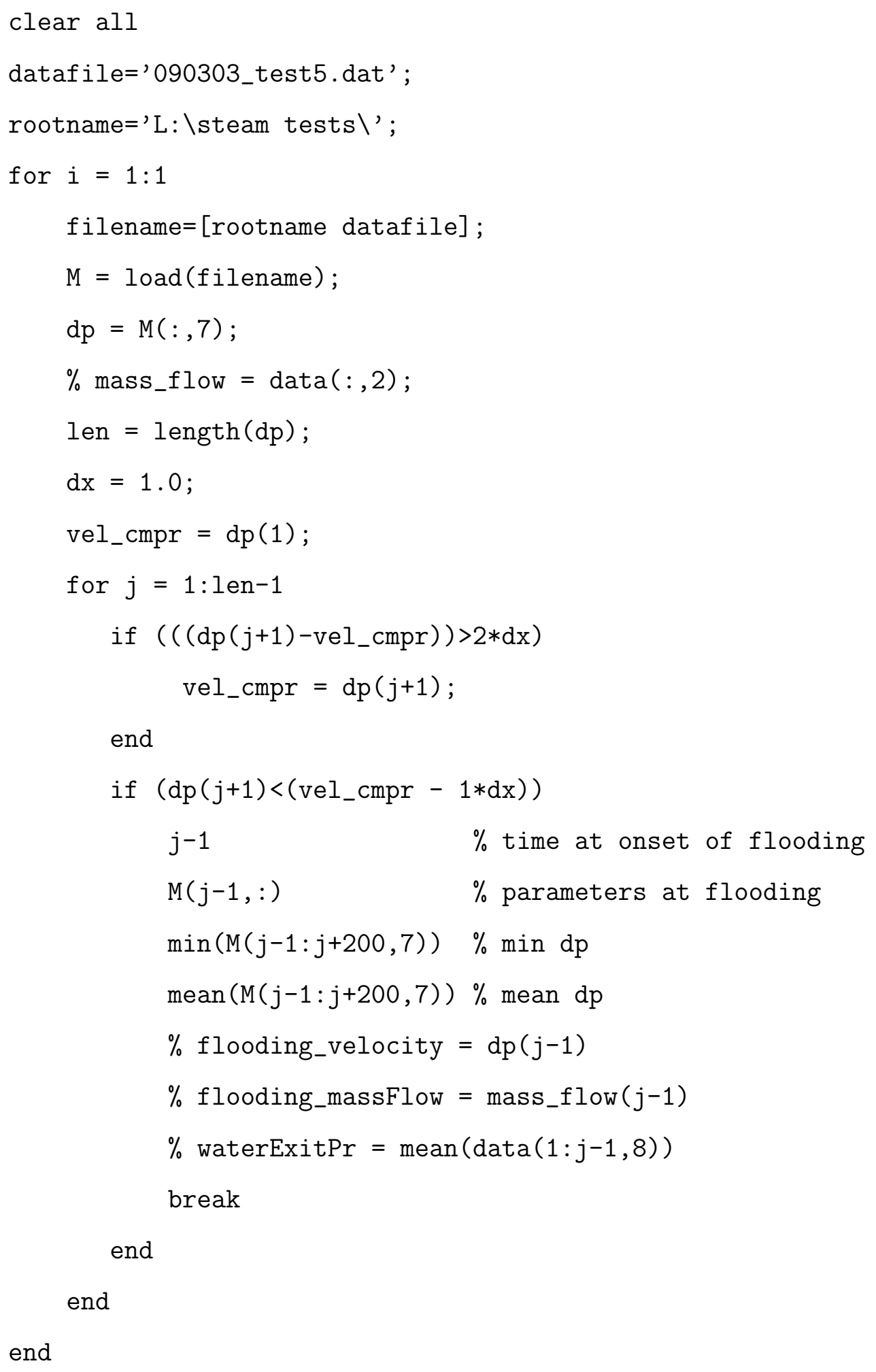


Below is the MATLAB script used to analyze the vortex flowmeter calibration data.

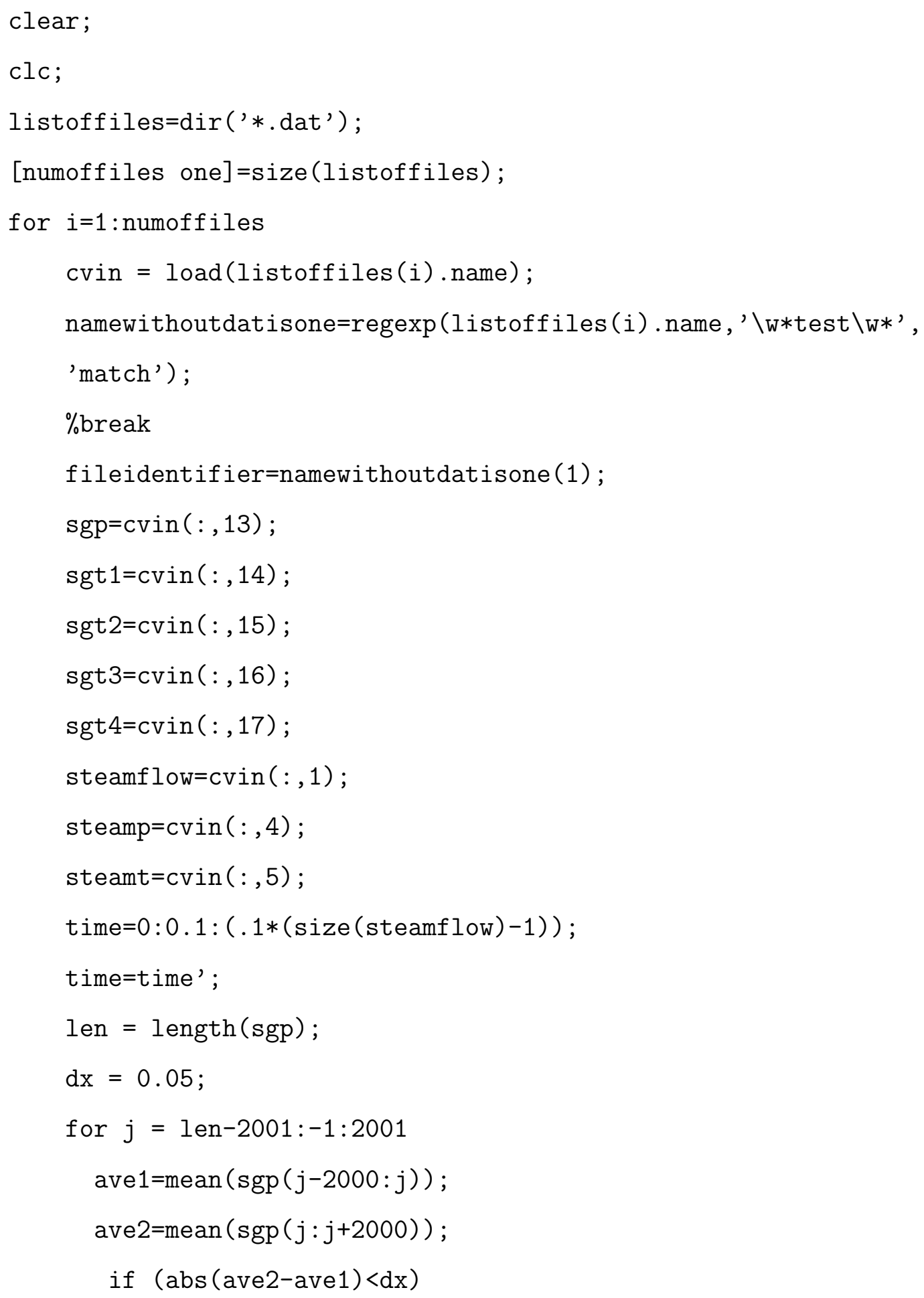




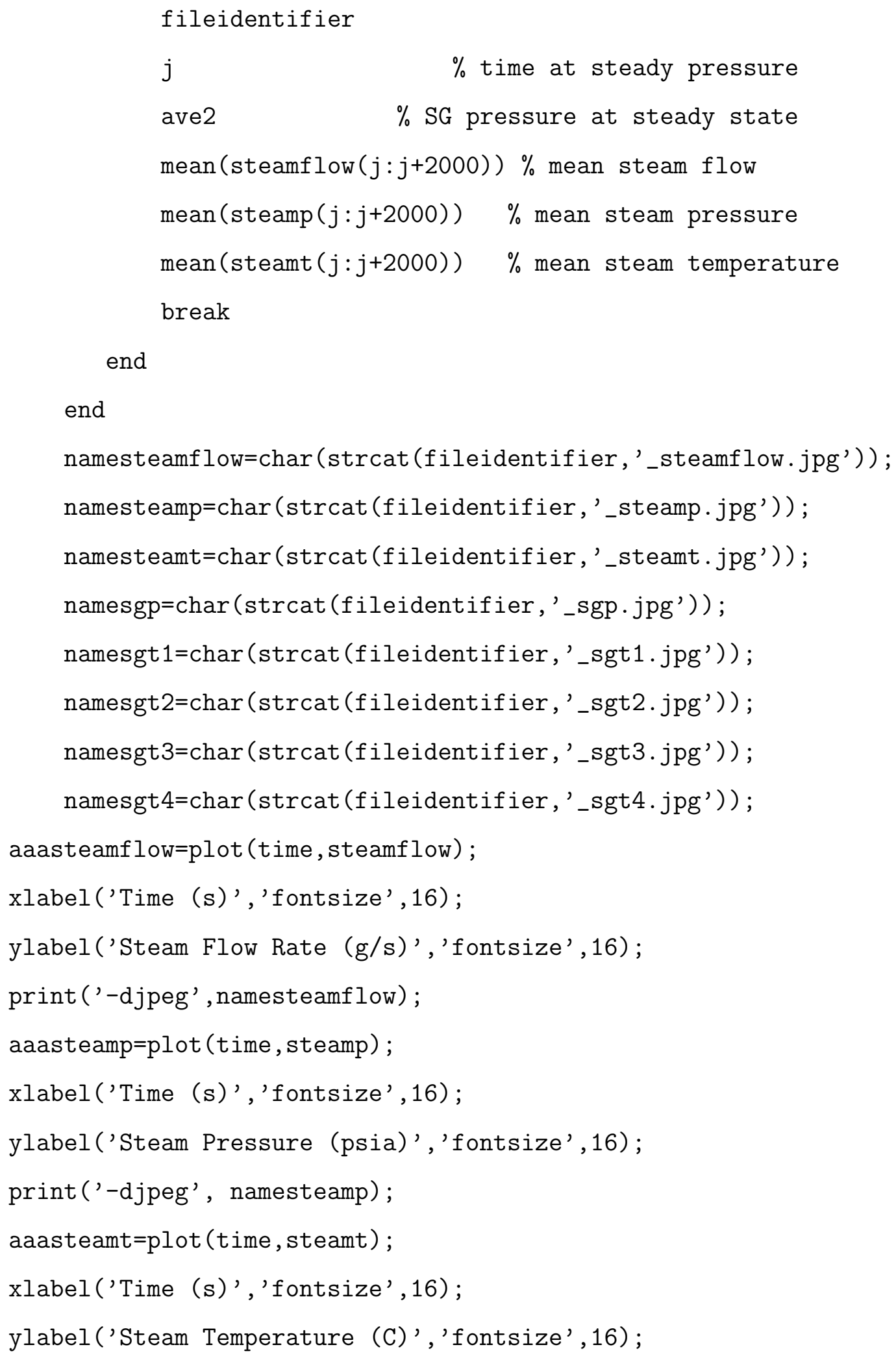




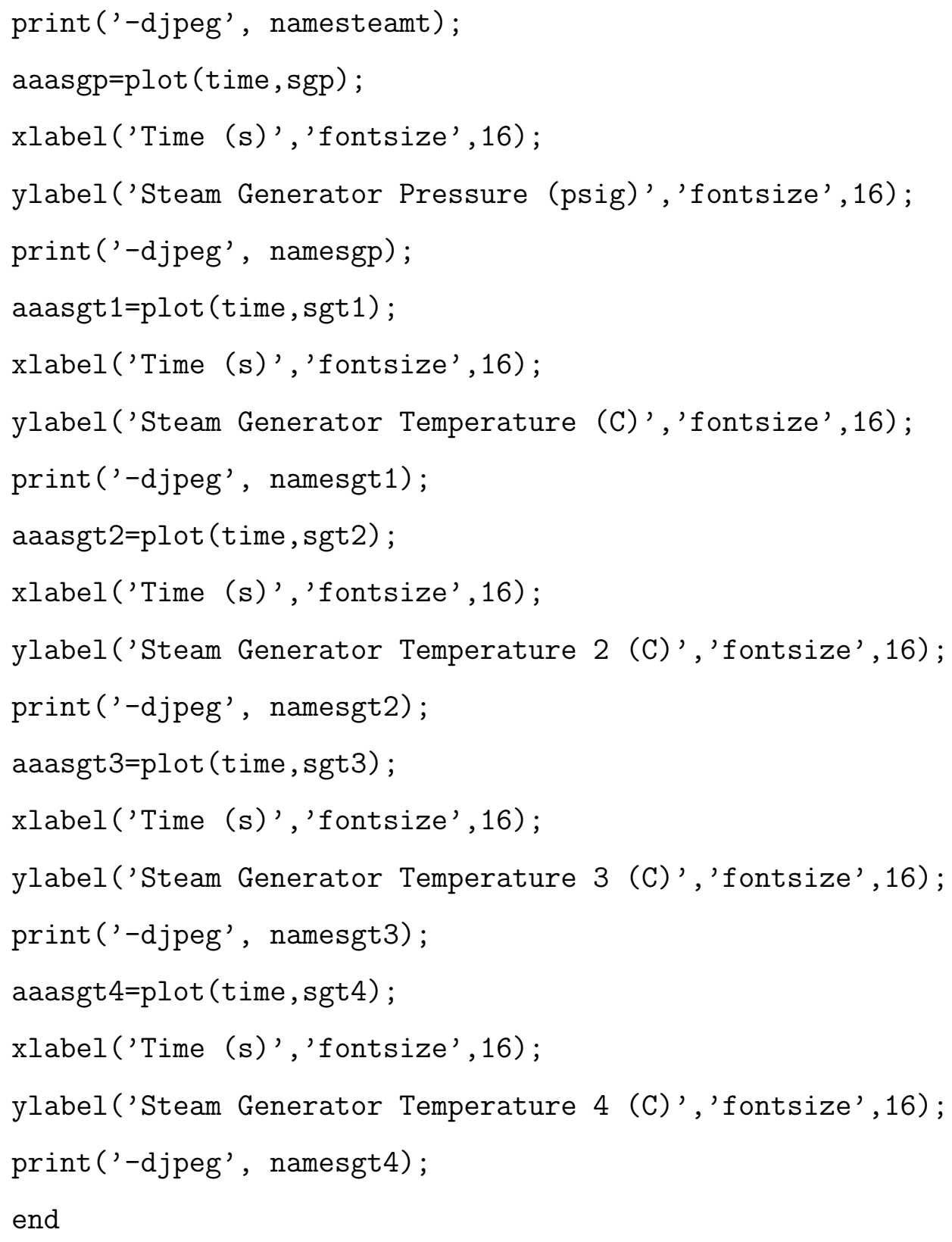




\section{APPENDIX D}

\section{GRAPHICAL DATA}

This appendix contains all of the time dependent data in graphical form for every steam-water test. Each plot has a caption that identifies its test number. This test number corresponds to the number listed in the table in Appendix B.

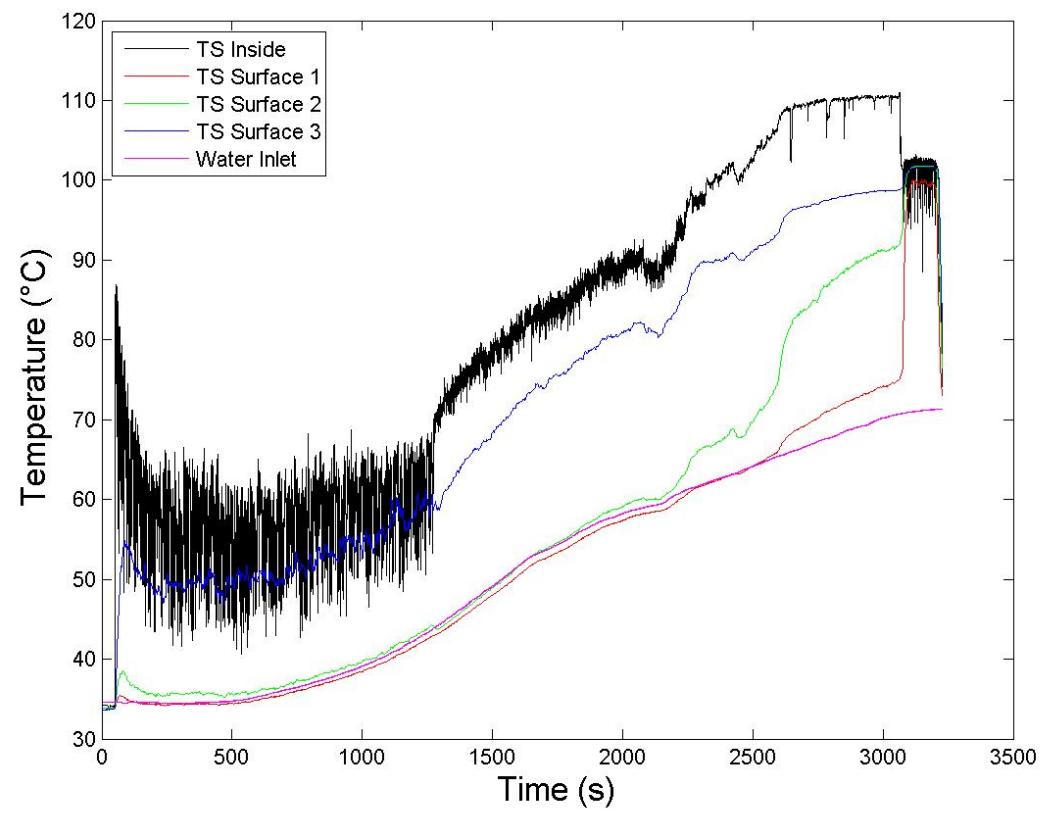

Fig. D.1.: Temperature measurements for Test 1. 


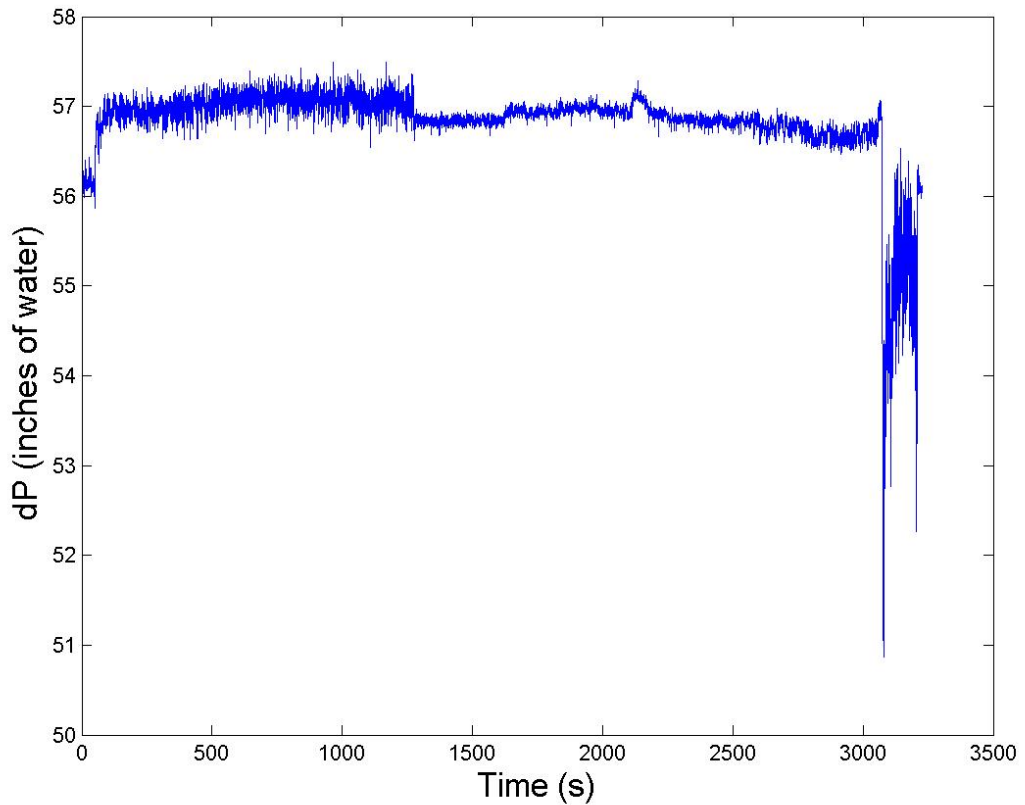

Fig. D.2.: Differential pressure measurements for Test 1.

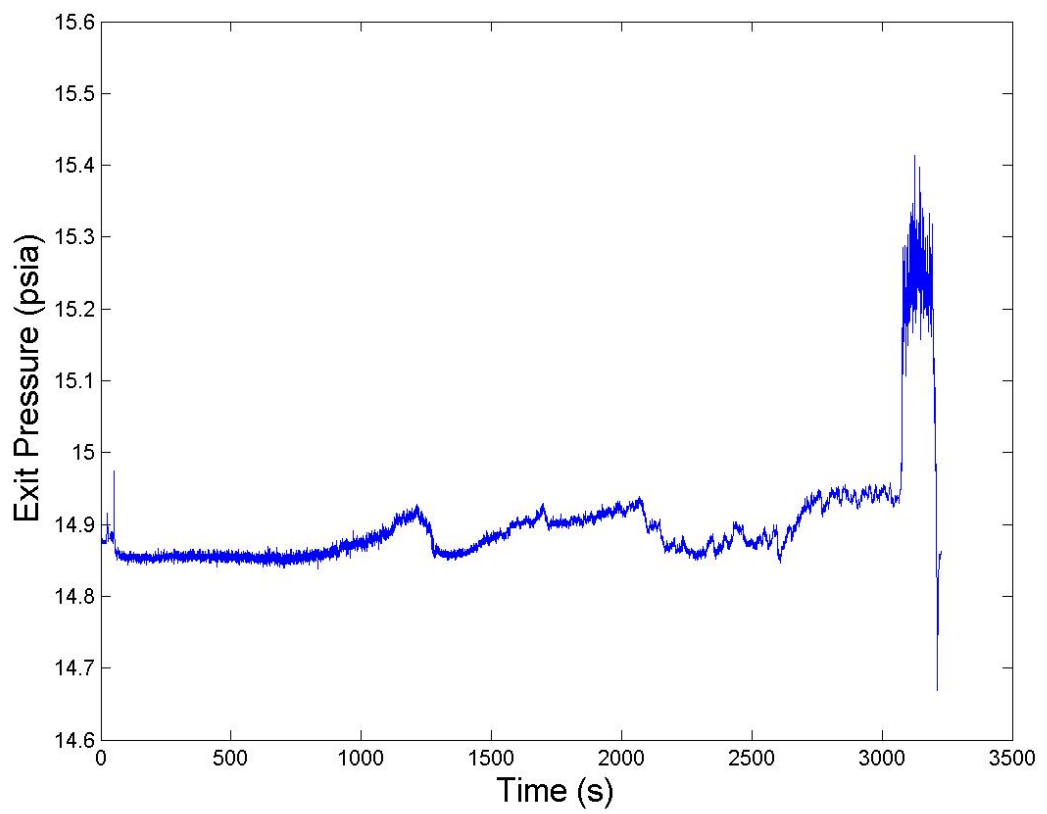

Fig. D.3.: Water exit tank pressure measurements for Test 1. 


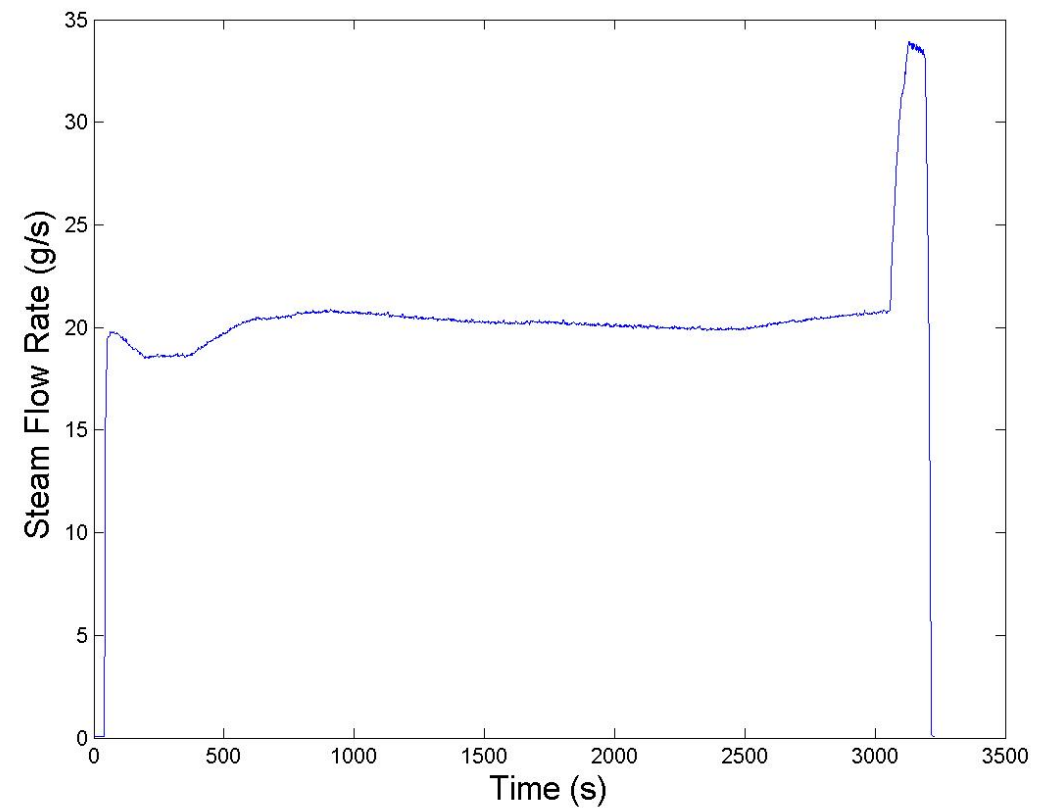

Fig. D.4.: Steam mass flow rate measurements for Test 1.

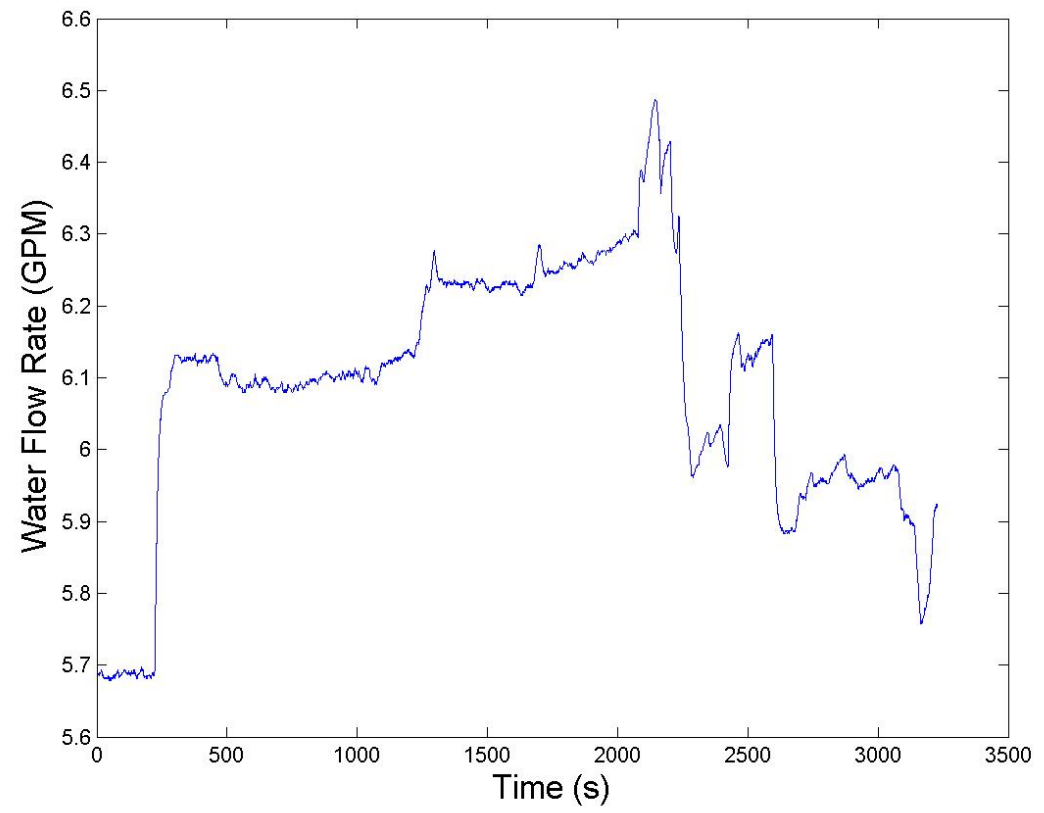

Fig. D.5.: Water flow rate measurements for Test 1. 


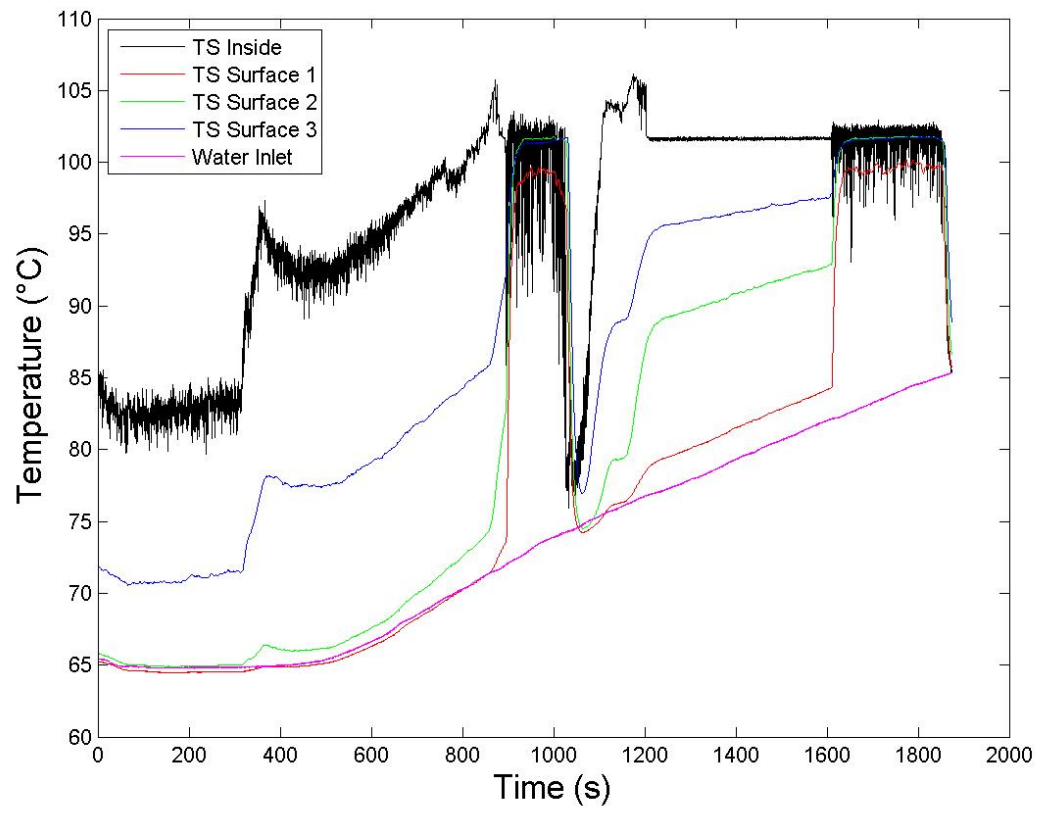

Fig. D.6.: Temperature measurements for Test 2.

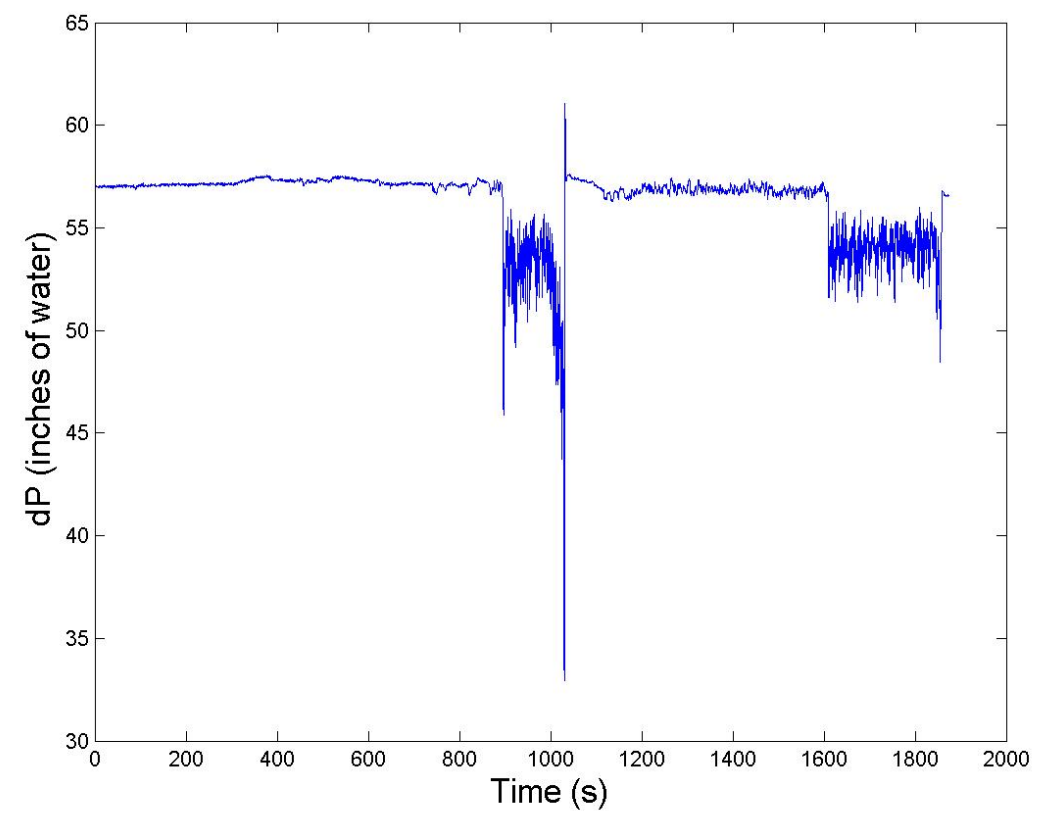

Fig. D.7.: Differential pressure measurements for Test 2. 


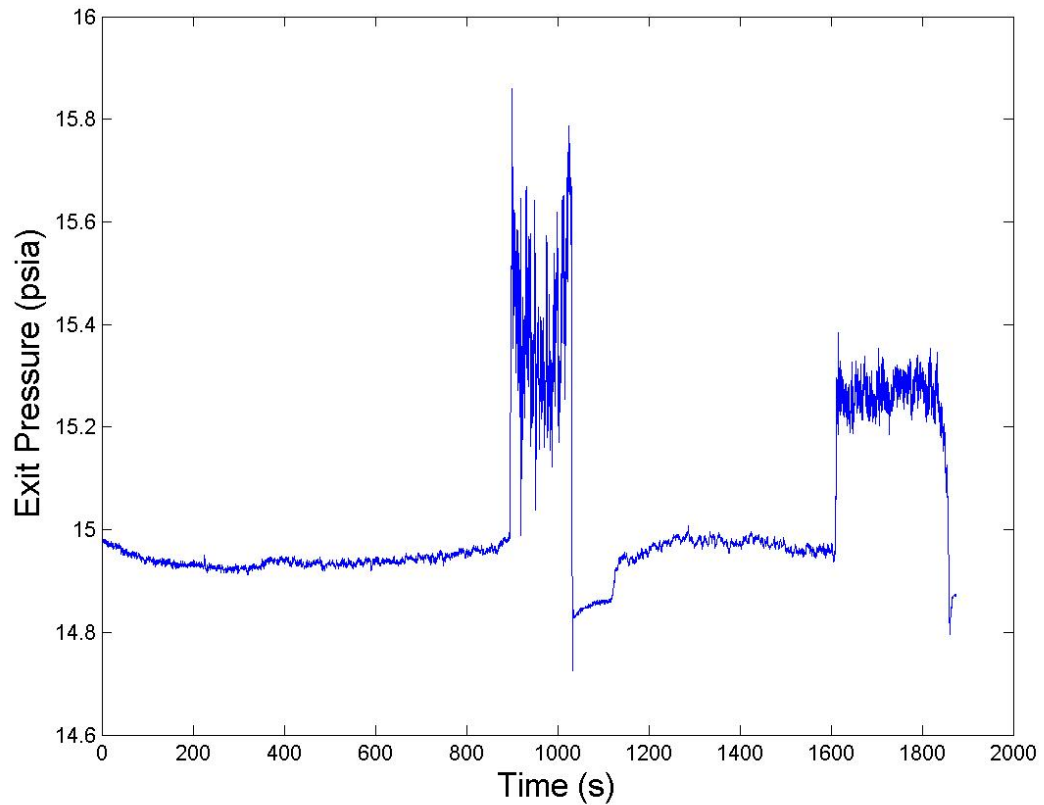

Fig. D.8.: Water exit tank pressure measurements for Test 2.

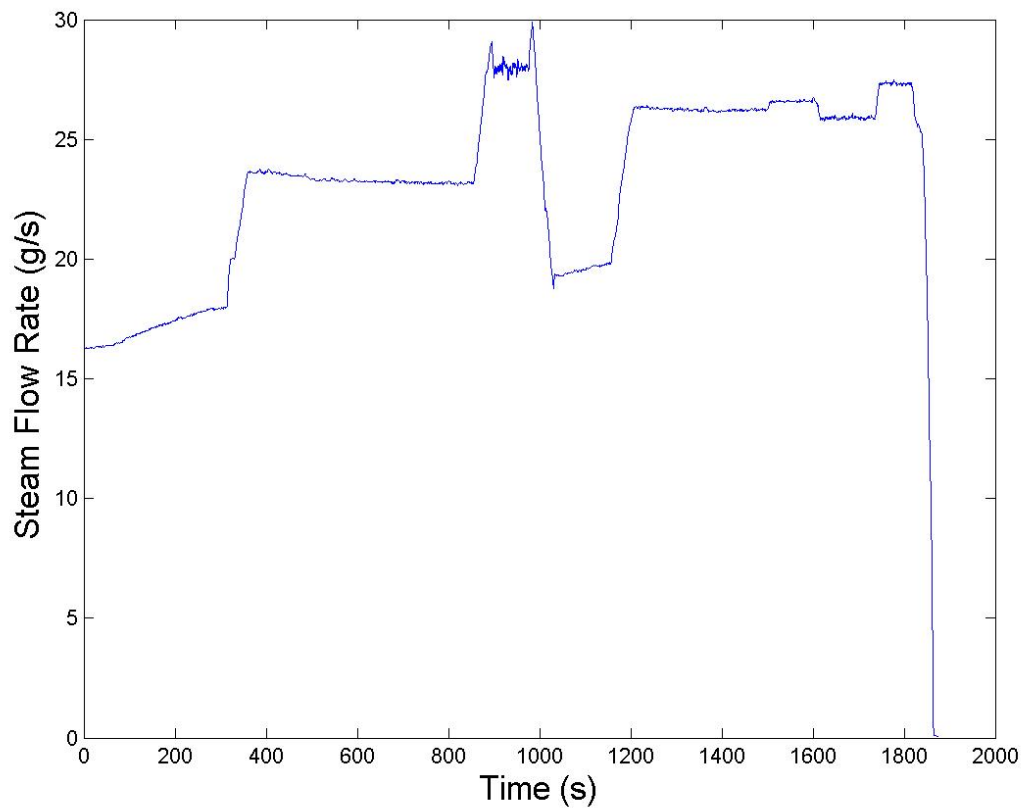

Fig. D.9.: Steam mass flow rate measurements for Test 2. 


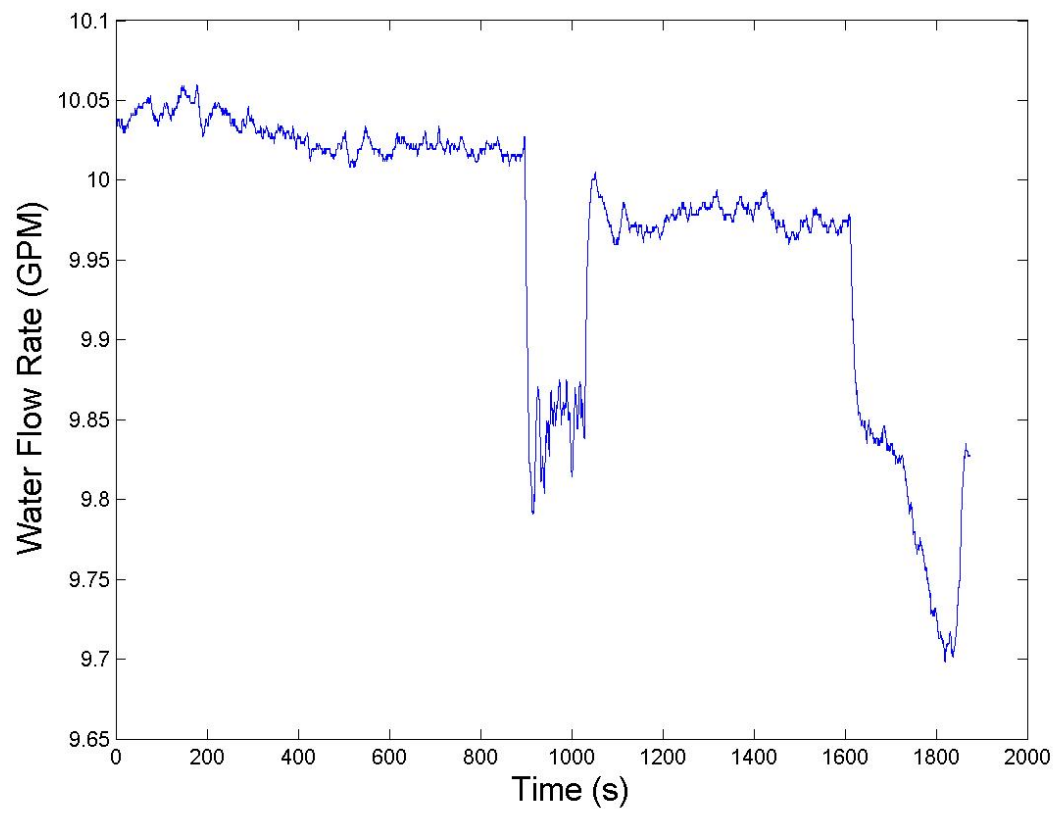

Fig. D.10.: Water flow rate measurements for Test 2.

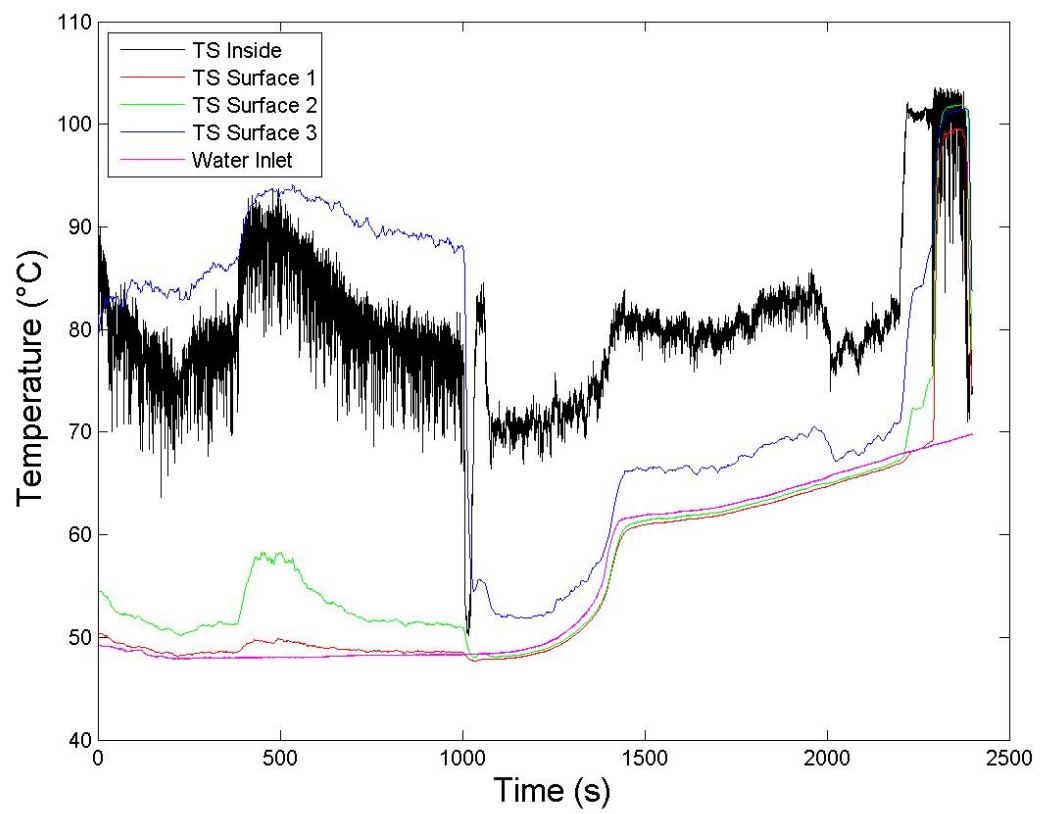

Fig. D.11.: Temperature measurements for Test 3. 


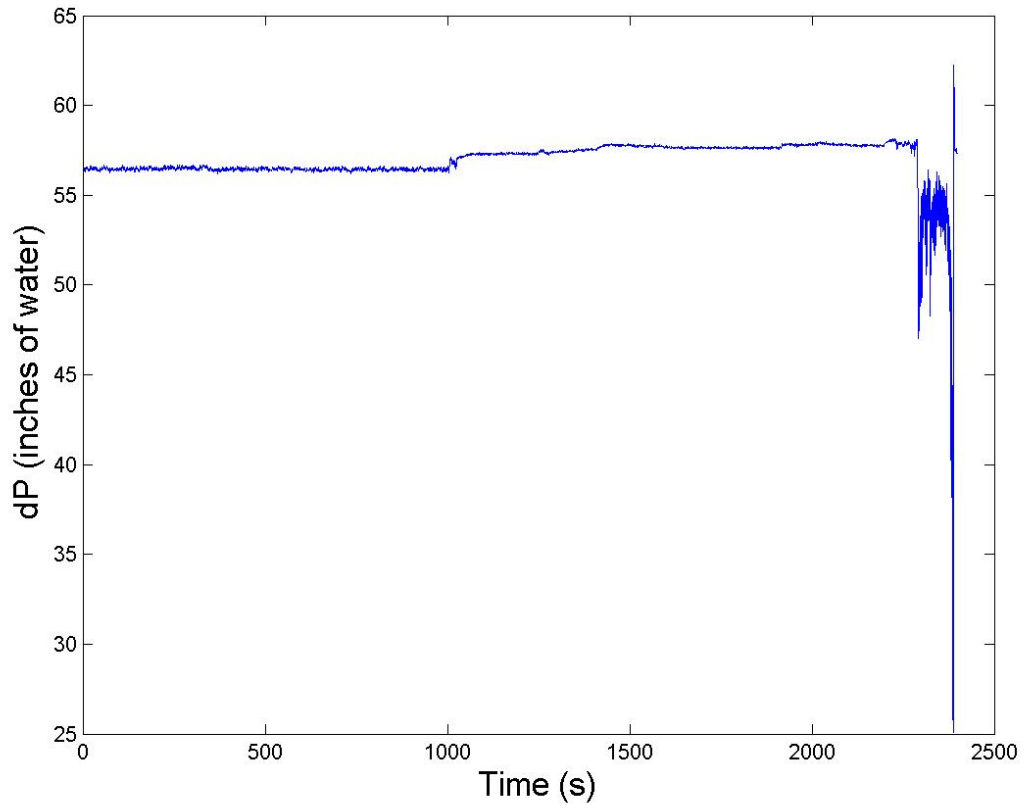

Fig. D.12.: Differential pressure measurements for Test 3.

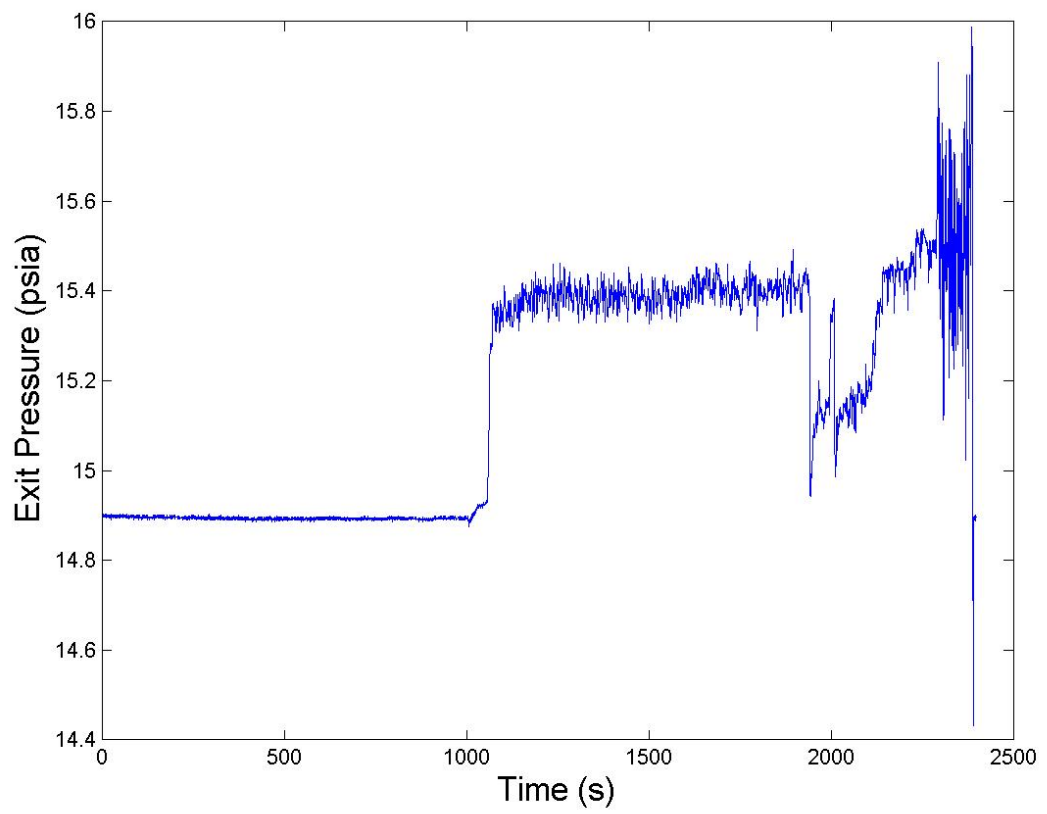

Fig. D.13.: Water exit tank pressure measurements for Test 3. 


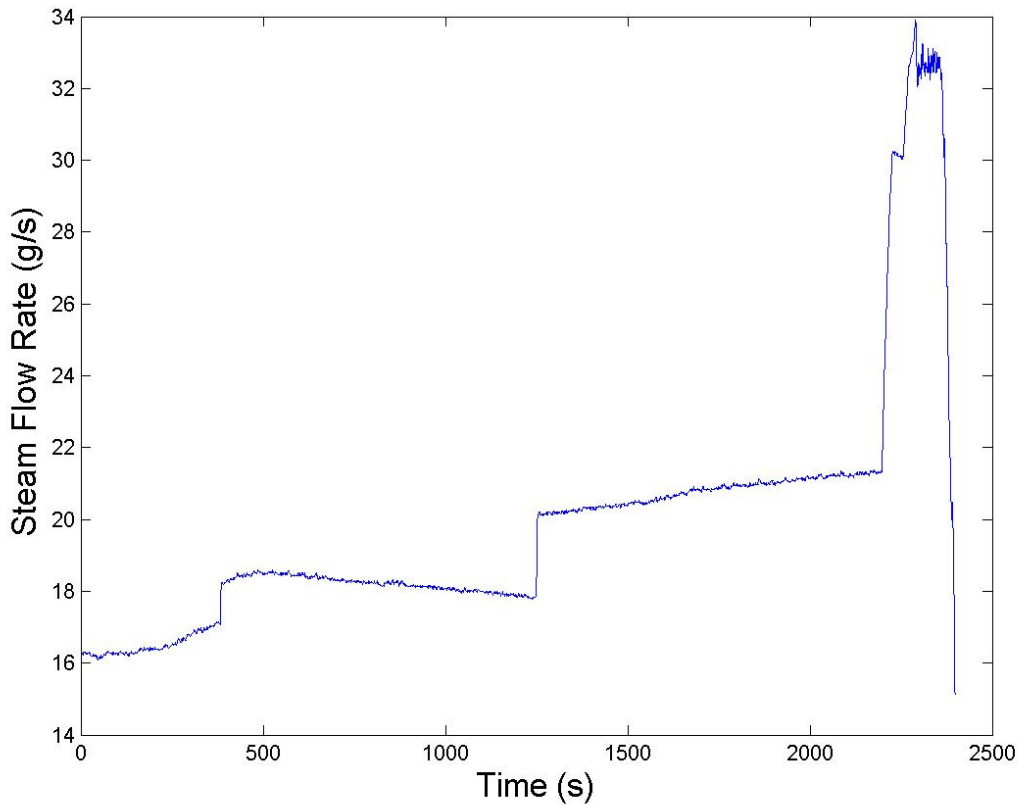

Fig. D.14.: Steam mass flow rate measurements for Test 3.

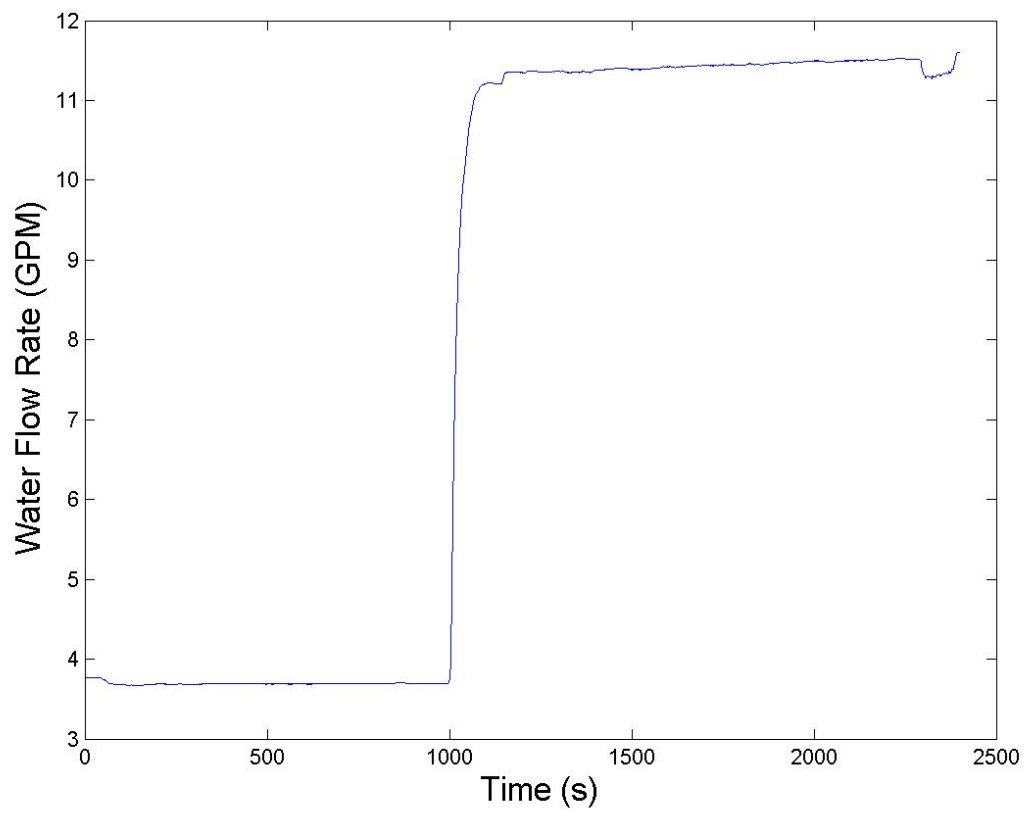

Fig. D.15.: Water flow rate measurements for Test 3. 


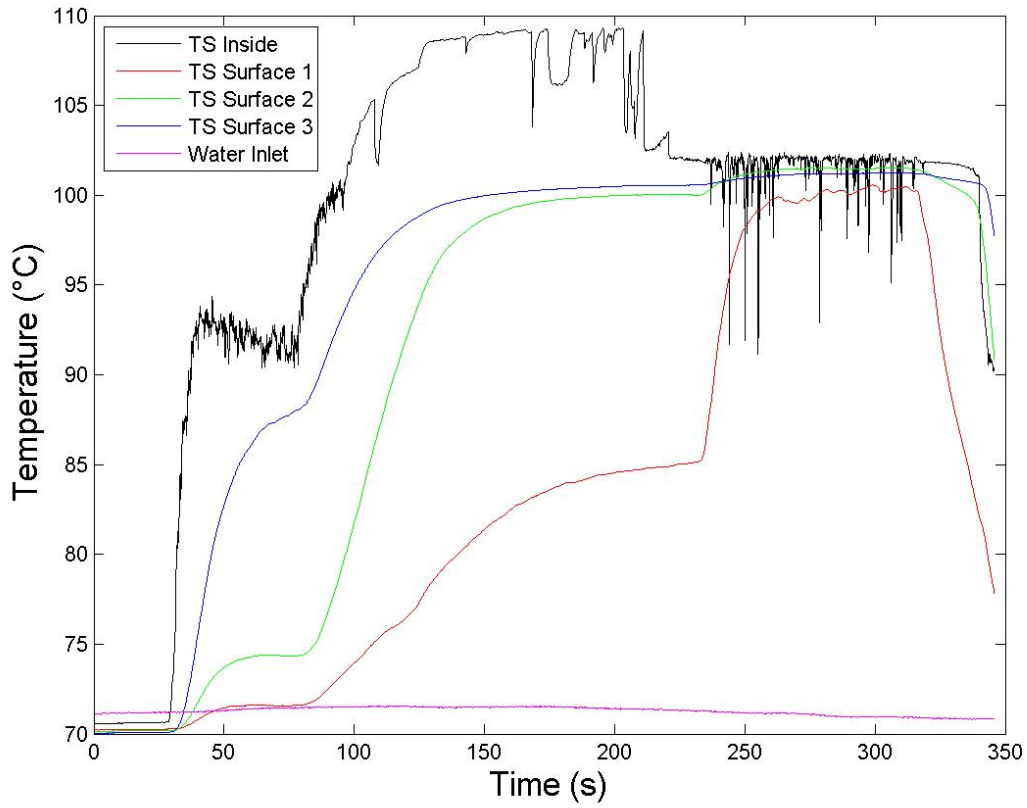

Fig. D.16.: Temperature measurements for Test 4 .

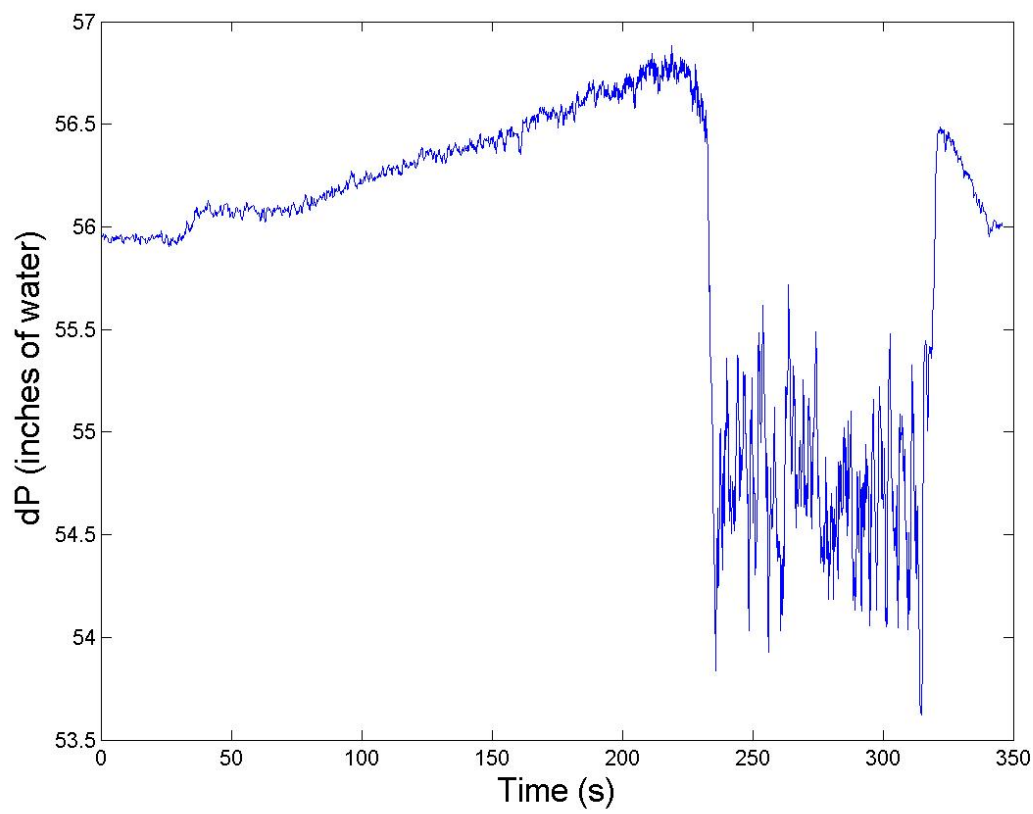

Fig. D.17.: Differential pressure measurements for Test 4. 


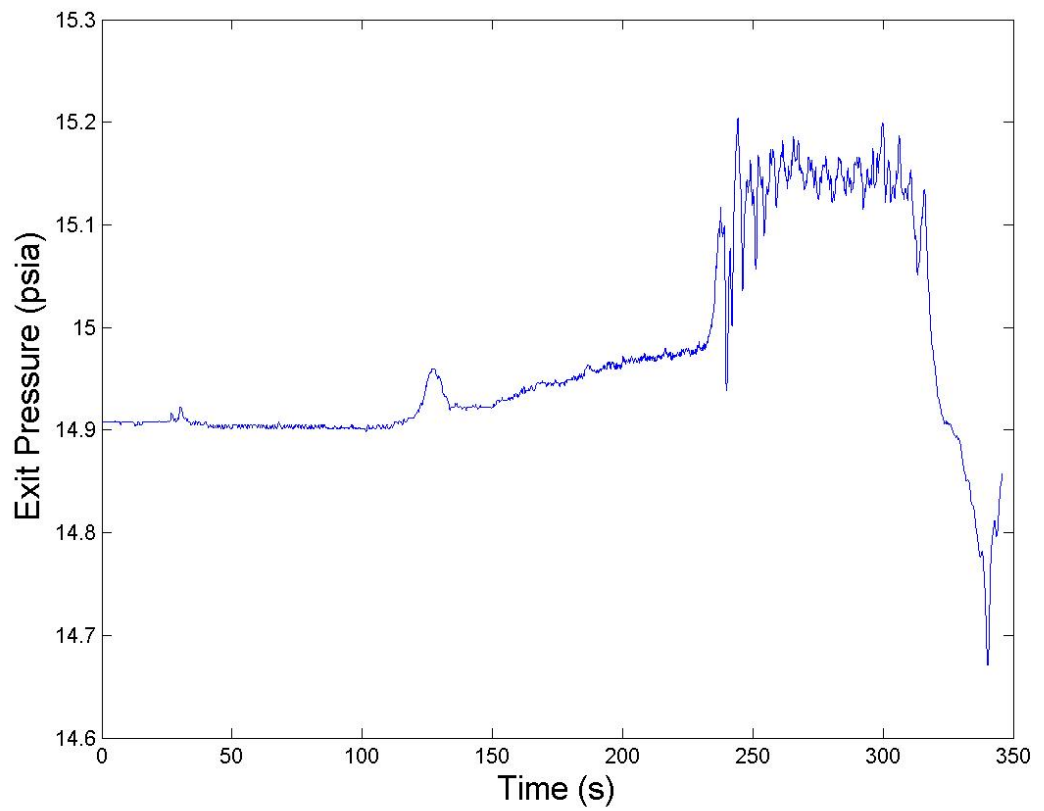

Fig. D.18.: Water exit tank pressure measurements for Test 4.

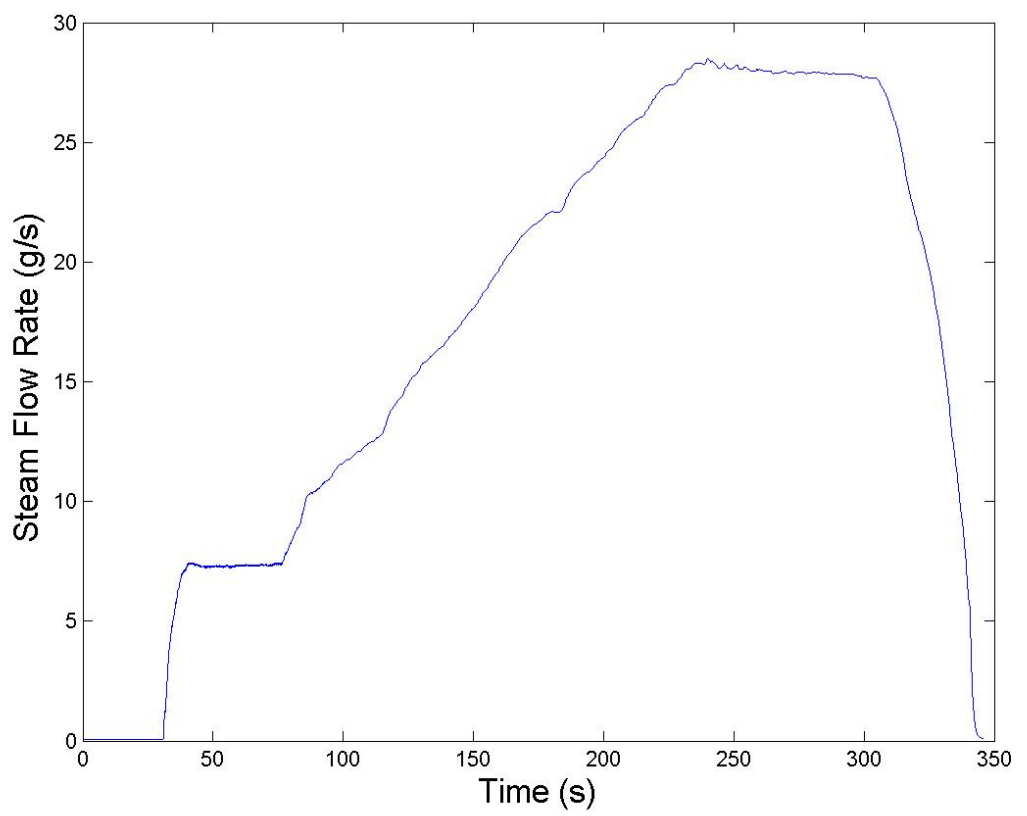

Fig. D.19.: Steam mass flow rate measurements for Test 4. 


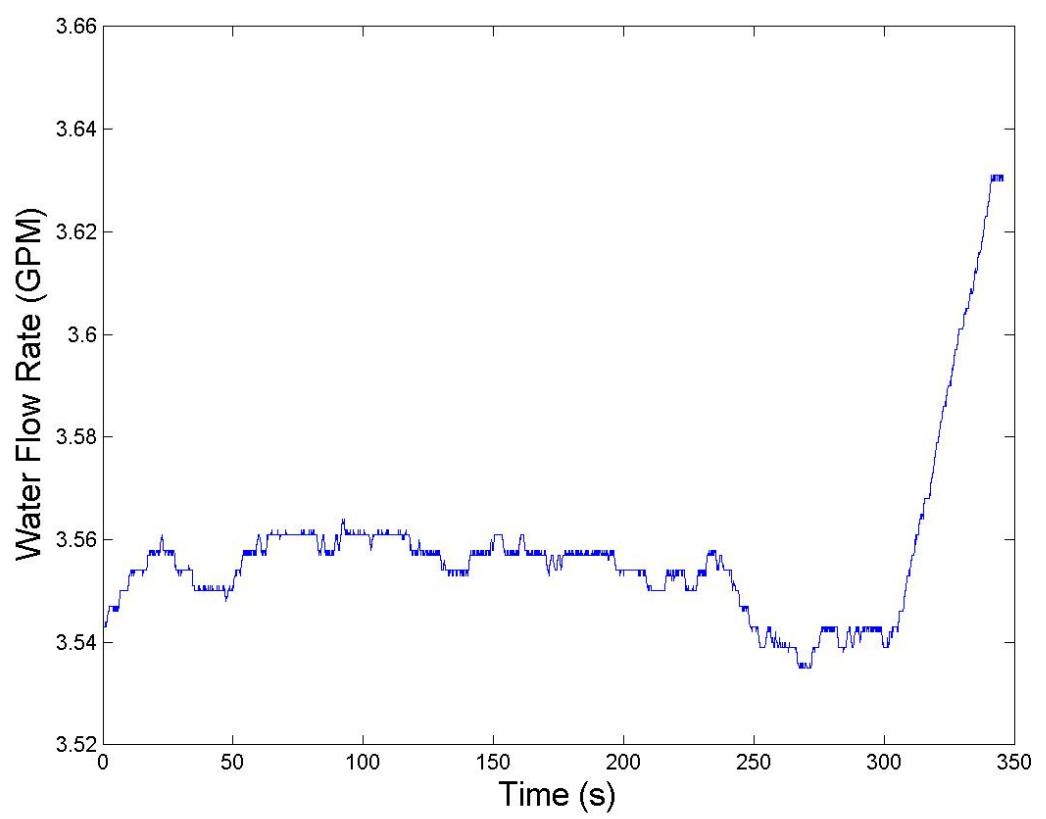

Fig. D.20.: Water flow rate measurements for Test 4.

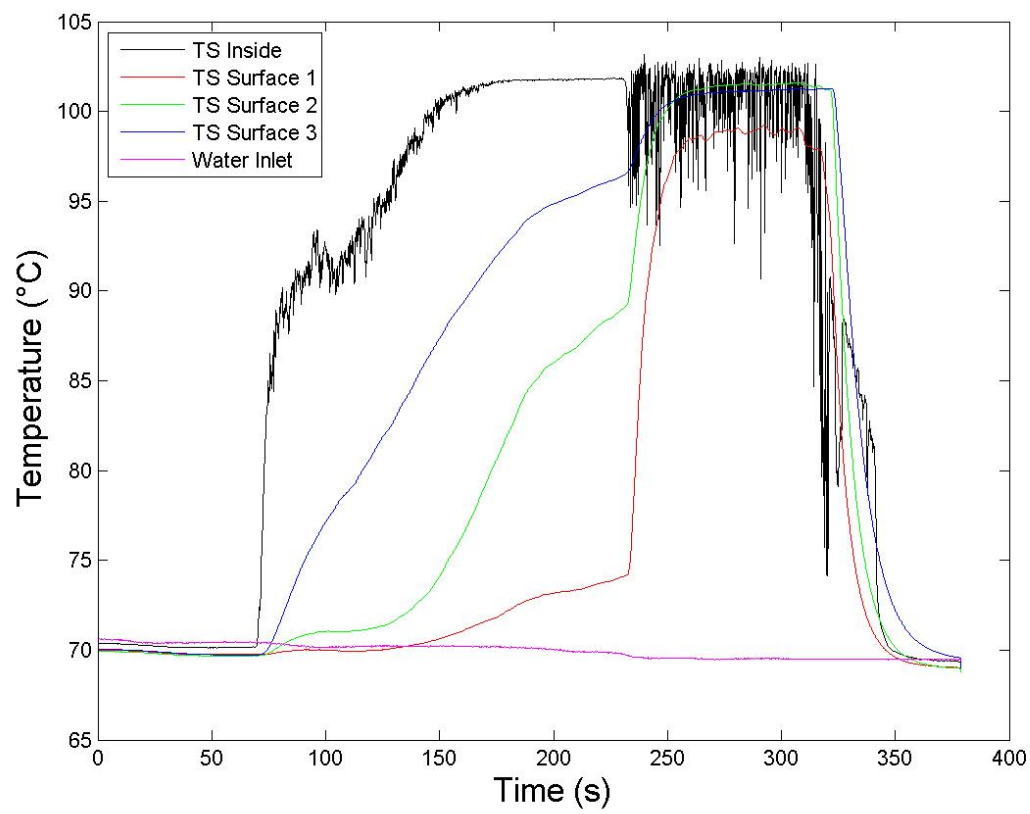

Fig. D.21.: Temperature measurements for Test 5 . 


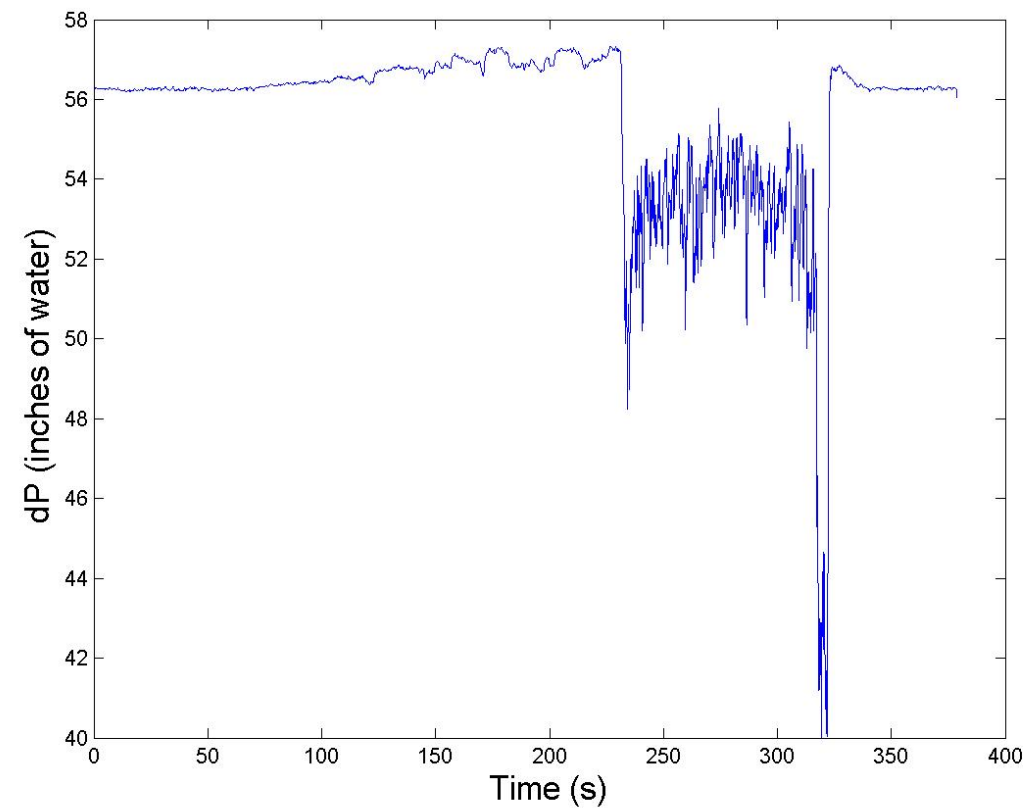

Fig. D.22.: Differential pressure measurements for Test 5.

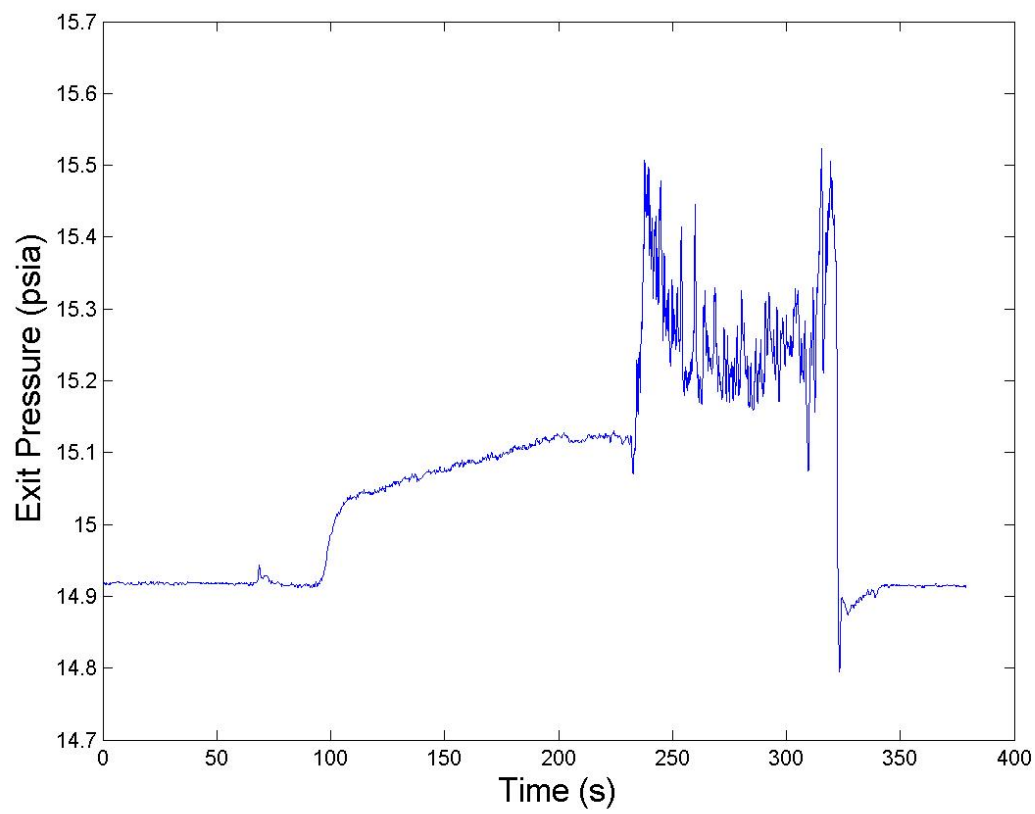

Fig. D.23.: Water exit tank pressure measurements for Test 5. 


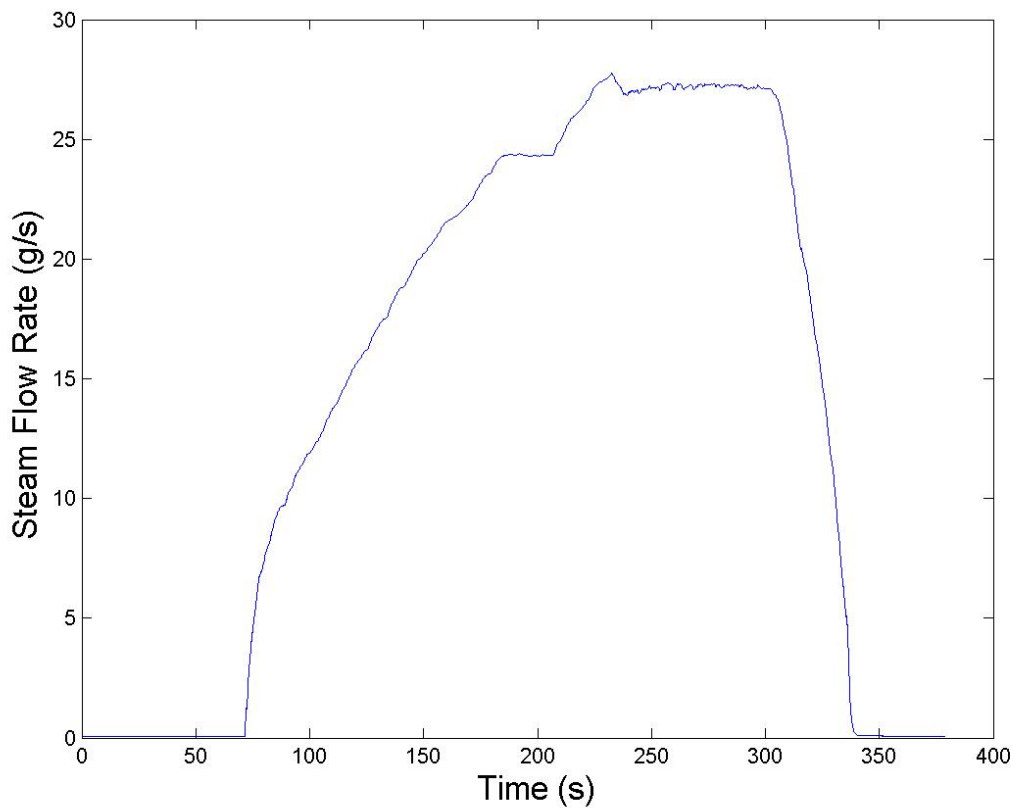

Fig. D.24.: Steam mass flow rate measurements for Test 5.

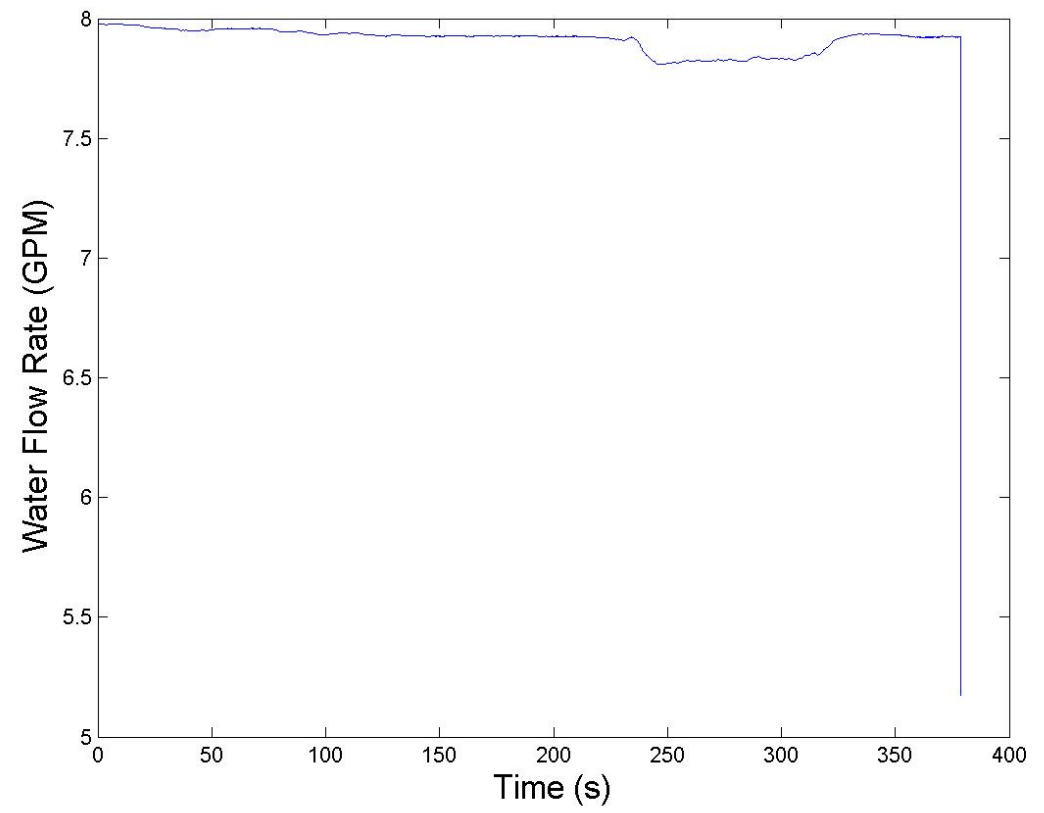

Fig. D.25.: Water flow rate measurements for Test 5. 


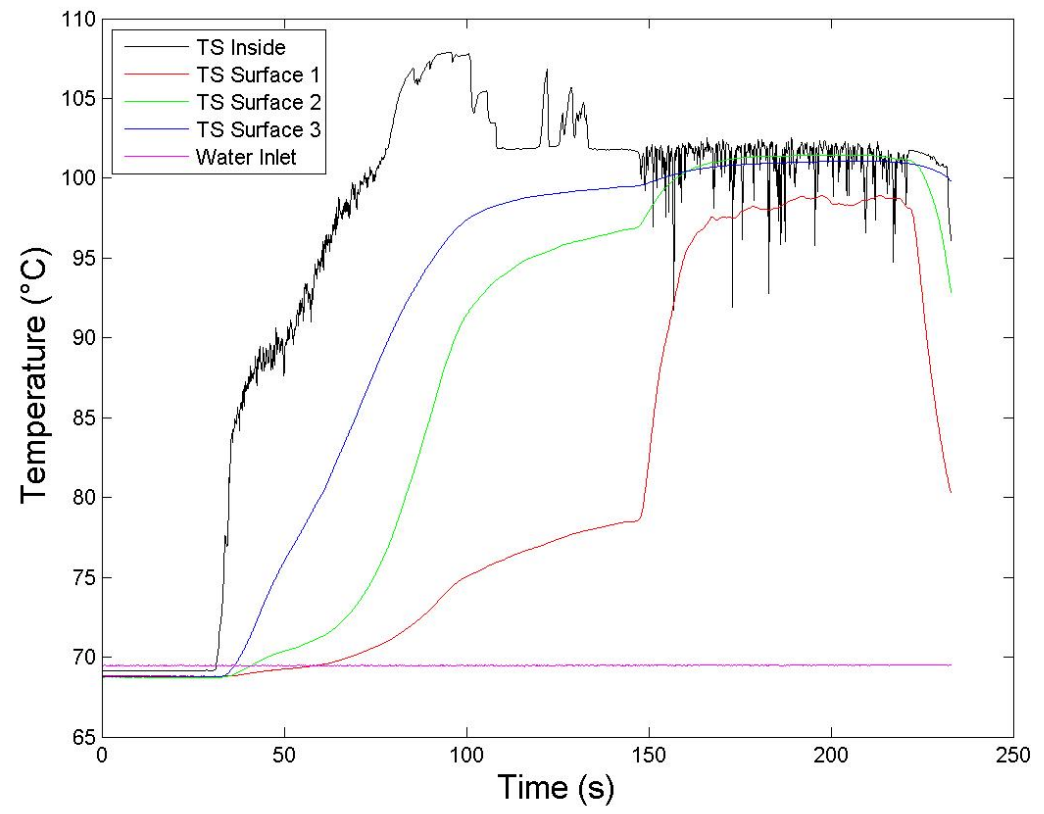

Fig. D.26.: Temperature measurements for Test 6 .

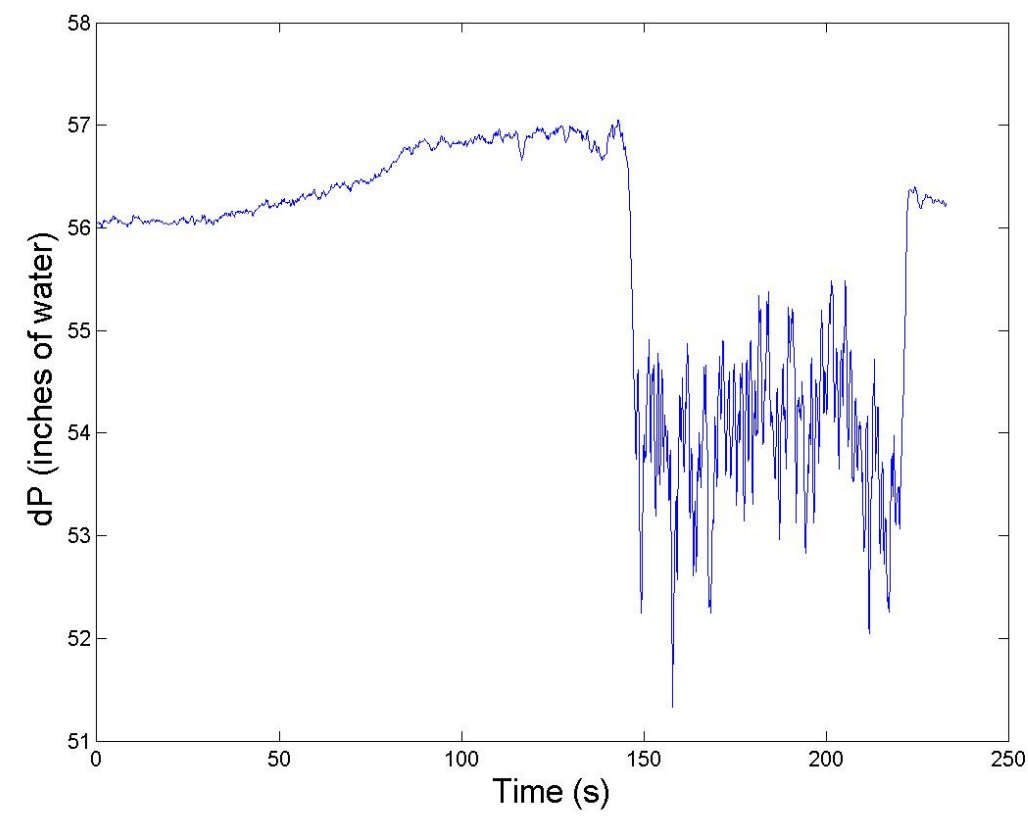

Fig. D.27.: Differential pressure measurements for Test 6 . 


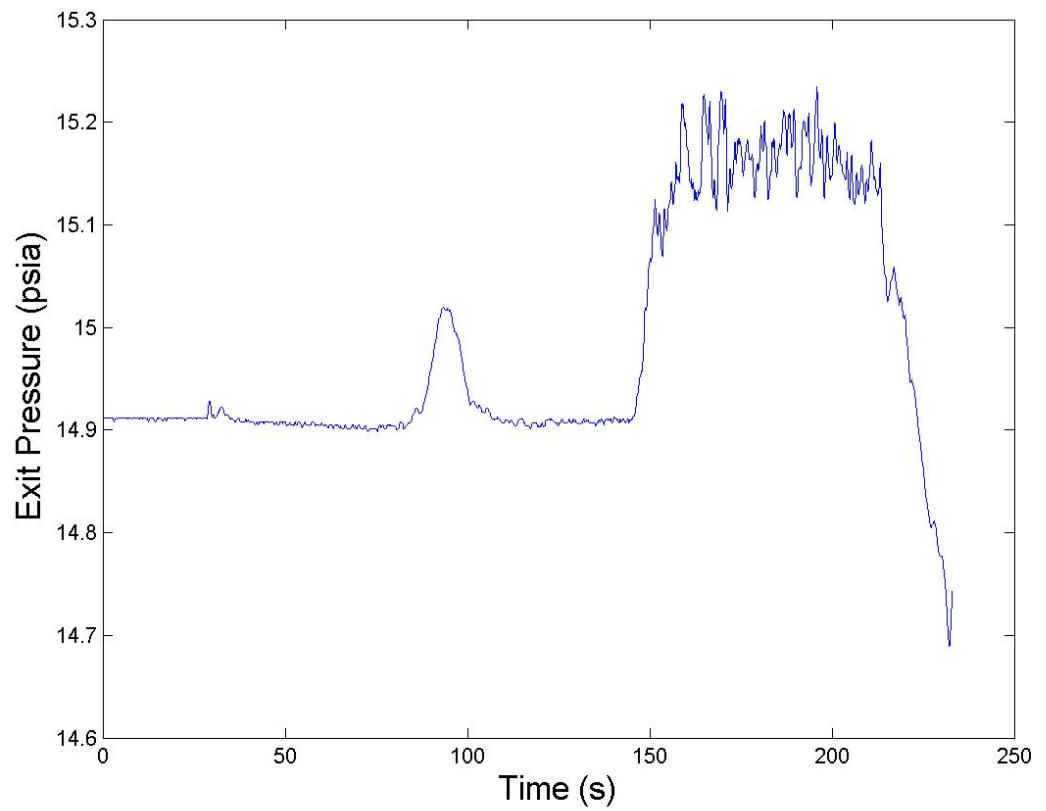

Fig. D.28.: Water exit tank pressure measurements for Test 6 .

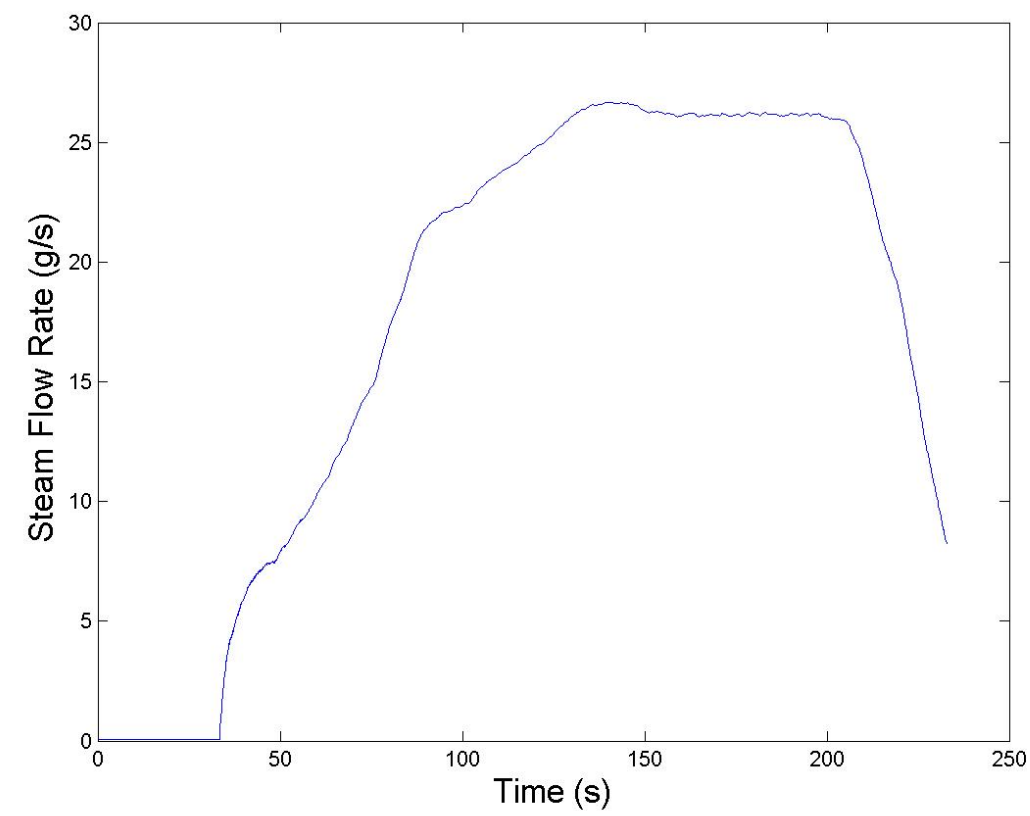

Fig. D.29.: Steam mass flow rate measurements for Test 6 . 


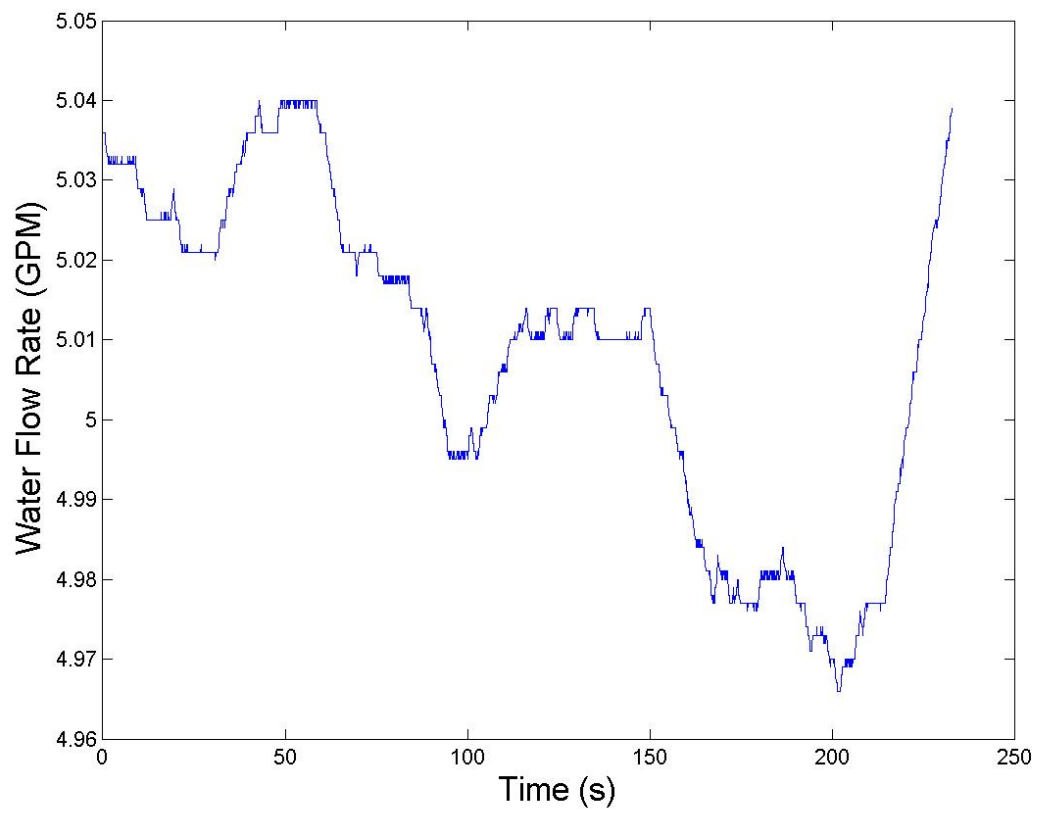

Fig. D.30.: Water flow rate measurements for Test 6 .

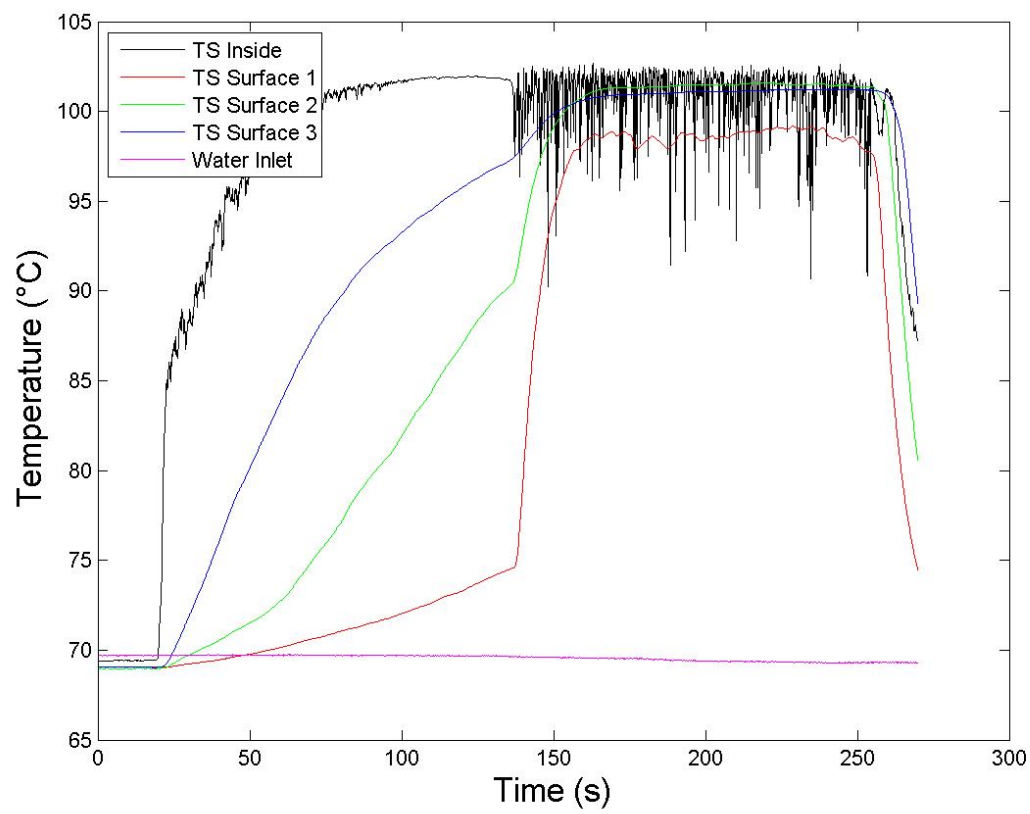

Fig. D.31.: Temperature measurements for Test 7. 


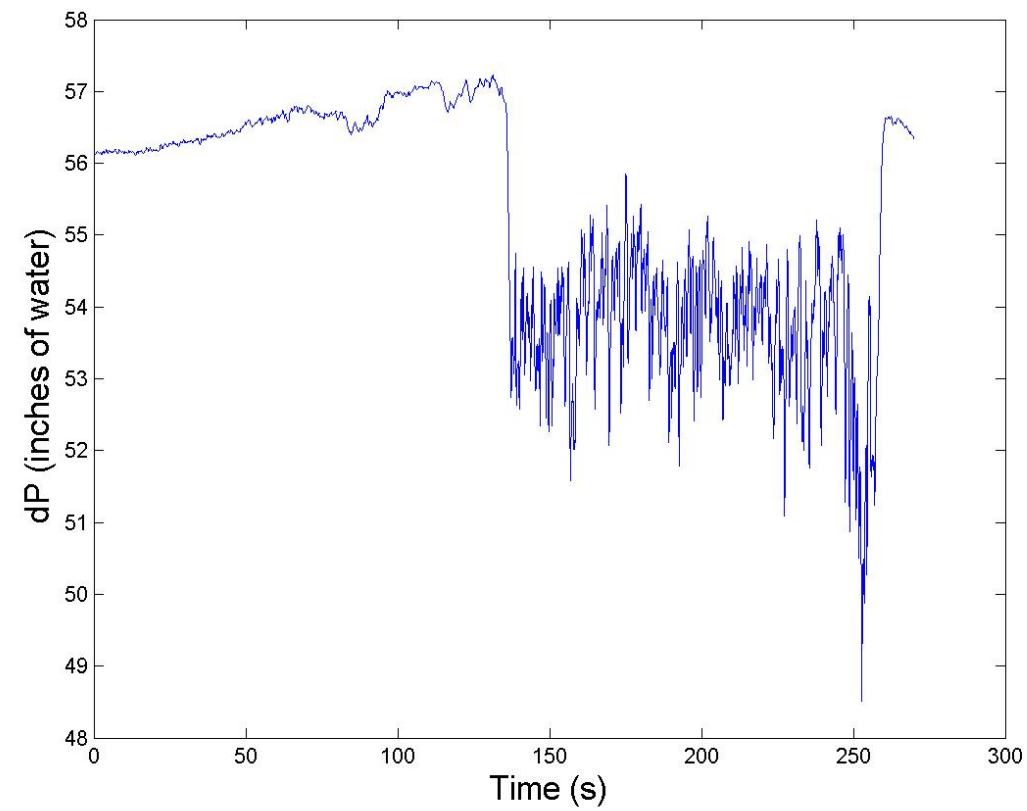

Fig. D.32.: Differential pressure measurements for Test 7.

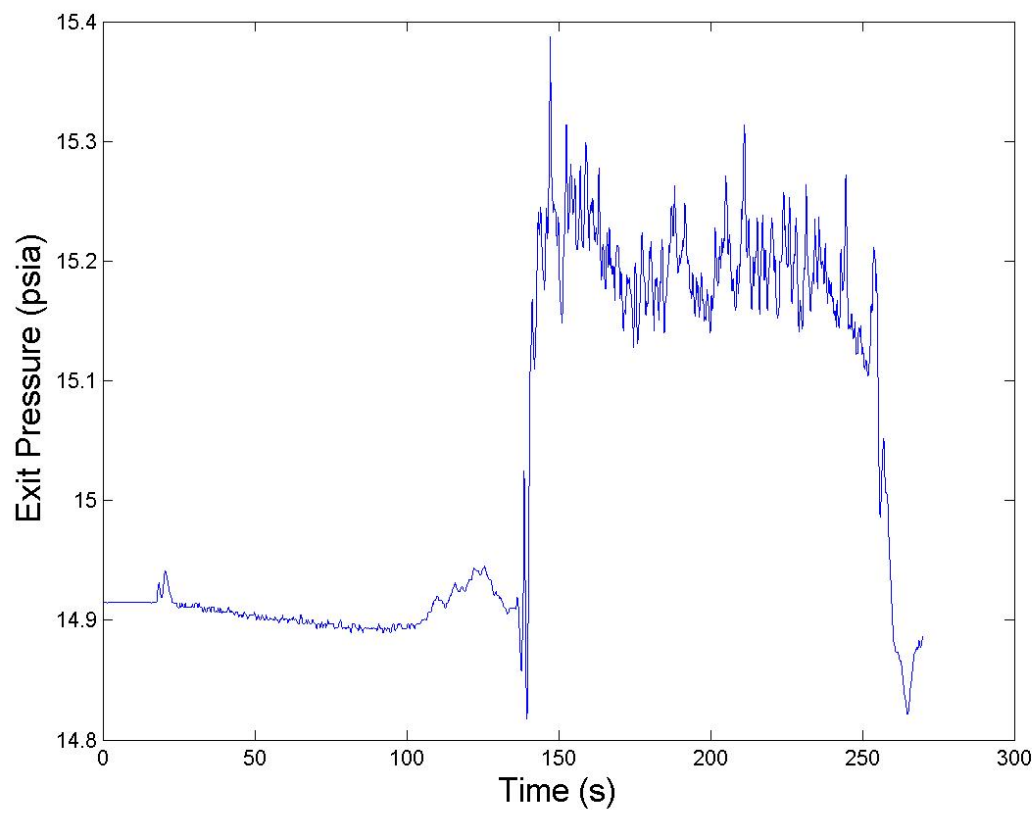

Fig. D.33.: Water exit tank pressure measurements for Test 7. 


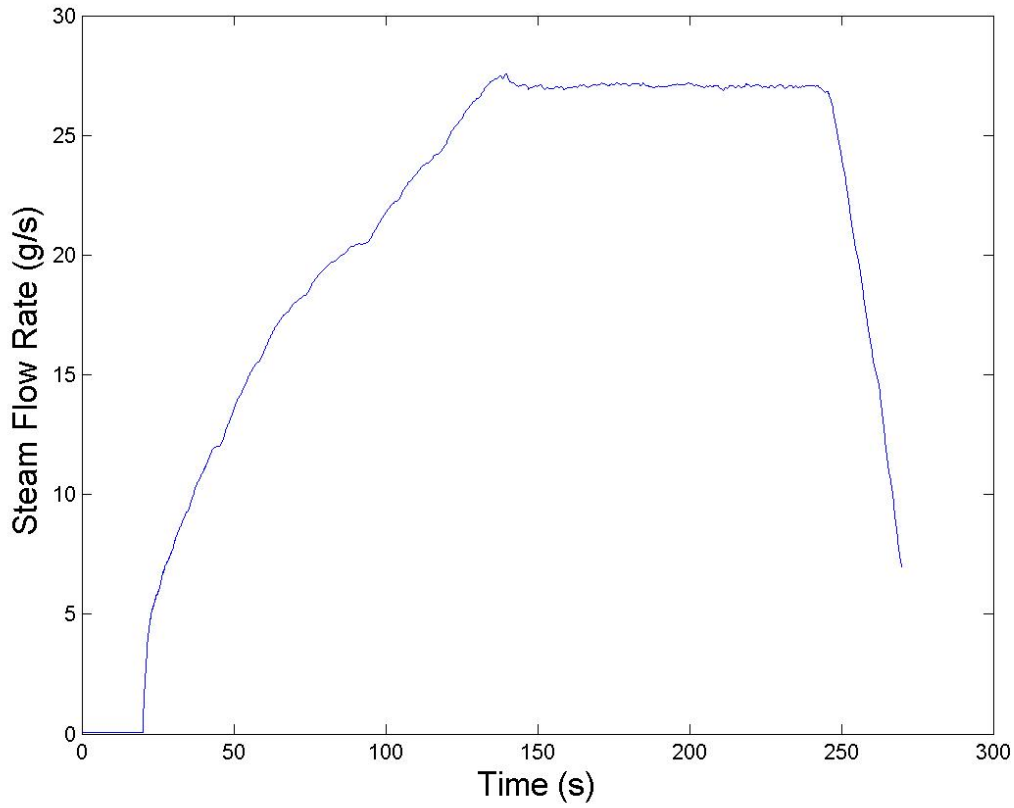

Fig. D.34.: Steam mass flow rate measurements for Test 7.

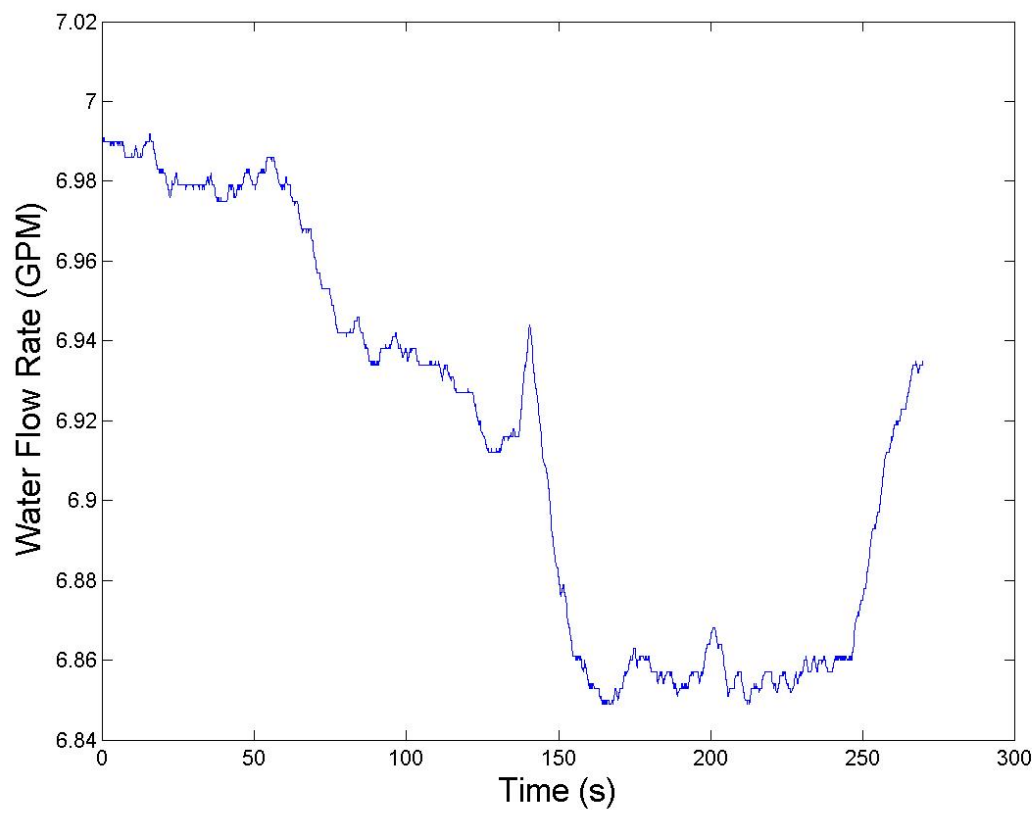

Fig. D.35.: Water flow rate measurements for Test 7. 


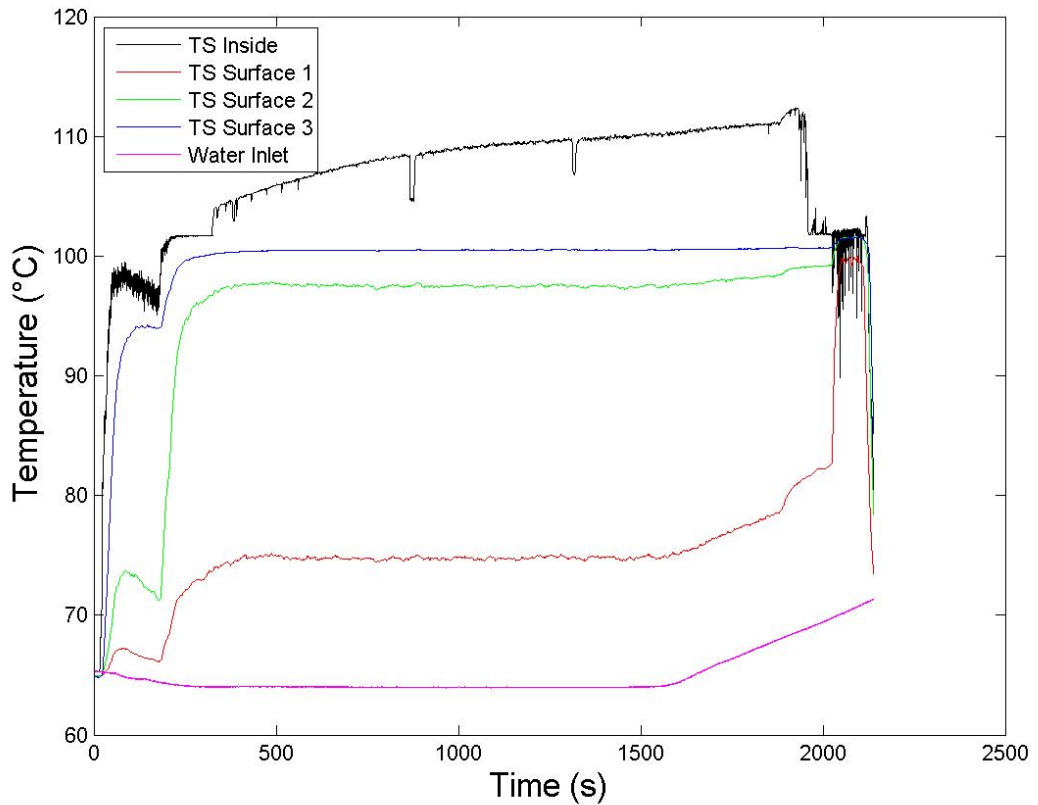

Fig. D.36.: Temperature measurements for Test 8 .

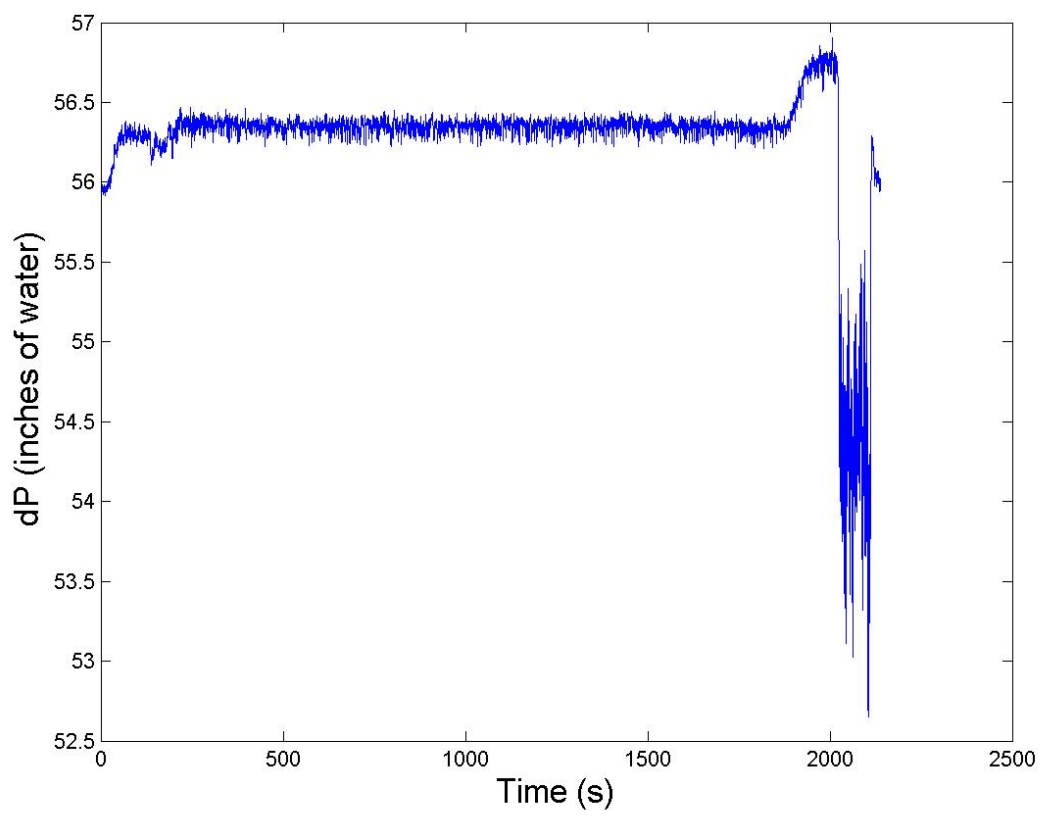

Fig. D.37.: Differential pressure measurements for Test 8. 


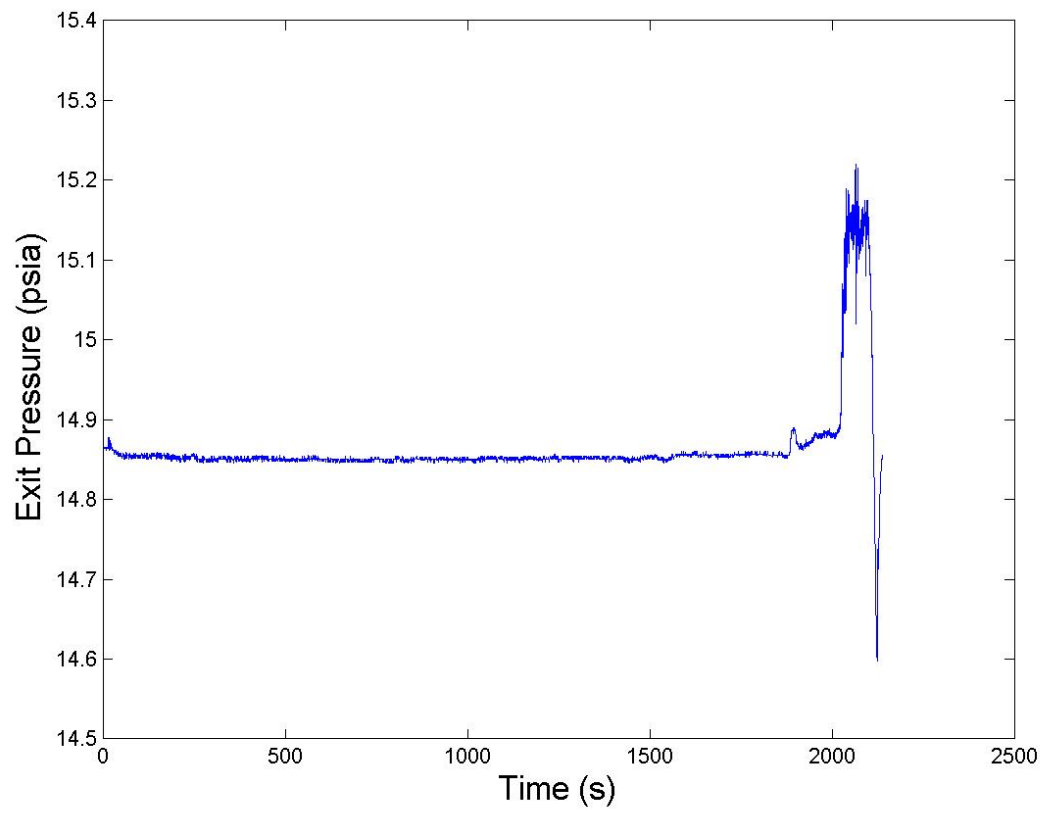

Fig. D.38.: Water exit tank pressure measurements for Test 8.

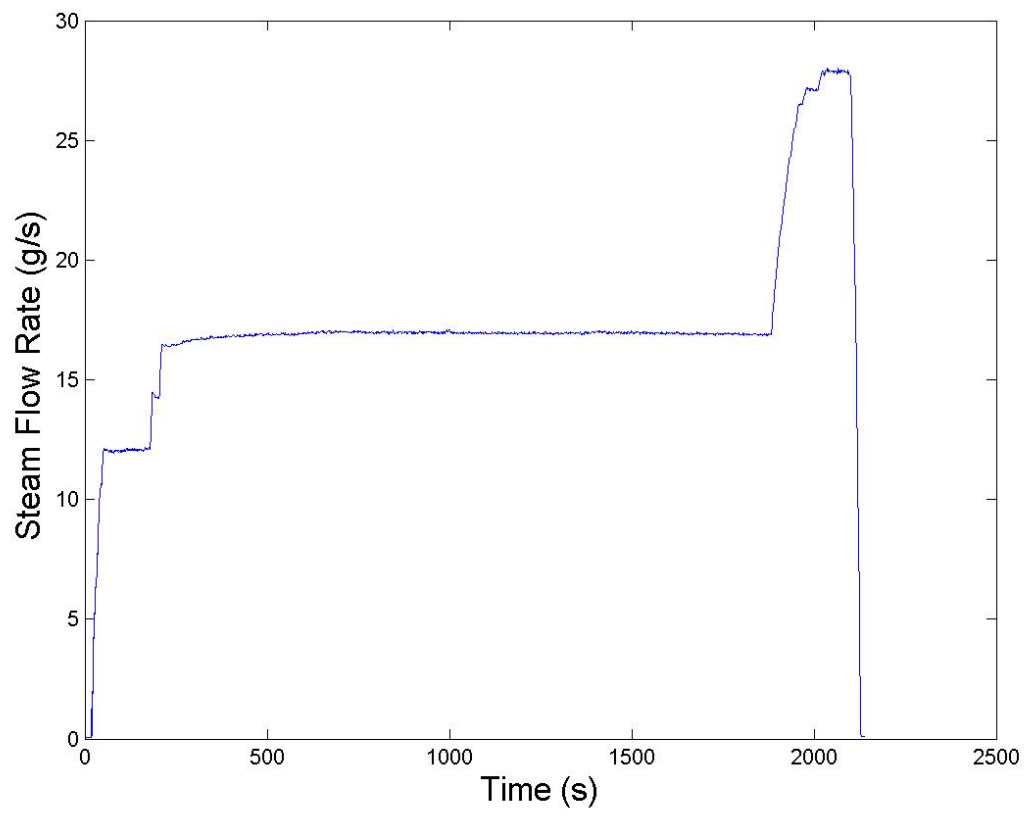

Fig. D.39.: Steam mass flow rate measurements for Test 8. 


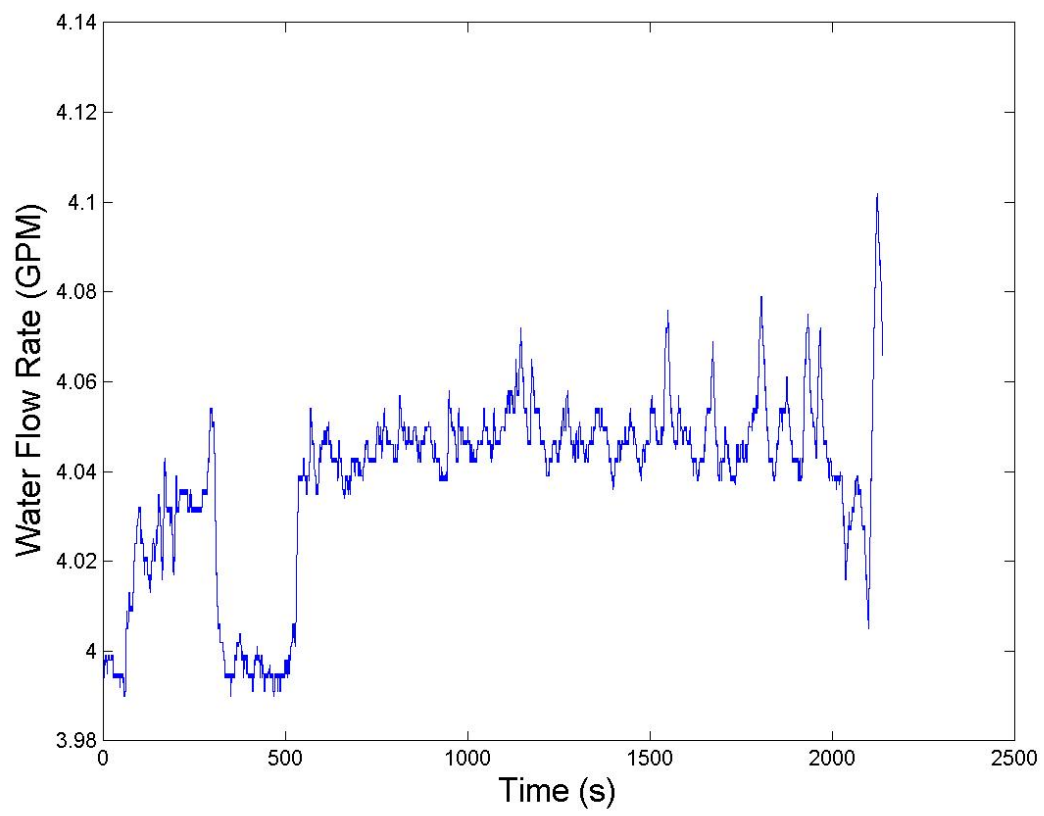

Fig. D.40.: Water flow rate measurements for Test 8.

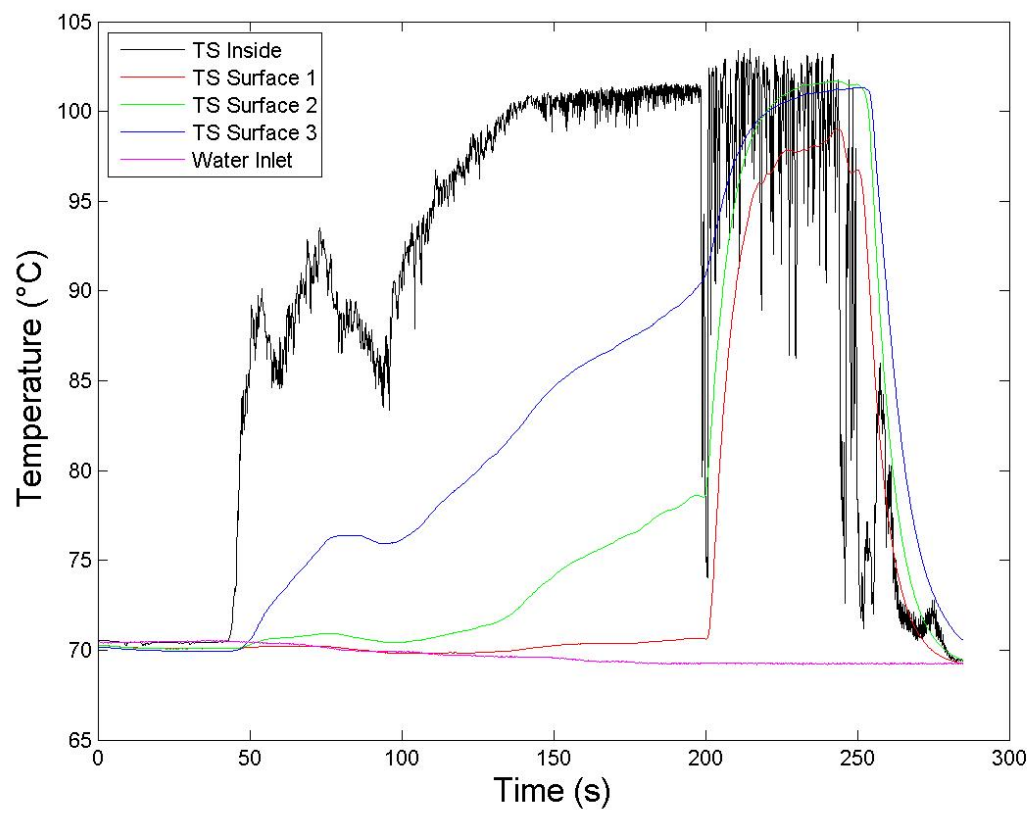

Fig. D.41.: Temperature measurements for Test 9. 


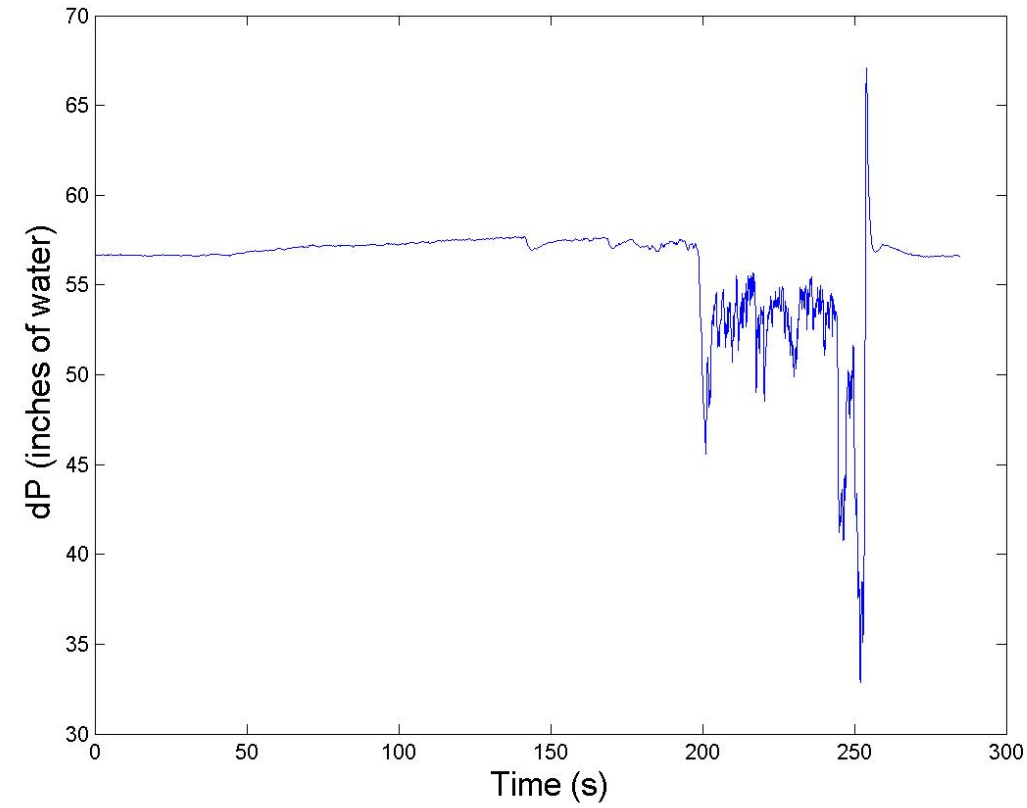

Fig. D.42.: Differential pressure measurements for Test 9.

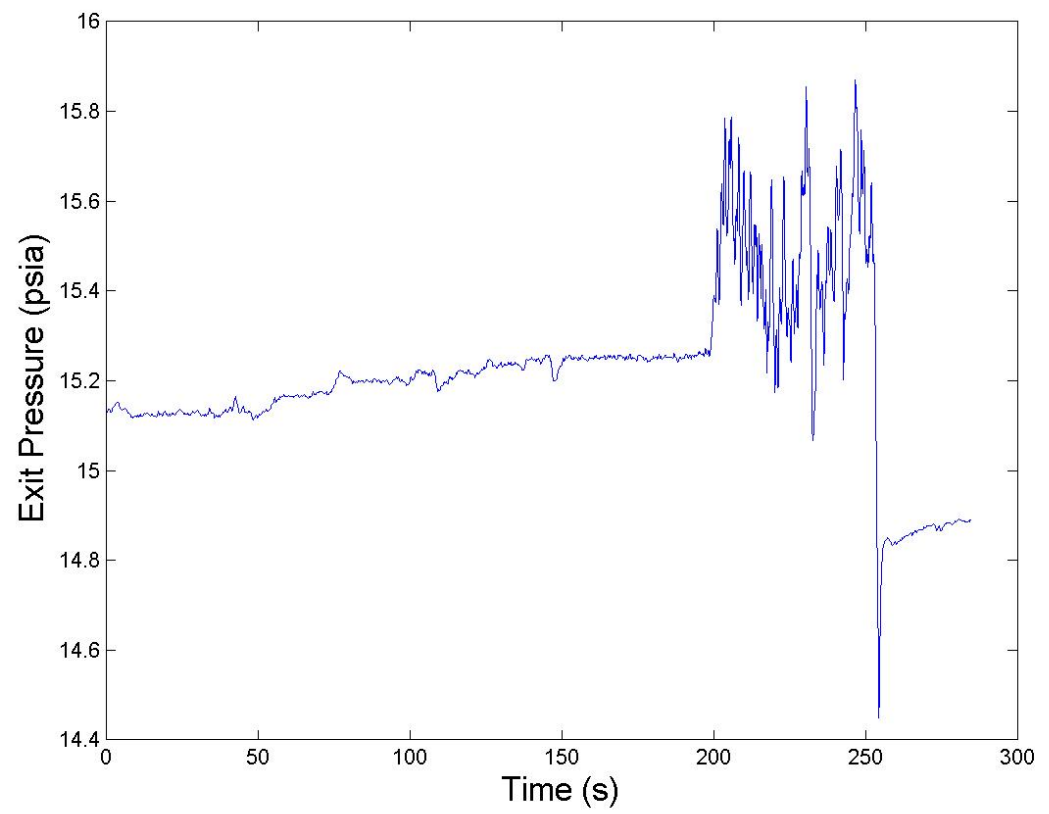

Fig. D.43.: Water exit tank pressure measurements for Test 9. 


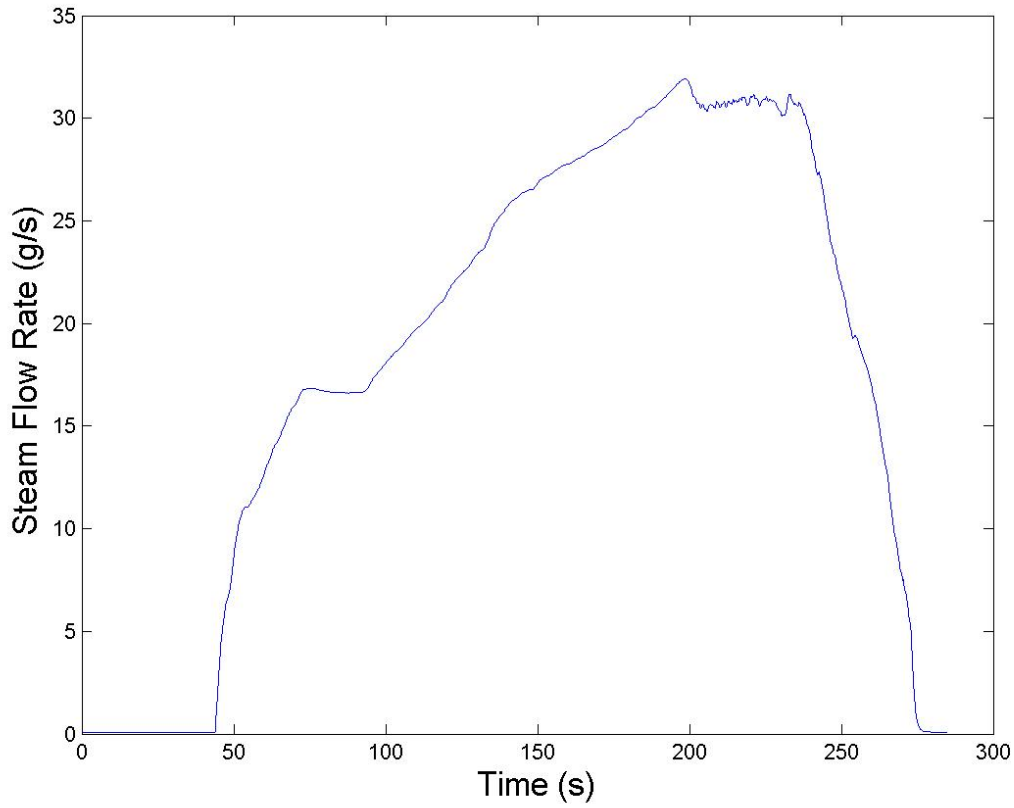

Fig. D.44.: Steam mass flow rate measurements for Test 9.

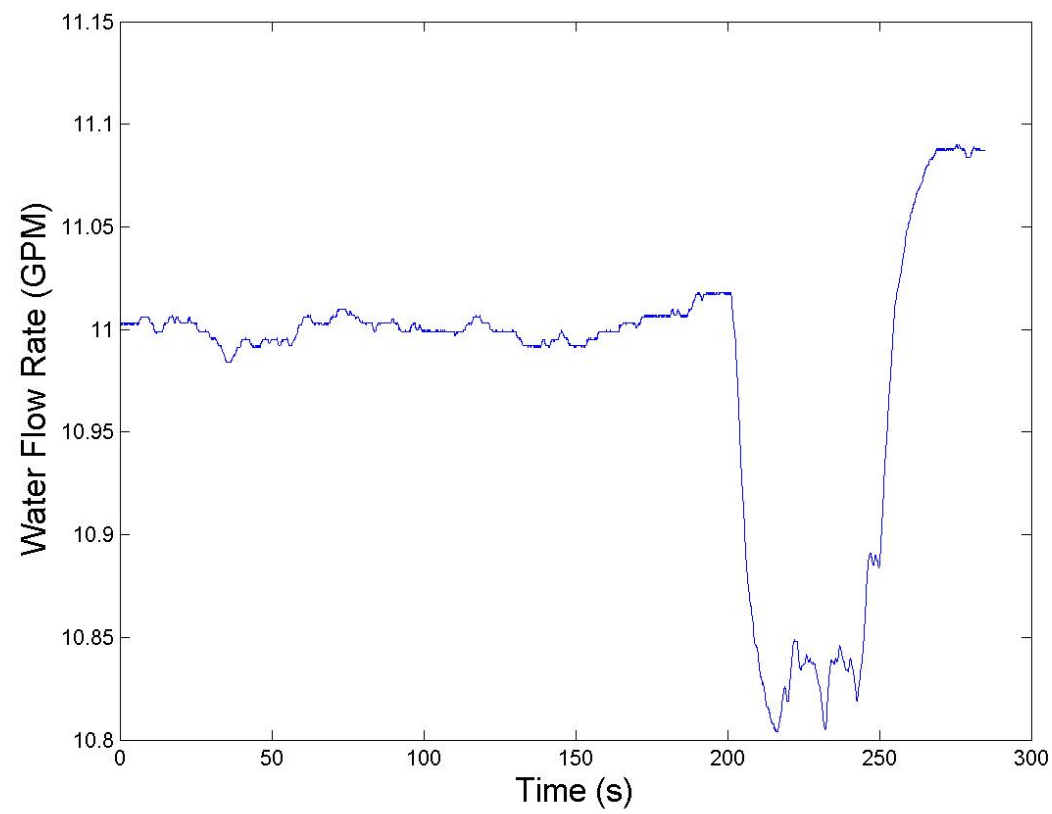

Fig. D.45.: Water flow rate measurements for Test 9. 


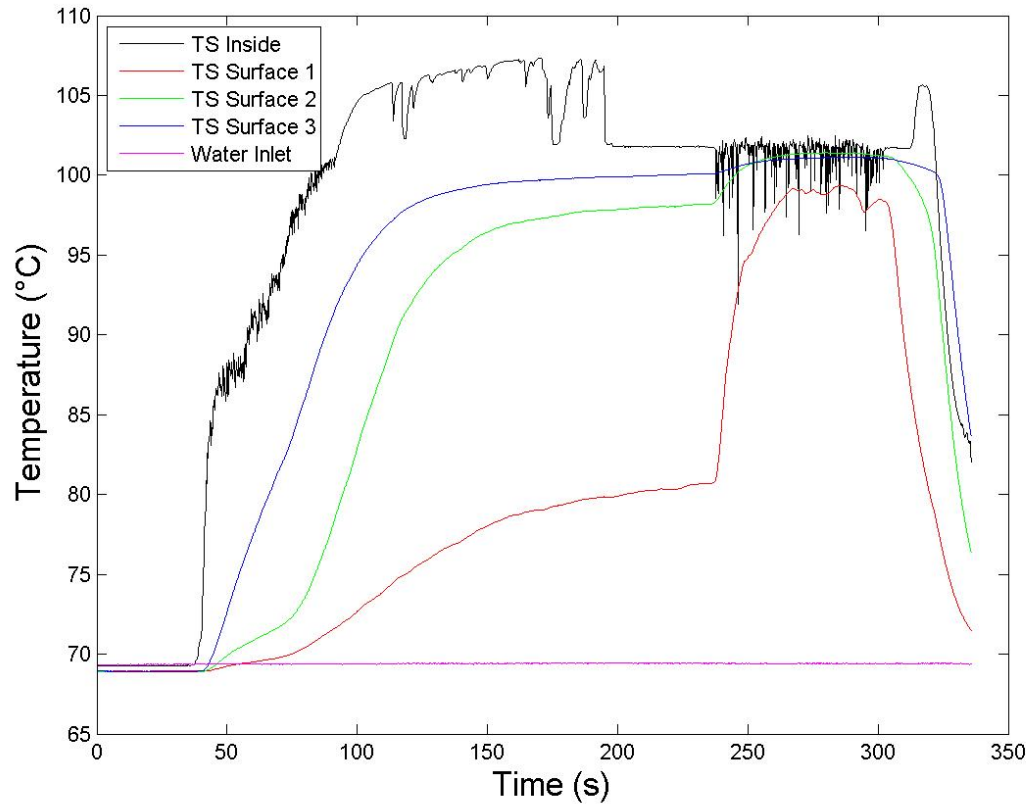

Fig. D.46.: Temperature measurements for Test 10 .

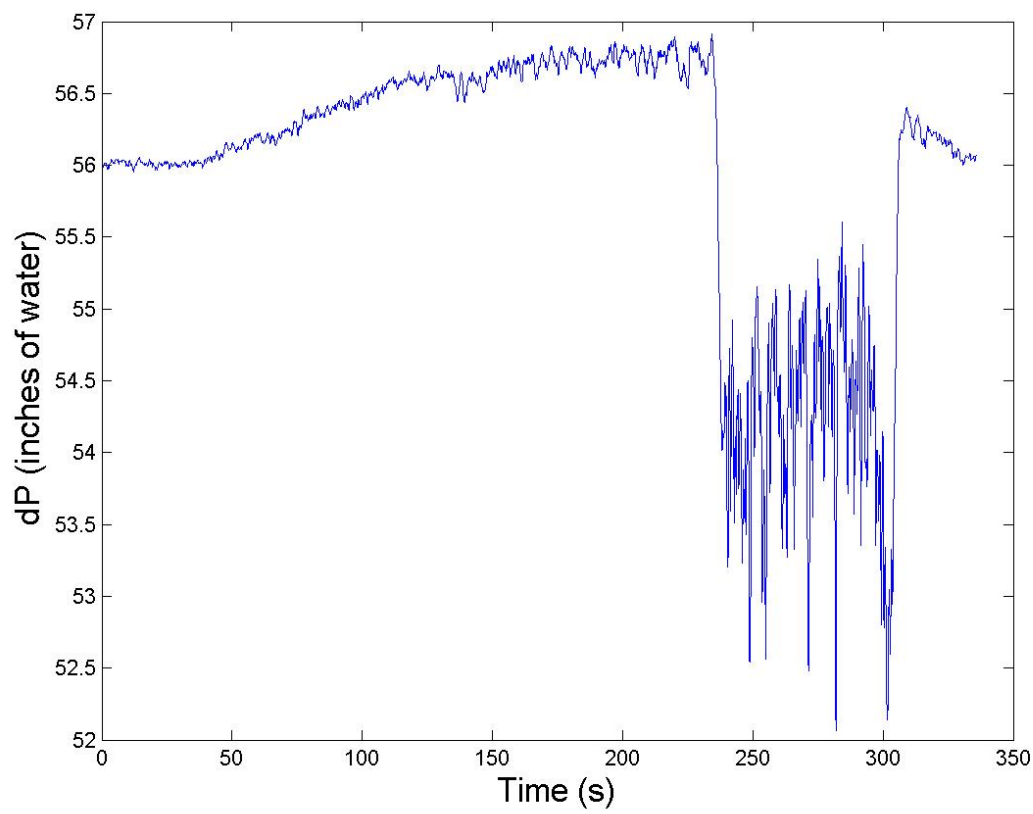

Fig. D.47.: Differential pressure measurements for Test 10. 


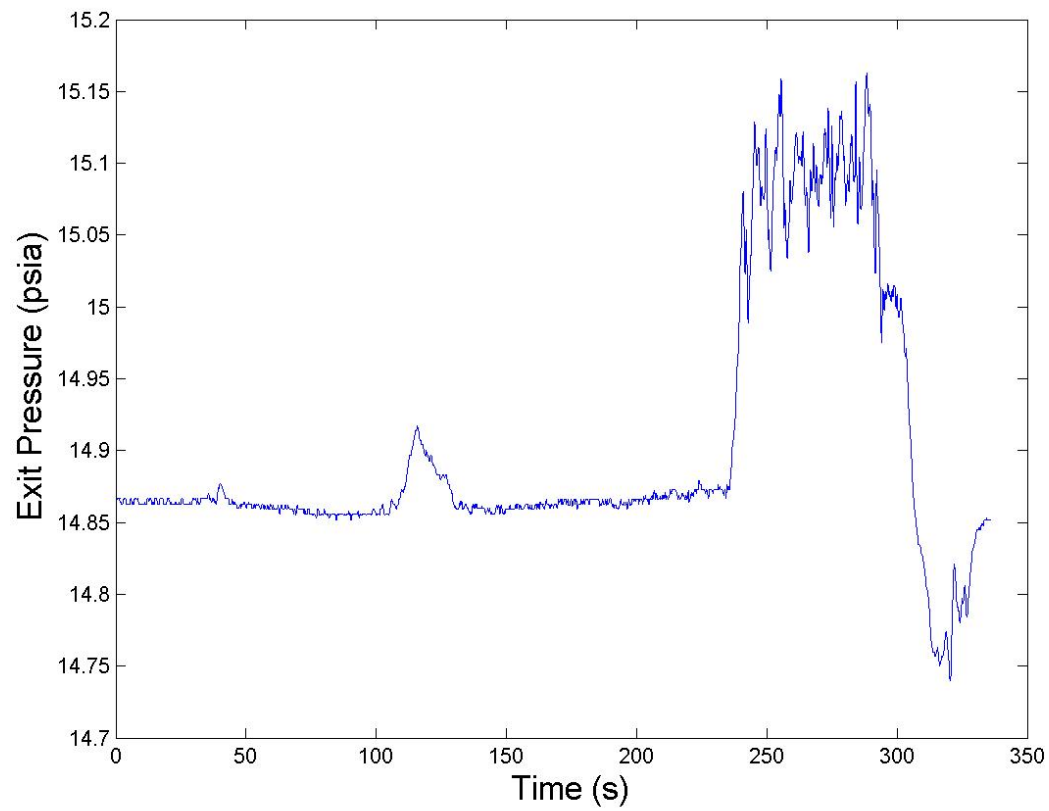

Fig. D.48.: Water exit tank pressure measurements for Test 10.

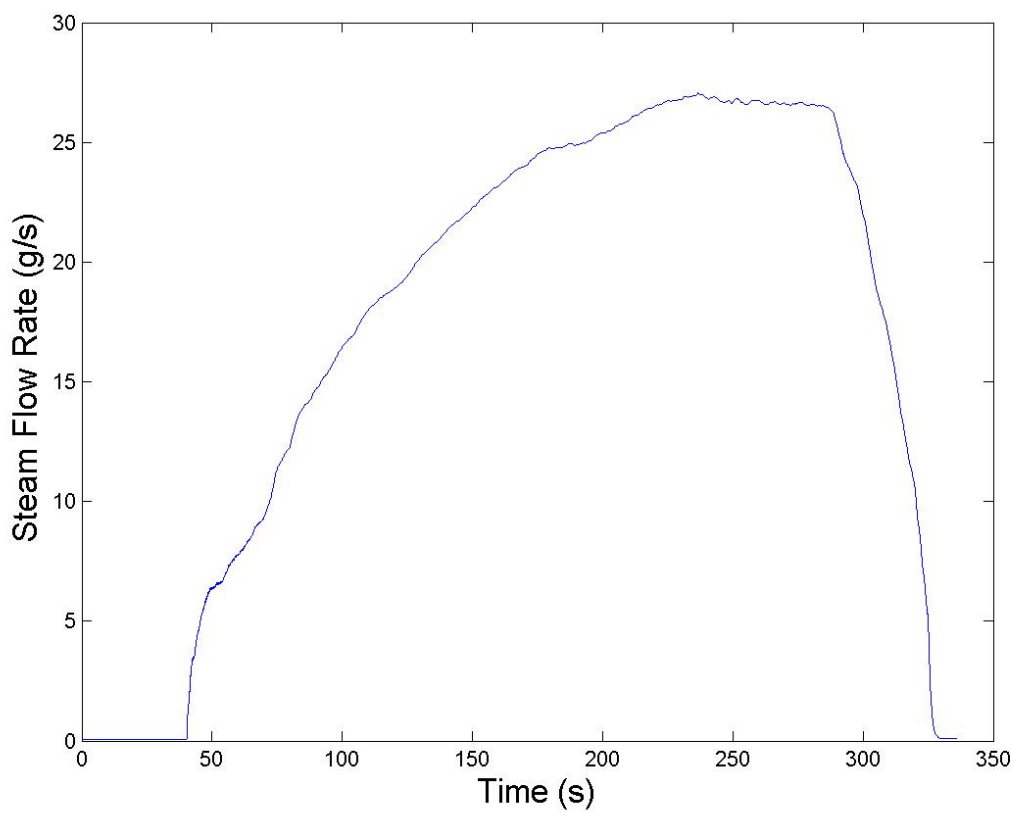

Fig. D.49.: Steam mass flow rate measurements for Test 10. 


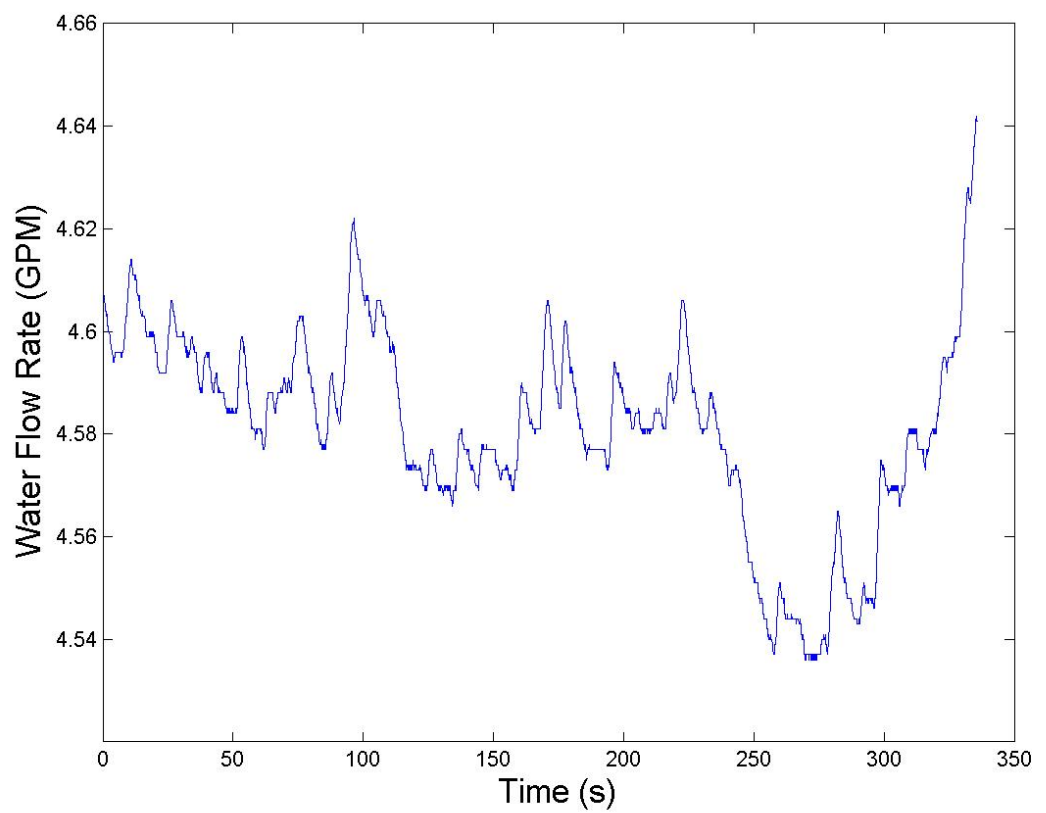

Fig. D.50.: Water flow rate measurements for Test 10.

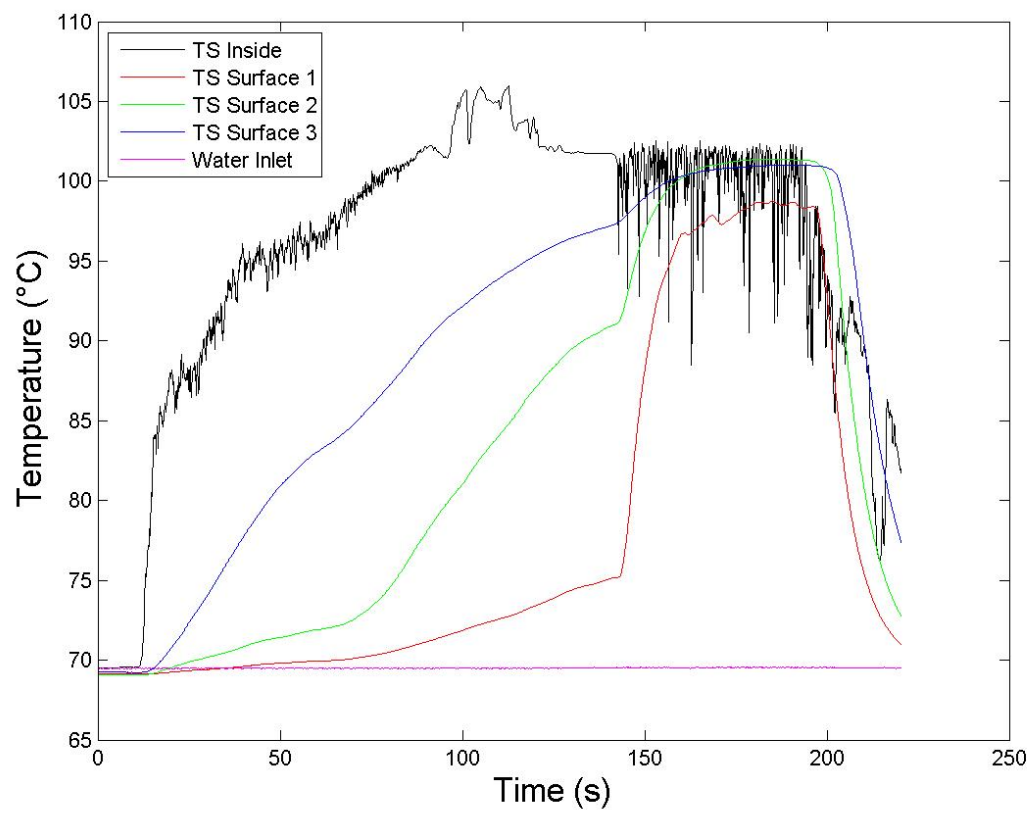

Fig. D.51.: Temperature measurements for Test 11. 


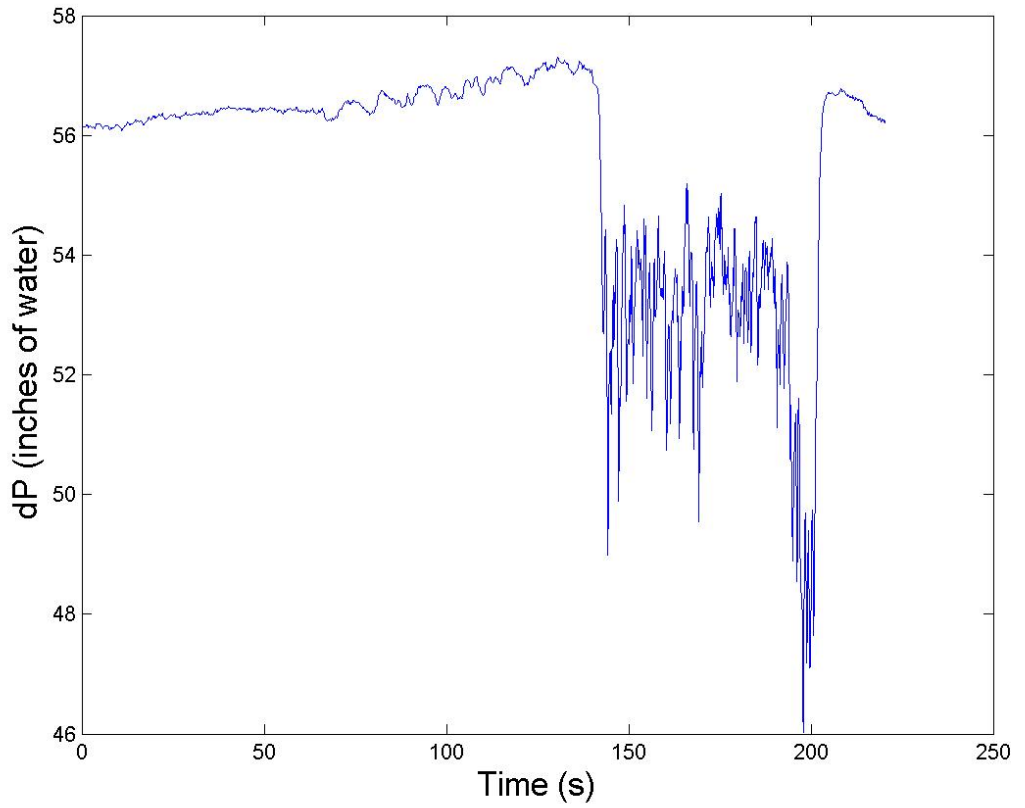

Fig. D.52.: Differential pressure measurements for Test 11.

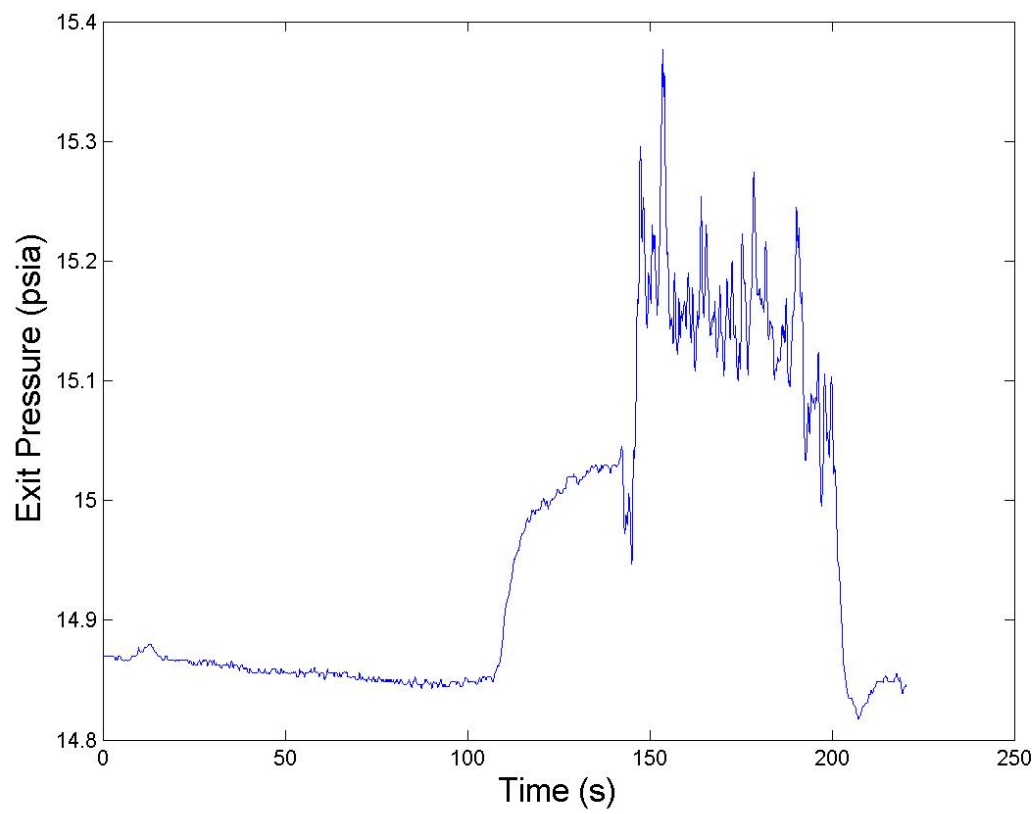

Fig. D.53.: Water exit tank pressure measurements for Test 11. 


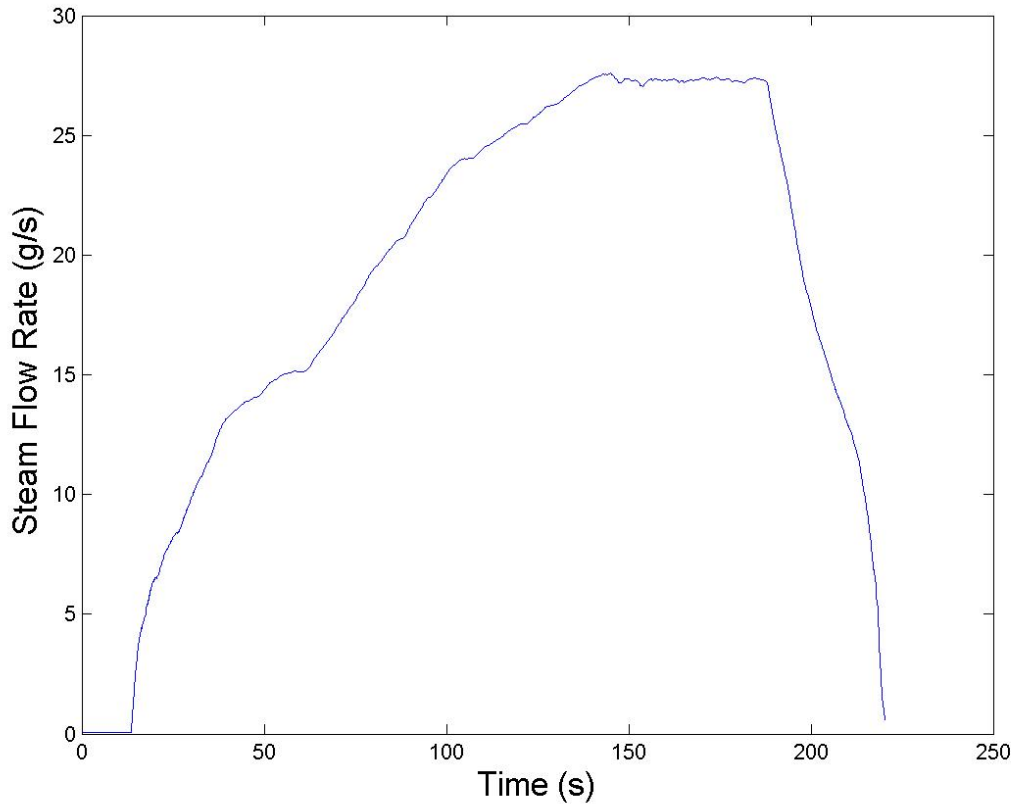

Fig. D.54.: Steam mass flow rate measurements for Test 11.

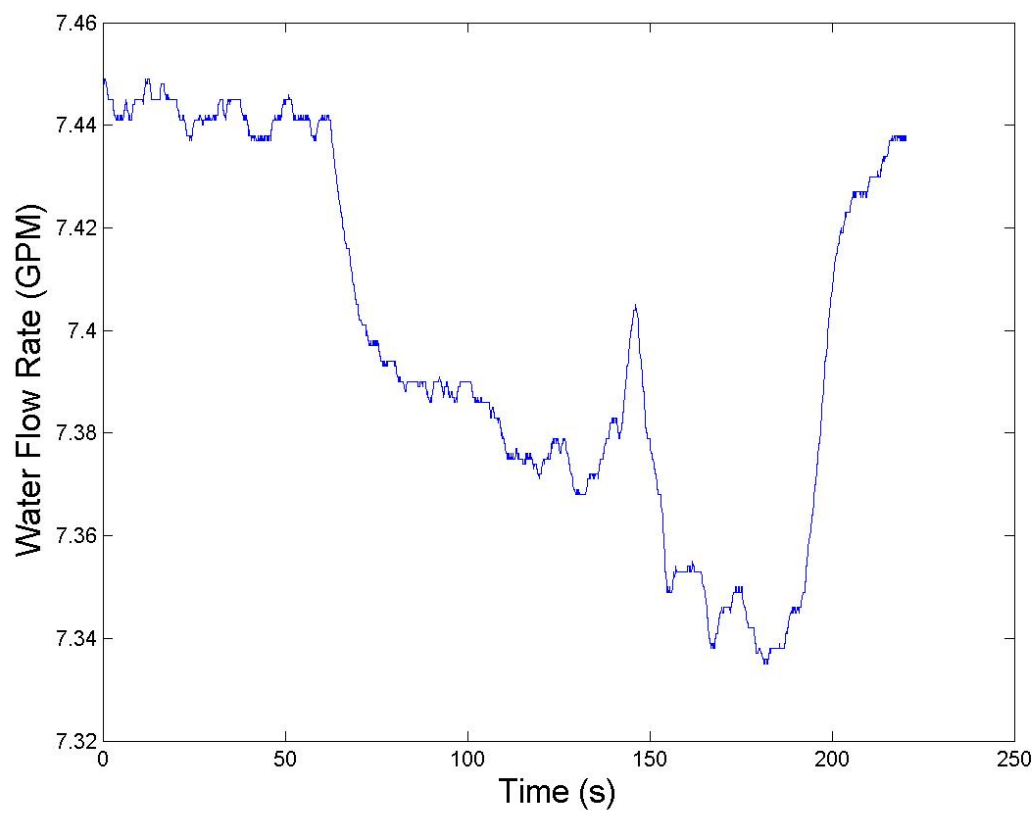

Fig. D.55.: Water flow rate measurements for Test 11. 


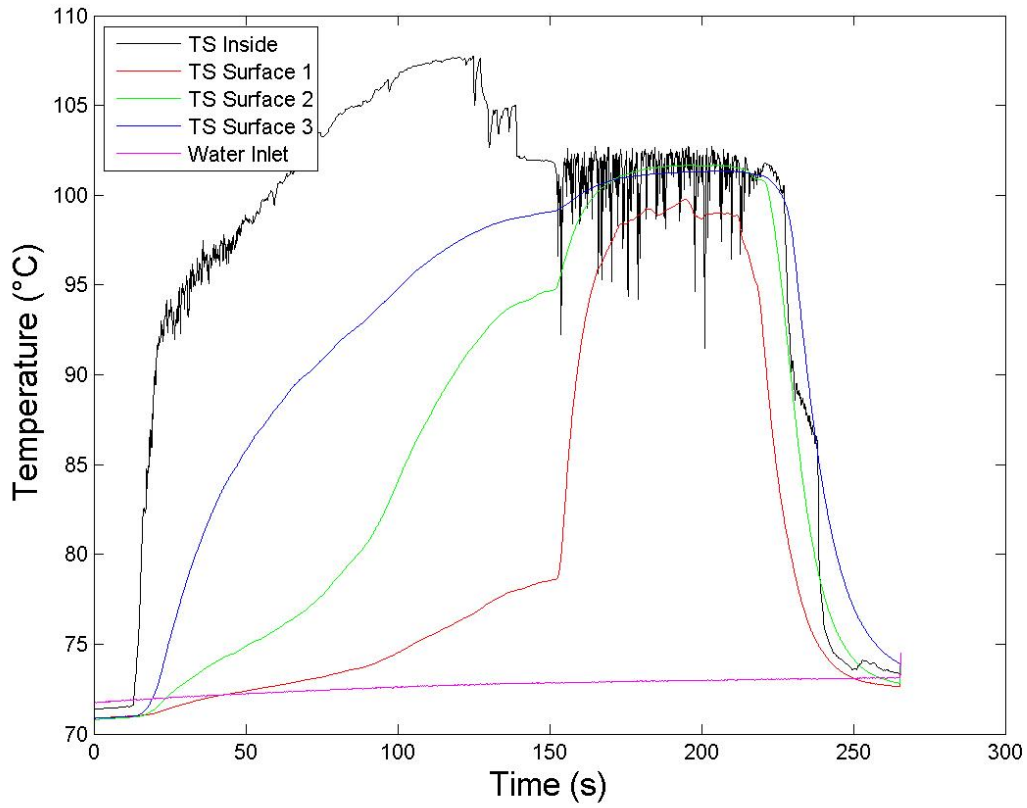

Fig. D.56.: Temperature measurements for Test 12 .

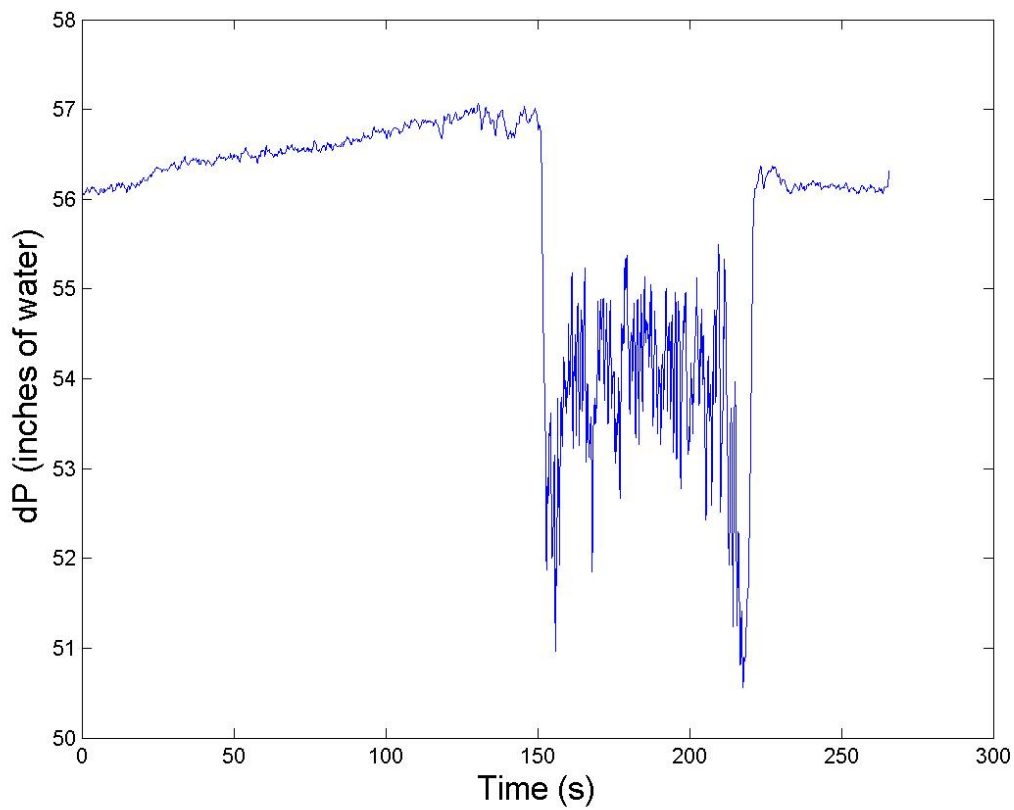

Fig. D.57.: Differential pressure measurements for Test 12. 


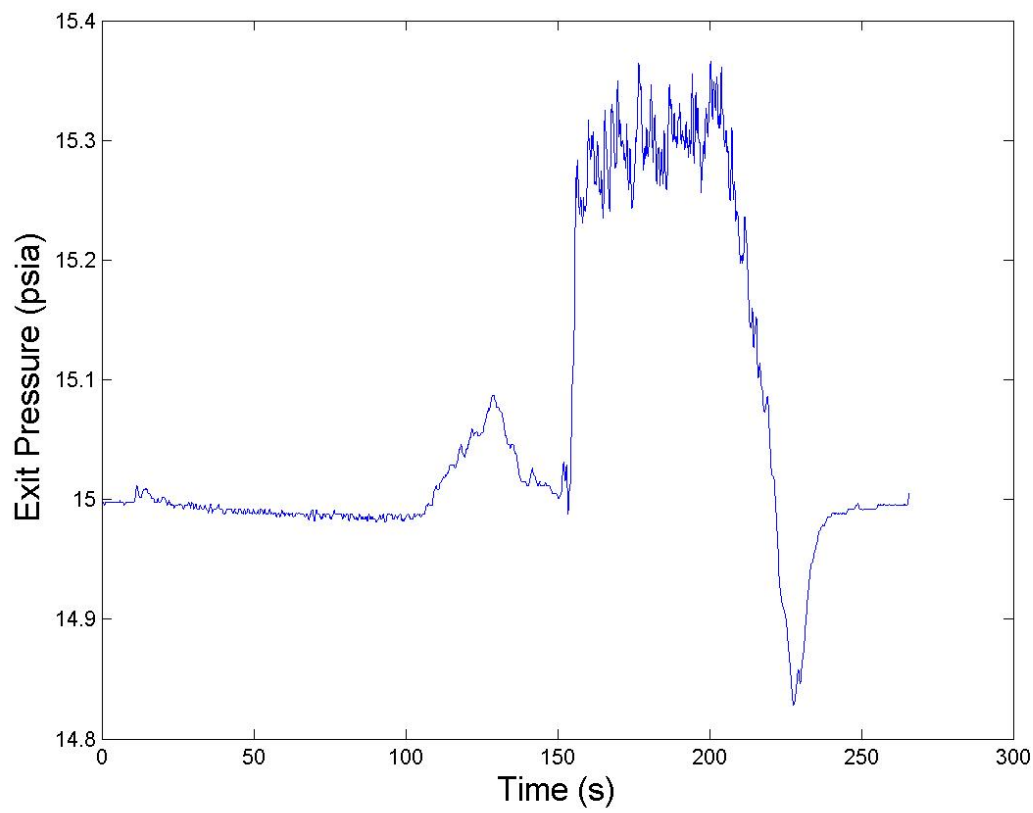

Fig. D.58.: Water exit tank pressure measurements for Test 12.

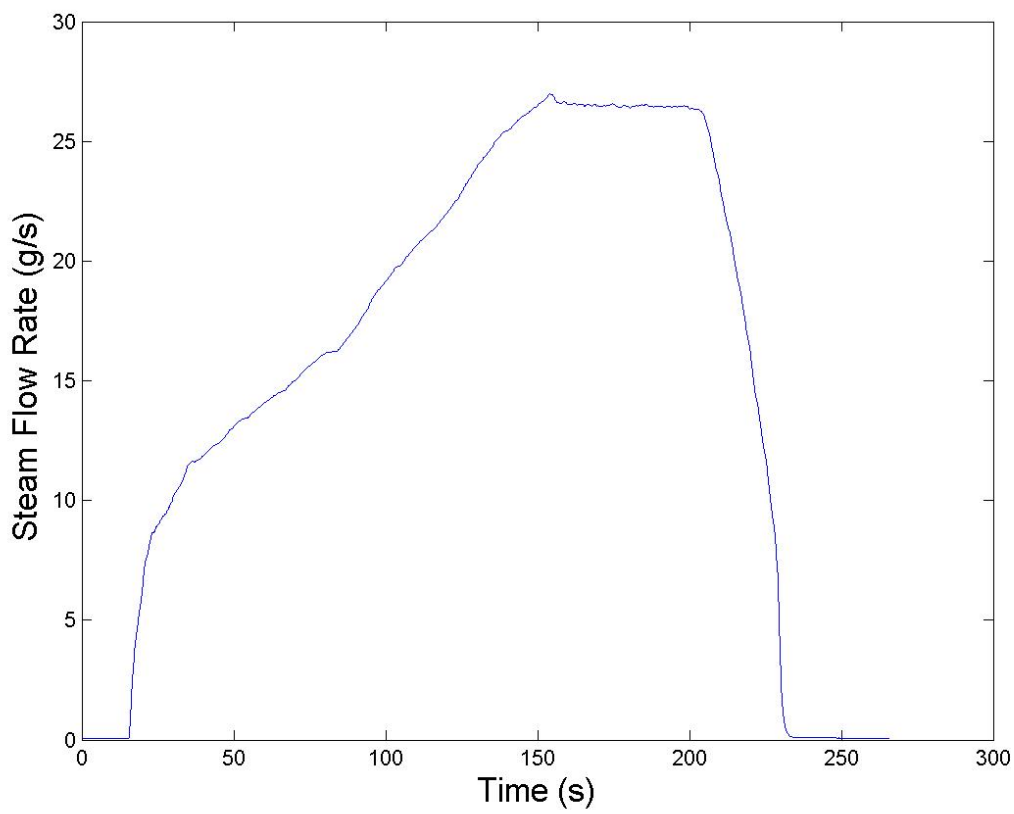

Fig. D.59.: Steam mass flow rate measurements for Test 12. 


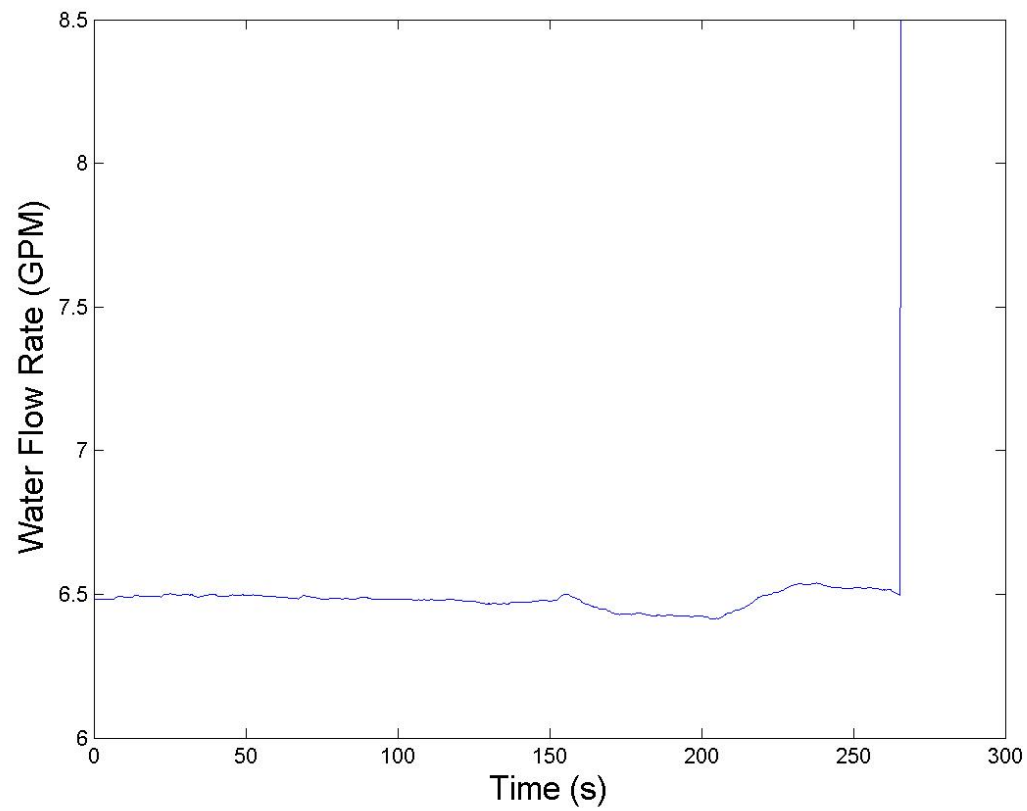

Fig. D.60.: Water flow rate measurements for Test 12 .

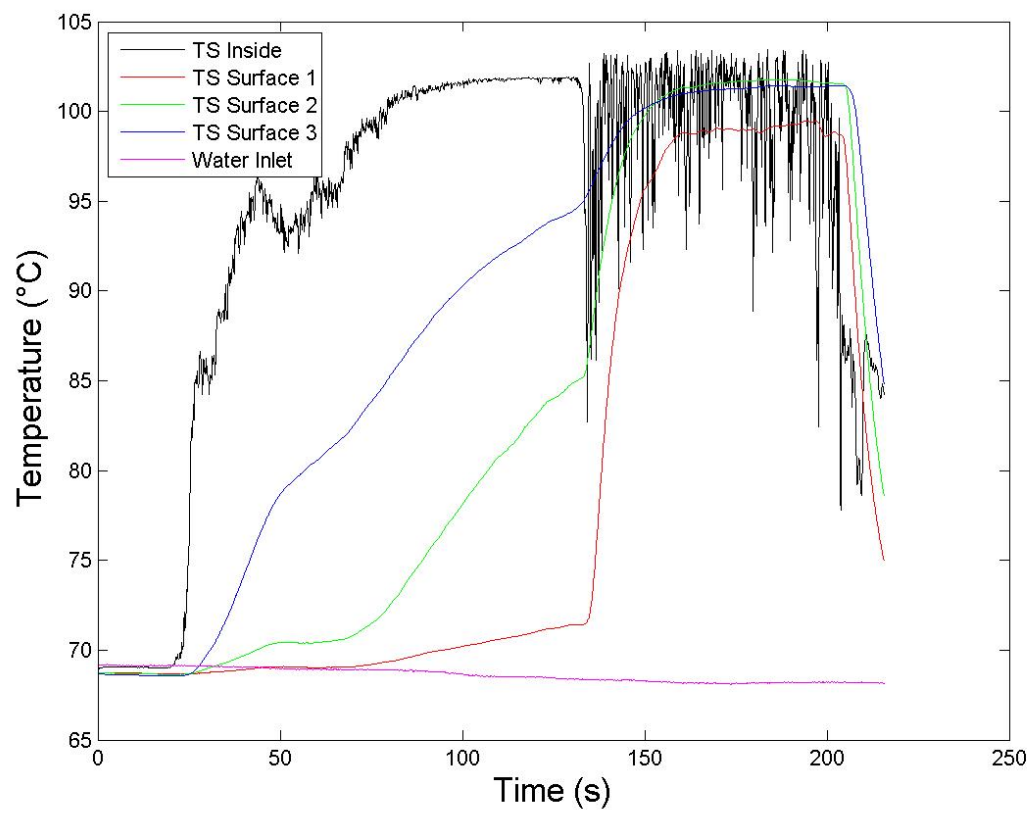

Fig. D.61.: Temperature measurements for Test 13. 


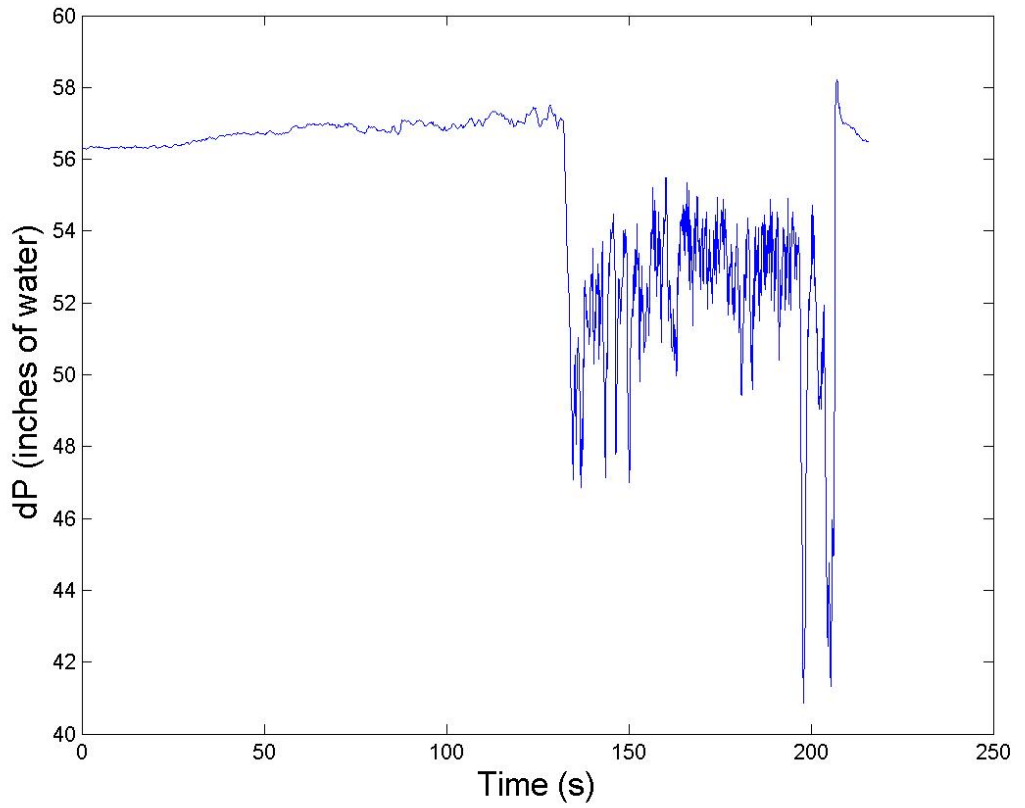

Fig. D.62.: Differential pressure measurements for Test 13.

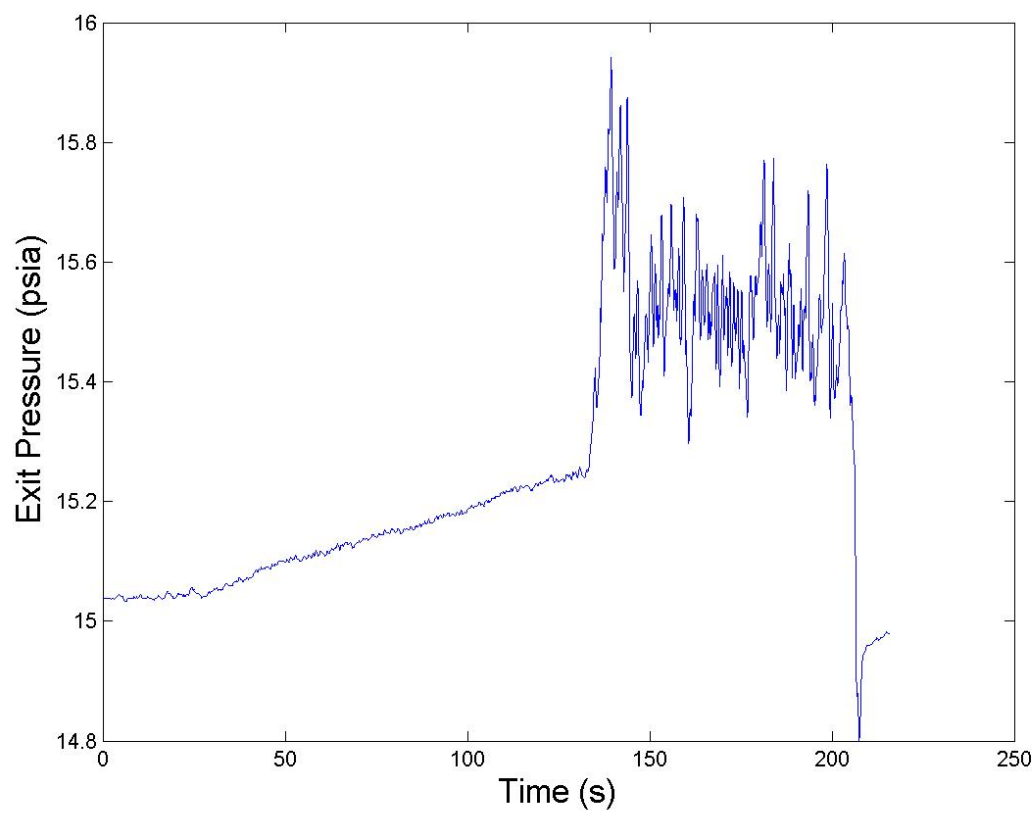

Fig. D.63.: Water exit tank pressure measurements for Test 13. 


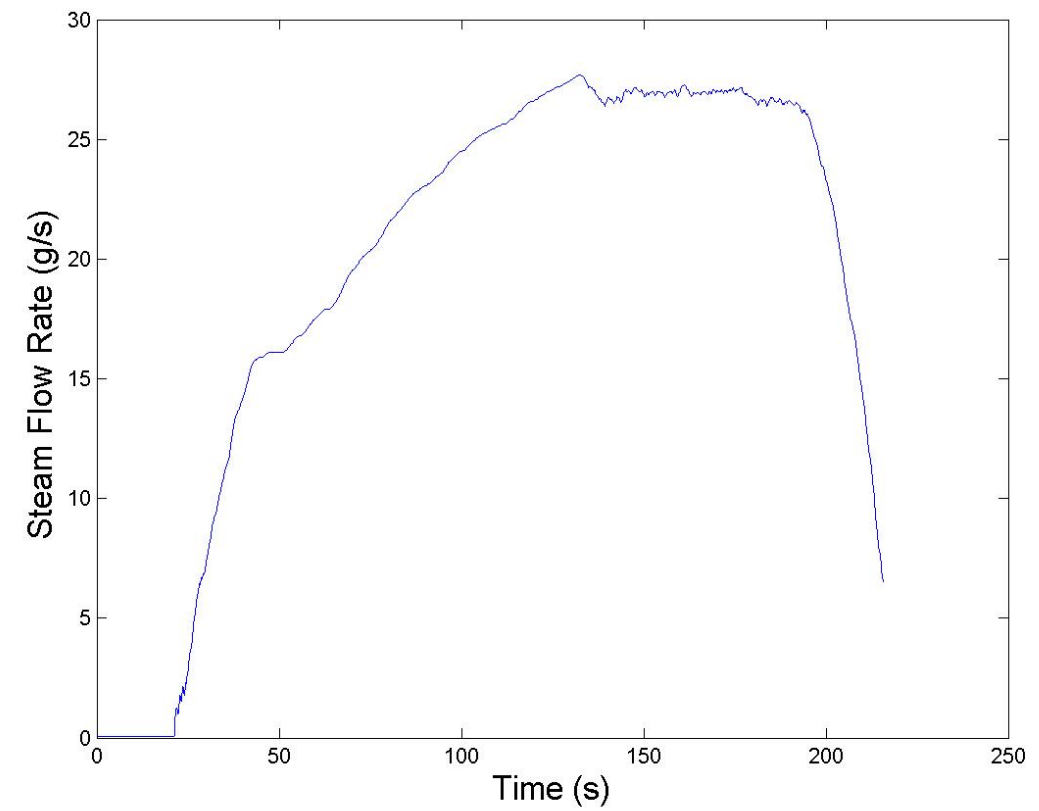

Fig. D.64.: Steam mass flow rate measurements for Test 13.

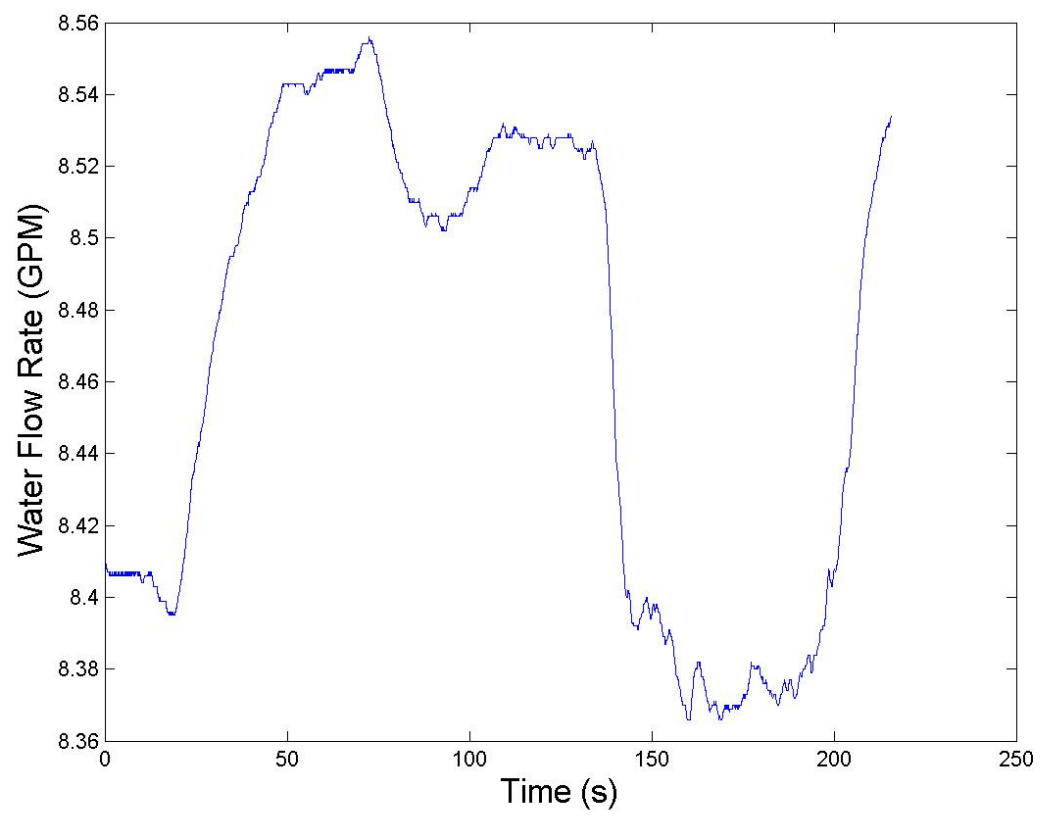

Fig. D.65.: Water flow rate measurements for Test 13. 


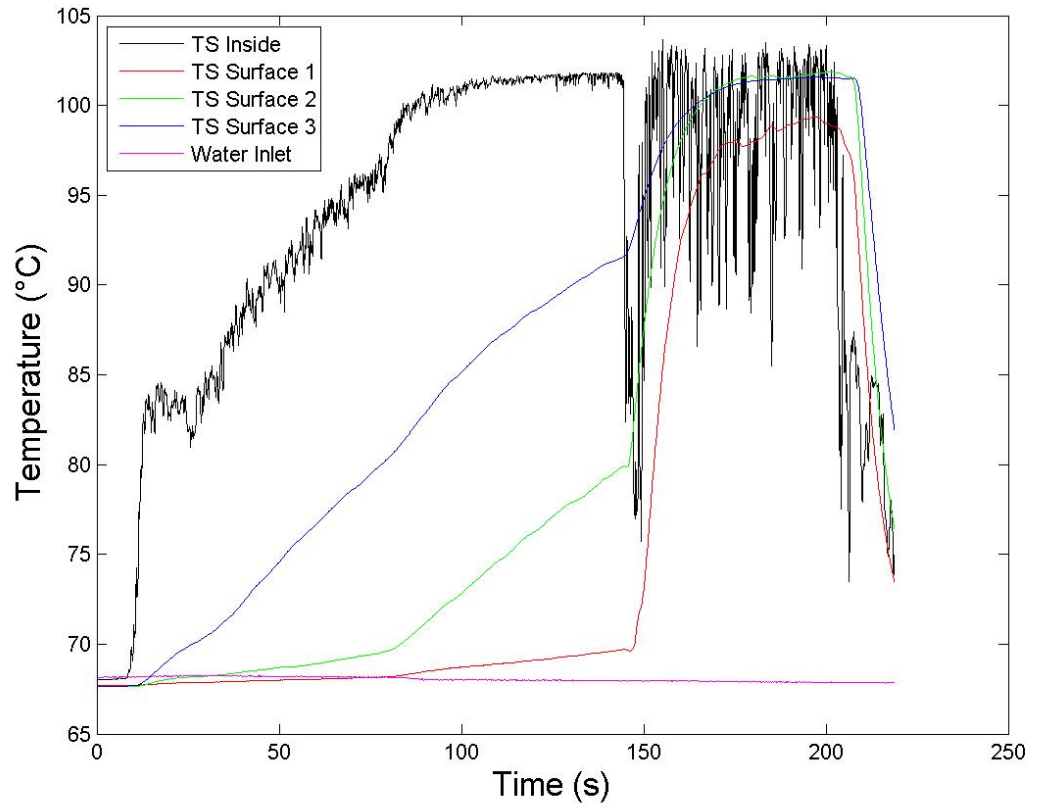

Fig. D.66.: Temperature measurements for Test 14 .

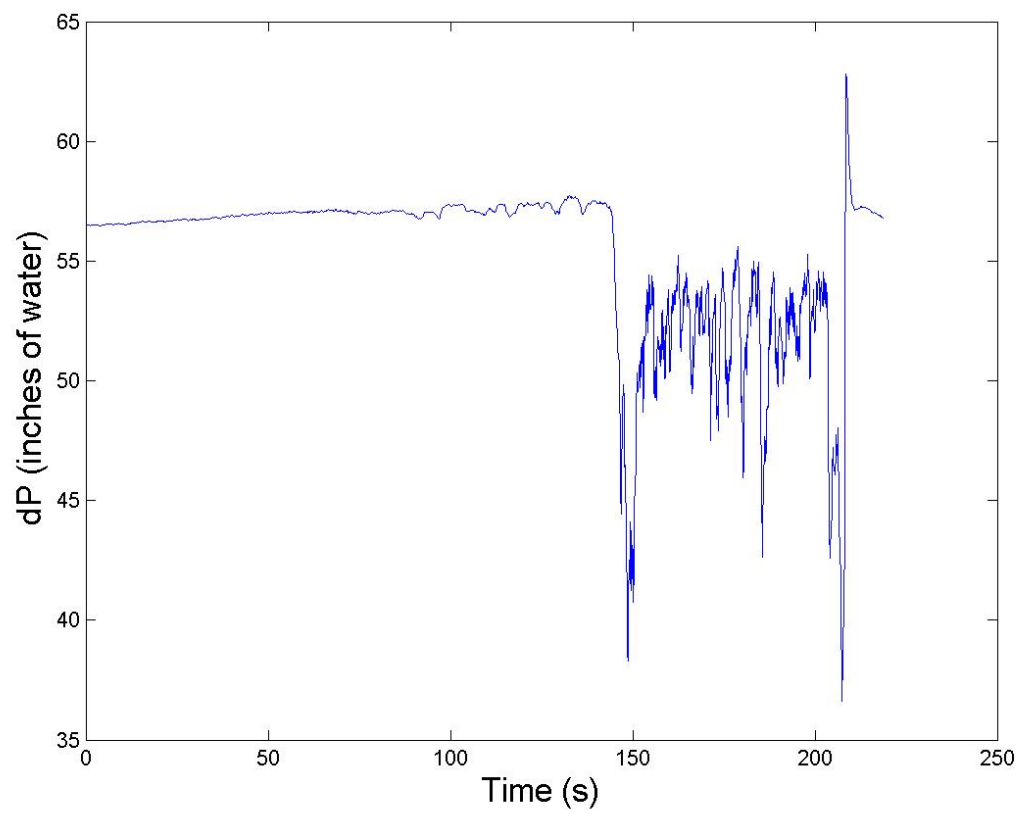

Fig. D.67.: Differential pressure measurements for Test 14. 


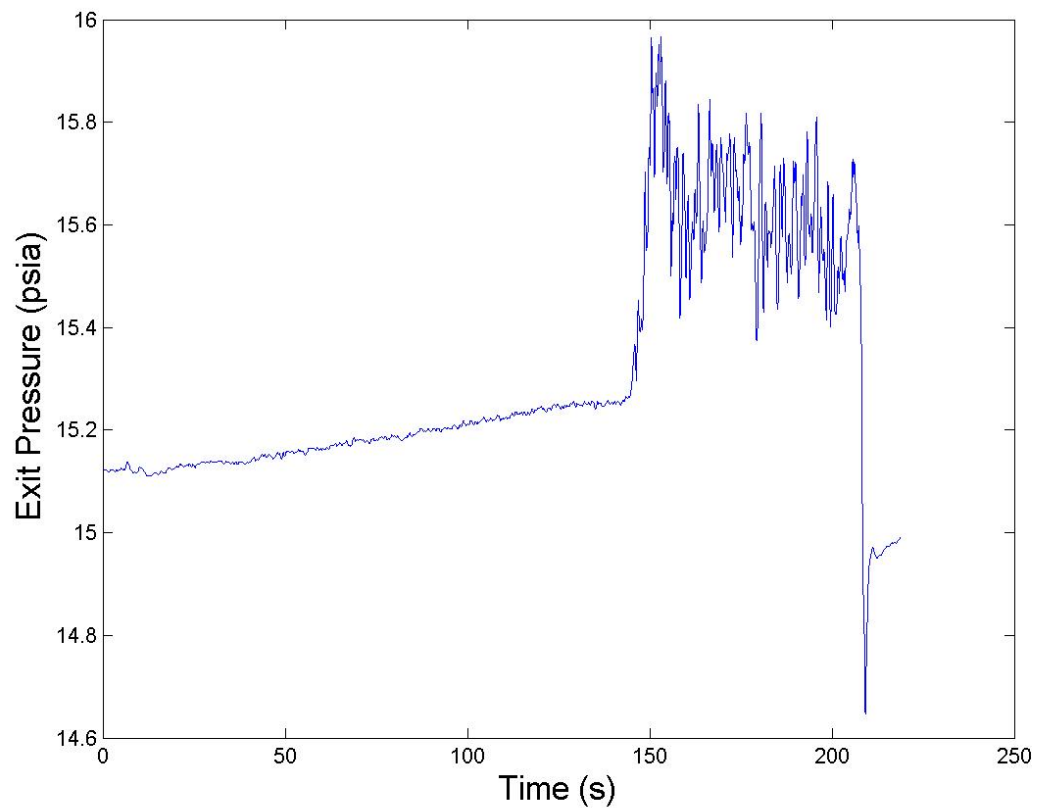

Fig. D.68.: Water exit tank pressure measurements for Test 14.

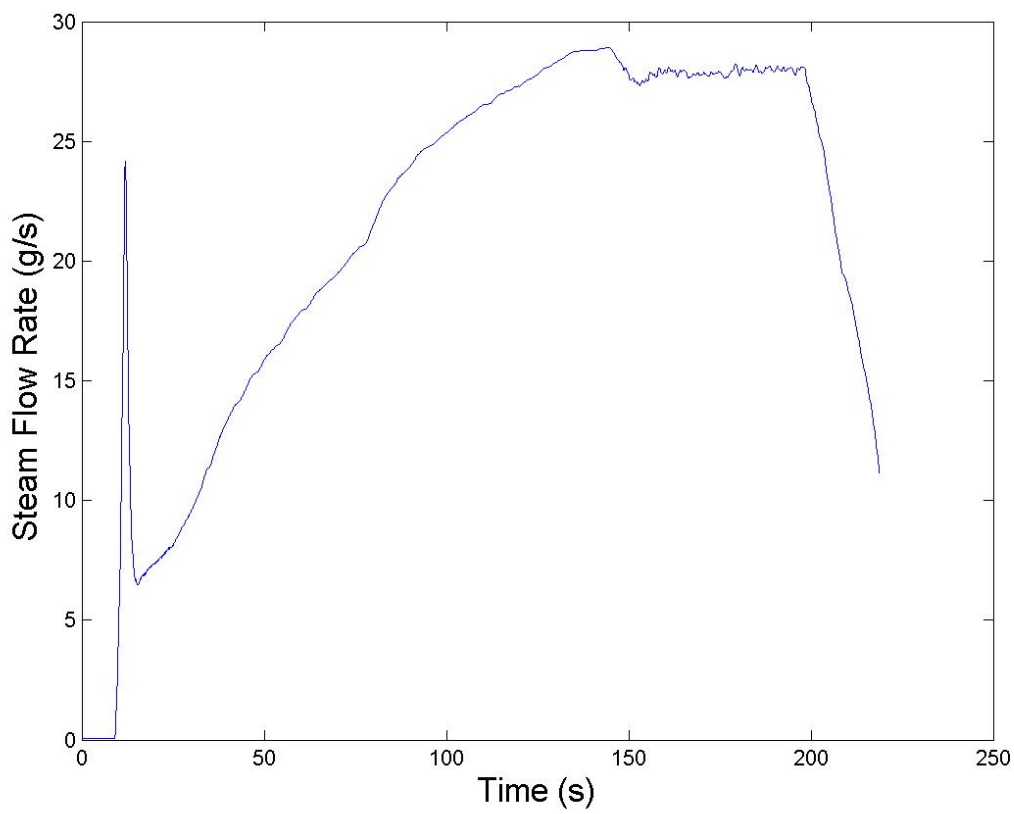

Fig. D.69.: Steam mass flow rate measurements for Test 14. 


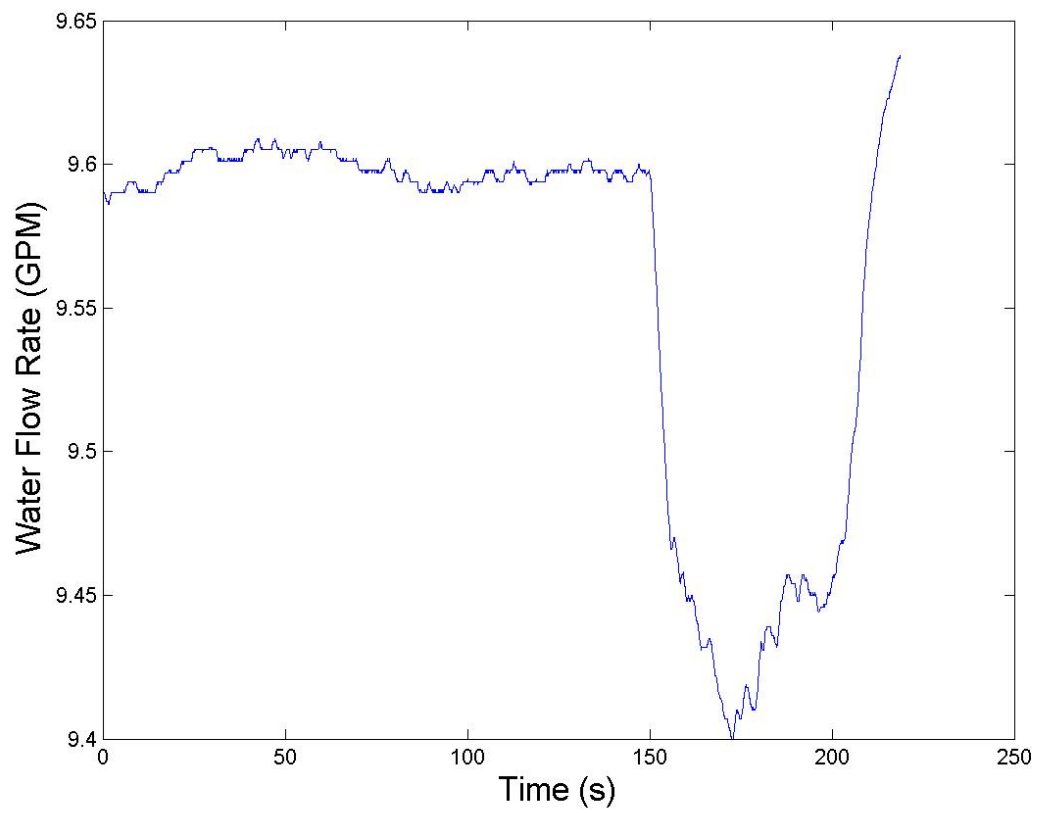

Fig. D.70.: Water flow rate measurements for Test 14.

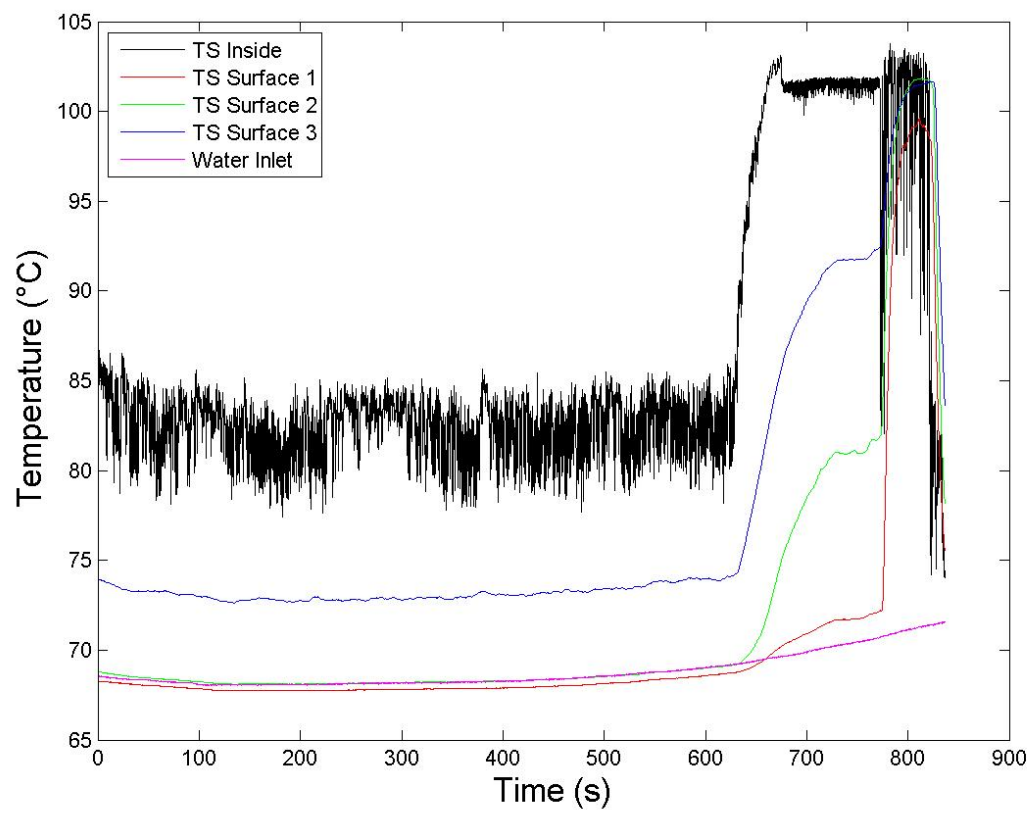

Fig. D.71.: Temperature measurements for Test 15. 


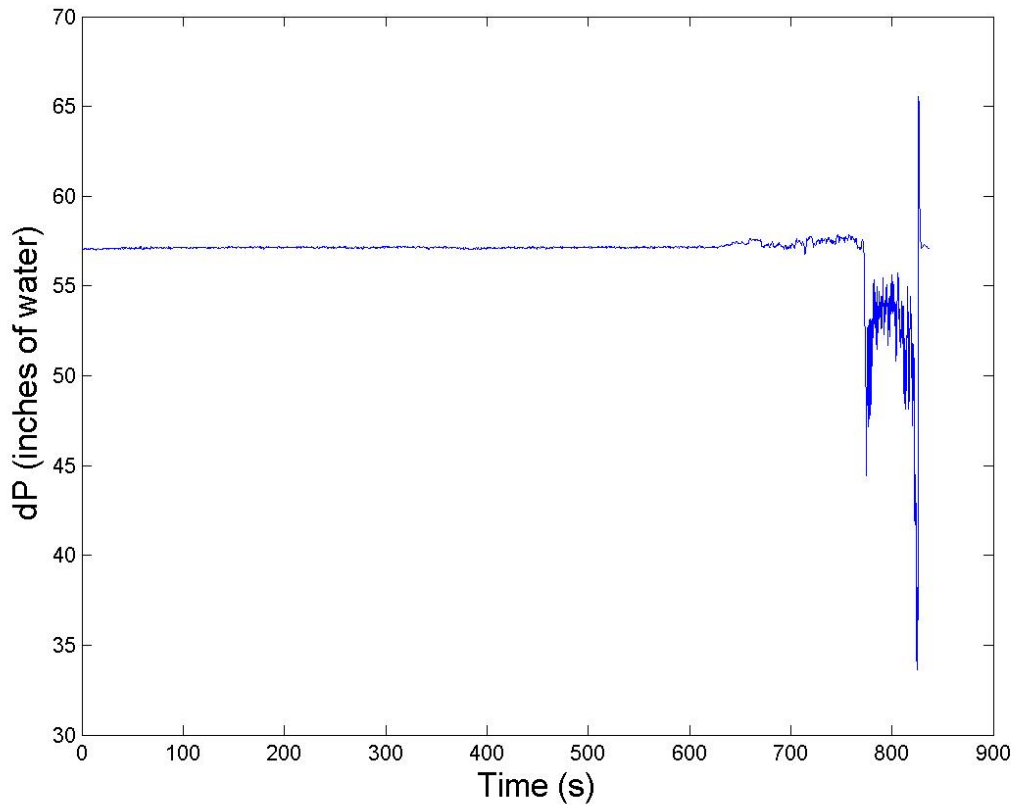

Fig. D.72.: Differential pressure measurements for Test 15.

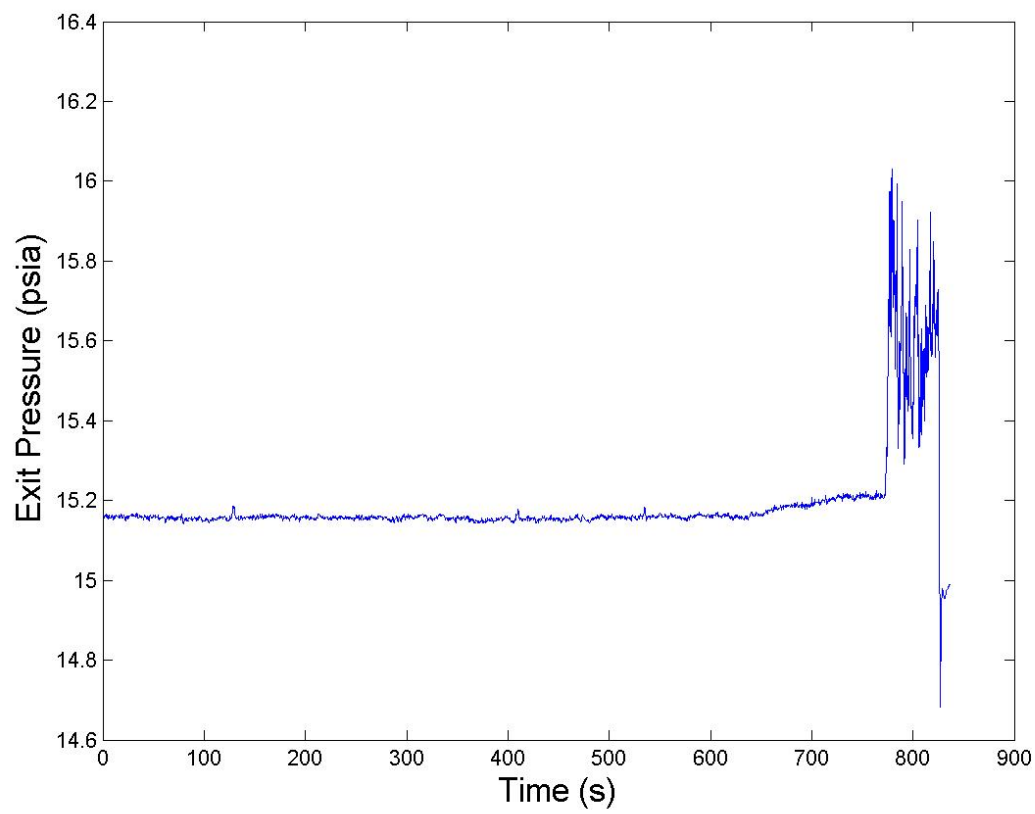

Fig. D.73.: Water exit tank pressure measurements for Test 15. 


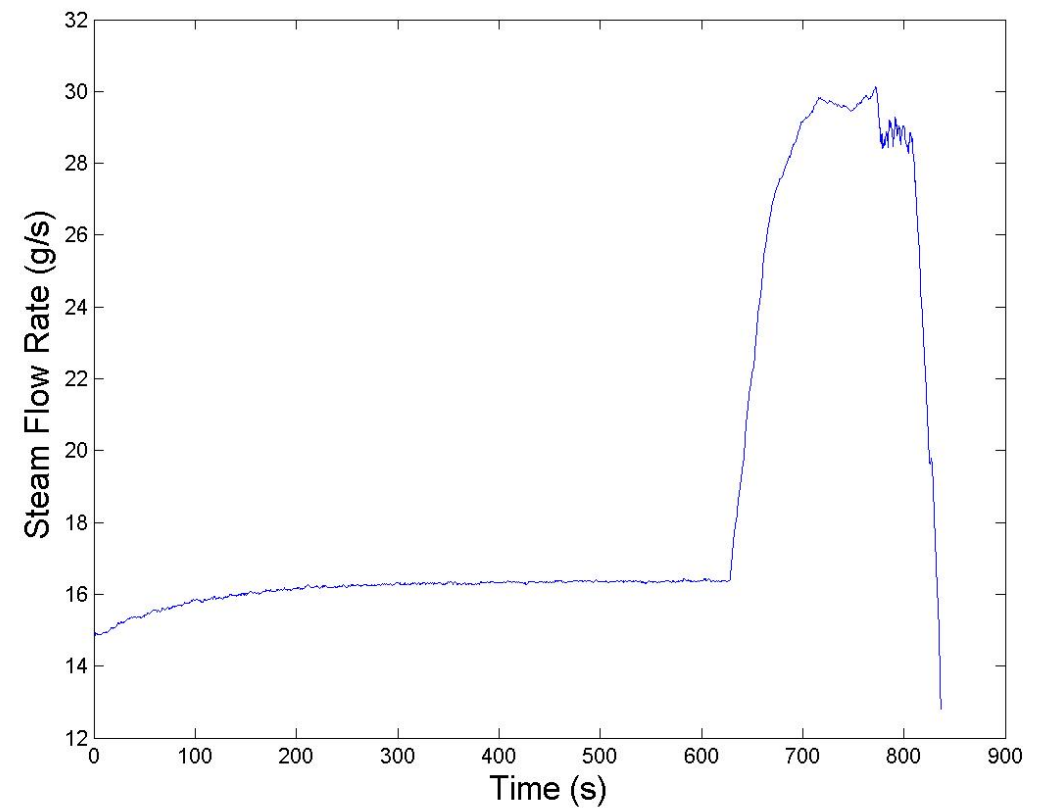

Fig. D.74.: Steam mass flow rate measurements for Test 15.

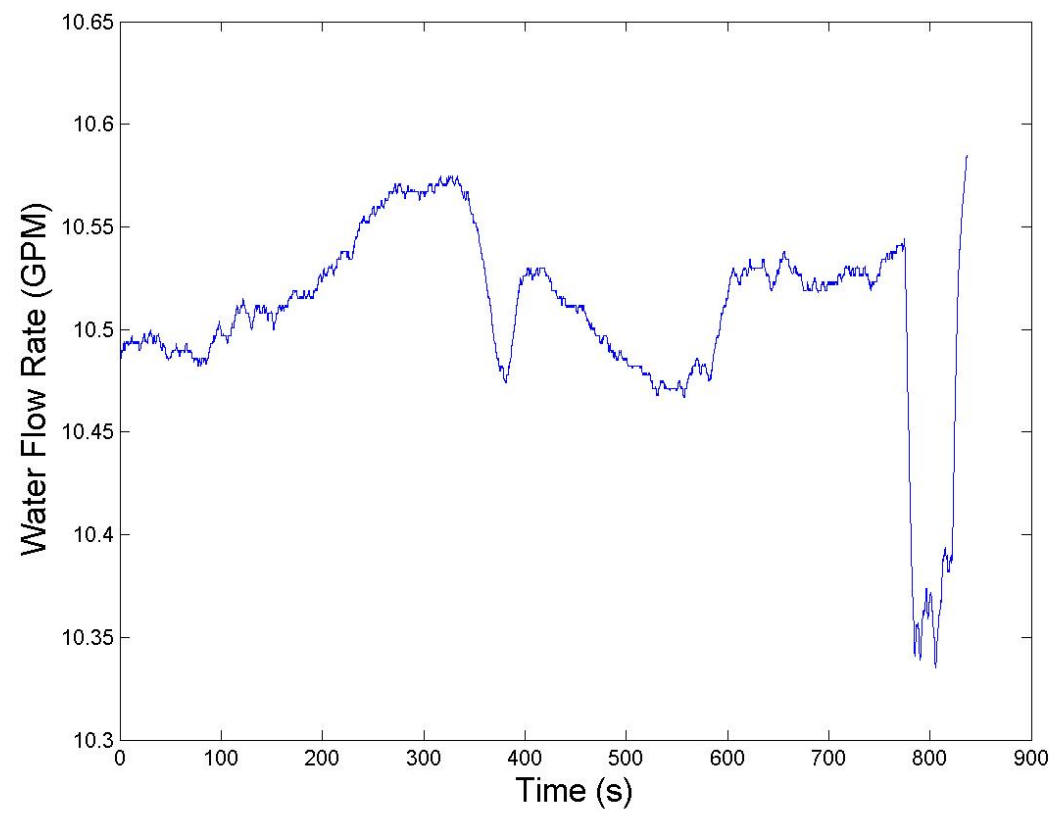

Fig. D.75.: Water flow rate measurements for Test 15. 


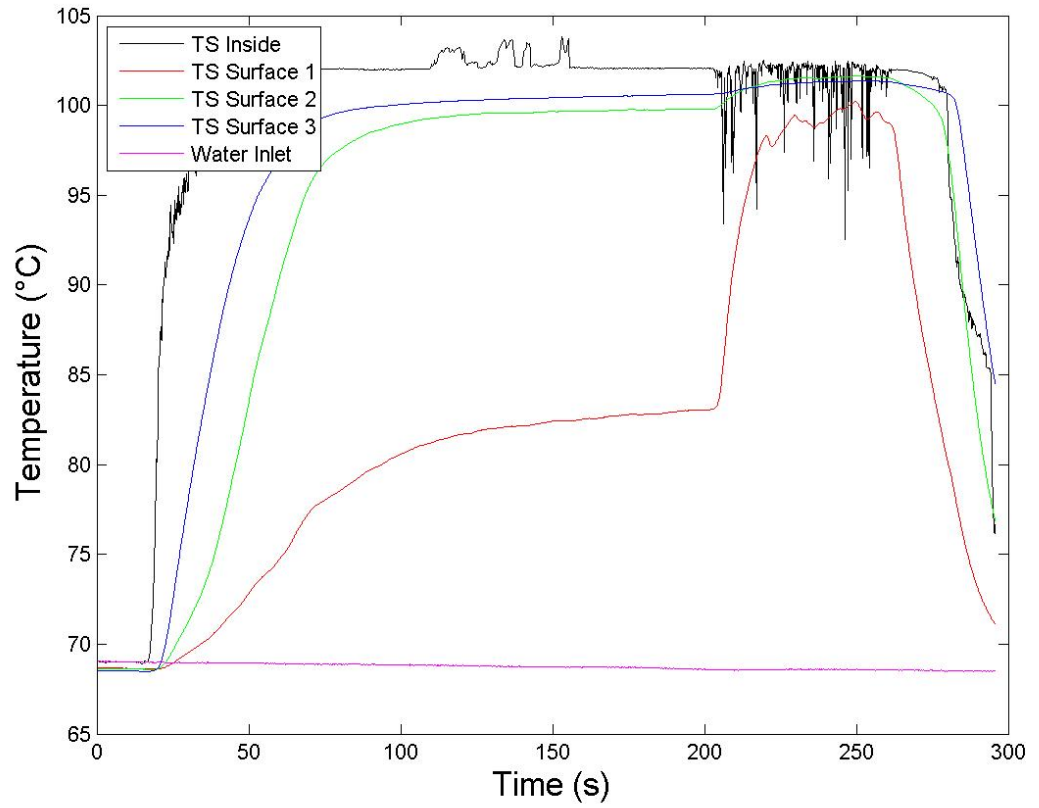

Fig. D.76.: Temperature measurements for Test 16.

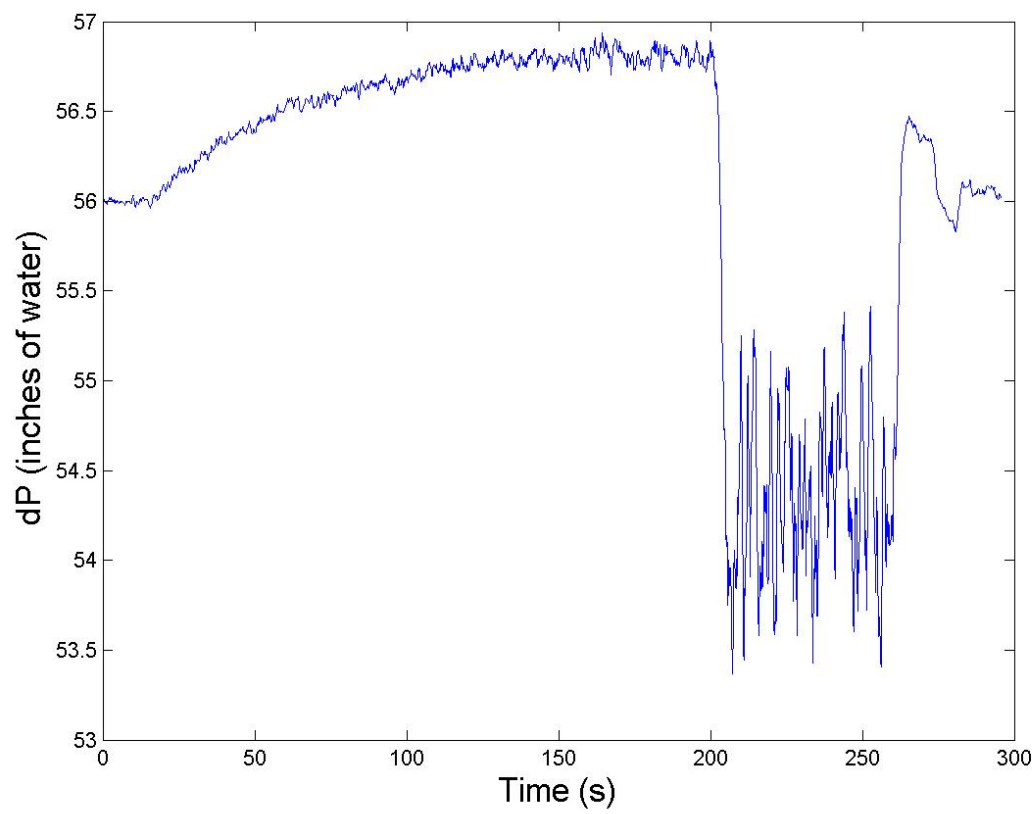

Fig. D.77.: Differential pressure measurements for Test 16. 


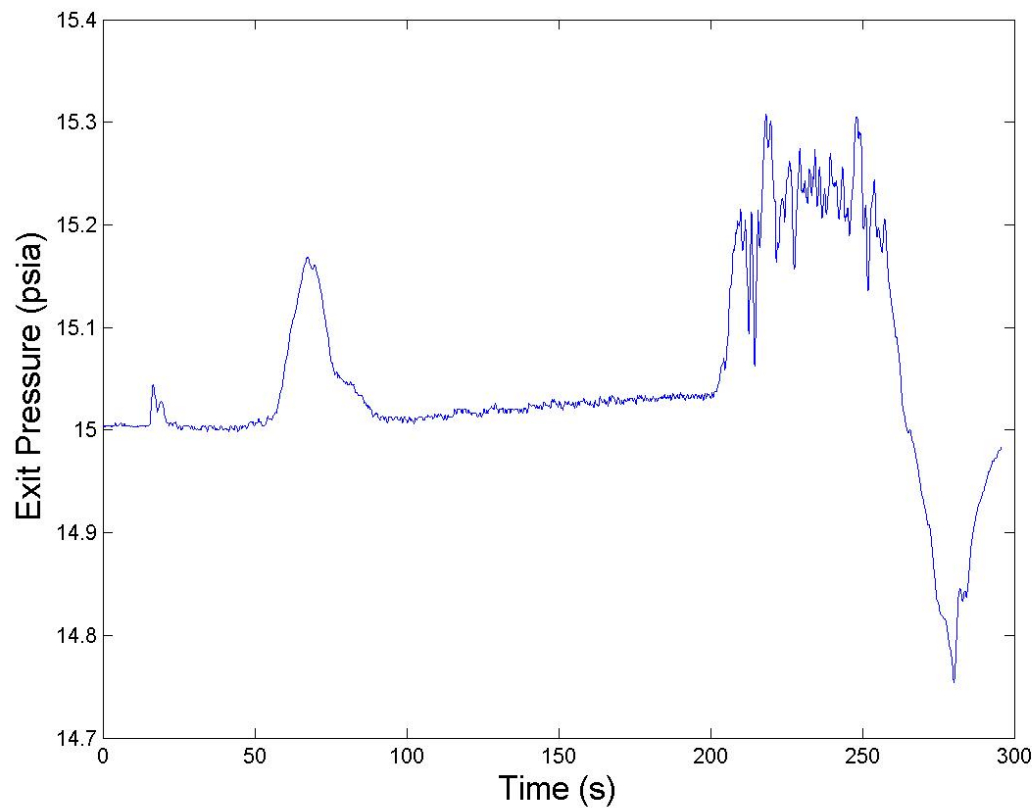

Fig. D.78.: Water exit tank pressure measurements for Test 16.

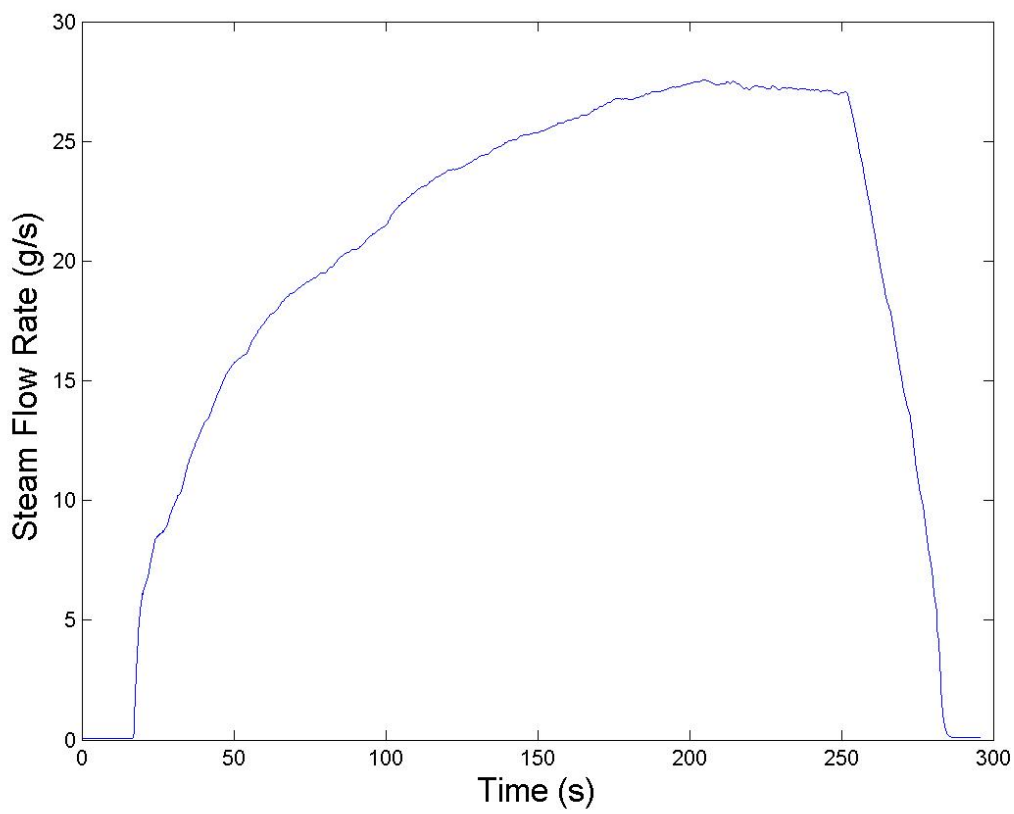

Fig. D.79.: Steam mass flow rate measurements for Test 16. 


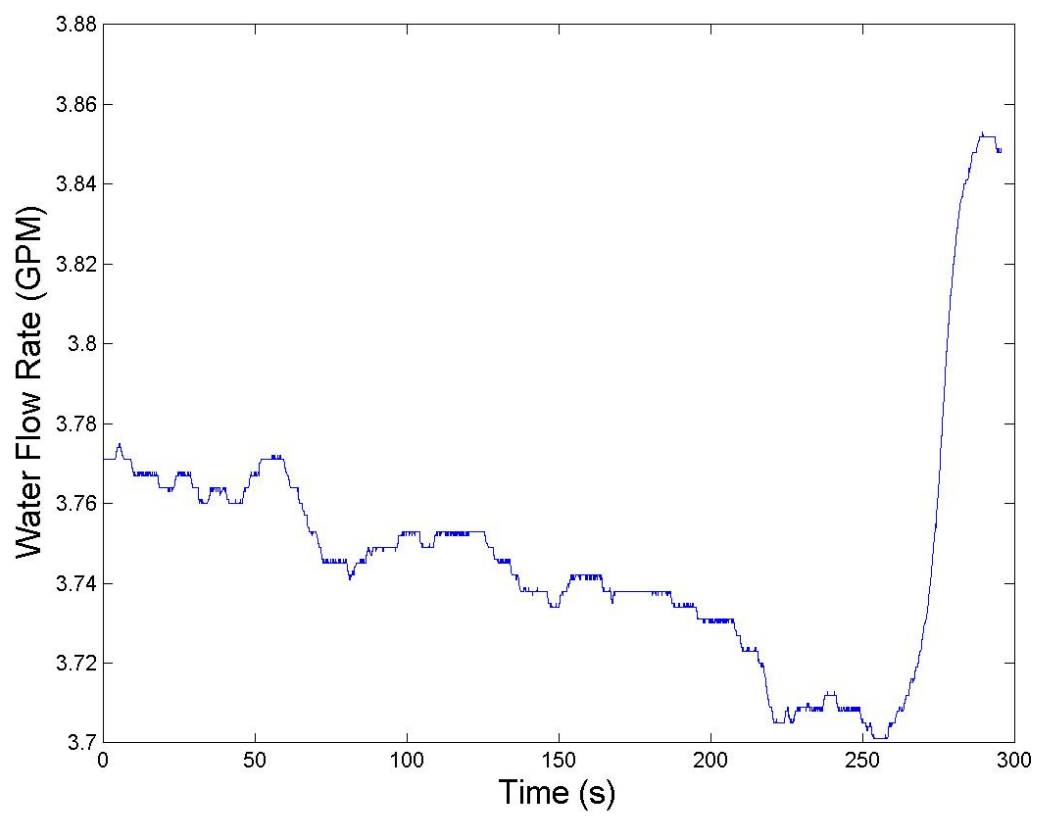

Fig. D.80.: Water flow rate measurements for Test 16 .

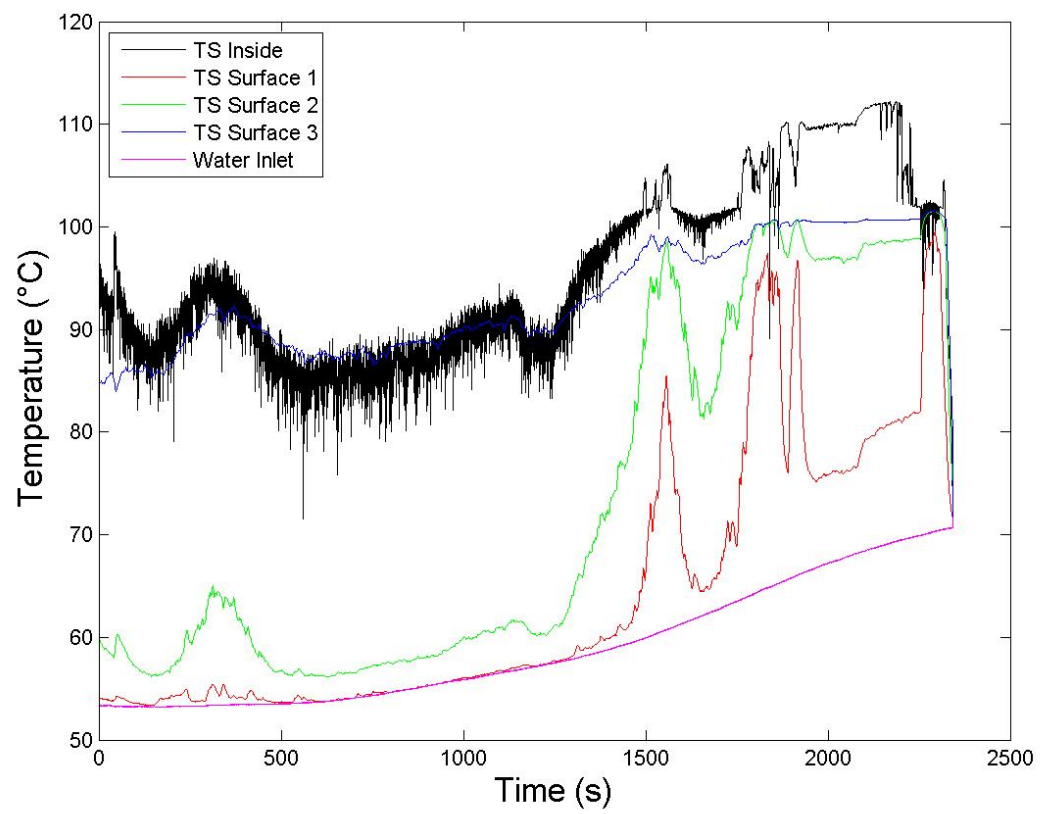

Fig. D.81.: Temperature measurements for Test 17. 


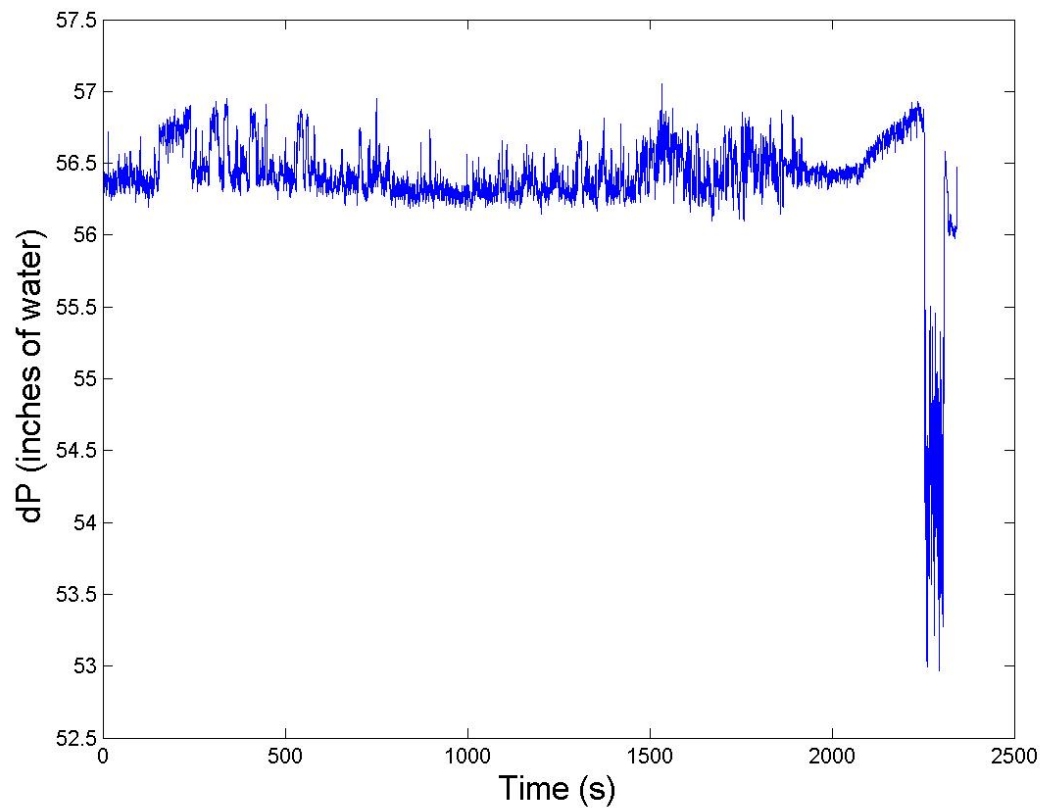

Fig. D.82.: Differential pressure measurements for Test 17.

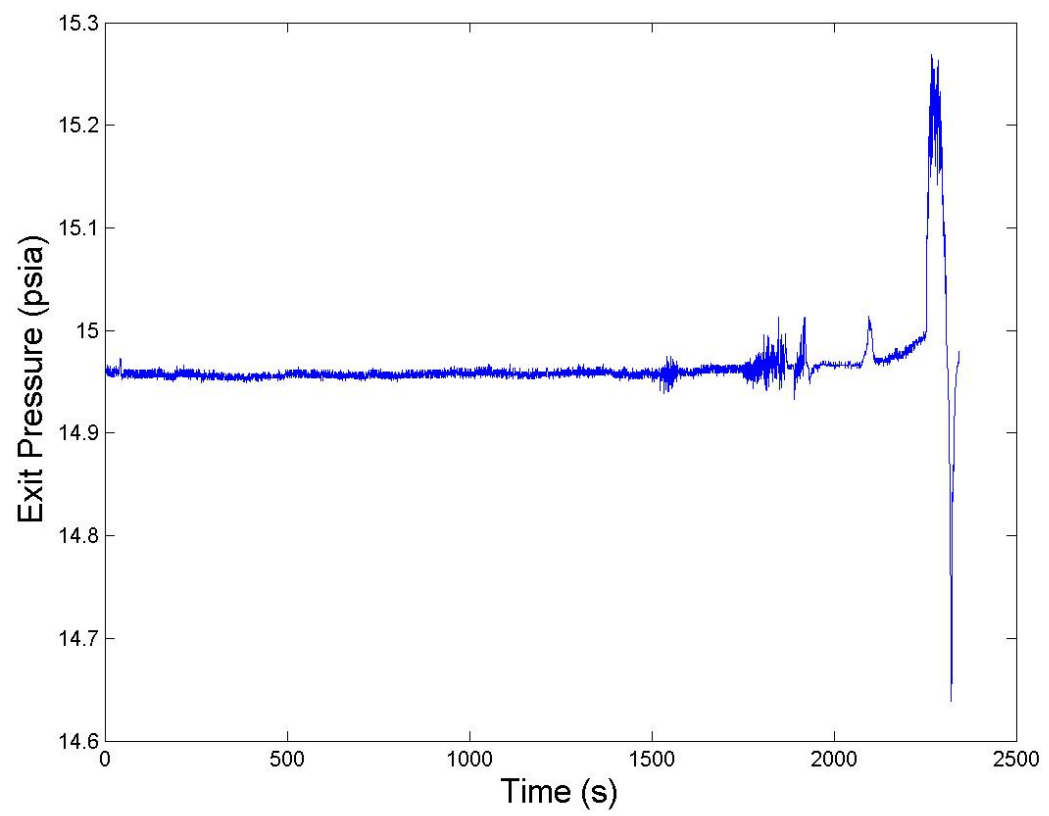

Fig. D.83.: Water exit tank pressure measurements for Test 17. 


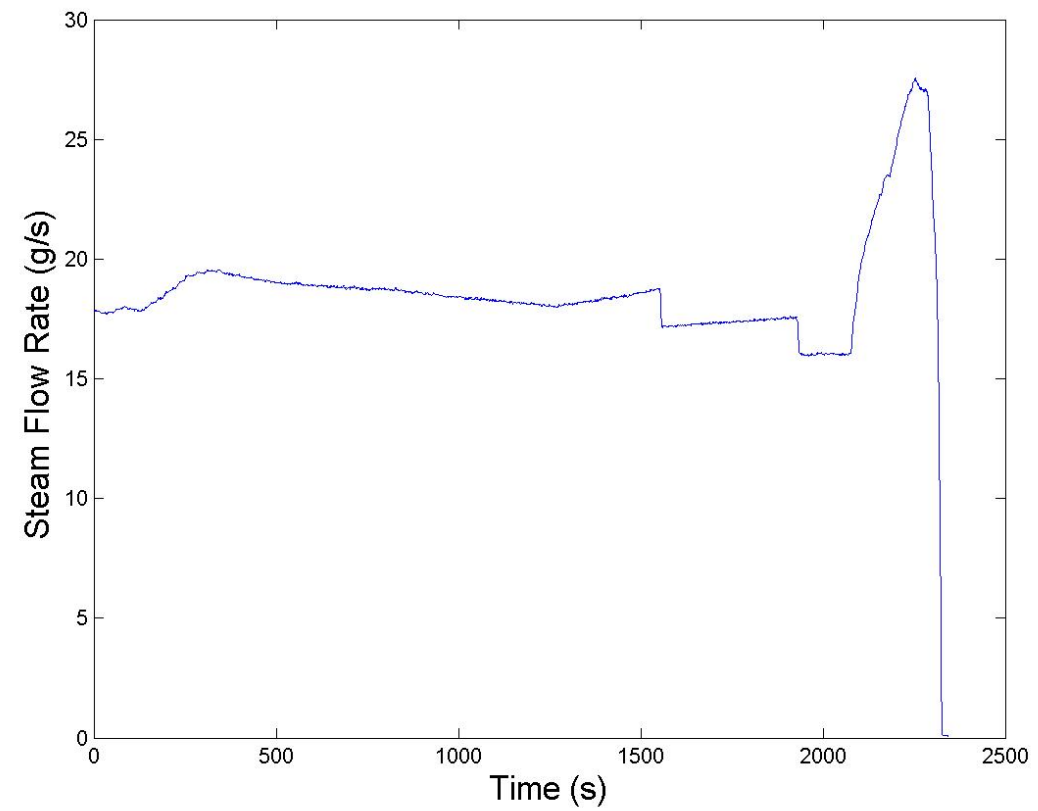

Fig. D.84.: Steam mass flow rate measurements for Test 17.

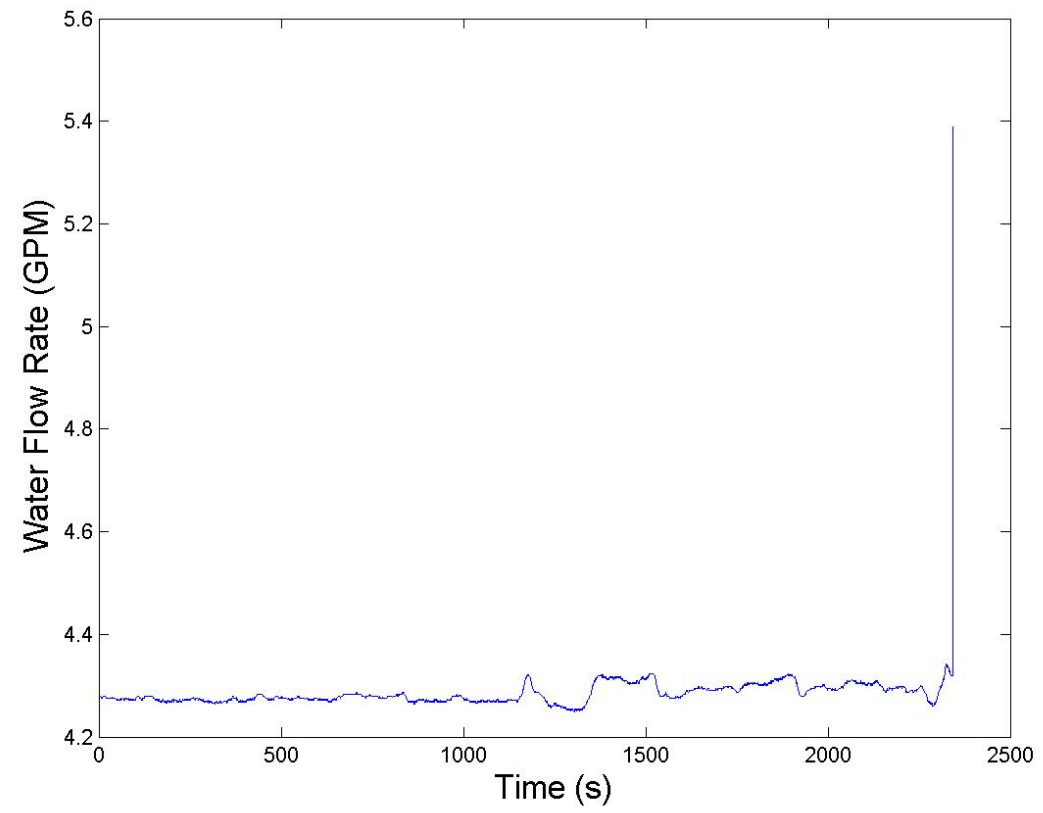

Fig. D.85.: Water flow rate measurements for Test 17. 


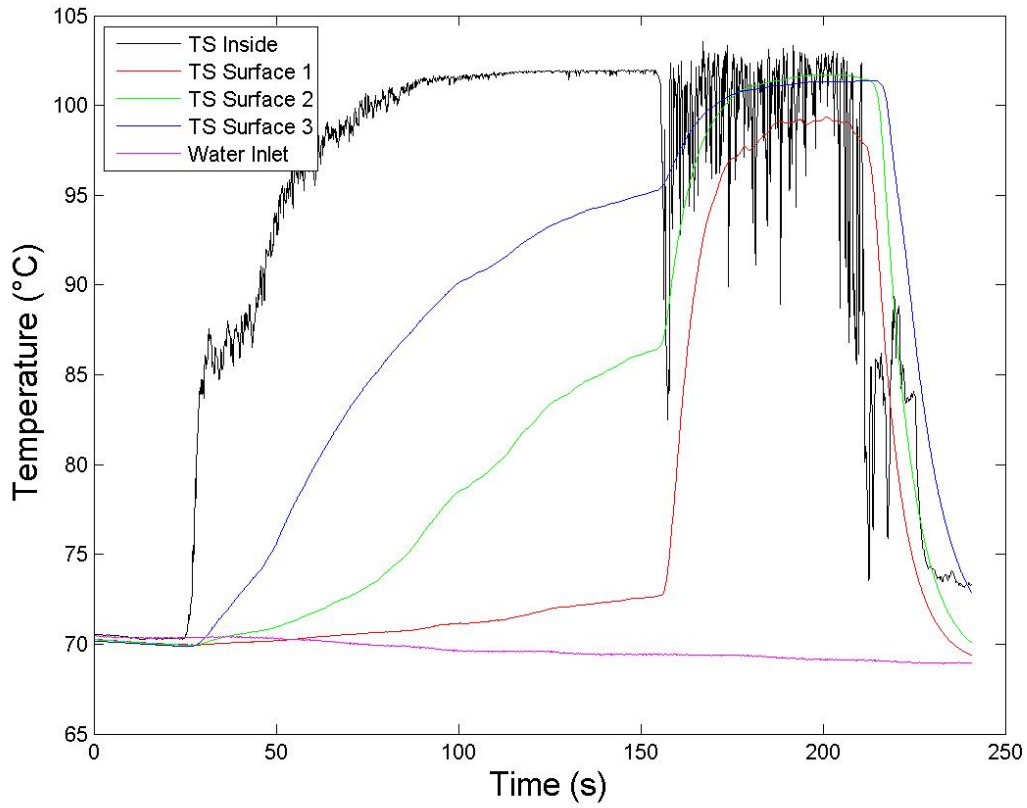

Fig. D.86.: Temperature measurements for Test 18.

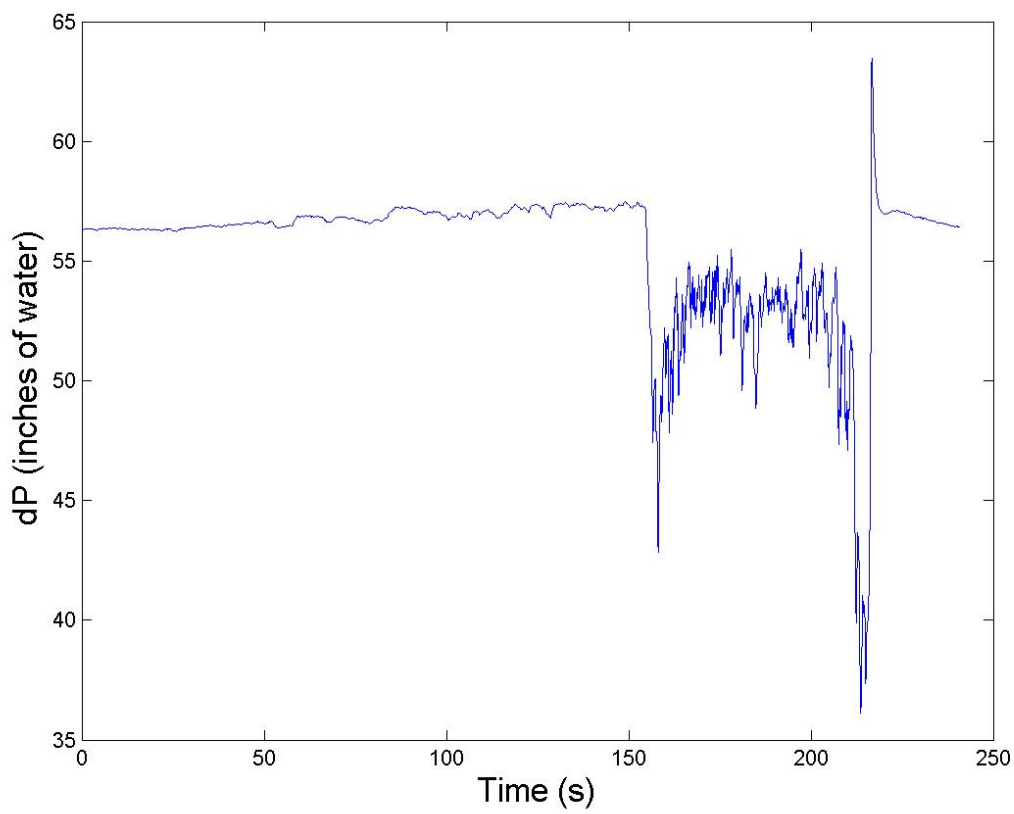

Fig. D.87.: Differential pressure measurements for Test 18. 


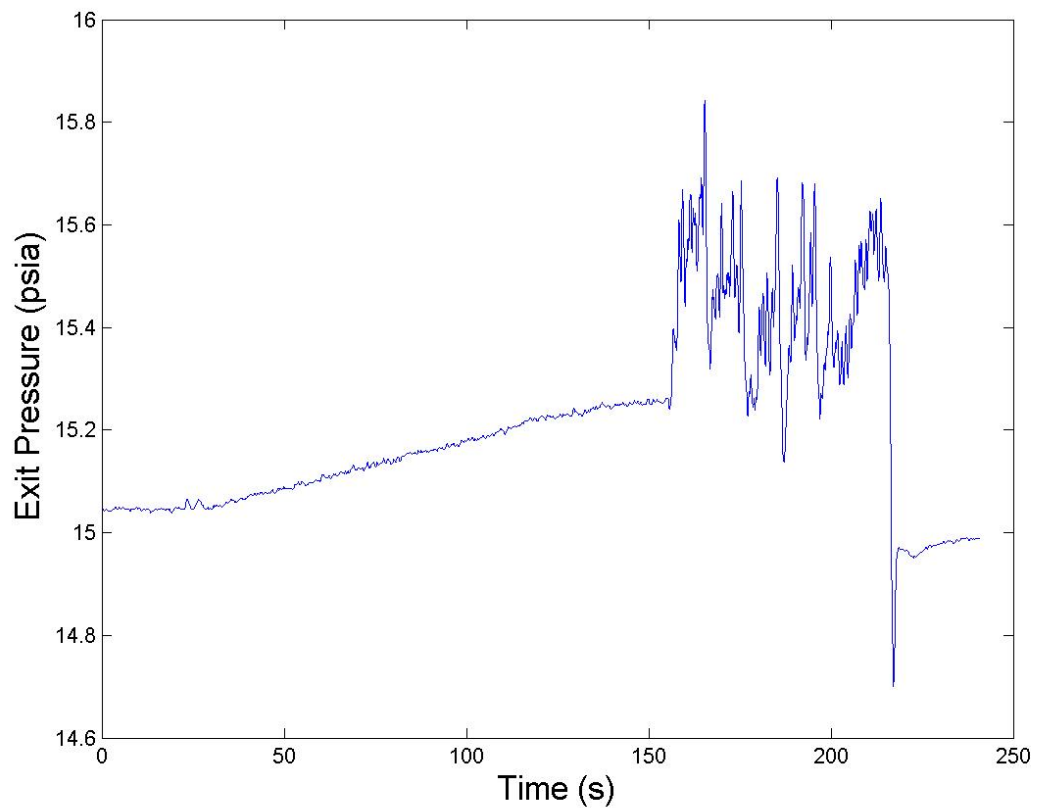

Fig. D.88.: Water exit tank pressure measurements for Test 18.

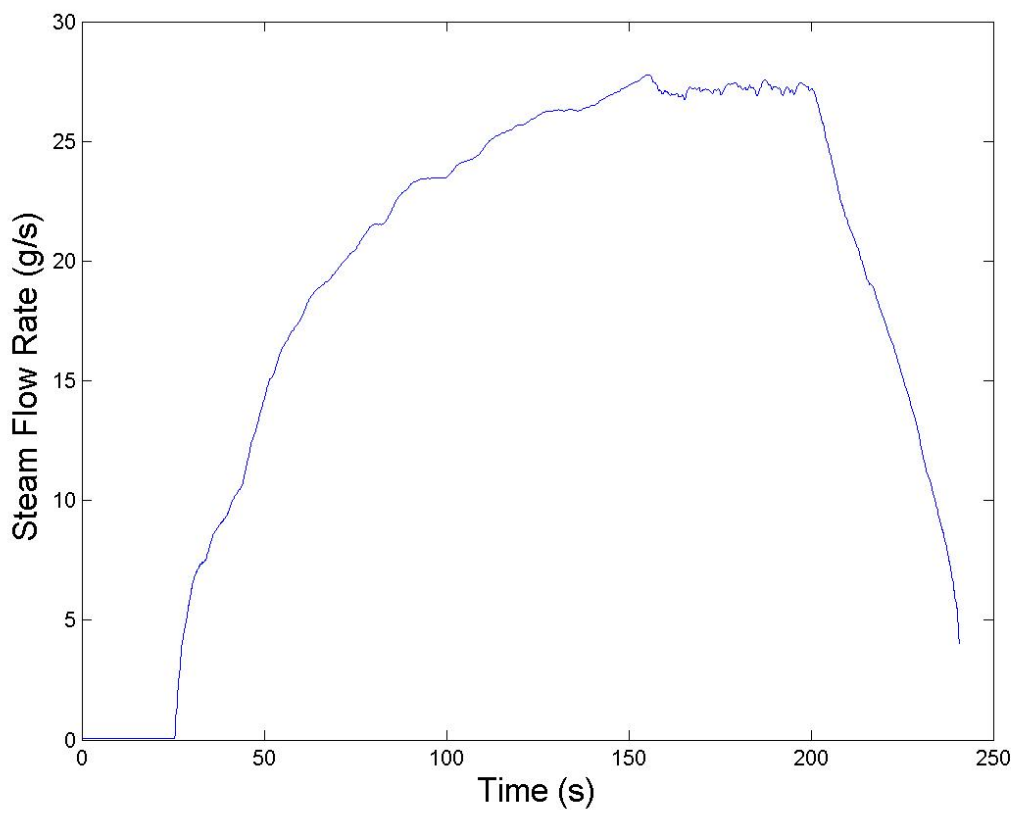

Fig. D.89.: Steam mass flow rate measurements for Test 18. 


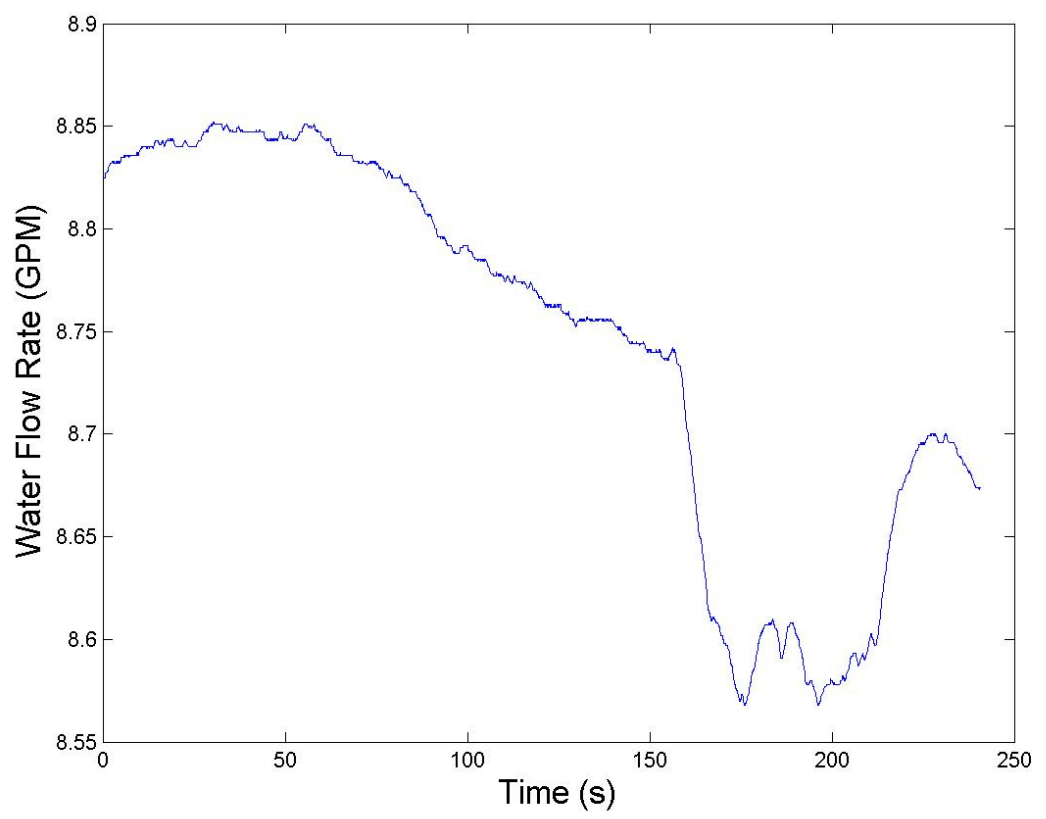

Fig. D.90.: Water flow rate measurements for Test 18.

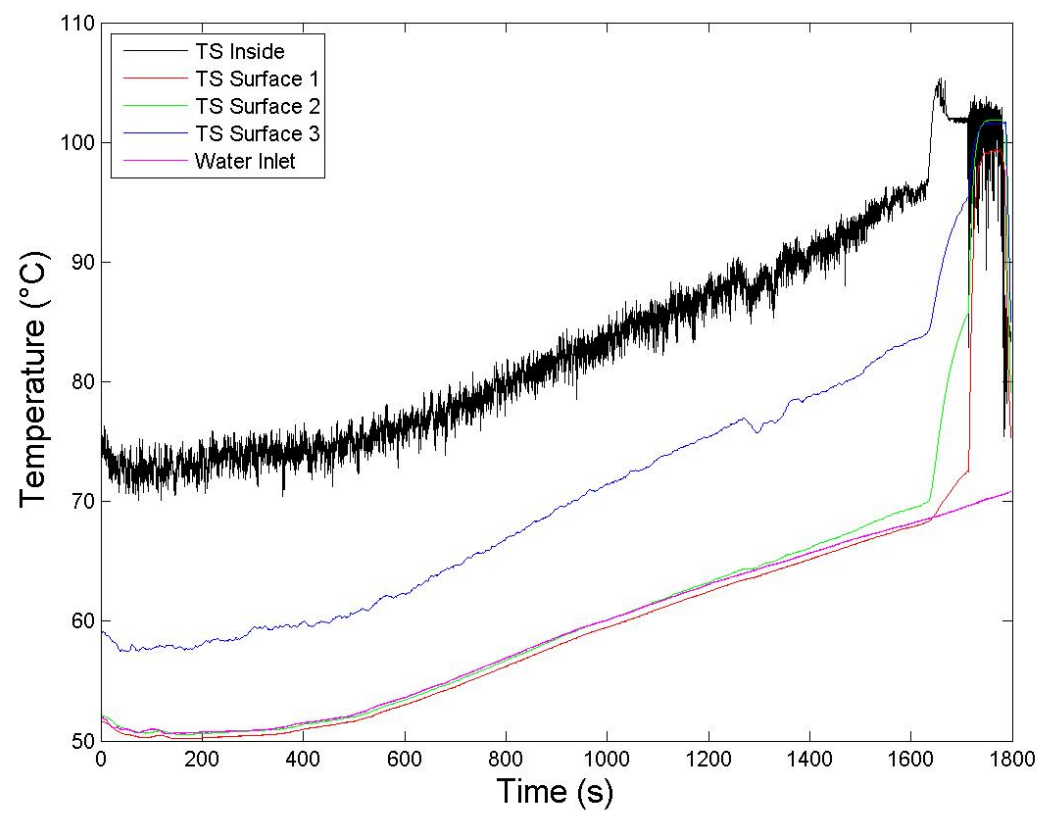

Fig. D.91.: Temperature measurements for Test 19. 


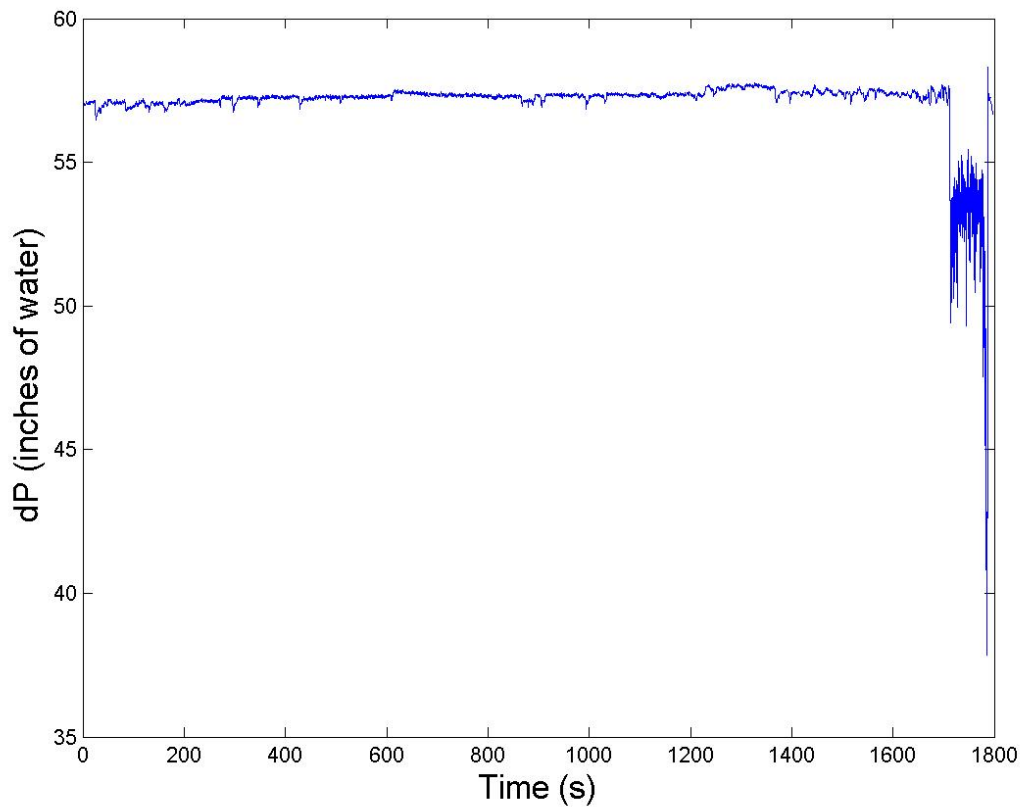

Fig. D.92.: Differential pressure measurements for Test 19.

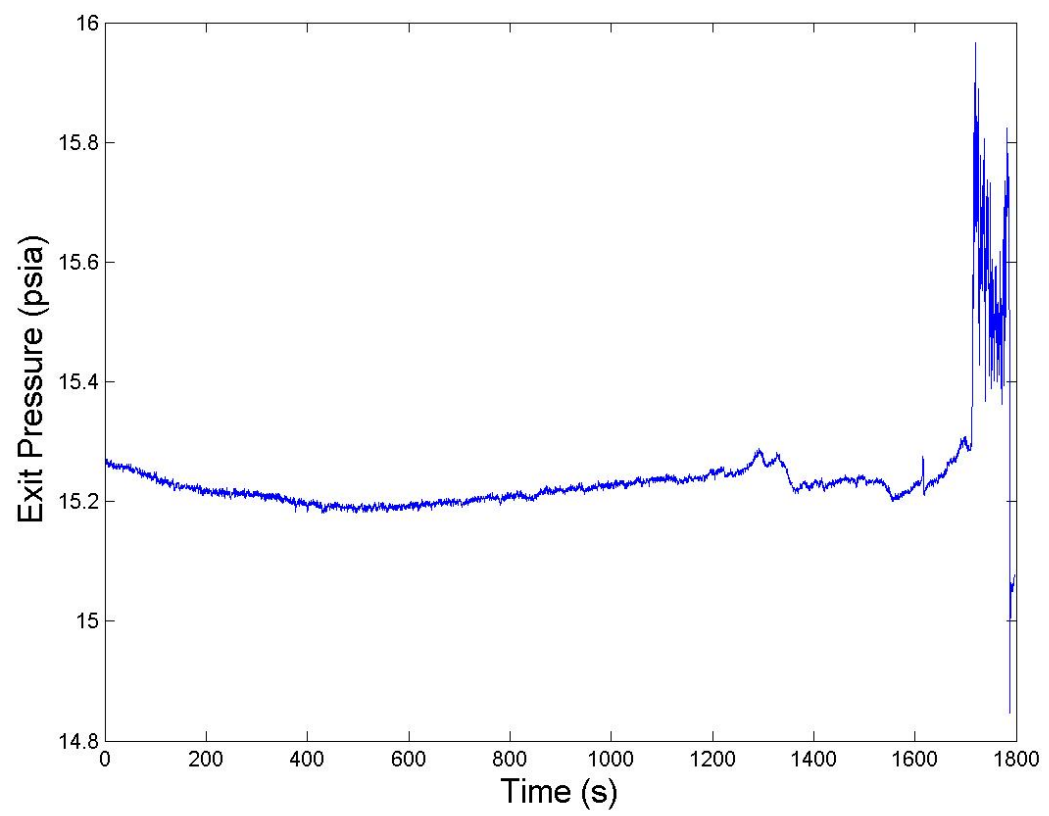

Fig. D.93.: Water exit tank pressure measurements for Test 19. 


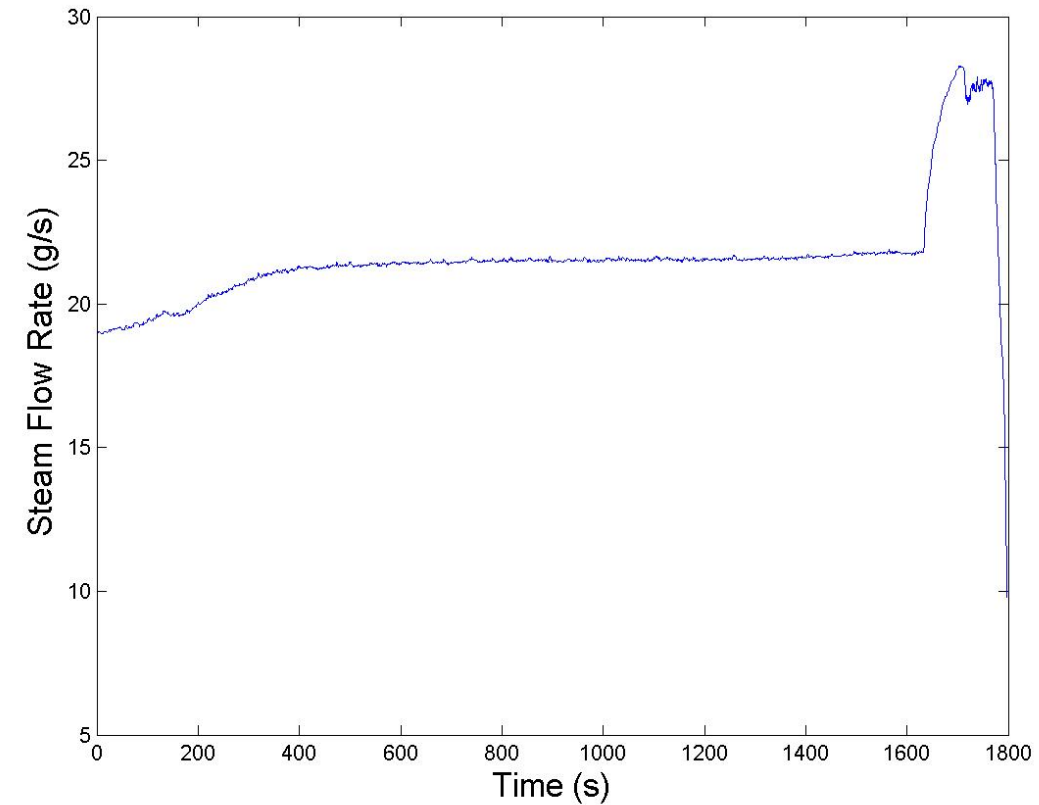

Fig. D.94.: Steam mass flow rate measurements for Test 19.

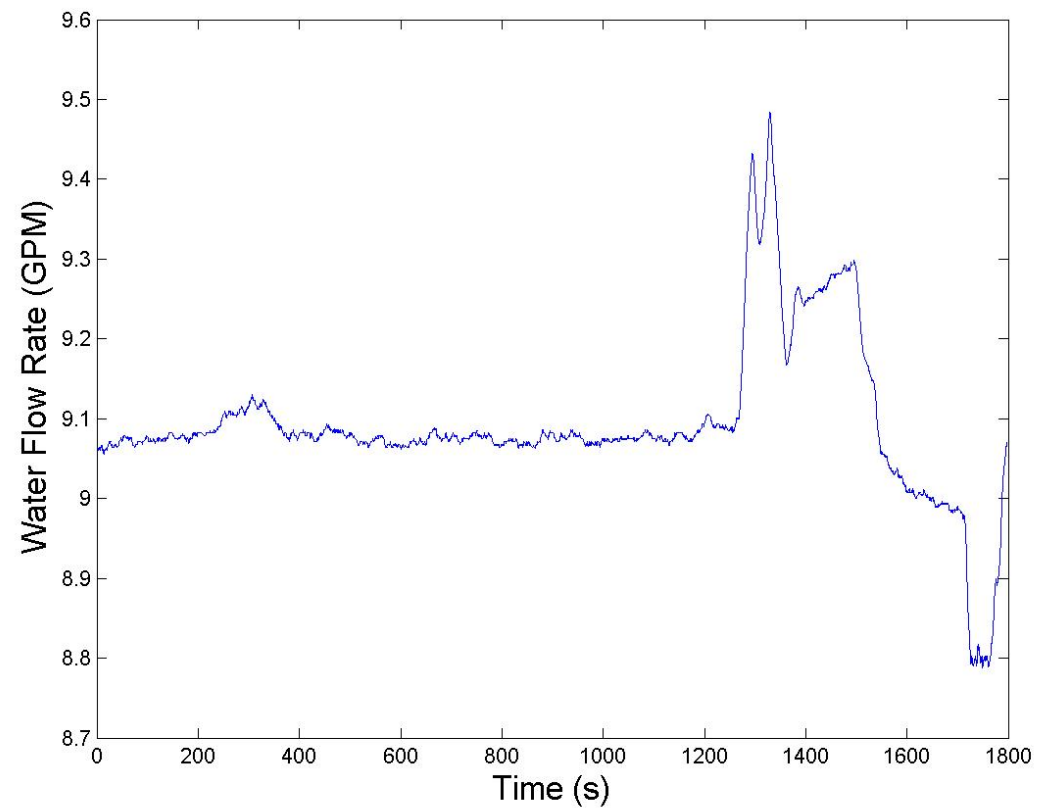

Fig. D.95.: Water flow rate measurements for Test 19. 


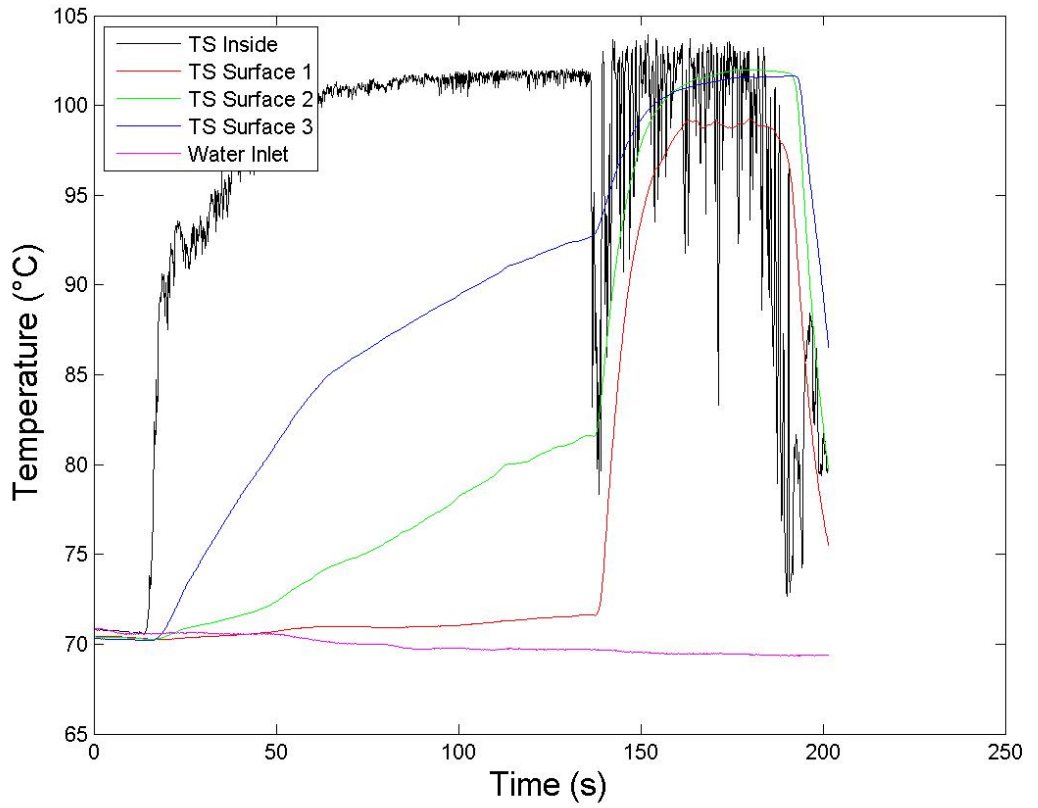

Fig. D.96.: Temperature measurements for Test 20.

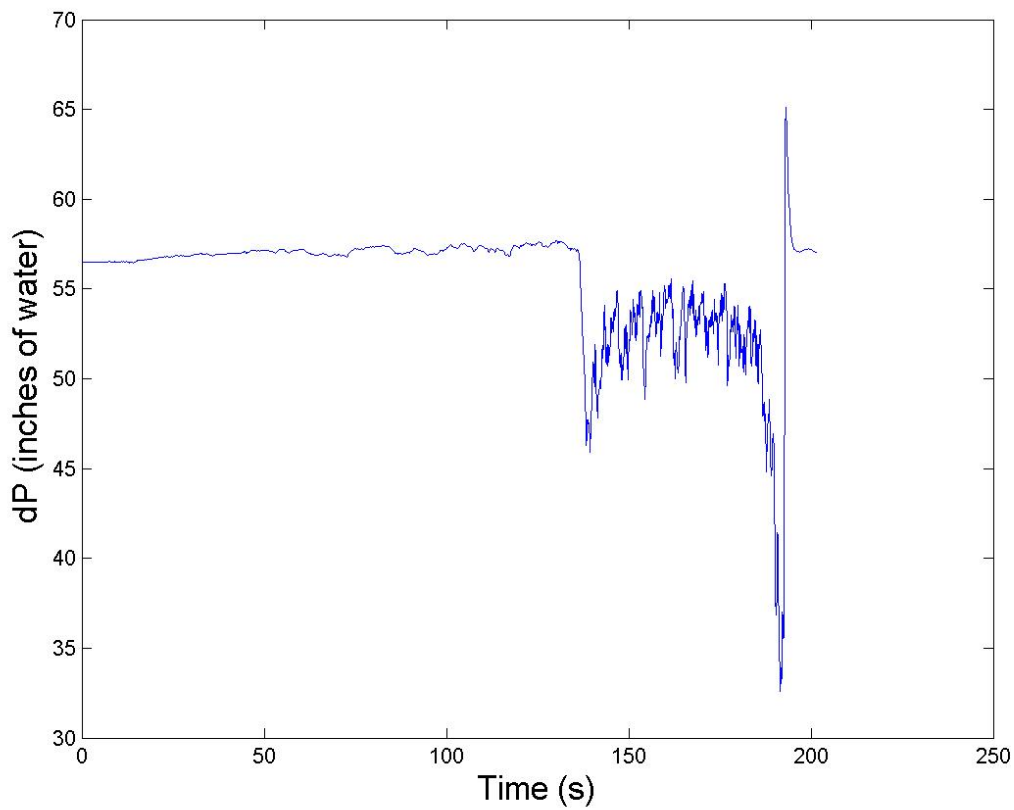

Fig. D.97.: Differential pressure measurements for Test 20. 


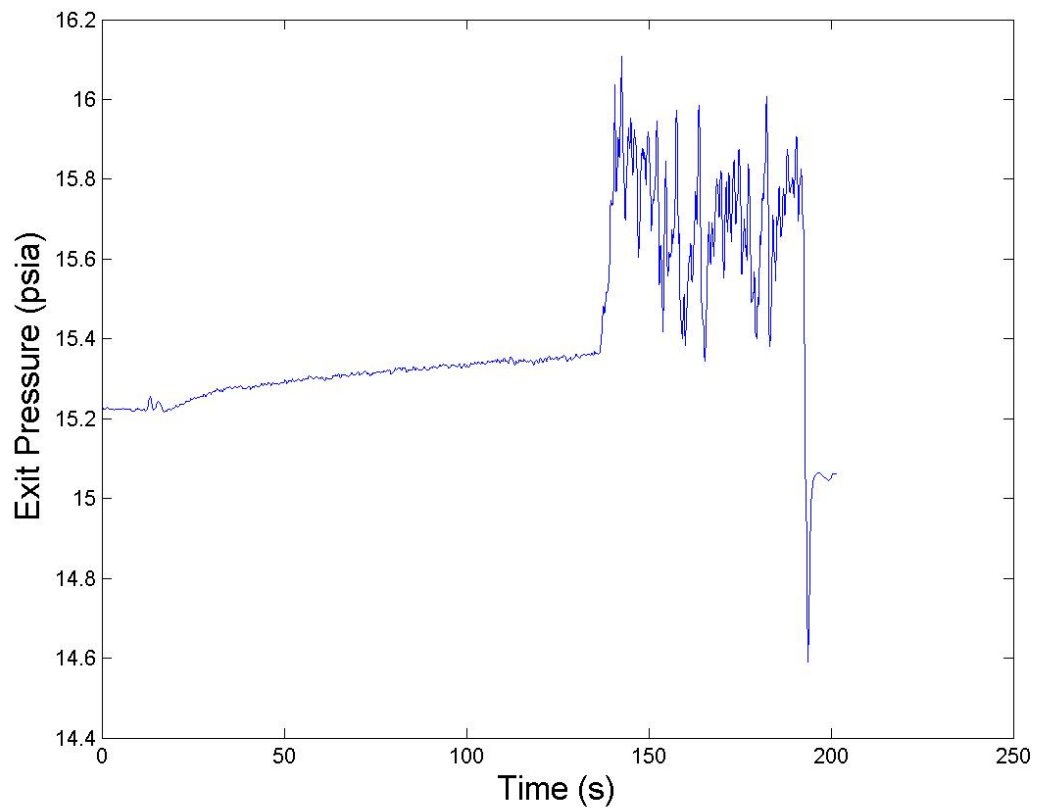

Fig. D.98.: Water exit tank pressure measurements for Test 20.

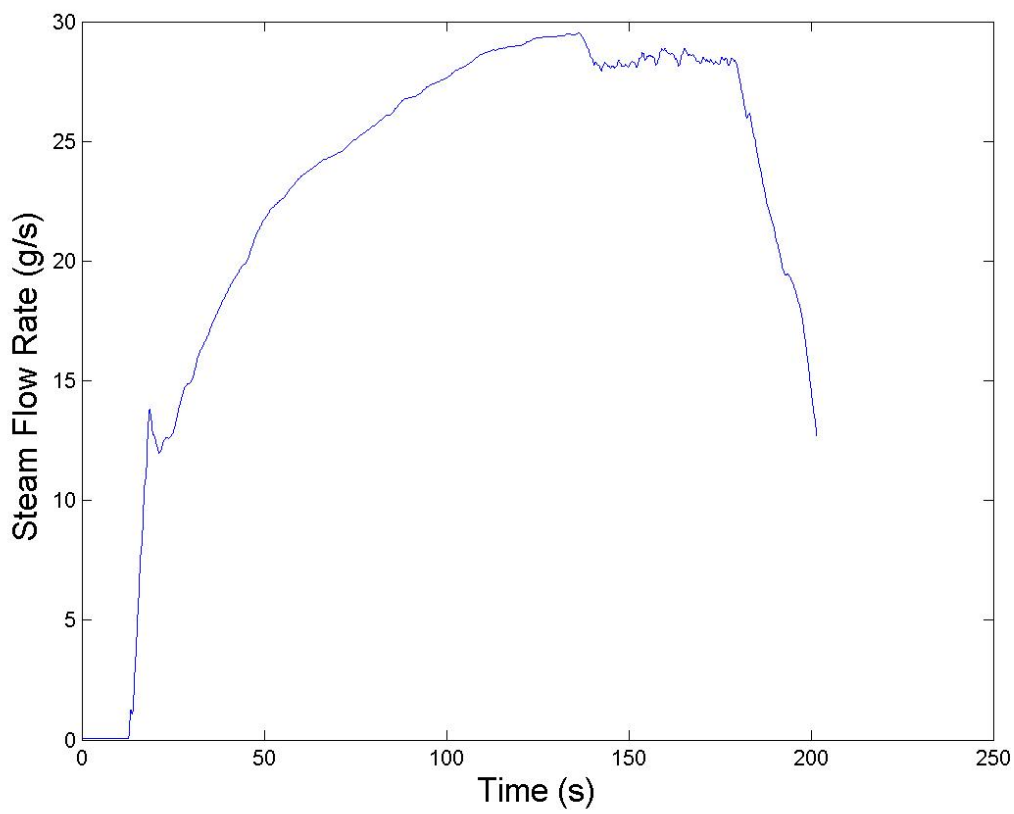

Fig. D.99.: Steam mass flow rate measurements for Test 20. 


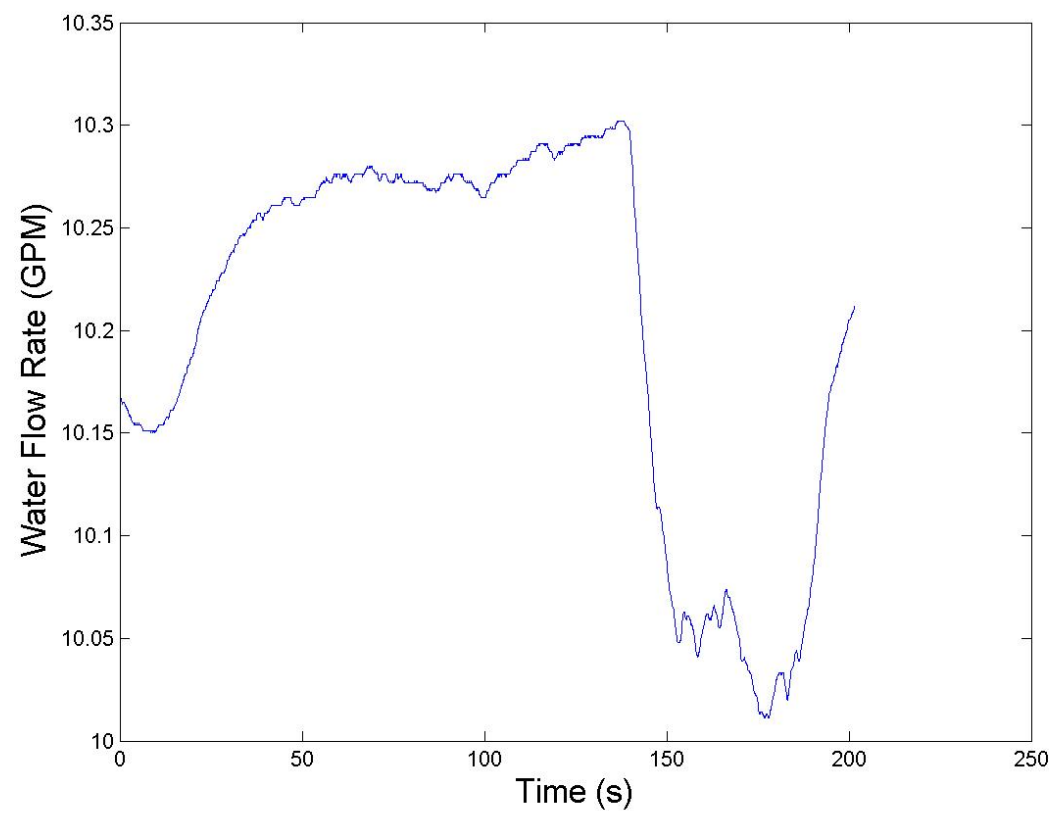

Fig. D.100.: Water flow rate measurements for Test 20.

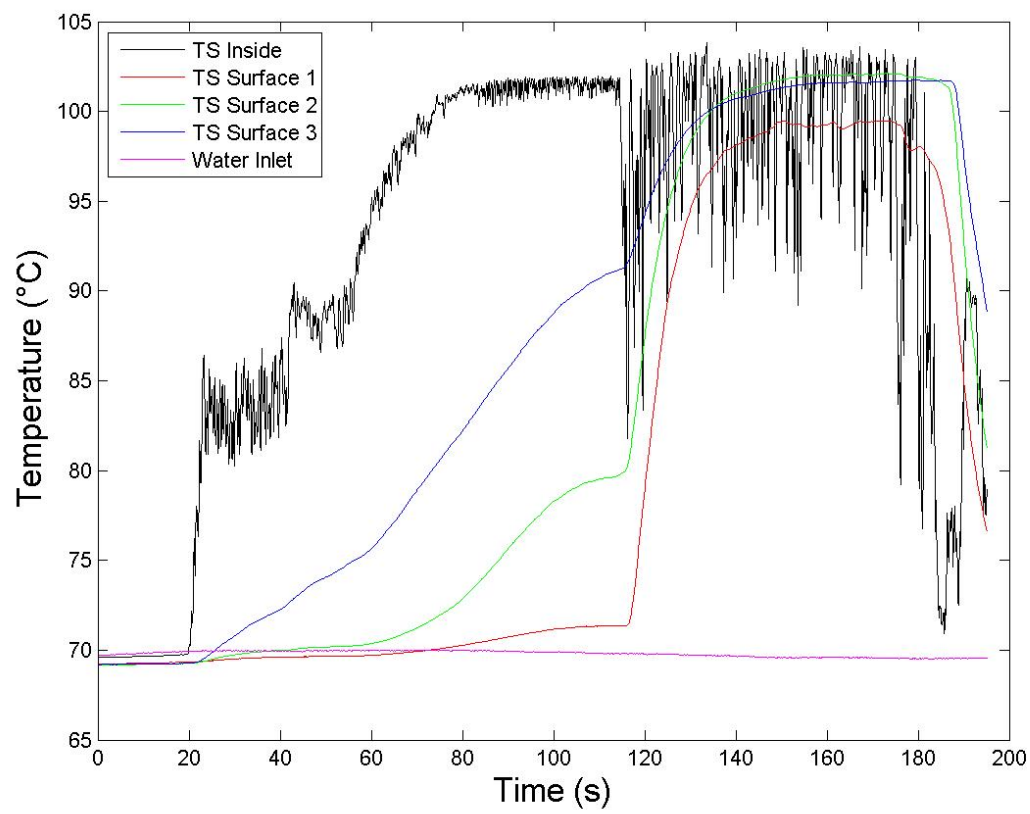

Fig. D.101.: Temperature measurements for Test 21. 


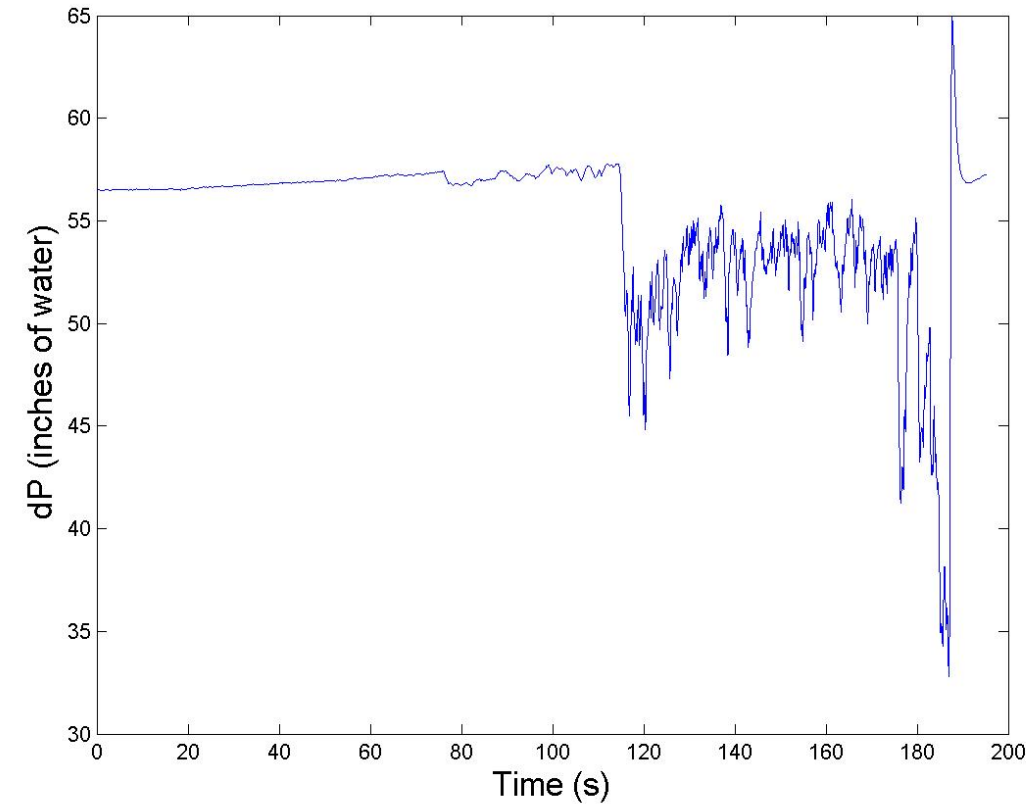

Fig. D.102.: Differential pressure measurements for Test 21.

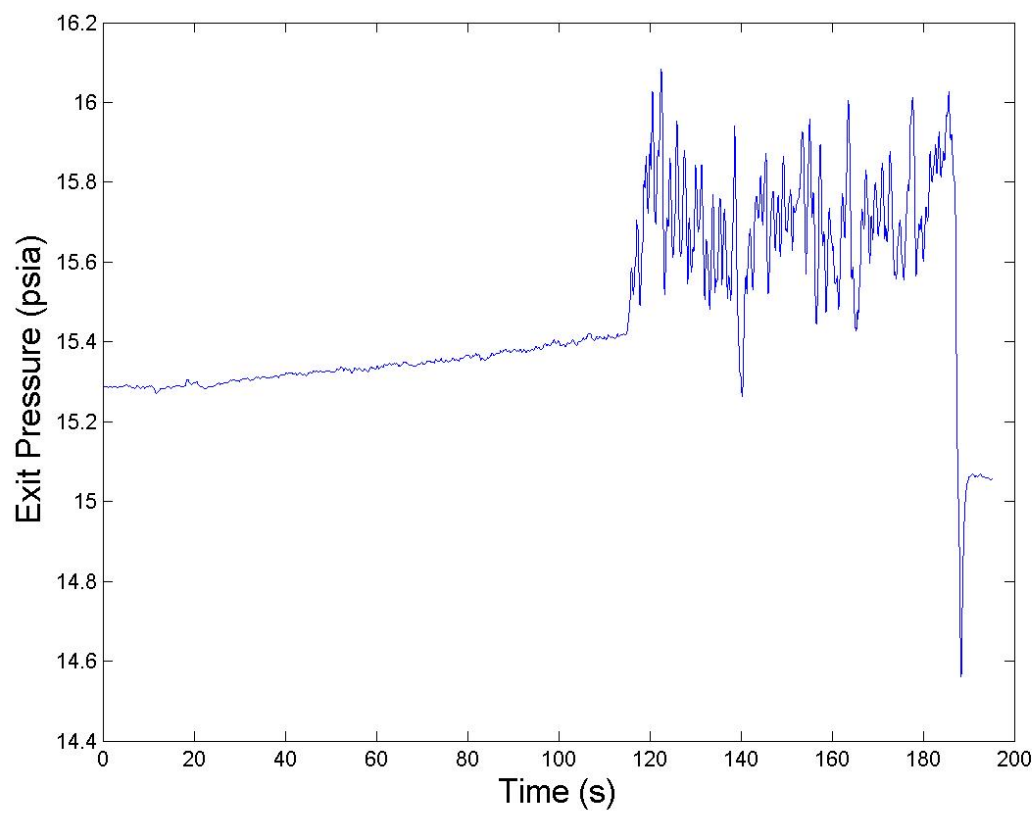

Fig. D.103.: Water exit tank pressure measurements for Test 21. 


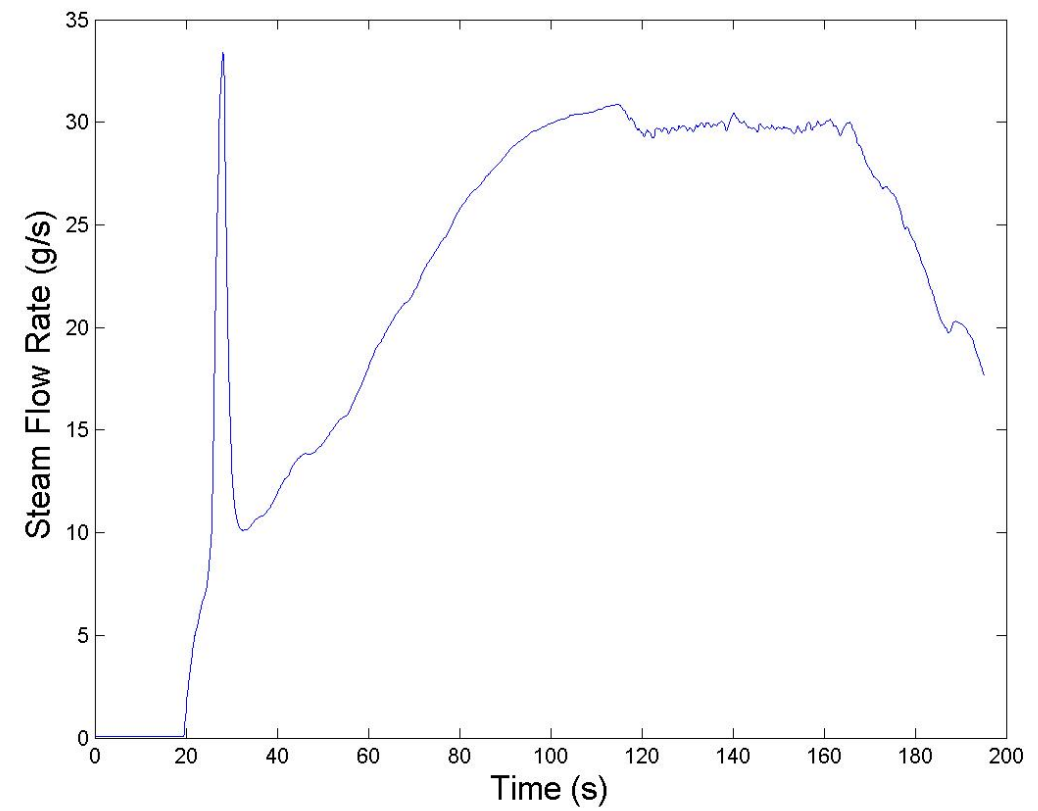

Fig. D.104.: Steam mass flow rate measurements for Test 21.

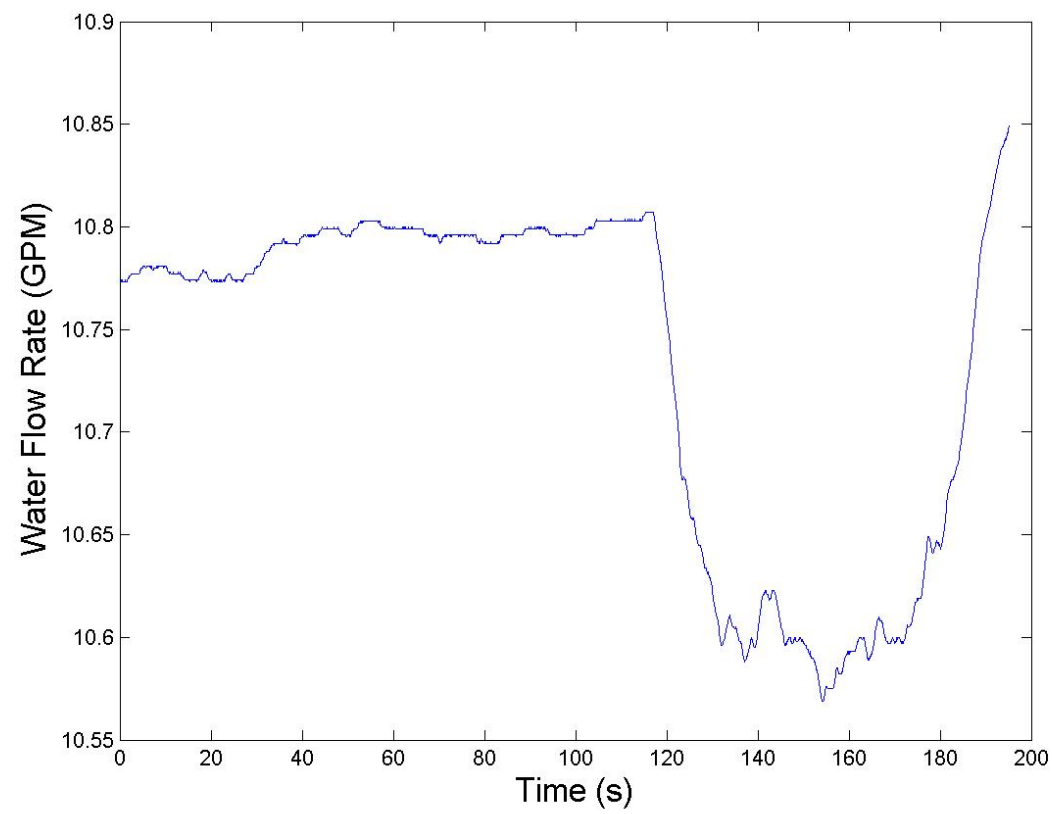

Fig. D.105.: Water flow rate measurements for Test 21. 


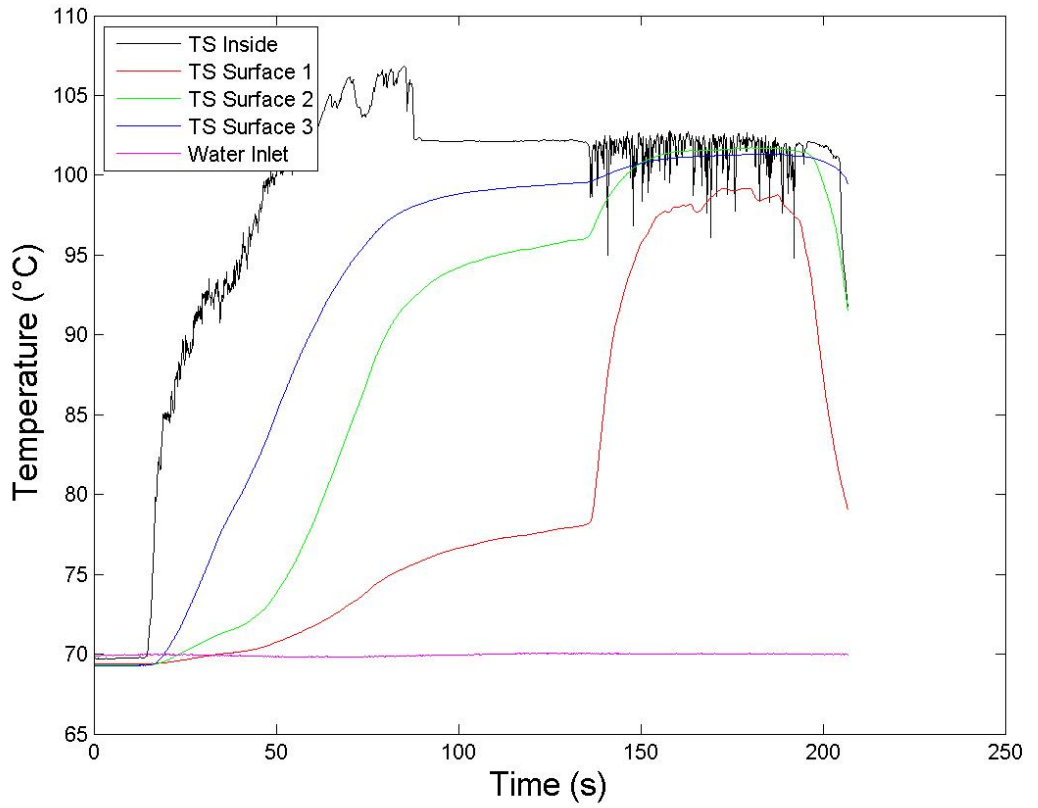

Fig. D.106.: Temperature measurements for Test 22.

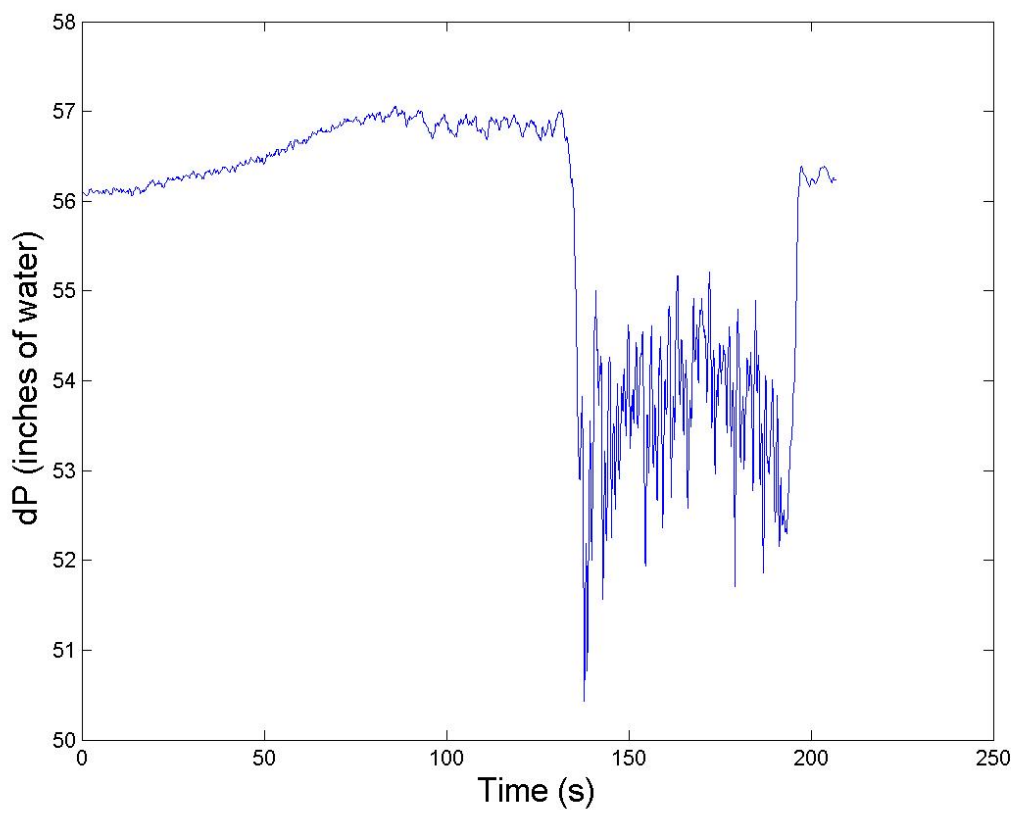

Fig. D.107.: Differential pressure measurements for Test 22. 


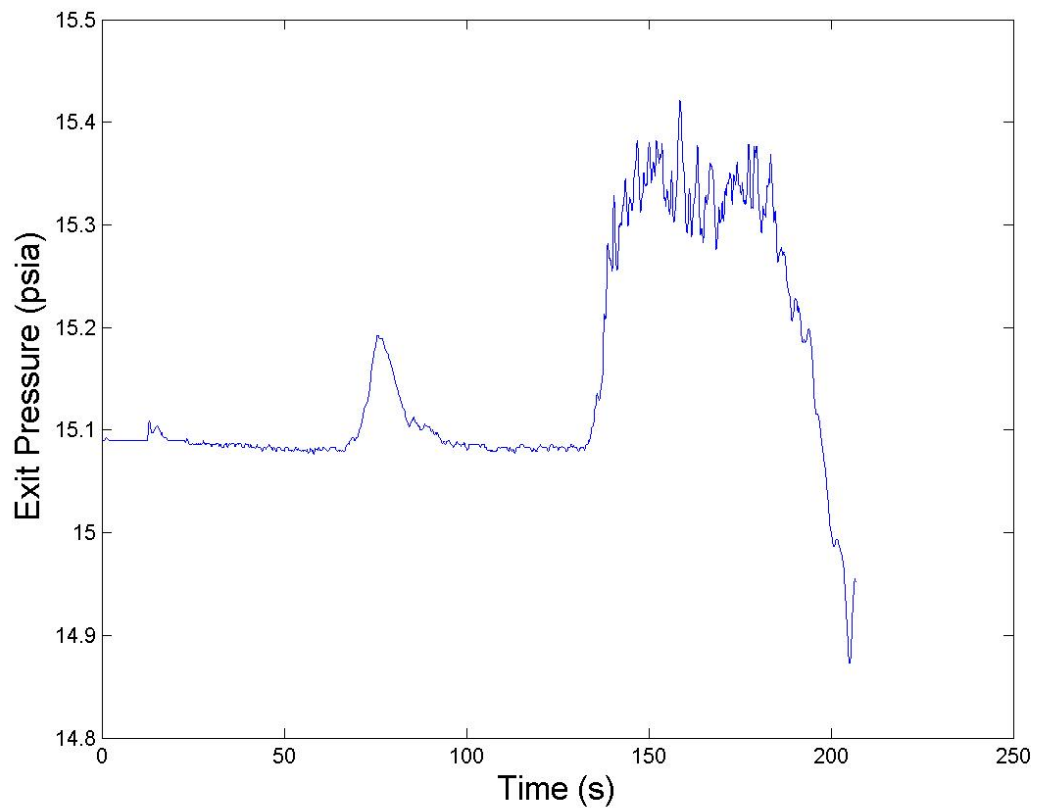

Fig. D.108.: Water exit tank pressure measurements for Test 22.

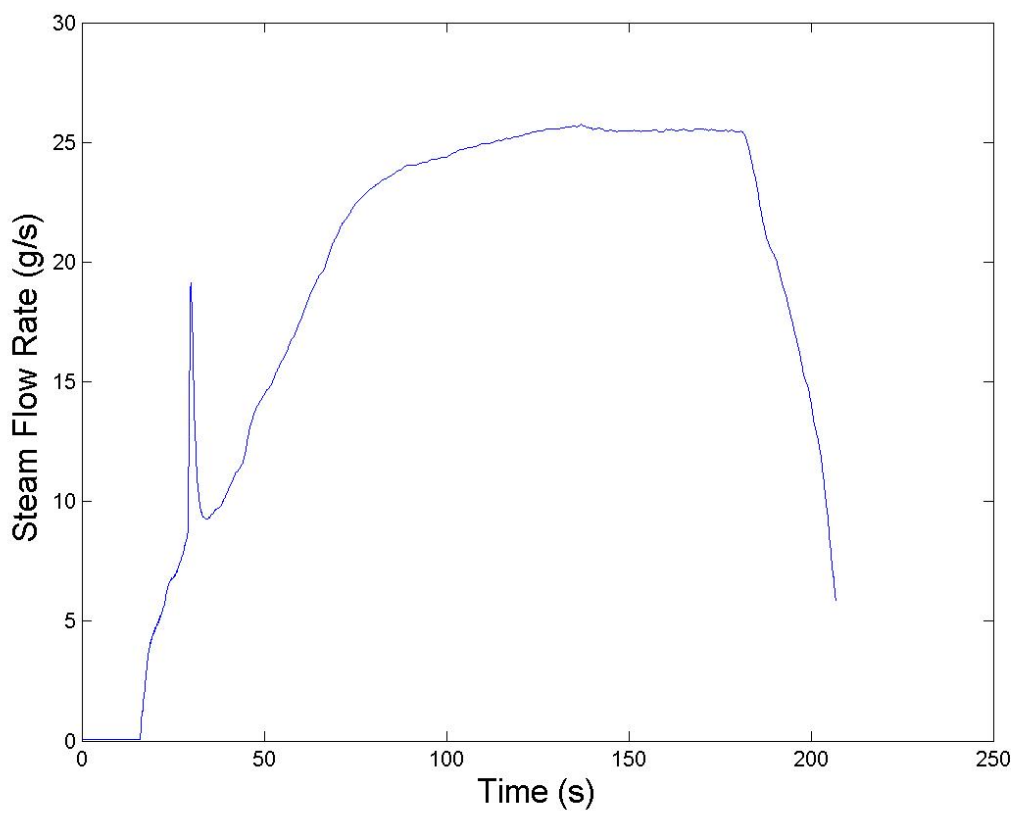

Fig. D.109.: Steam mass flow rate measurements for Test 22. 


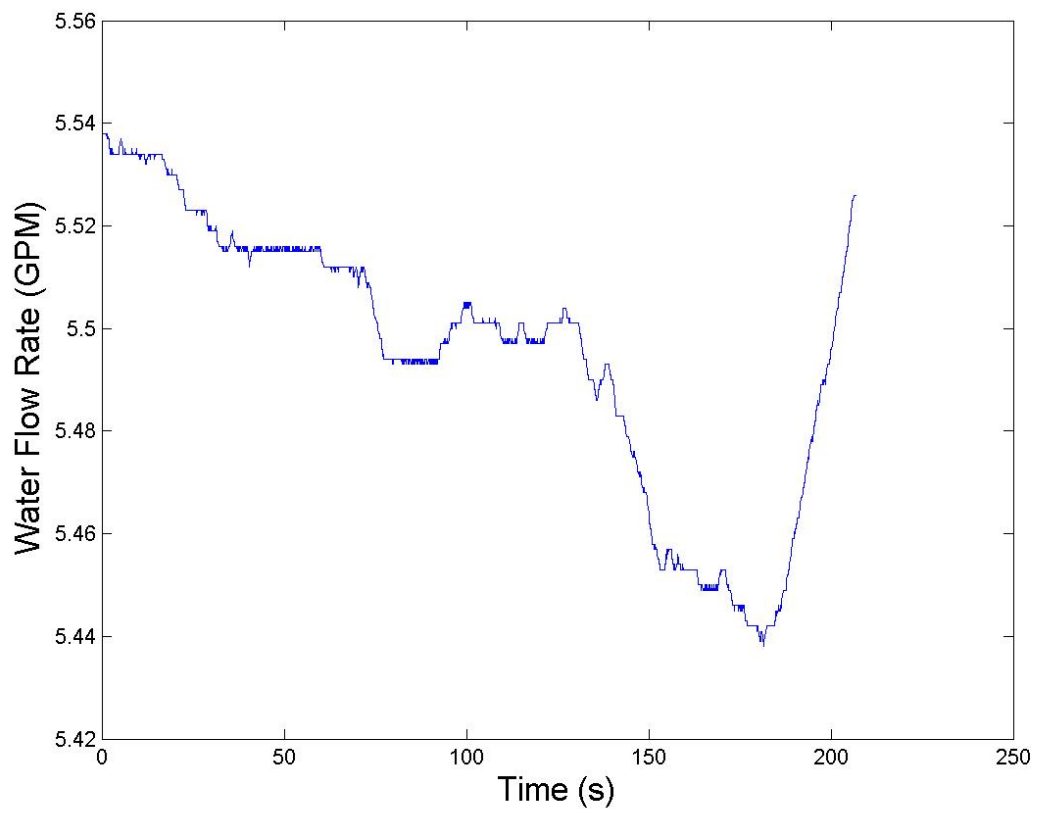

Fig. D.110.: Water flow rate measurements for Test 22.

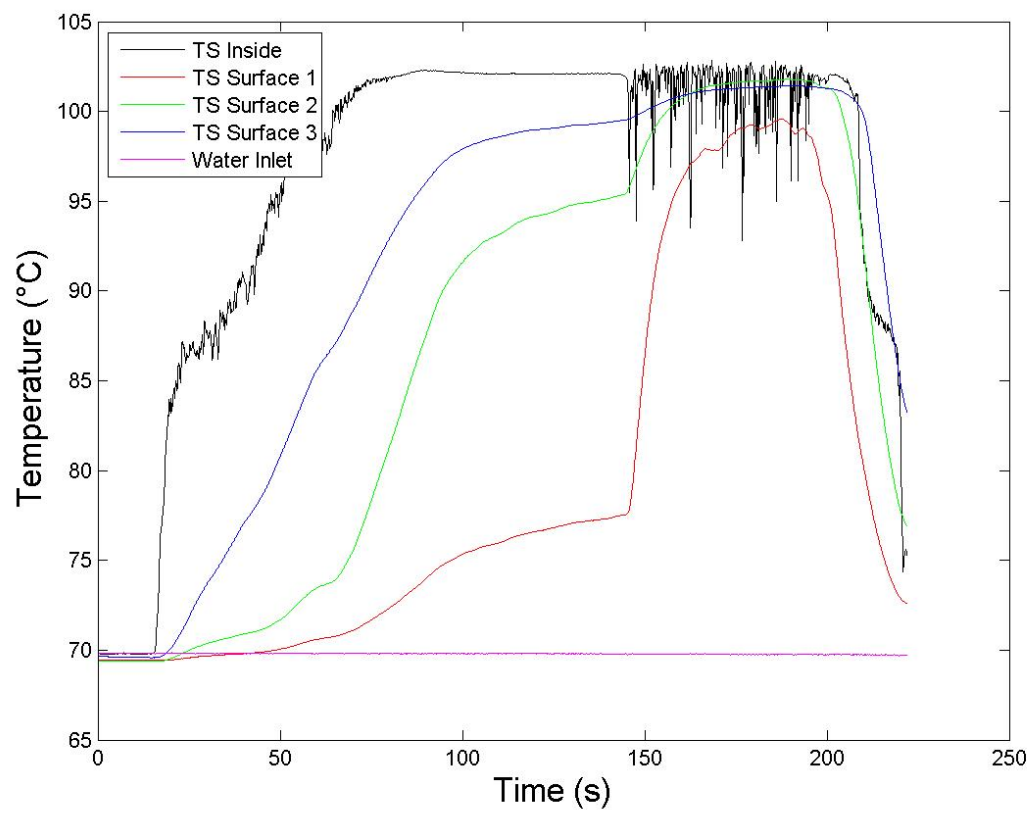

Fig. D.111.: Temperature measurements for Test 23. 


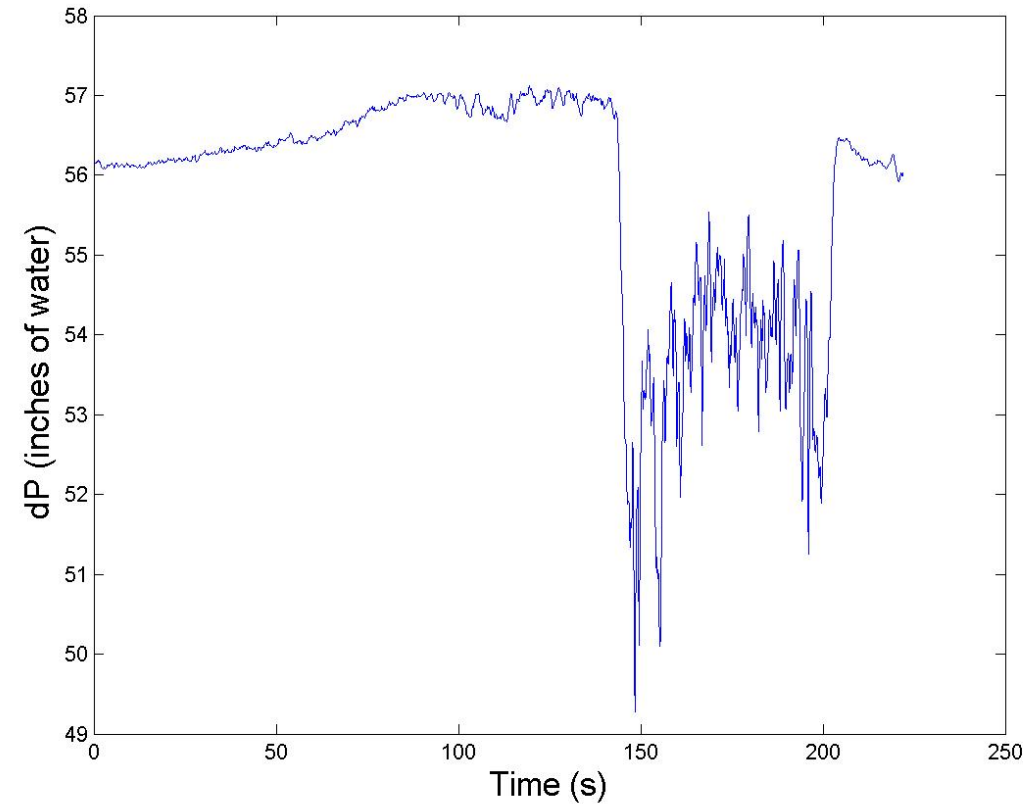

Fig. D.112.: Differential pressure measurements for Test 23.

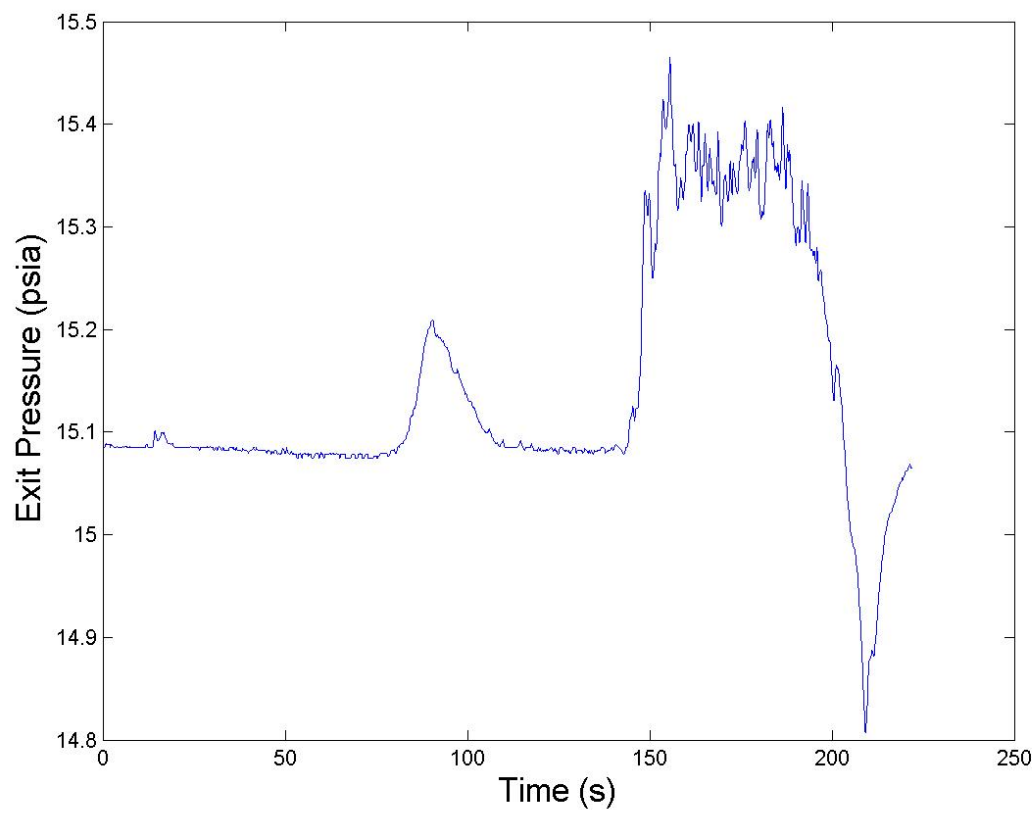

Fig. D.113.: Water exit tank pressure measurements for Test 23. 


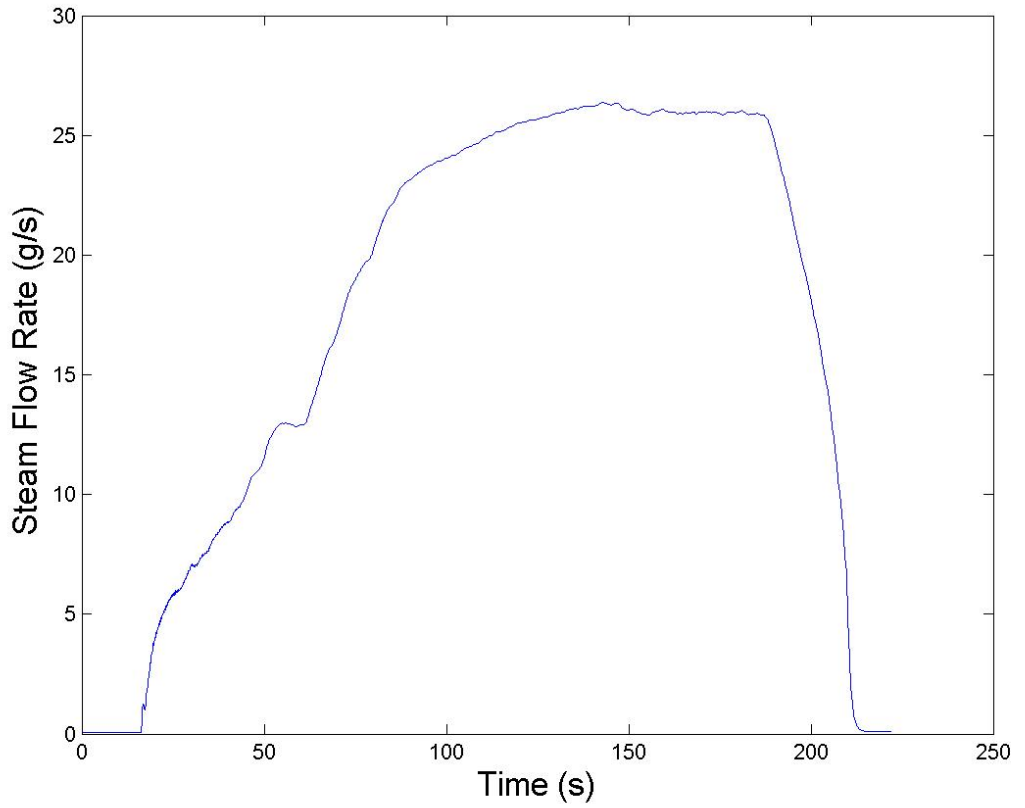

Fig. D.114.: Steam mass flow rate measurements for Test 23.

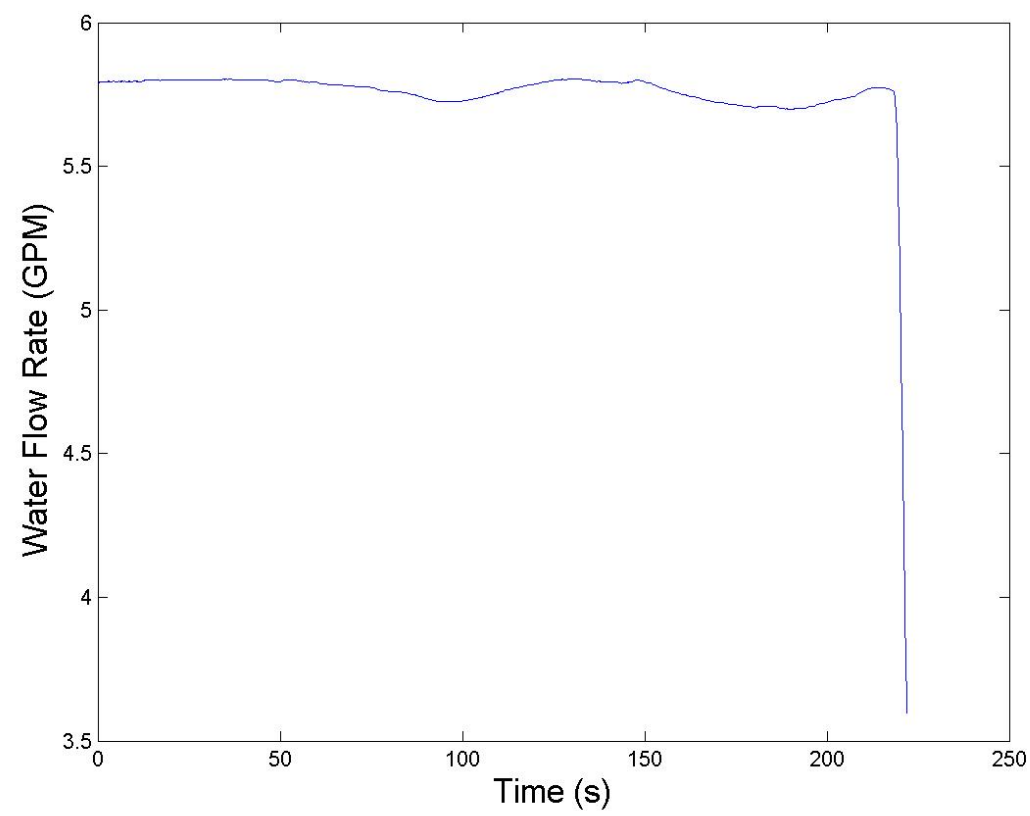

Fig. D.115.: Water flow rate measurements for Test 23. 


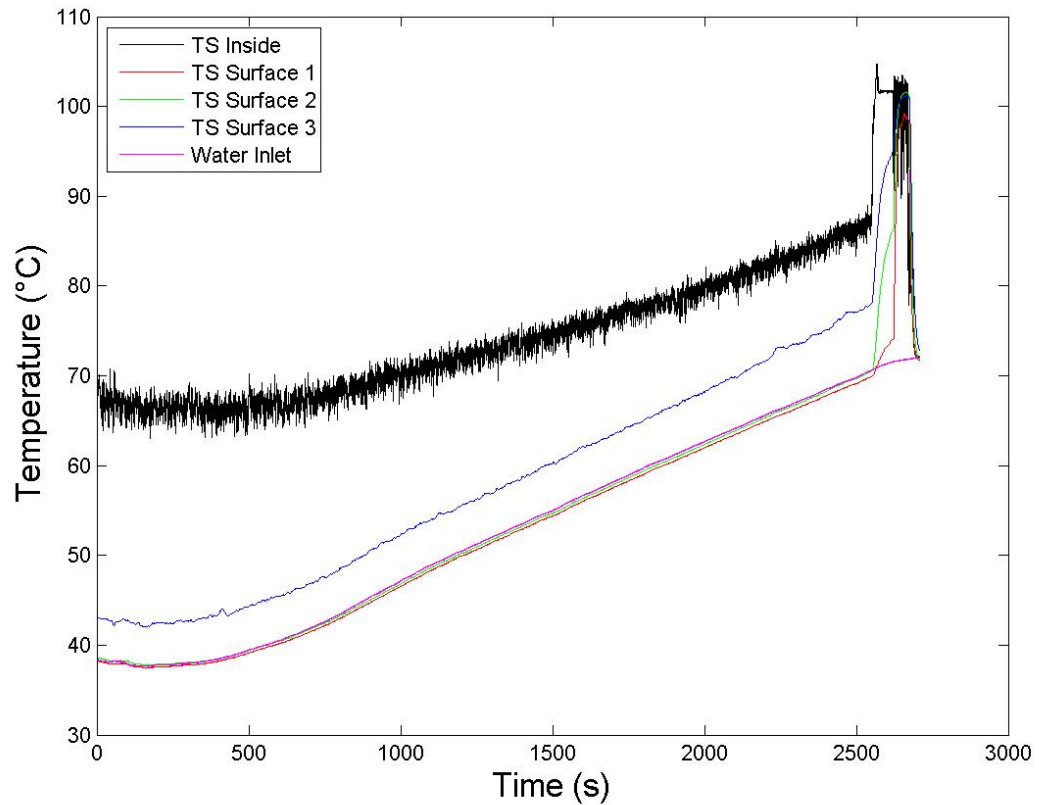

Fig. D.116.: Temperature measurements for Test 24.

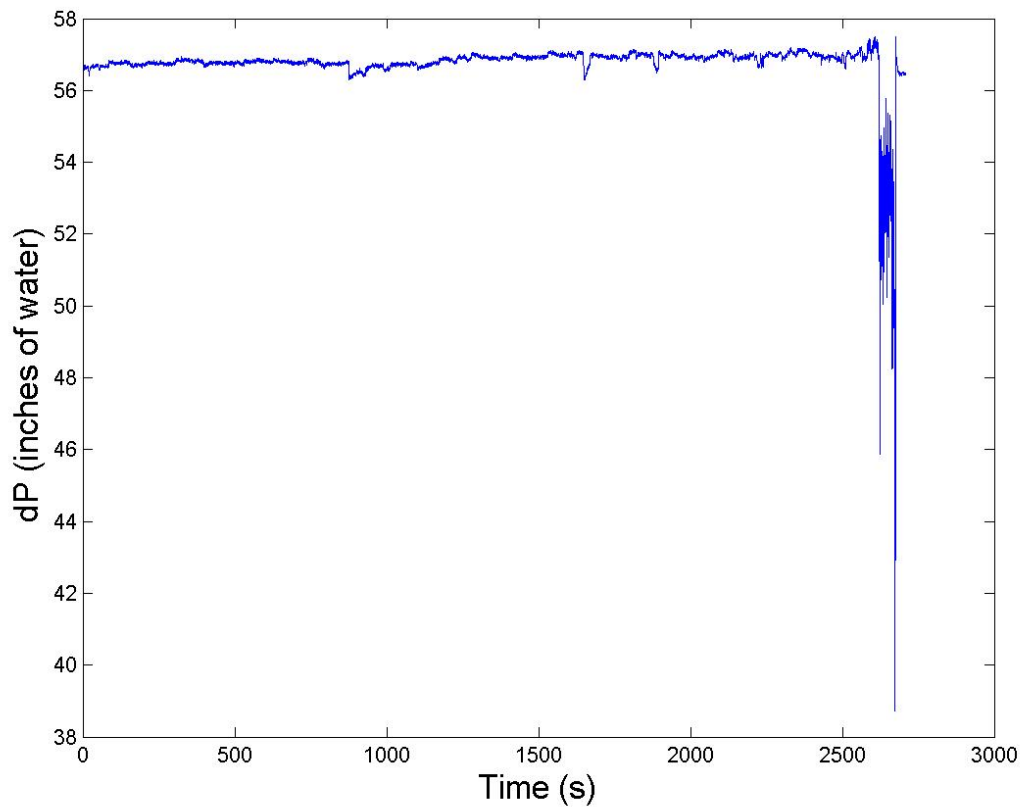

Fig. D.117.: Differential pressure measurements for Test 24. 


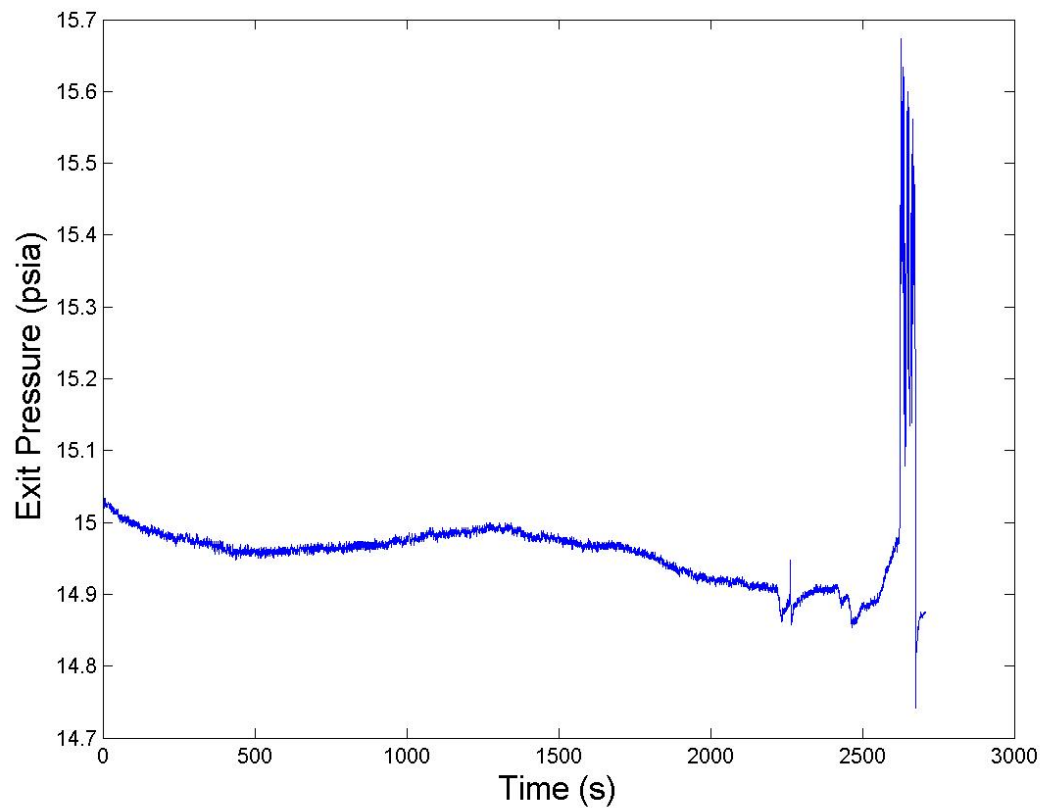

Fig. D.118.: Water exit tank pressure measurements for Test 24.

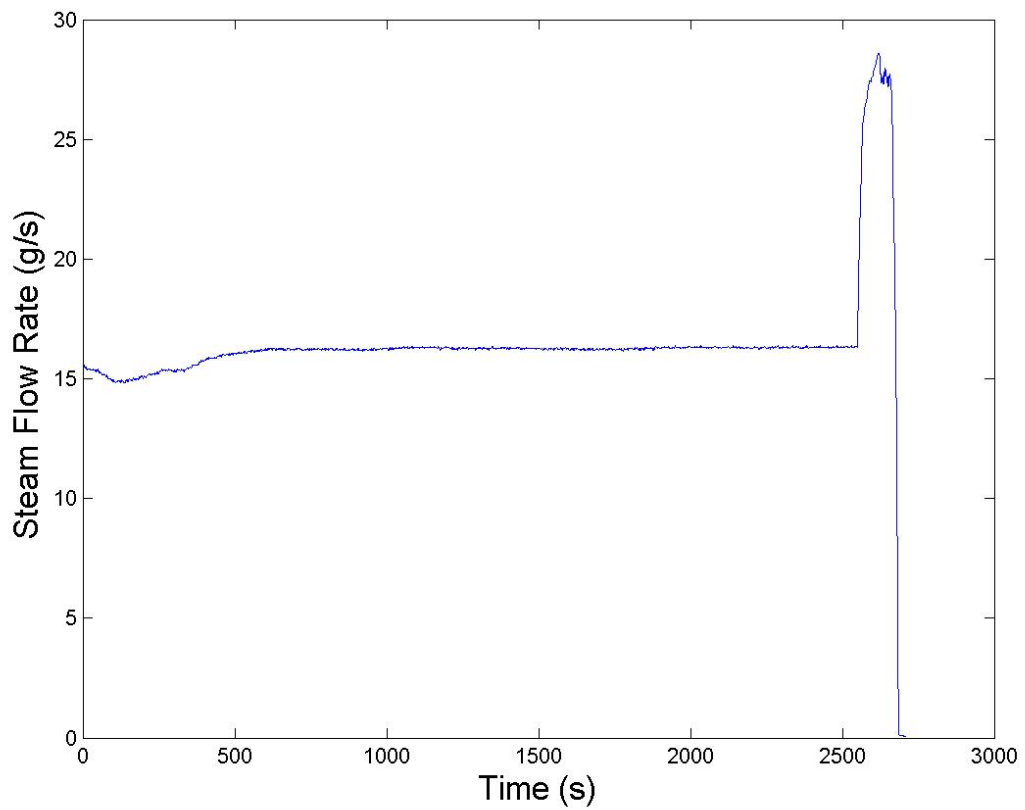

Fig. D.119.: Steam mass flow rate measurements for Test 24. 


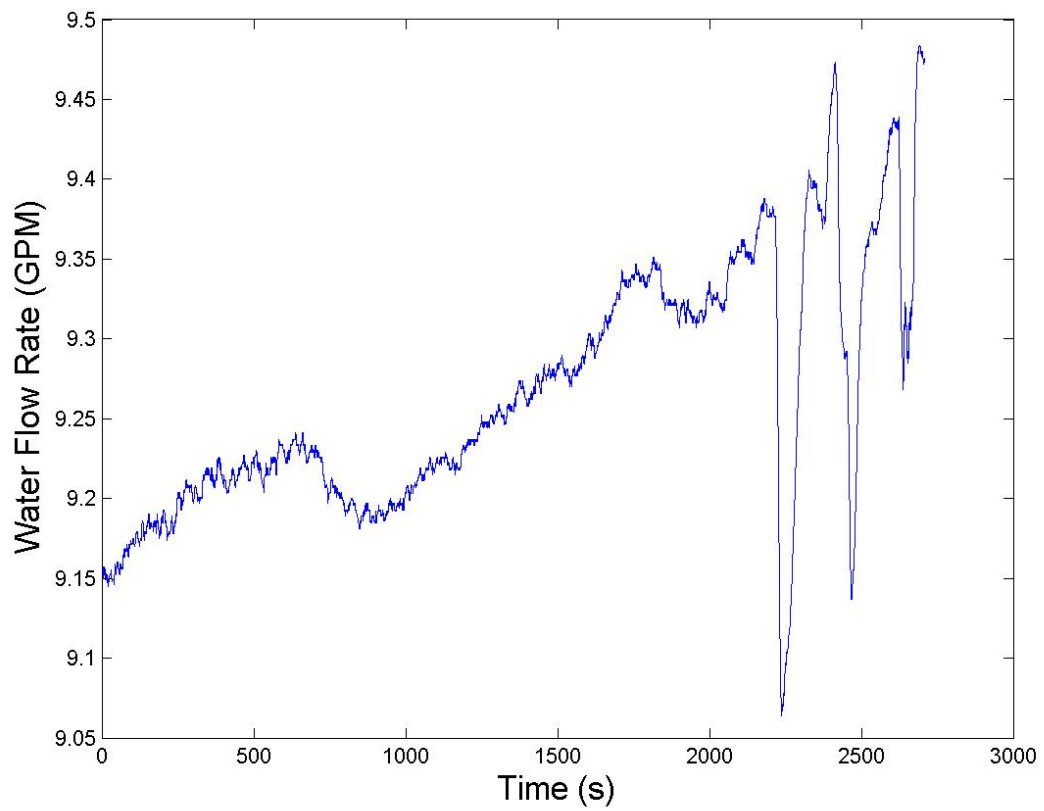

Fig. D.120.: Water flow rate measurements for Test 24.

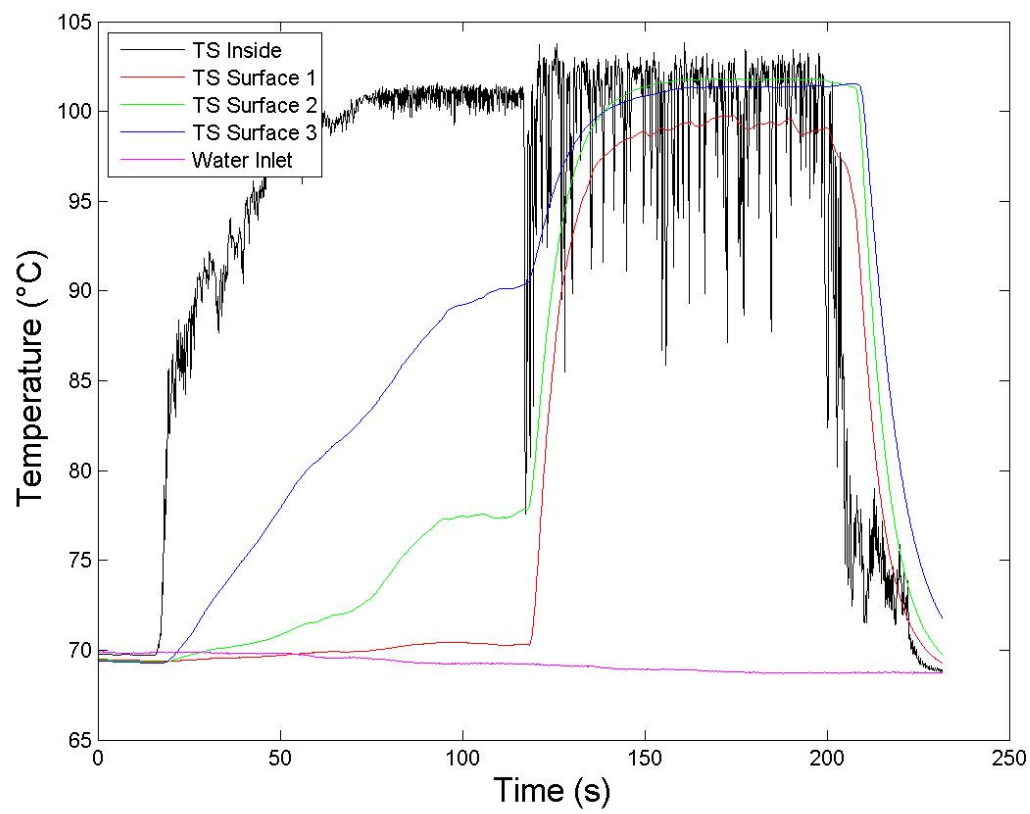

Fig. D.121.: Temperature measurements for Test 25. 


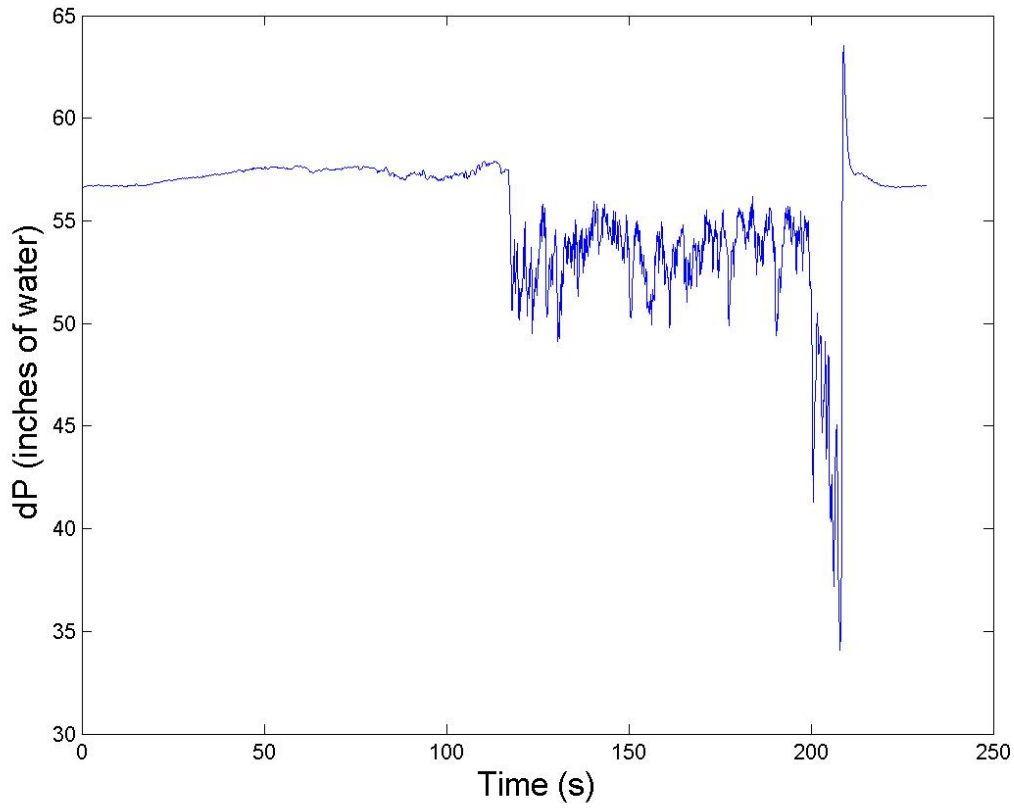

Fig. D.122.: Differential pressure measurements for Test 25.

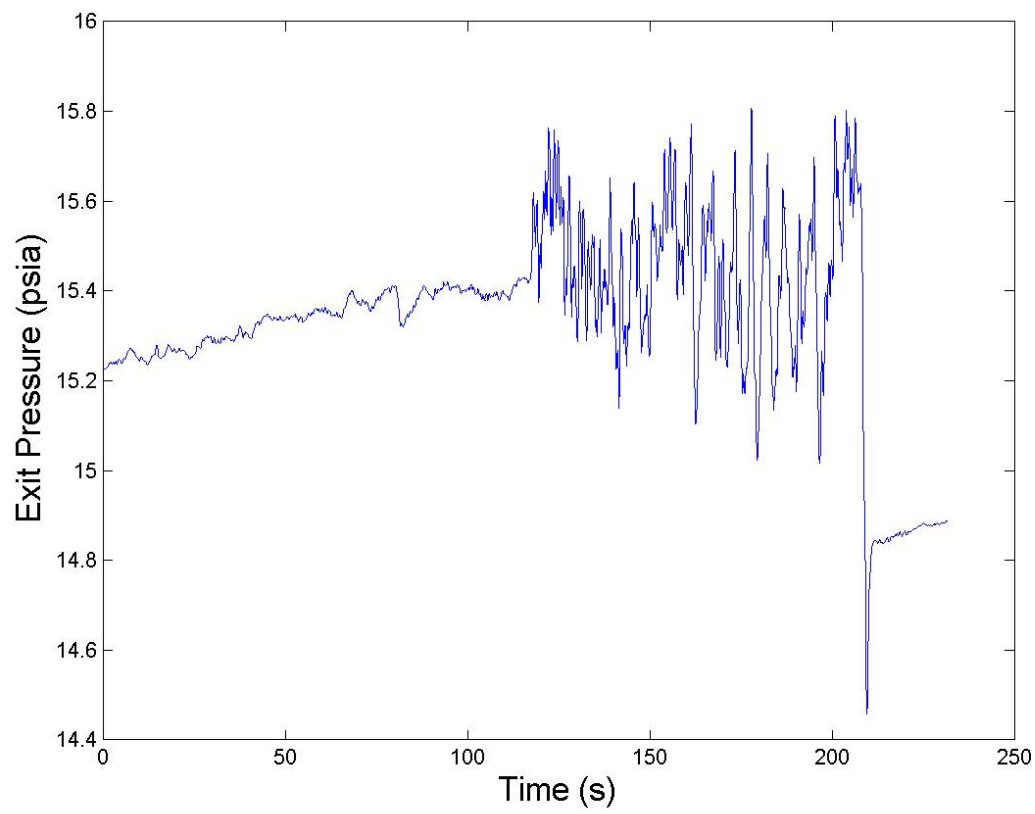

Fig. D.123.: Water exit tank pressure measurements for Test 25. 


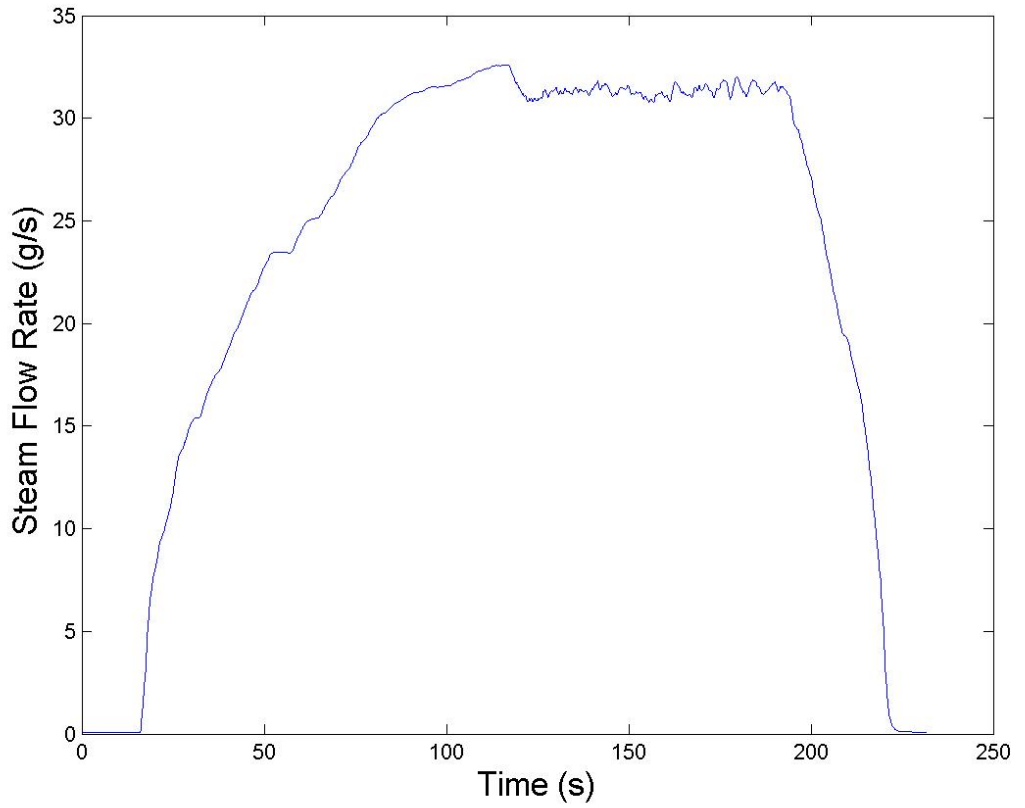

Fig. D.124.: Steam mass flow rate measurements for Test 25.

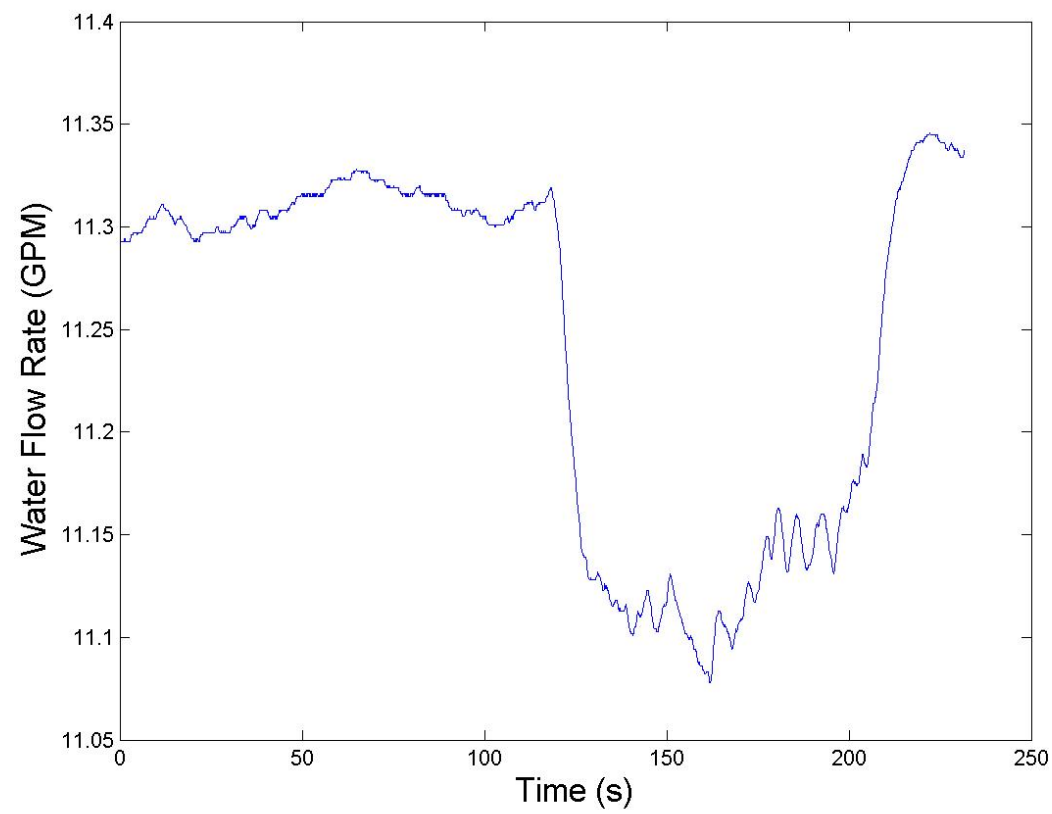

Fig. D.125.: Water flow rate measurements for Test 25. 


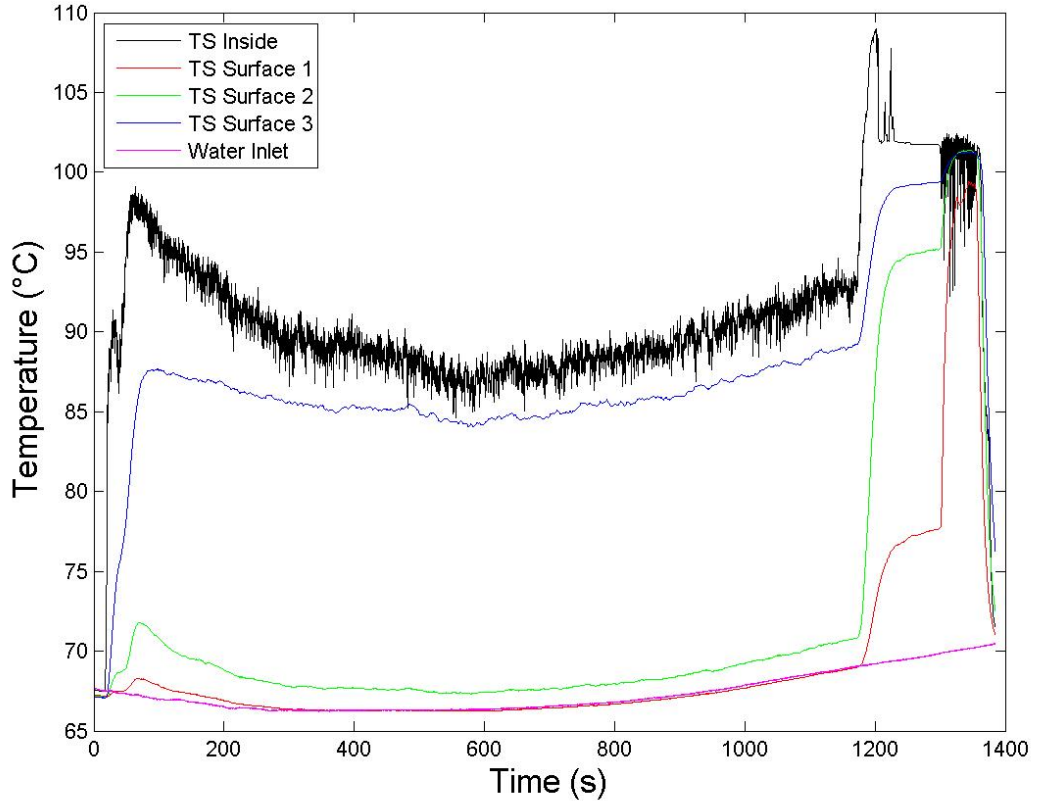

Fig. D.126.: Temperature measurements for Test 26.

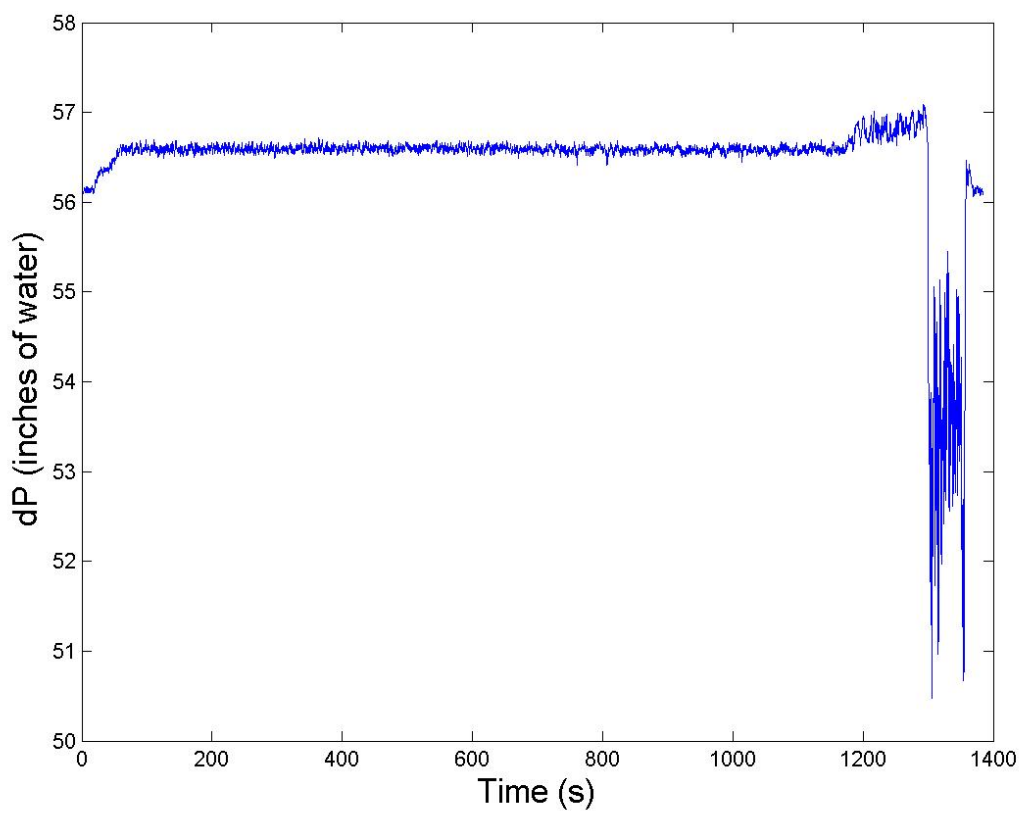

Fig. D.127.: Differential pressure measurements for Test 26 . 


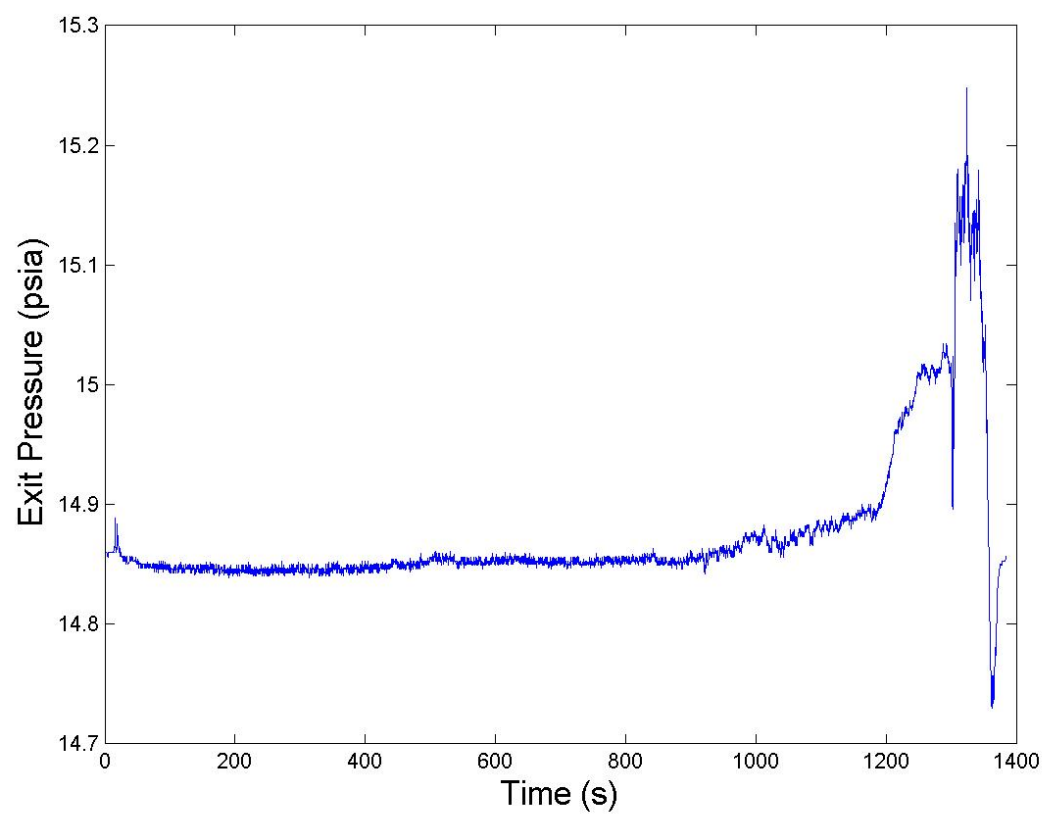

Fig. D.128.: Water exit tank pressure measurements for Test 26.

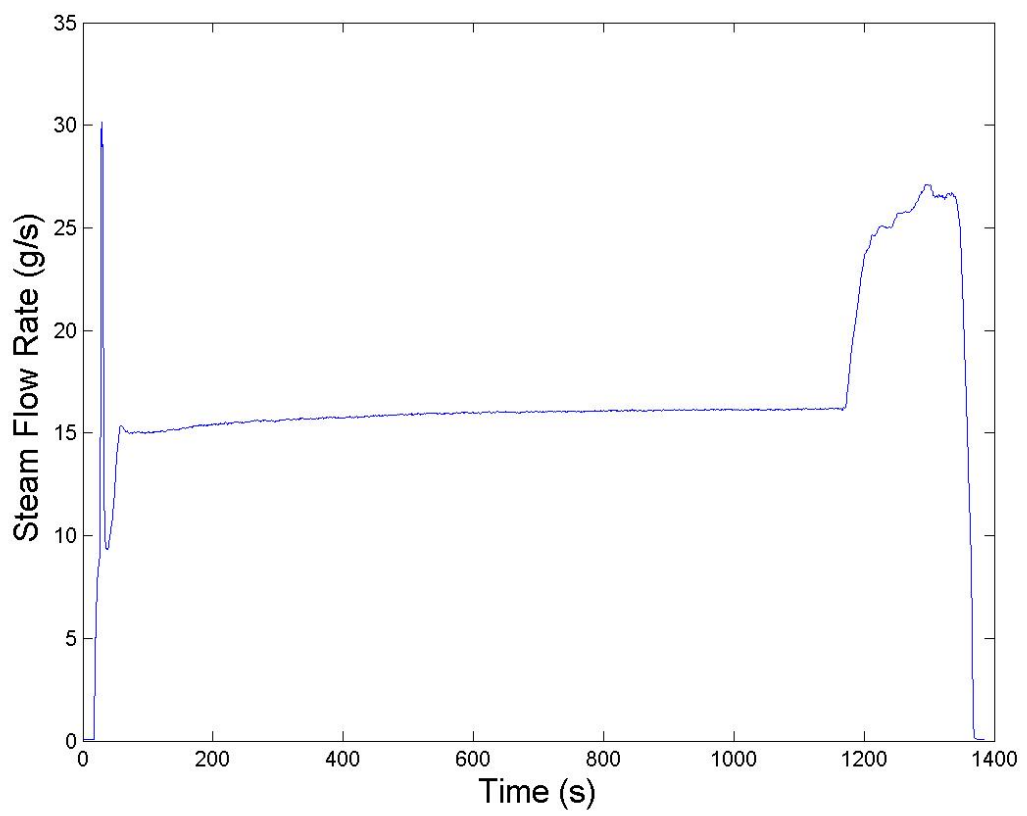

Fig. D.129.: Steam mass flow rate measurements for Test 26. 


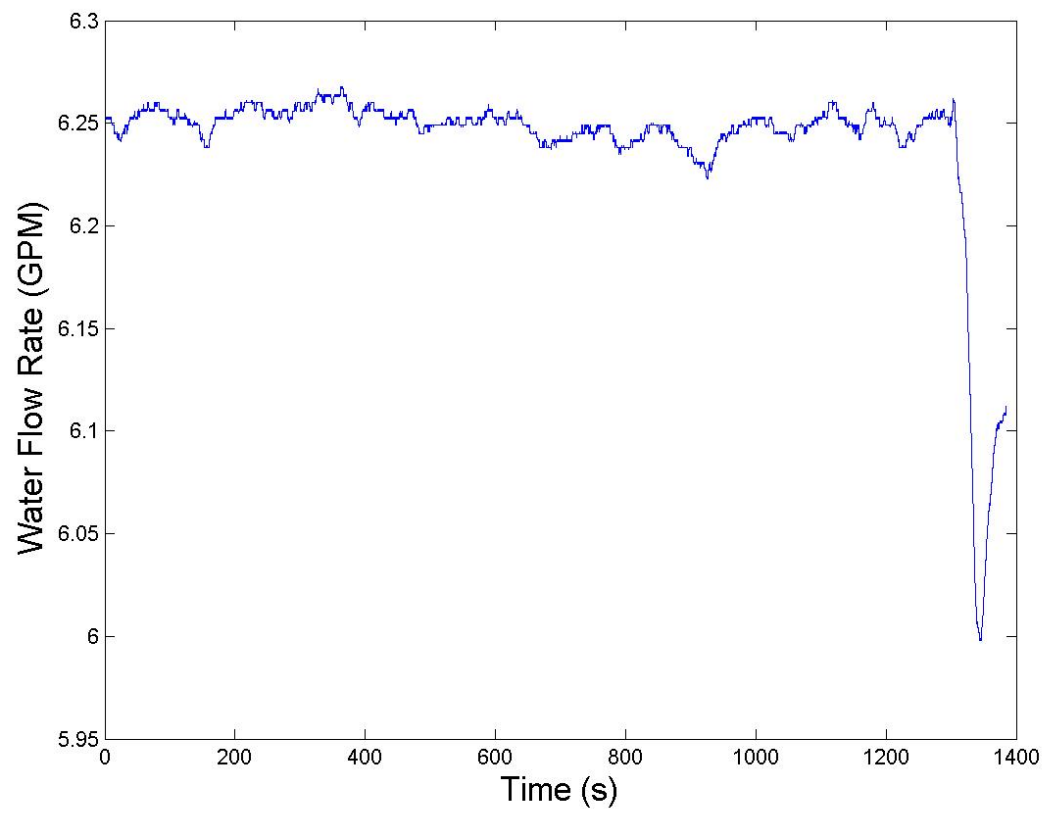

Fig. D.130.: Water flow rate measurements for Test 26.

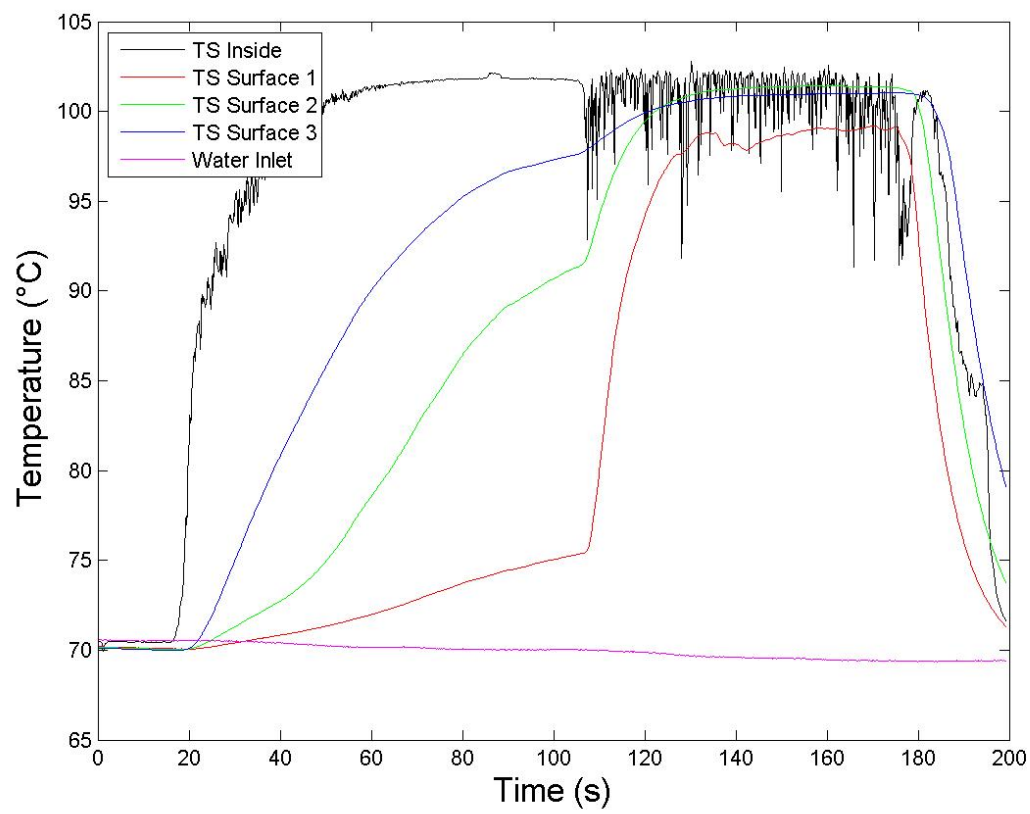

Fig. D.131.: Temperature measurements for Test 27. 


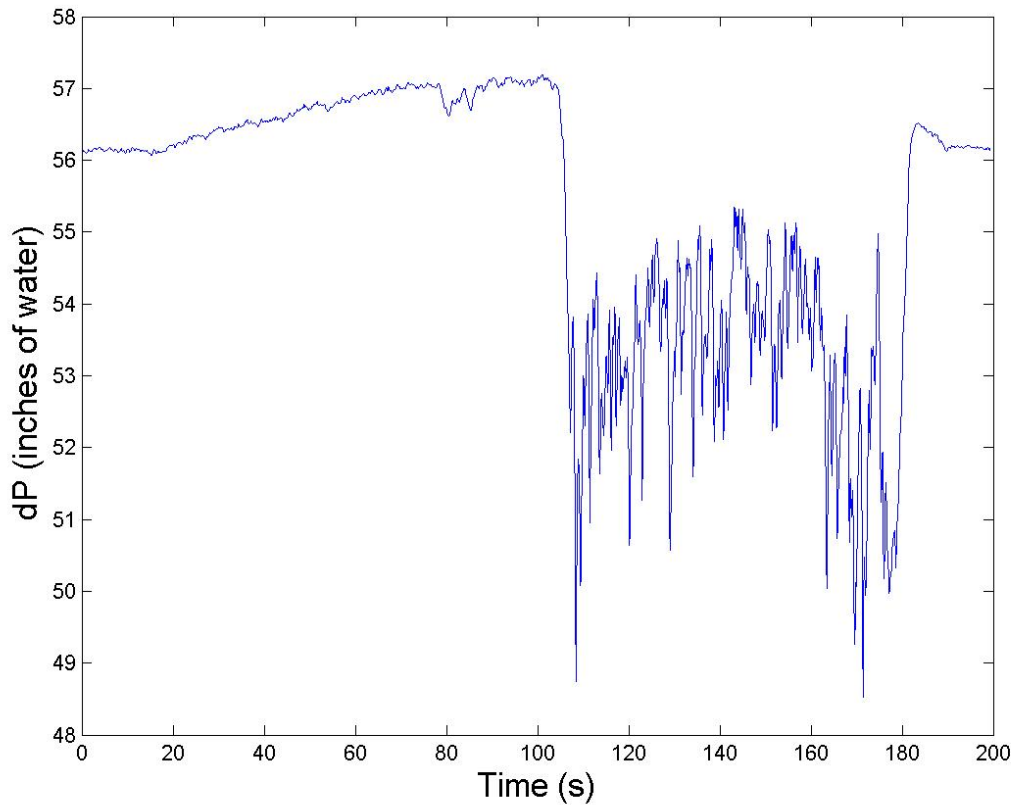

Fig. D.132.: Differential pressure measurements for Test 27.

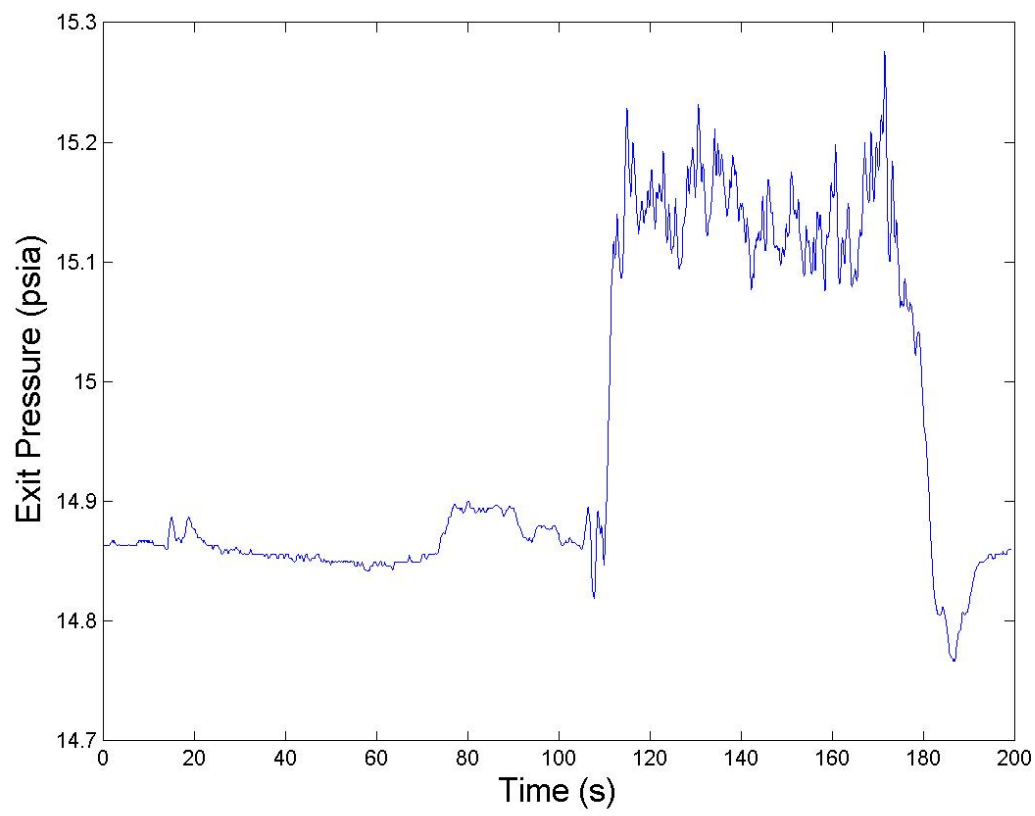

Fig. D.133.: Water exit tank pressure measurements for Test 27. 


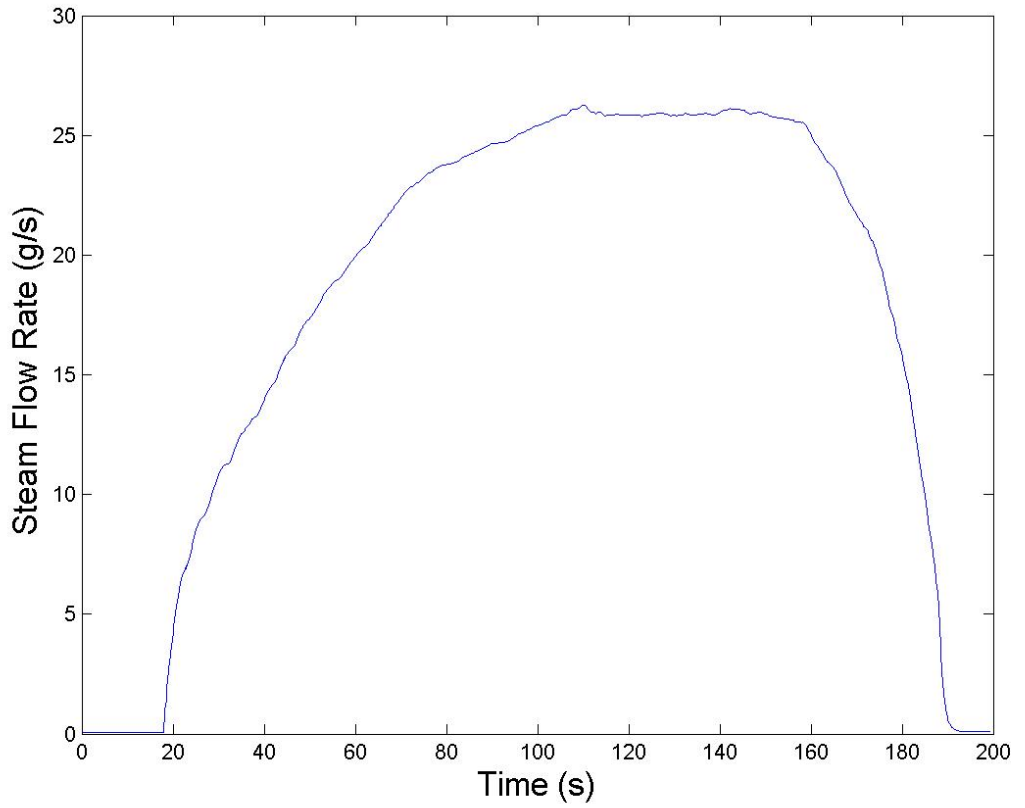

Fig. D.134.: Steam mass flow rate measurements for Test 27.

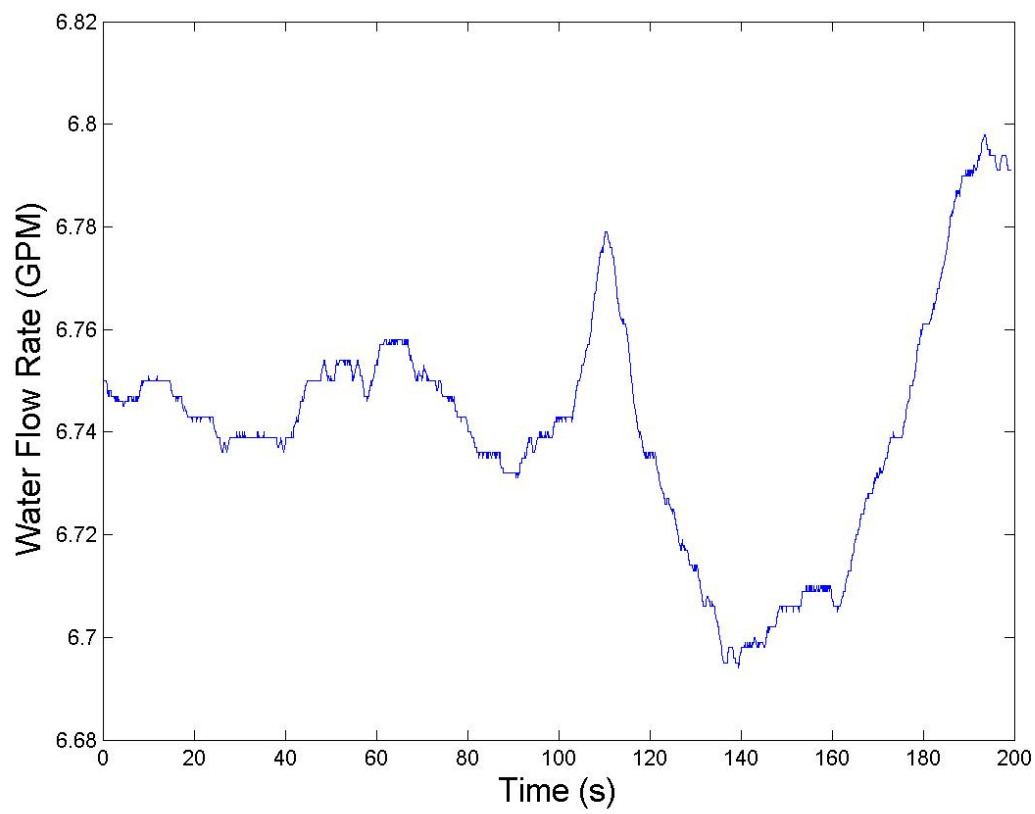

Fig. D.135.: Water flow rate measurements for Test 27. 


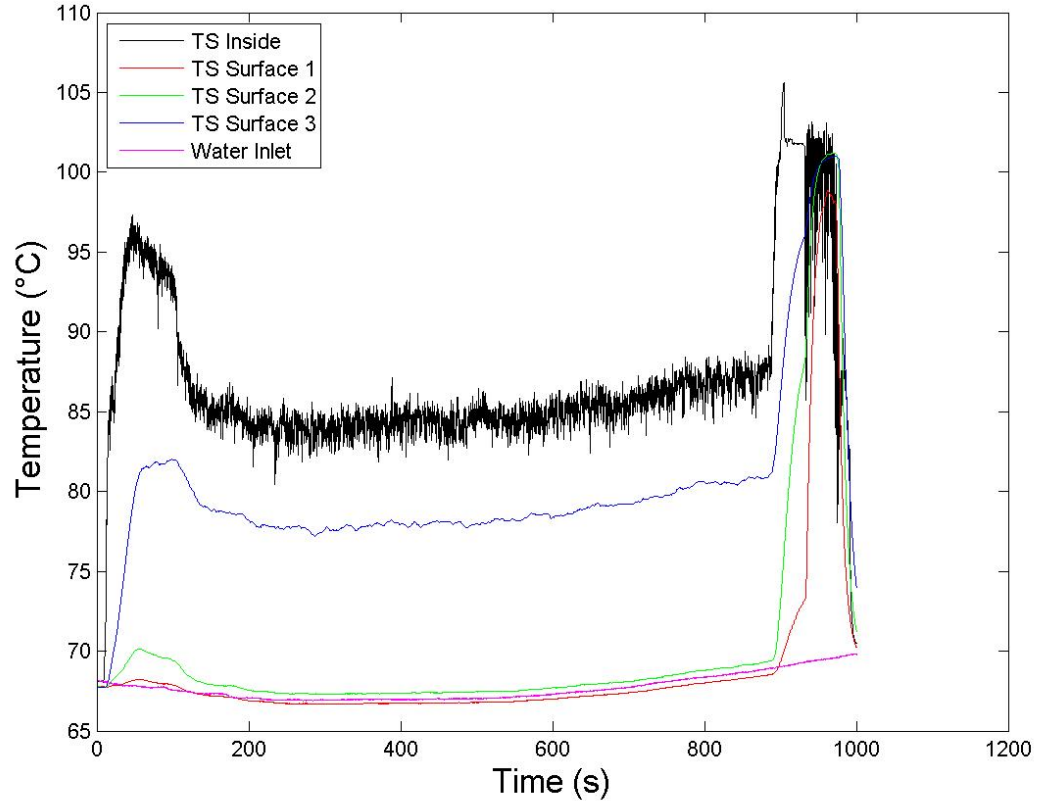

Fig. D.136.: Temperature measurements for Test 28.

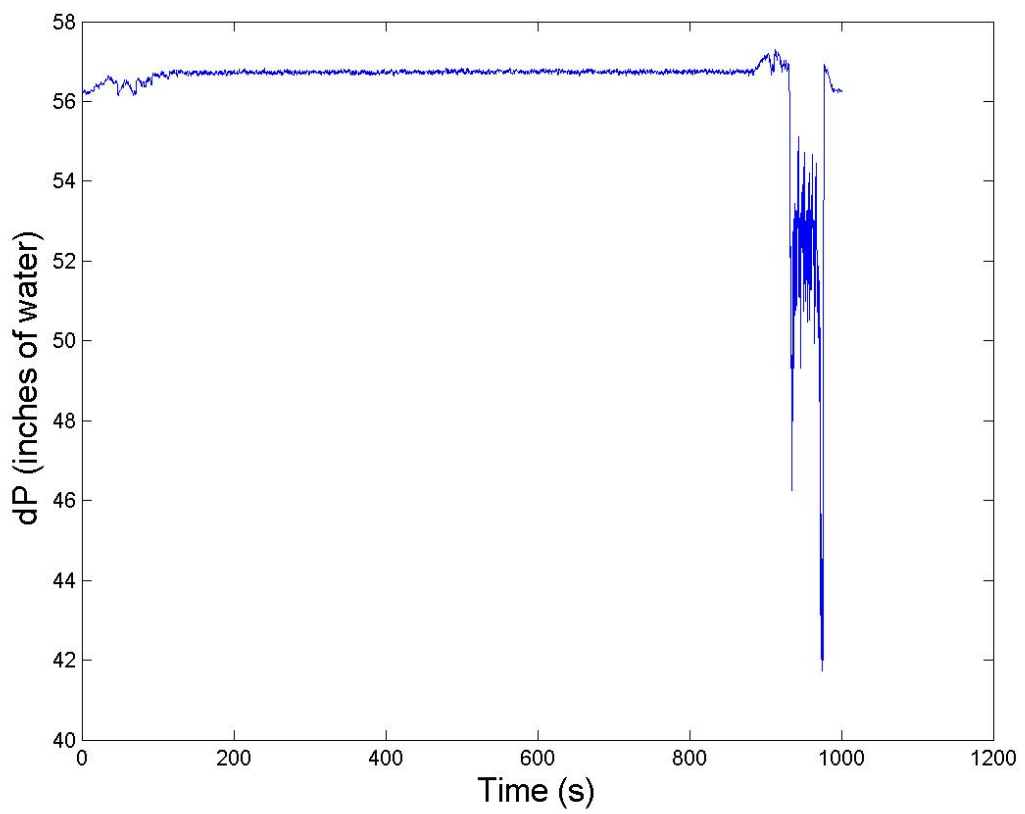

Fig. D.137.: Differential pressure measurements for Test 28. 


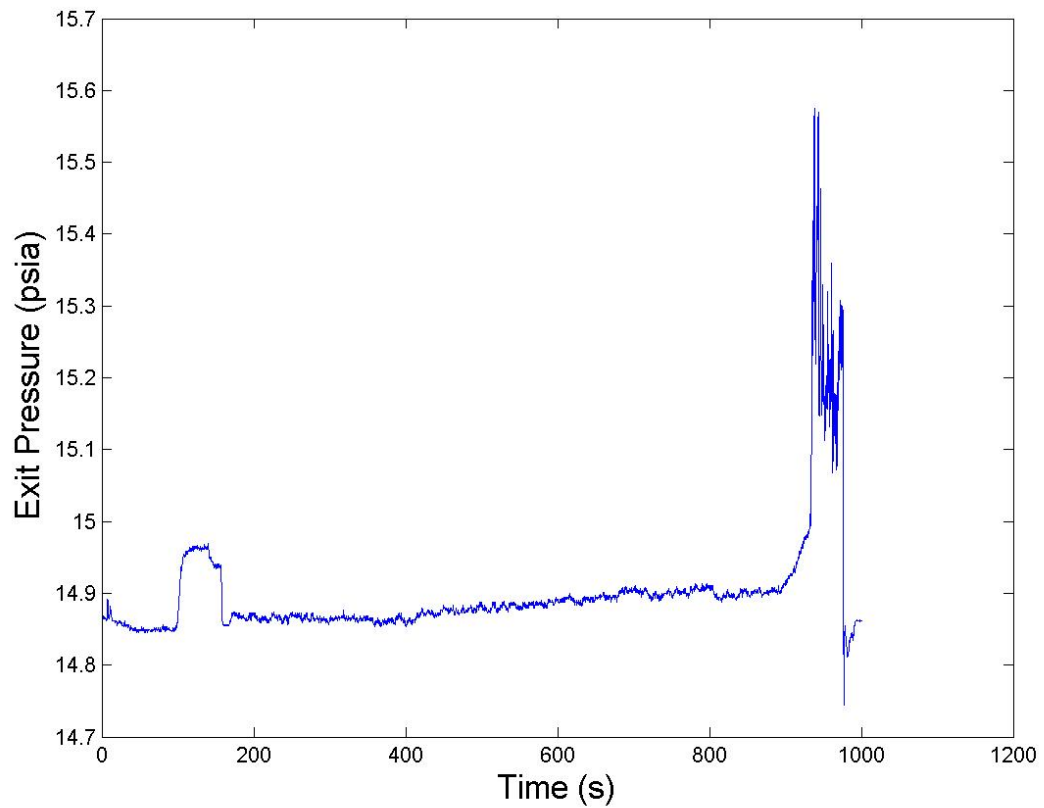

Fig. D.138.: Water exit tank pressure measurements for Test 28.

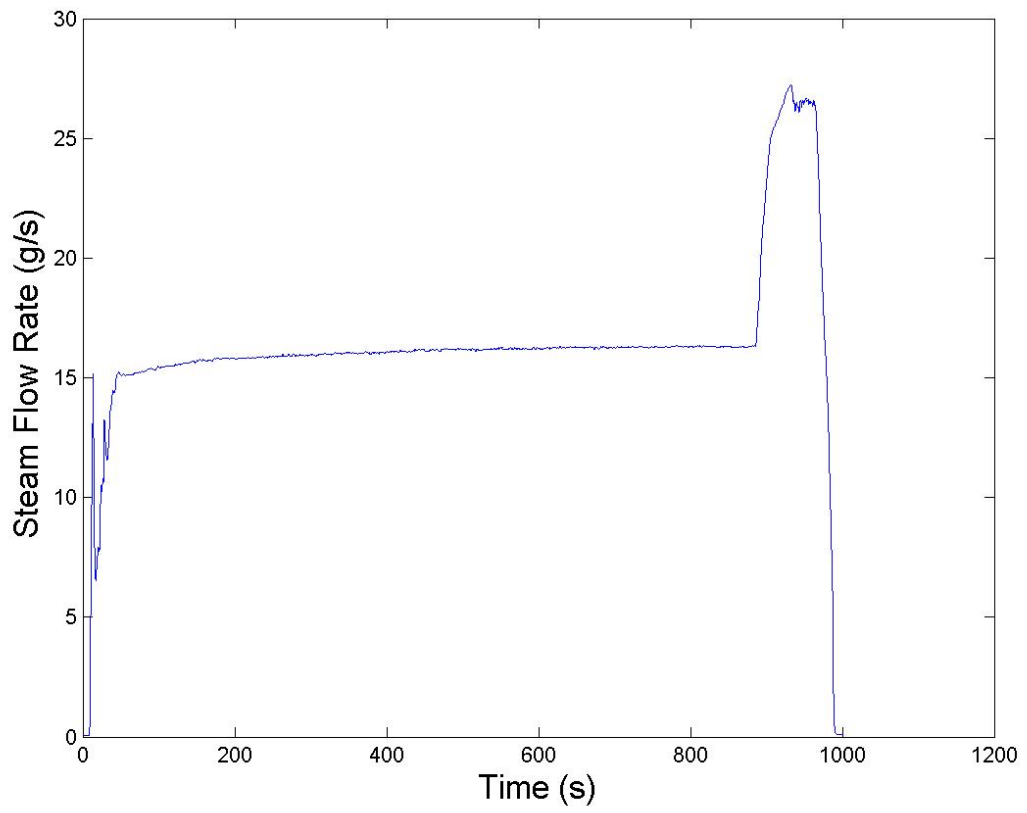

Fig. D.139.: Steam mass flow rate measurements for Test 28. 


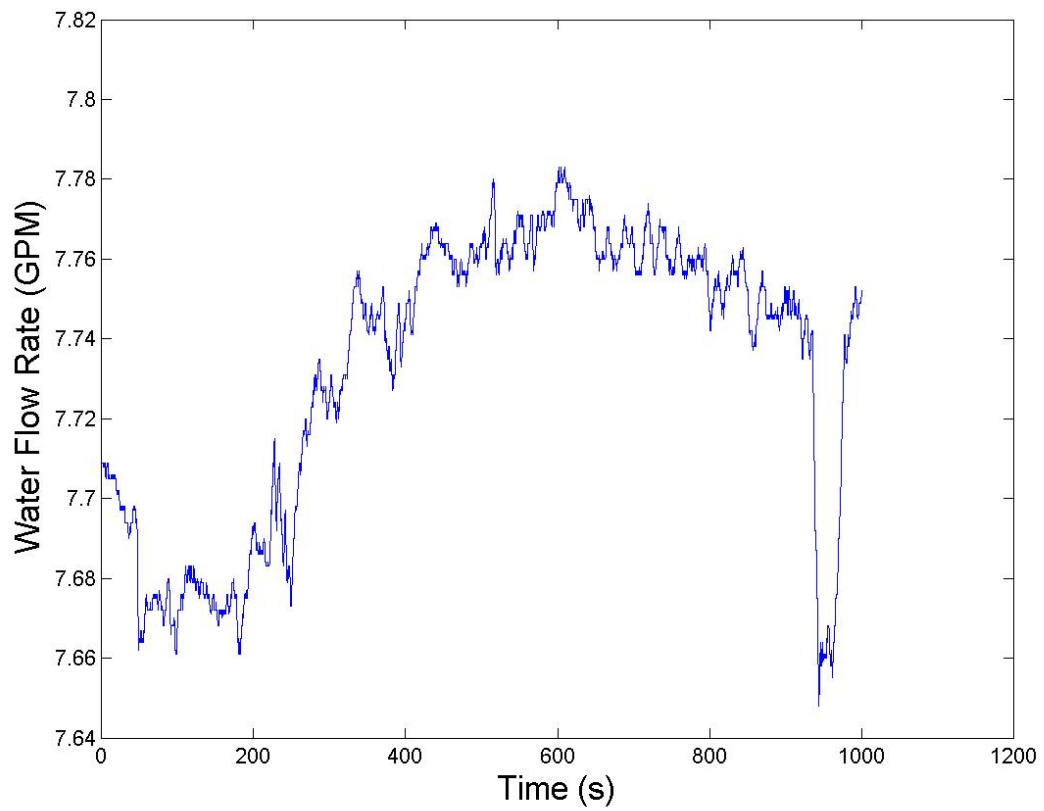

Fig. D.140.: Water flow rate measurements for Test 28.

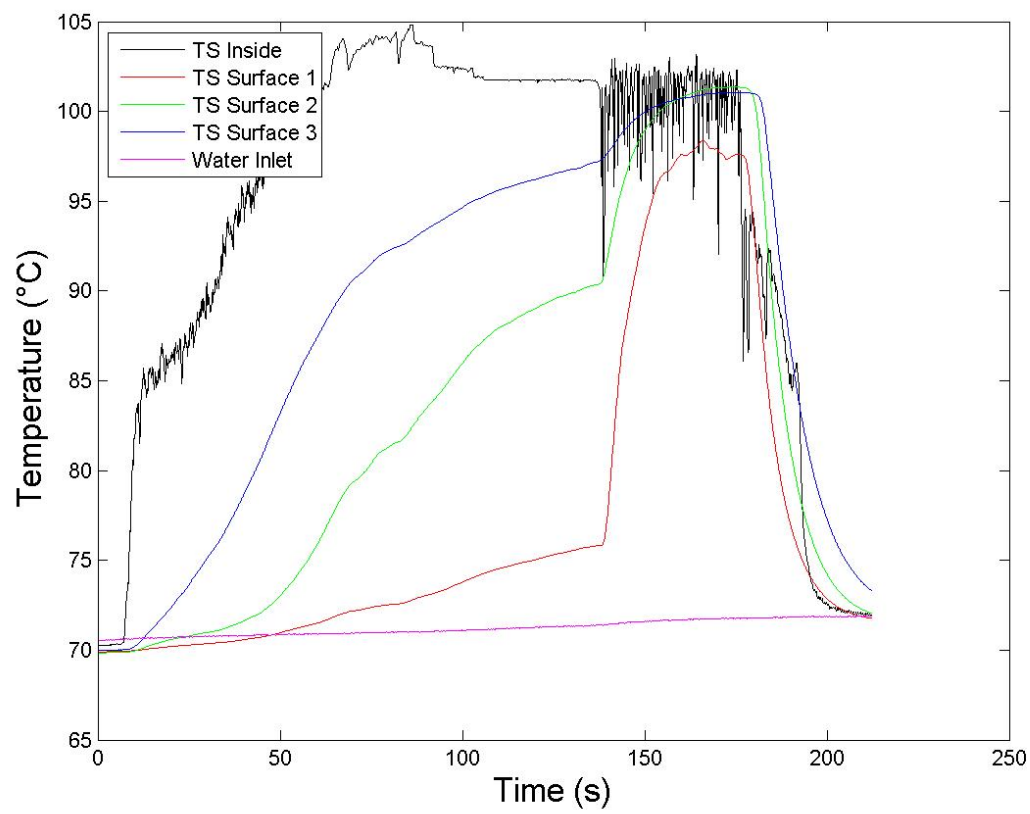

Fig. D.141.: Temperature measurements for Test 29. 


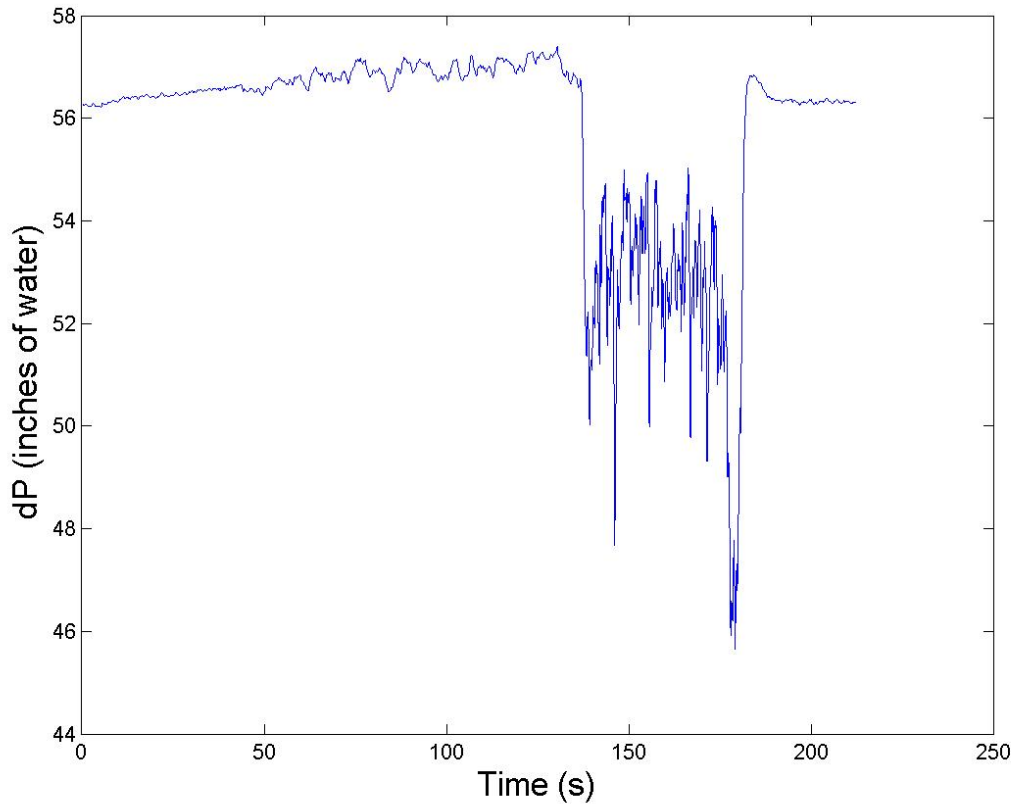

Fig. D.142.: Differential pressure measurements for Test 29.

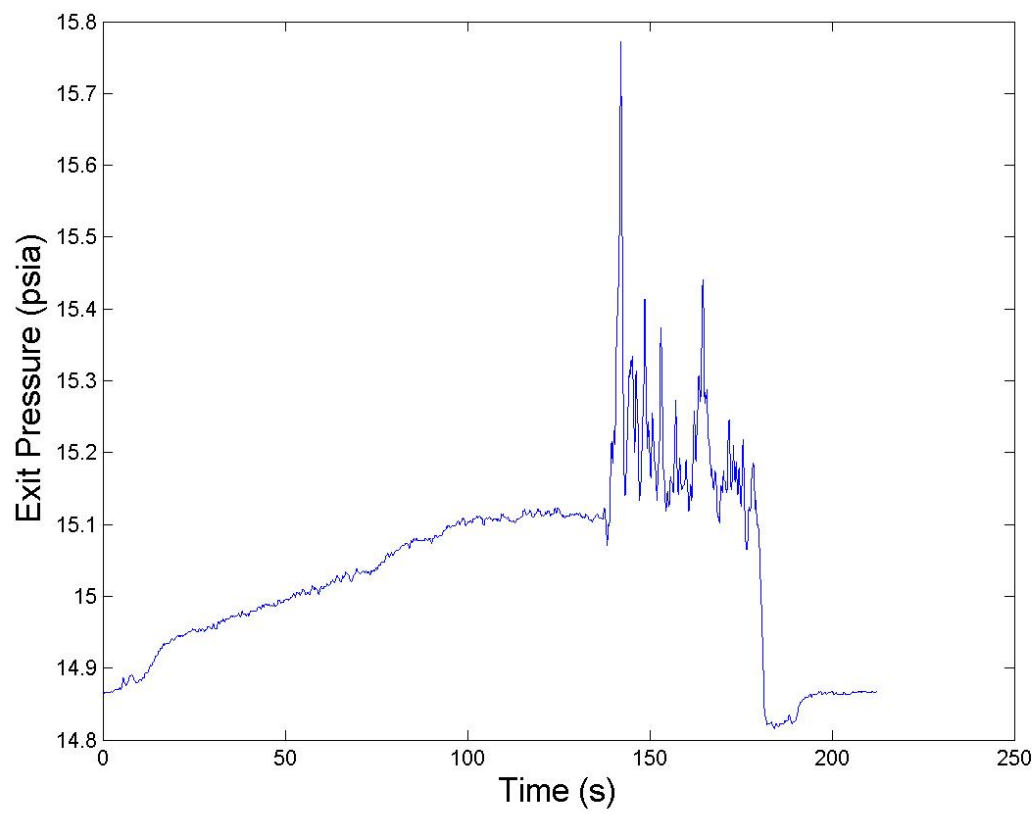

Fig. D.143.: Water exit tank pressure measurements for Test 29. 


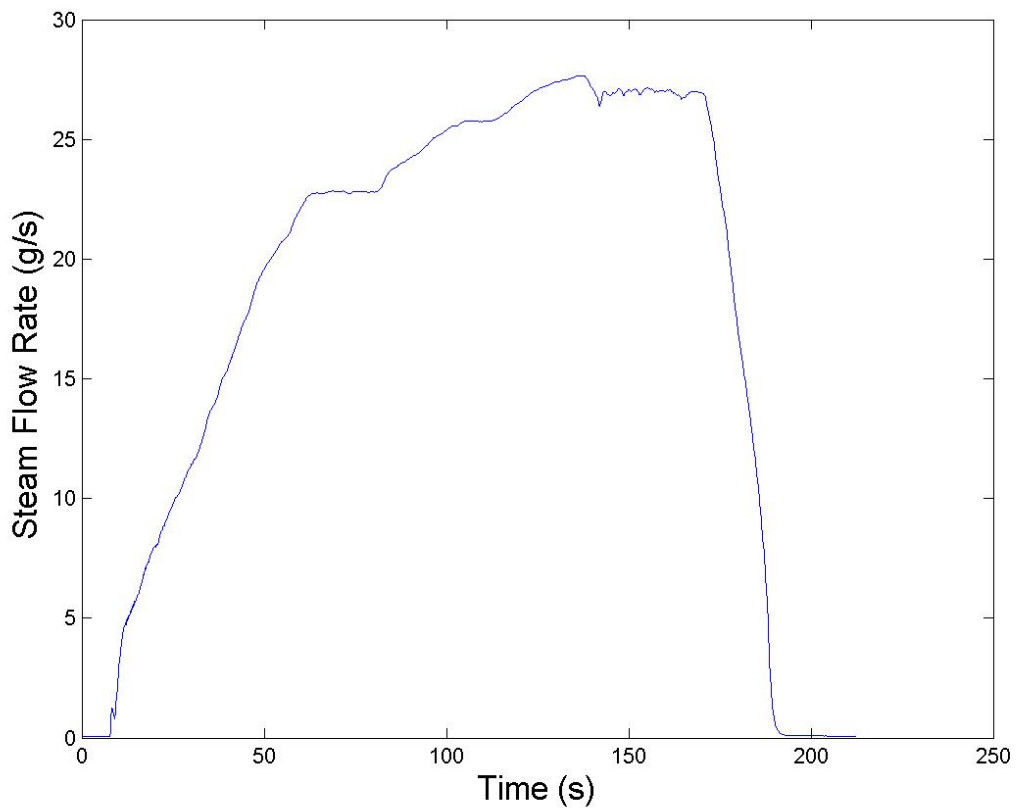

Fig. D.144.: Steam mass flow rate measurements for Test 29.

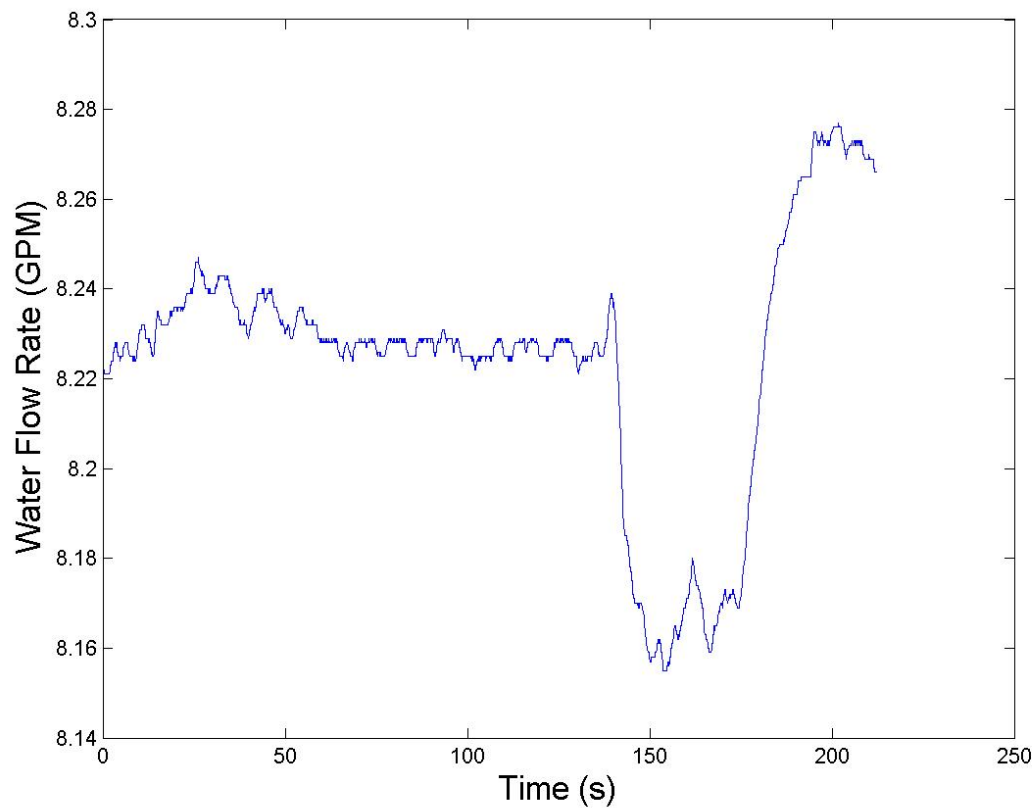

Fig. D.145.: Water flow rate measurements for Test 29. 


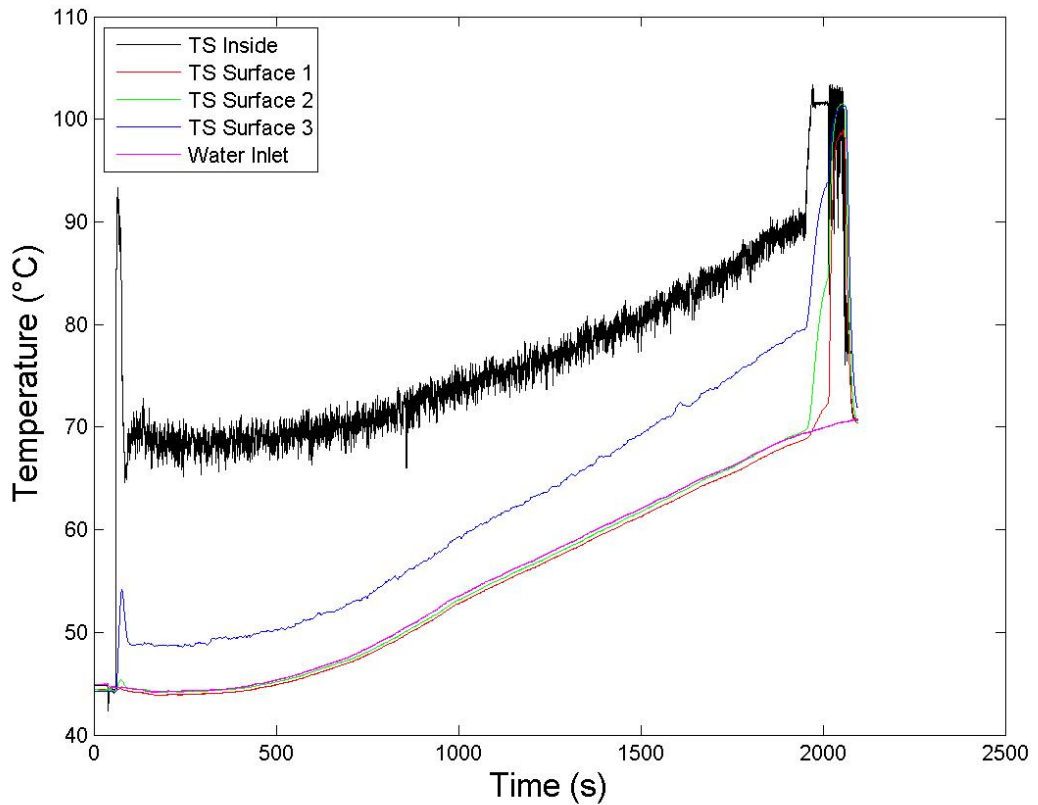

Fig. D.146.: Temperature measurements for Test 30.

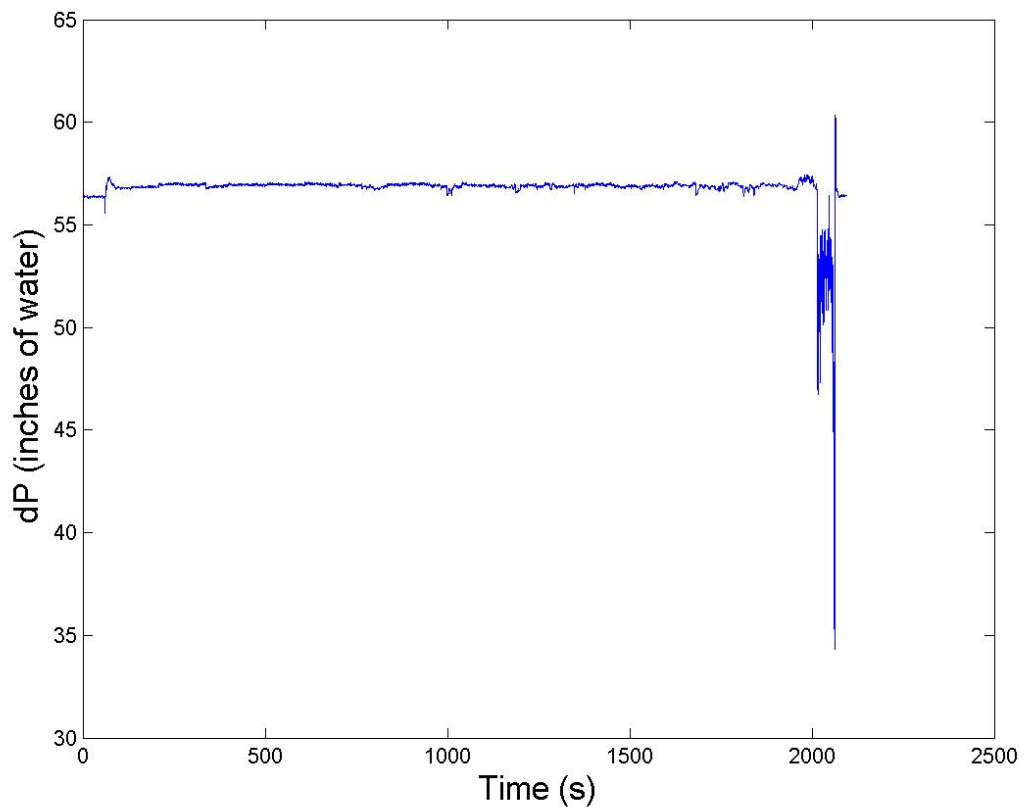

Fig. D.147.: Differential pressure measurements for Test 30. 


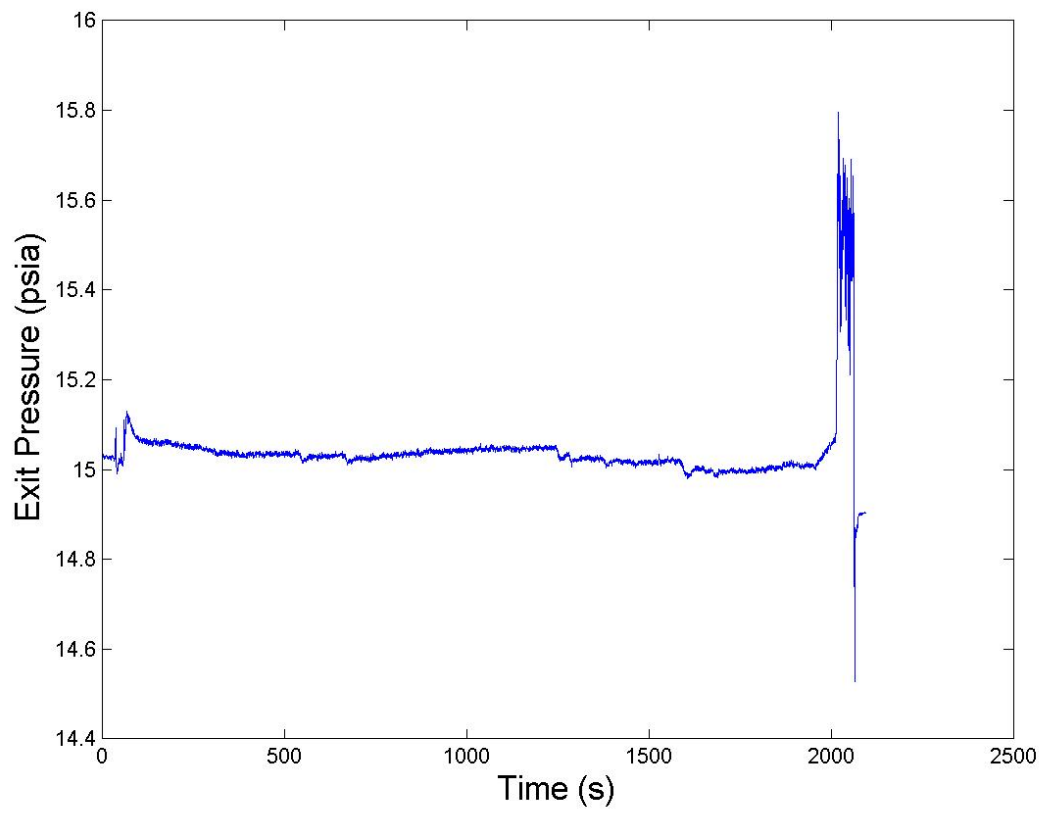

Fig. D.148.: Water exit tank pressure measurements for Test 30.

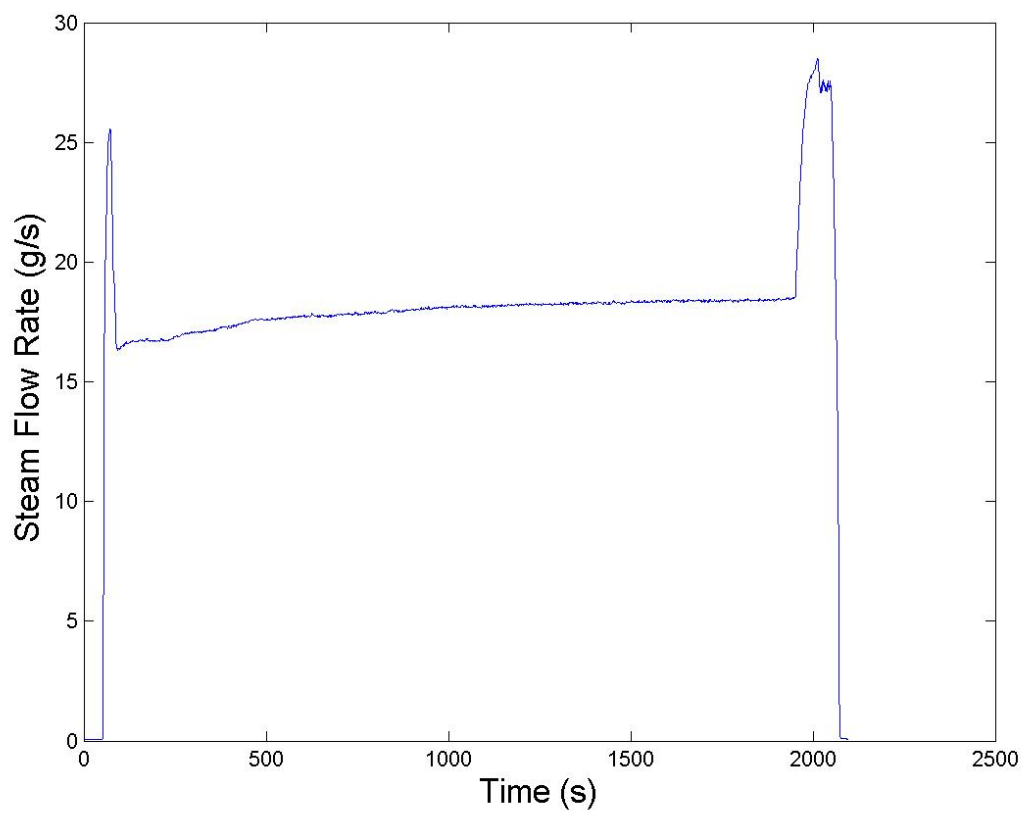

Fig. D.149.: Steam mass flow rate measurements for Test 30. 


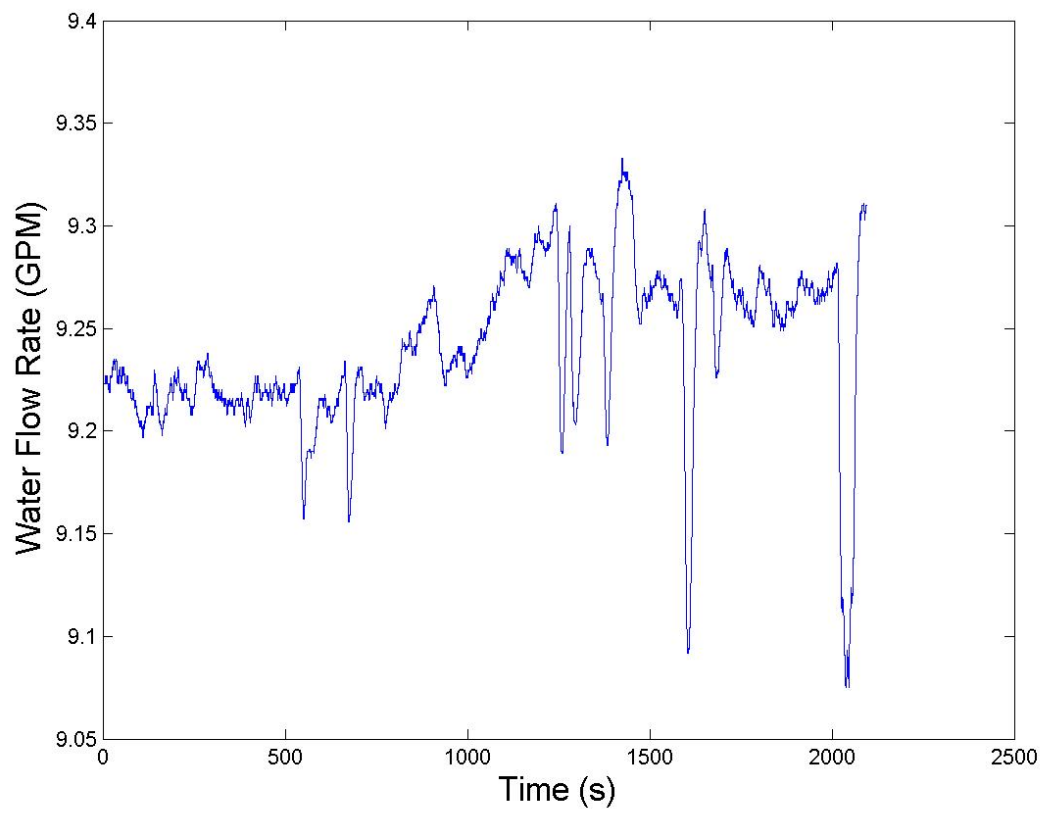

Fig. D.150.: Water flow rate measurements for Test 30.

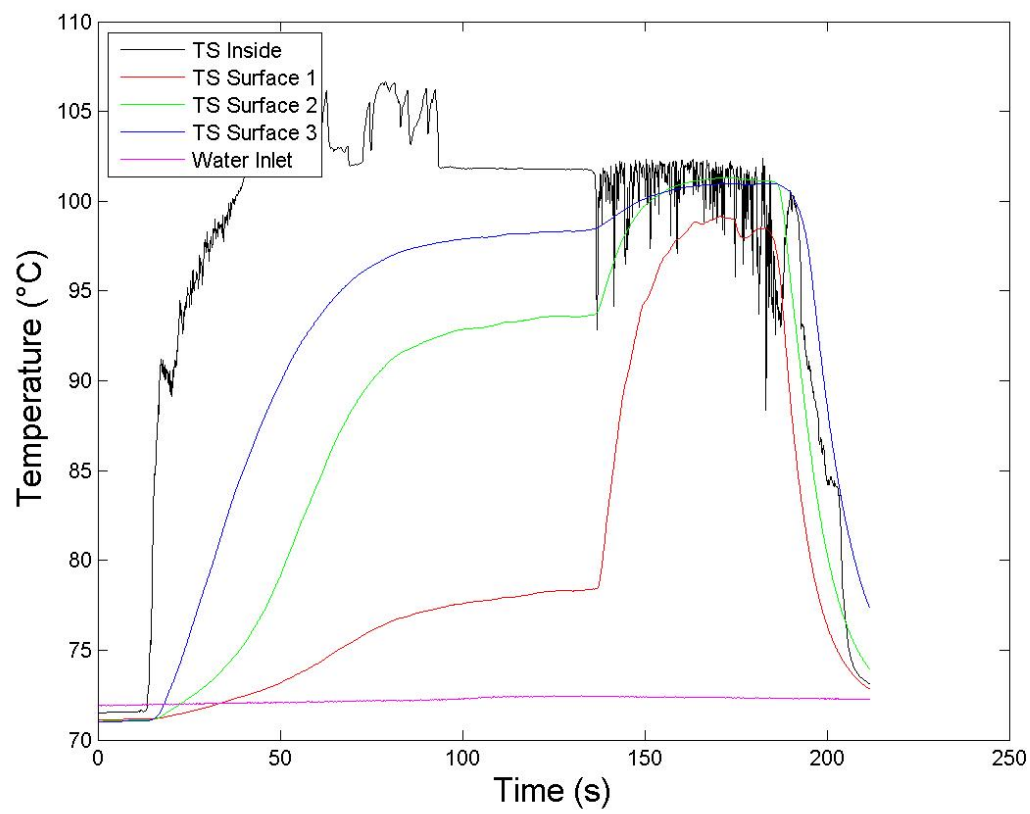

Fig. D.151.: Temperature measurements for Test 31. 


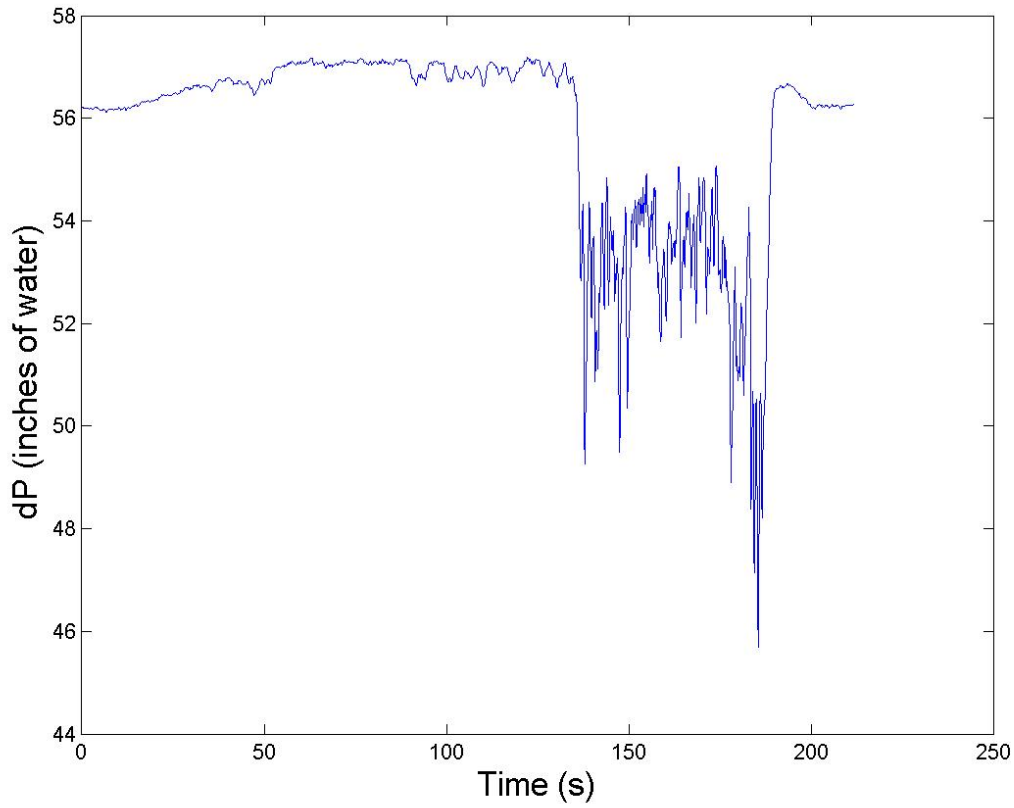

Fig. D.152.: Differential pressure measurements for Test 31.

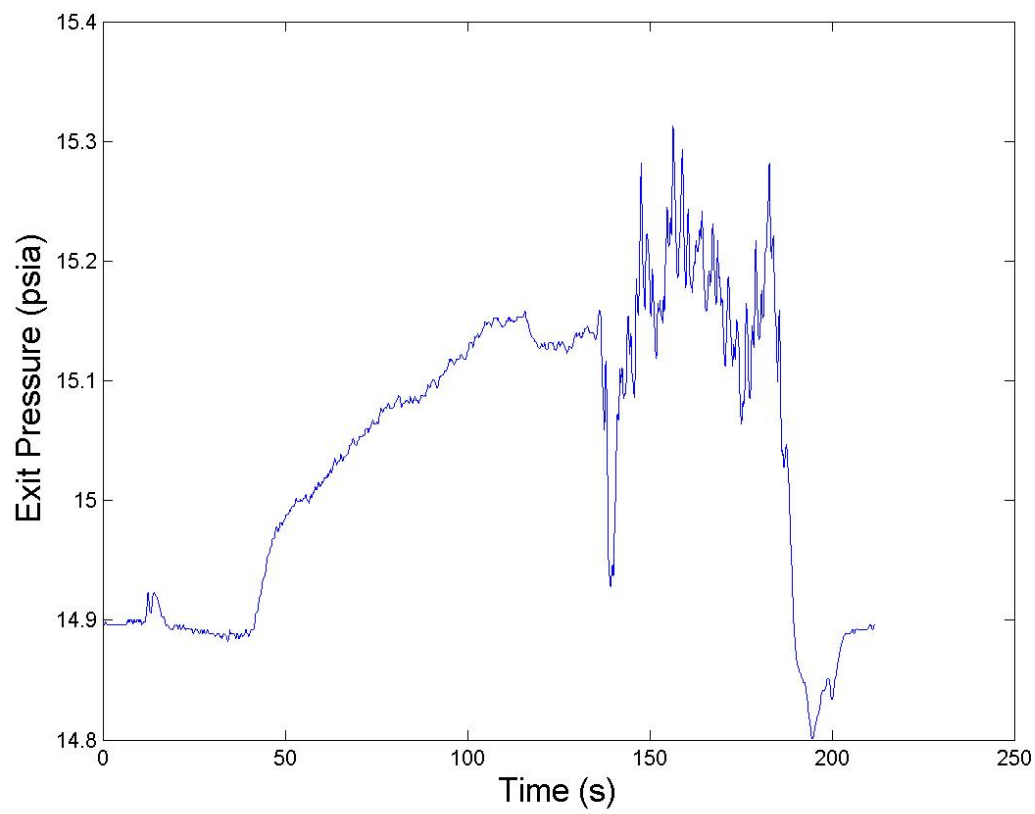

Fig. D.153.: Water exit tank pressure measurements for Test 31. 


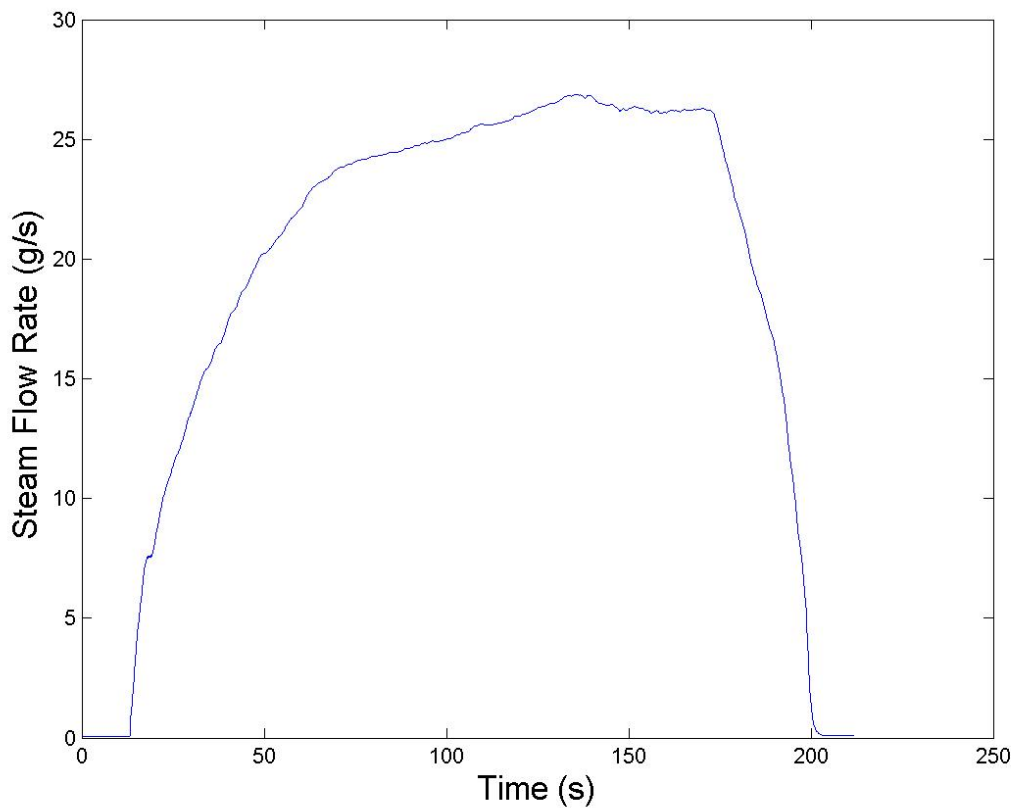

Fig. D.154.: Steam mass flow rate measurements for Test 31.

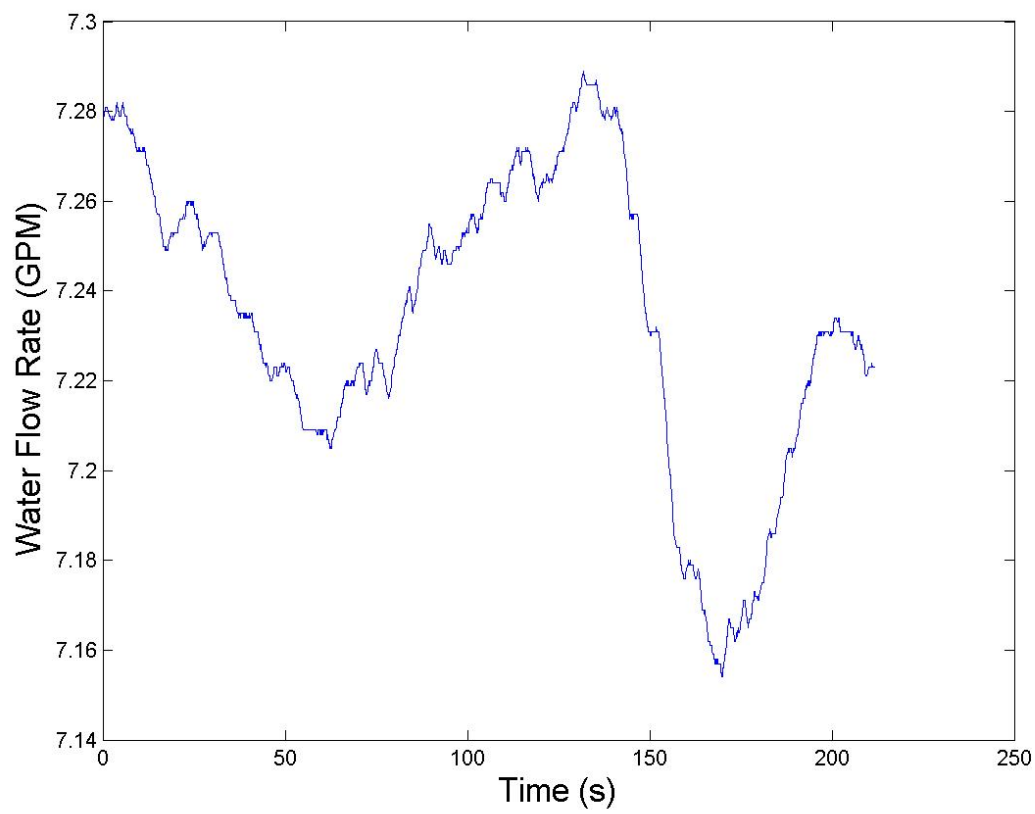

Fig. D.155.: Water flow rate measurements for Test 31. 


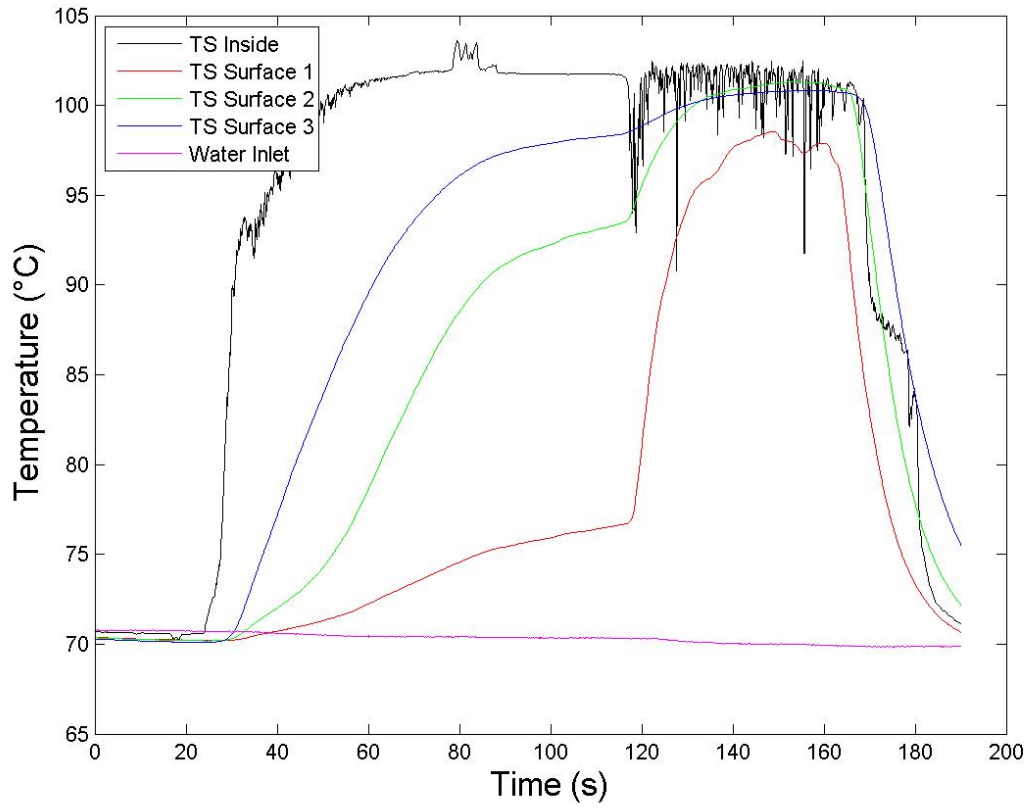

Fig. D.156.: Temperature measurements for Test 32.

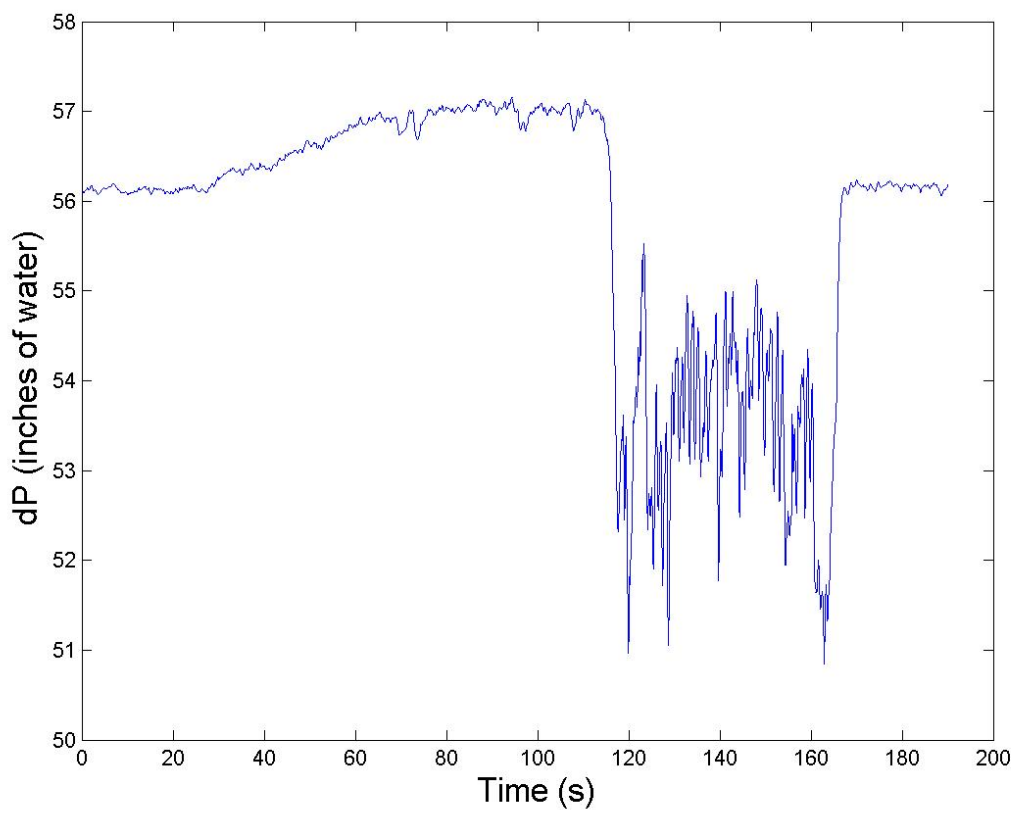

Fig. D.157.: Differential pressure measurements for Test 32. 


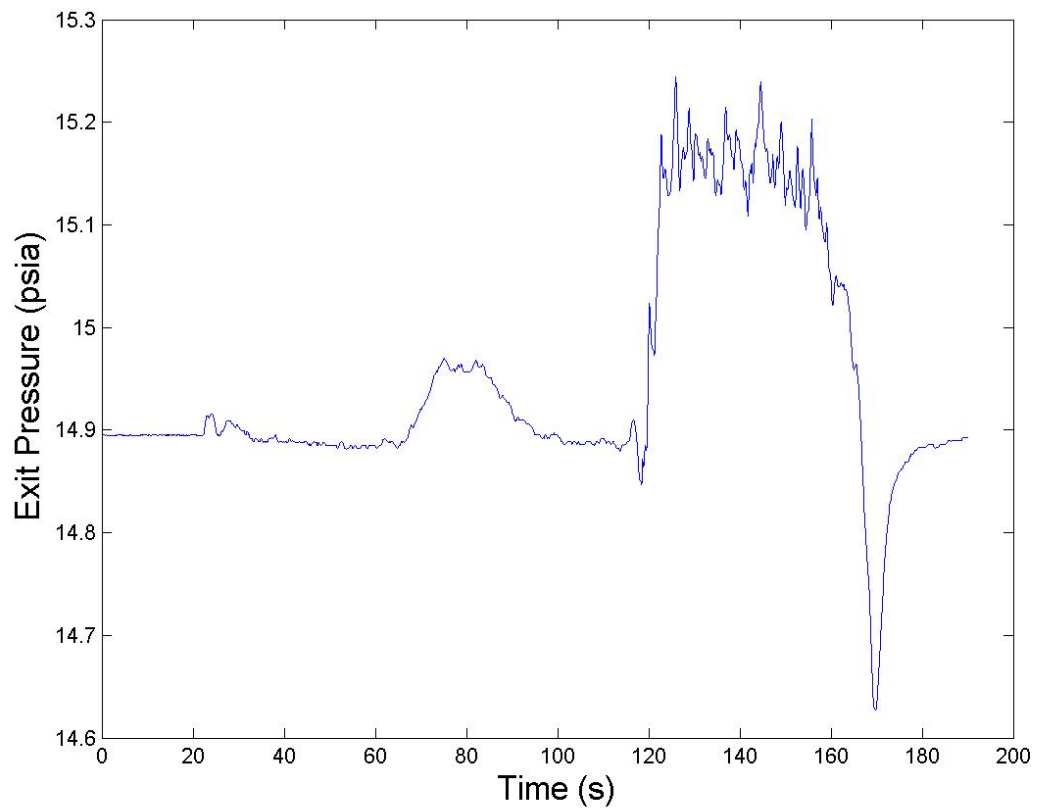

Fig. D.158.: Water exit tank pressure measurements for Test 32.

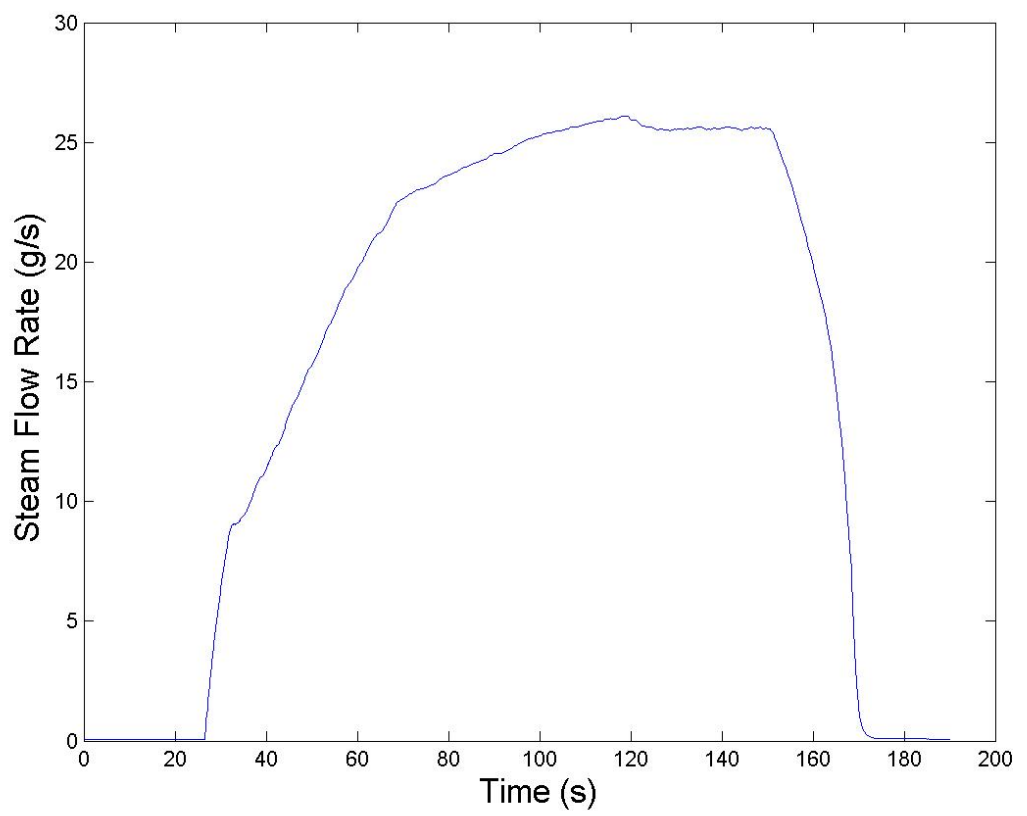

Fig. D.159.: Steam mass flow rate measurements for Test 32. 


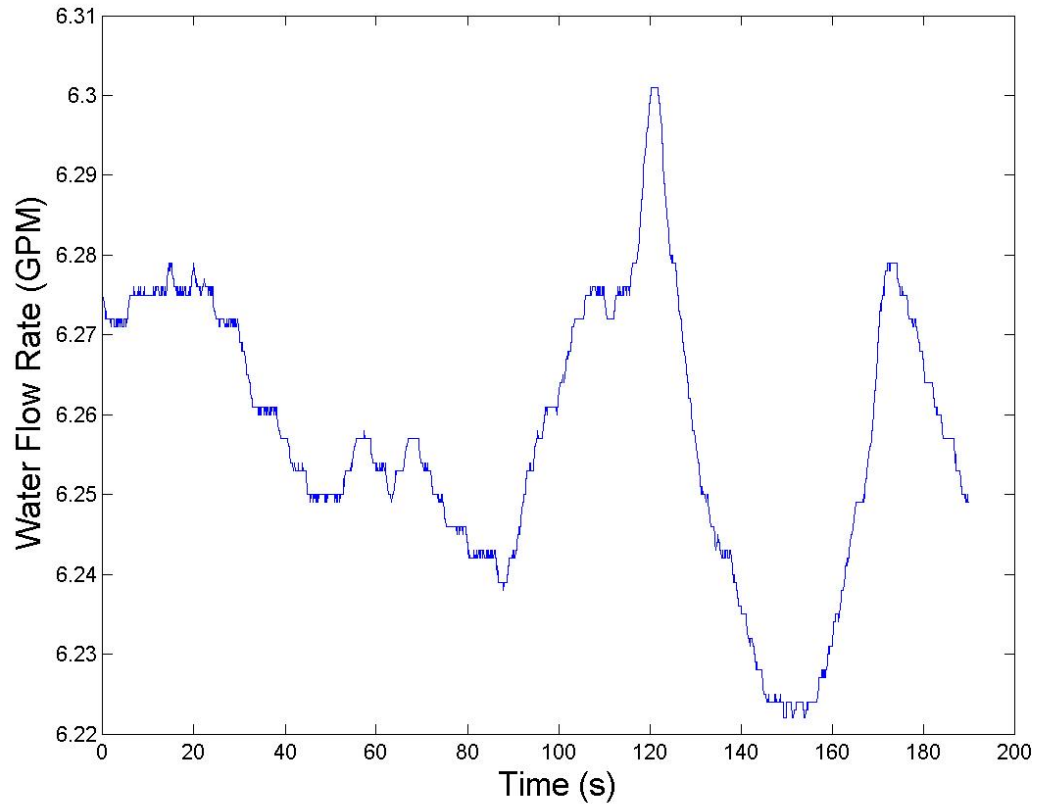

Fig. D.160.: Water flow rate measurements for Test 32.

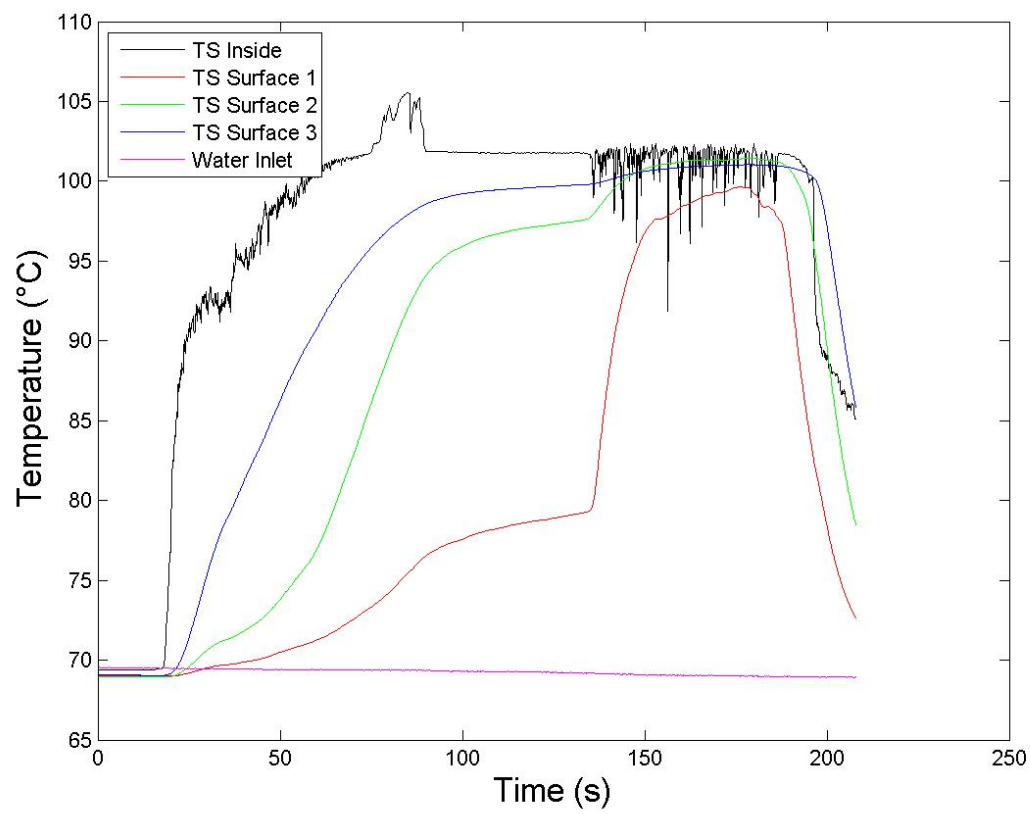

Fig. D.161.: Temperature measurements for Test 33. 


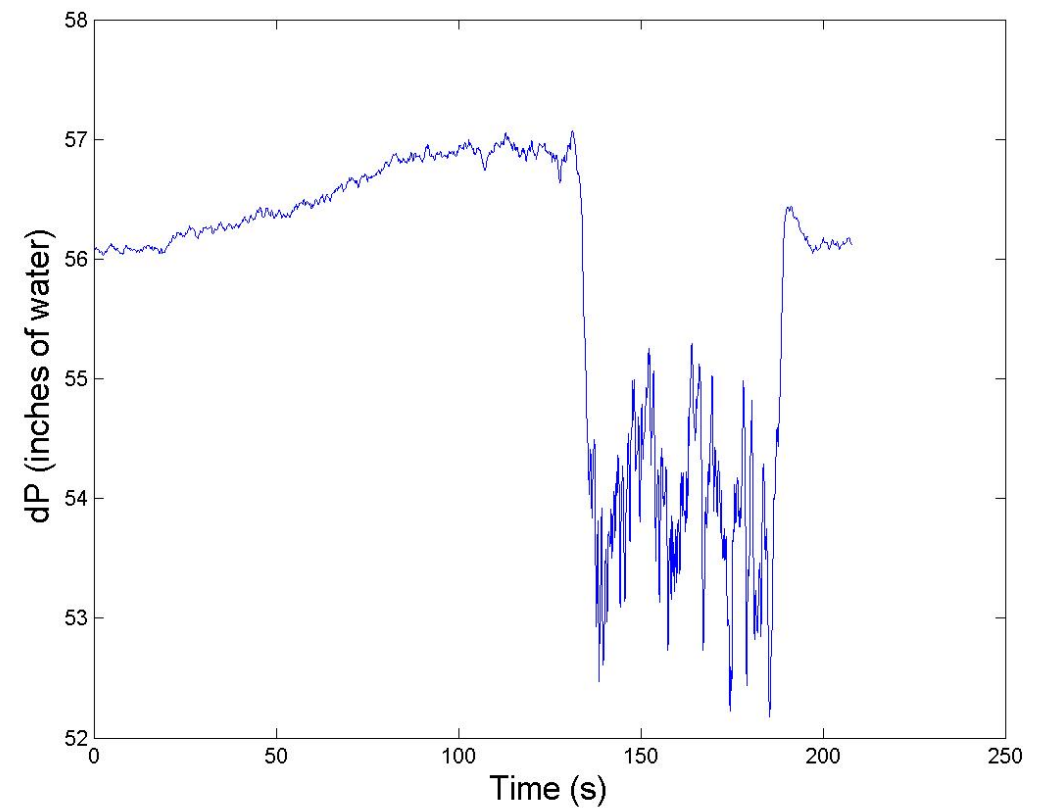

Fig. D.162.: Differential pressure measurements for Test 33.

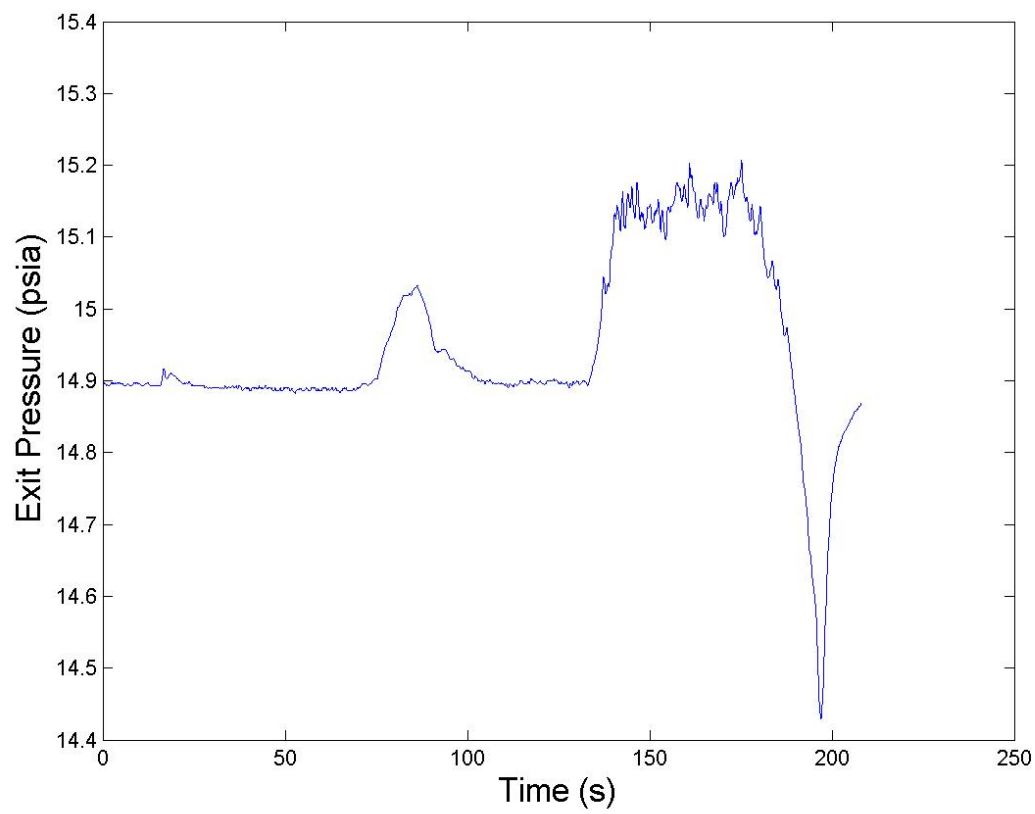

Fig. D.163.: Water exit tank pressure measurements for Test 33. 


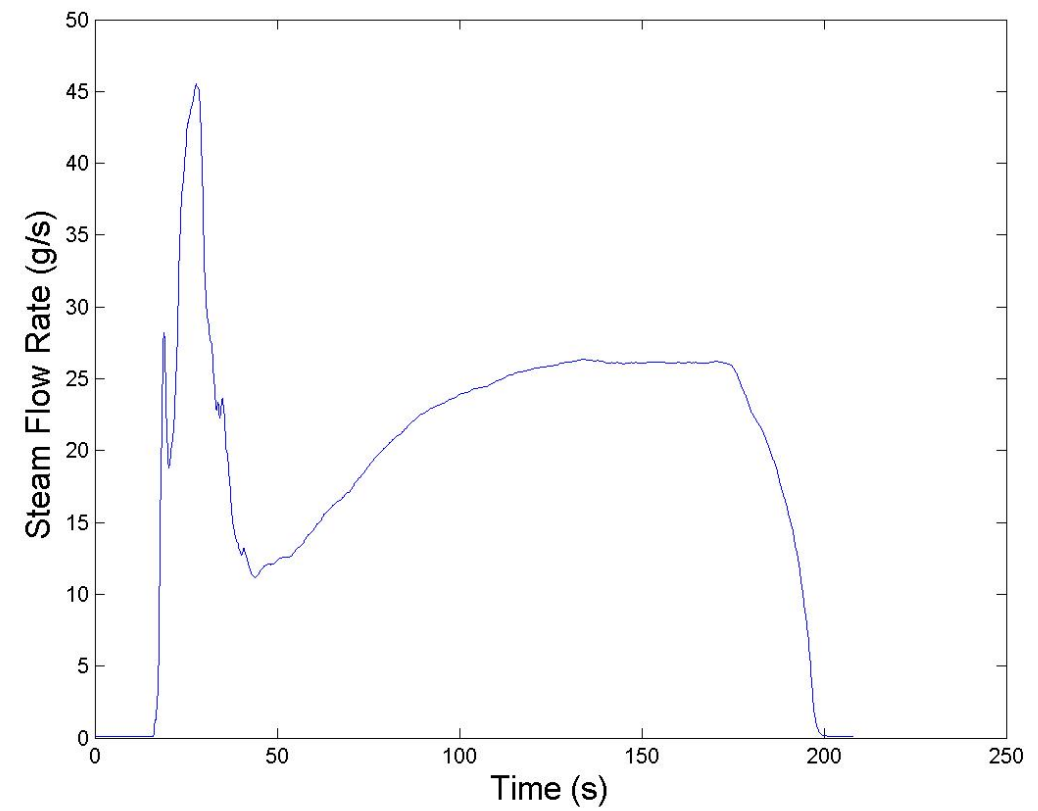

Fig. D.164.: Steam mass flow rate measurements for Test 33.

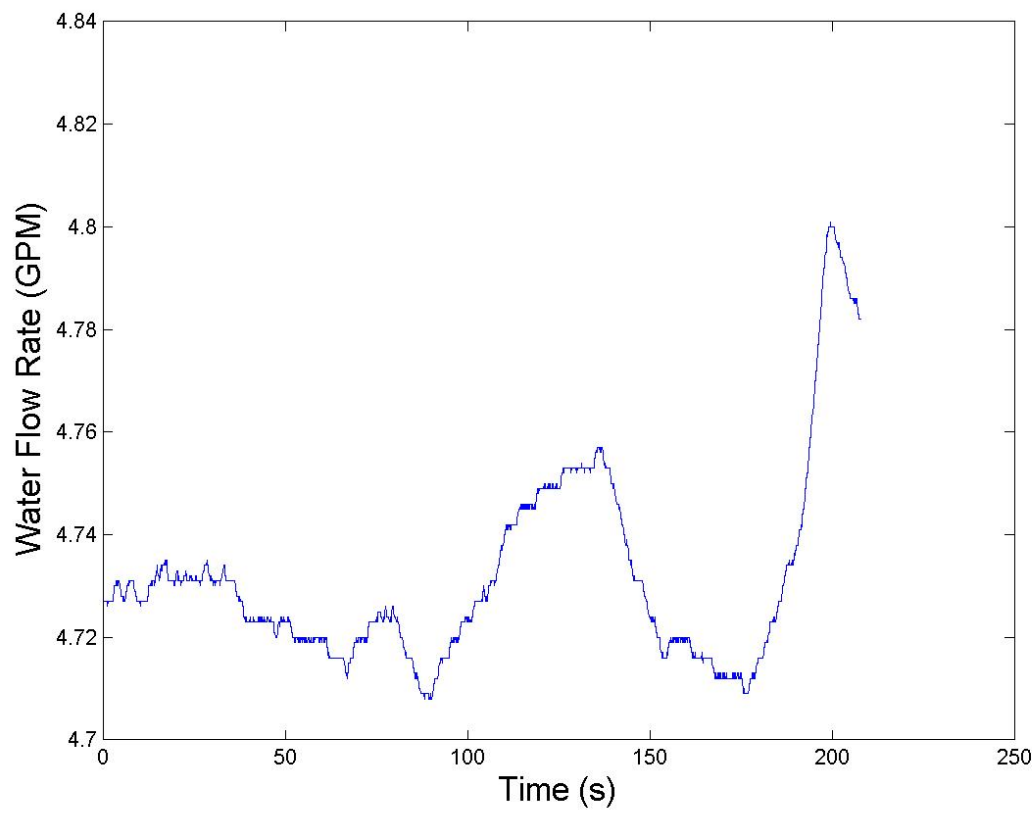

Fig. D.165.: Water flow rate measurements for Test 33. 


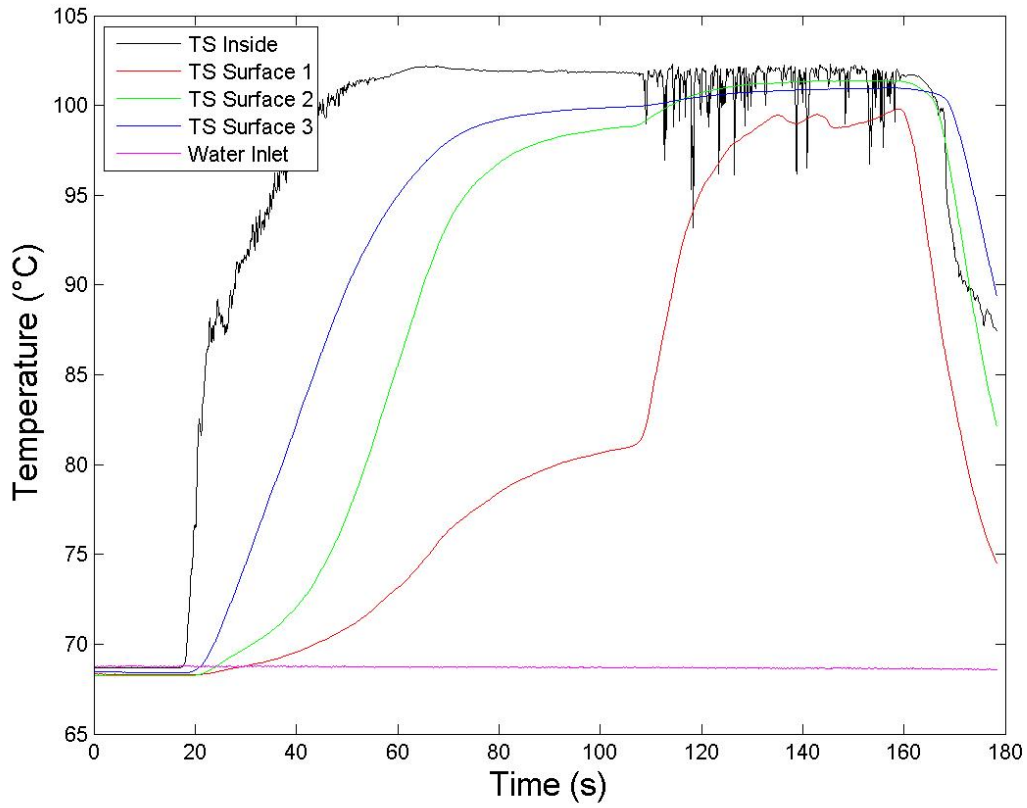

Fig. D.166.: Temperature measurements for Test 34.

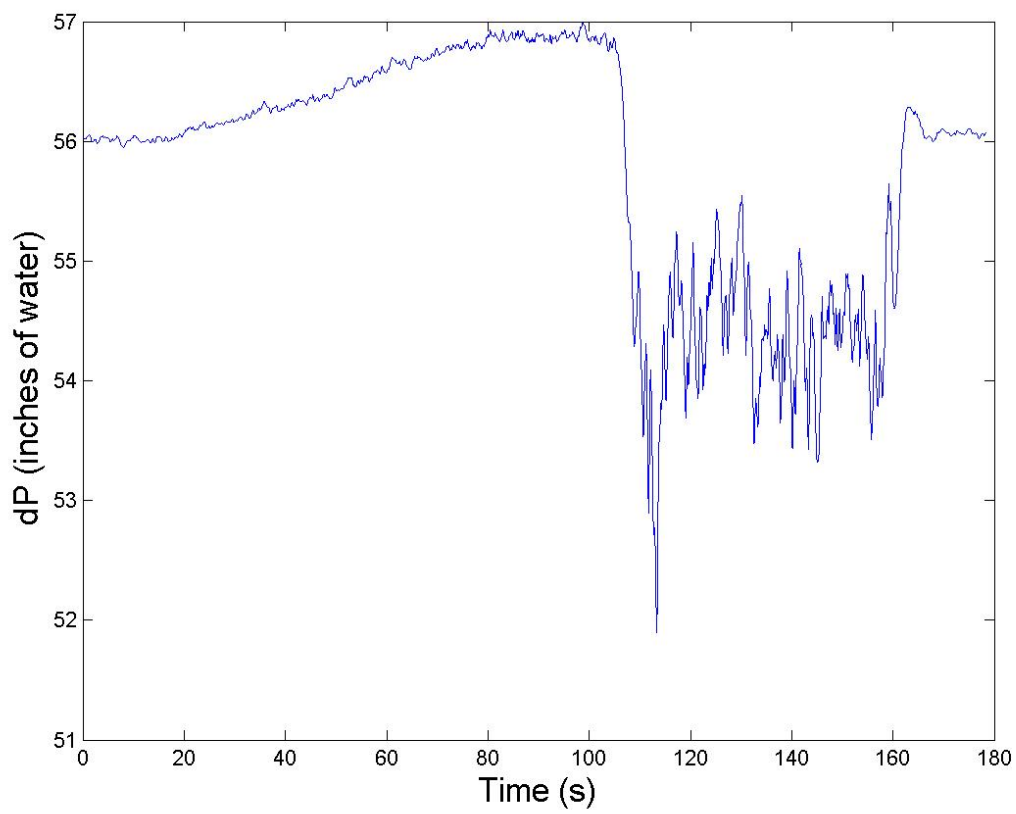

Fig. D.167.: Differential pressure measurements for Test 34. 


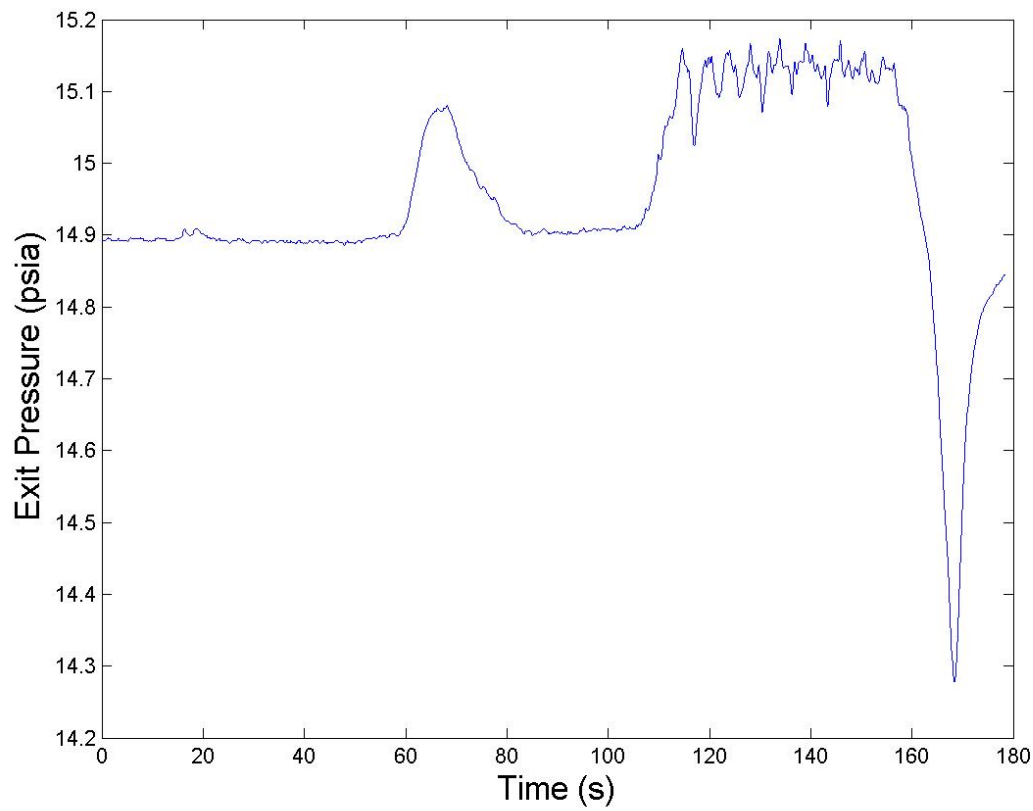

Fig. D.168.: Water exit tank pressure measurements for Test 34.

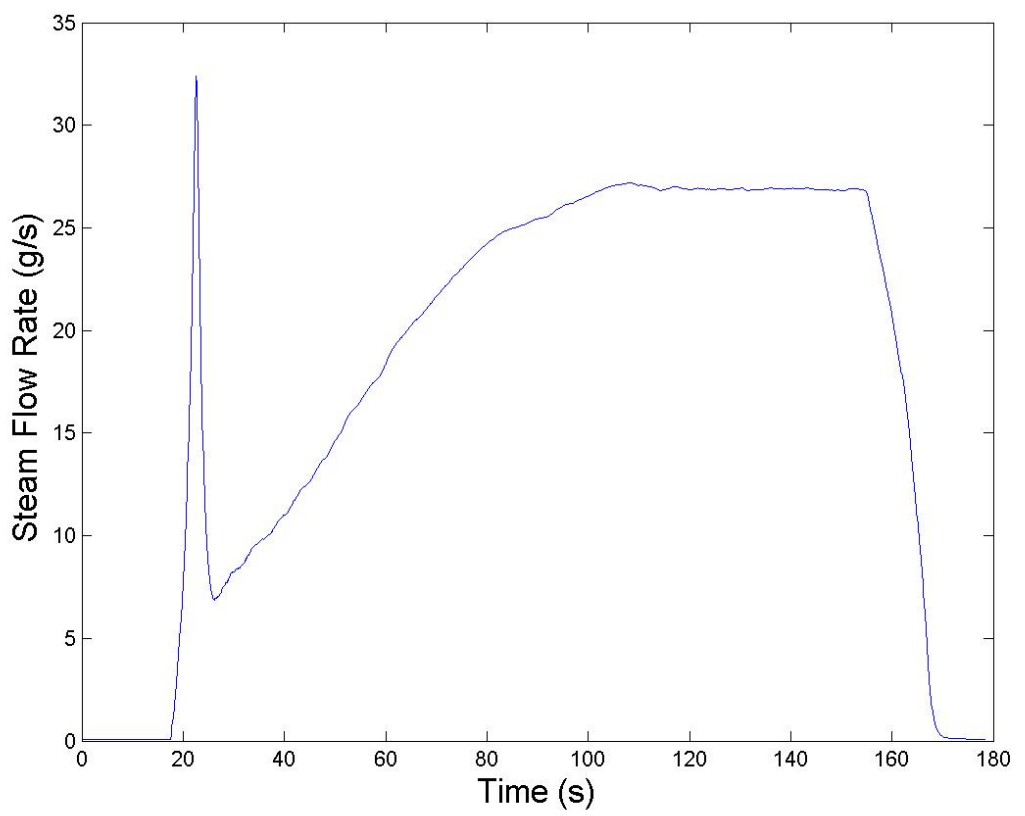

Fig. D.169.: Steam mass flow rate measurements for Test 34. 


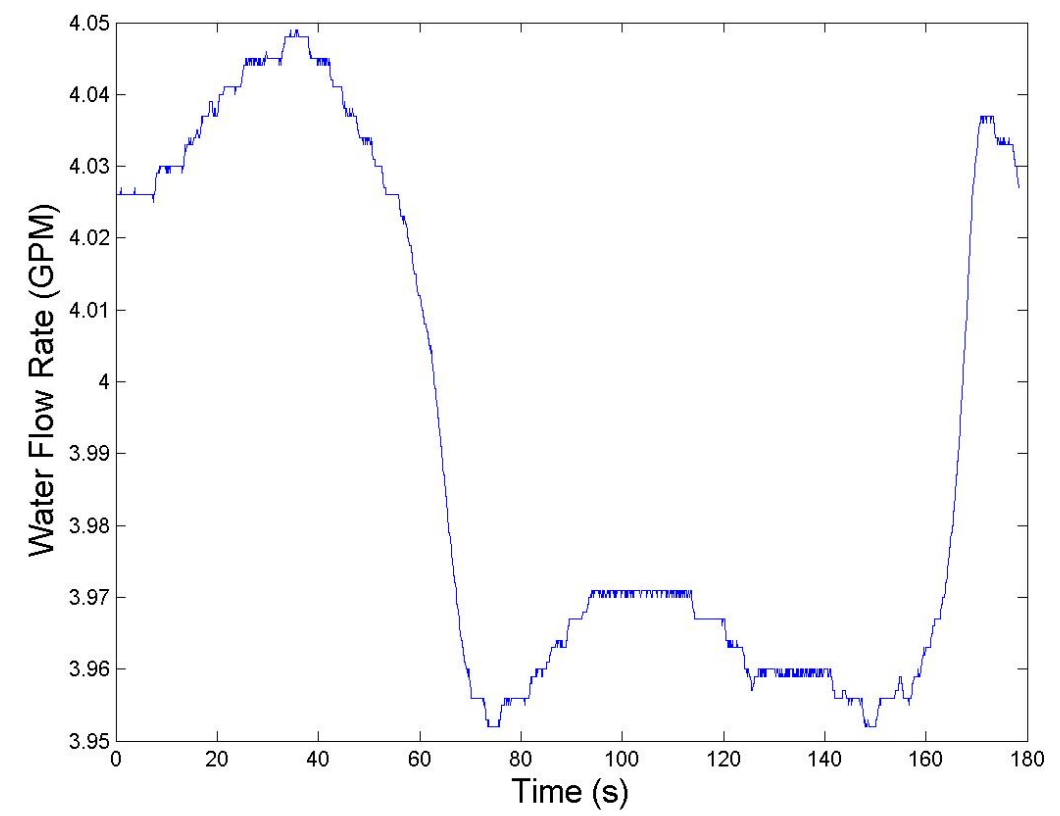

Fig. D.170.: Water flow rate measurements for Test 34 .

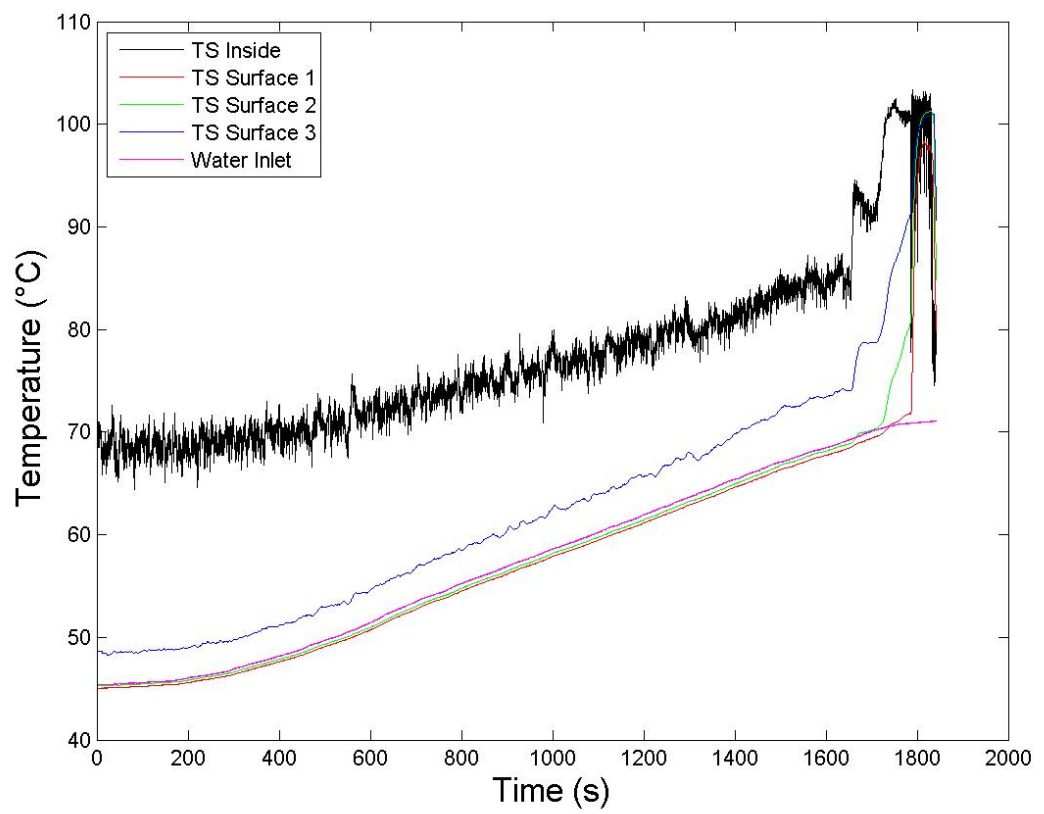

Fig. D.171.: Temperature measurements for Test 35. 


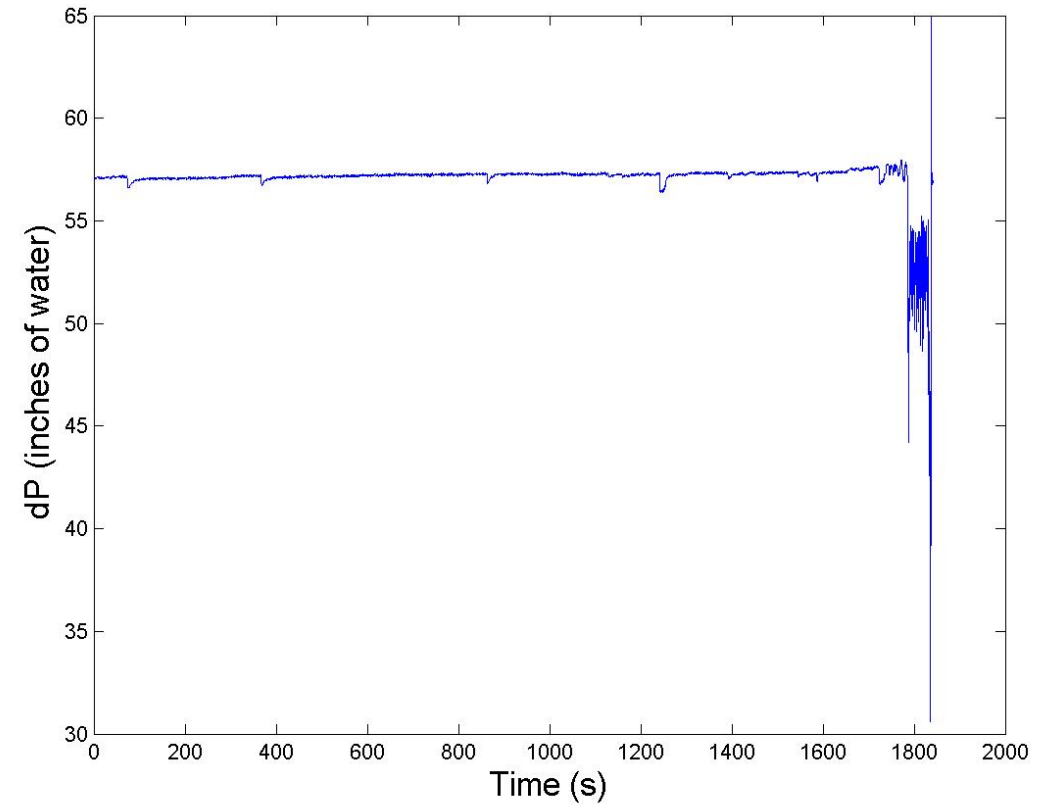

Fig. D.172.: Differential pressure measurements for Test 35.

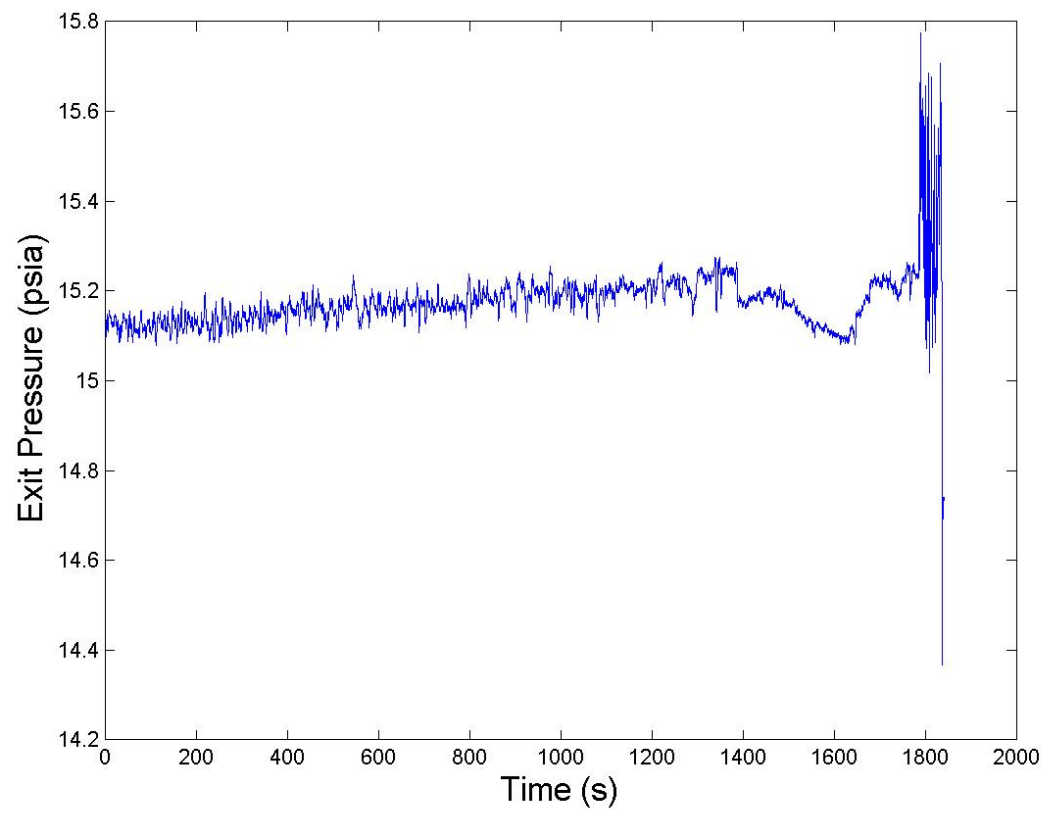

Fig. D.173.: Water exit tank pressure measurements for Test 35. 


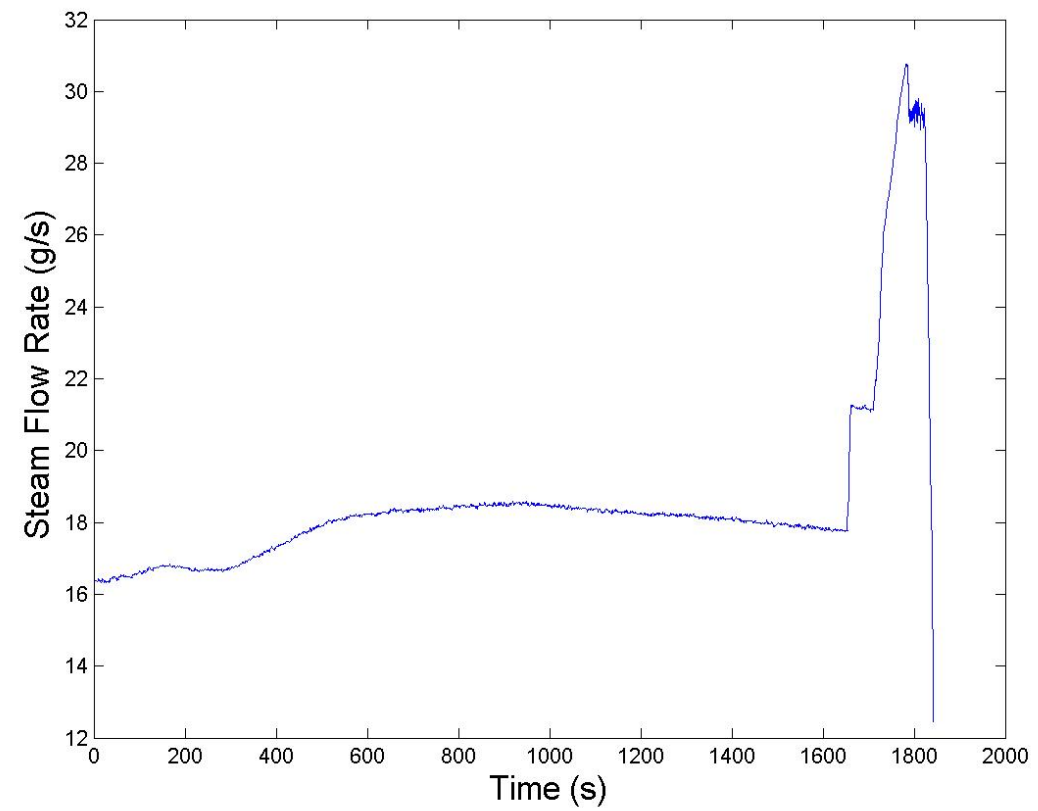

Fig. D.174.: Steam mass flow rate measurements for Test 35.

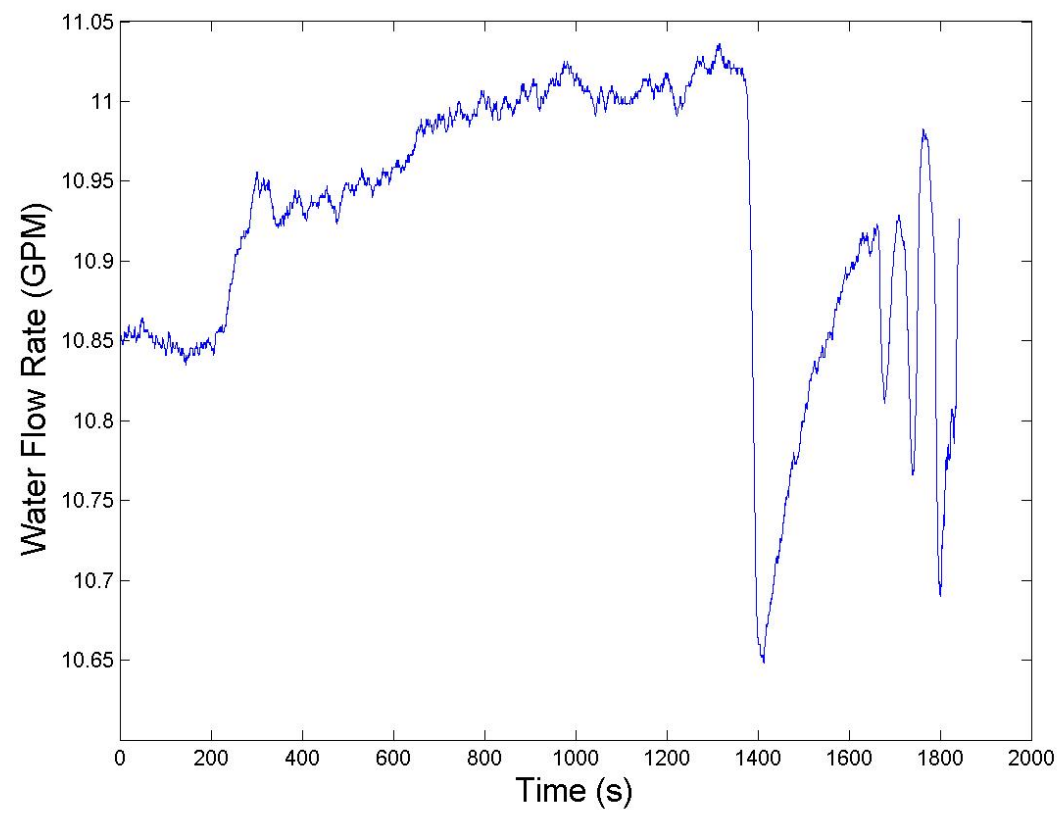

Fig. D.175.: Water flow rate measurements for Test 35. 


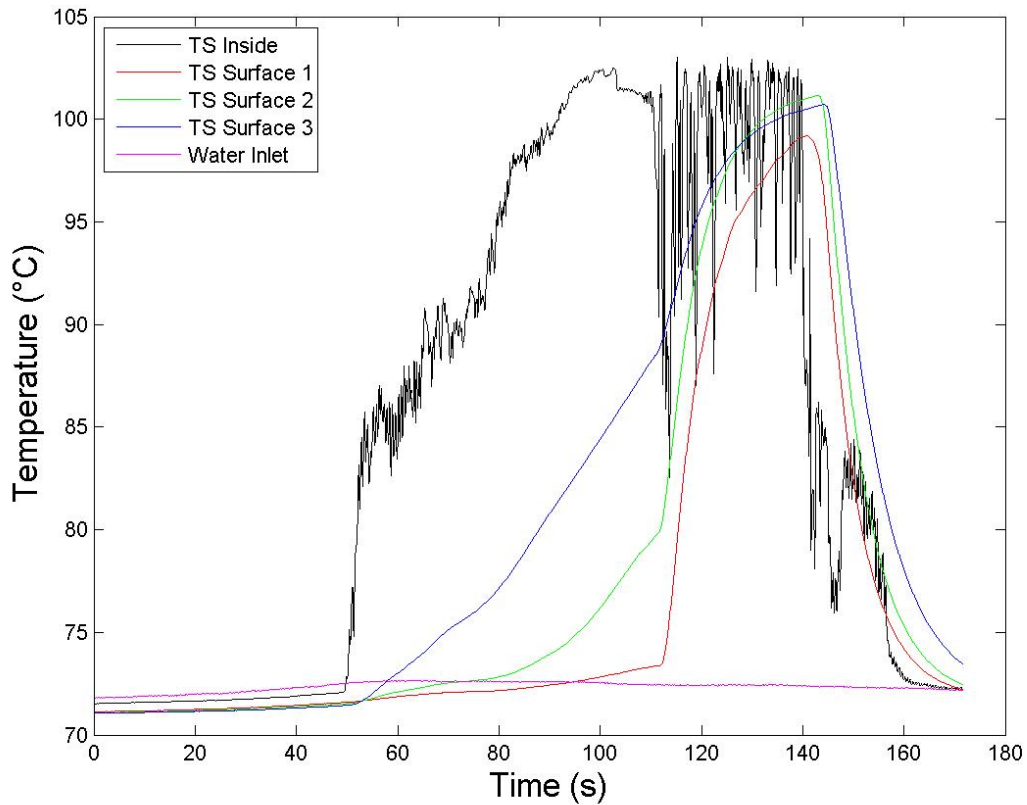

Fig. D.176.: Temperature measurements for Test 36.

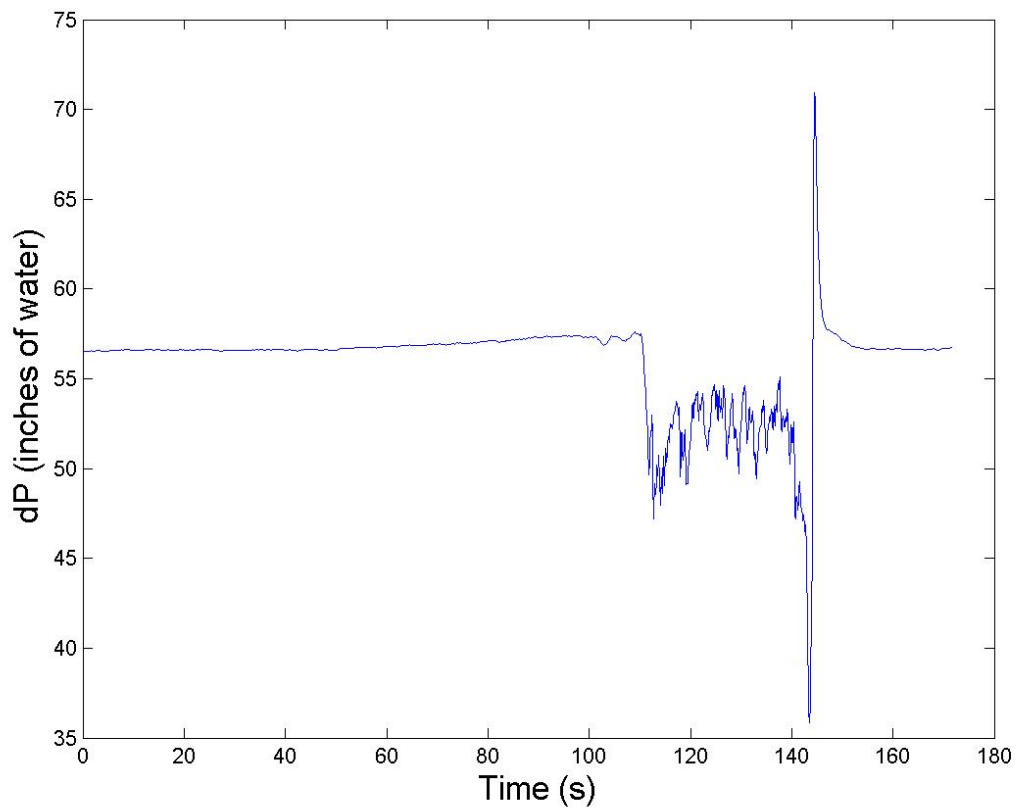

Fig. D.177.: Differential pressure measurements for Test 36. 


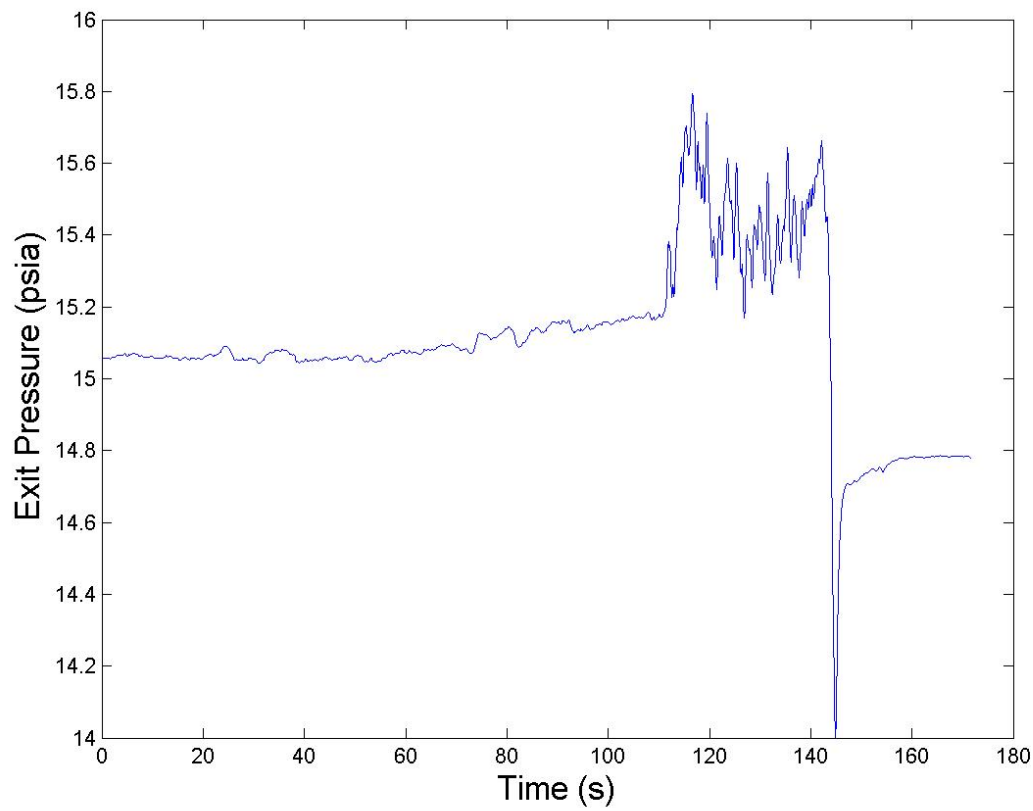

Fig. D.178.: Water exit tank pressure measurements for Test 36.

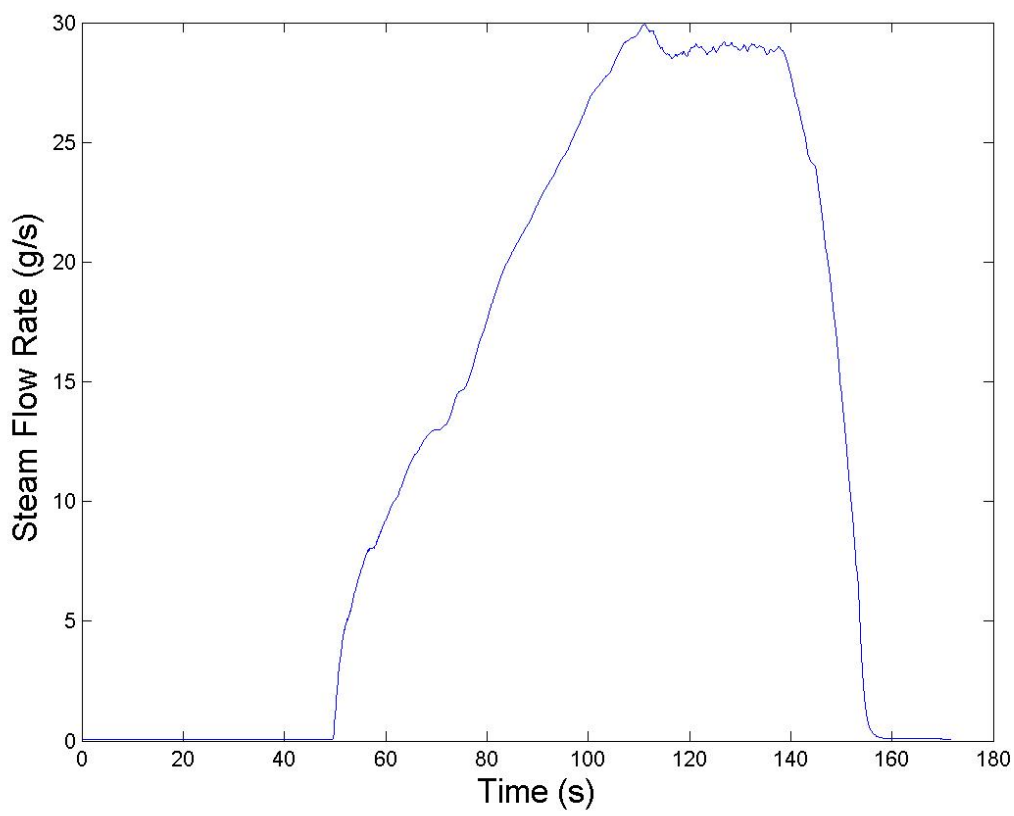

Fig. D.179.: Steam mass flow rate measurements for Test 36. 


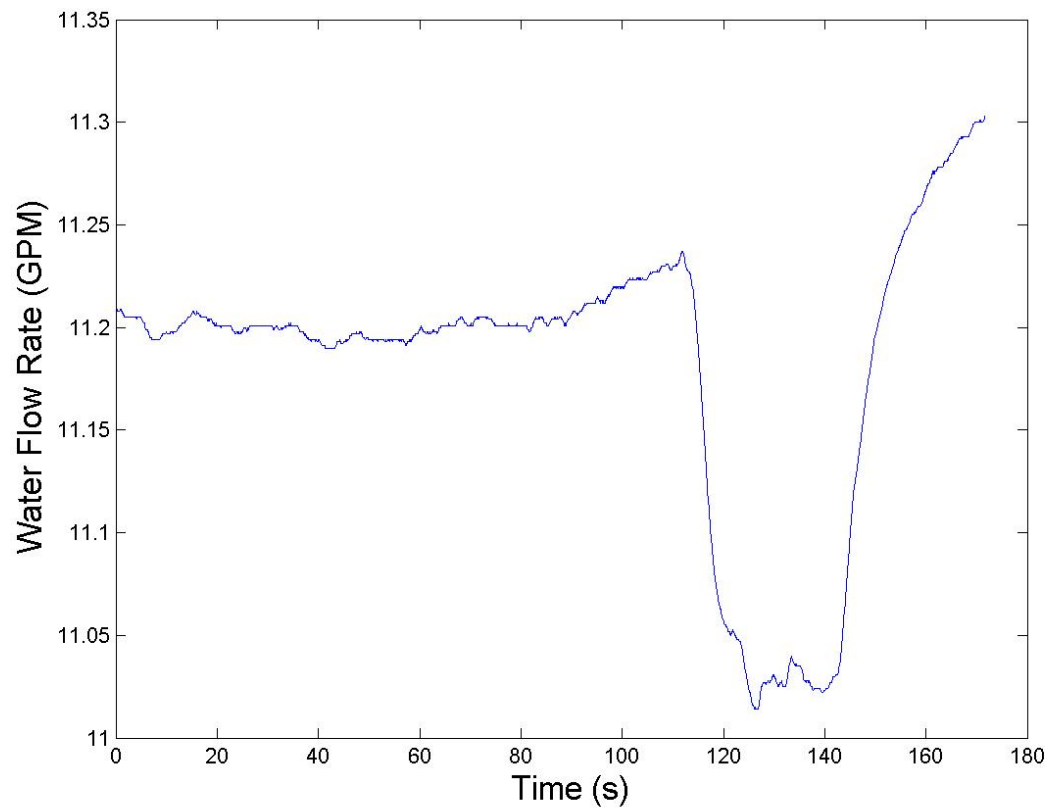

Fig. D.180.: Water flow rate measurements for Test 36.

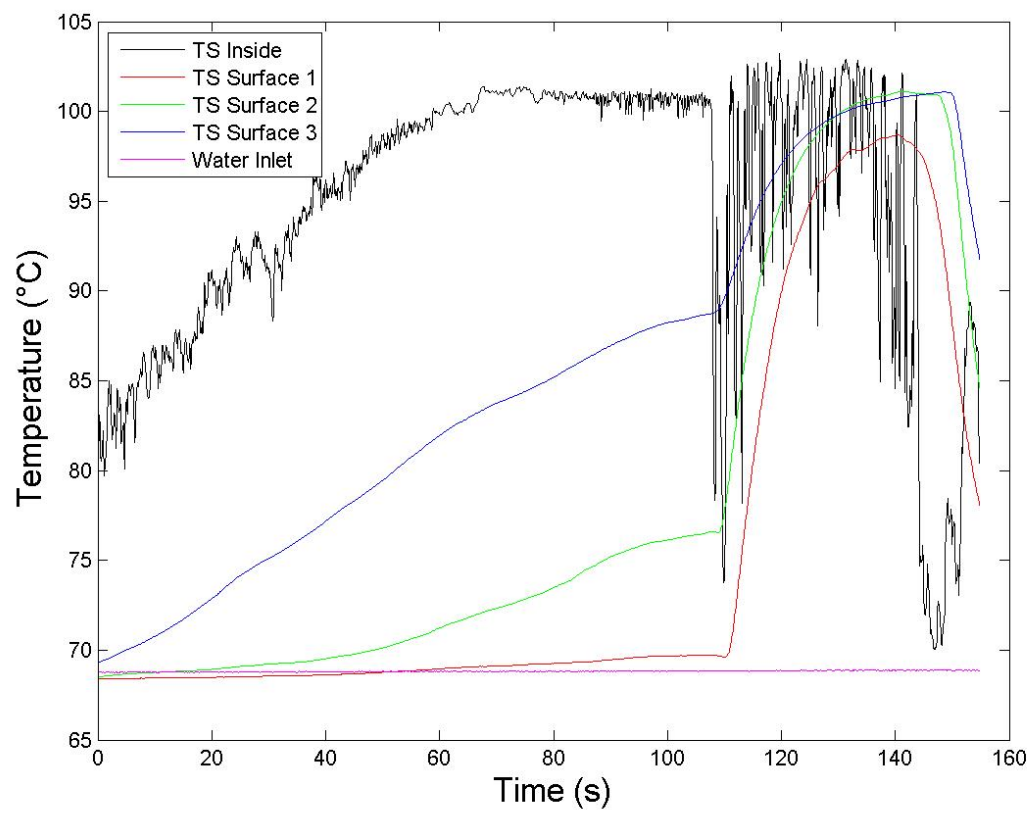

Fig. D.181.: Temperature measurements for Test 37. 


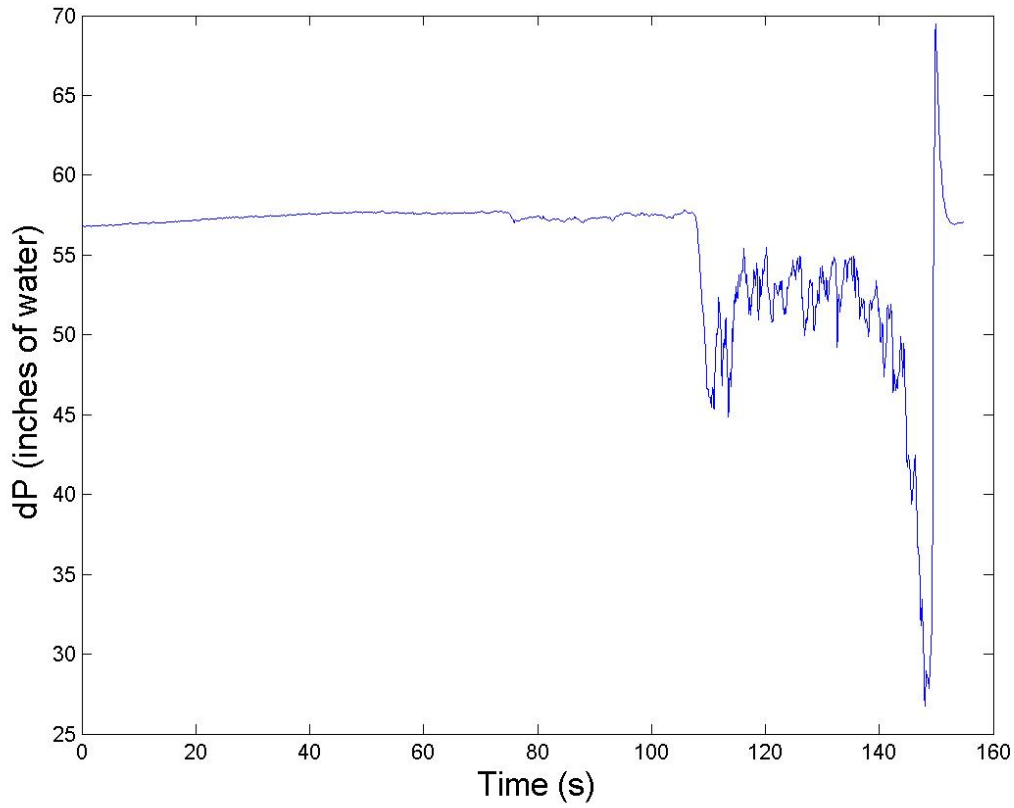

Fig. D.182.: Differential pressure measurements for Test 37.

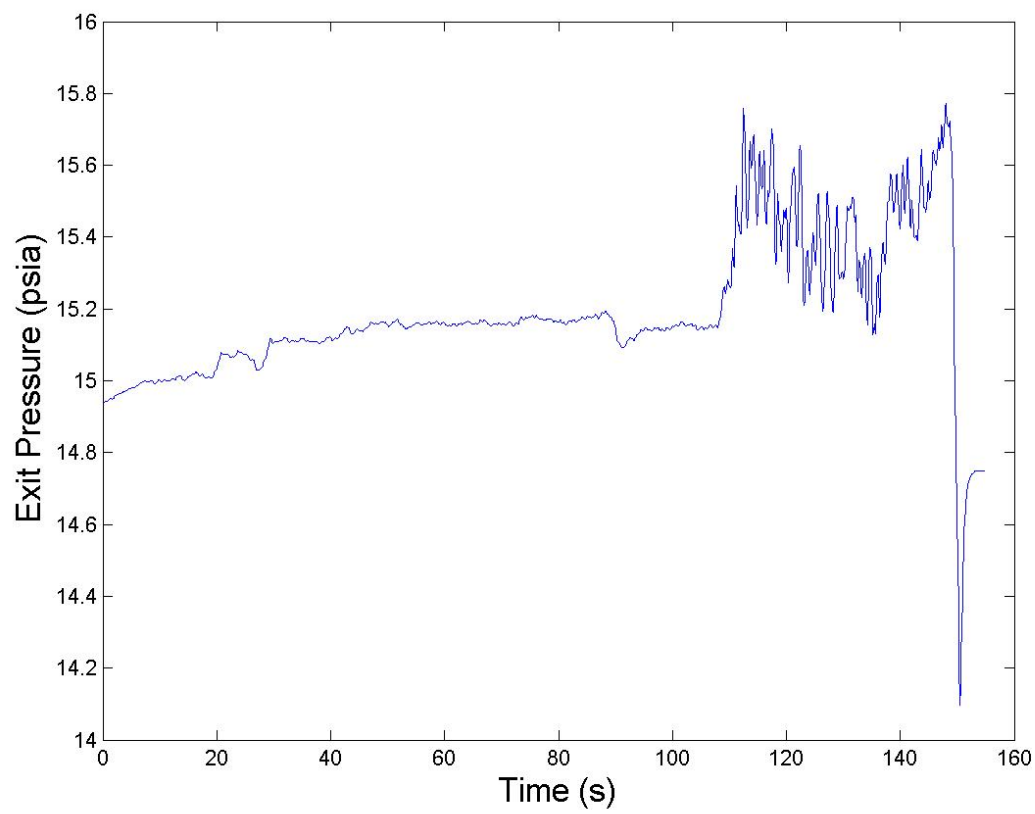

Fig. D.183.: Water exit tank pressure measurements for Test 37. 


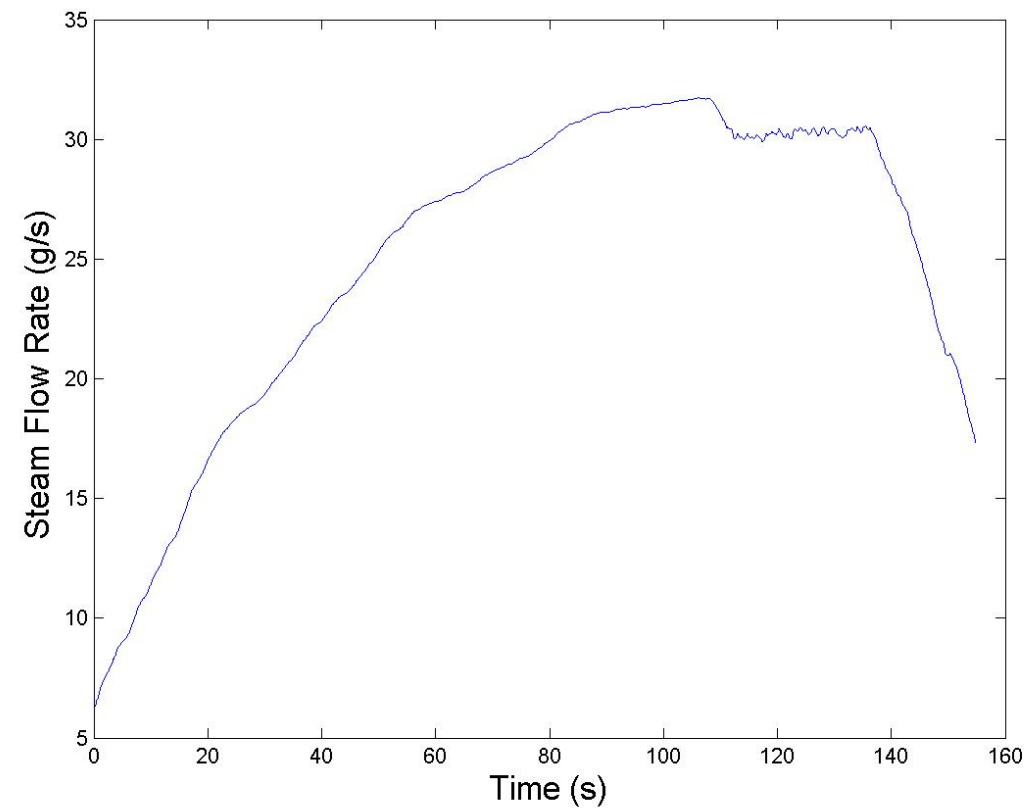

Fig. D.184.: Steam mass flow rate measurements for Test 37.

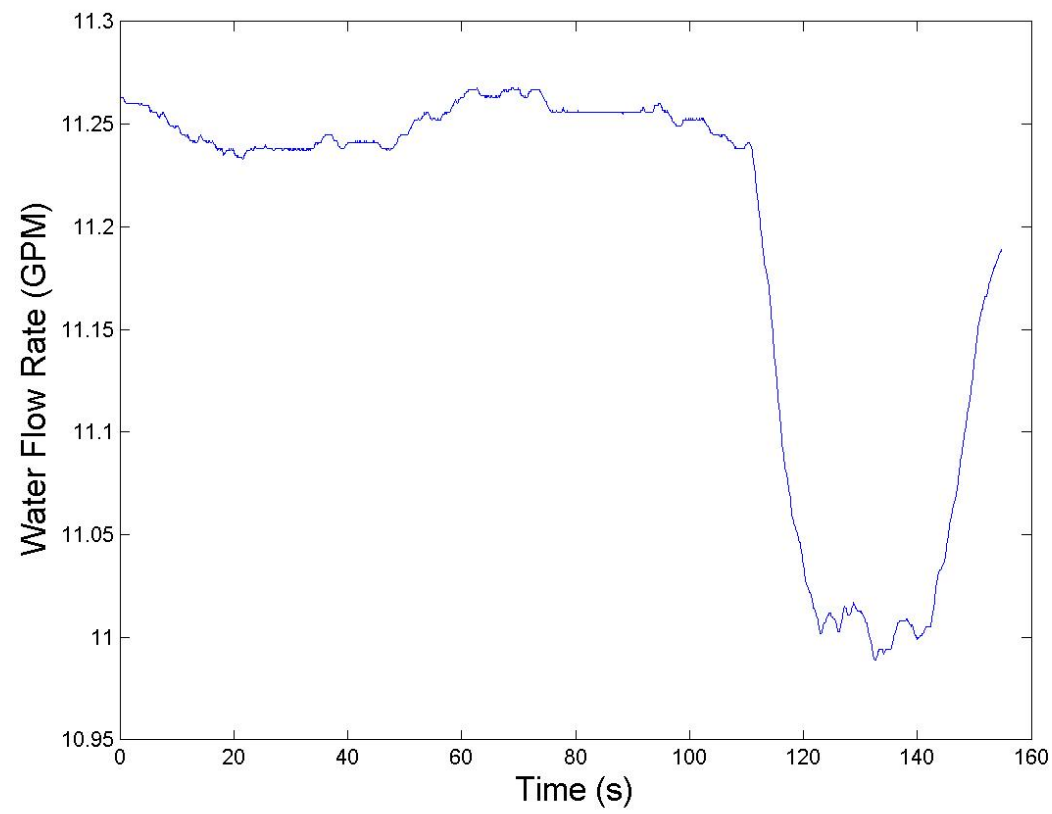

Fig. D.185.: Water flow rate measurements for Test 37. 


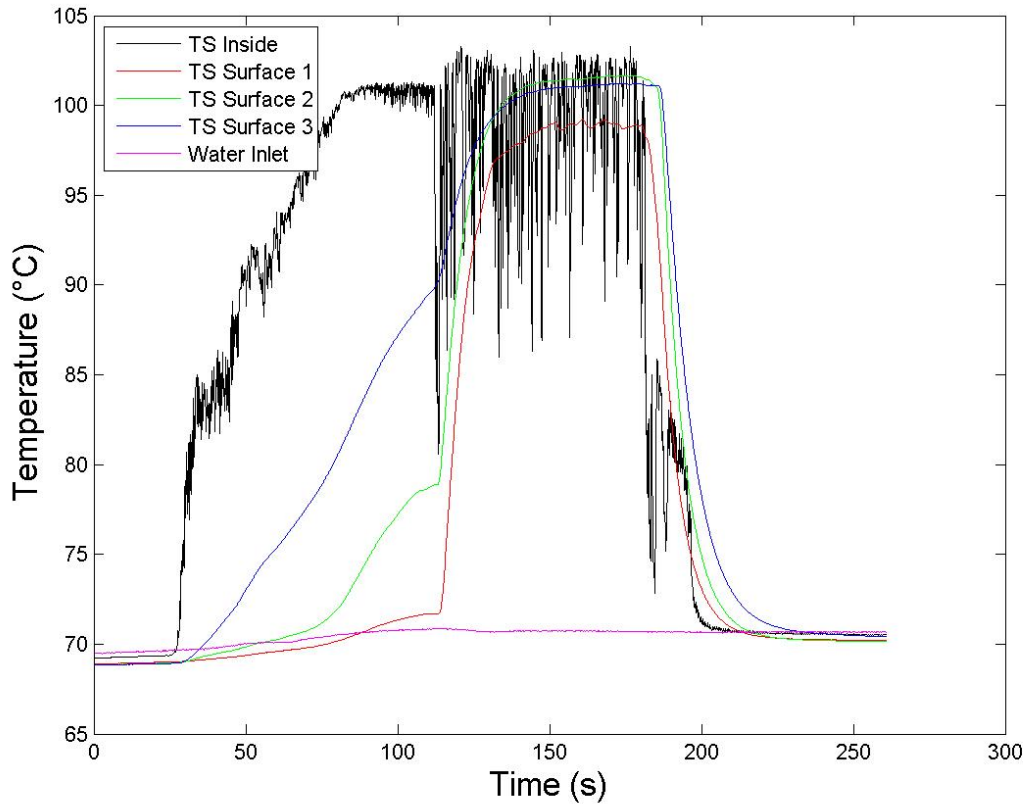

Fig. D.186.: Temperature measurements for Test 38.

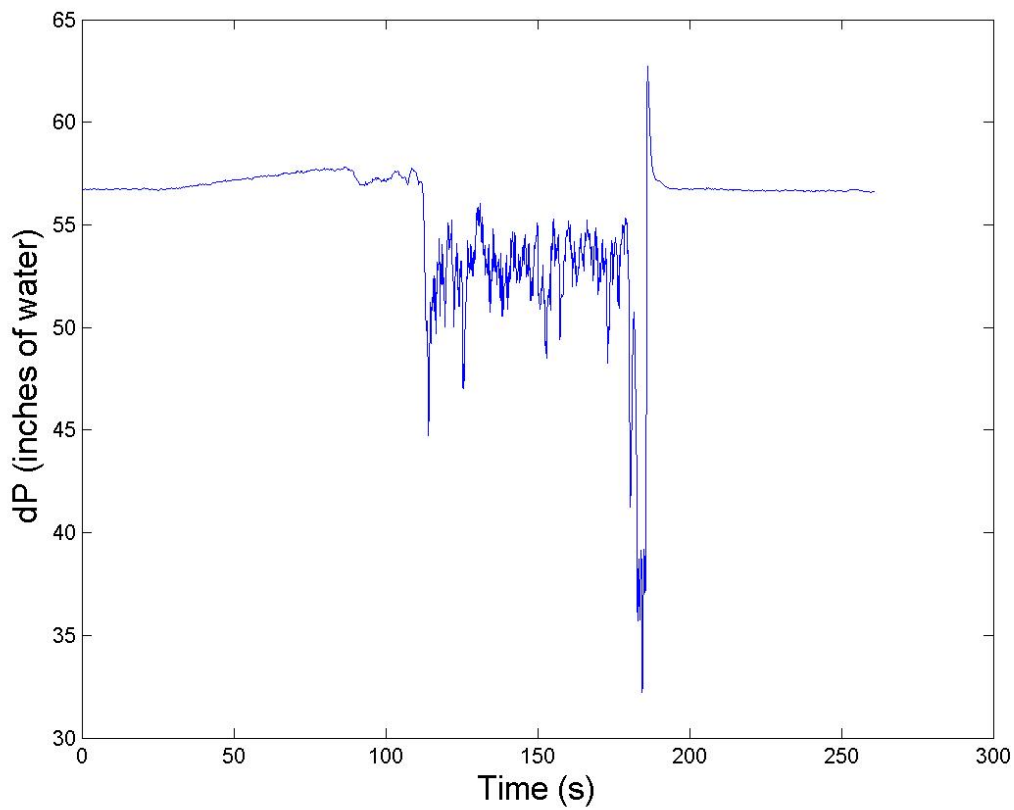

Fig. D.187.: Differential pressure measurements for Test 38. 


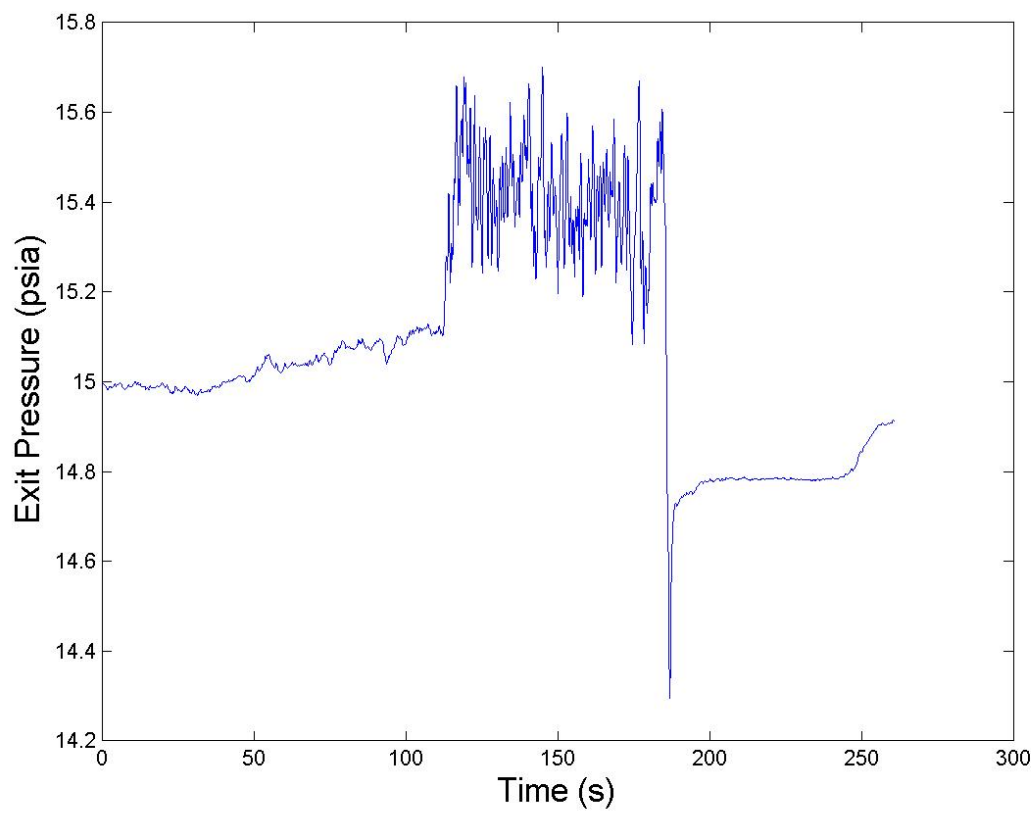

Fig. D.188.: Water exit tank pressure measurements for Test 38 .

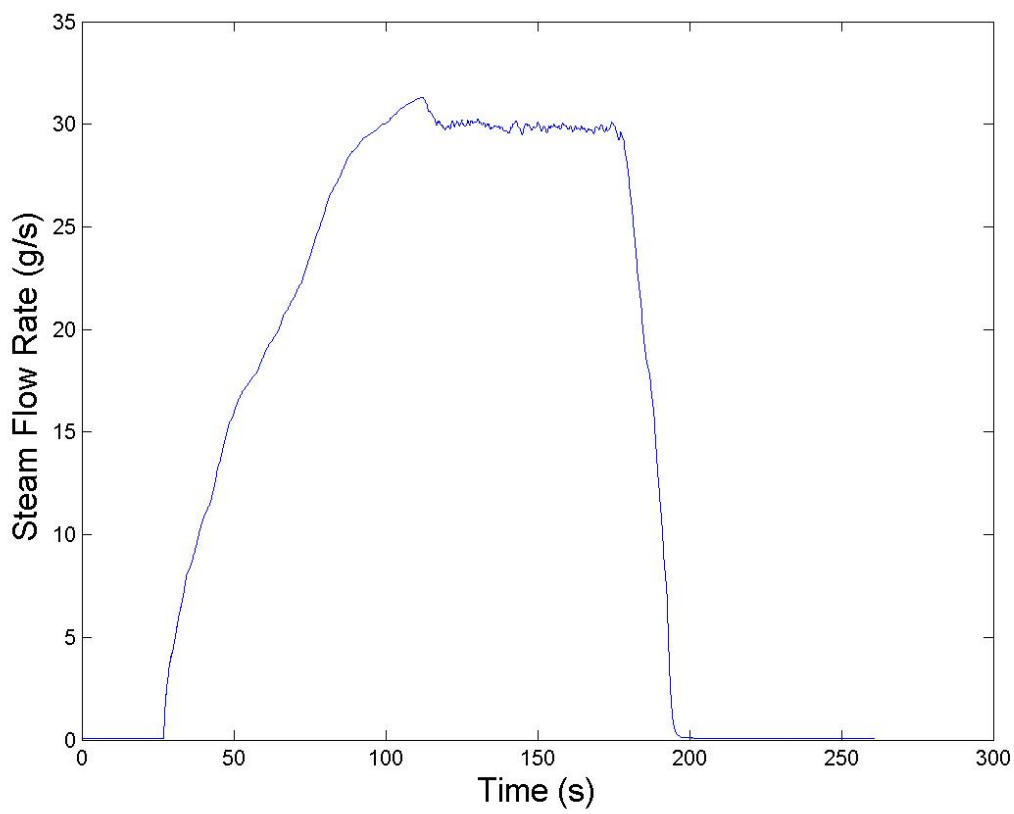

Fig. D.189.: Steam mass flow rate measurements for Test 38. 


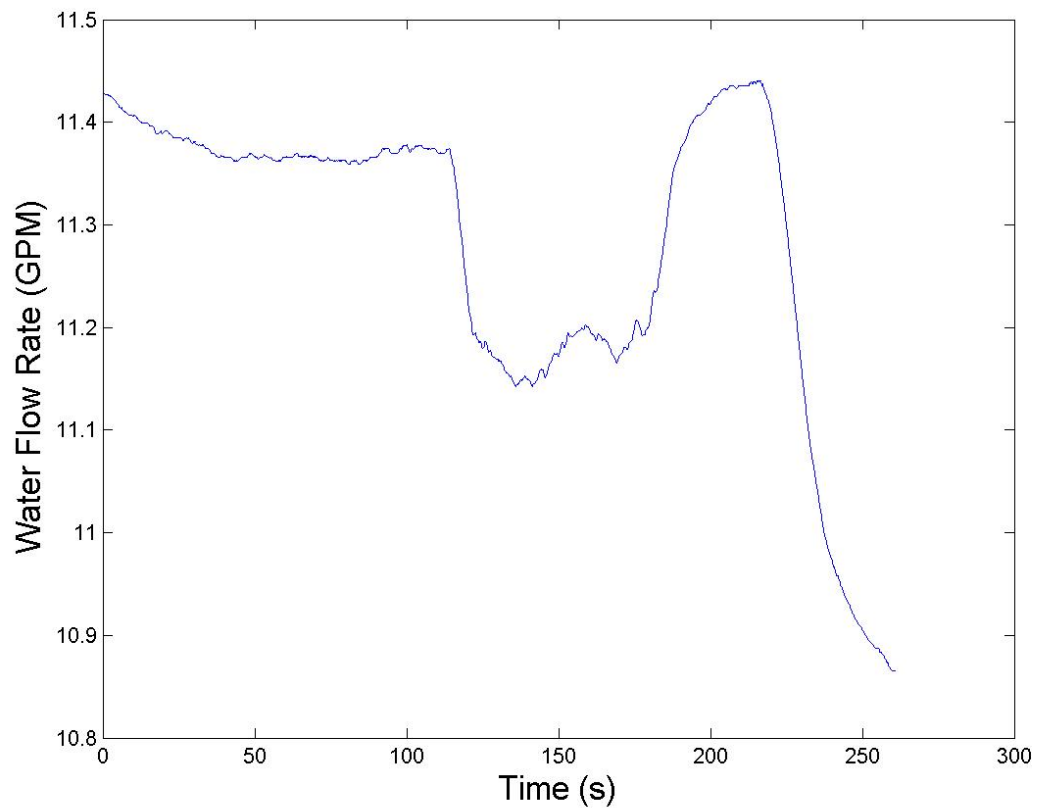

Fig. D.190.: Water flow rate measurements for Test 38.

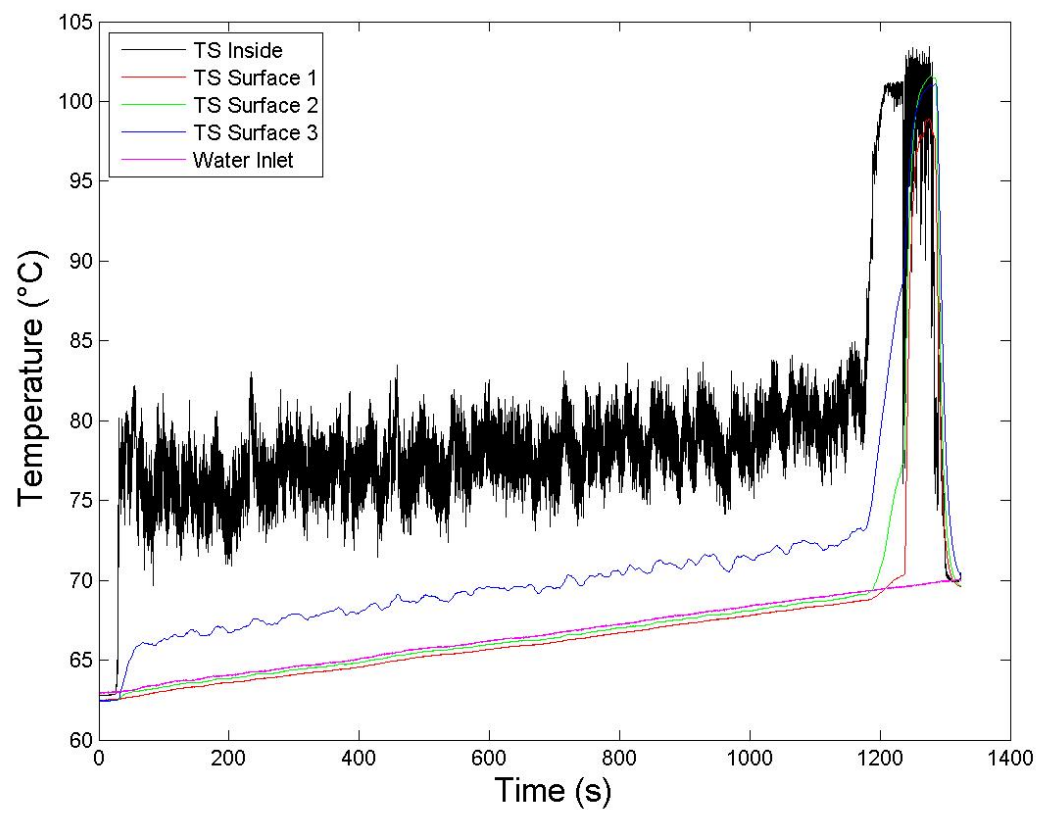

Fig. D.191.: Temperature measurements for Test 39. 


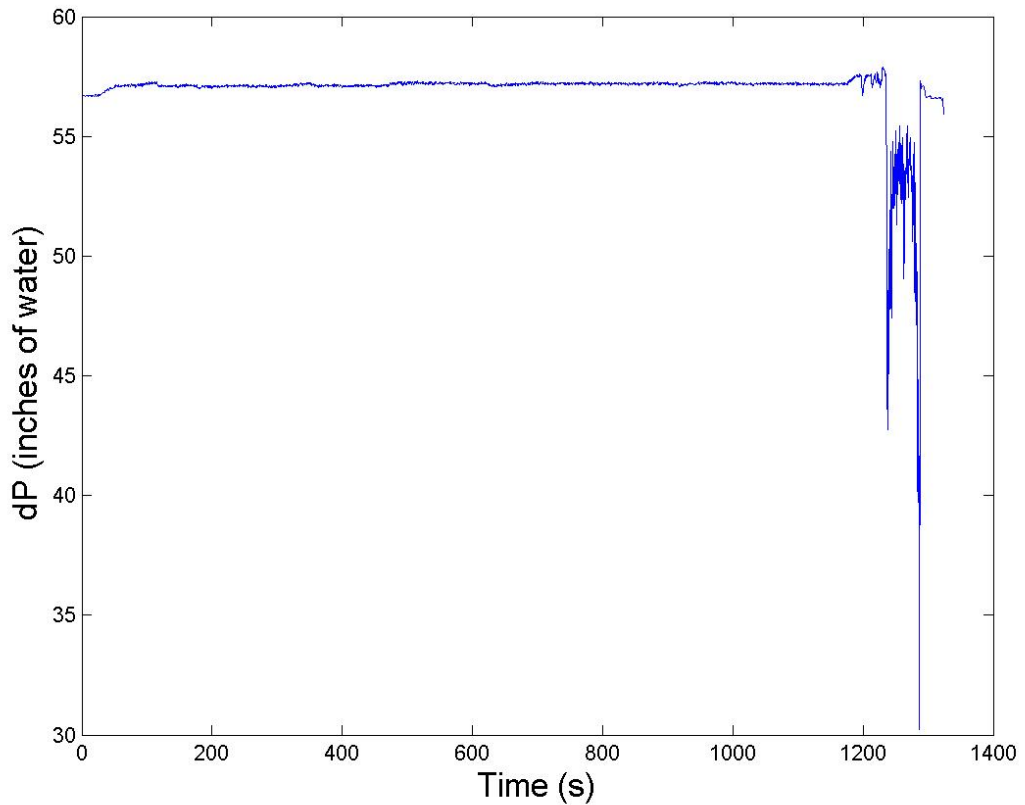

Fig. D.192.: Differential pressure measurements for Test 39.

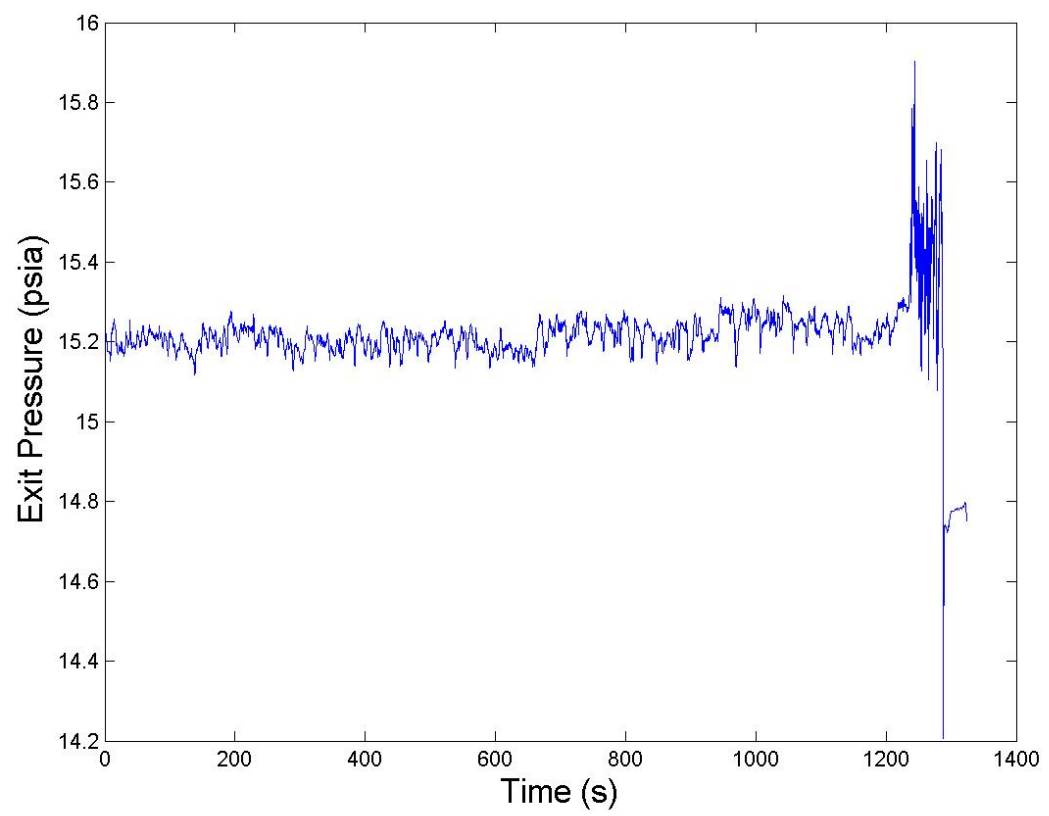

Fig. D.193.: Water exit tank pressure measurements for Test 39. 


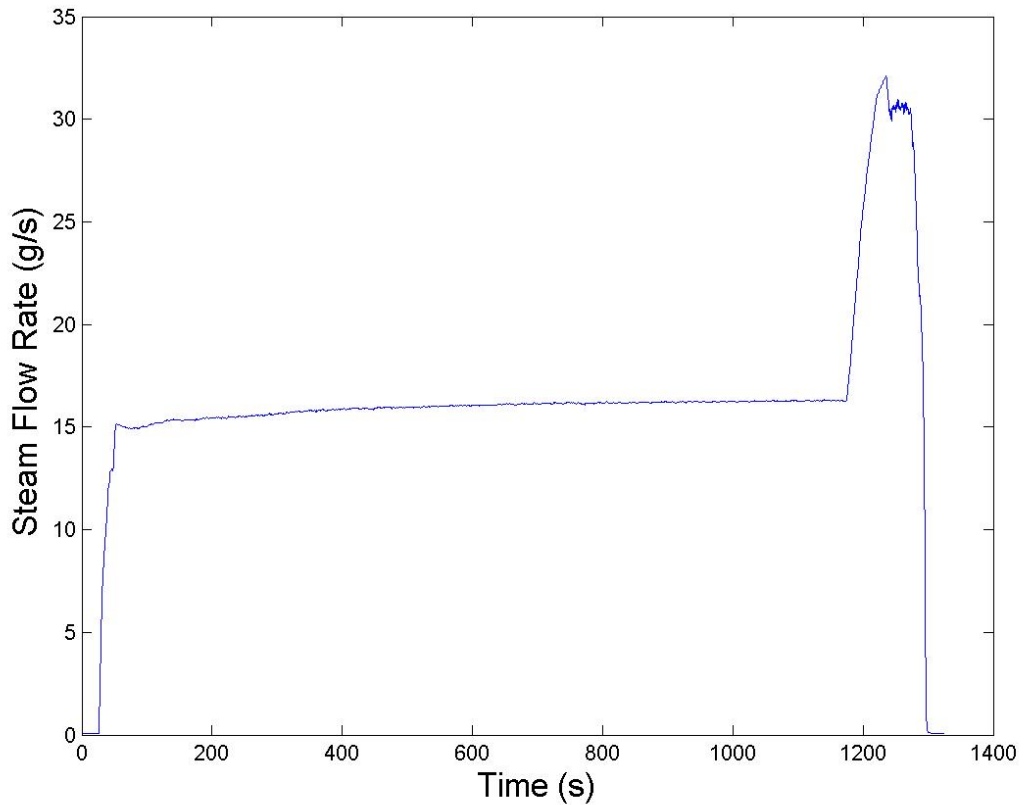

Fig. D.194.: Steam mass flow rate measurements for Test 39.

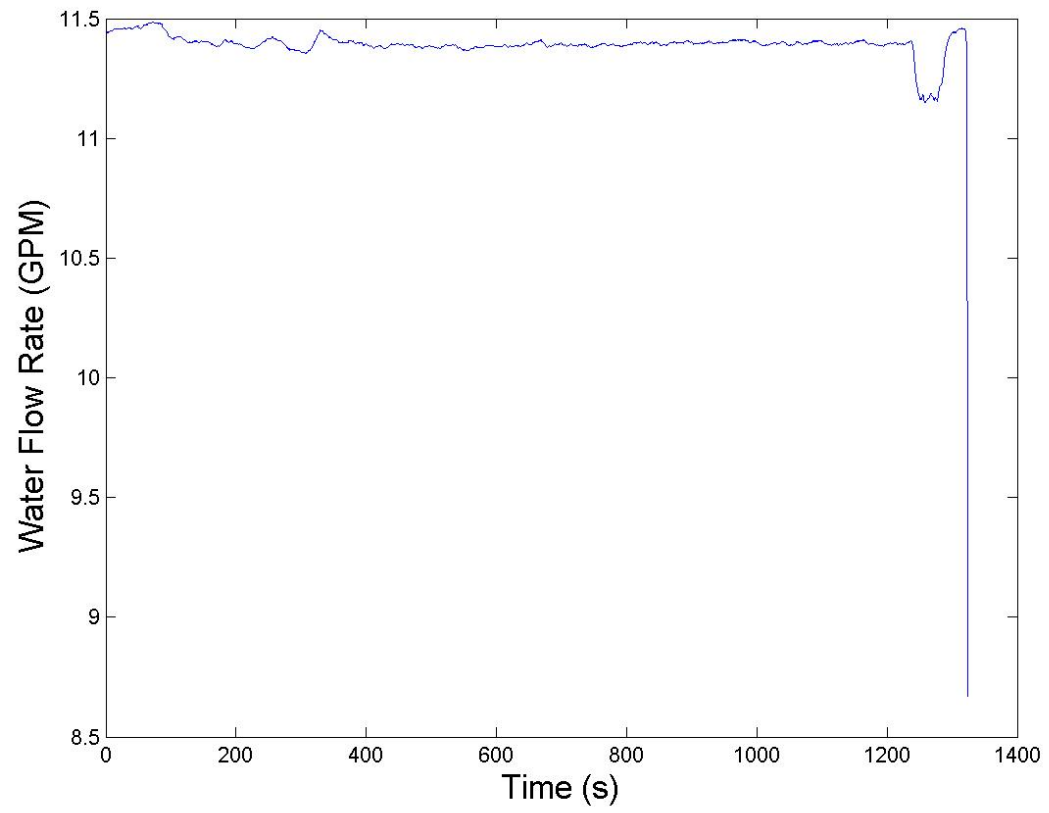

Fig. D.195.: Water flow rate measurements for Test 39. 


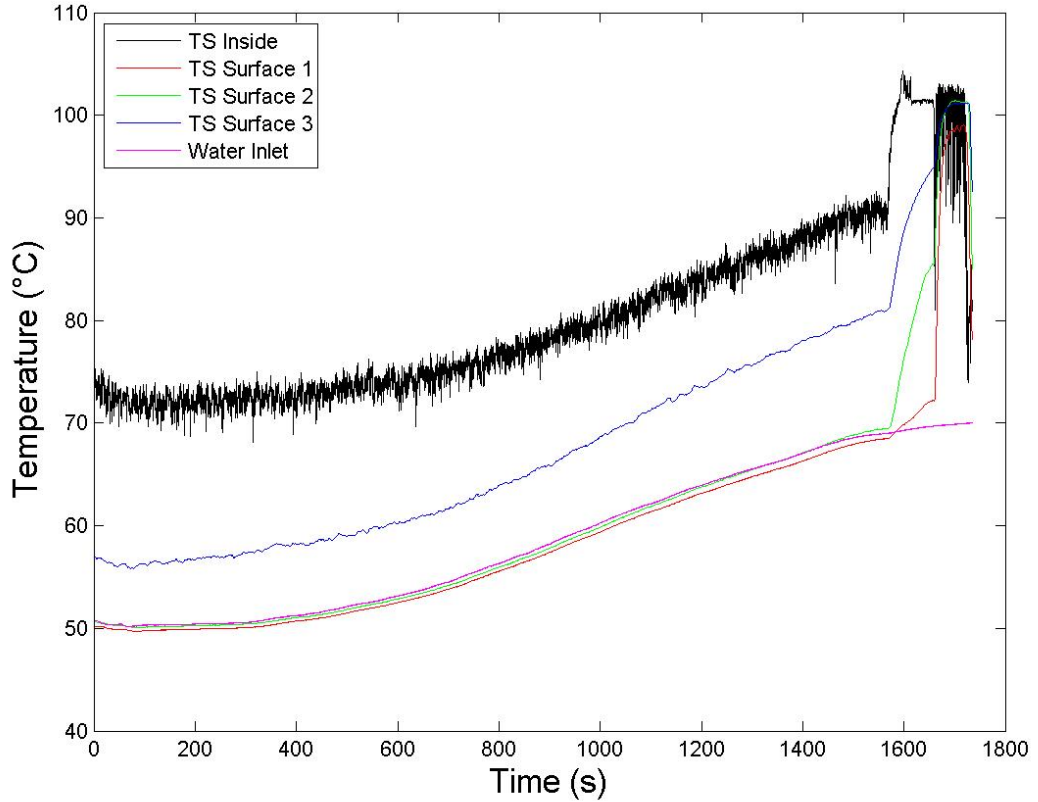

Fig. D.196.: Temperature measurements for Test 40.

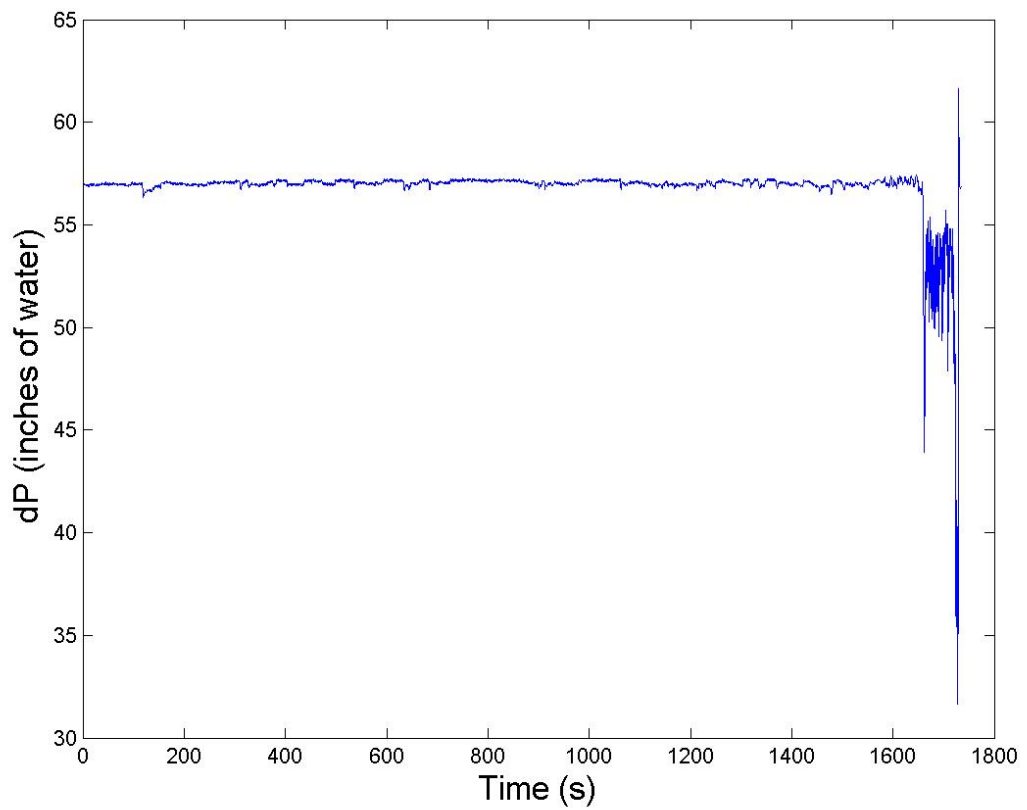

Fig. D.197.: Differential pressure measurements for Test 40. 


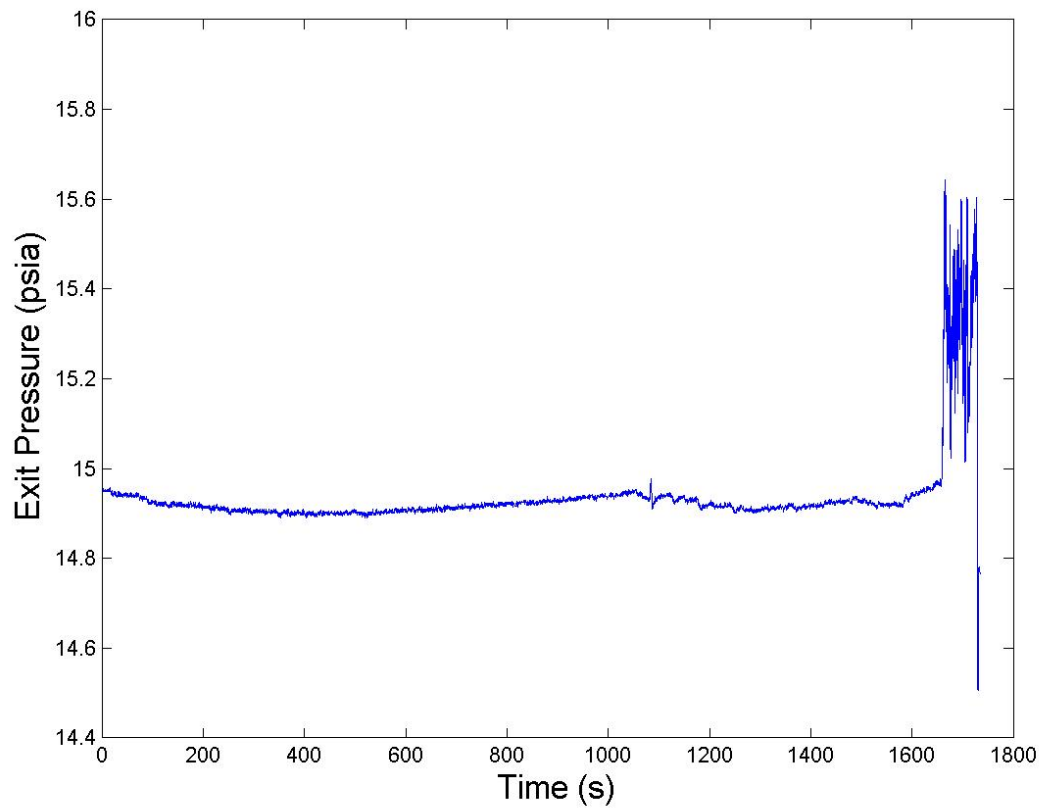

Fig. D.198.: Water exit tank pressure measurements for Test 40.

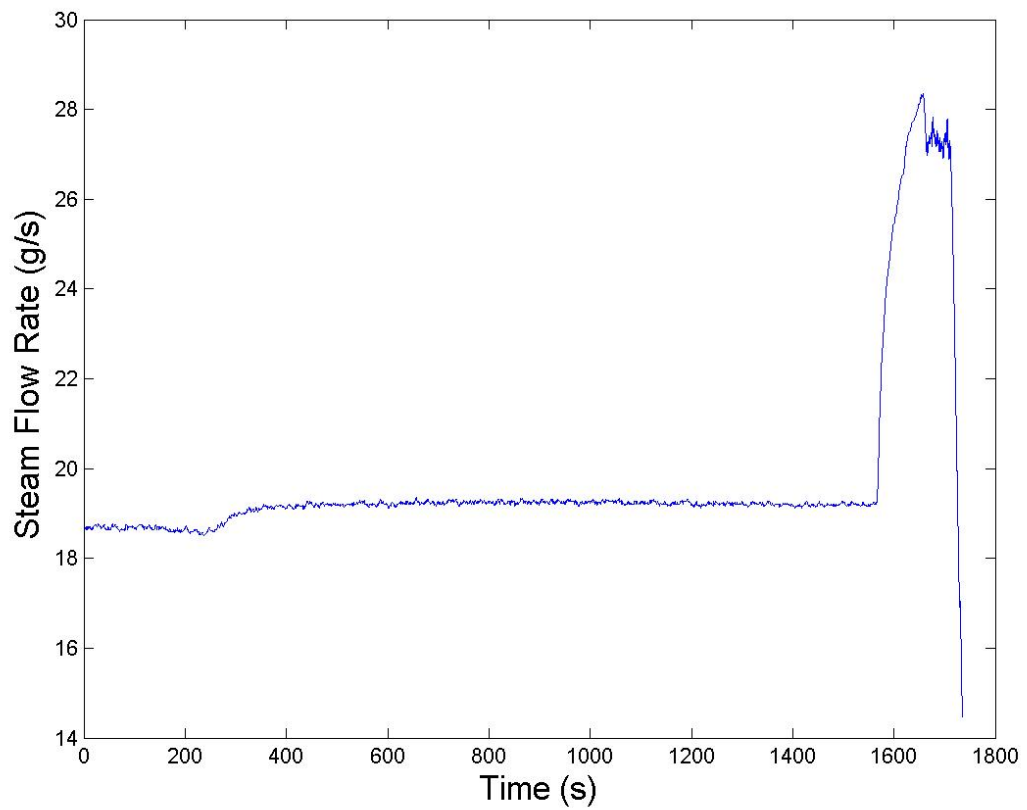

Fig. D.199.: Steam mass flow rate measurements for Test 40. 


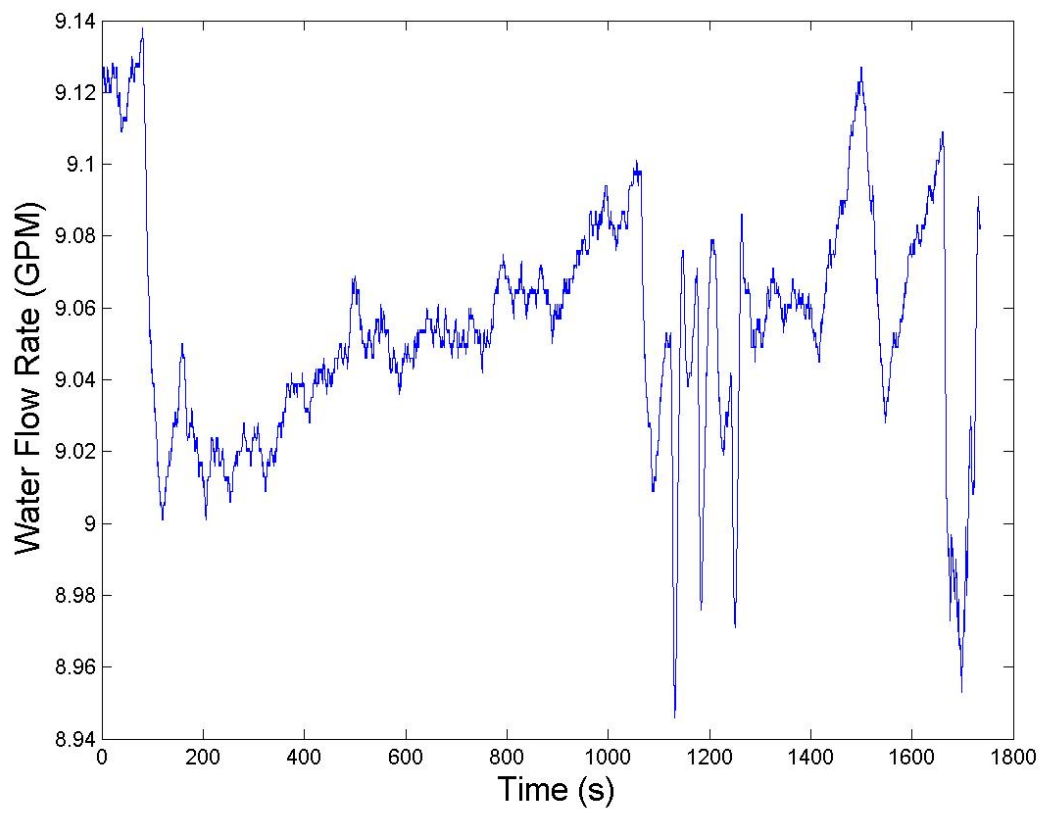

Fig. D.200.: Water flow rate measurements for Test 40.

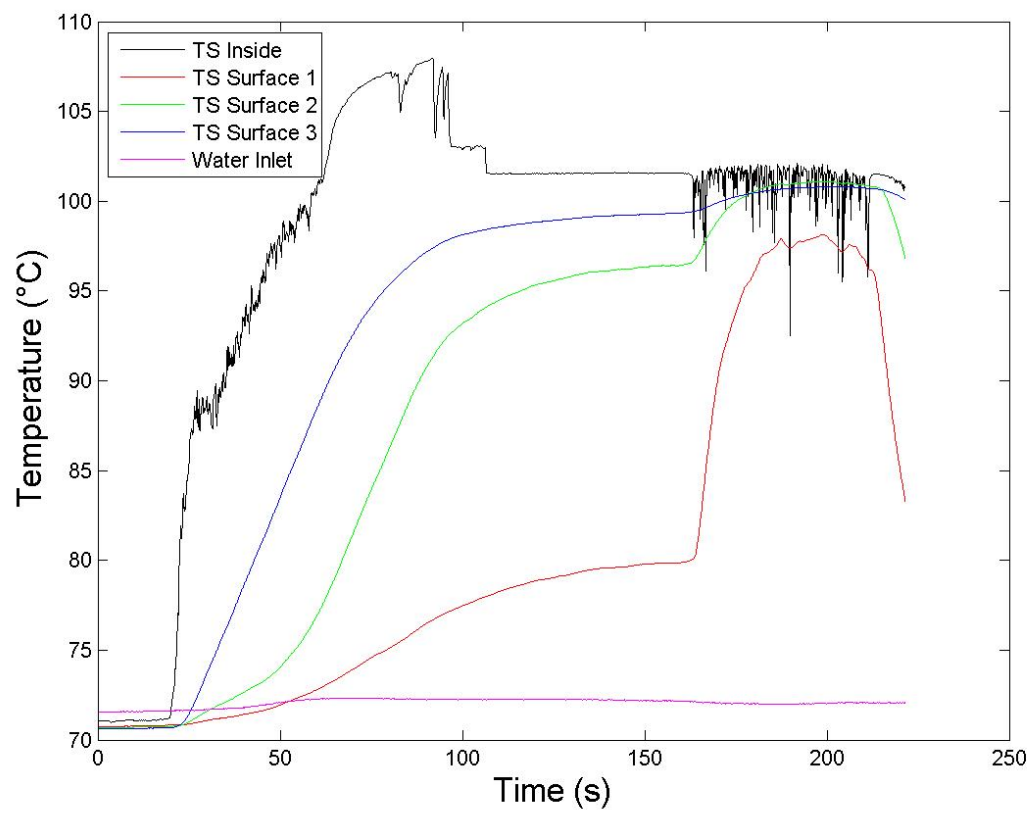

Fig. D.201.: Temperature measurements for Test 41. 


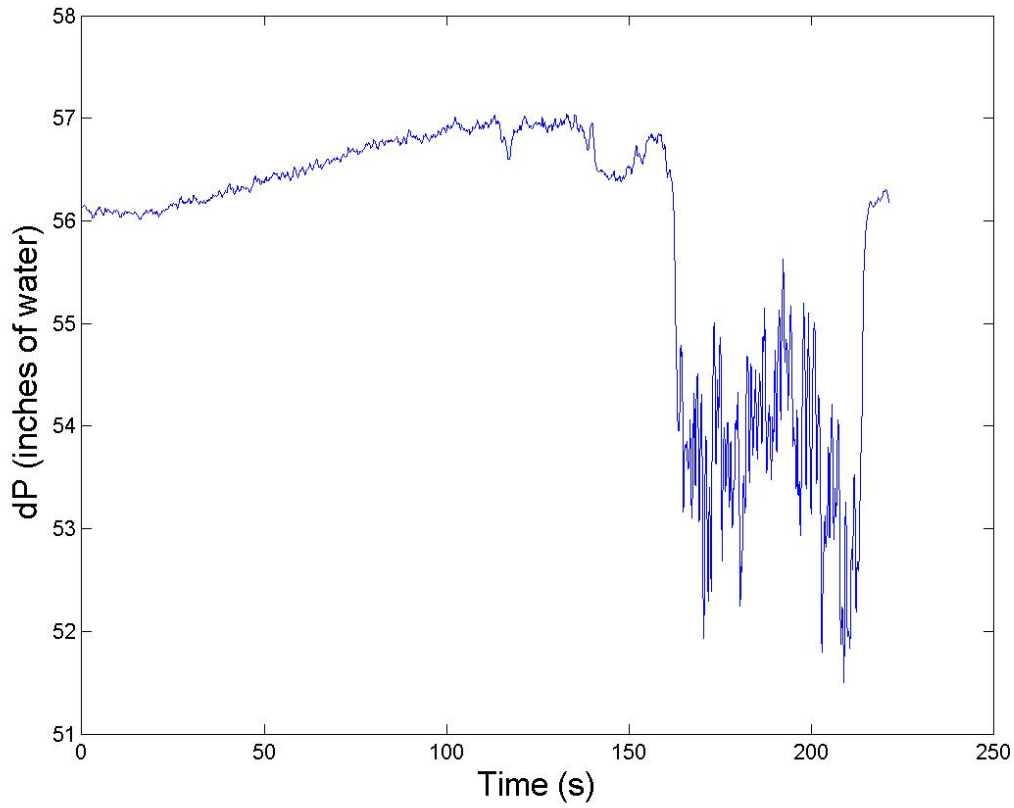

Fig. D.202.: Differential pressure measurements for Test 41.

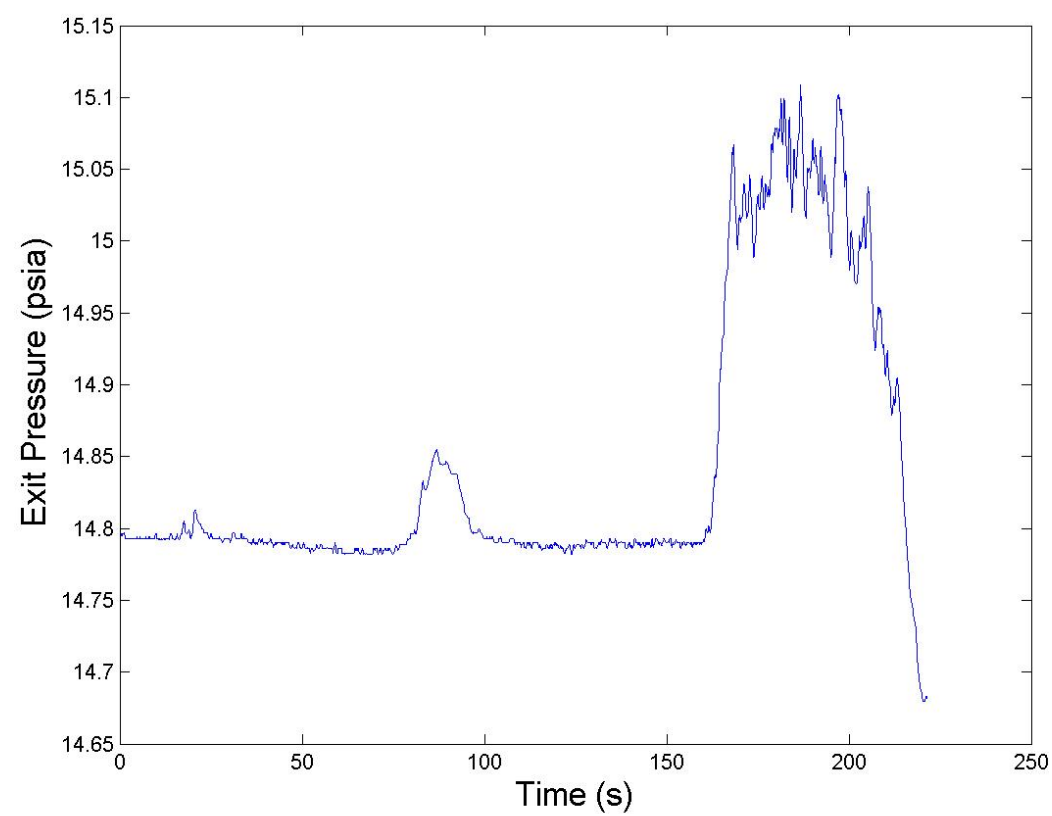

Fig. D.203.: Water exit tank pressure measurements for Test 41. 


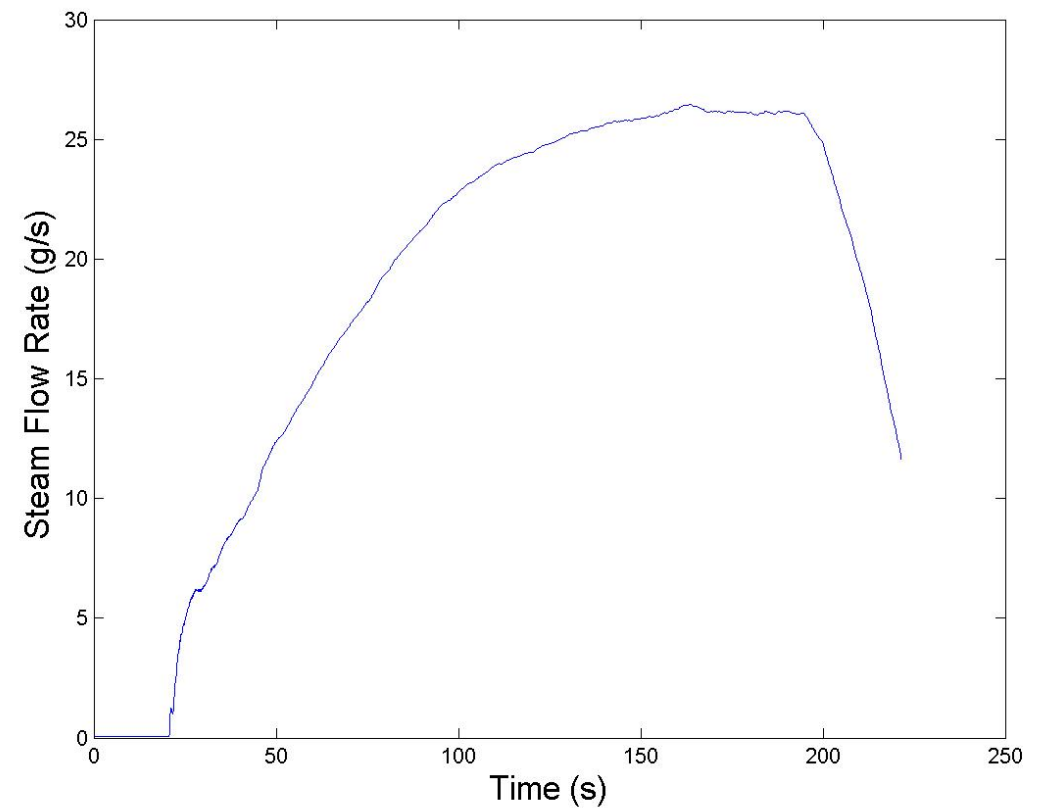

Fig. D.204.: Steam mass flow rate measurements for Test 41.

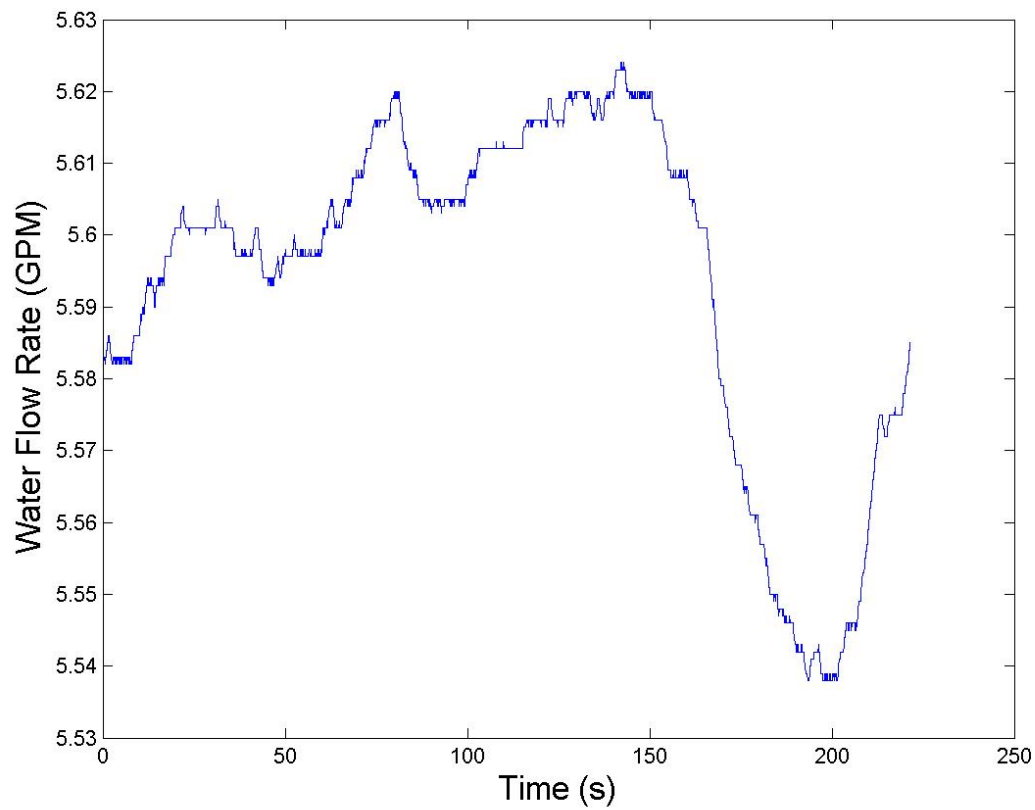

Fig. D.205.: Water flow rate measurements for Test 41. 


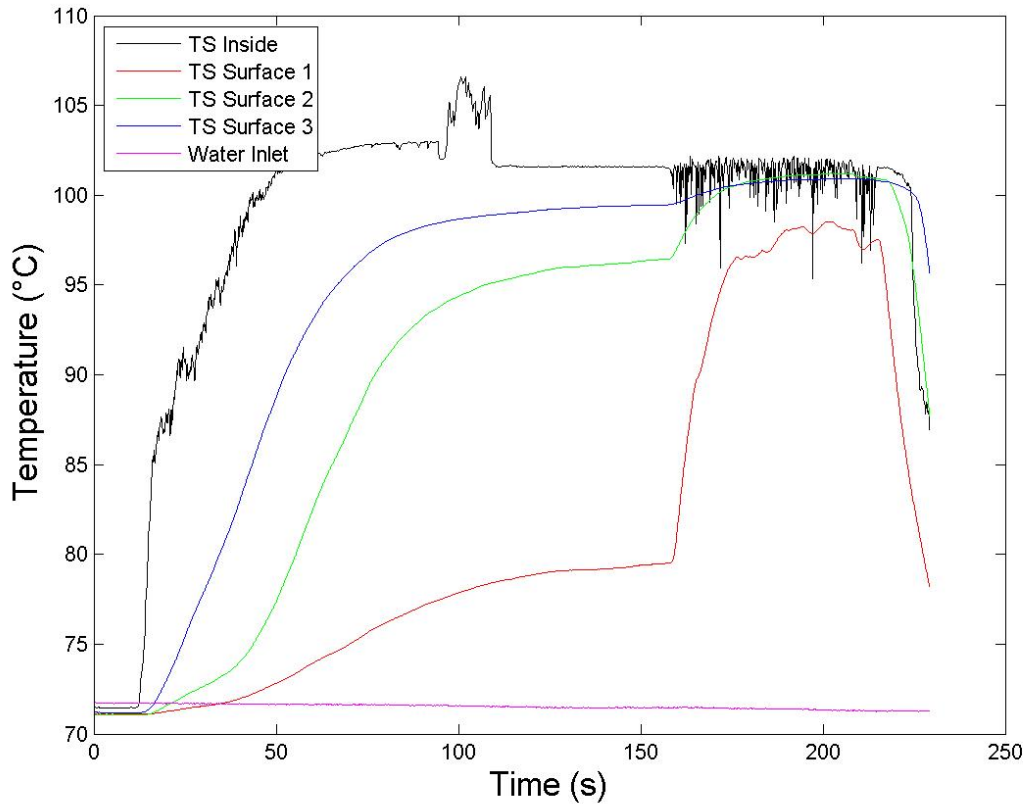

Fig. D.206.: Temperature measurements for Test 42.

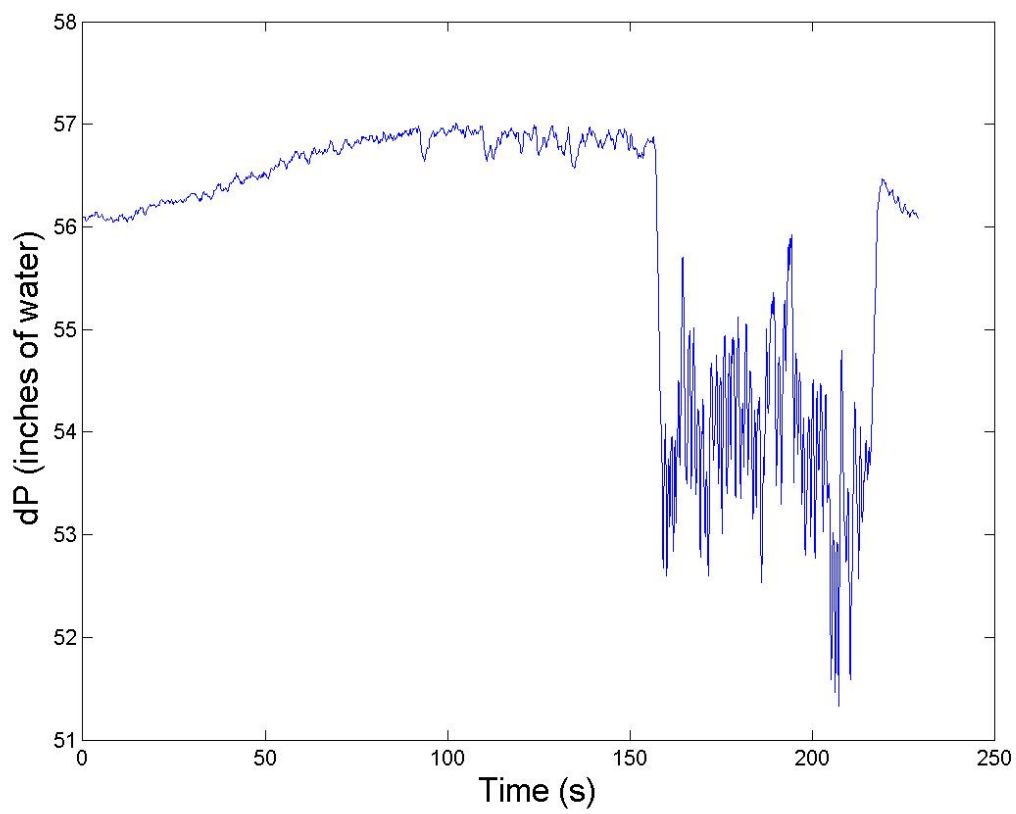

Fig. D.207.: Differential pressure measurements for Test 42. 


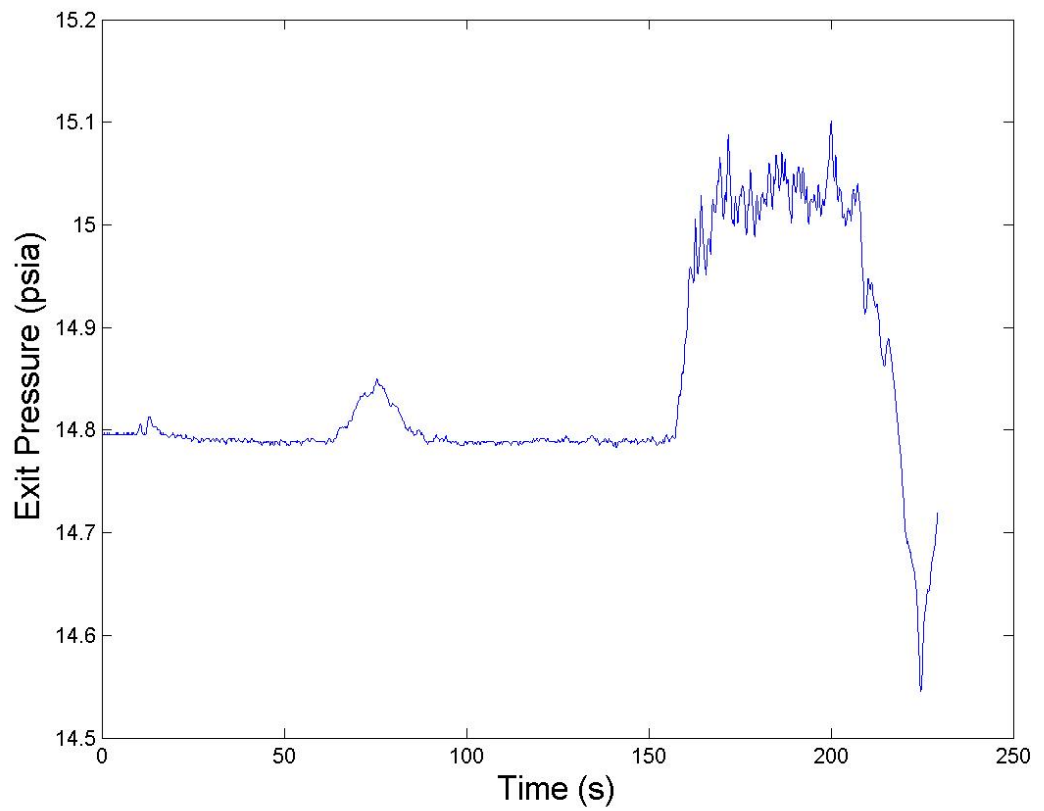

Fig. D.208.: Water exit tank pressure measurements for Test 42.

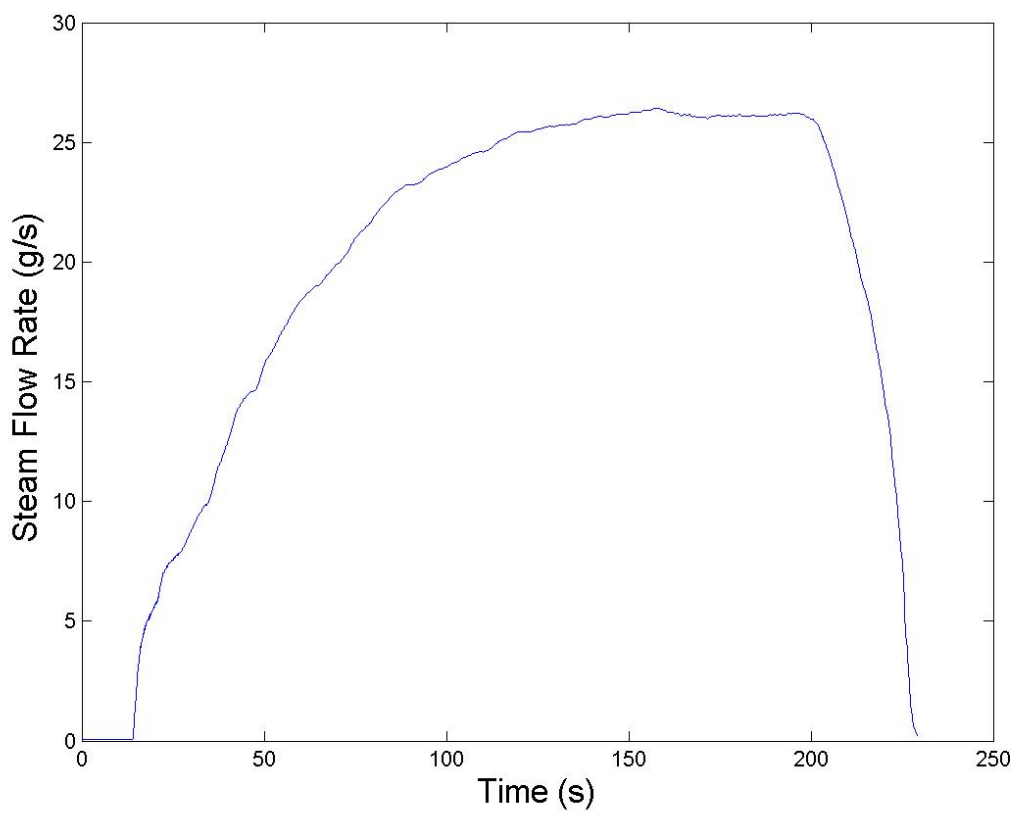

Fig. D.209.: Steam mass flow rate measurements for Test 42. 


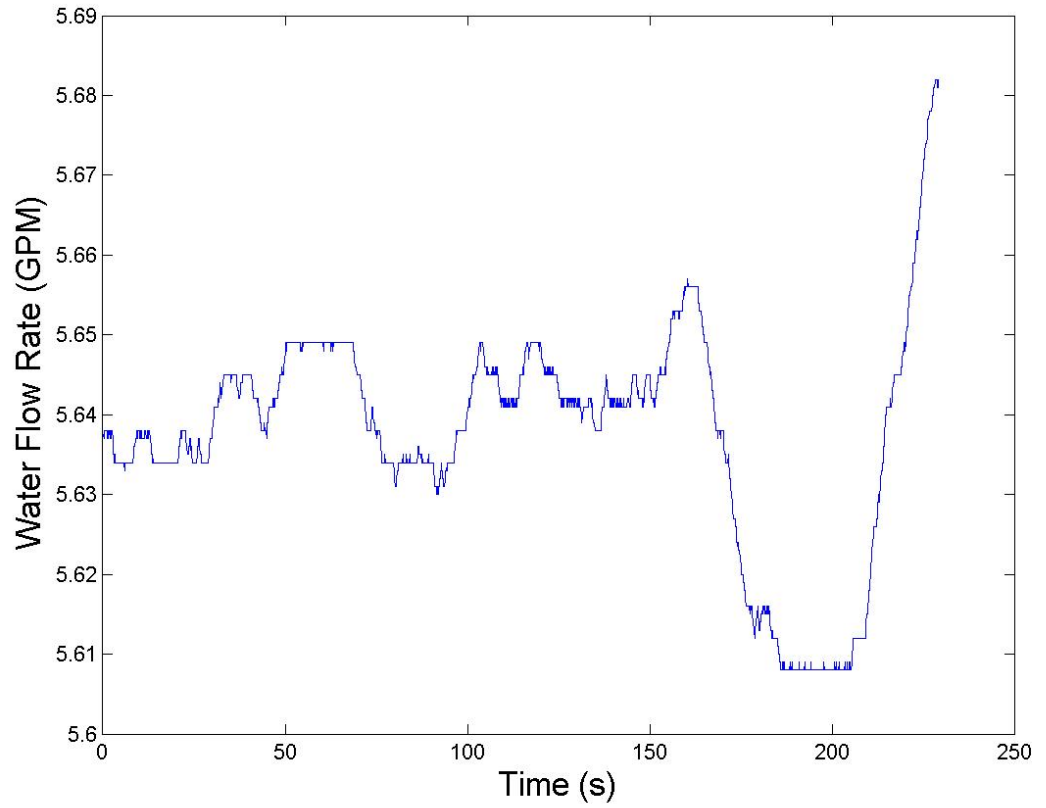

Fig. D.210.: Water flow rate measurements for Test 42 .

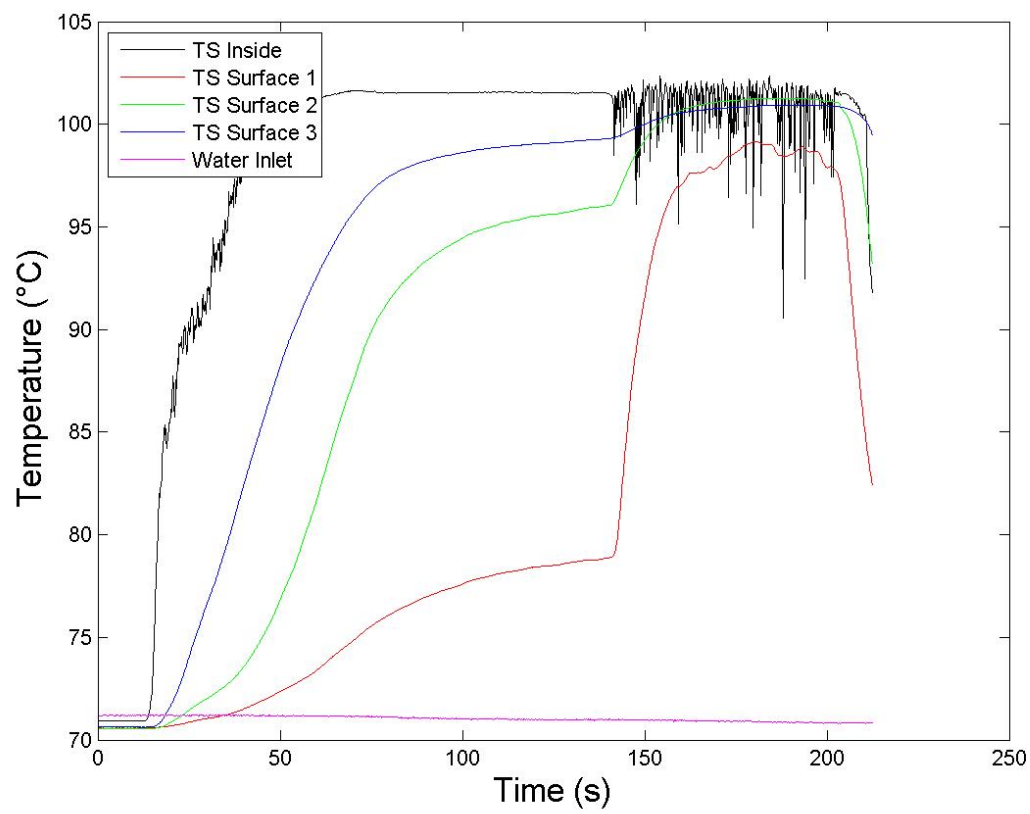

Fig. D.211.: Temperature measurements for Test 43. 


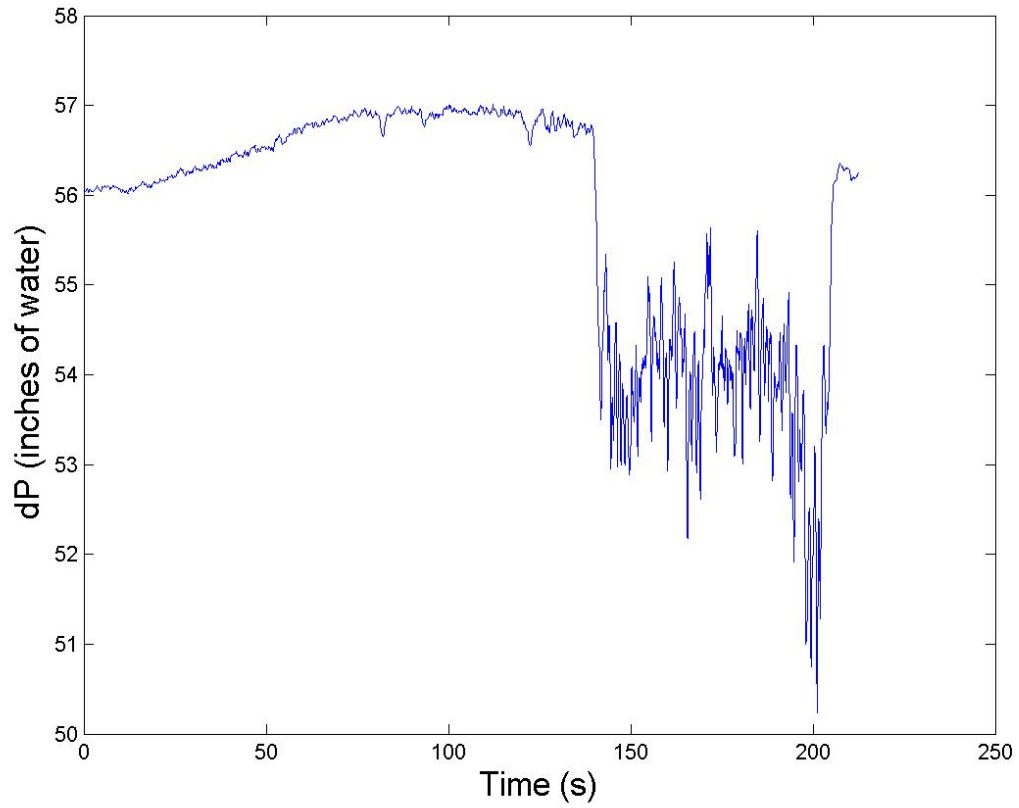

Fig. D.212.: Differential pressure measurements for Test 43.

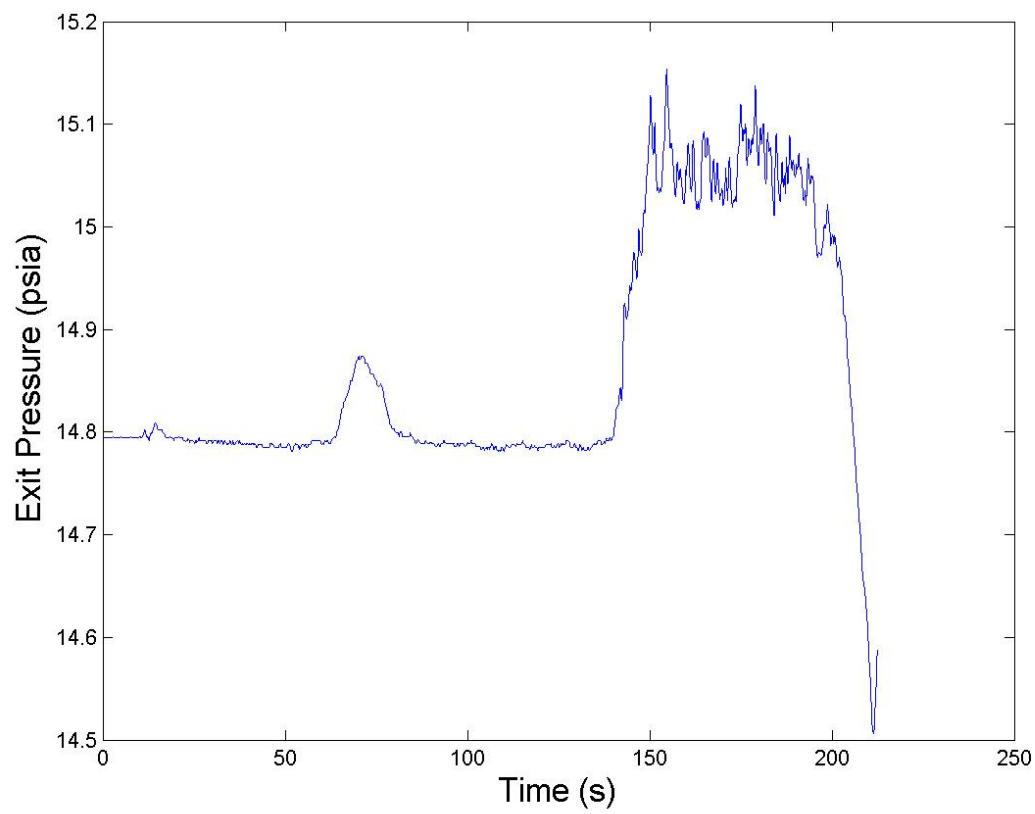

Fig. D.213.: Water exit tank pressure measurements for Test 43. 


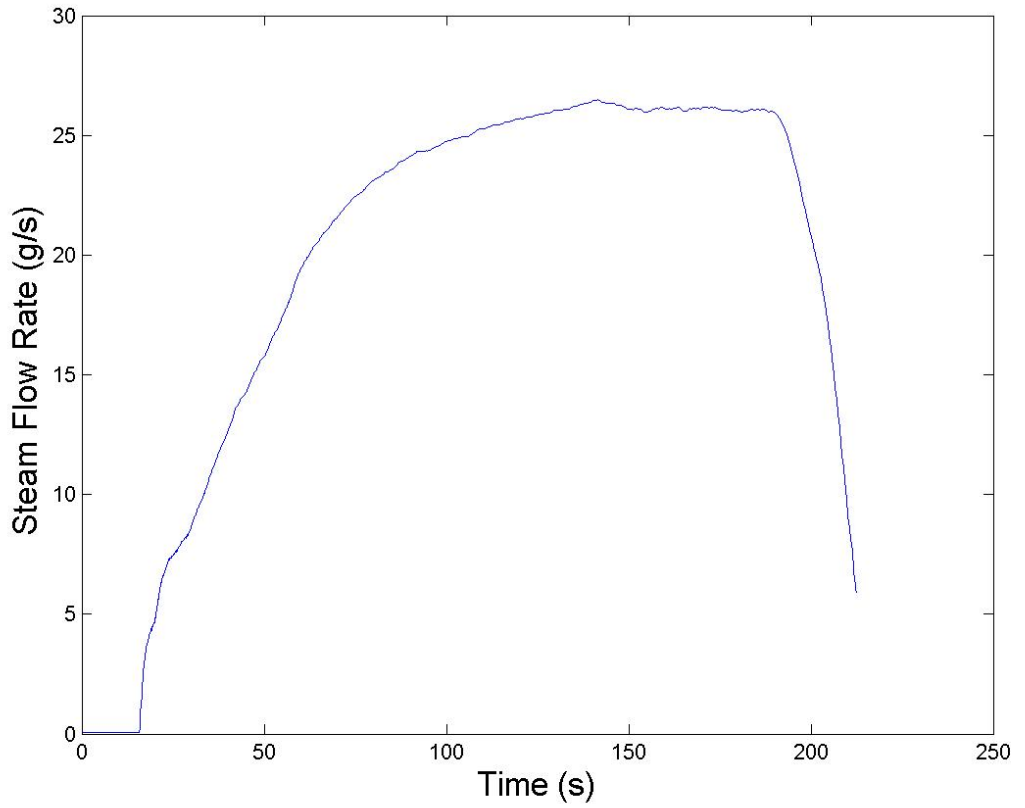

Fig. D.214.: Steam mass flow rate measurements for Test 43.

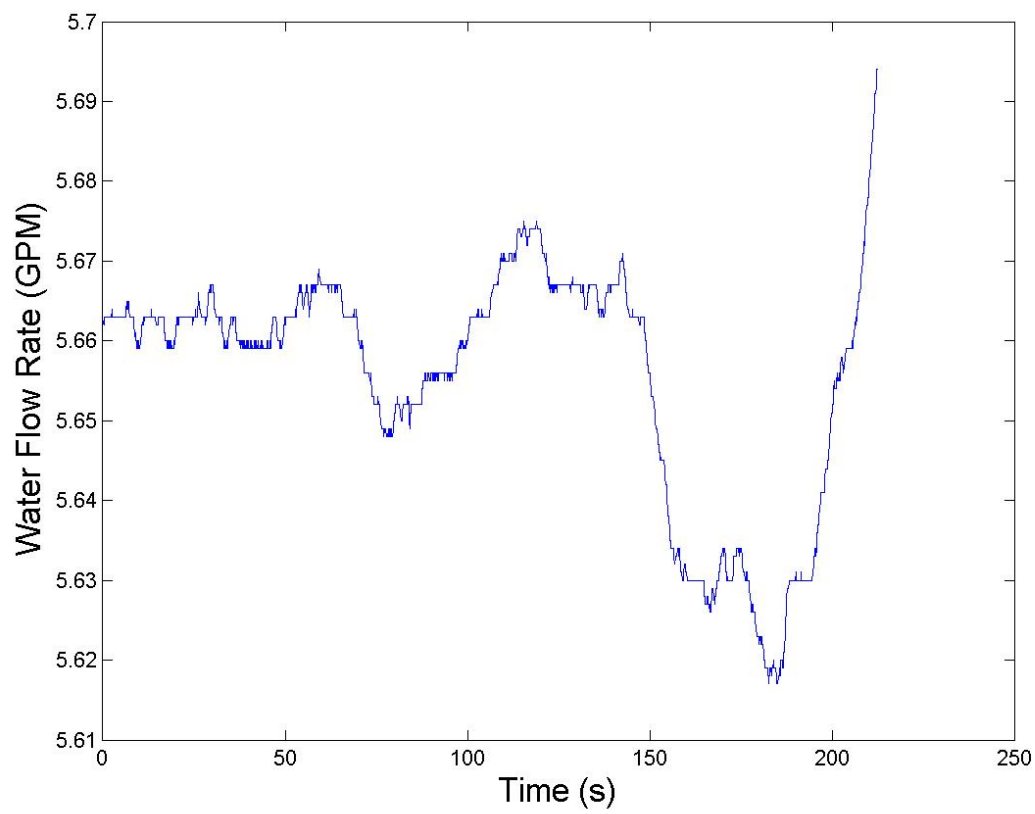

Fig. D.215.: Water flow rate measurements for Test 43. 


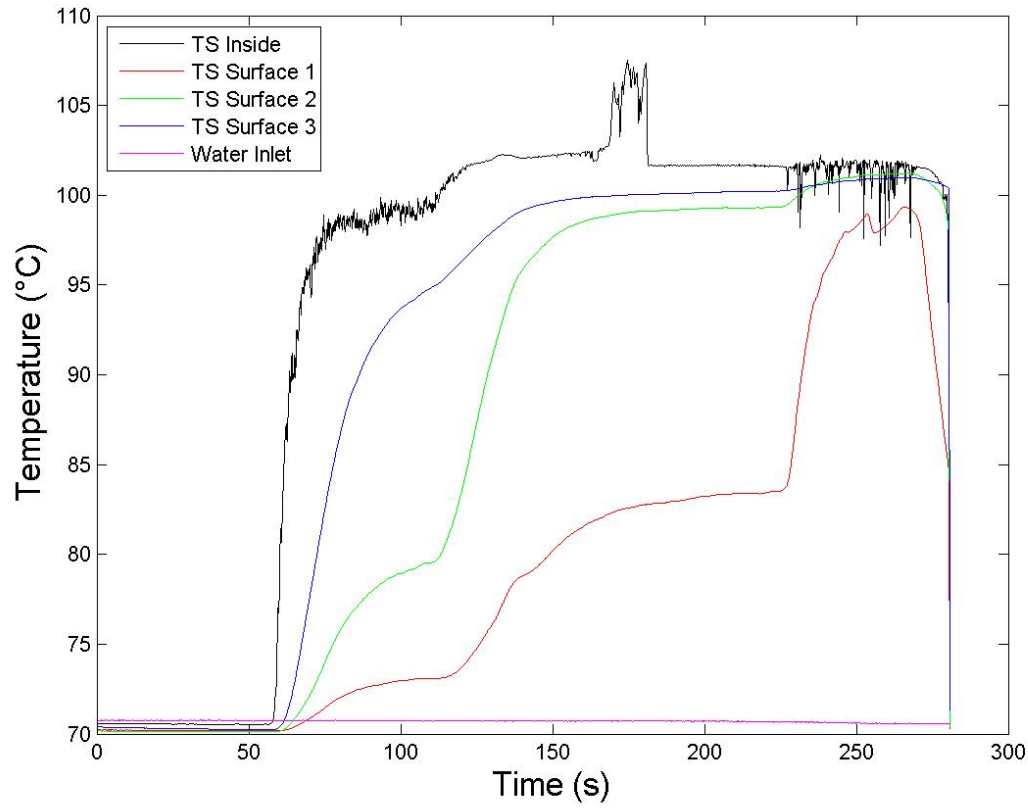

Fig. D.216.: Temperature measurements for Test 44 .

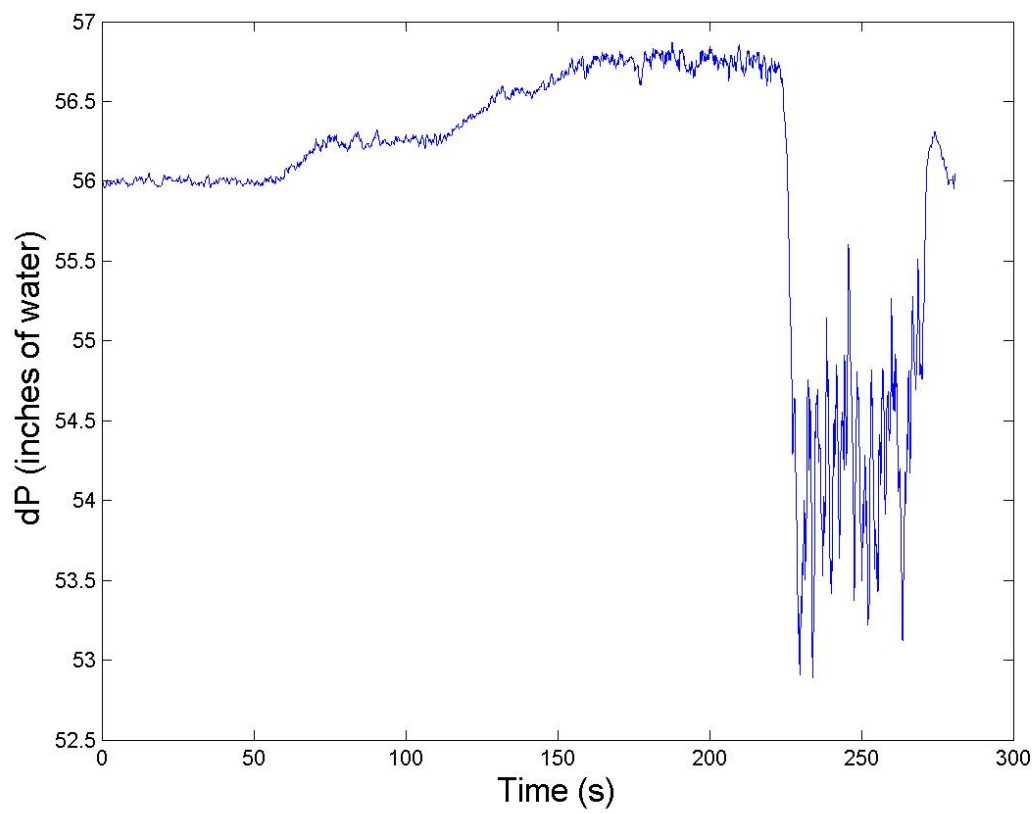

Fig. D.217.: Differential pressure measurements for Test 44. 


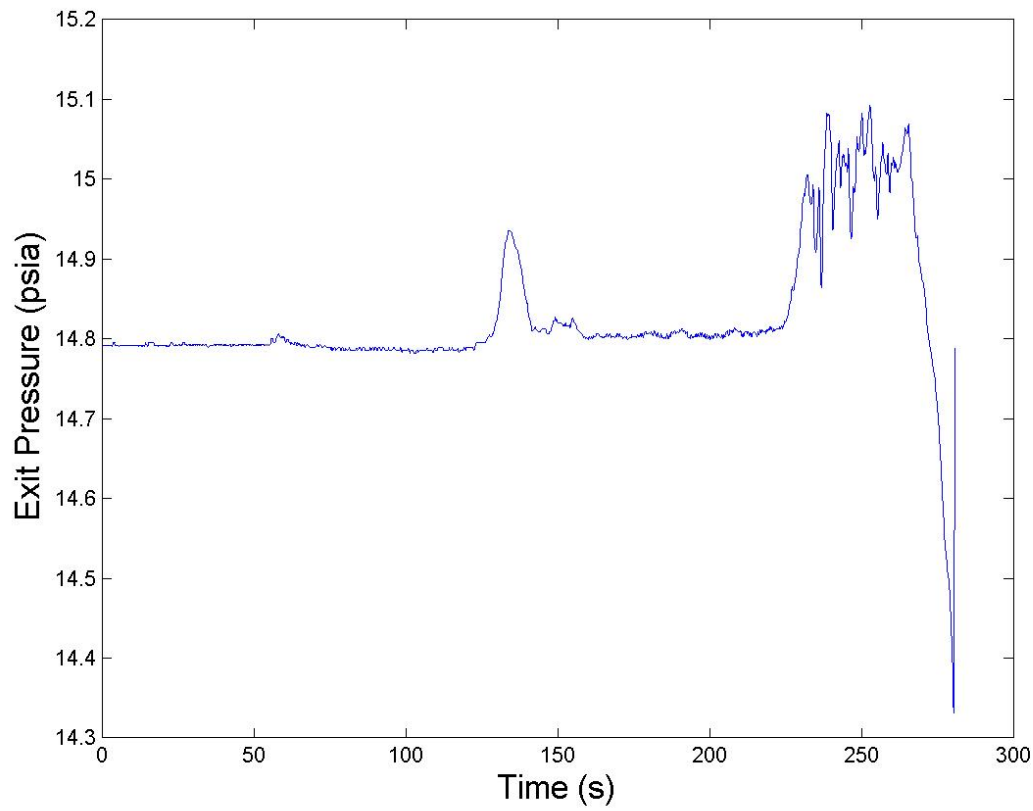

Fig. D.218.: Water exit tank pressure measurements for Test 44.

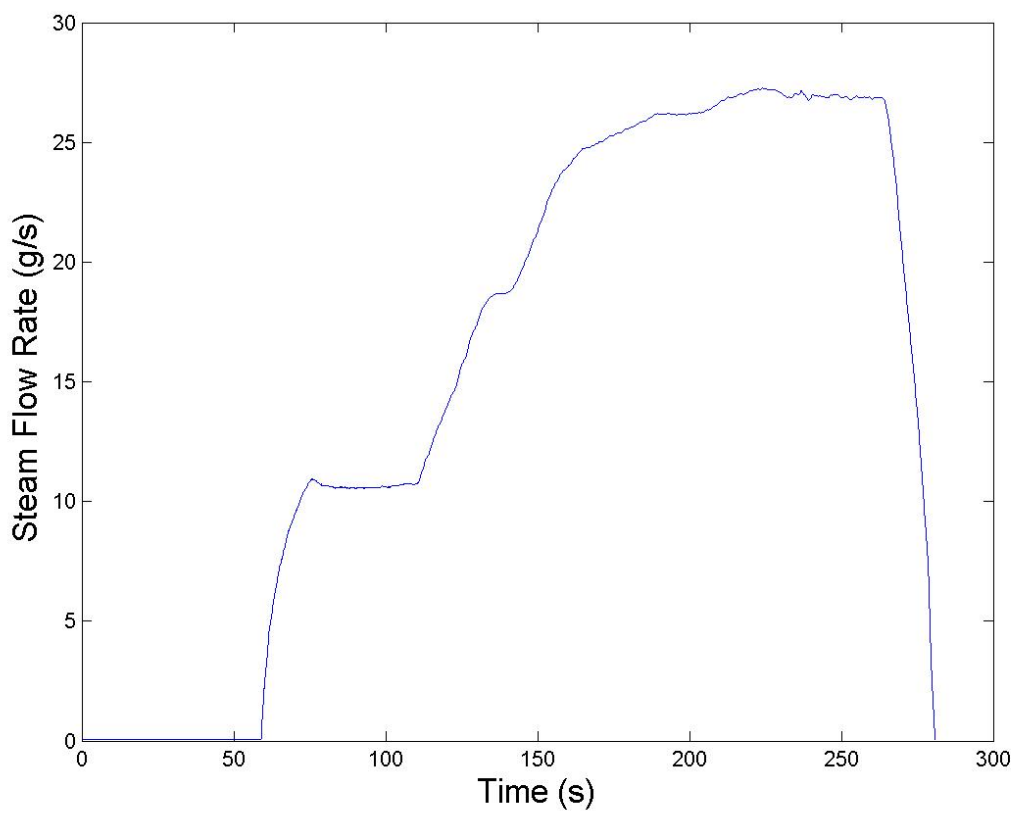

Fig. D.219.: Steam mass flow rate measurements for Test 44. 


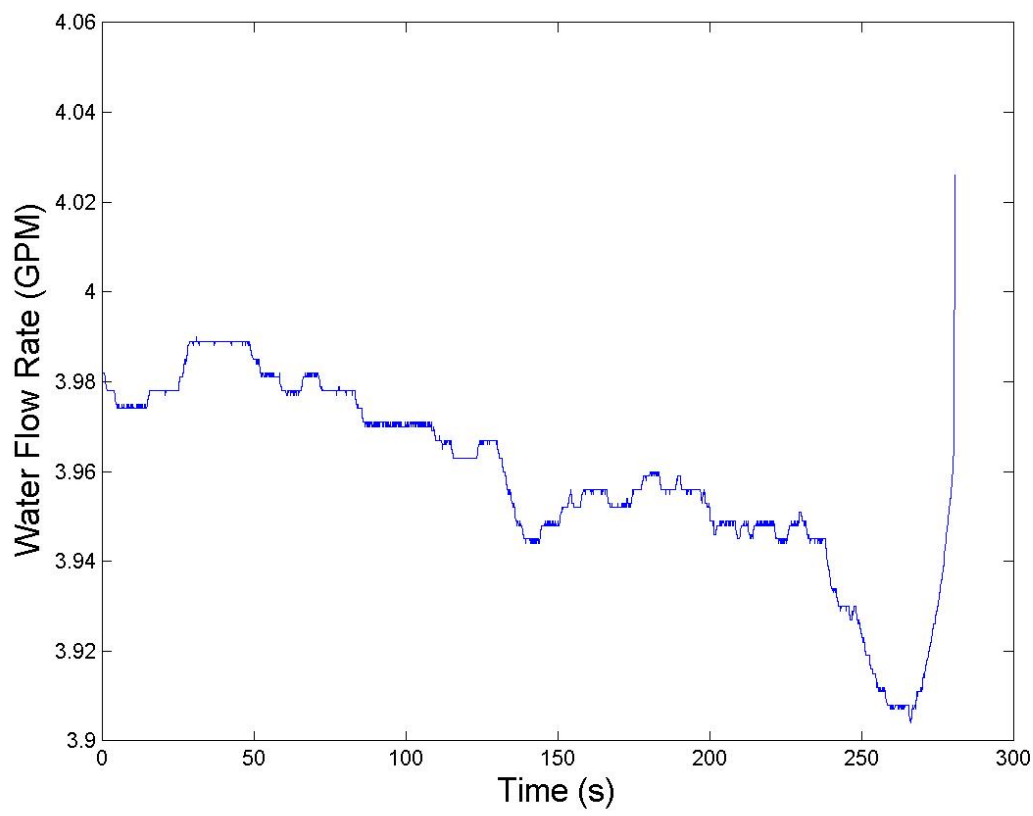

Fig. D.220.: Water flow rate measurements for Test 44 .

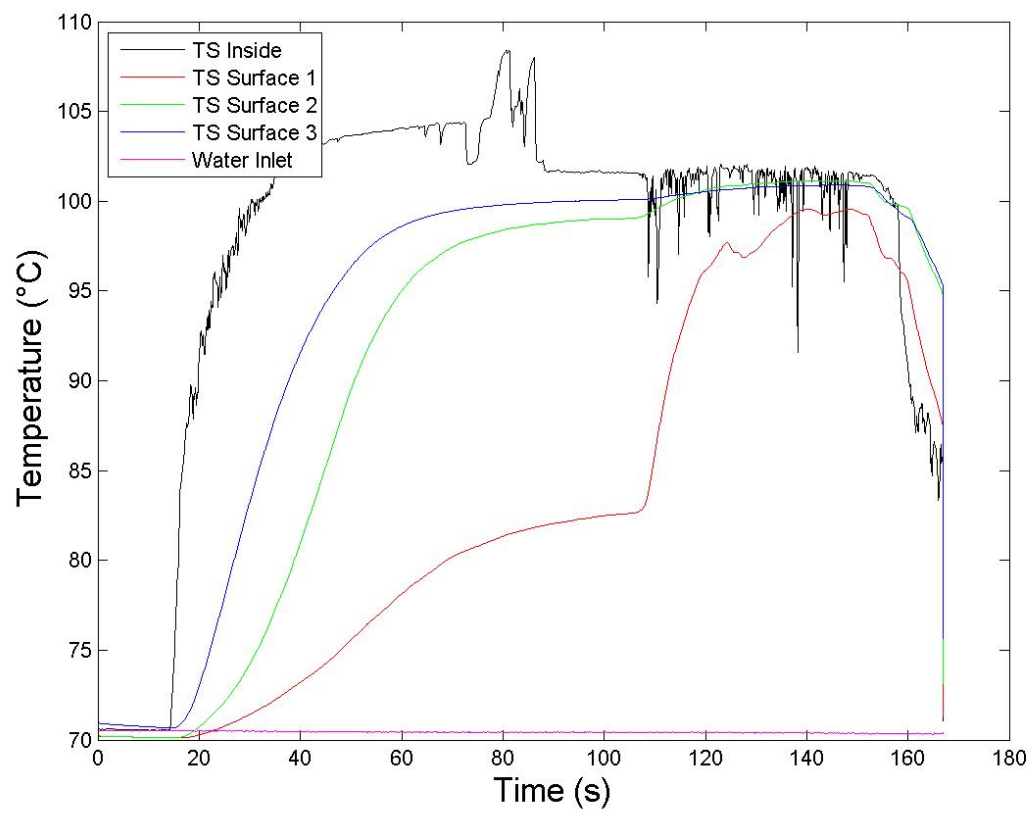

Fig. D.221.: Temperature measurements for Test 45. 


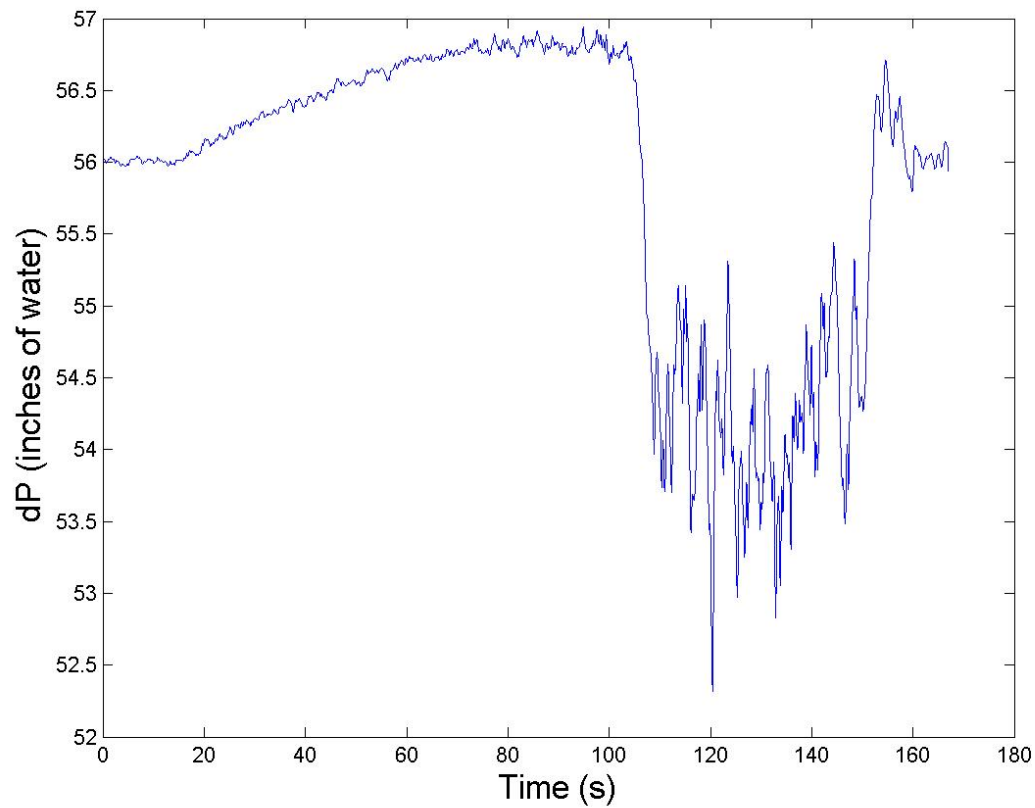

Fig. D.222.: Differential pressure measurements for Test 45.

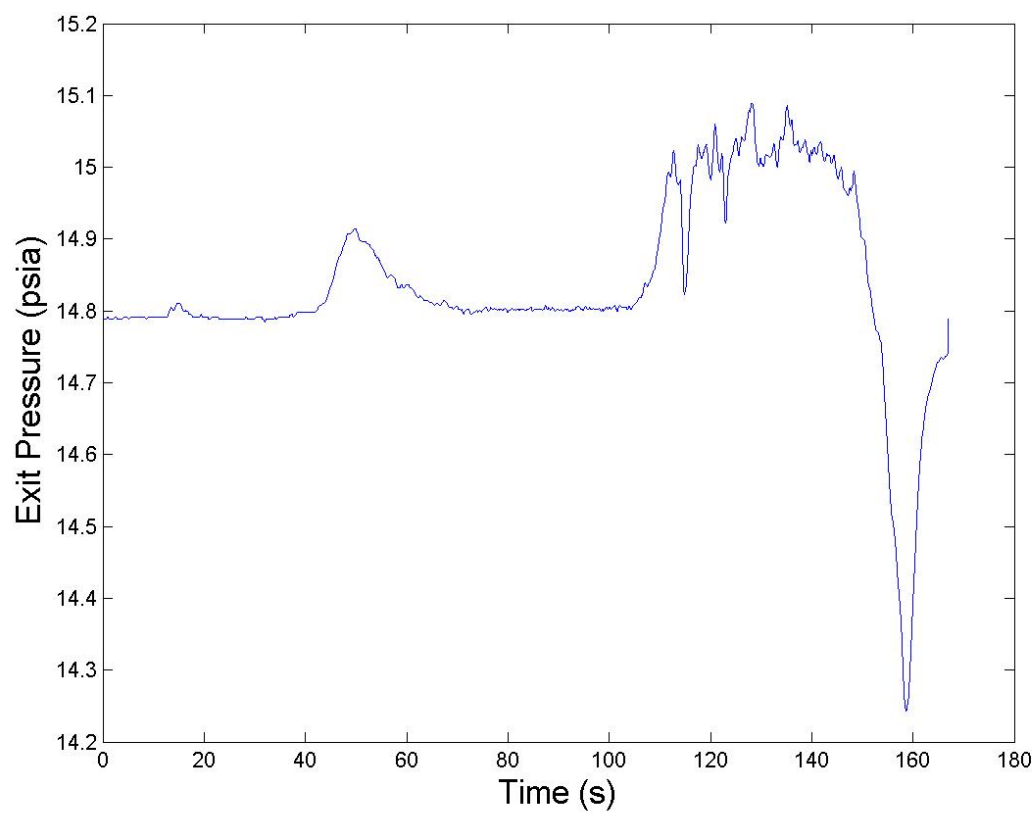

Fig. D.223.: Water exit tank pressure measurements for Test 45. 


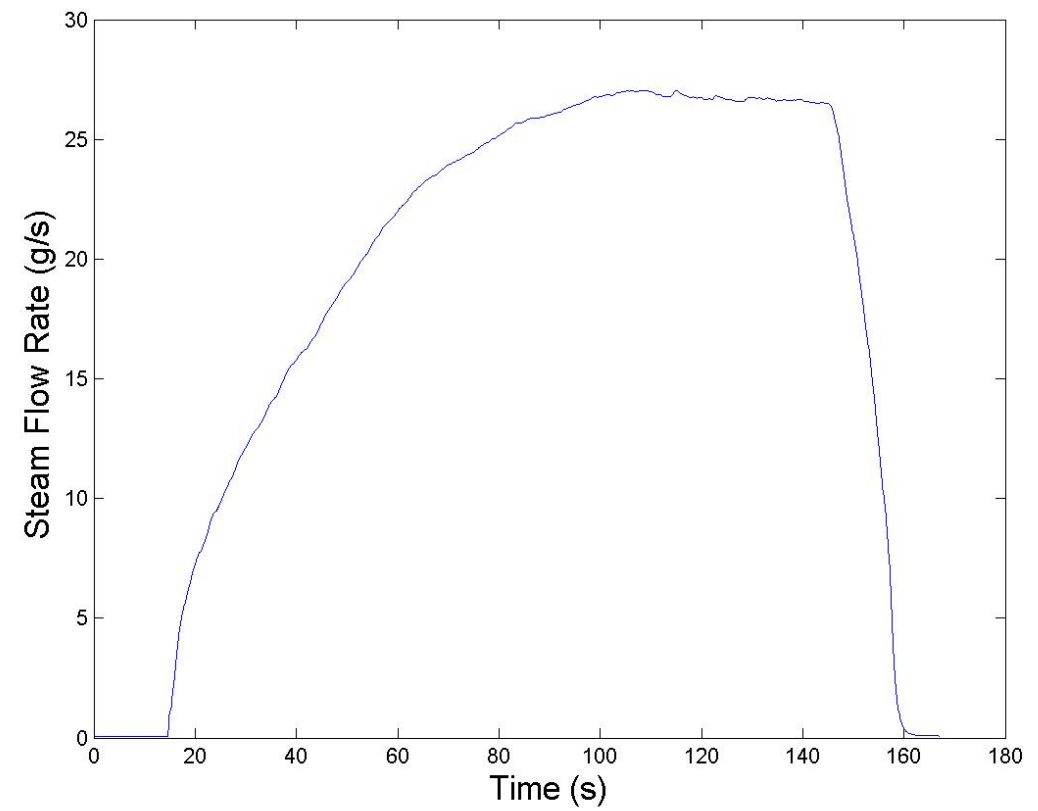

Fig. D.224.: Steam mass flow rate measurements for Test 45.

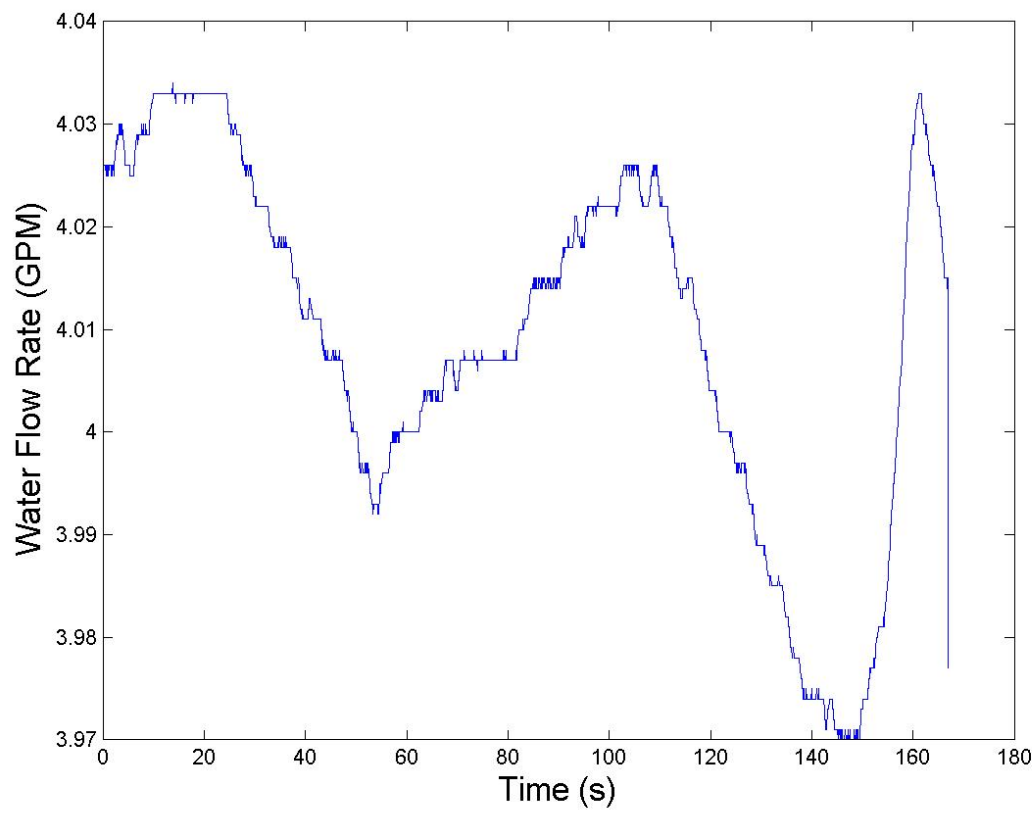

Fig. D.225.: Water flow rate measurements for Test 45 . 


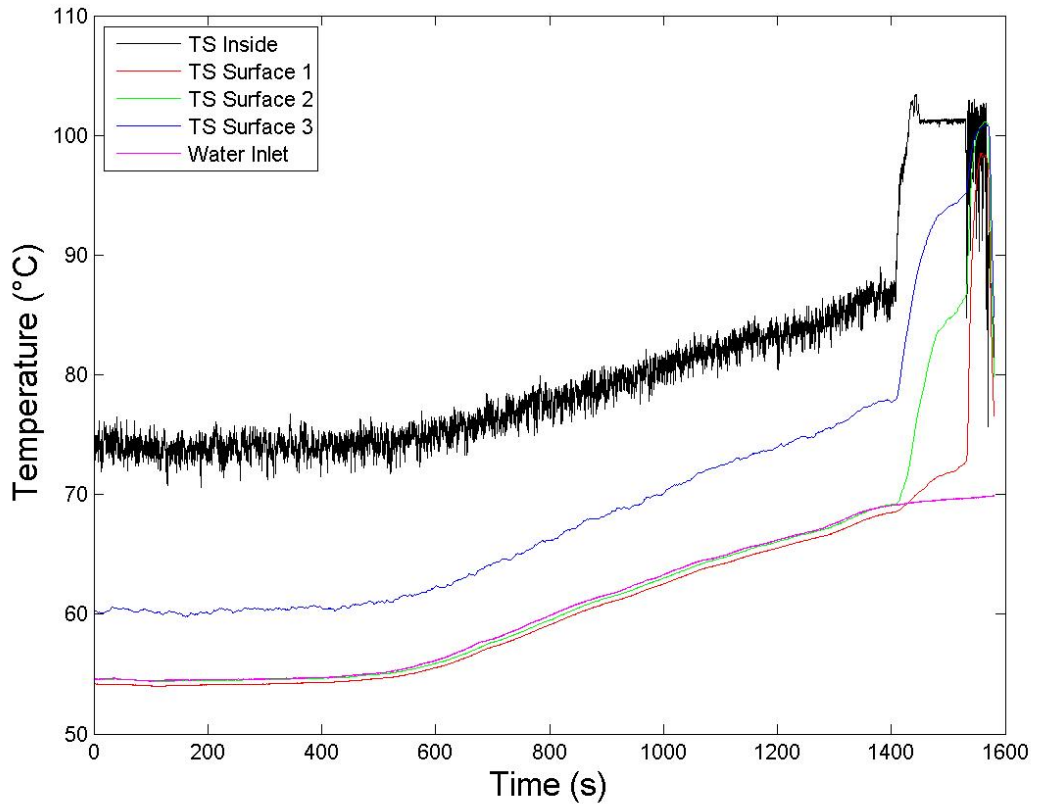

Fig. D.226.: Temperature measurements for Test 46.

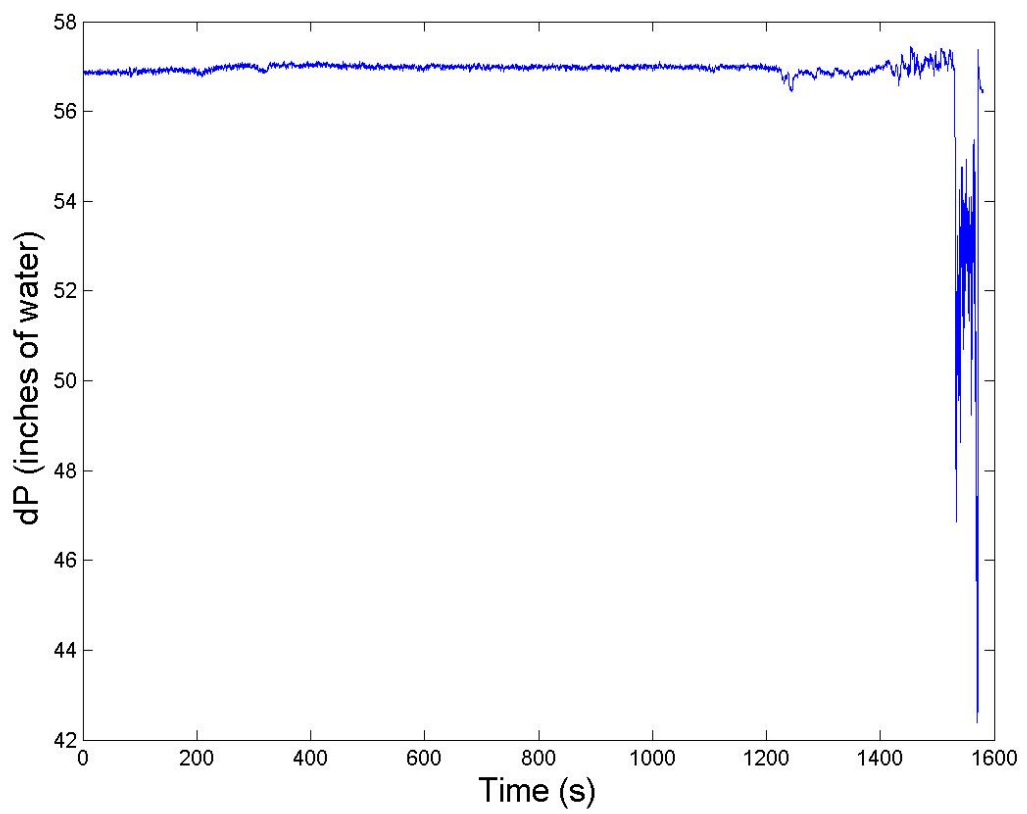

Fig. D.227.: Differential pressure measurements for Test 46 . 


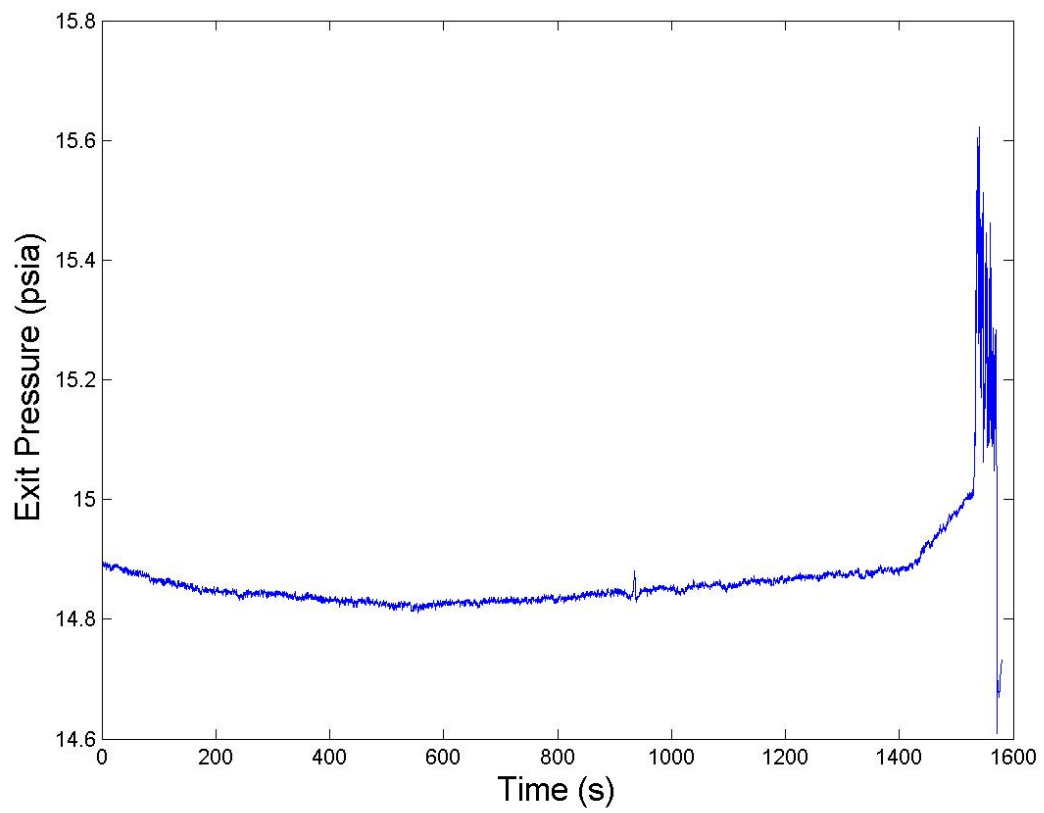

Fig. D.228.: Water exit tank pressure measurements for Test 46 .

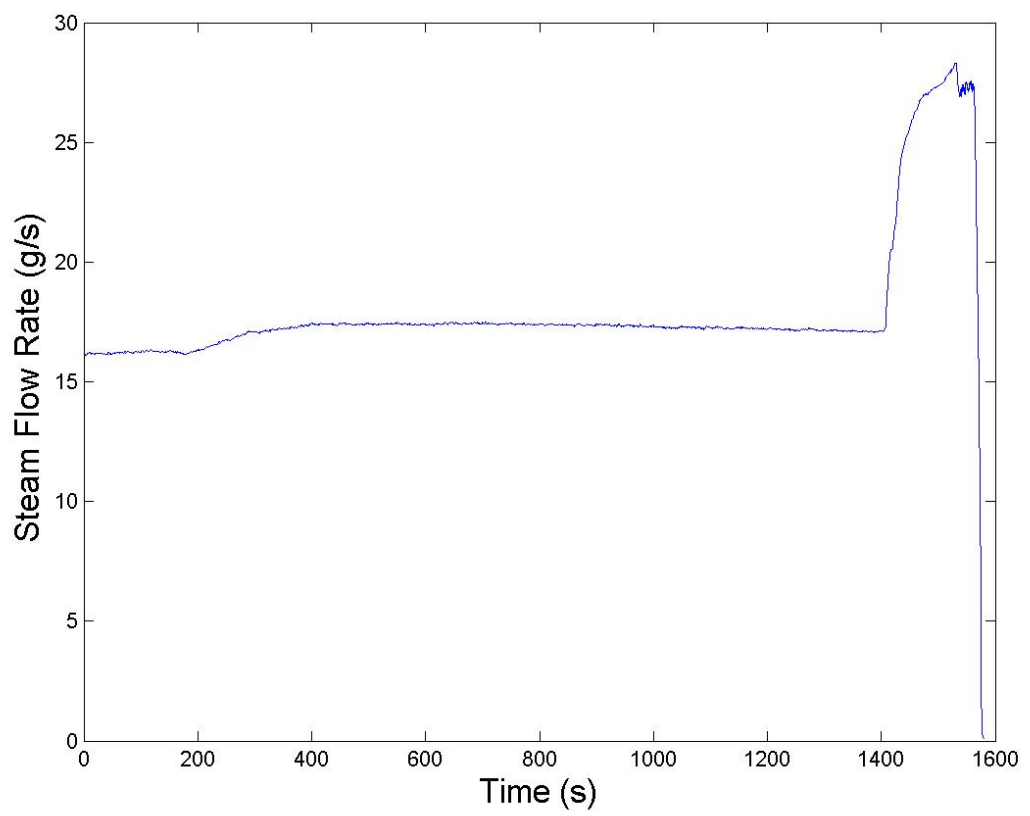

Fig. D.229.: Steam mass flow rate measurements for Test 46 . 


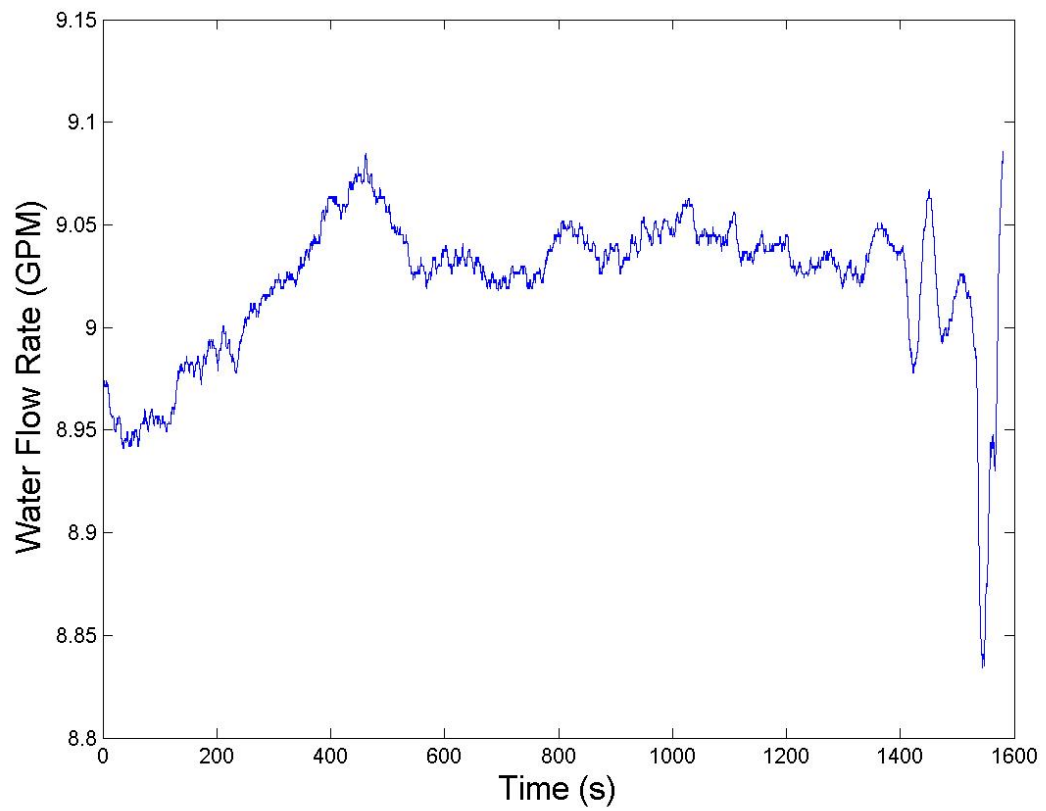

Fig. D.230.: Water flow rate measurements for Test 46 .

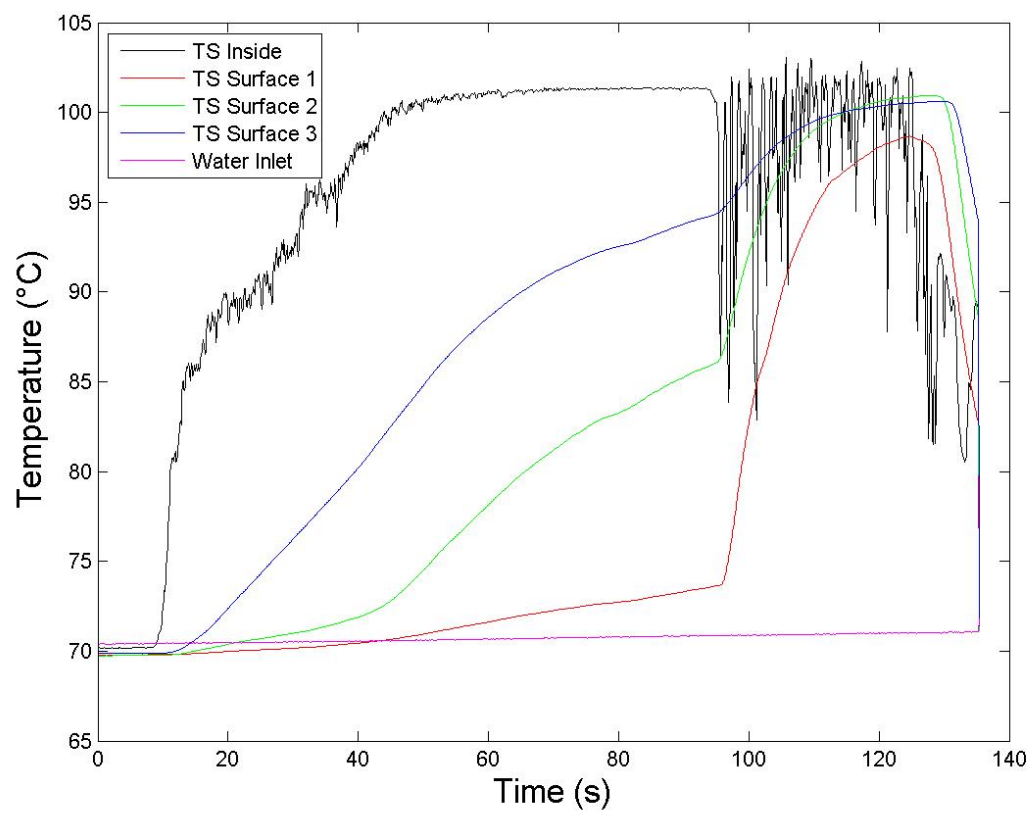

Fig. D.231.: Temperature measurements for Test 47. 


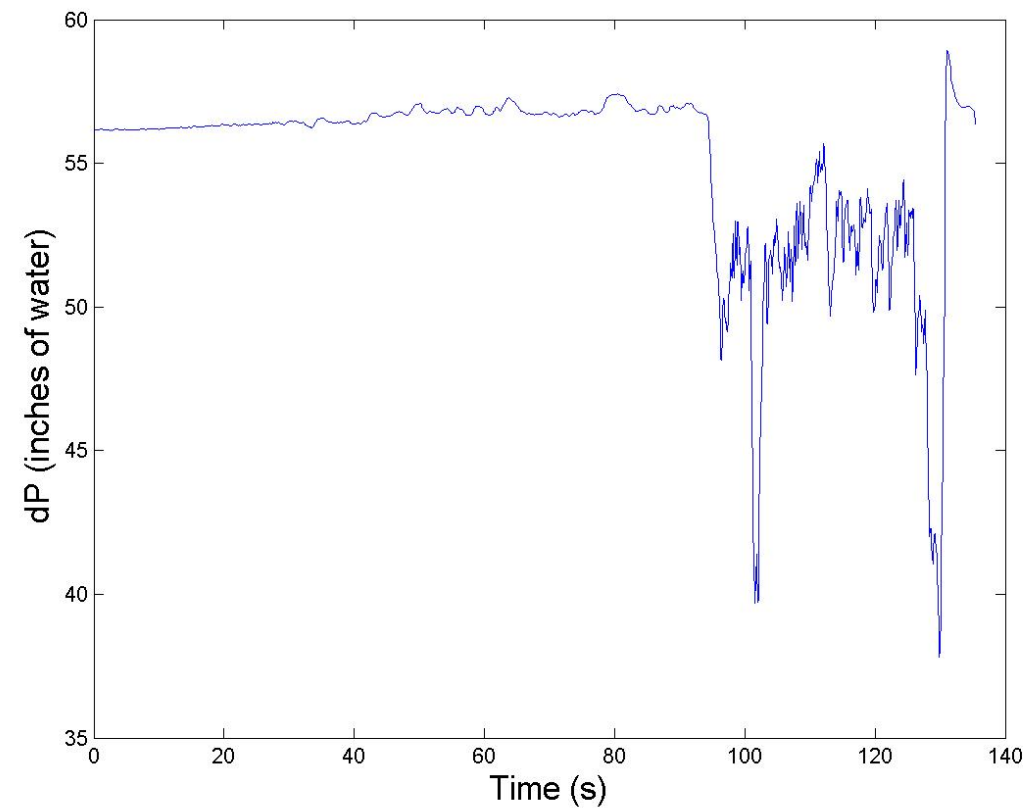

Fig. D.232.: Differential pressure measurements for Test 47.

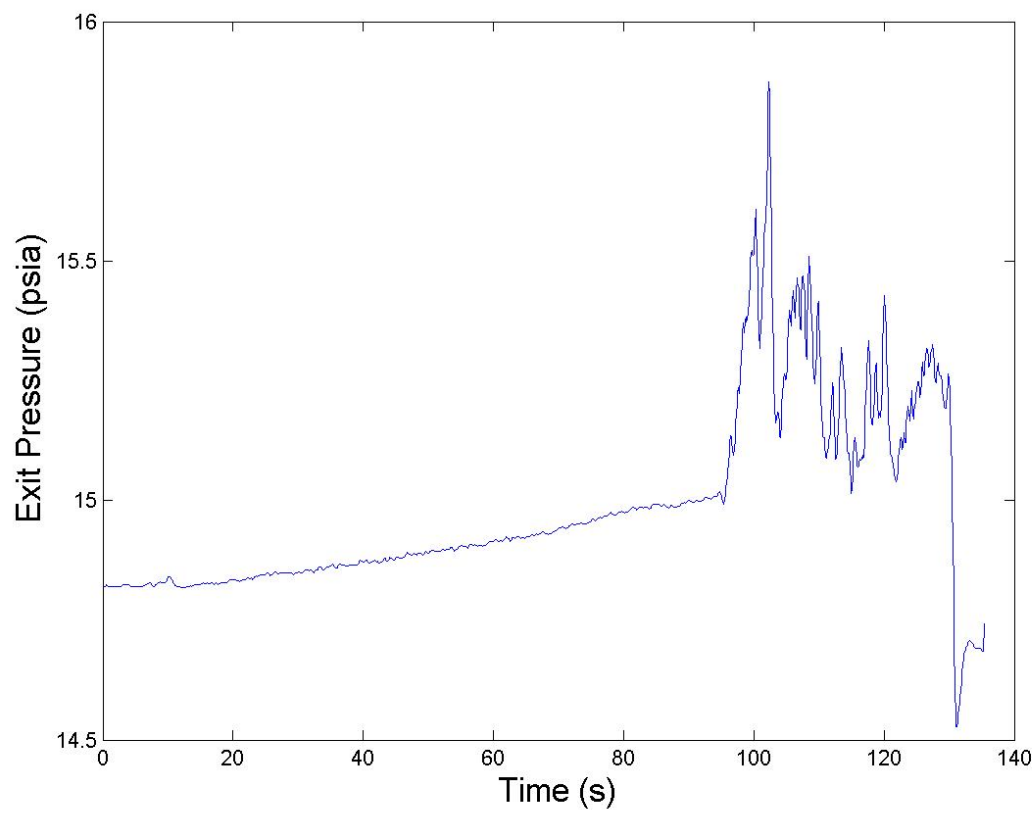

Fig. D.233.: Water exit tank pressure measurements for Test 47. 


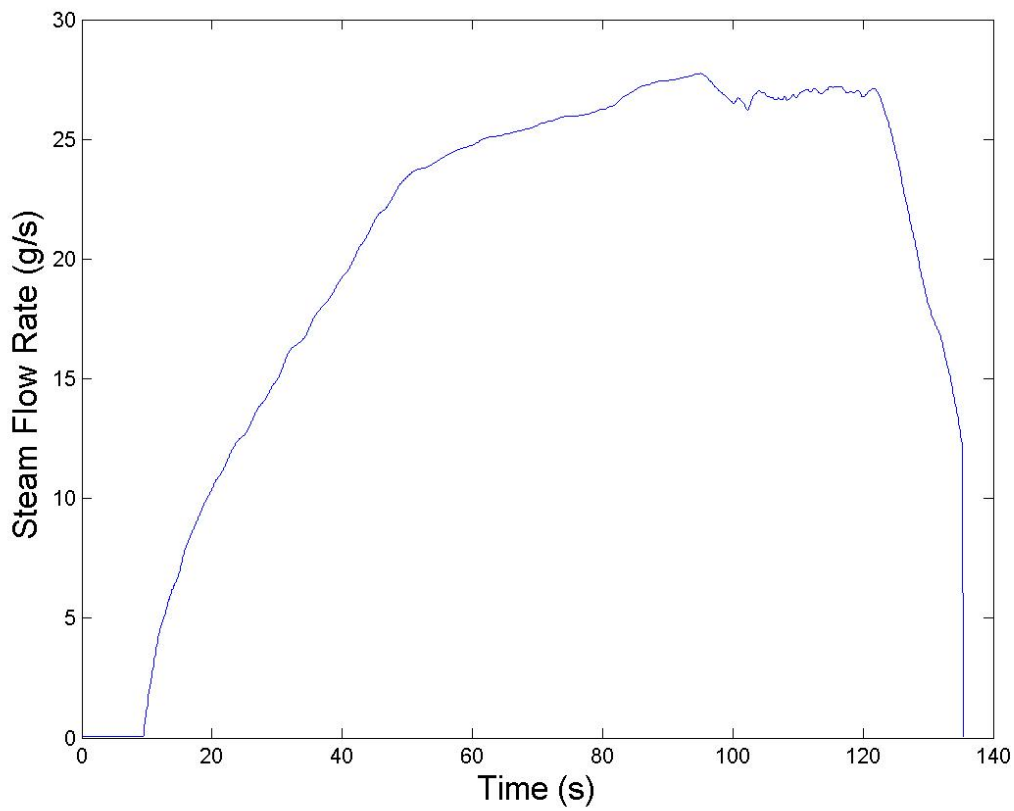

Fig. D.234.: Steam mass flow rate measurements for Test 47.

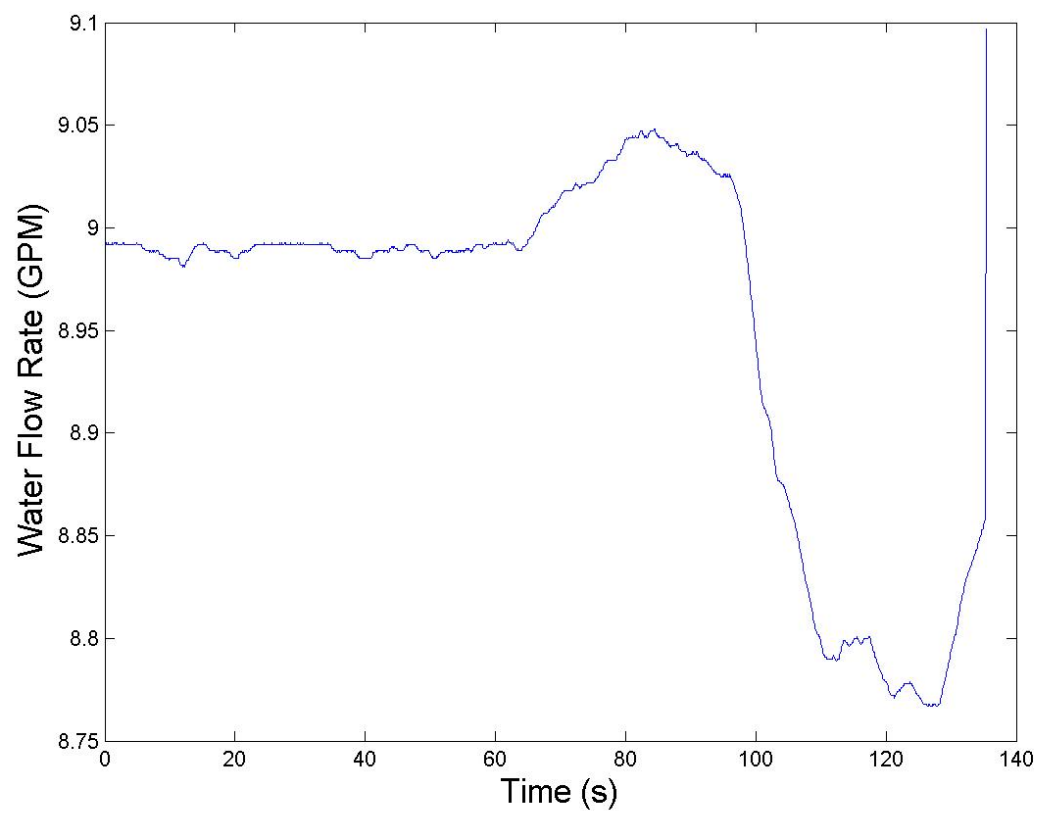

Fig. D.235.: Water flow rate measurements for Test 47. 


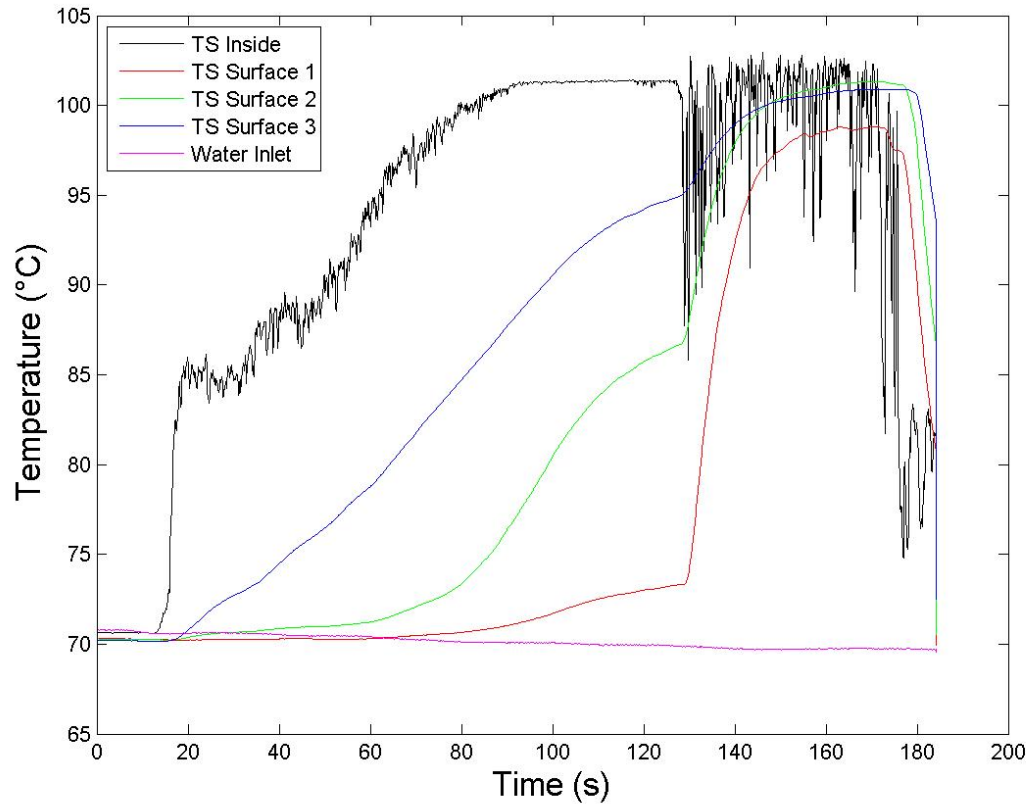

Fig. D.236.: Temperature measurements for Test 48.

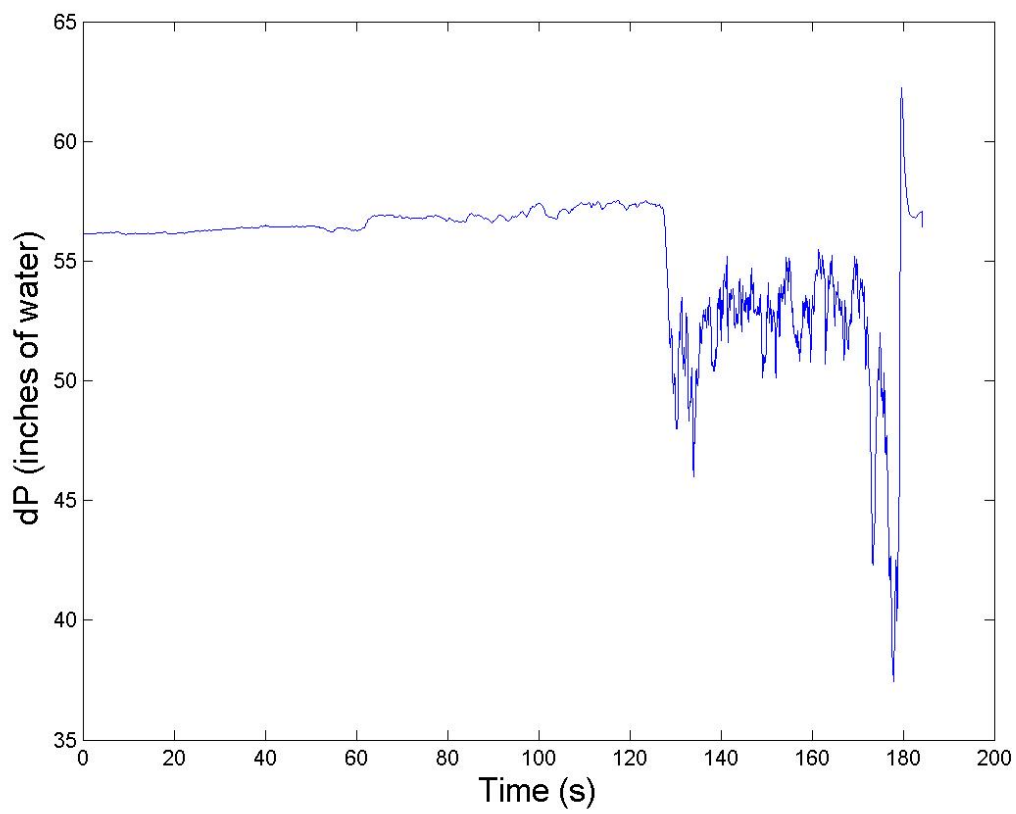

Fig. D.237.: Differential pressure measurements for Test 48 . 


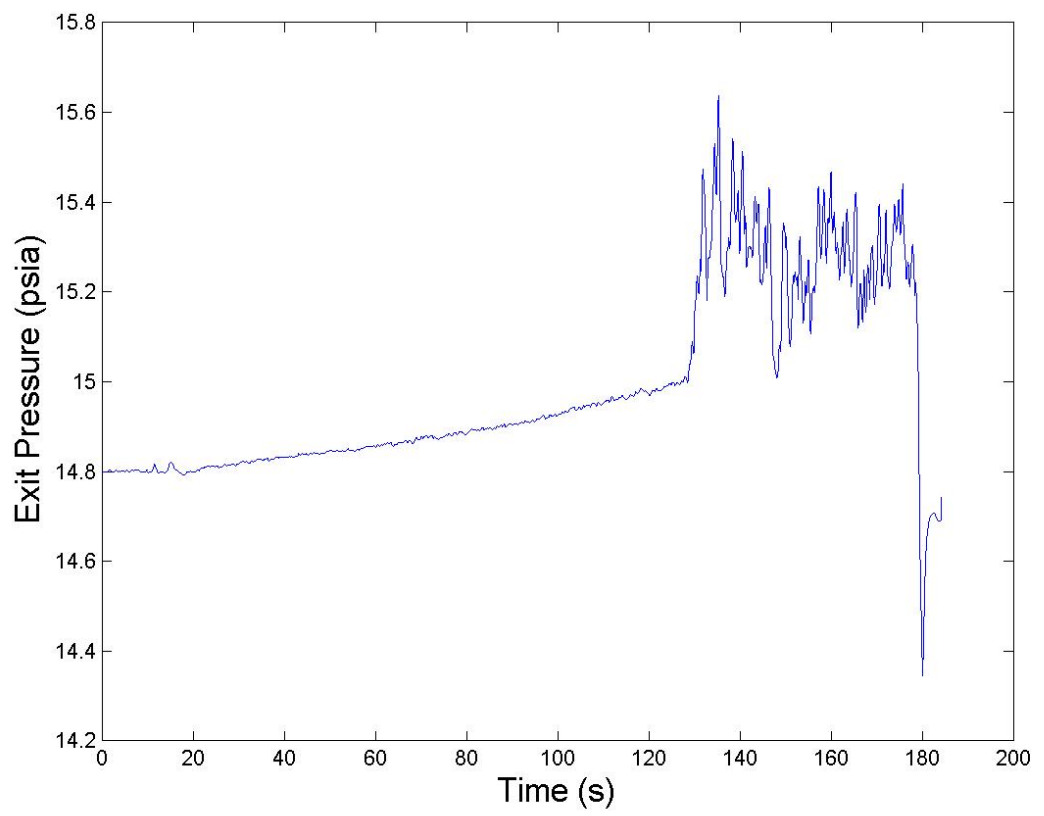

Fig. D.238.: Water exit tank pressure measurements for Test 48 .

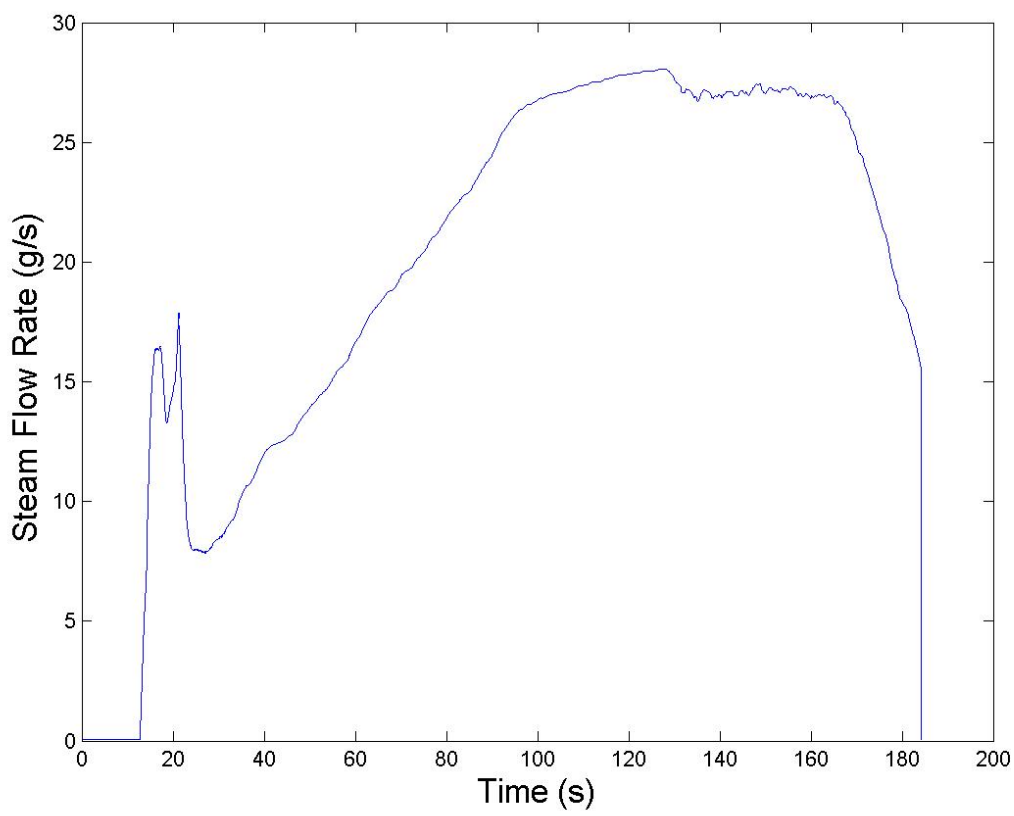

Fig. D.239.: Steam mass flow rate measurements for Test 48 . 


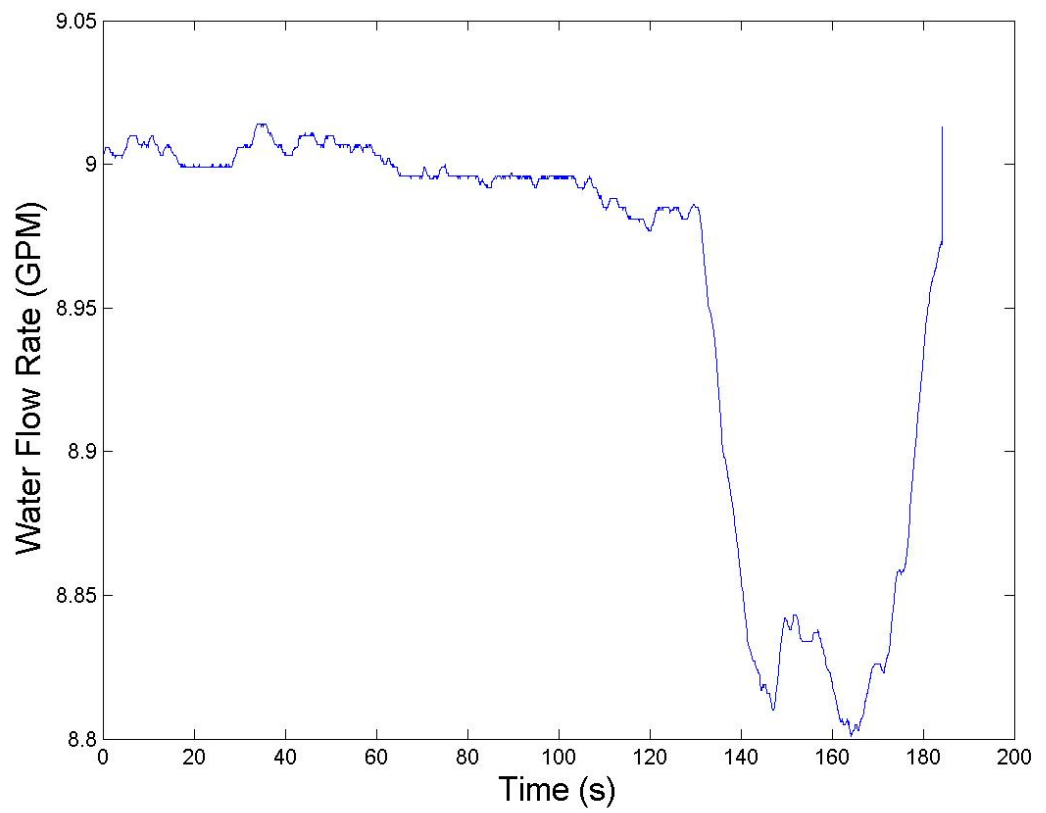

Fig. D.240.: Water flow rate measurements for Test 48 .

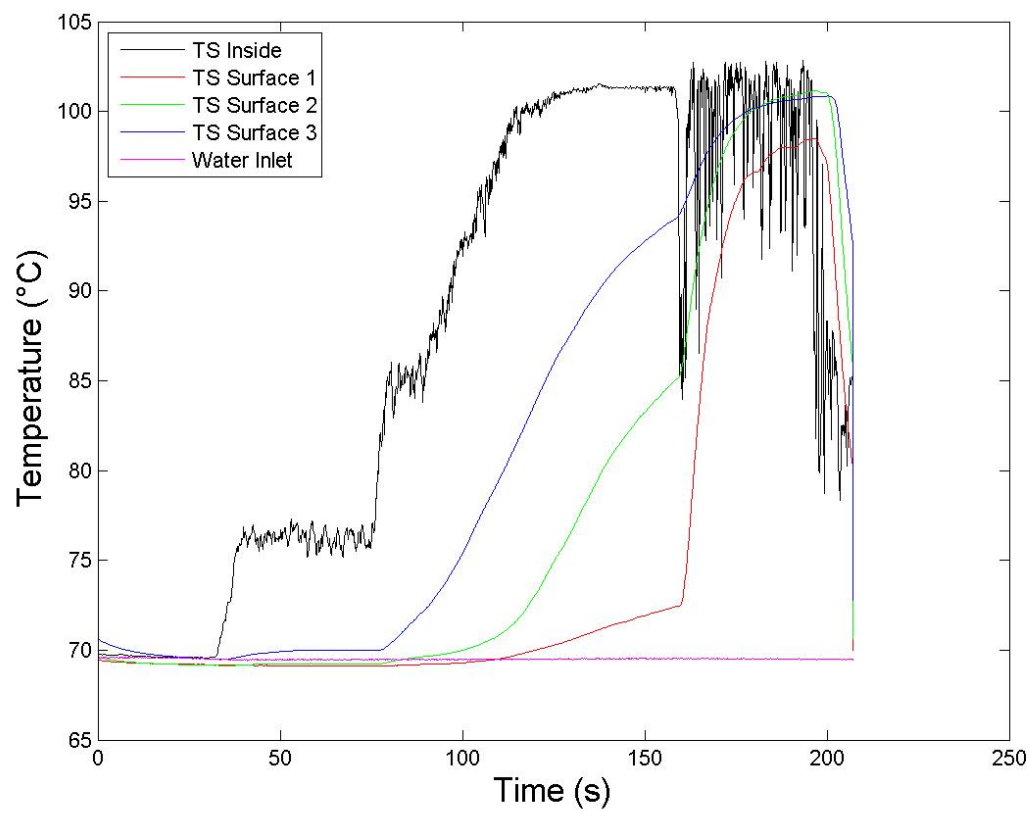

Fig. D.241.: Temperature measurements for Test 49. 


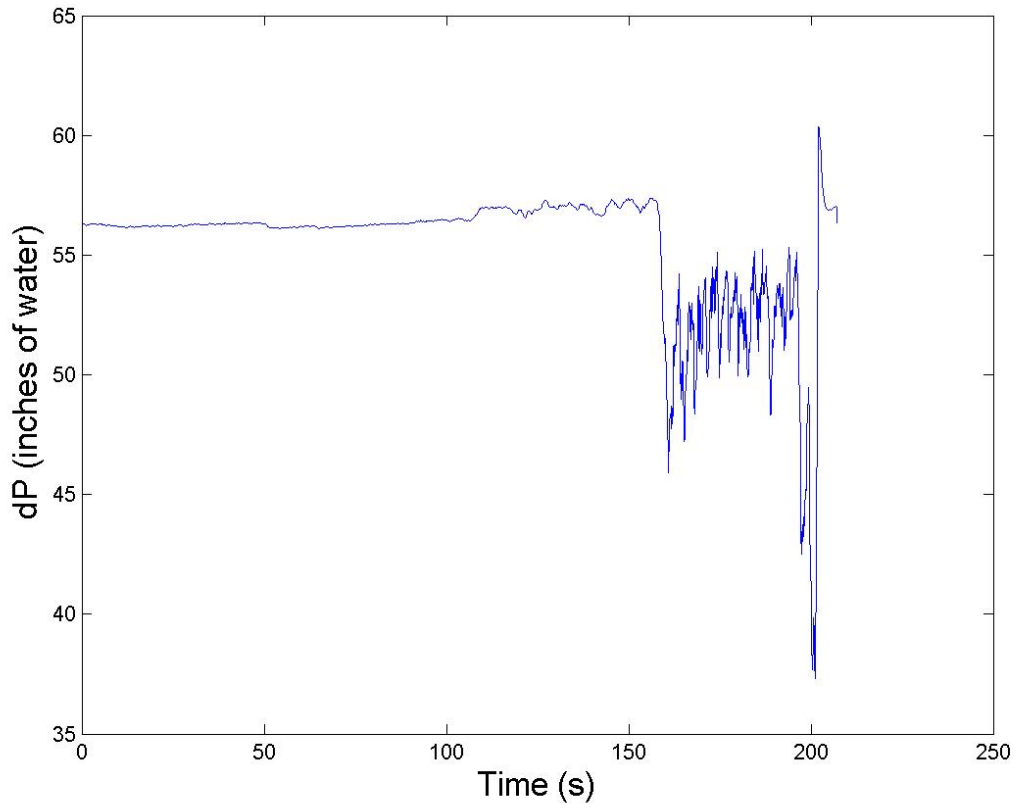

Fig. D.242.: Differential pressure measurements for Test 49.

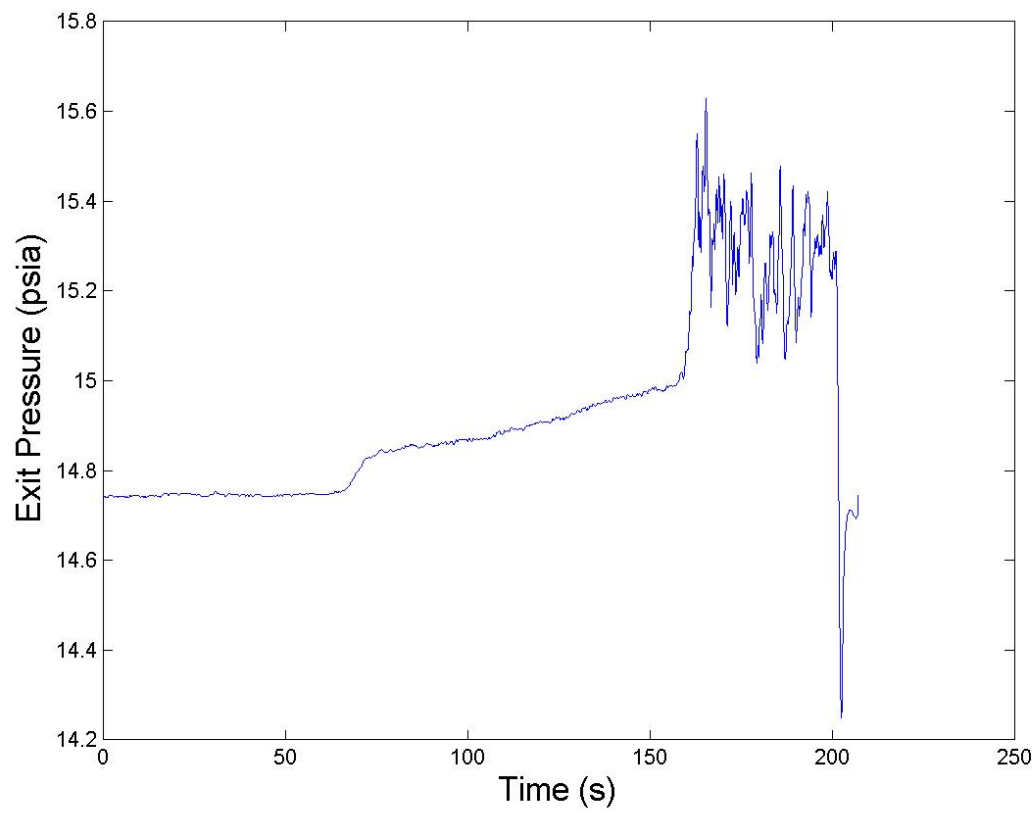

Fig. D.243.: Water exit tank pressure measurements for Test 49. 


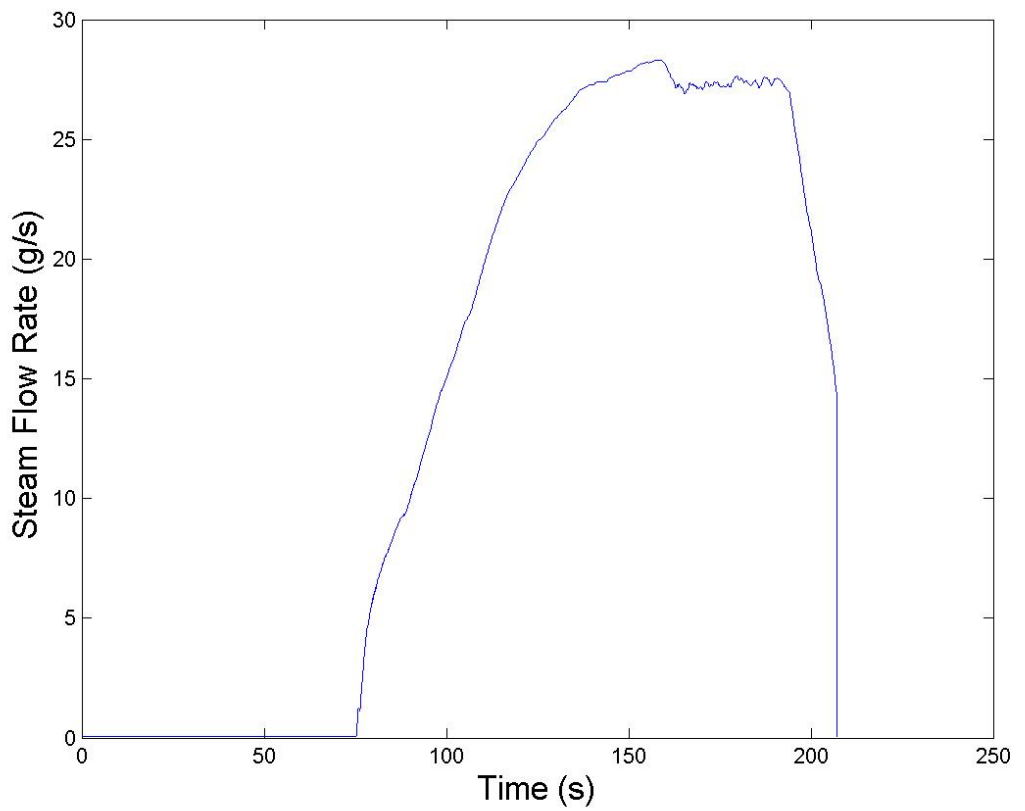

Fig. D.244.: Steam mass flow rate measurements for Test 49.

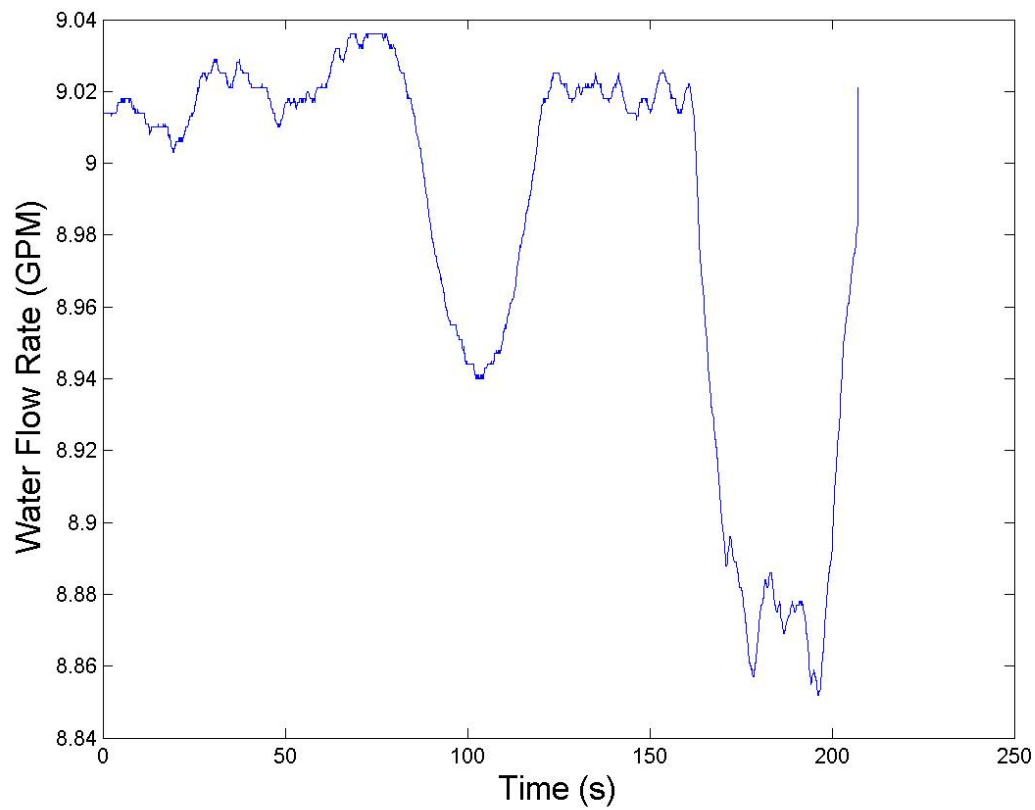

Fig. D.245.: Water flow rate measurements for Test 49. 


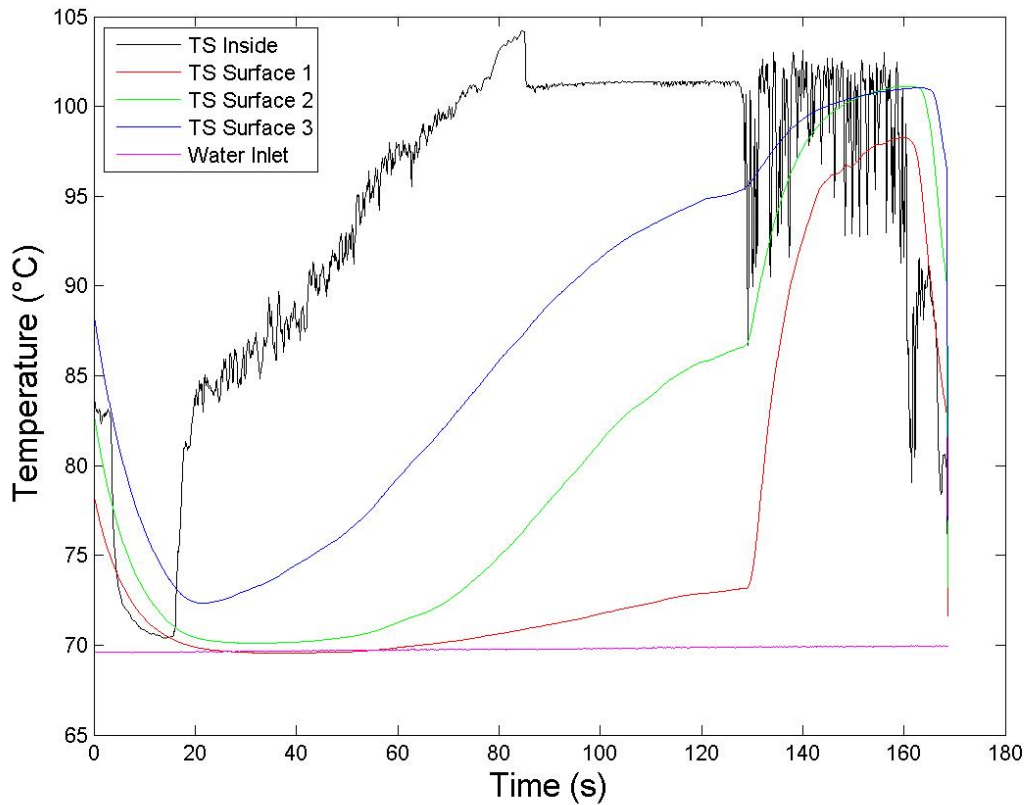

Fig. D.246.: Temperature measurements for Test 50.

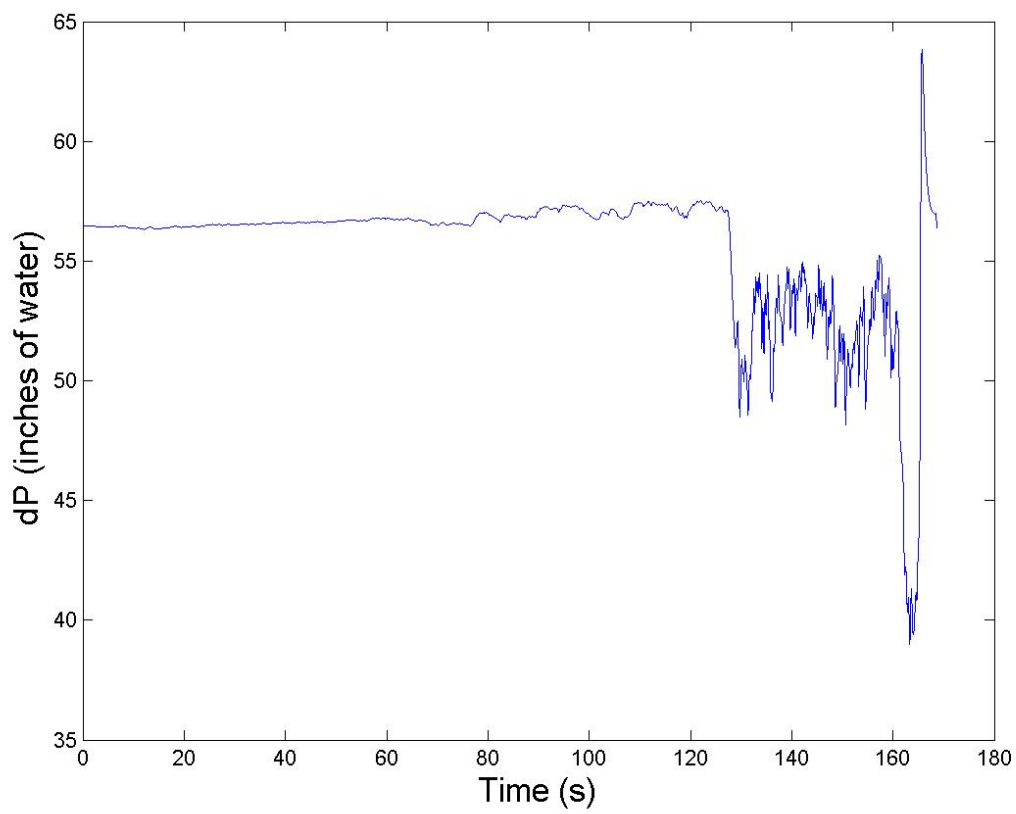

Fig. D.247.: Differential pressure measurements for Test 50. 


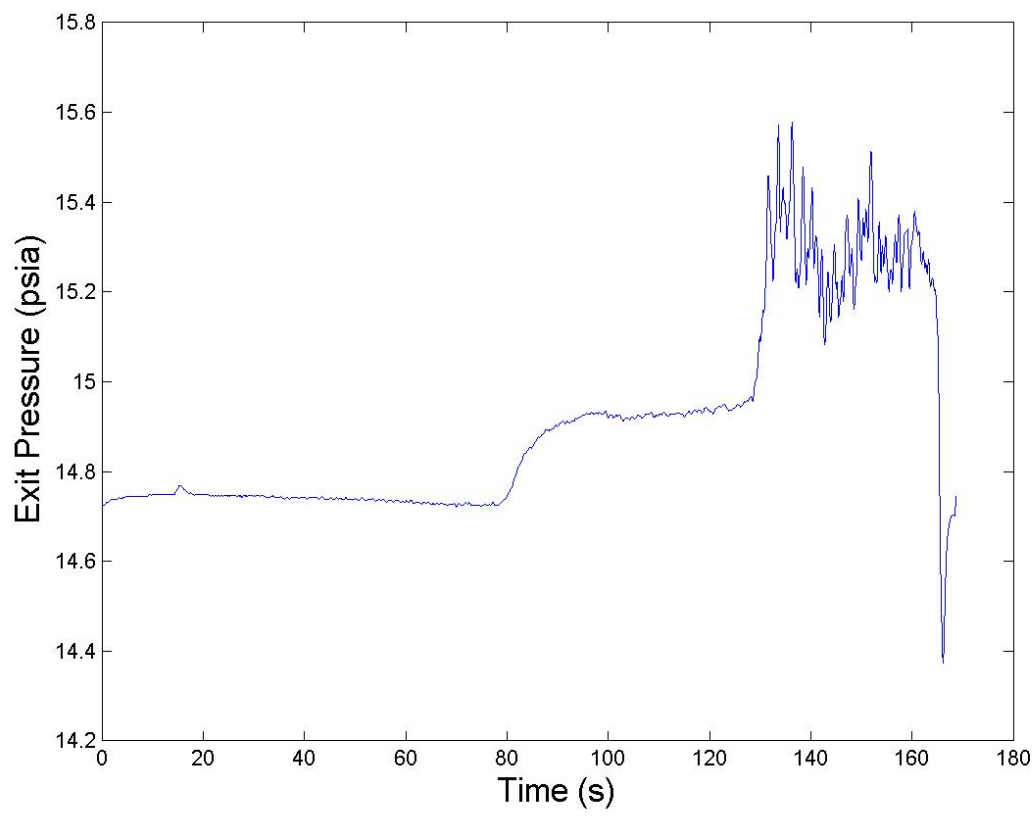

Fig. D.248.: Water exit tank pressure measurements for Test 50 .

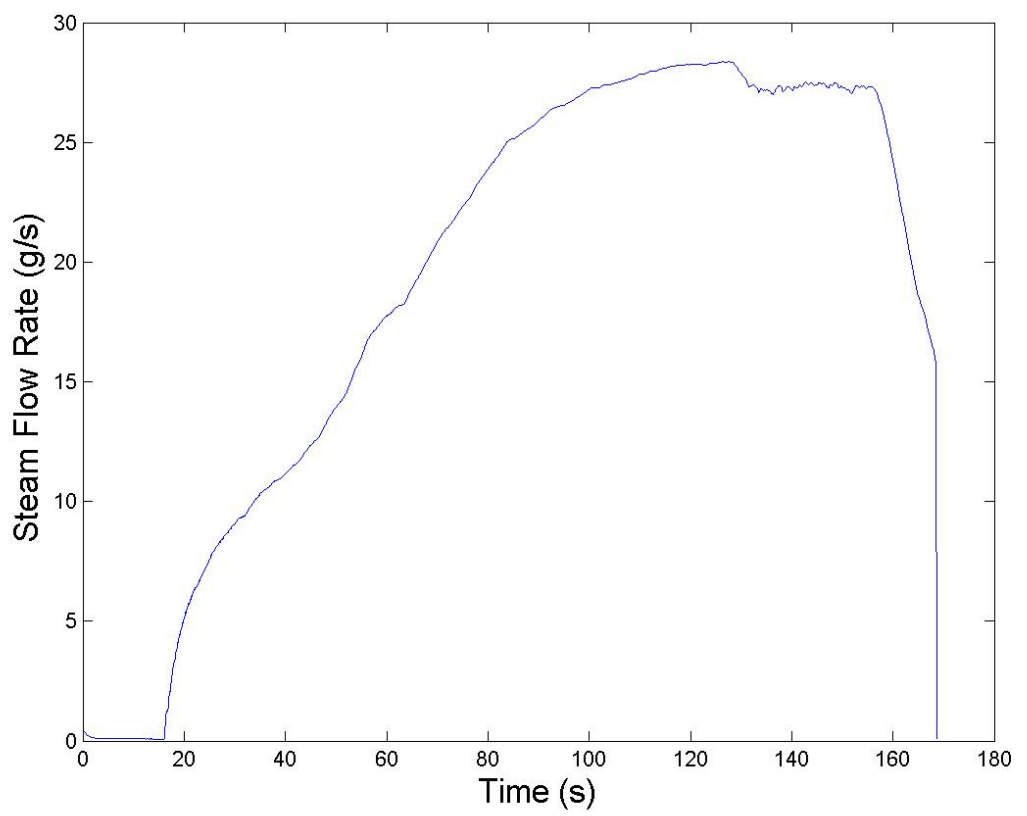

Fig. D.249.: Steam mass flow rate measurements for Test 50 . 


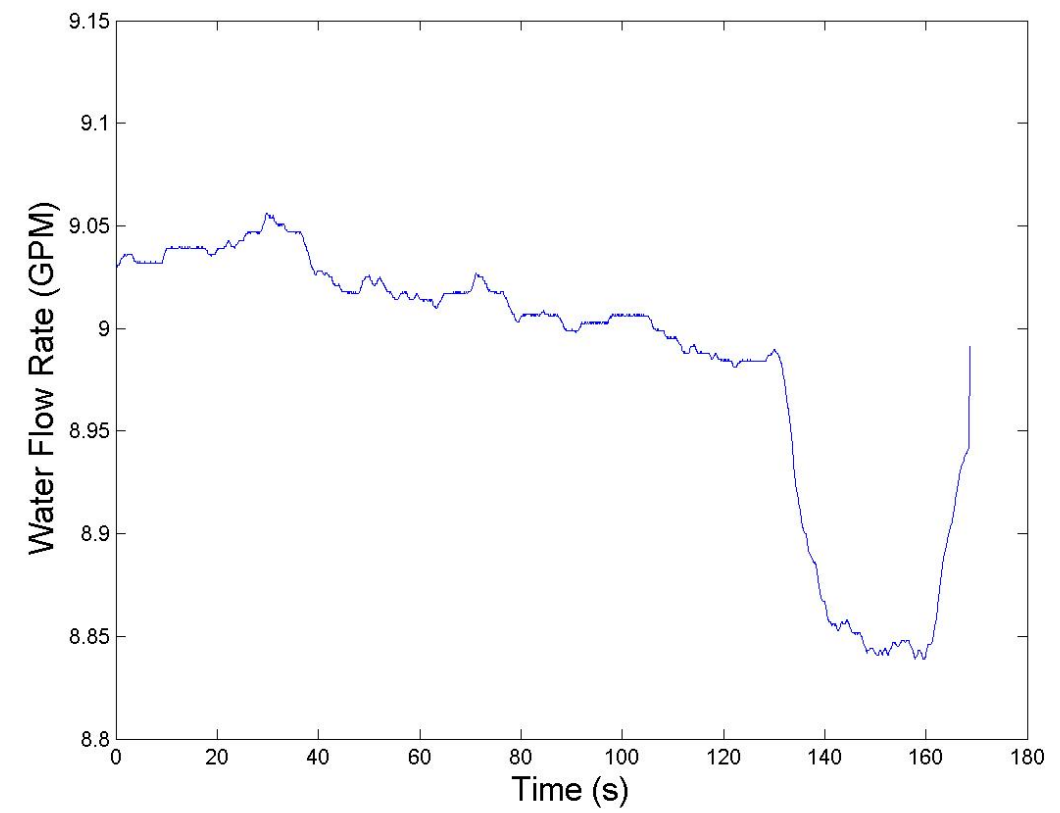

Fig. D.250.: Water flow rate measurements for Test 50 .

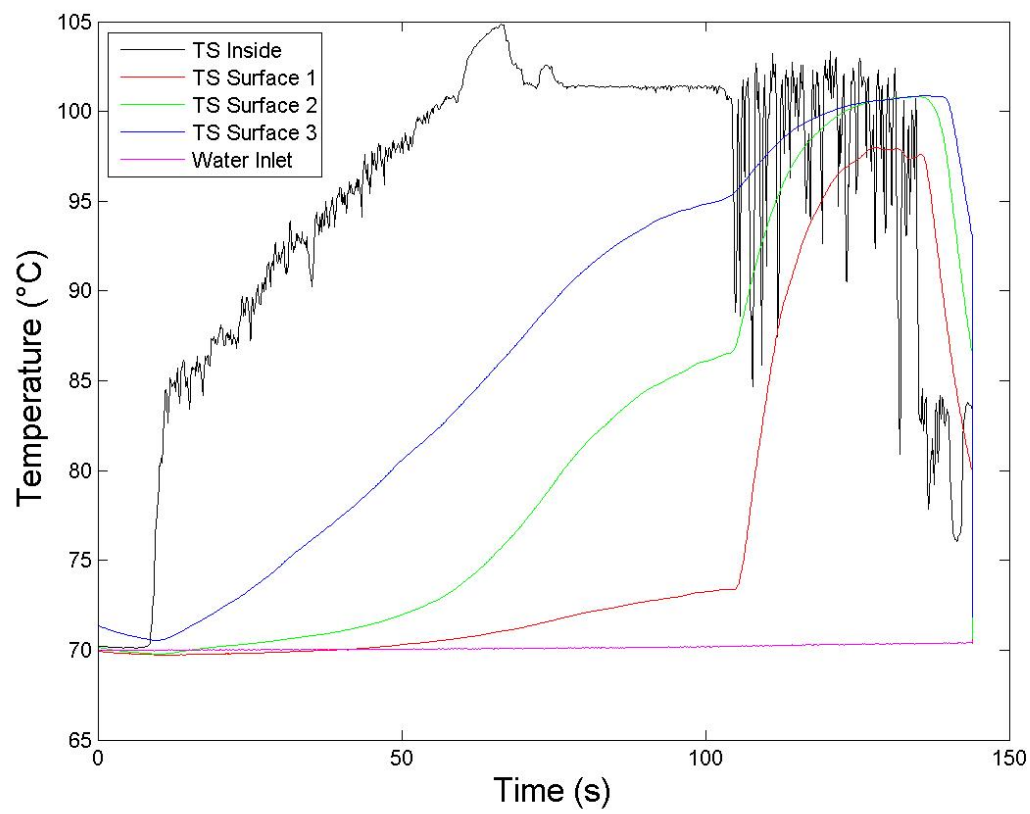

Fig. D.251.: Temperature measurements for Test 51. 


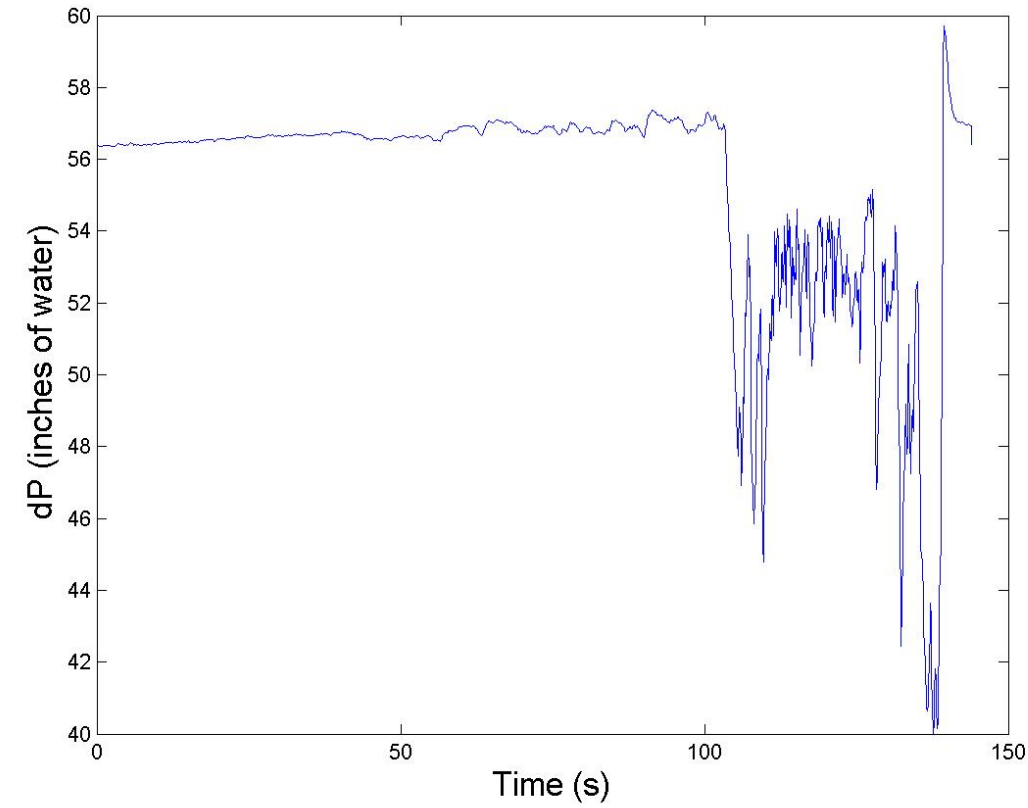

Fig. D.252.: Differential pressure measurements for Test 51 .

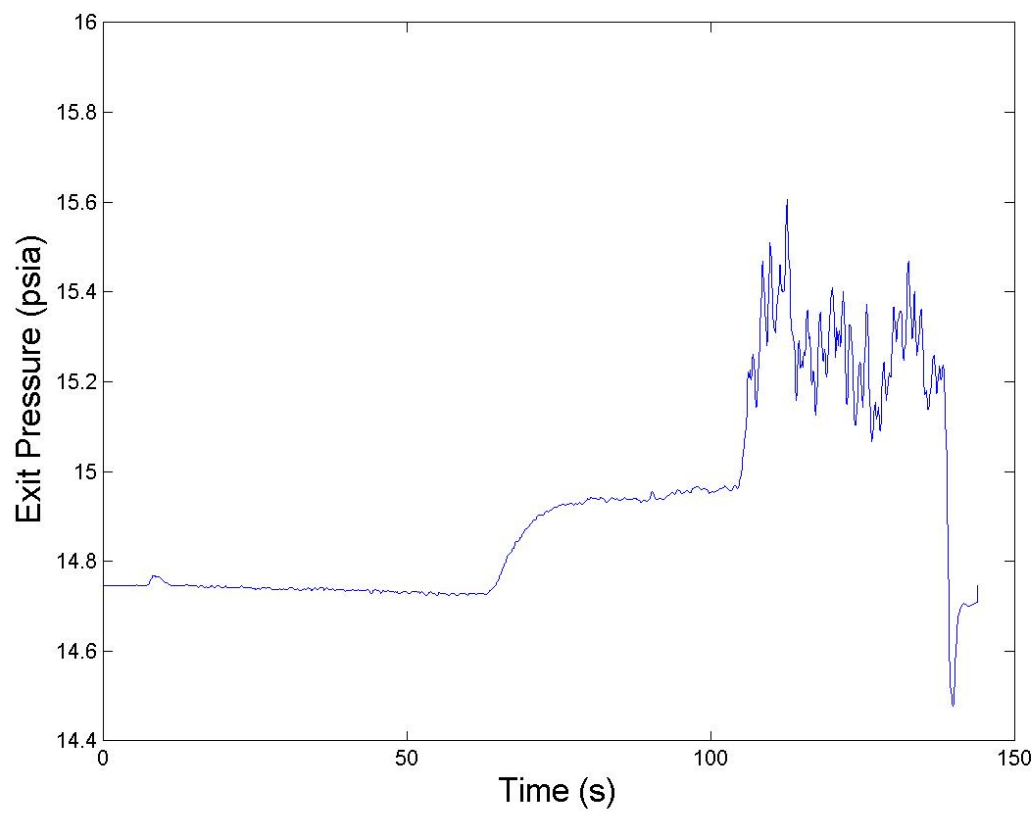

Fig. D.253.: Water exit tank pressure measurements for Test 51. 


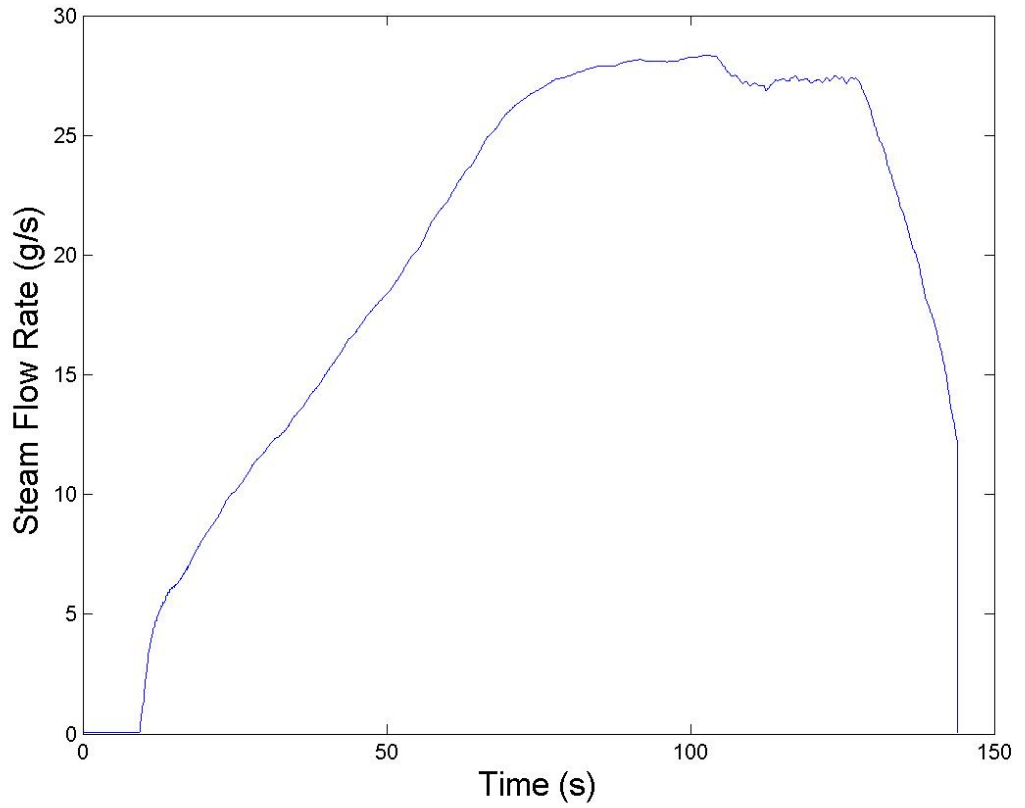

Fig. D.254.: Steam mass flow rate measurements for Test 51.

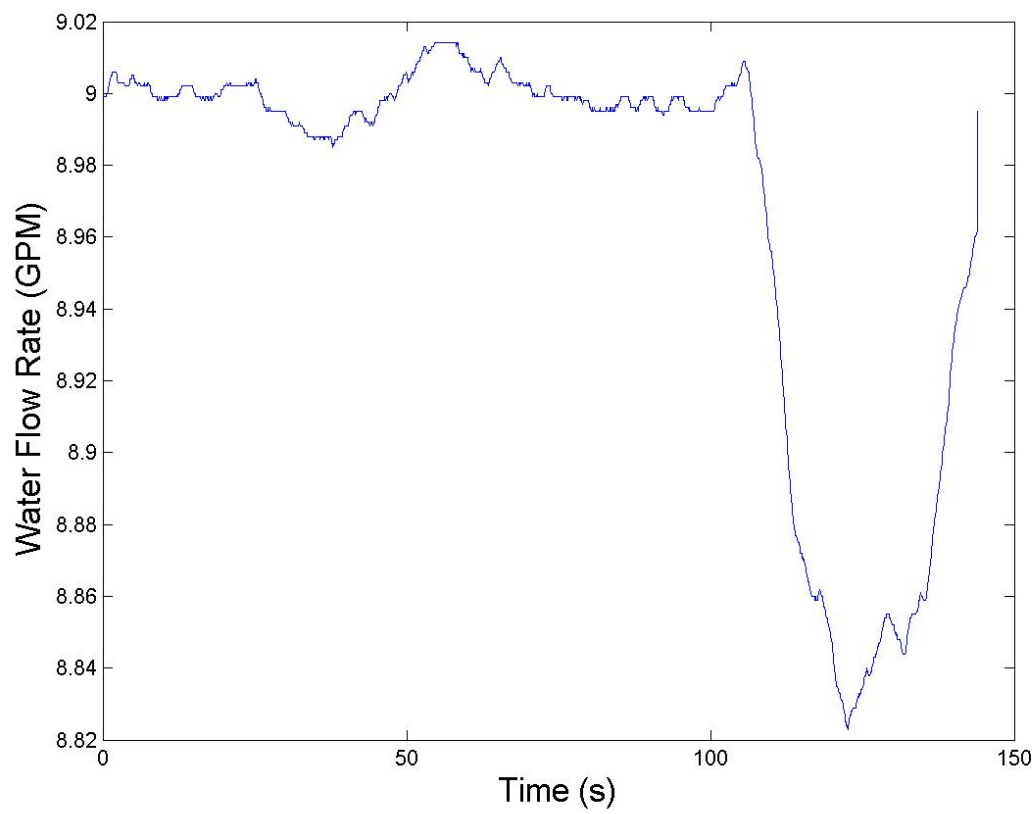

Fig. D.255.: Water flow rate measurements for Test 51. 


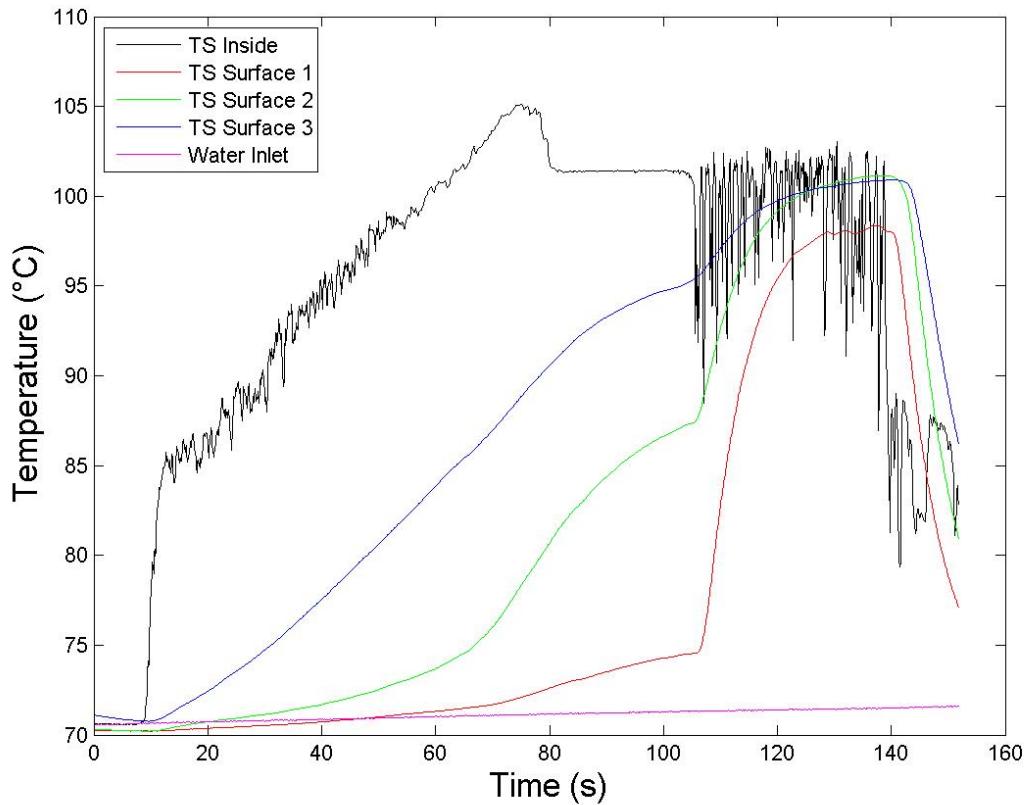

Fig. D.256.: Temperature measurements for Test 52.

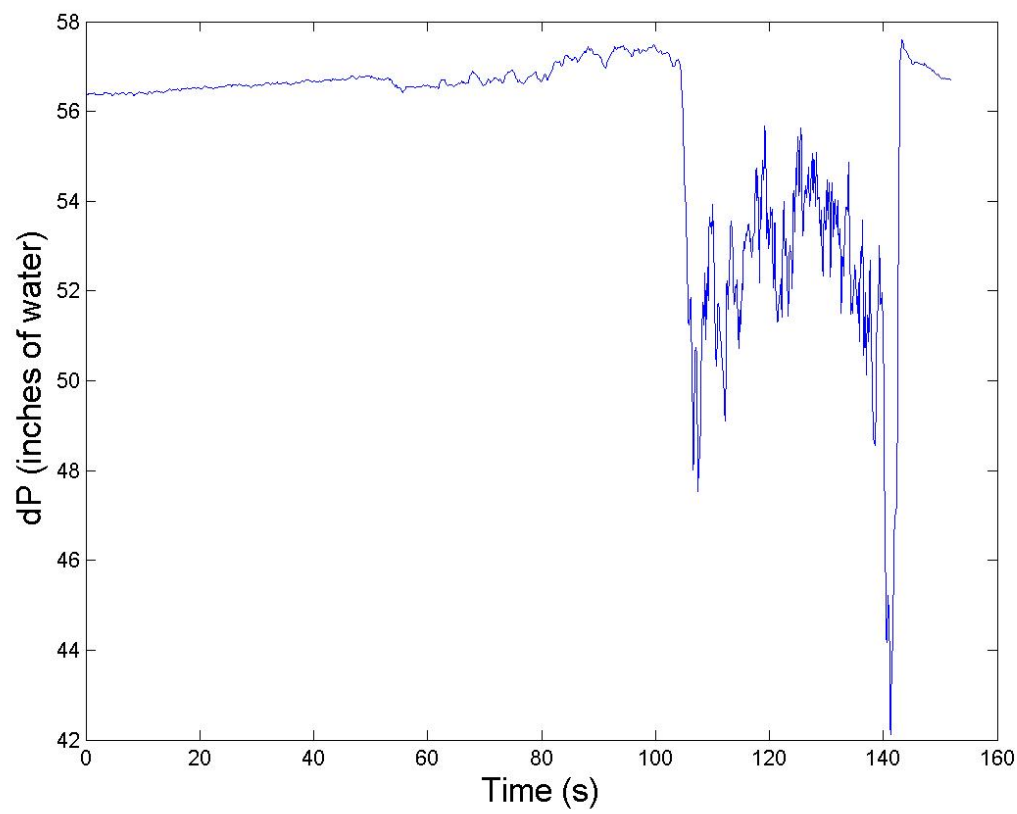

Fig. D.257.: Differential pressure measurements for Test 52. 


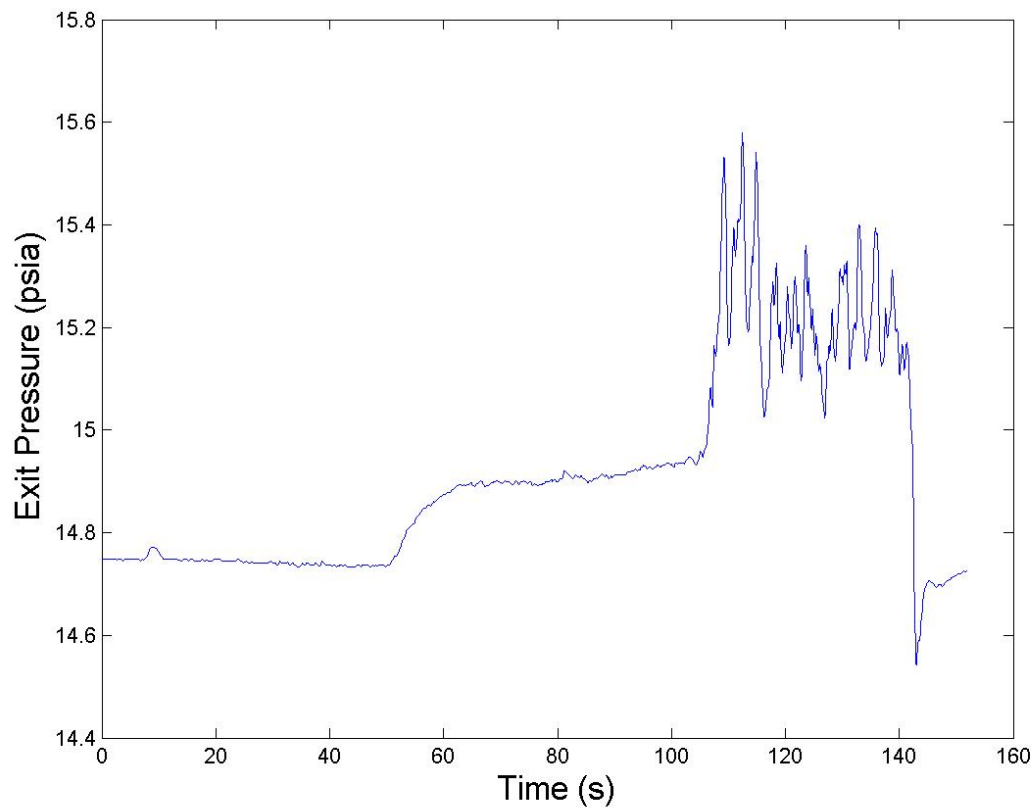

Fig. D.258.: Water exit tank pressure measurements for Test 52.

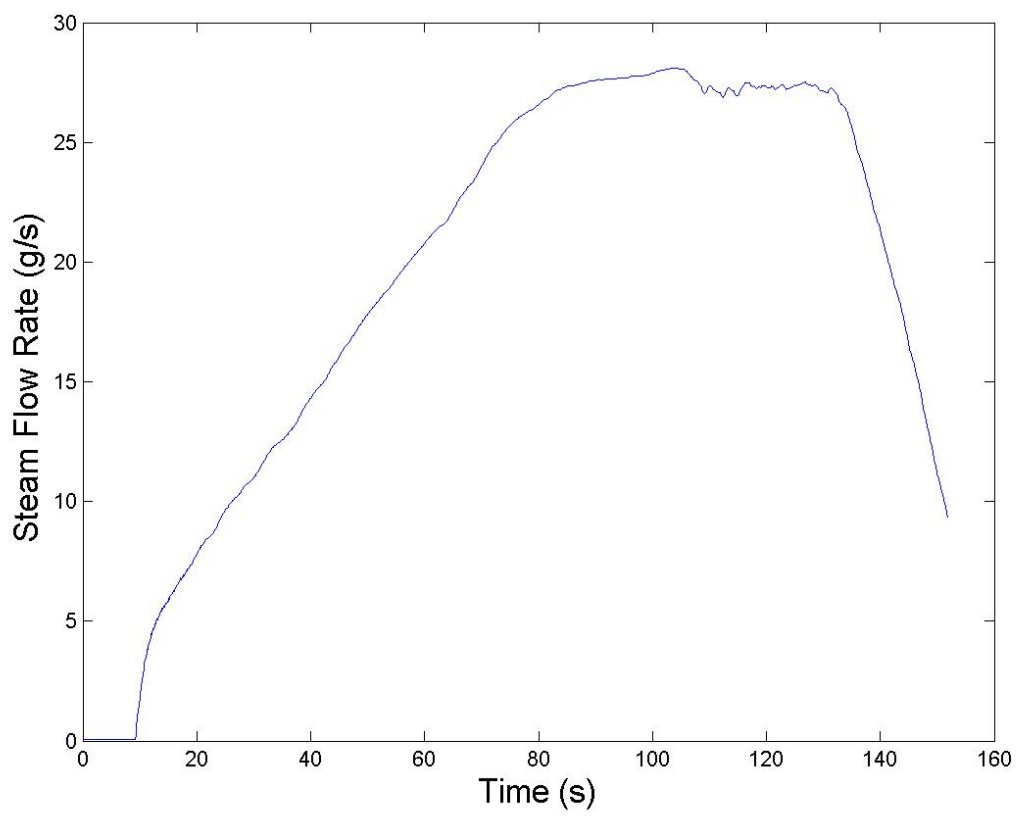

Fig. D.259.: Steam mass flow rate measurements for Test 52. 


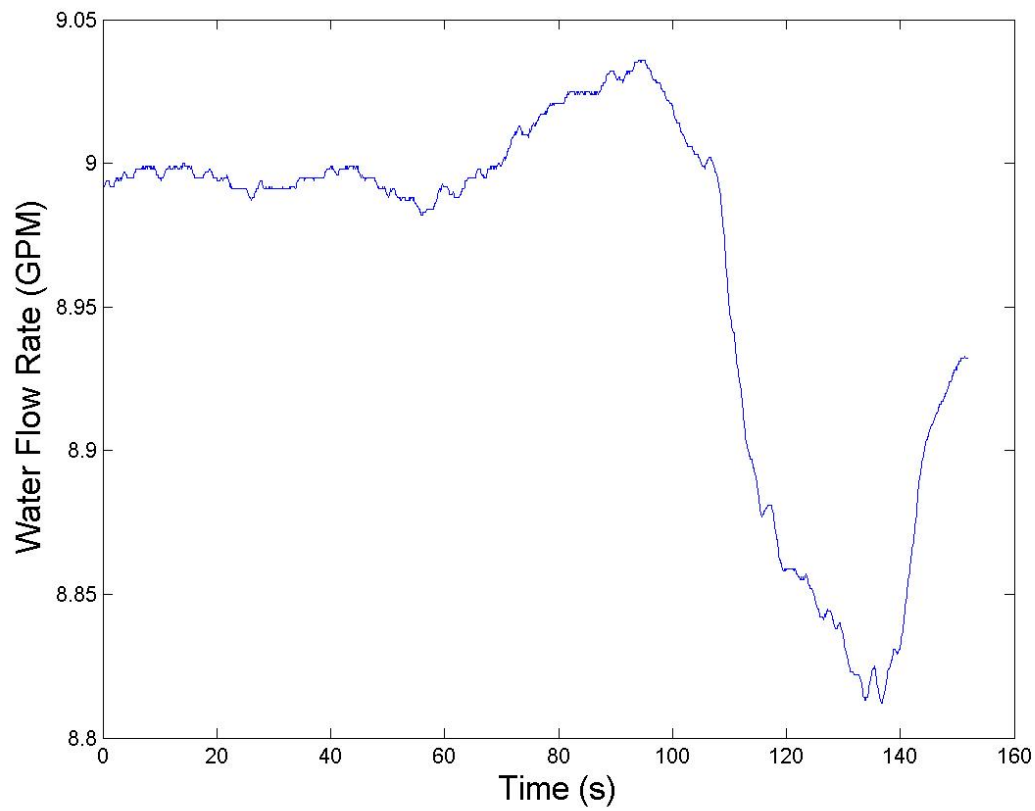

Fig. D.260.: Water flow rate measurements for Test 52 .

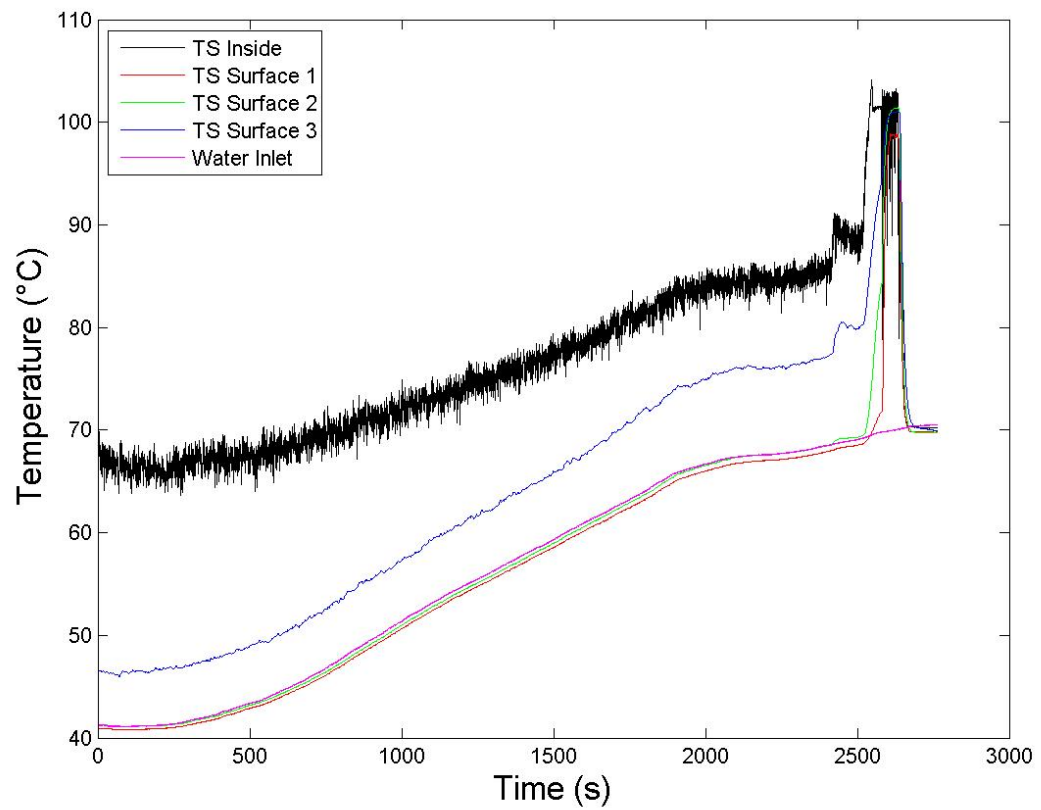

Fig. D.261.: Temperature measurements for Test 53. 


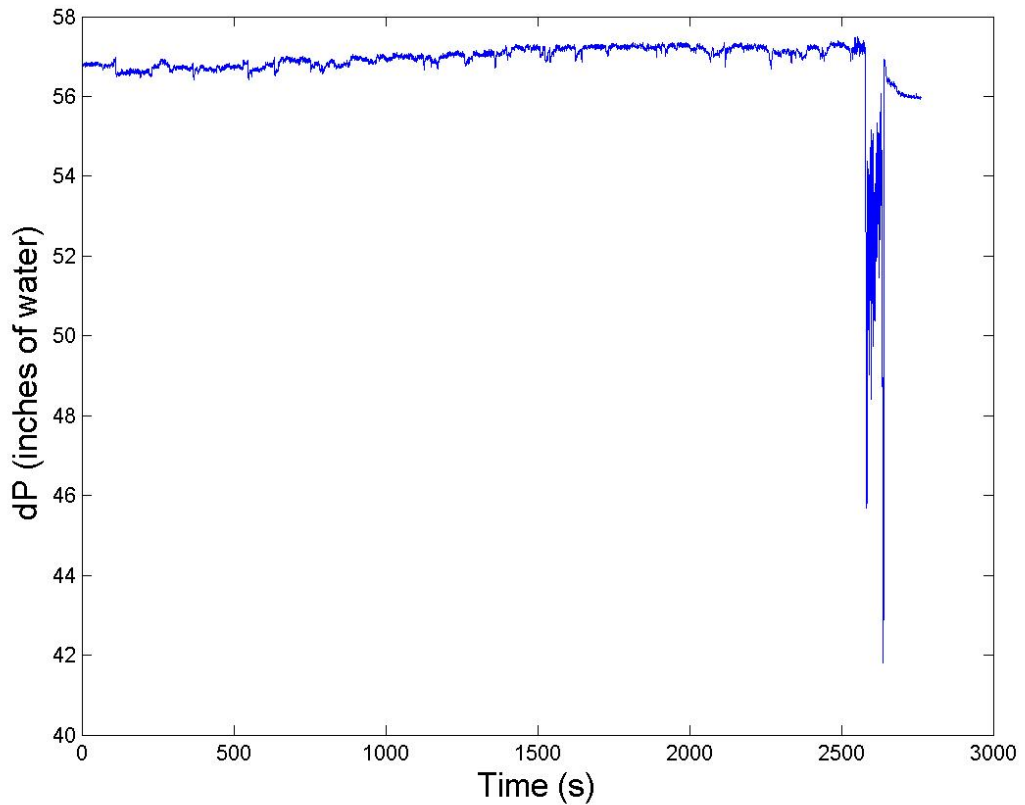

Fig. D.262.: Differential pressure measurements for Test 53.

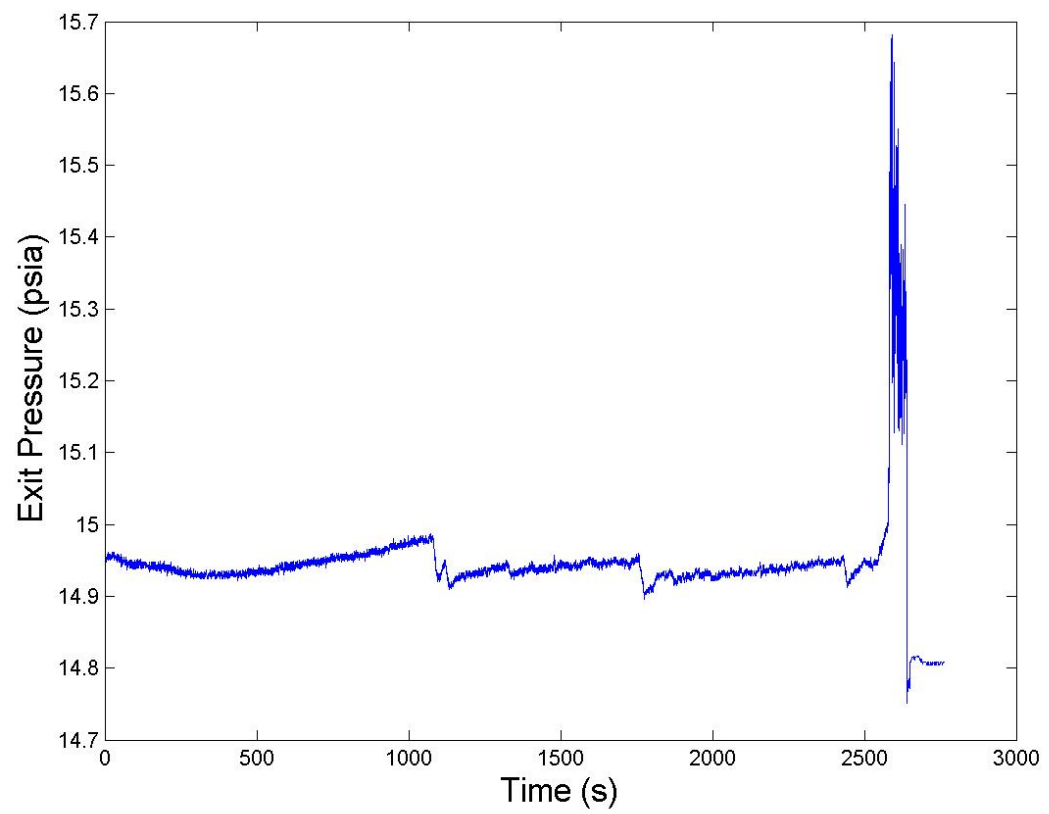

Fig. D.263.: Water exit tank pressure measurements for Test 53 . 


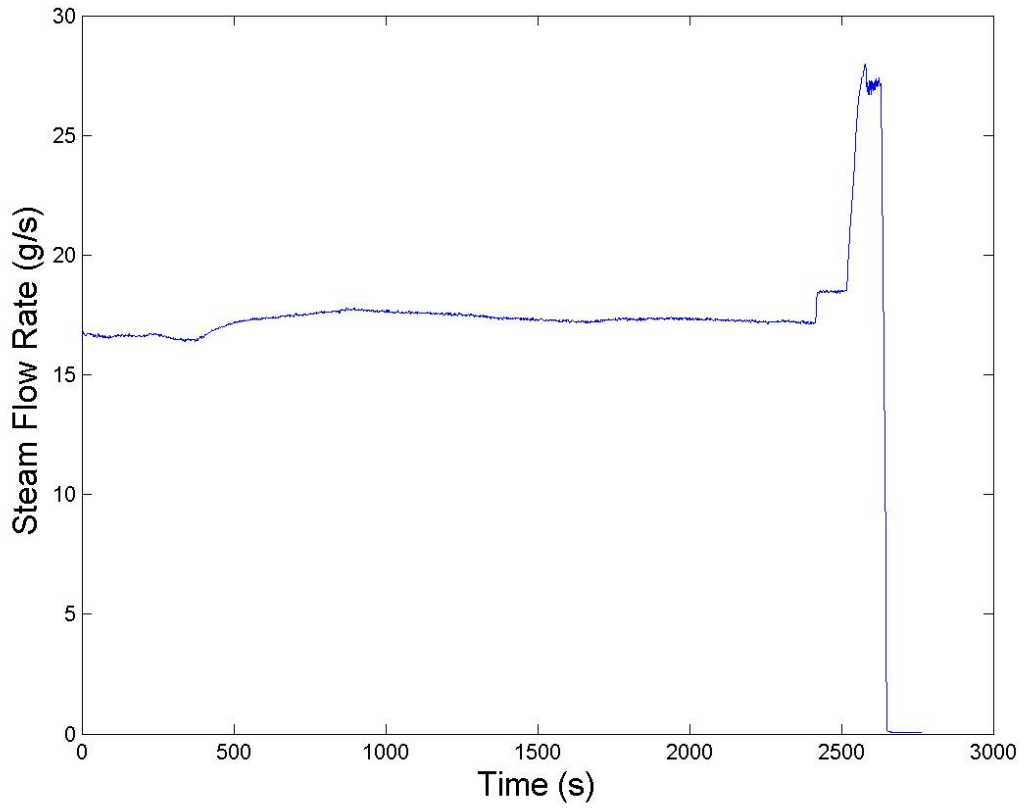

Fig. D.264.: Steam mass flow rate measurements for Test 53.

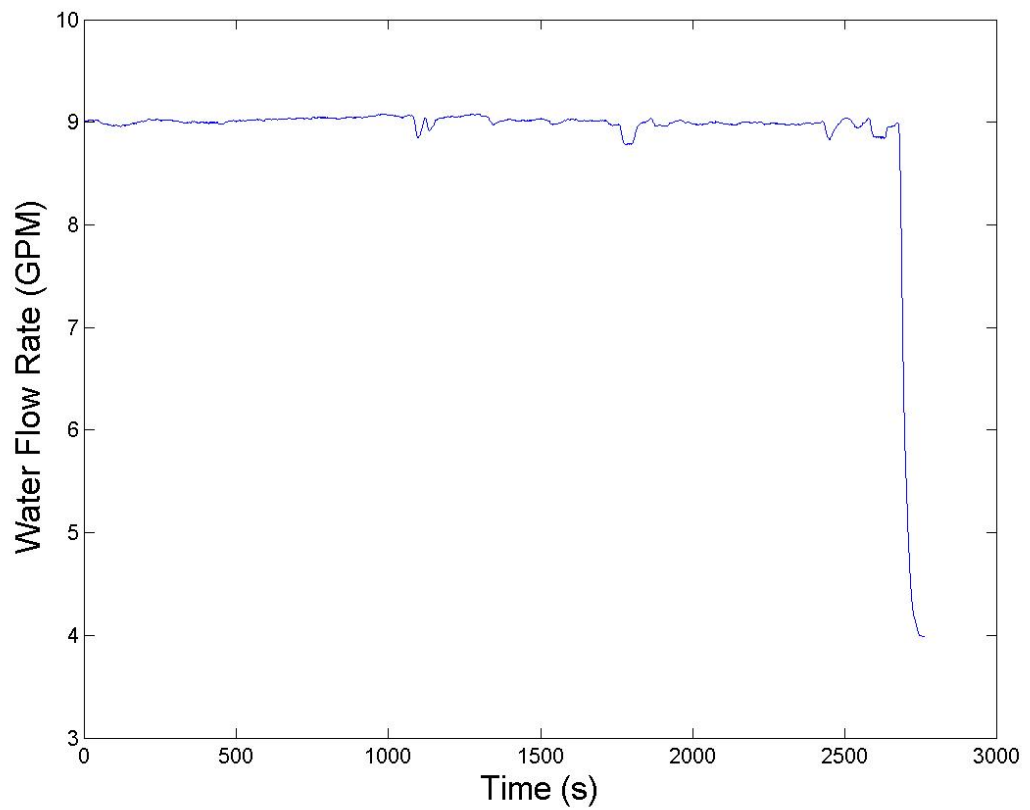

Fig. D.265.: Water flow rate measurements for Test 53. 


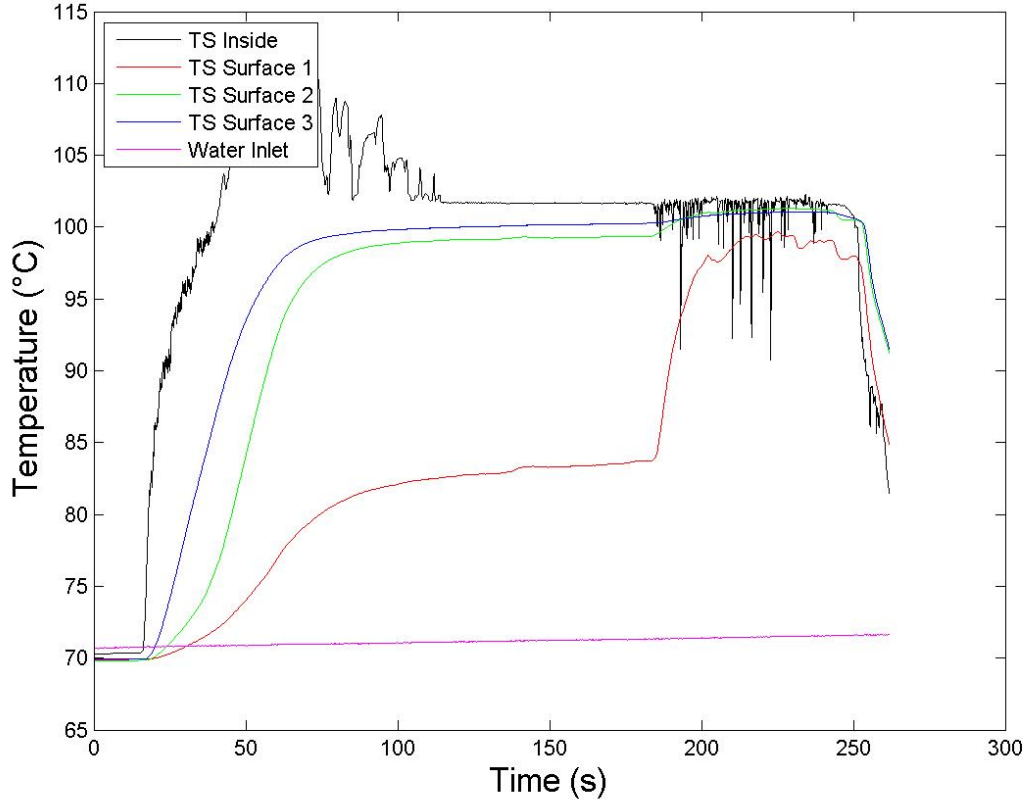

Fig. D.266.: Temperature measurements for Test 54 .

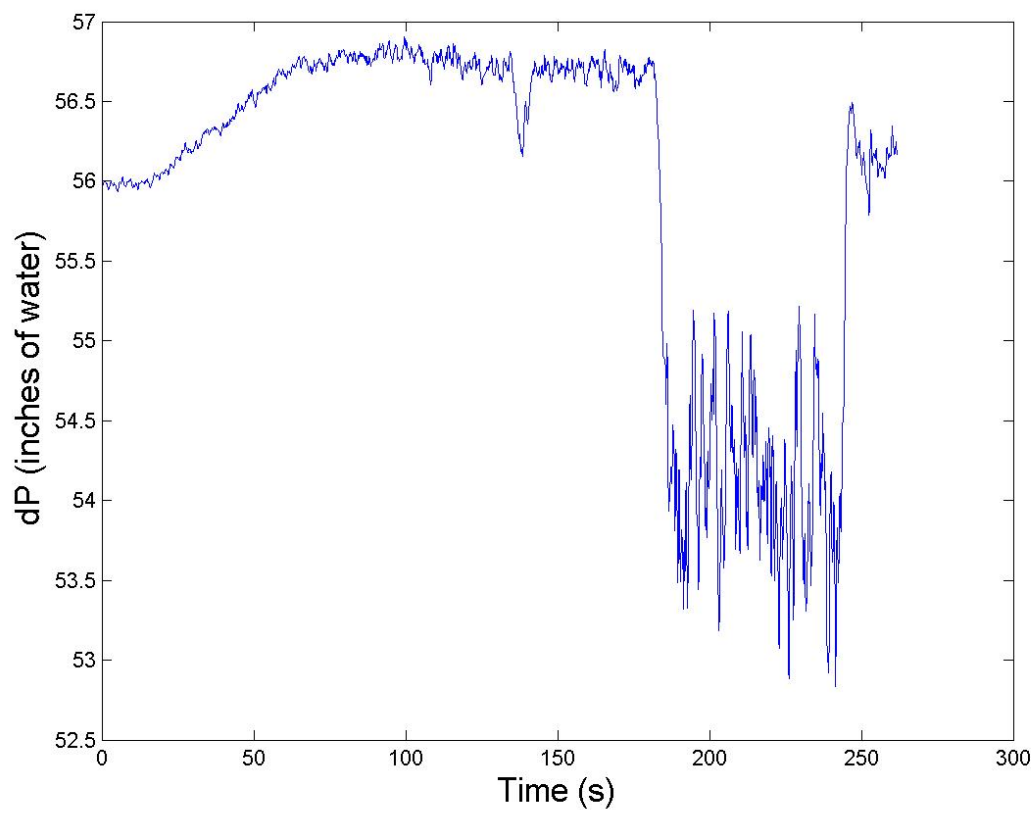

Fig. D.267.: Differential pressure measurements for Test 54 . 


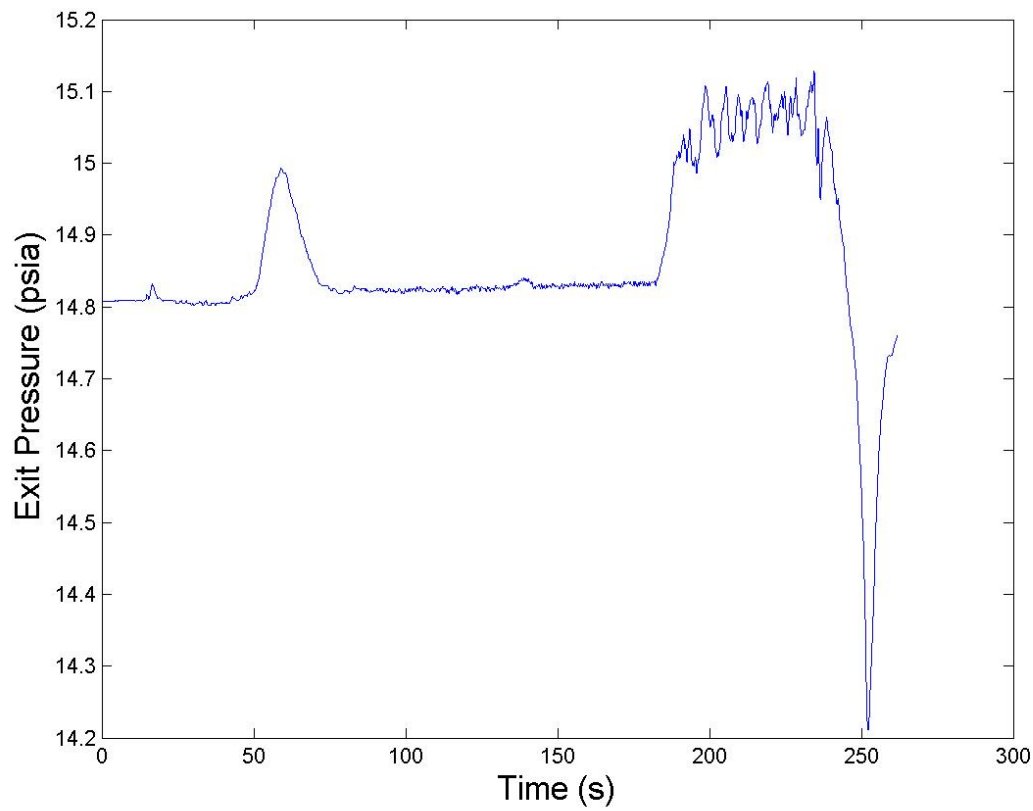

Fig. D.268.: Water exit tank pressure measurements for Test 54 .

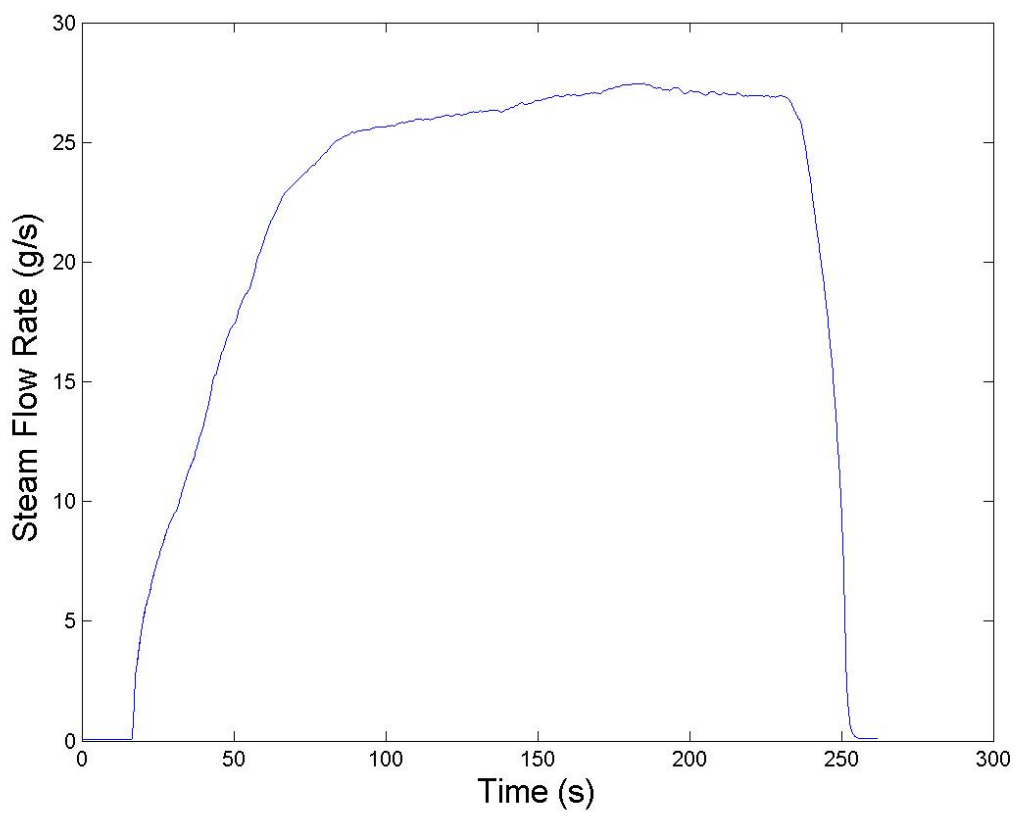

Fig. D.269.: Steam mass flow rate measurements for Test 54 . 


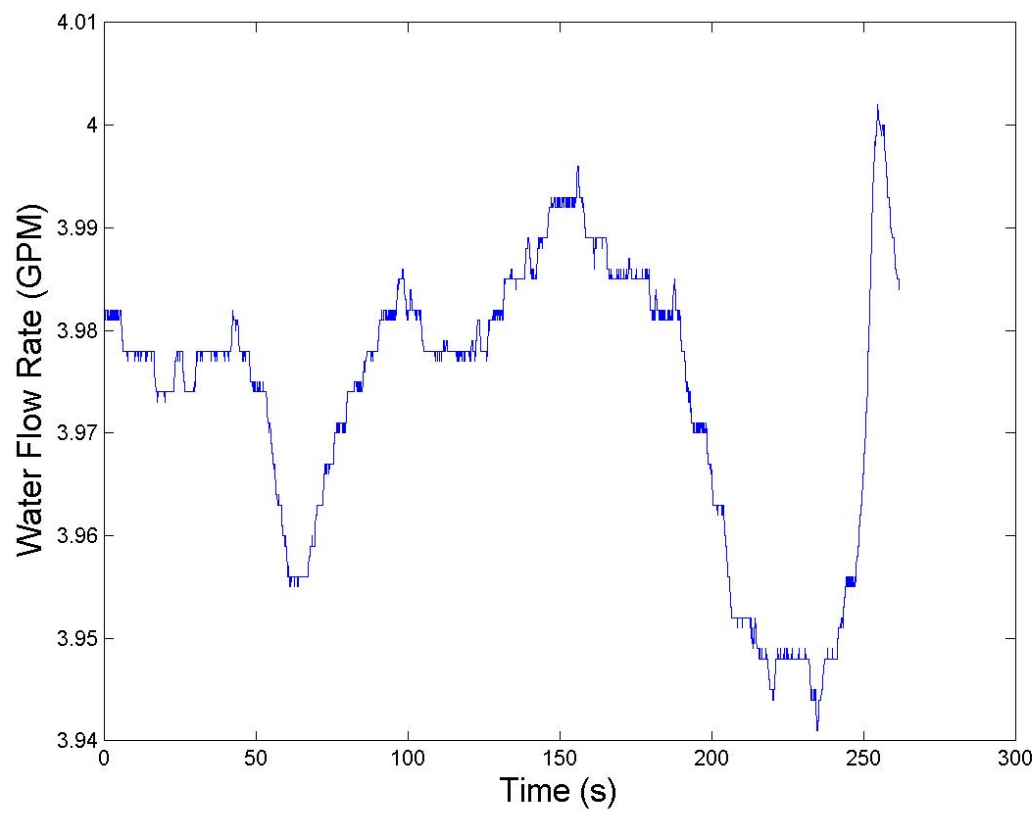

Fig. D.270.: Water flow rate measurements for Test 54 .

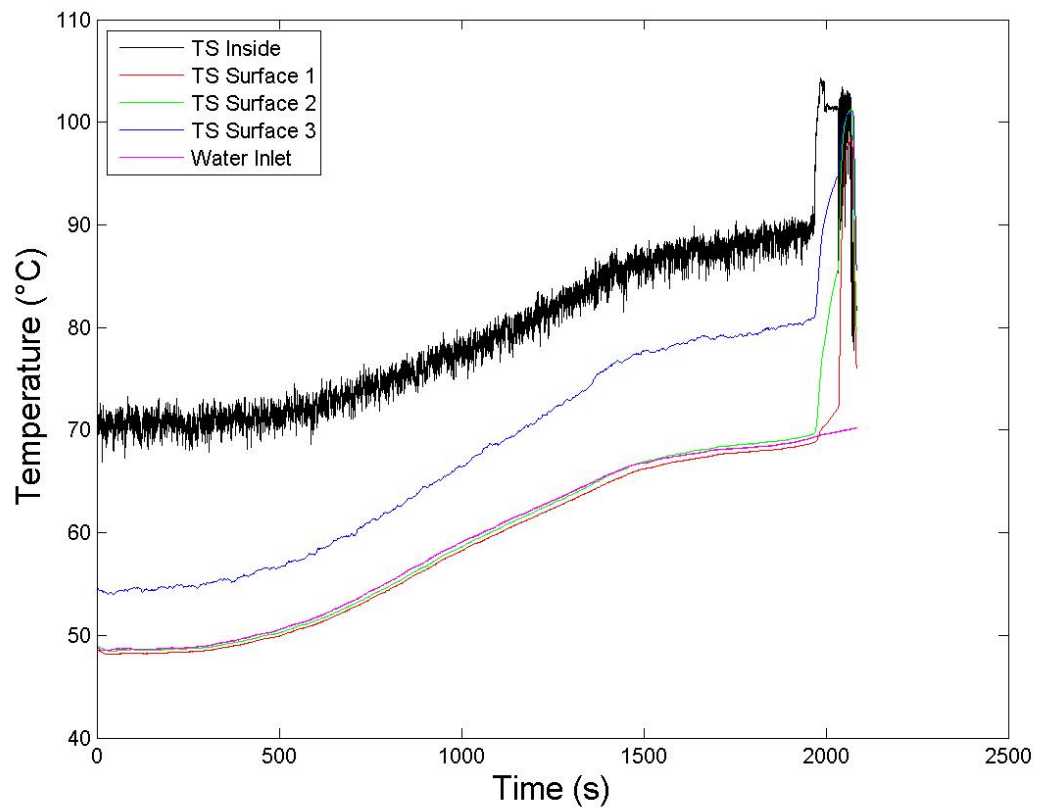

Fig. D.271.: Temperature measurements for Test 55. 


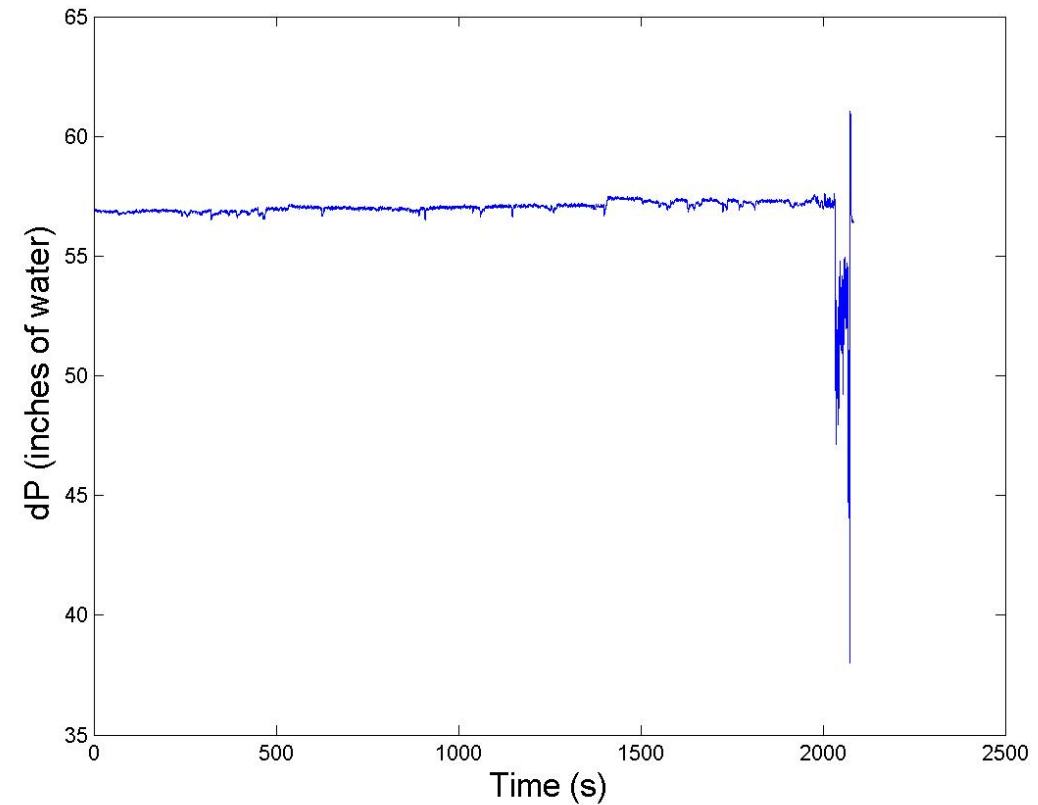

Fig. D.272.: Differential pressure measurements for Test 55 .

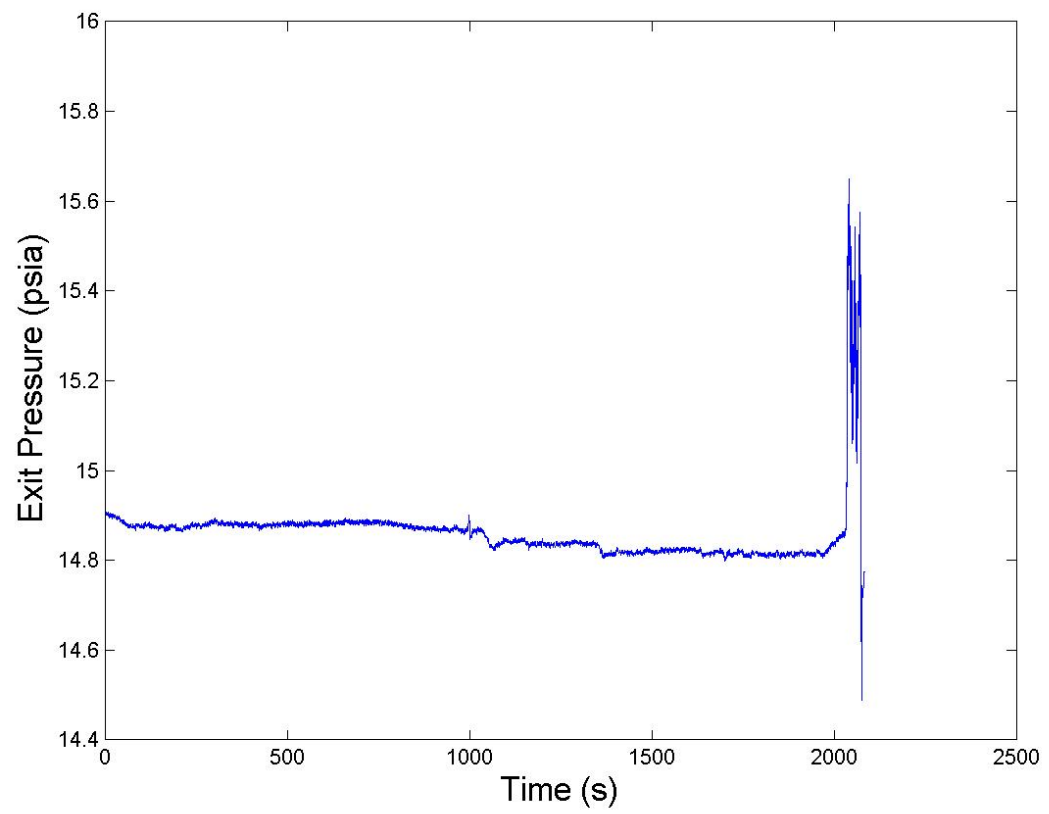

Fig. D.273.: Water exit tank pressure measurements for Test 55. 


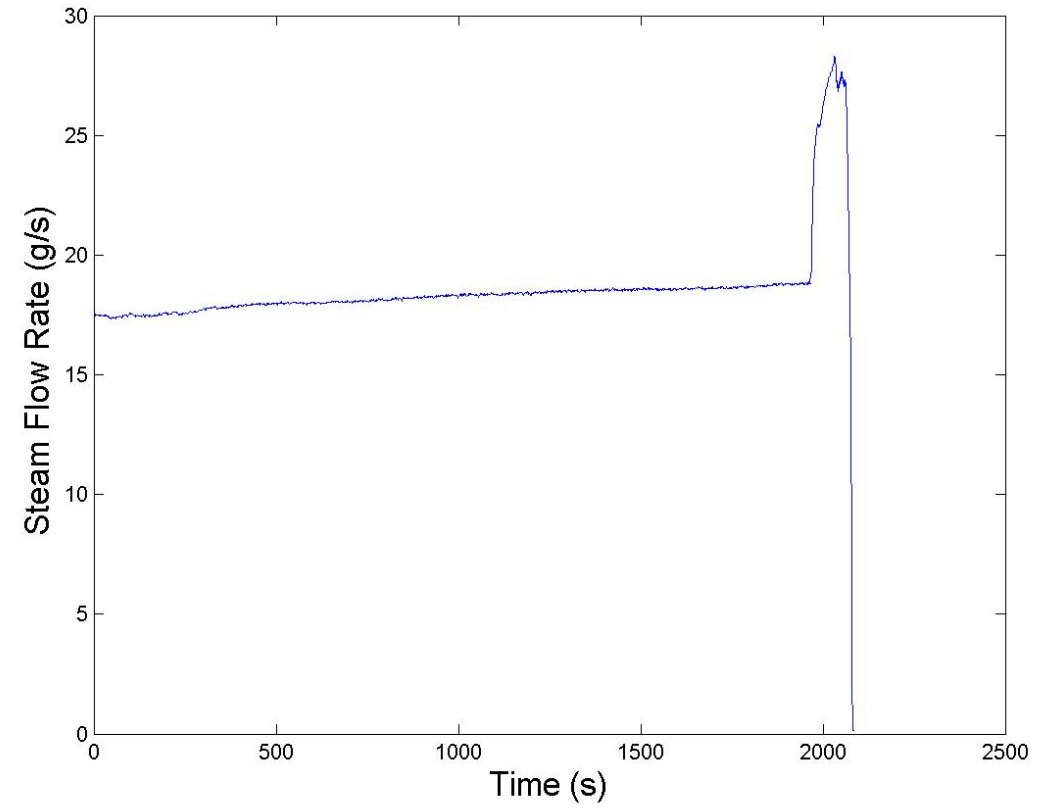

Fig. D.274.: Steam mass flow rate measurements for Test 55.

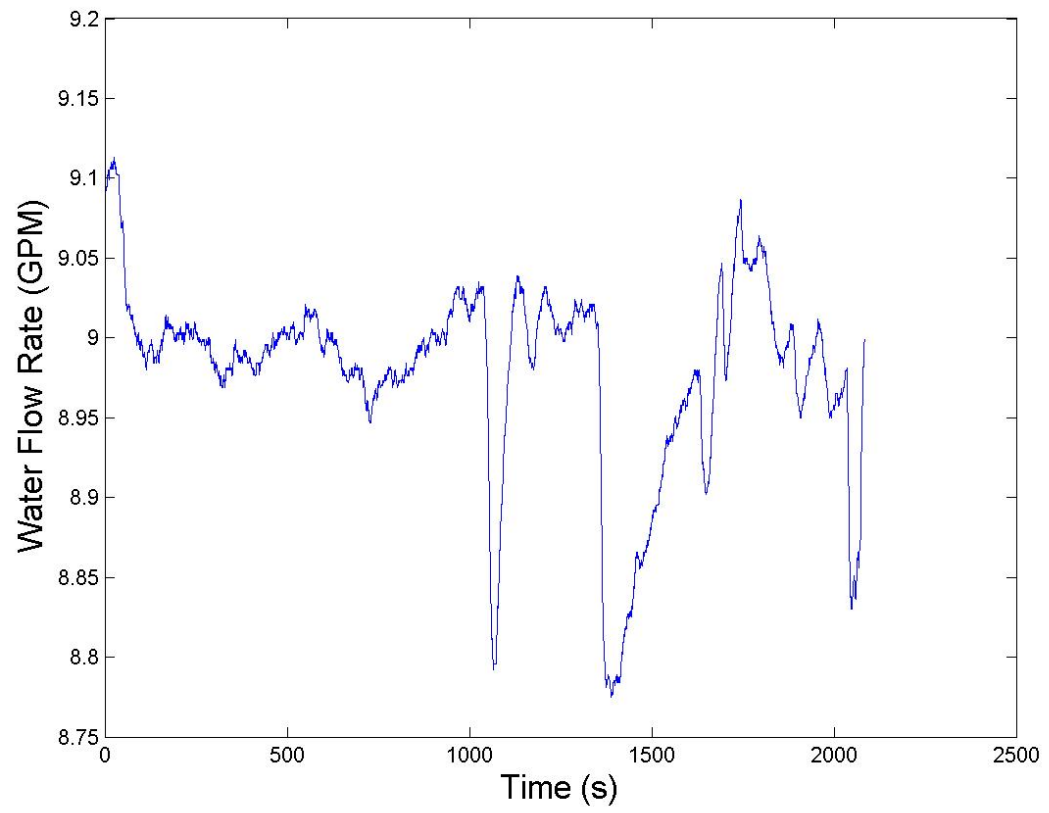

Fig. D.275.: Water flow rate measurements for Test 55. 


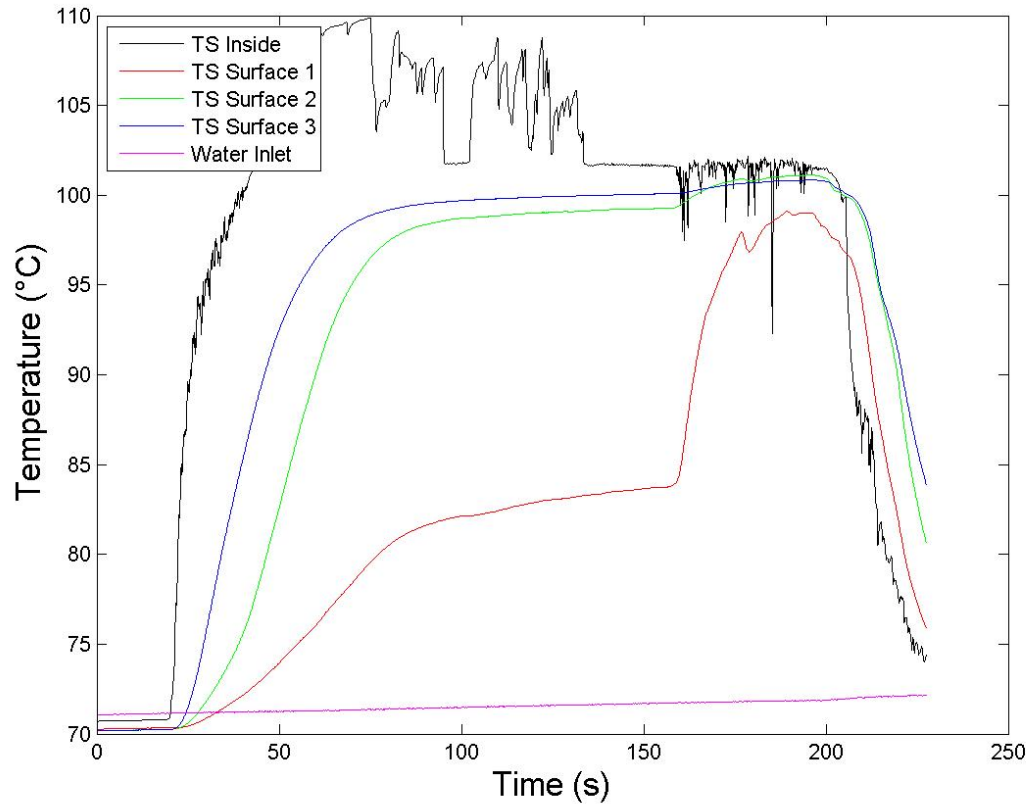

Fig. D.276.: Temperature measurements for Test 56.

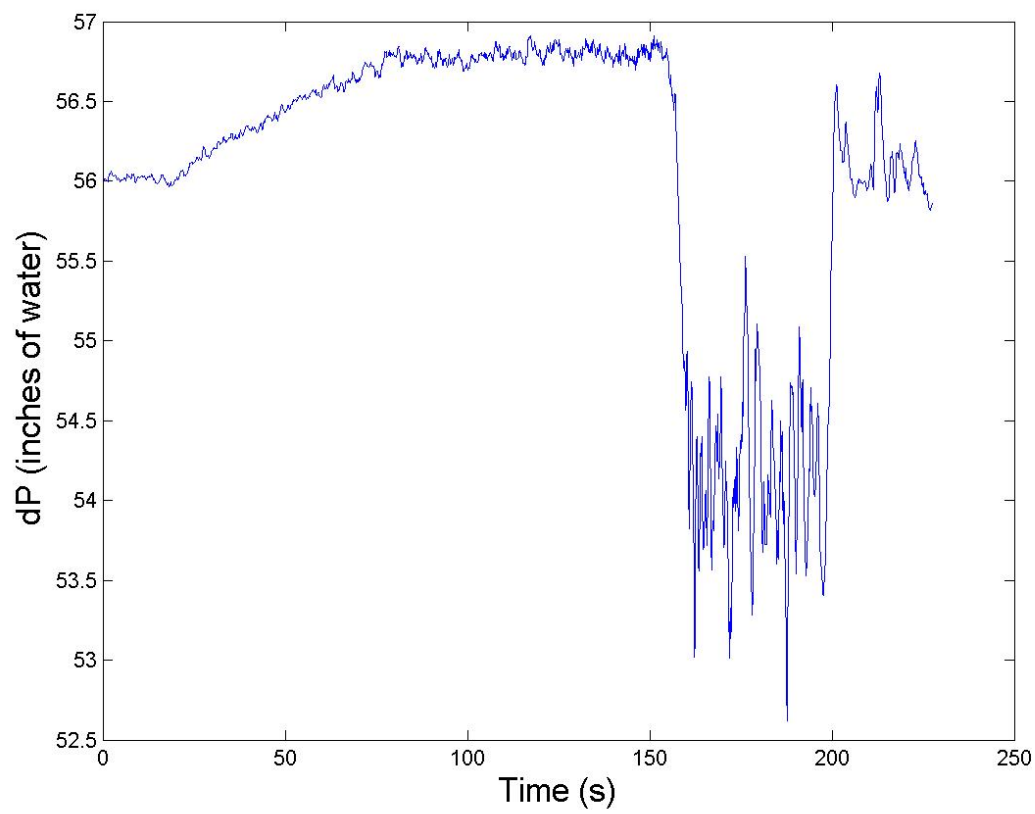

Fig. D.277.: Differential pressure measurements for Test 56. 


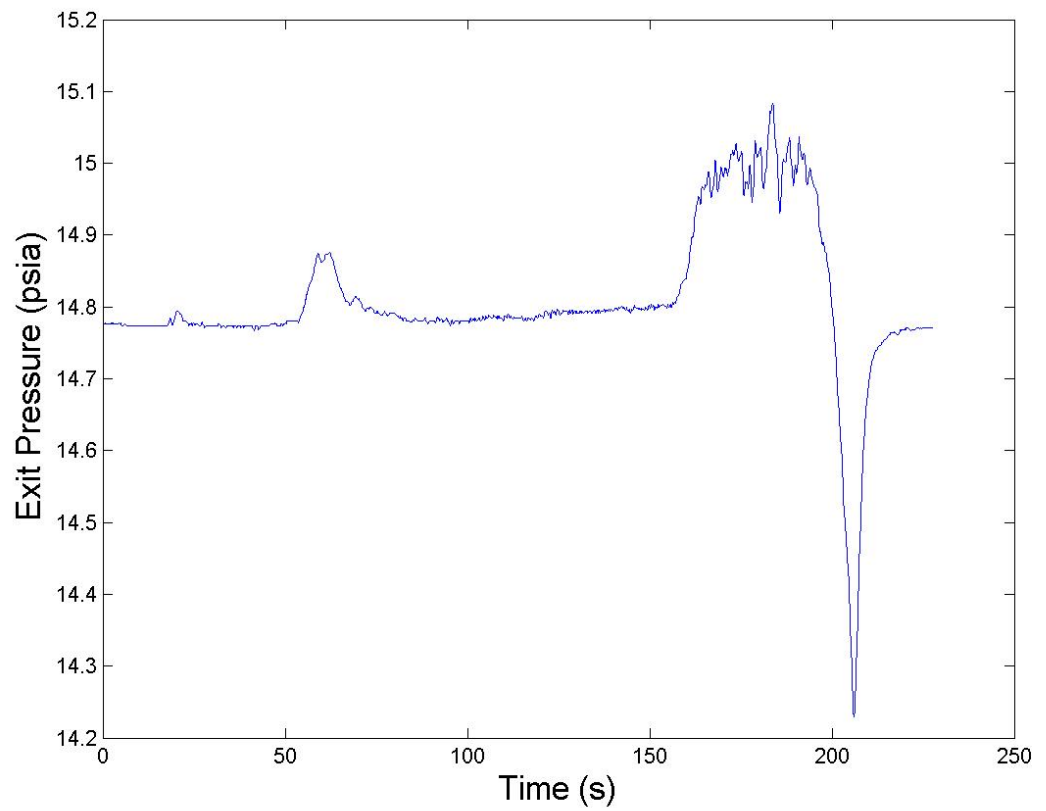

Fig. D.278.: Water exit tank pressure measurements for Test 56.

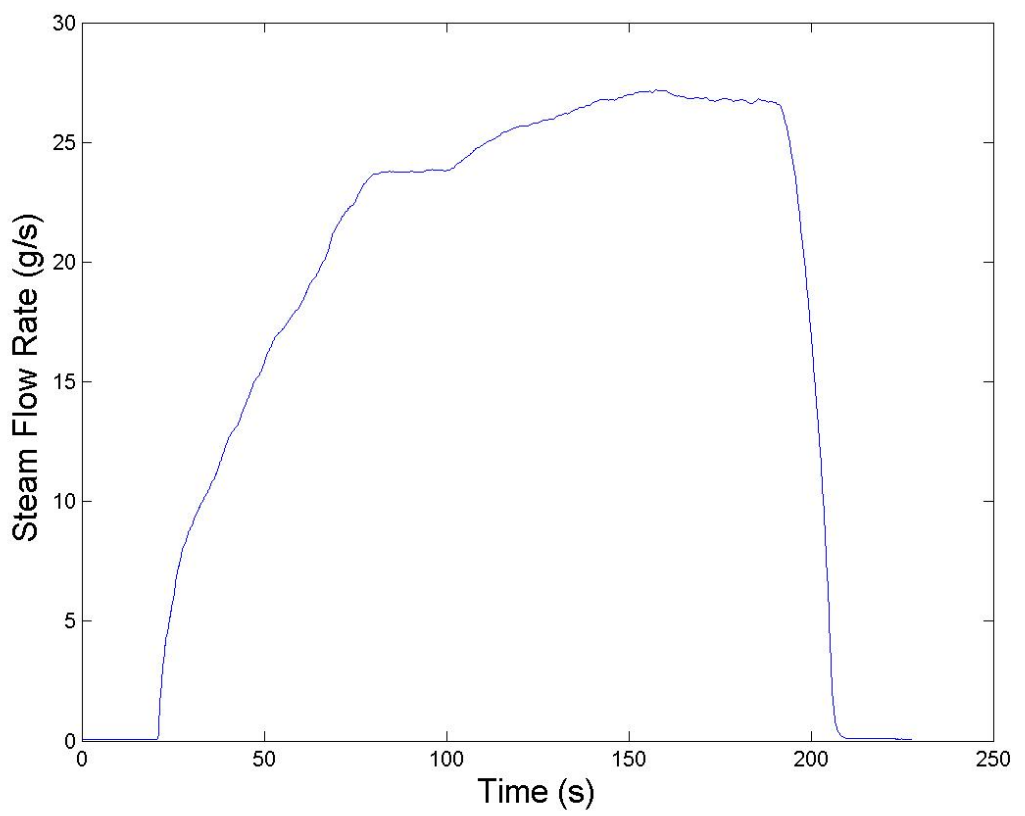

Fig. D.279.: Steam mass flow rate measurements for Test 56. 


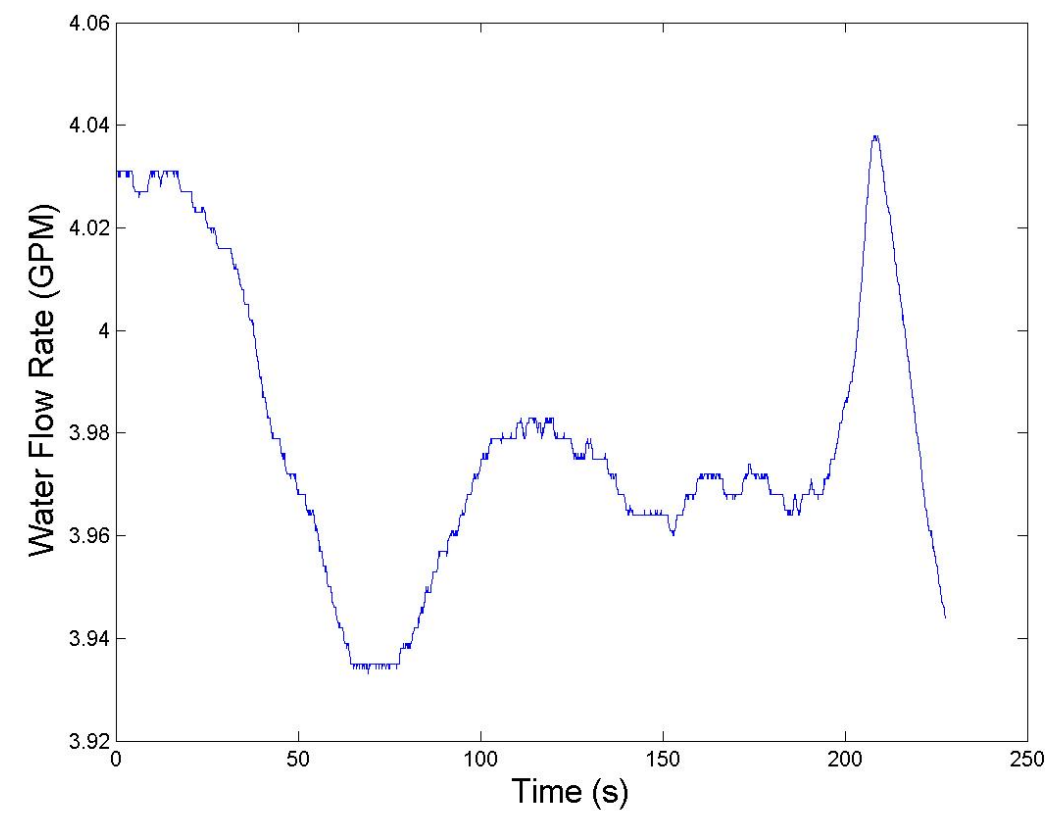

Fig. D.280.: Water flow rate measurements for Test 56 .

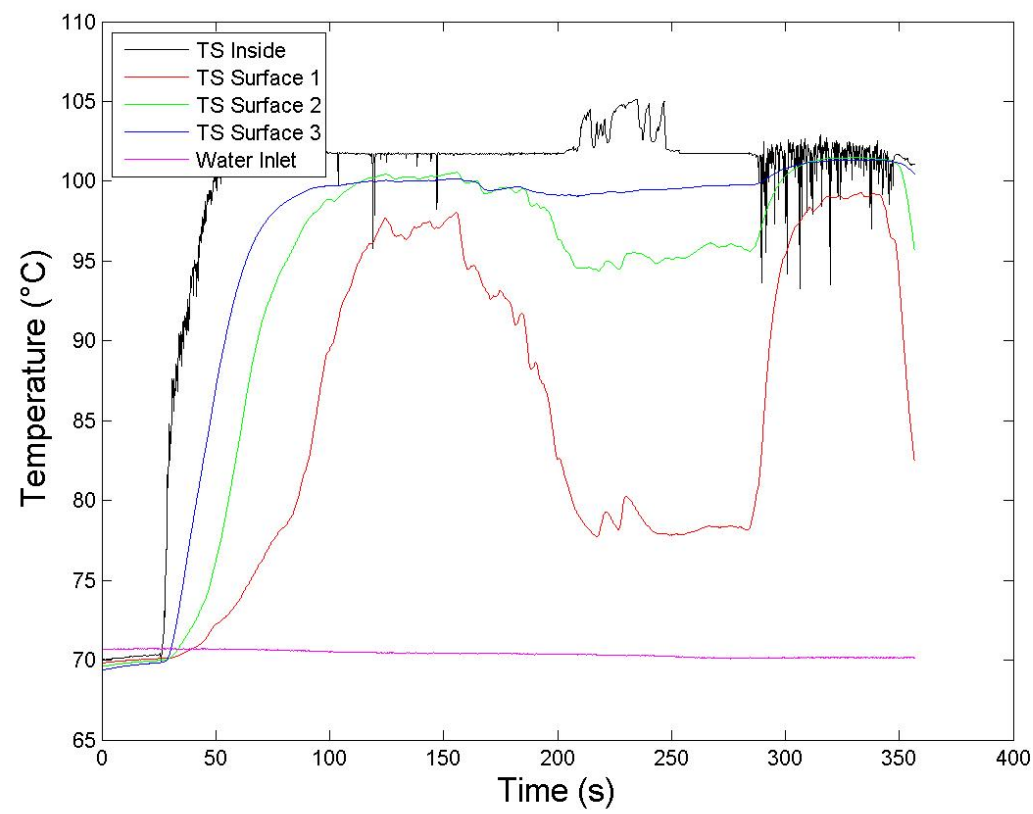

Fig. D.281.: Temperature measurements for Test 57. 


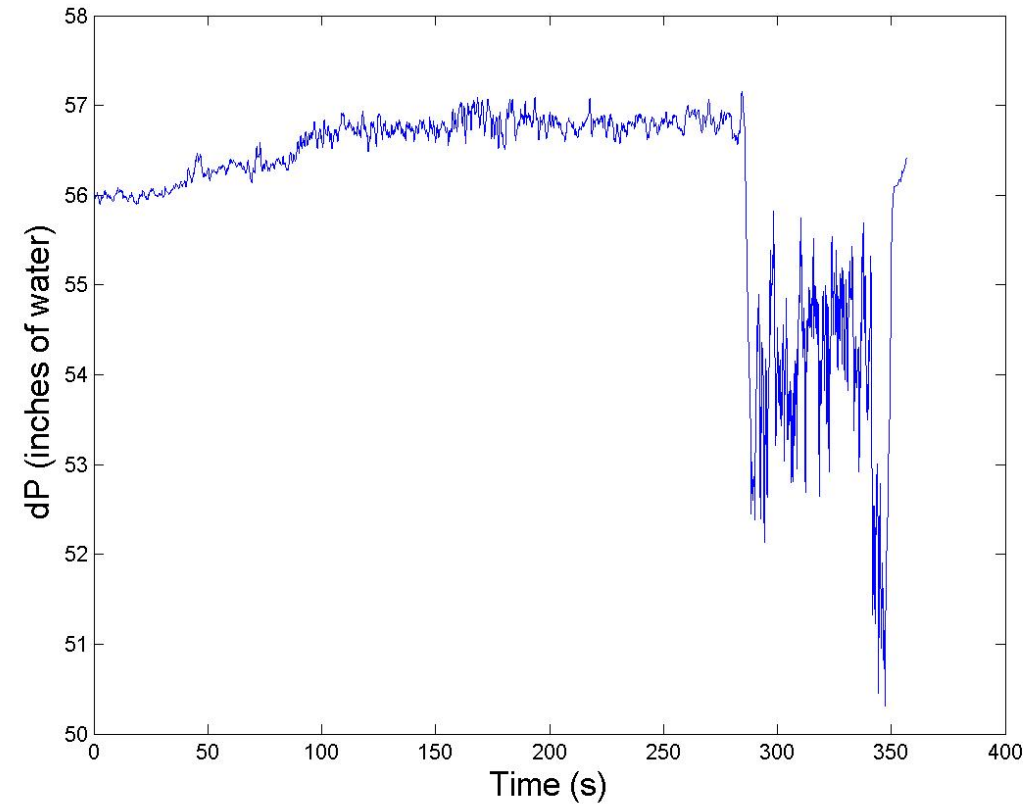

Fig. D.282.: Differential pressure measurements for Test 57.

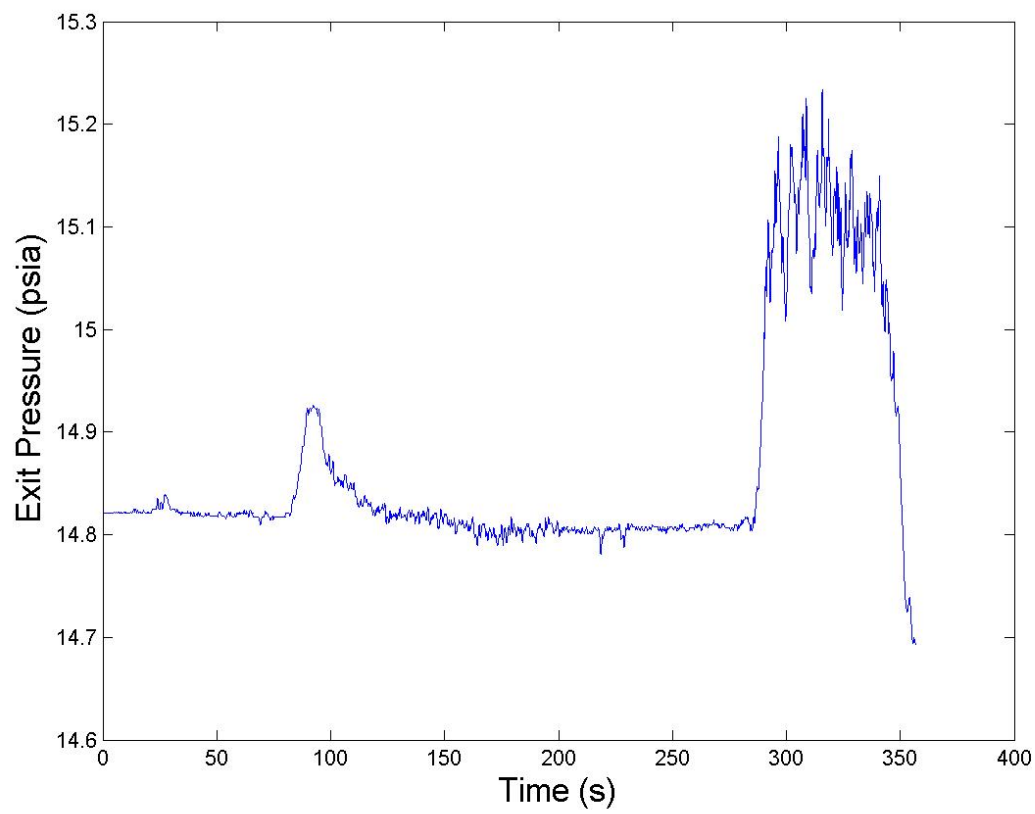

Fig. D.283.: Water exit tank pressure measurements for Test 57. 


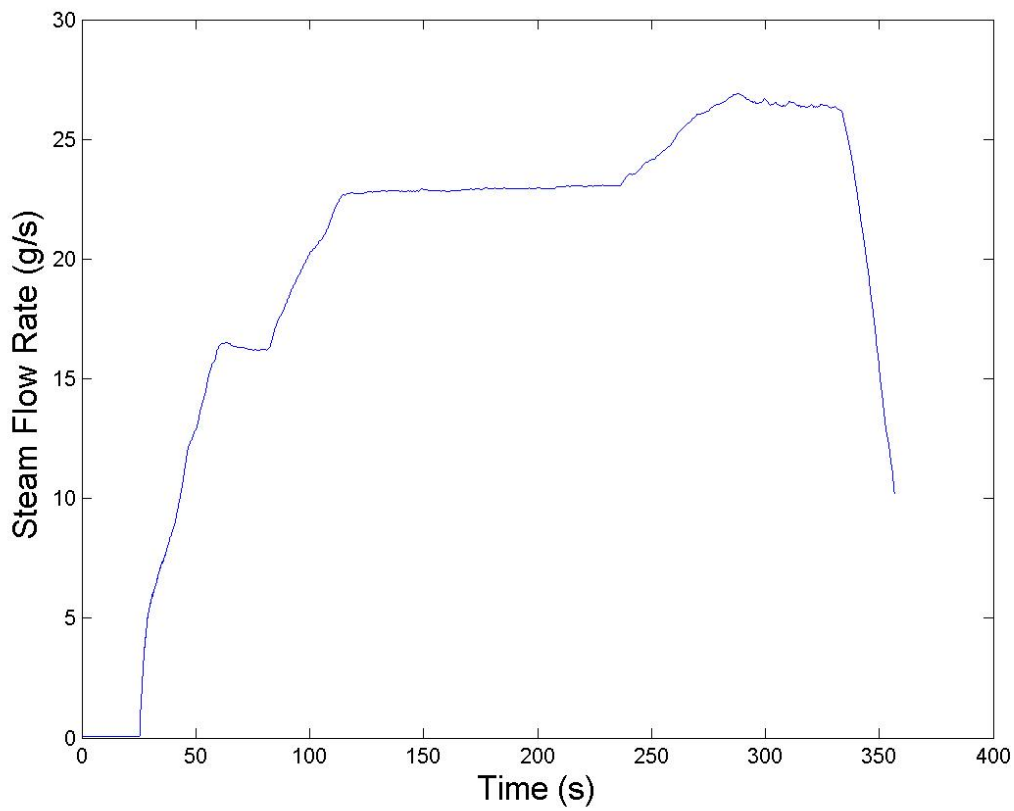

Fig. D.284.: Steam mass flow rate measurements for Test 57.

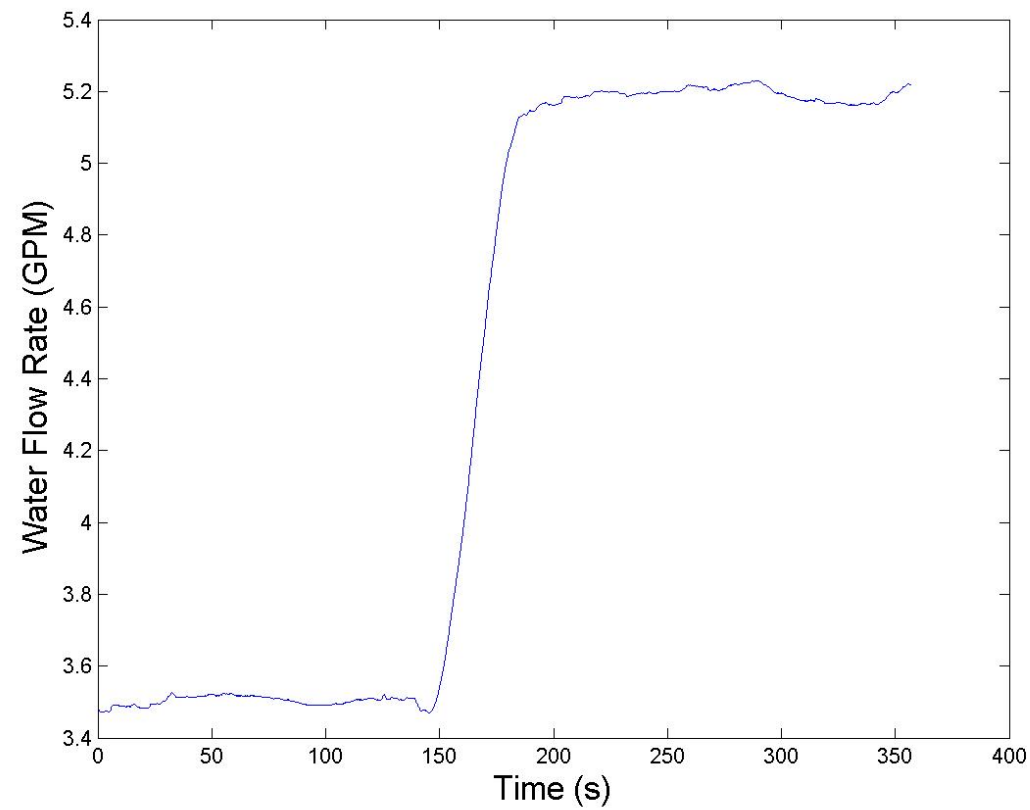

Fig. D.285.: Water flow rate measurements for Test 57. 


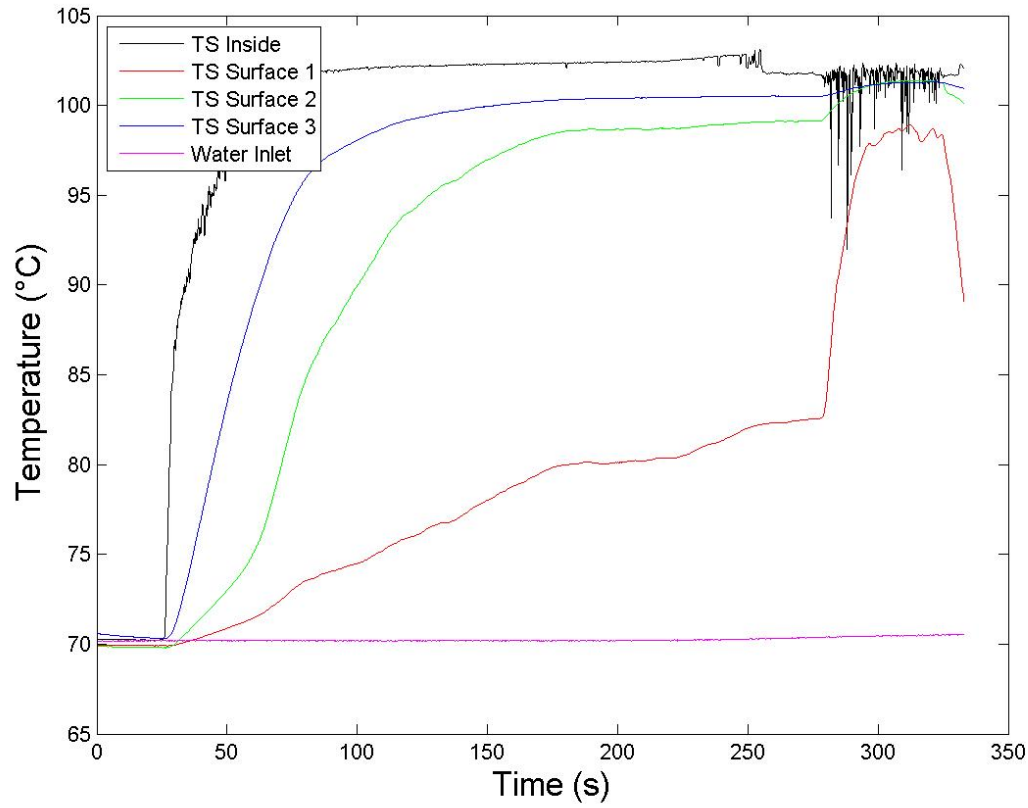

Fig. D.286.: Temperature measurements for Test 58.

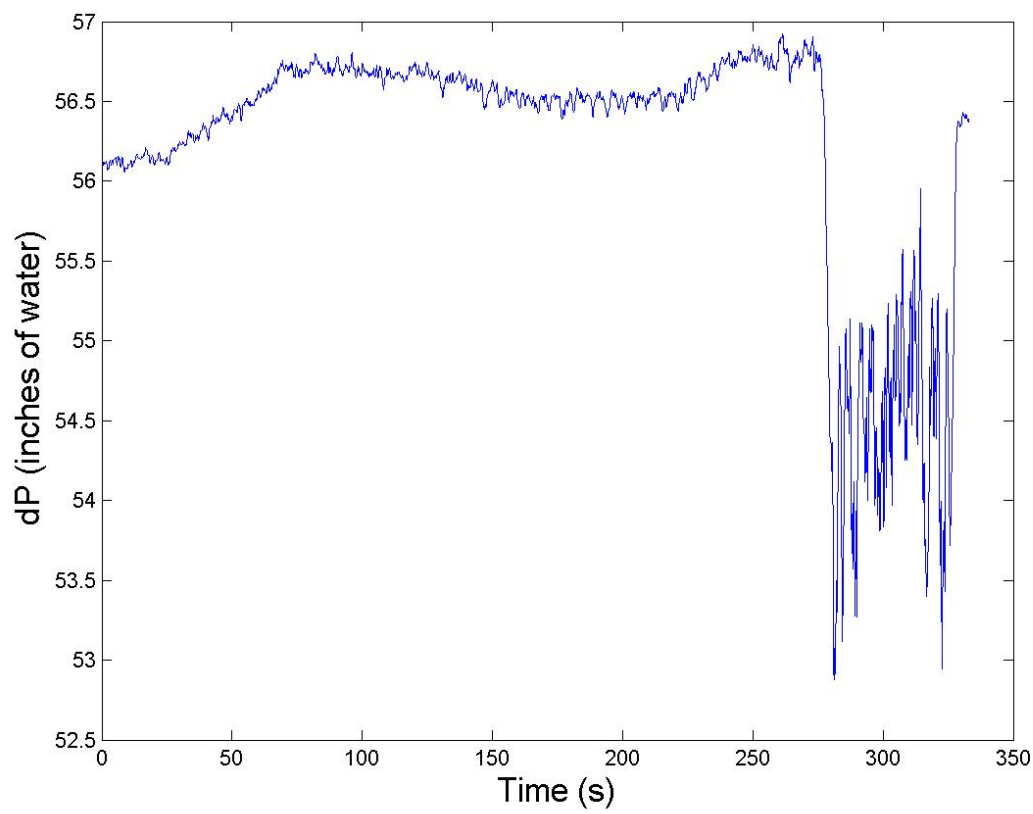

Fig. D.287.: Differential pressure measurements for Test 58. 


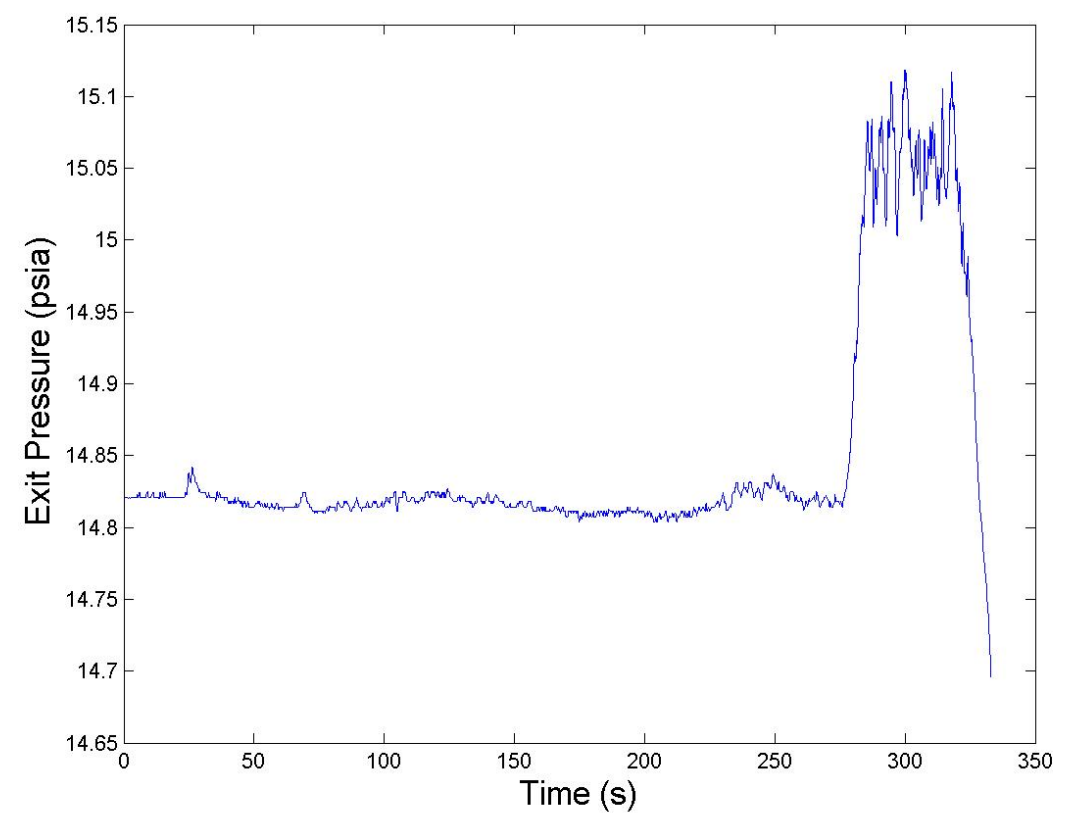

Fig. D.288.: Water exit tank pressure measurements for Test 58 .

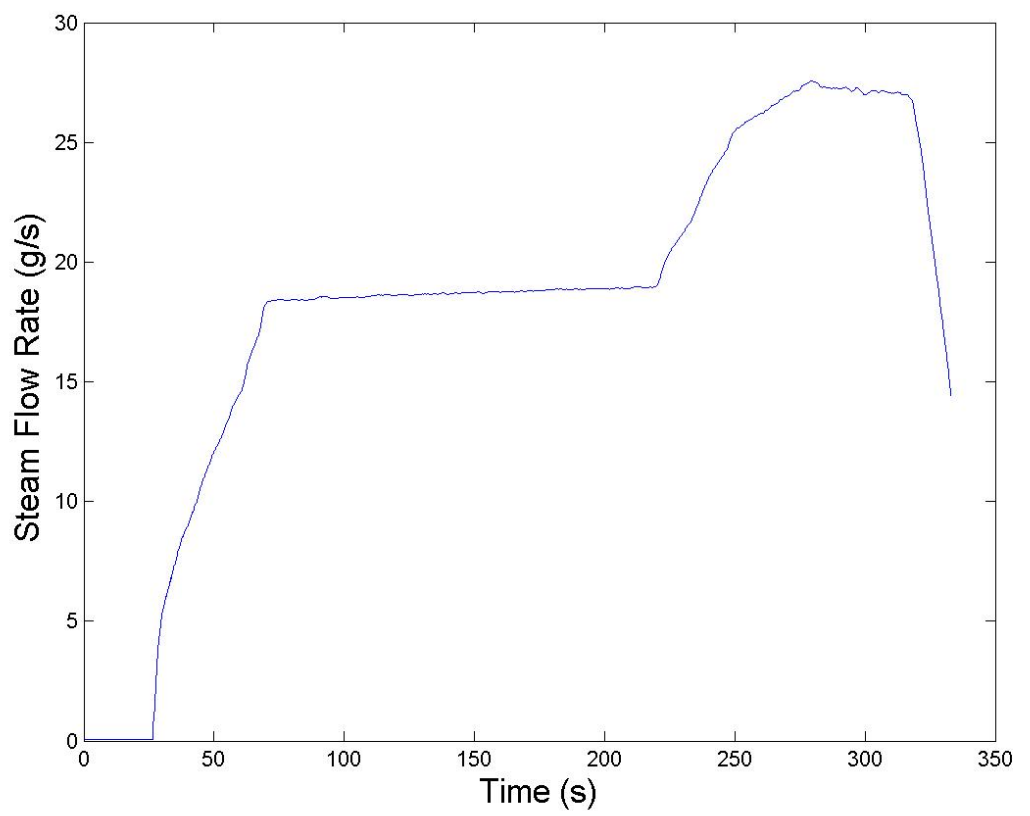

Fig. D.289.: Steam mass flow rate measurements for Test 58 . 


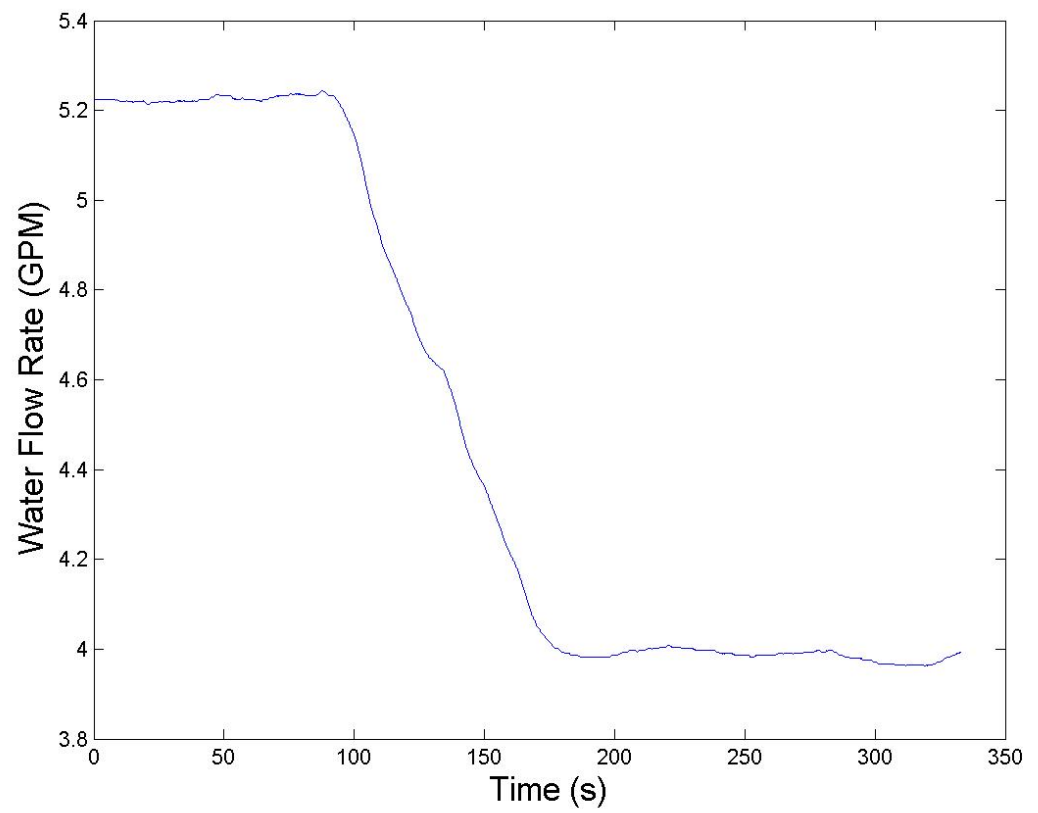

Fig. D.290.: Water flow rate measurements for Test 58 .

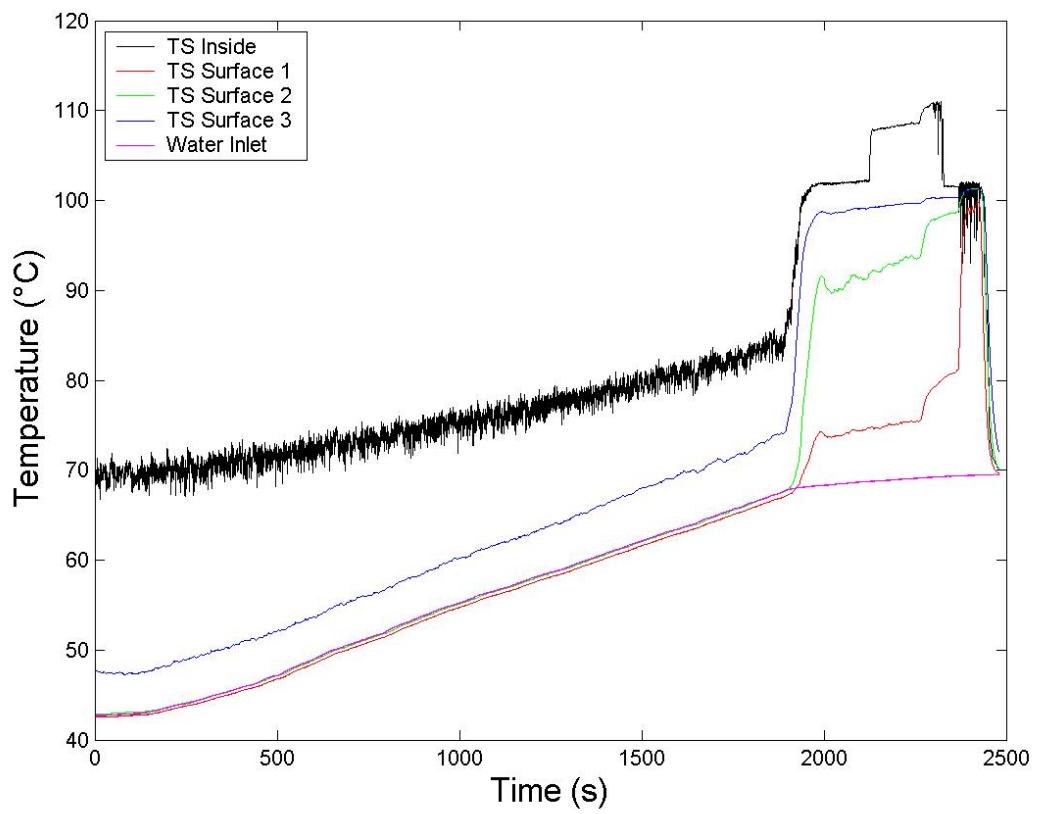

Fig. D.291.: Temperature measurements for Test 59. 


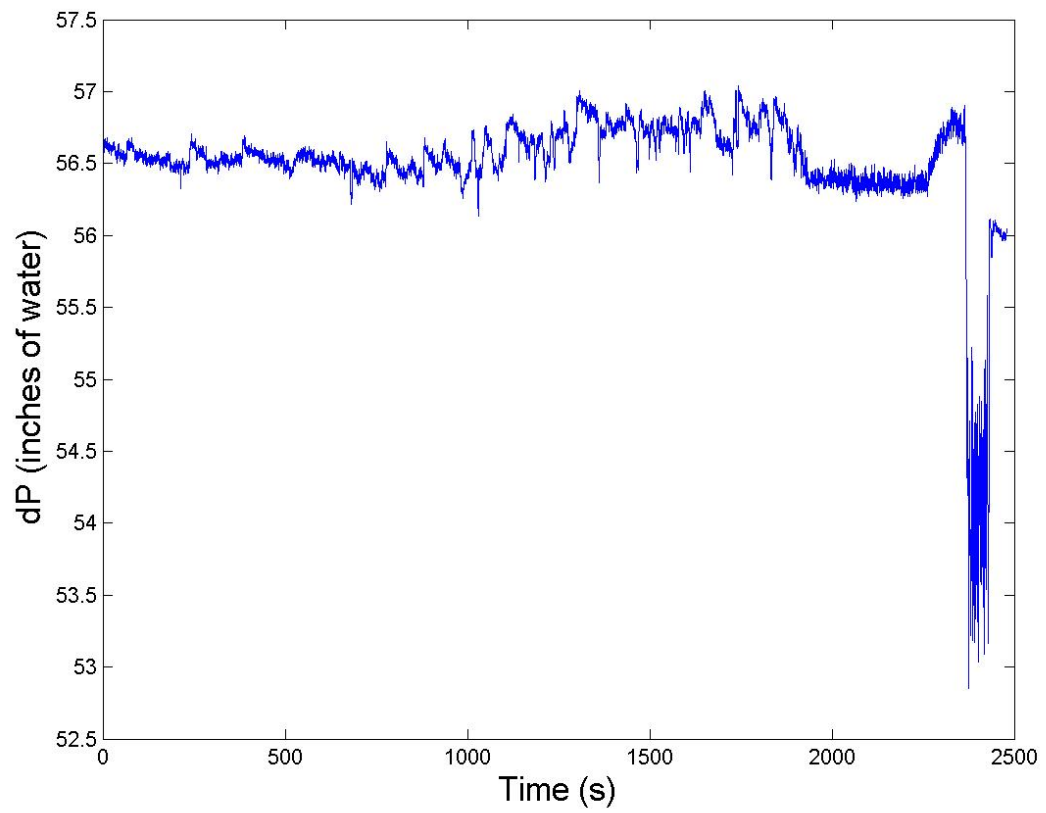

Fig. D.292.: Differential pressure measurements for Test 59.

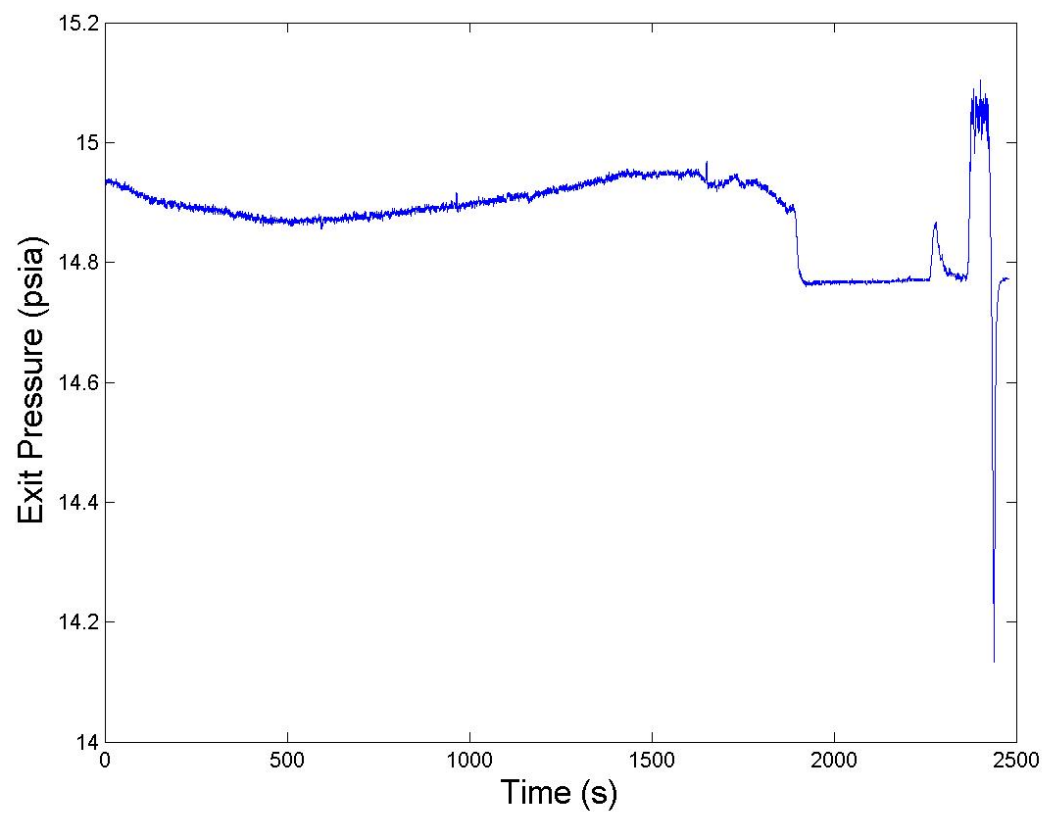

Fig. D.293.: Water exit tank pressure measurements for Test 59. 


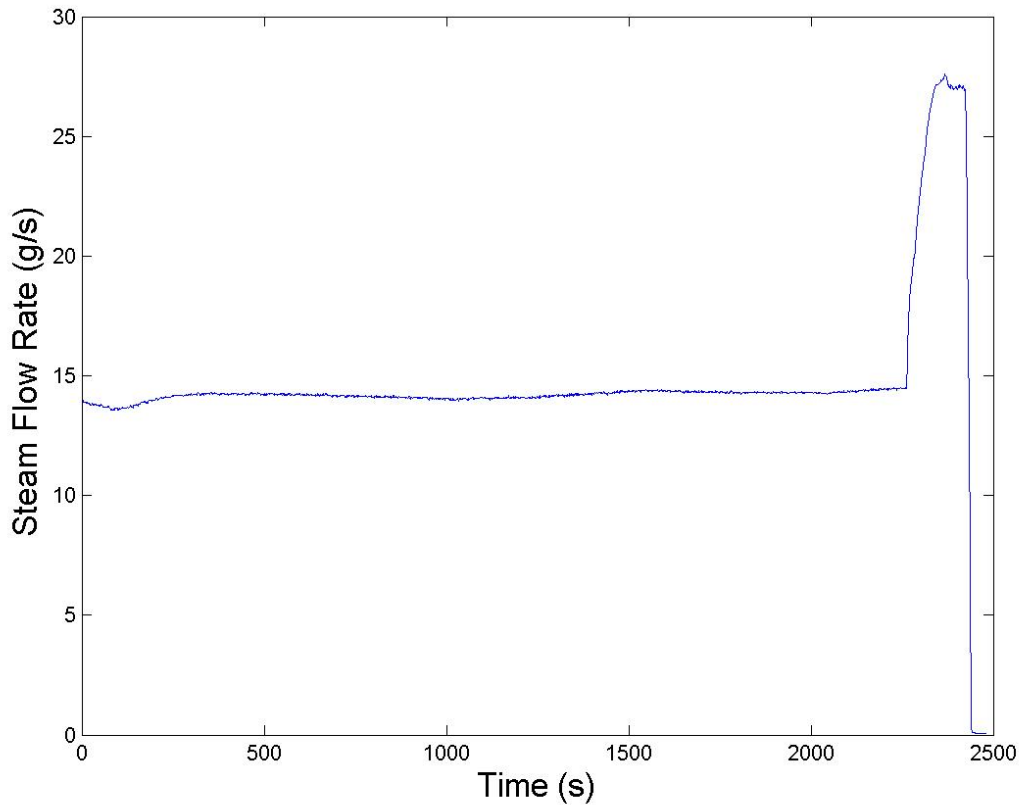

Fig. D.294.: Steam mass flow rate measurements for Test 59.

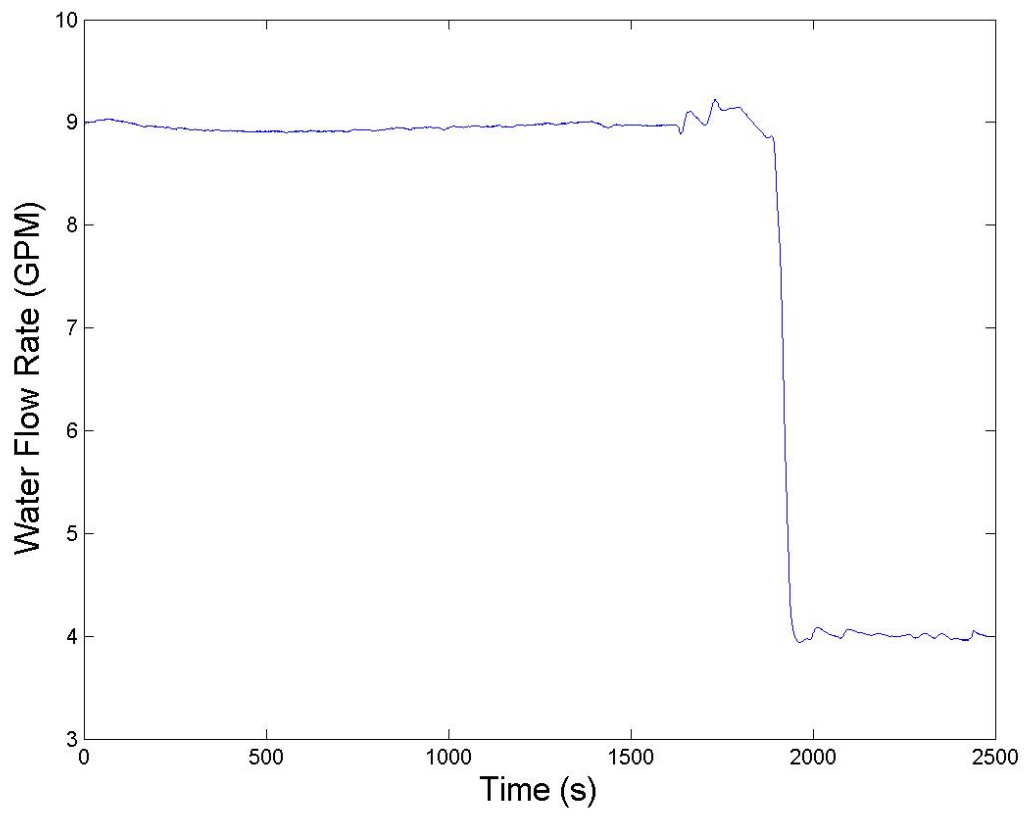

Fig. D.295.: Water flow rate measurements for Test 59. 


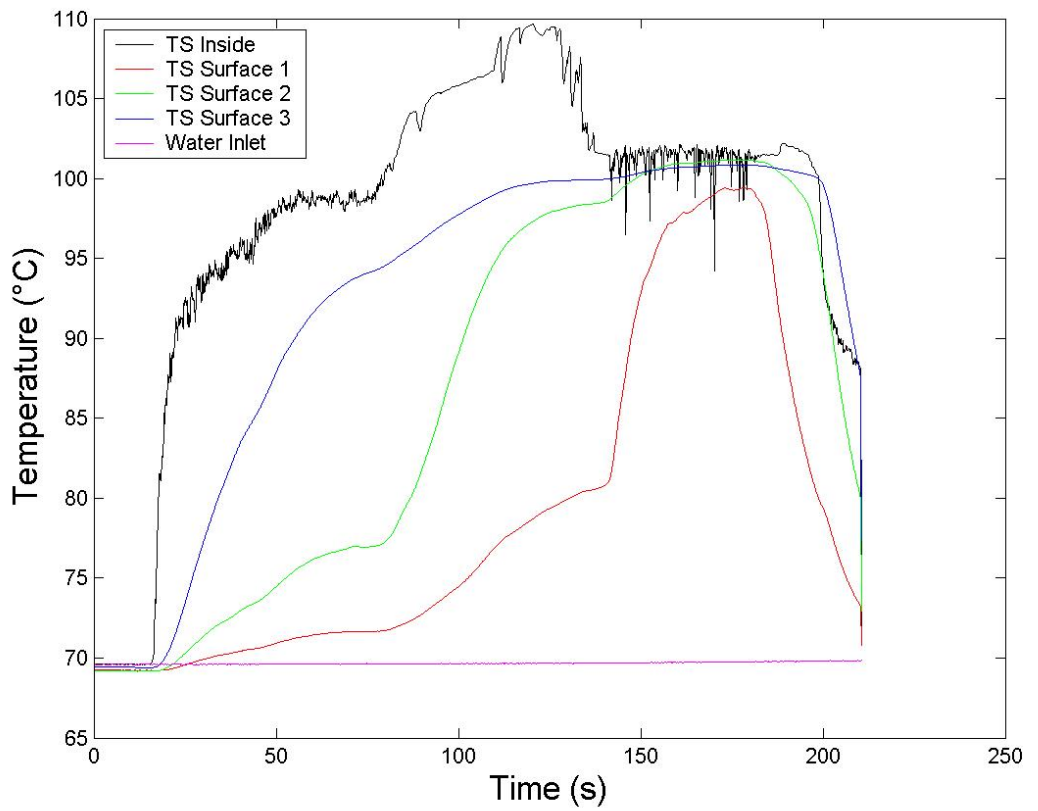

Fig. D.296.: Temperature measurements for Test 60 .

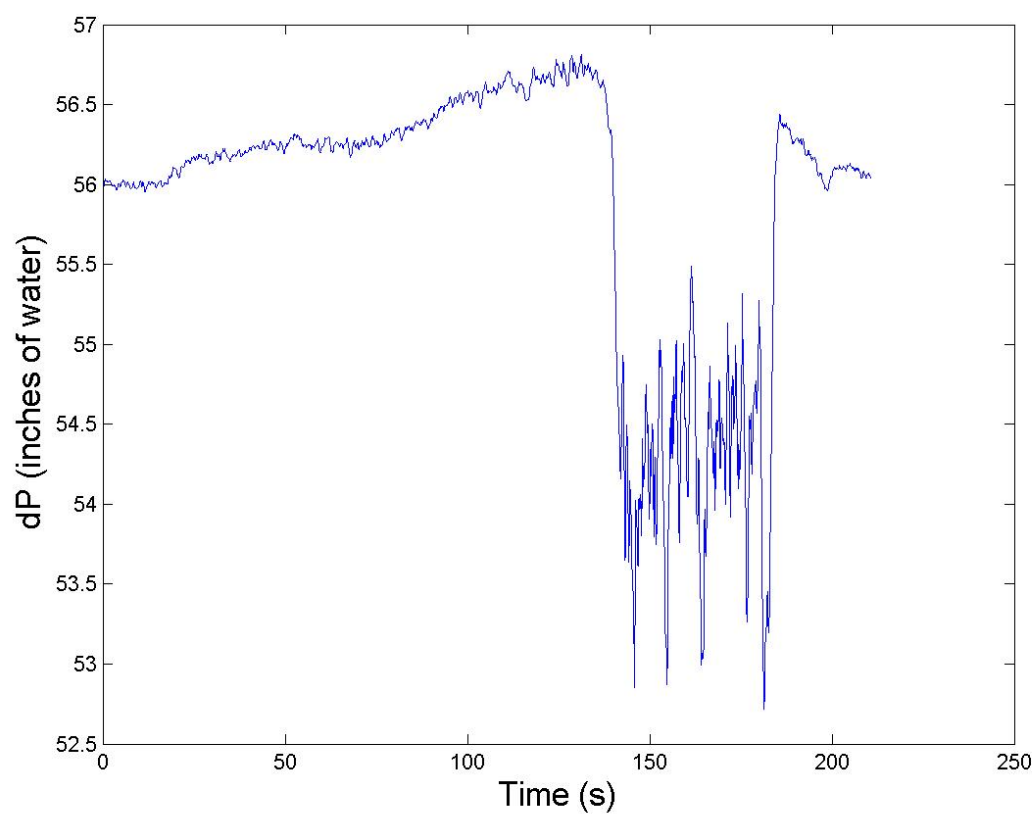

Fig. D.297.: Differential pressure measurements for Test 60 . 


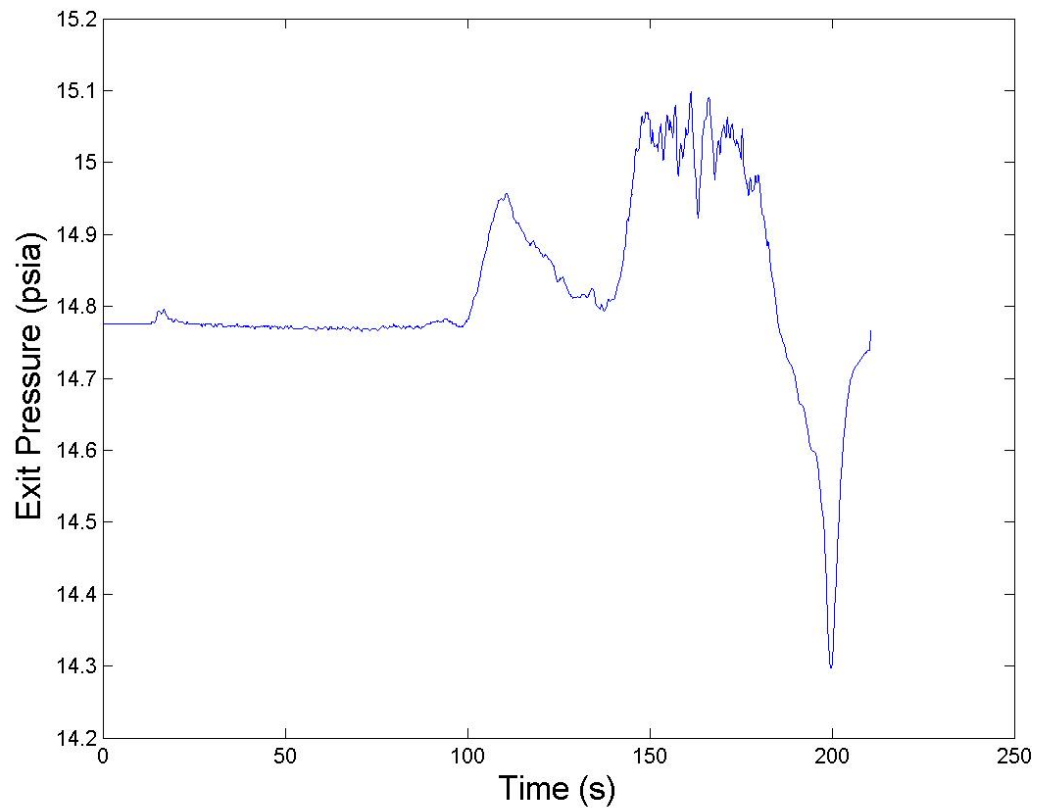

Fig. D.298.: Water exit tank pressure measurements for Test 60 .

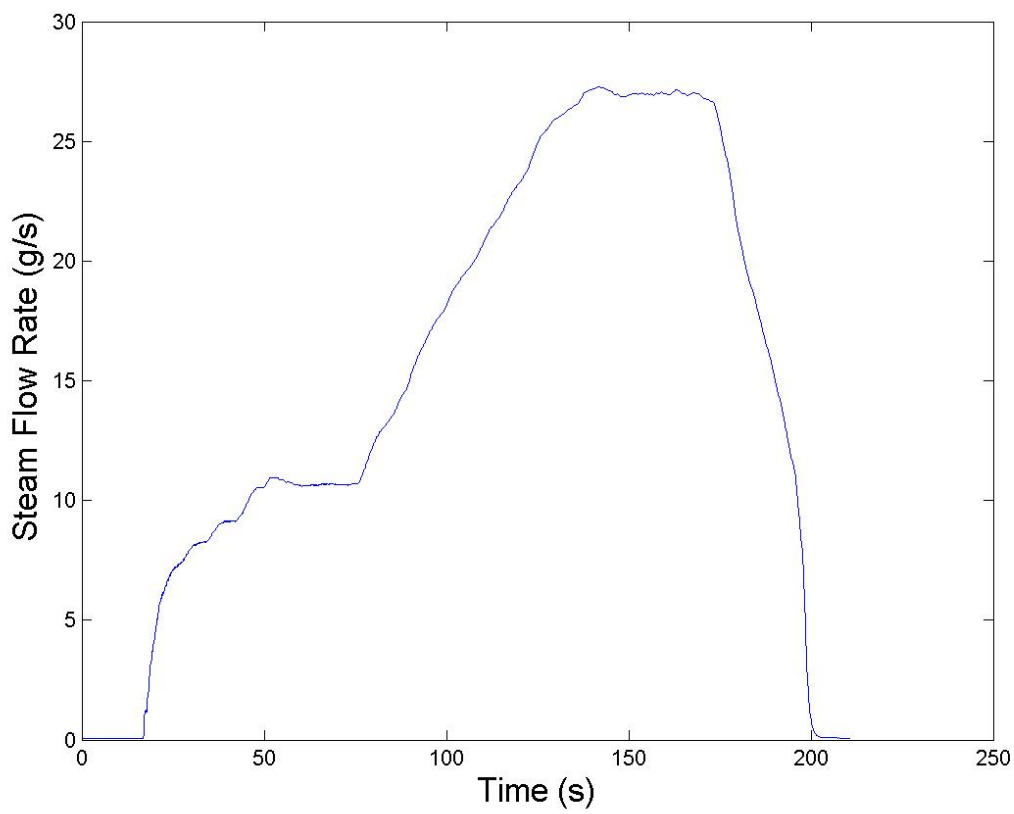

Fig. D.299.: Steam mass flow rate measurements for Test 60 . 


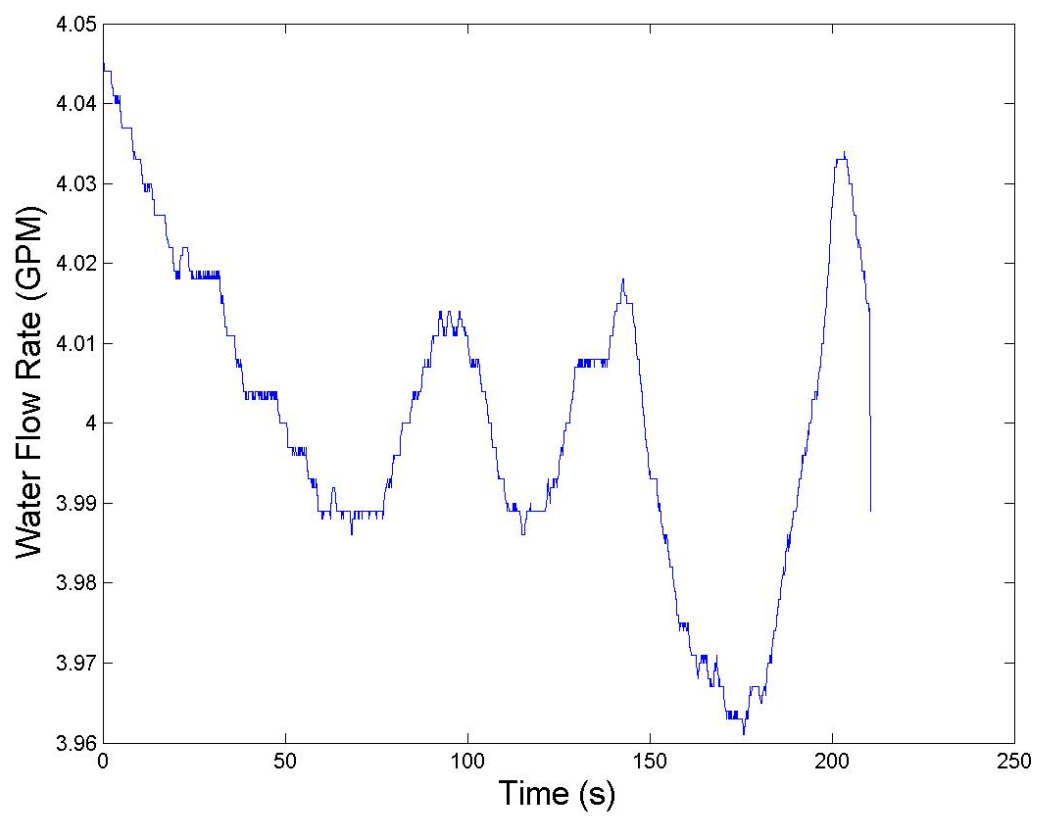

Fig. D.300.: Water flow rate measurements for Test 60 .

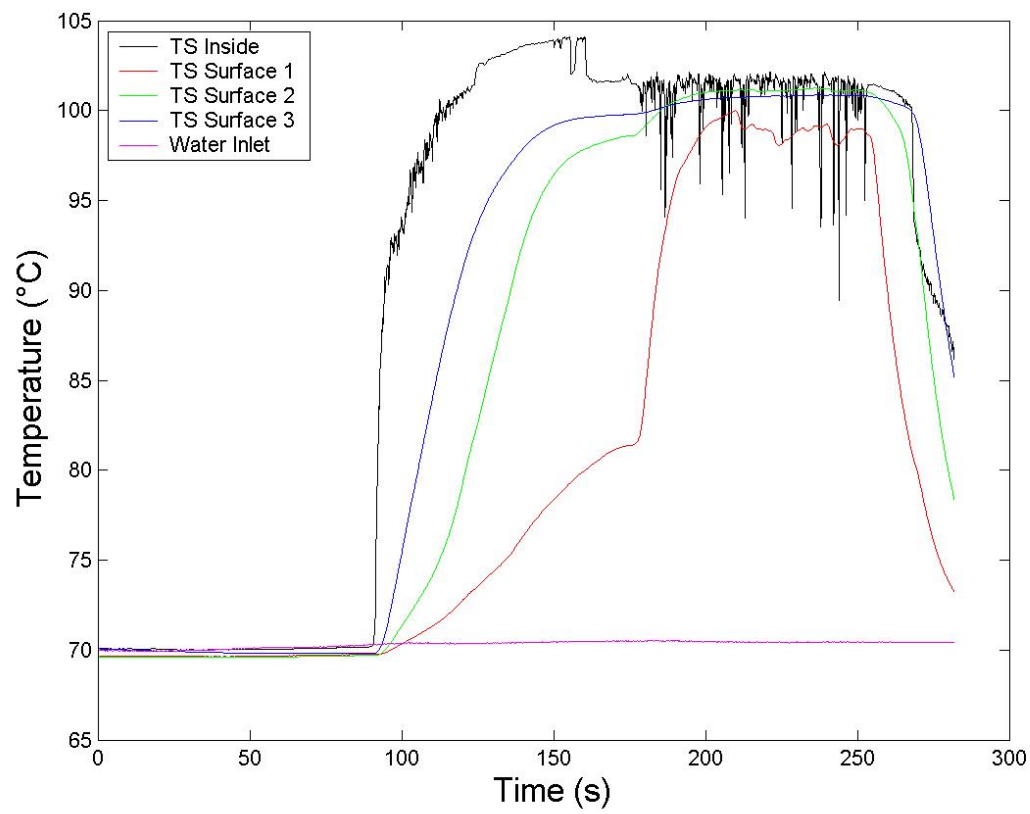

Fig. D.301.: Temperature measurements for Test 61. 


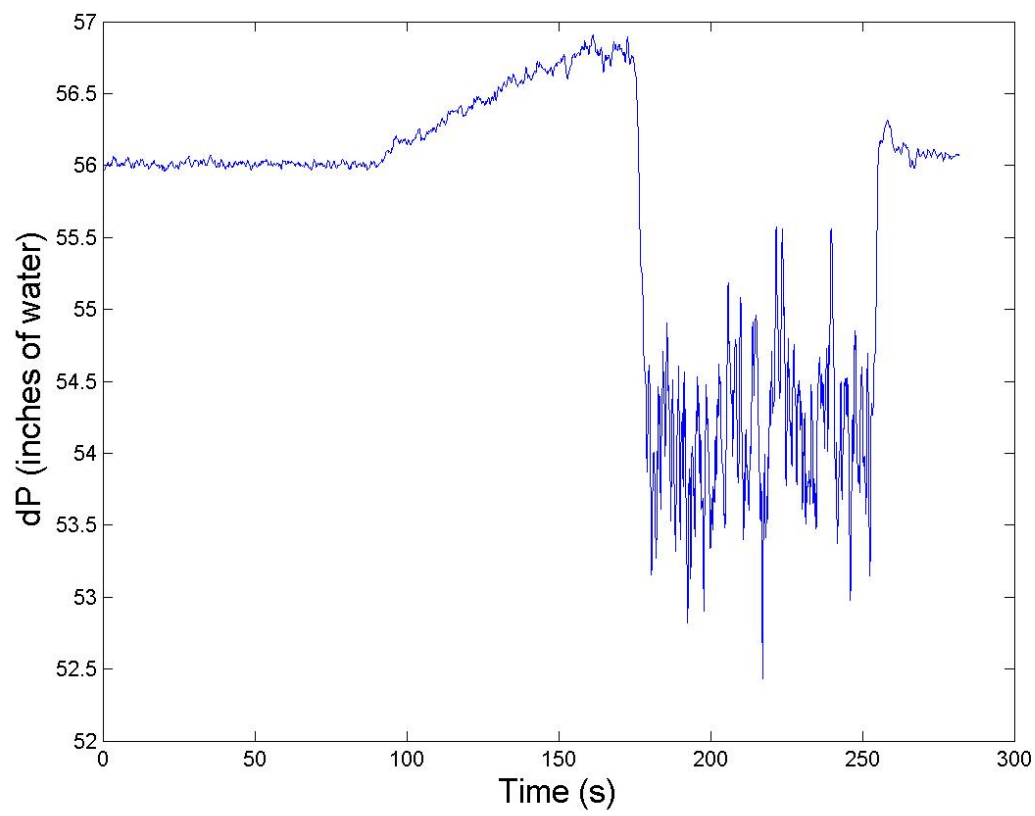

Fig. D.302.: Differential pressure measurements for Test 61 .

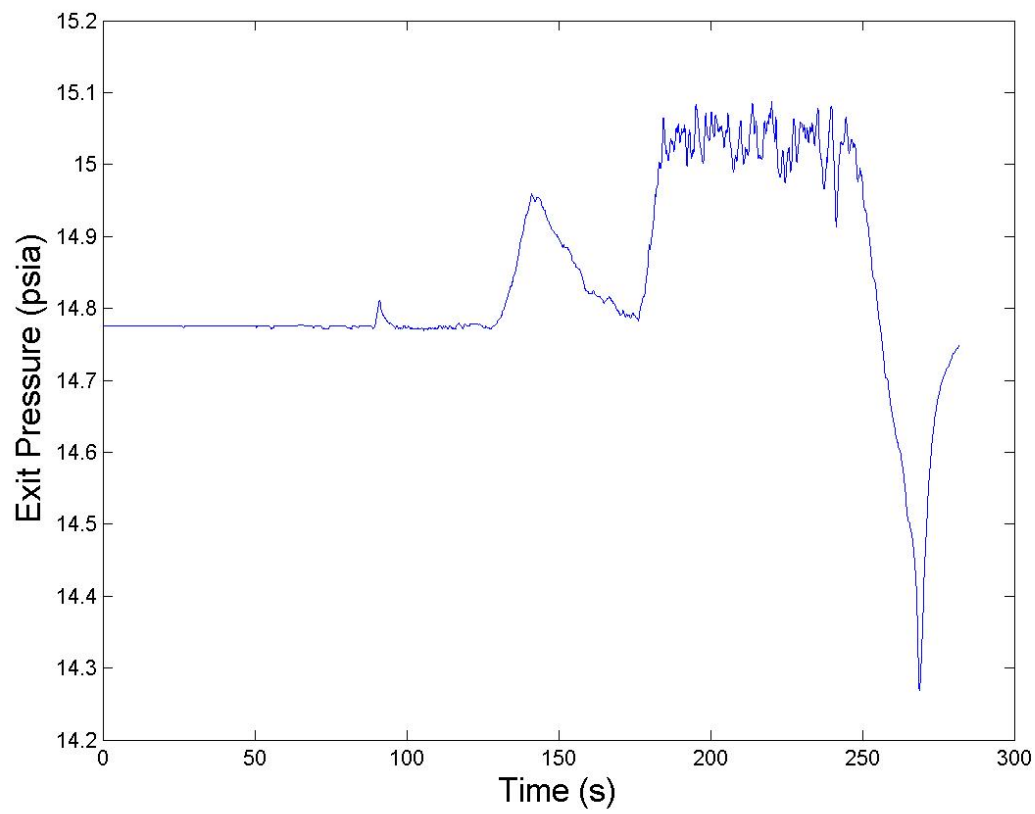

Fig. D.303.: Water exit tank pressure measurements for Test 61 . 


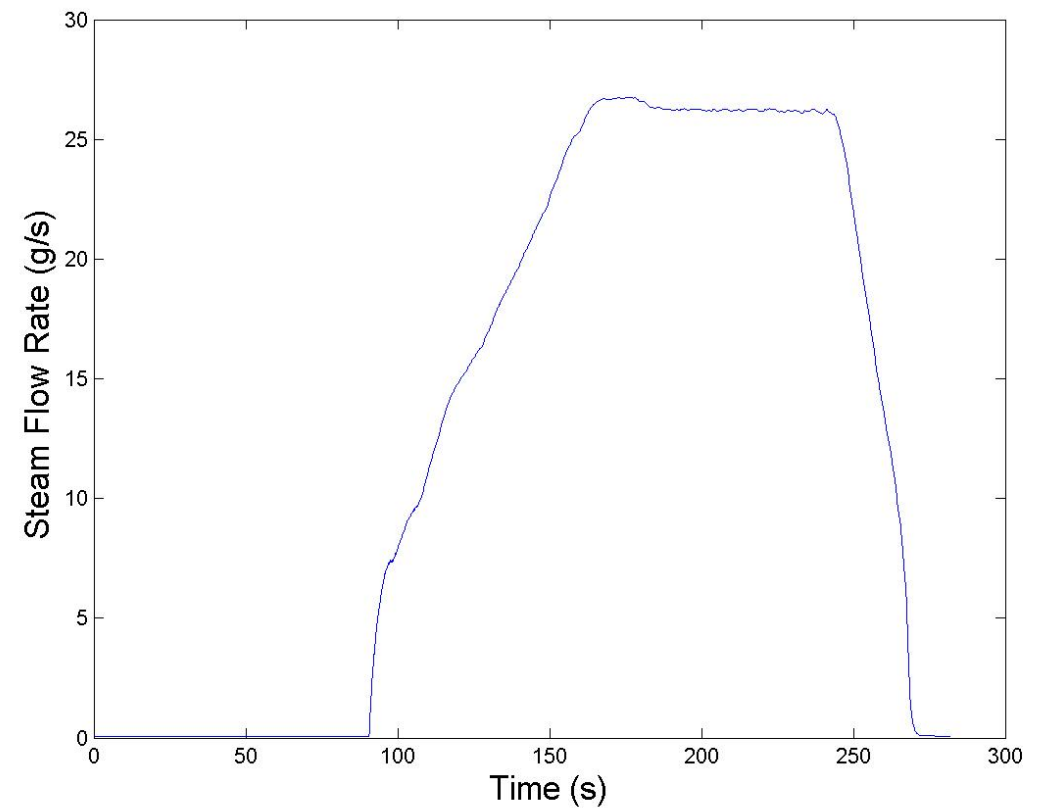

Fig. D.304.: Steam mass flow rate measurements for Test 61 .

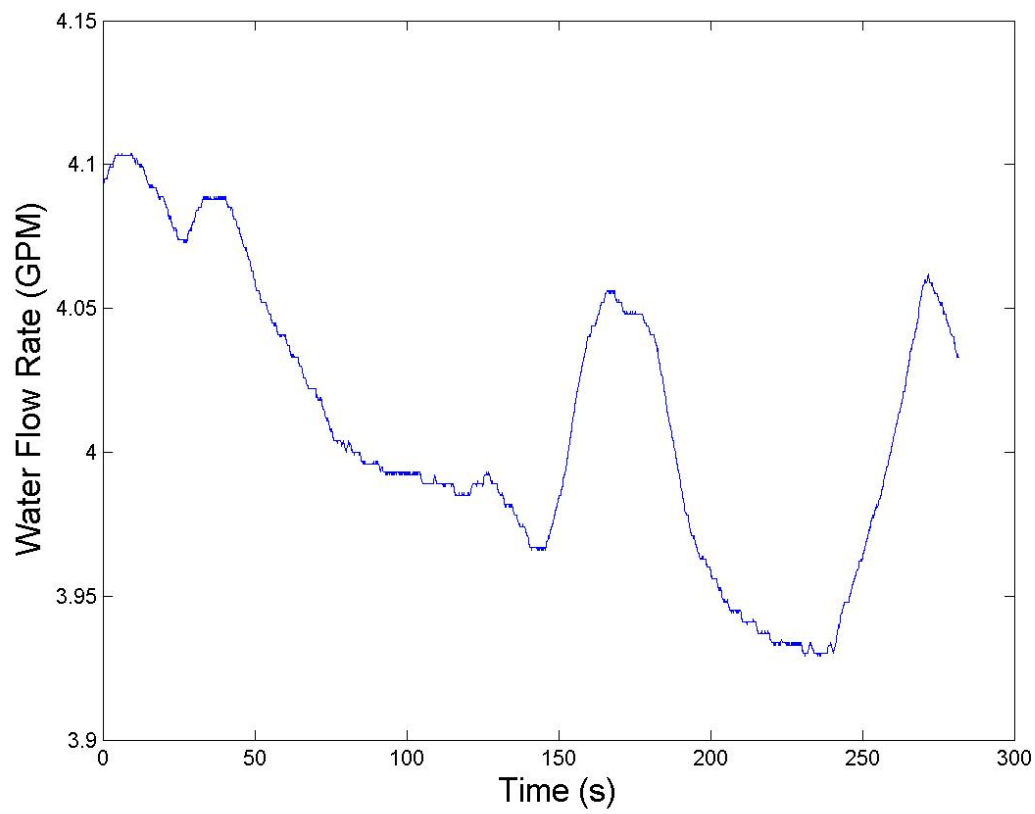

Fig. D.305.: Water flow rate measurements for Test 61 . 


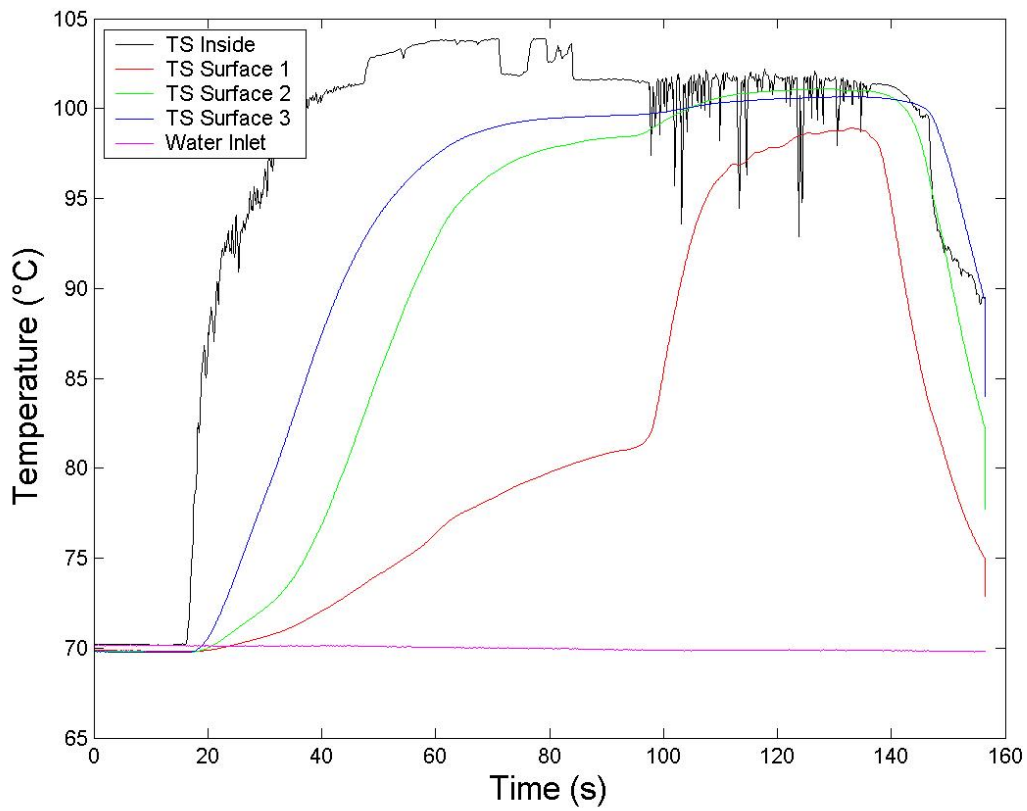

Fig. D.306.: Temperature measurements for Test 62 .

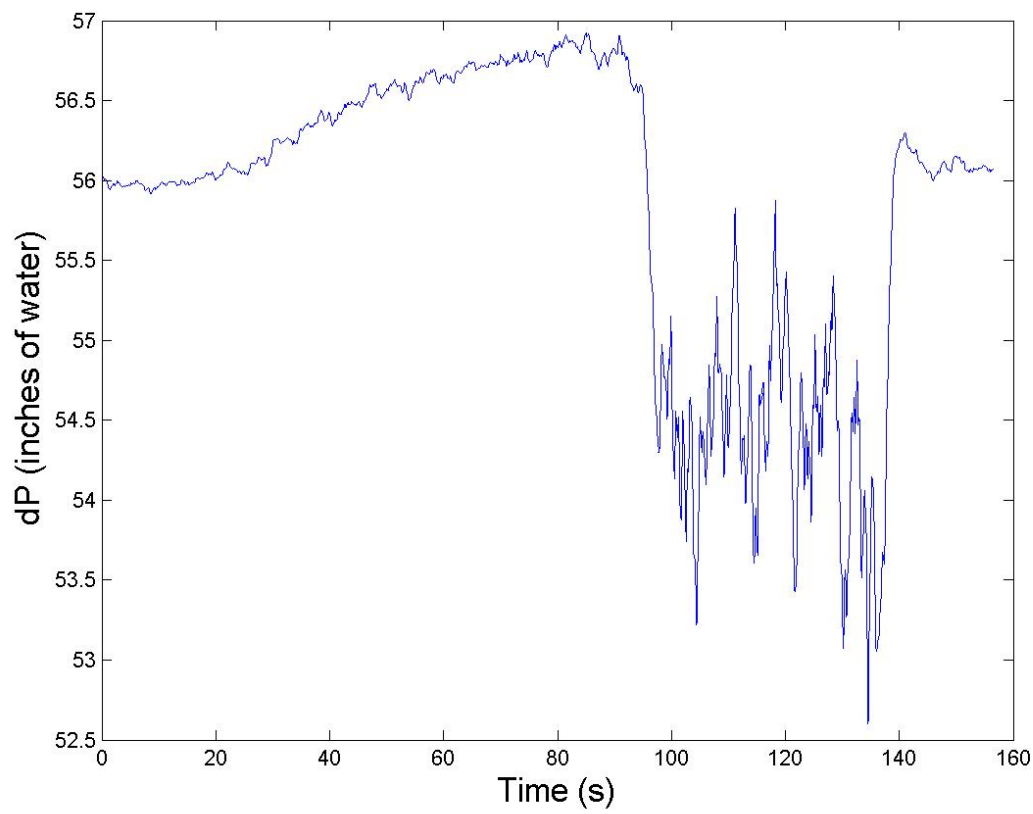

Fig. D.307.: Differential pressure measurements for Test 62 . 


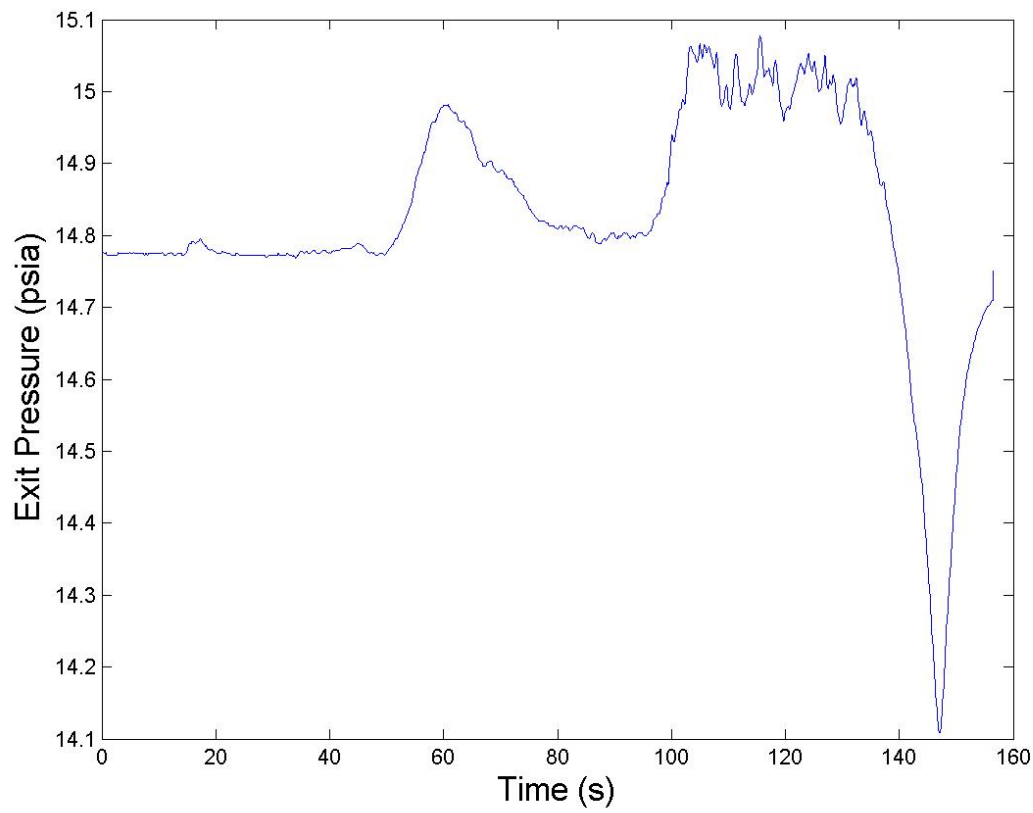

Fig. D.308.: Water exit tank pressure measurements for Test 62 .

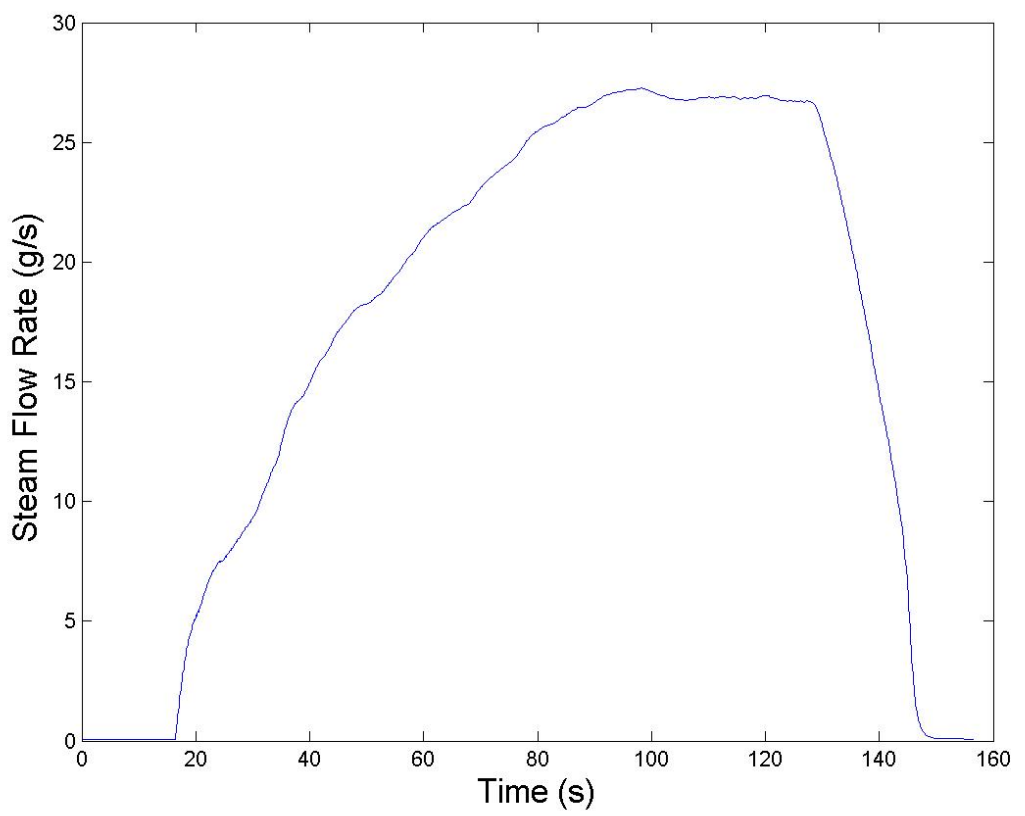

Fig. D.309.: Steam mass flow rate measurements for Test 62 . 


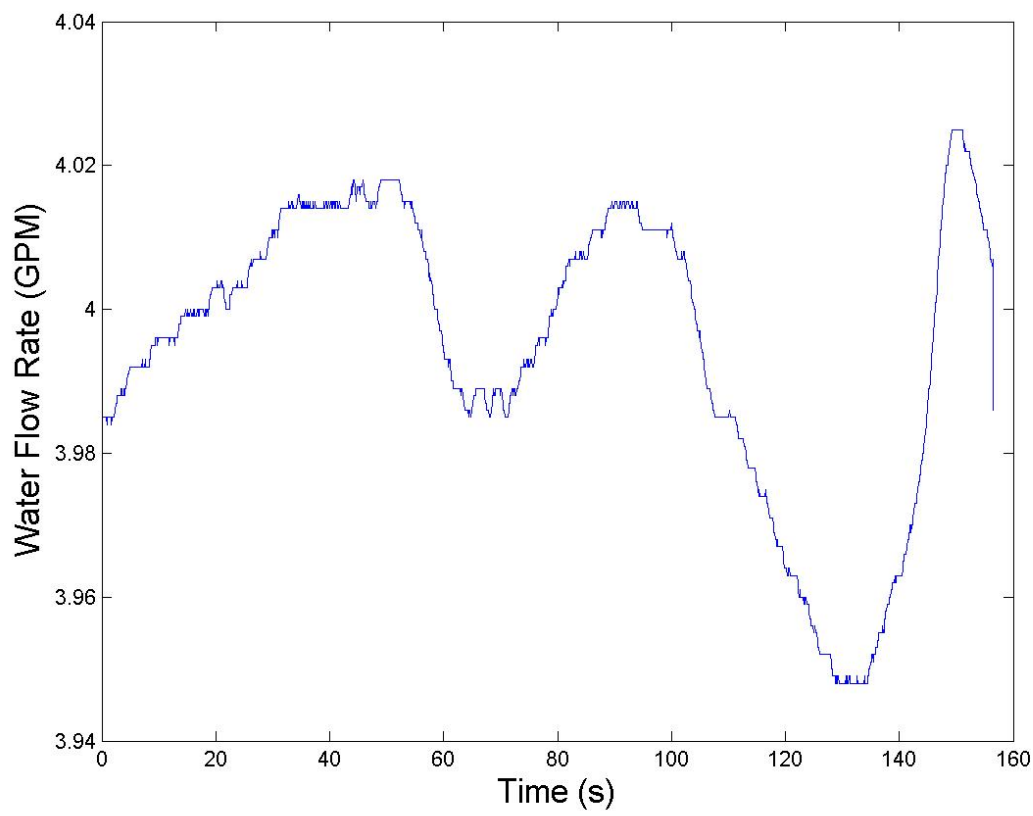

Fig. D.310.: Water flow rate measurements for Test 62.

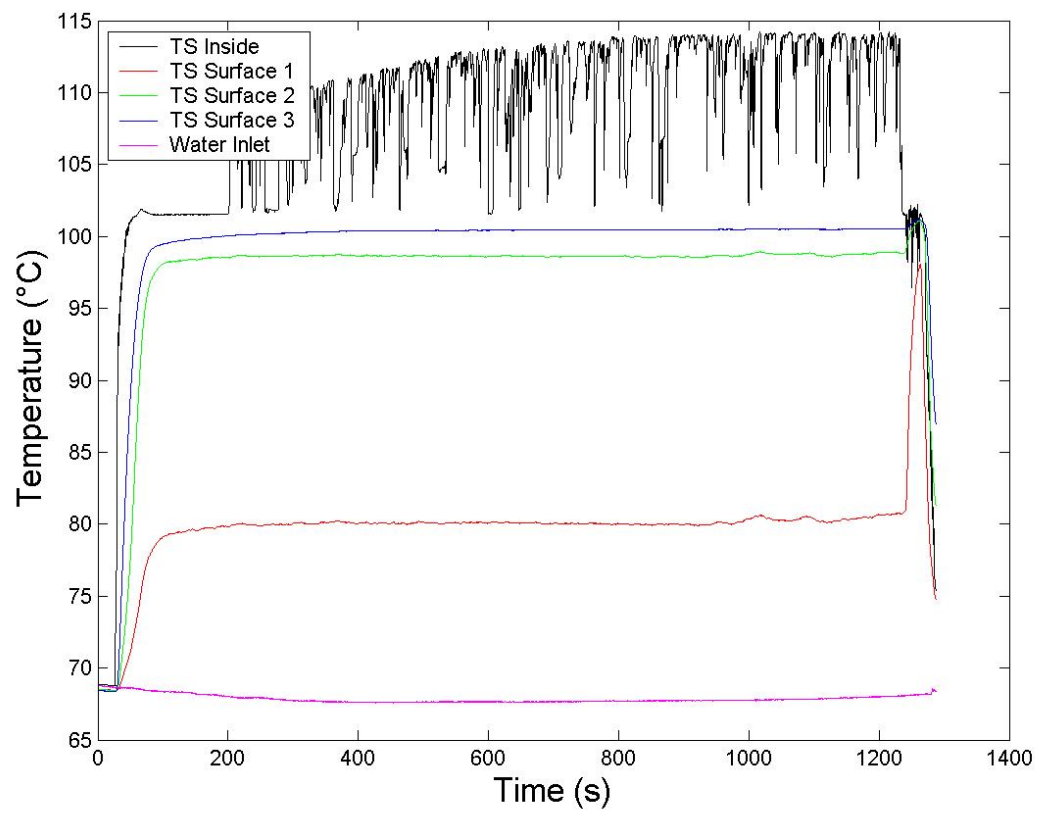

Fig. D.311.: Temperature measurements for Test 63. 


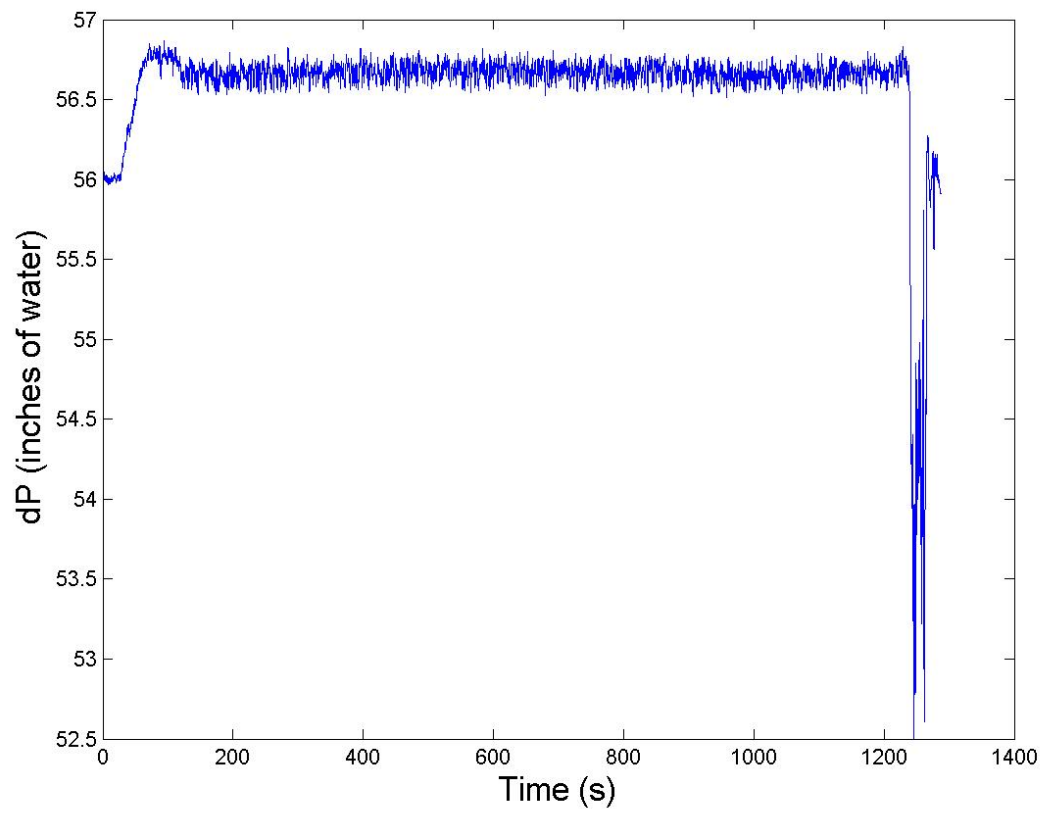

Fig. D.312.: Differential pressure measurements for Test 63.

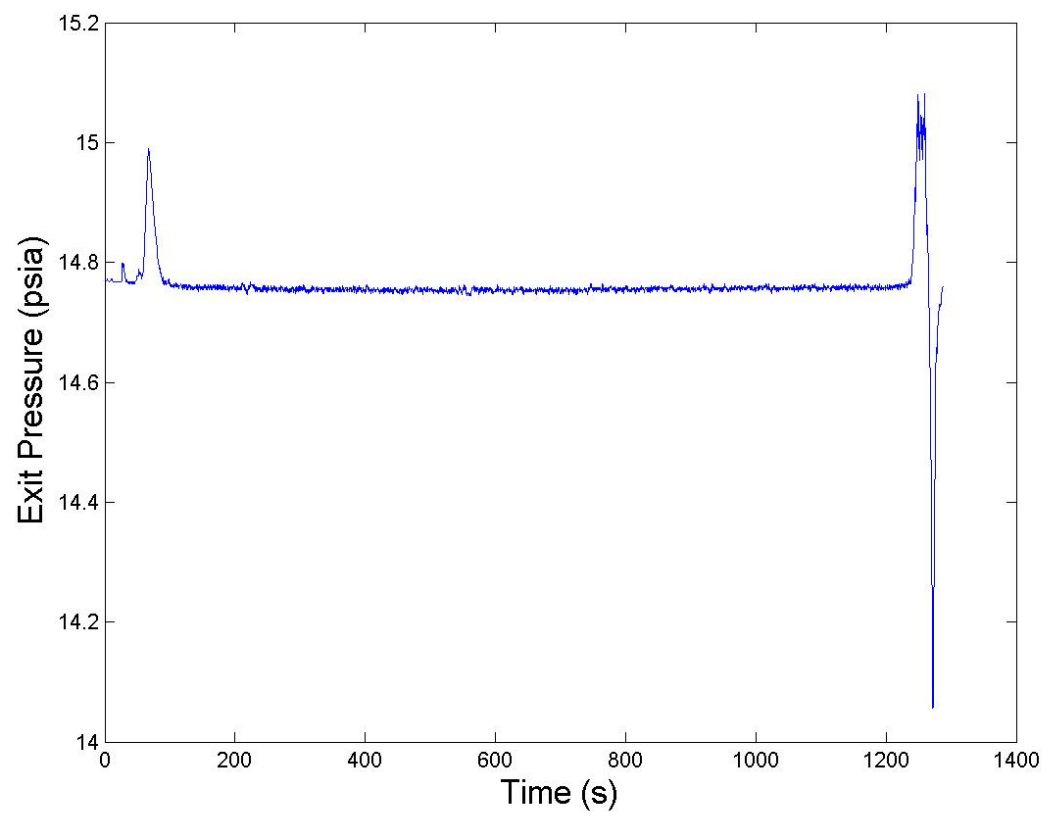

Fig. D.313.: Water exit tank pressure measurements for Test 63 . 


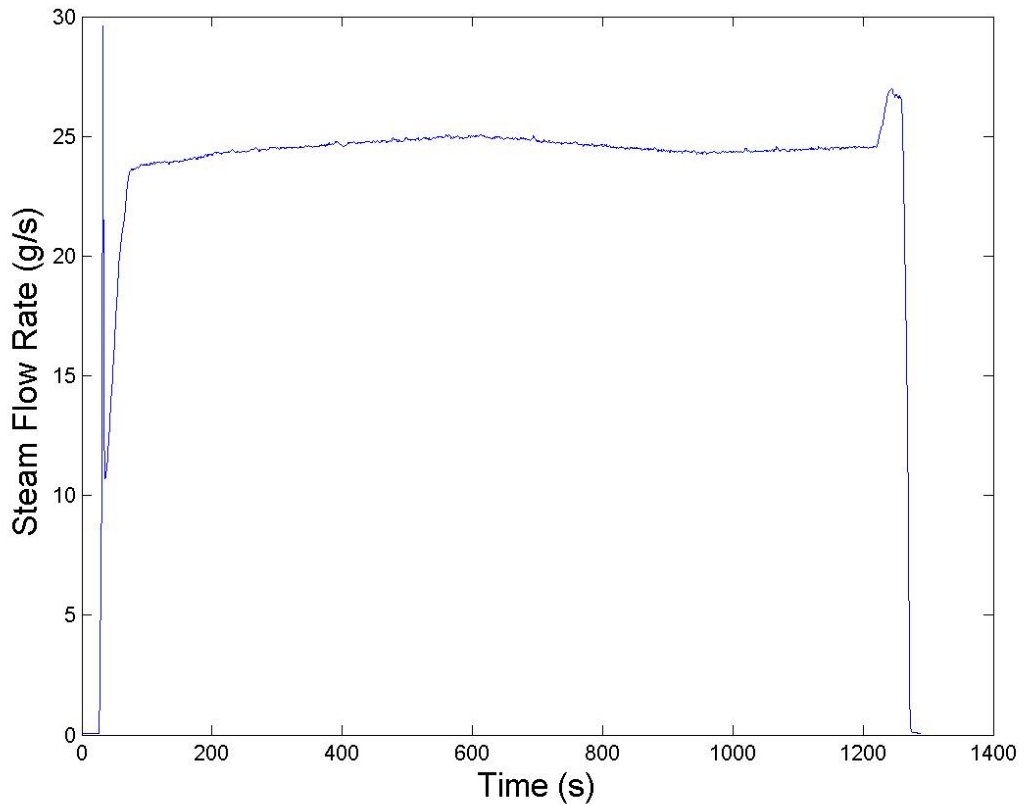

Fig. D.314.: Steam mass flow rate measurements for Test 63.

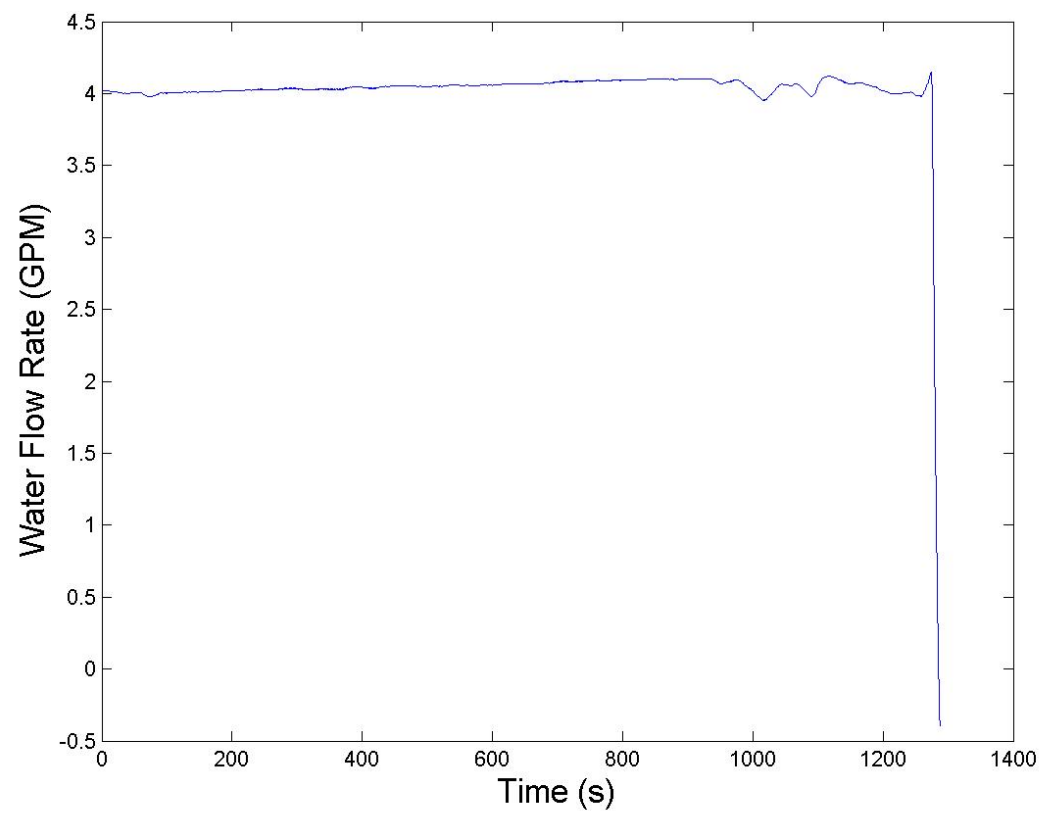

Fig. D.315.: Water flow rate measurements for Test 63. 


\section{VITA}

Name: $\quad$ Susan Nicole Williams

Address: $\quad$ ATTN: Karen Vierow

Department of Nuclear Engineering

Texas A\&M University

129 Zachry Engineering Center, 3133 TAMU

College Station, TX 77843-3133

Email Address: nikiwilliams@tamu.edu

Education: $\quad$ B.S., Nuclear Engineering, Texas A\&M University, 2007

B.S., Radiological Health Engineering, Texas A\&M

University, 2007

M.S., Nuclear Engineering, Texas A\&M University, 2009 